\title{
Lao People's Democratic Republic: Poverty Reduction Strategy Paper
}

Poverty Reduction Strategy Papers (PRSPs) are prepared by member countries in broad consultation with stakeholders and development partners, including the staffs of the World Bank and the IMF. Updated every three years with annual progress reports, they describe the country's macroeconomic, structural, and social policies in support of growth and poverty reduction, as well as associated external financing needs and major sources of financing. This country document for the Lao People's Democratic Republic, dated June 2004, is being made available on the IMF website by agreement with the member country as a service to users of the IMF website.

To assist the IMF in evaluating the publication policy, reader comments are invited and may be sent by e-mail to publicationpolicy@imf.org.

Copies of this report are available to the public from

International Monetary Fund $\bullet$ Publication Services

$70019^{\text {th }}$ Street, N.W. • Washington, D.C. 20431

Telephone: (202) 623-7430 • Telefax: (202) 623-7201

E-mail: publications@imf.org • Internet: http://www.imf.org

Price: $\$ 15.00$ a copy

\section{International Monetary Fund Washington, D.C.}





\section{LAO PEOPLE'S DEMOCRATIC REPUBLIC}

Peace Independence Democracy Unity Prosperity

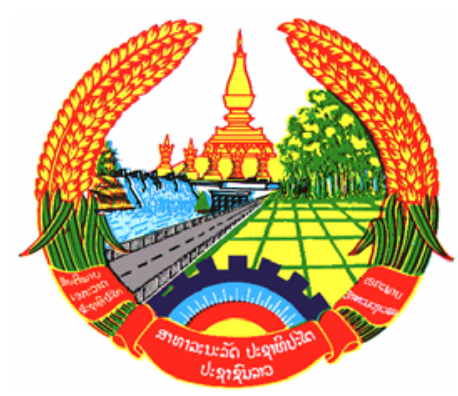

\section{National Growth and Poverty Eradication Strategy}

(NGPES) 


\section{LAO PEOPLE'S DEMOCRATIC REPUBLIC}

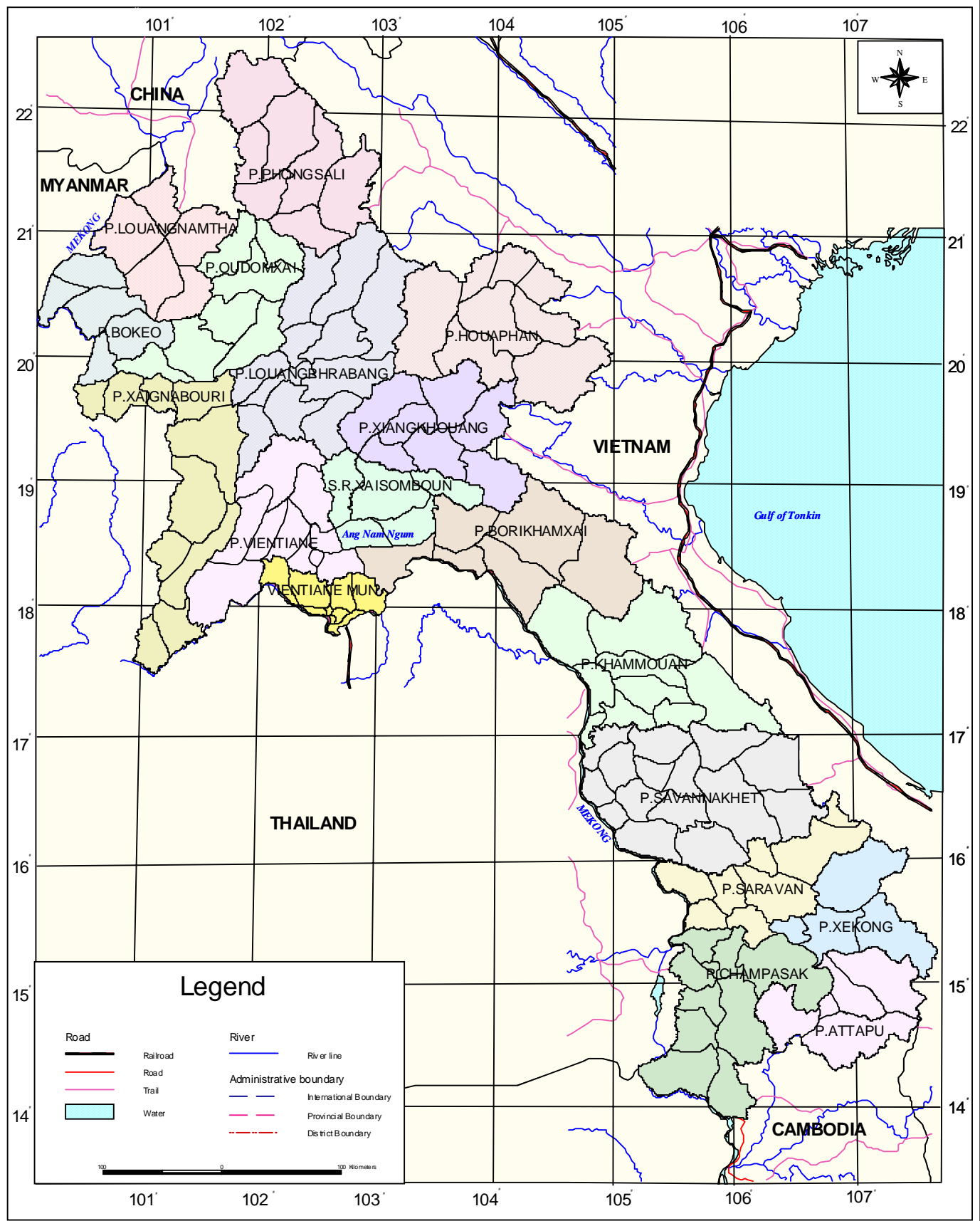




\section{LAO PDR - FACT SHEET}

\begin{tabular}{|c|c|c|}
\hline GDP Per capita 2002 (US\$). & 331 & NSC, 2002 \\
\hline \multicolumn{3}{|l|}{ GEOGRAPHY } \\
\hline Total land area. & $236,800 \mathrm{~km} 2$ & NSC, Pop. Census 1995 \\
\hline Number of provinces in 1999. & 18 & NSC, BS 2002 \\
\hline Number of districts in 2002. & 142 & NSC,BS 2002 \\
\hline Number of villages in 2002. & 10,868 & NSC,BS 2002 \\
\hline \multicolumn{3}{|l|}{ POPULATION } \\
\hline Total population (estimated). & $5,525.9$ & NSC,BS 2002 \\
\hline Population density in 2002. & 23.3 & NSC,BS 2002 \\
\hline Population growth rate. & 2.8 & NSC,BS 2002 \\
\hline Life expectancy at birth. & 59 & NSC LRHS 2000 \\
\hline Population below 20 years old. & 54.9 & CPC/NSC 2002 \\
\hline Population between 20 and 39 years old. & 27.8 & CPC/NSC 2002 \\
\hline Population aged 40 years and above. & 17.4 & CPC/NSC 2002 \\
\hline Women in the overall population in 2002. & 49.5 & CPC/NSC 2002 \\
\hline Population living in rural areas in 2000. & 17.4 & CPC/NSC 2002 \\
\hline Number of households in 2002. & 881,596 & NSC, BS 2002 \\
\hline Household size in 1998. & 6.5 & LECS 2 1997/1998 \\
\hline \multicolumn{3}{|l|}{ SERVICES } \\
\hline Proportion of the population using public electricity. & $32.2 \%$ & CPC/NSC2000 \\
\hline Proportion of households with access to radio 1998. & $52 \%$ & LECS 2 1997/98 \\
\hline Proportion of households with access to television 1998. & $30 \%$ & LECS 2 1997/98 \\
\hline Proportion of households with access to car/van: 1998. & $4 \%$ & LECS 2 1997/98 \\
\hline Proportion of households with access to motorbike. & $15 \%$ & LECS 2 1997/98 \\
\hline \multicolumn{3}{|l|}{ UXO } \\
\hline Proportion of land contaminated by UXO. & $50 \%$ & Living with UXO \\
\hline Number of provinces contaminated by UXO. & 15 & Living with UXO \\
\hline Proportion of villages contaminated by UXO. & $25 \%$ & Living with UXO \\
\hline Reported UXO related casualties in 1999. & 102 & UXO Accident. Rep. \\
\hline UXO contaminated land cleared in 1999. & 578 ha & UXO Annual Report \\
\hline
\end{tabular}




\title{
LAO PEOPLE'S DEMOCRATIC REPUBLIC
}

Peace Independence Democracy Unity Prosperity

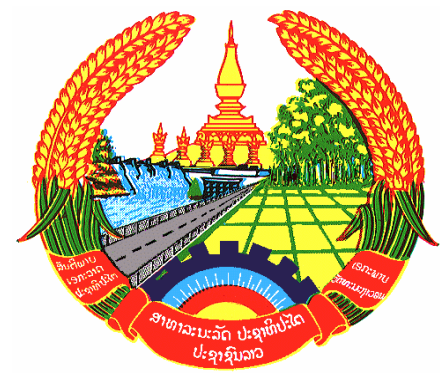

\section{National Growth and Poverty Eradication Strategy}

\author{
(NGPES)
}


Lao PDR - National Growth and Poverty Eradication Strategy (NGPES)

\section{TABLE OF CONTENT}

PART I: The National Growth and Poverty Eradication Strategy: An Overview ................................ 1

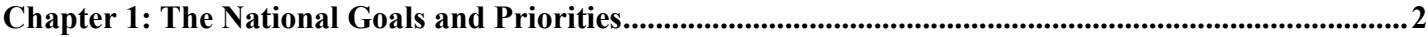

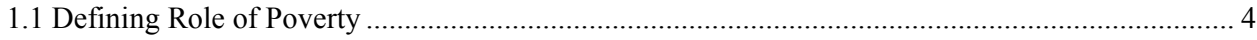

Chapter 2: An Enabling Environment for Growth and Development ........................................................

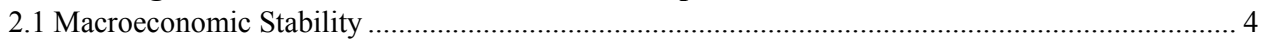

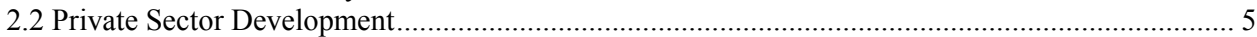

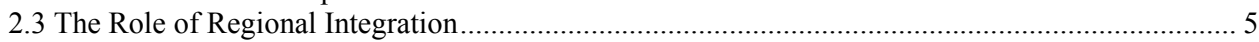

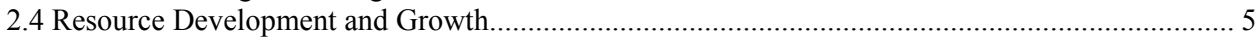

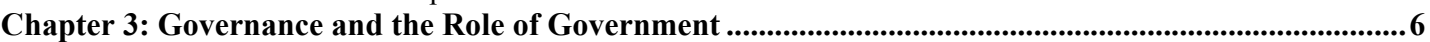

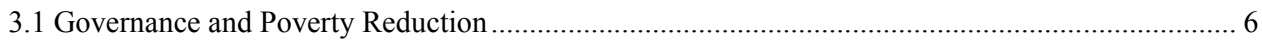

3.2 Strengthening the Capacity of the Government and Rule of Law ................................................. 6

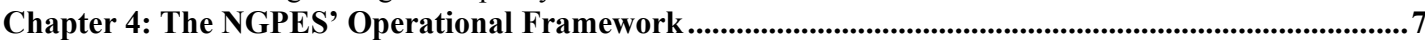

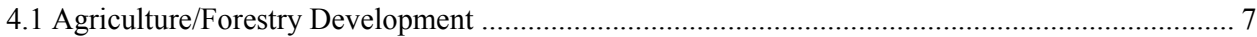

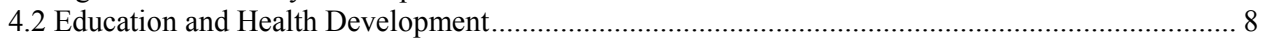

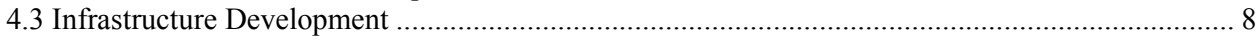

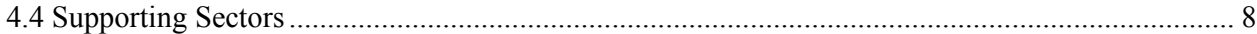

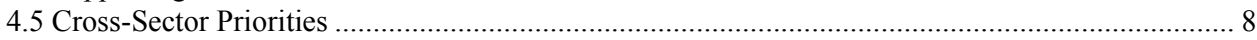

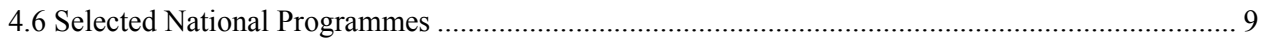

Chapter 5: Rural Development and the Poor-District Focus...........................................................................9

Chapter 6: The Thammasat Way of Development ….............................................................................................11

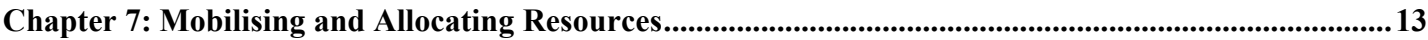

7.1 The Medium-Term Expenditure Framework FY 2003-2004 to FY 2005-2006 ............................ 13

7.2 Resource Allocation for 2003-2004 FY to 2005-2006 FY ....................................................... 15

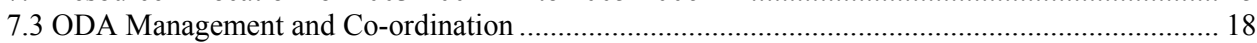

7.4 Participatory Planning, Implementation and Monitoring ……...................................................... 18

PART II: Poverty Assessment of the Lao PDR ...........................................................................20

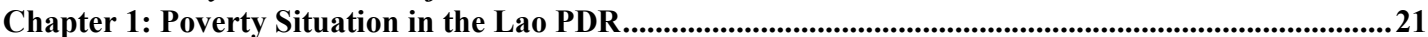

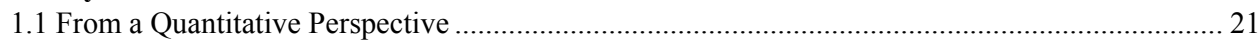

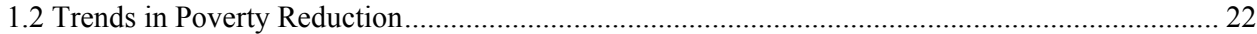

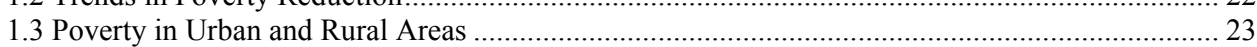

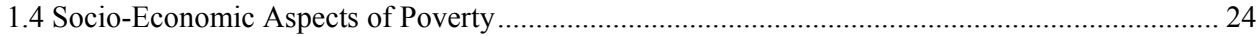

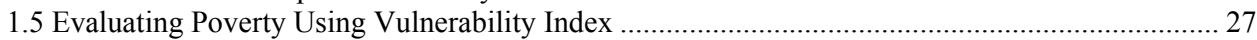

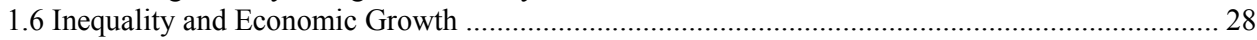

Chapter 2: Qualitative Participatory Approaches to Poverty Analysis .....................................................28

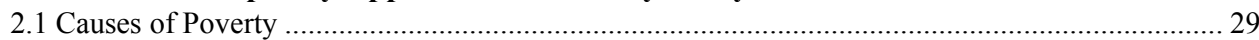

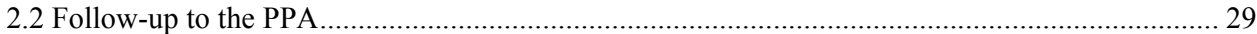

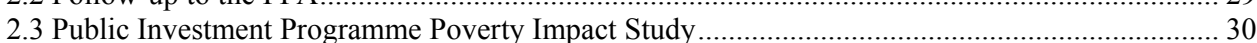

Chapter 3: Poverty Criteria and District Poverty ....................................................................................................30

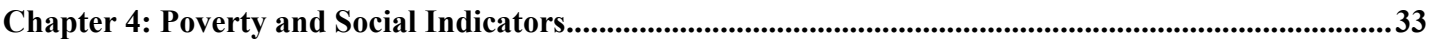

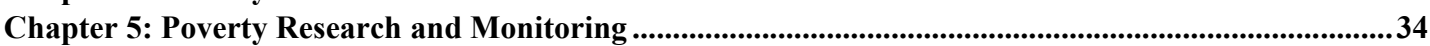

5.1 Poverty Monitoring of Households via Village Level Statistical Data........................................ 35

5.2 Quantitative Poverty Monitoring Using the LECS III 2002/03 Survey.......................................... 35

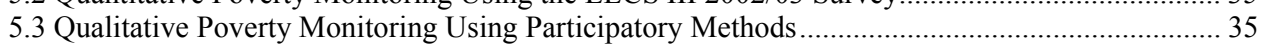

5.4 Linkages between National and International Efforts ............................................................... 36

Chapter 6: Poverty Vulnerability Assessments and Coping Strategies.....................................................36

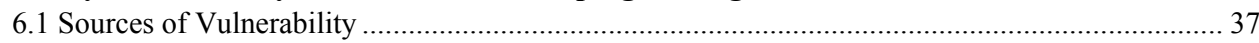

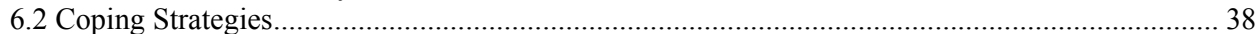

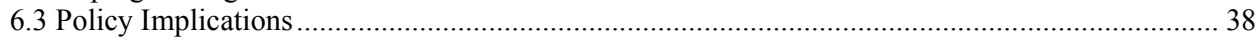

PART III: Strengthening the Overall Environment for Sustainable Growth and Development..... 40

Chapter 1: Macroeconomic Stability as a Fundamental Requirement for Growth and Poverty

Eradication

1.1 Overview of Macro-economic Performance During the Past Decade ............................................ 42

1.2 Macroeconomic Policy Measures and Poverty Reduction .......................................................... 43

Chapter 2: An Enabling Business Environment for Enhancing Growth and Eradicating Poverty 45

2.1 Macro-economic Stability and Financial Flows to the Private Sector............................................ 45

2.2 Specific Measures to Accelerate Private Sector Development.......................................................... 45

Chapter 3: Consolidating Public Sector Governance ..................................................................................46

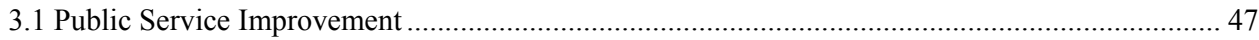

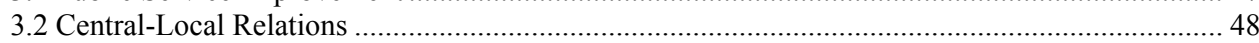

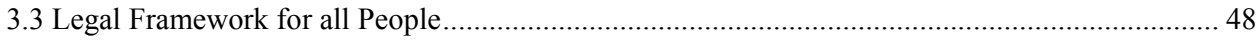

3.4 Socio-economic Management: Land Use and Administration ........................................................ 49 
Lao PDR - National Growth and Poverty Eradication Strategy (NGPES)

Chapter 4: Sustainable Revenue Development .....................................................................................................49

PART IV: National Sector Plans to Promote Sustainable Growth and Poverty Eradication ........... 52

Chapter 1: Poverty-Focused Agriculture/Forestry Development Plan: Policy and Investment

Priorities

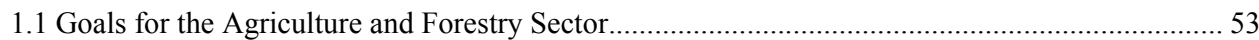

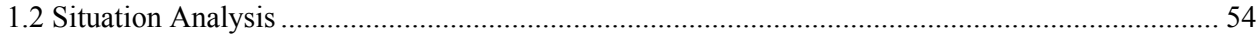

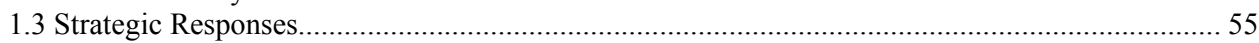

1.4 Poverty-Focused Agriculture/Forestry Development Priorities .................................................... 57

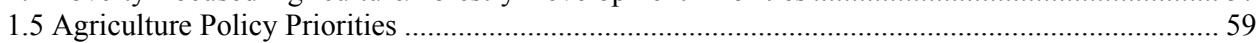

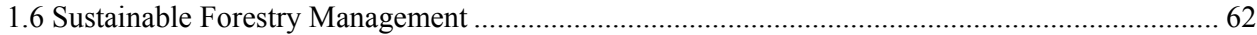

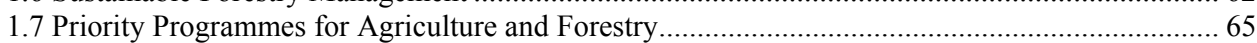

1.8 Overall Coherence, Institutional Development and Capacity Building ........................................ 67

Chapter 2: Poverty-focused Education Development Action Plan:Policy and Investment Priorities .......68

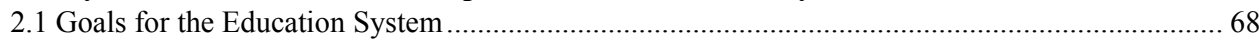

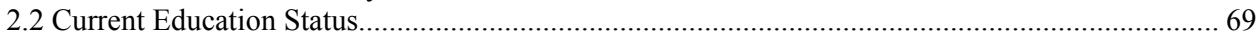

2.3 Poverty-focused Education Priorities ................................................................................ 72

2.4 Strategic Framework for Development of the Education Sector ................................................. 72

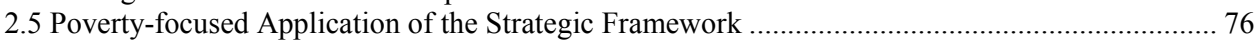

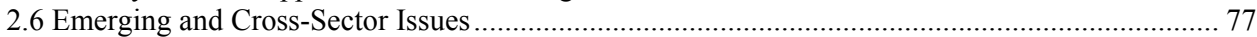

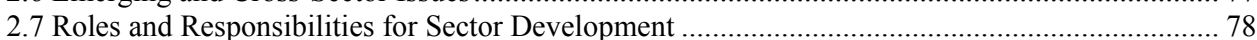

Chapter 3: Poverty-focused Health Development Plan: Policy and Investment Priorities ..........................80

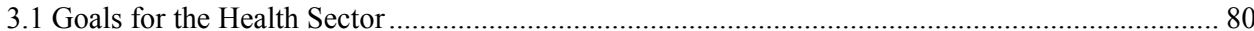

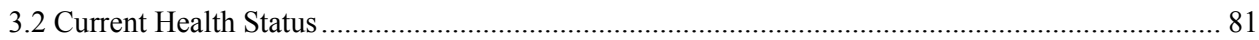

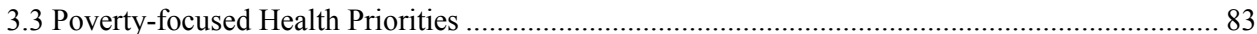

3.4 Strategic Responses for Poverty-focused Health Development ............................................. 83

Chapter 4 : Transport and Poverty Eradication: Policy and Investment Priorities.....................................93

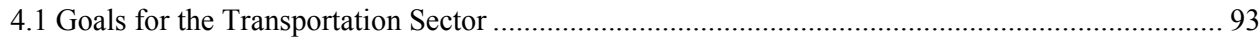

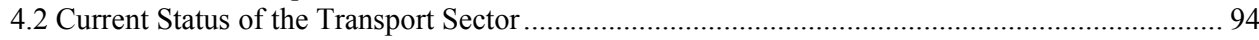

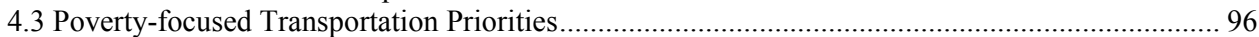

4.4 Principles of Poverty-Focused Transport Interventions .............................................................. 97

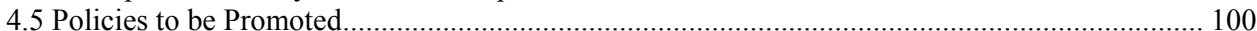

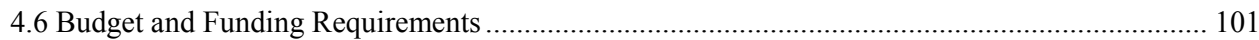

4.7 Investment Support, Institutional Strengthening and Capacity Building .................................... 101

Chapter 5: Industrialisation and Modernisation: Vital Role of the Supporting Sectors.......................... 102

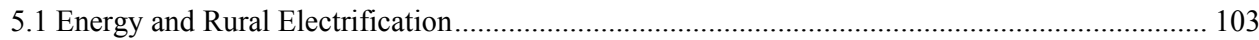

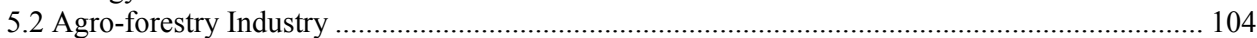

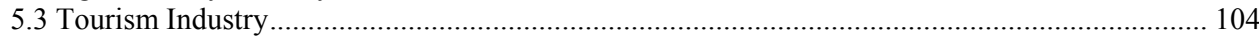

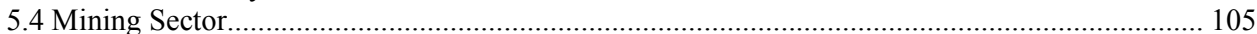

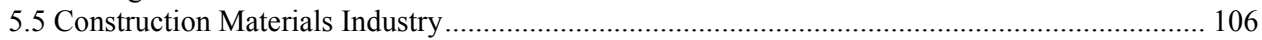

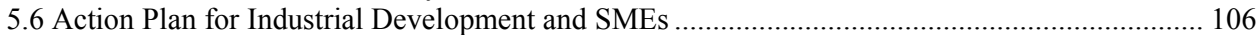

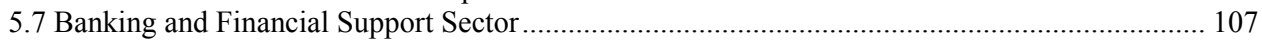

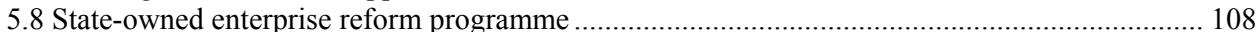

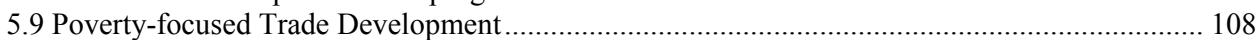

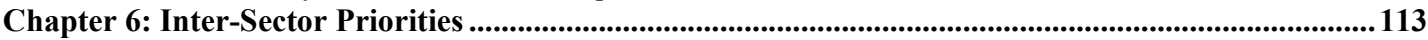

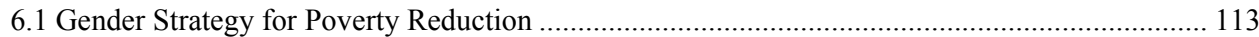

6.2 Environment Conservation and Poverty Eradication ................................................................. 116

6.3 Population Policy for Poverty Reduction ......................................................................... 118

6.4 An Efficient Social Security System to Prevent Poverty........................................................... 119

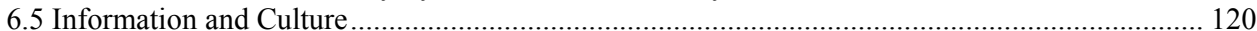

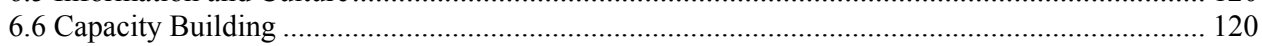

Chapter 7: Poverty-Related National Programmes ....................................................................................... 122

7.1 The National Drug Control Programme …….......................................................................... 122

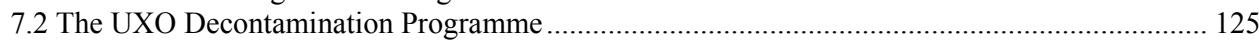

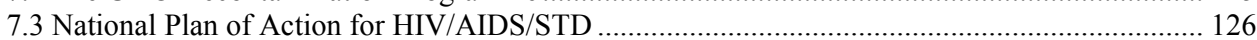

Chapter 8: Community-Driven Rural Development, Poor Districts and Poverty Eradication ............... 128

Part V: Mobilising and Allocating Resources - Reconciling Development Priorities with the

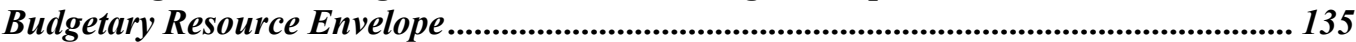

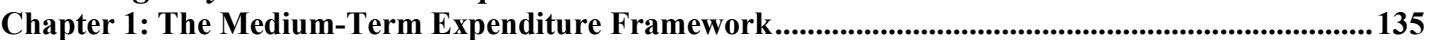

Chapter 2: Resource Allocation and Investment Requirements...........................................................142

Chapter 3: Strengthening Effectiveness and Accountability ...................................................................148

PART VI: Participation, Monitoring, Evaluation ........................................................................... 149

Annexes 1 - 4

List of Acronyms 


\section{Preface}

The National Poverty Eradication Programme (NPEP) has been renamed by the Government of the Lao PDR in order to avoid confusion with the 8 national programmes and to better reflect its true substance. This decision was based on suggestions of the National Assembly and other national stakeholders. The new name adopted after internal consultations is the National Growth and Poverty Eradication Strategy (NGPES).

The NGPES is the strategic framework under which all of the Government's future growth and poverty eradication programmes will be developed and implemented. The NGPES is the result of a process that started in 1996 when the $6^{\text {th }}$ Party Congress defined the long-term development objective as freeing the country from the status of least-developed country (LDC) by 2020 .

Exiting the status of LDC requires eradicating poverty in a sustainable manner. Adhering to this conviction, the Government presented at the $7^{\text {th }}$ Roundtable Meeting in November 2000 its medium-term strategic approach: "Fighting Poverty through Human Resource Development, Rural Development and People's Participation". This was further developed into the NPEP, which was presented at the $8^{\text {th }}$ Roundtable Meeting in September 2003. In October 2003, in its final resolutions on the adoption of the Plan and State Budget, the National Assembly mandated the Government to implement it.

The NGPES is a comprehensive framework for growth and development, and has a particular focus on the improvement of the poverty situation in the poorest districts. It has thus a dual objective: enhancing growth and development, and reducing poverty.

The NGPES is designed to accelerate the positive trend in reducing poverty in the Lao PDR. Poverty has decreased dramatically over the last decade, from 45 per cent of the population in $1992 / 93$ to about 30 per cent in 2002/03.

The implementation of the NGPES requires a synergetic undertaking based on four main sectors, several supporting sectors, cross-sector priorities and a series of specific, poverty-related national programmes. The evolving nature of the strategy demonstrates that it is as much a process as a document. Many of the issues raised in the document will therefore be addressed during the implementation phase. As such, the NGPES is both a point of arrival and a point of departure.

As the NGPES clearly states, it is the Government's firm commitment to gradually lessen the Lao PDR's high dependency on official development assistance (ODA). This will happen progressively and result from the consistent efforts undertaken to create a broad base for countrywide growth and from the many significant investments in the national resource base which will yield substantial revenues to the budget, over time. This, together with a greatly improved tax administration and the systematic enhancement of all economic sectors, in particular private sector development, will markedly increase revenue flows to the budget and, consequently, reduce the country's dependency on ODA. However, until these resources eventuate, we will still need to address the issue of the existing resource gap in order to keep the momentum of growth and poverty eradication. 
The development partnership that the Government has always advocated has reached a new level of achievement with the NGPES. The NGPES consultation process was extensive and involved both the Lao PDR's partners in development and national stakeholders at all levels. The NGPES will be widely distributed in order to promote debate and its anchoring at the local level. Monitoring progress in NGPES implementation is a task conferred to the Committee for Planning and Investment (CPI), while co-ordination of its implementation is the task of the new Roundtable Steering Committee.

The Government of the Lao PDR is thoroughly committed to implement the NGPES in the best possible way. Indeed, the NGPES is at the centre of the national development agenda and reflects the Government's policy and strategy framework to achieve the country's 2020 goal.

May I, on behalf of the Government and the People of the Lao PDR, convey to the international donor community our unwavering determination to further the socio-economic development of the country and our conviction that with their continued support we will achieve our development goals, and thus contribute to the realisation of the Millennium Development Goals and the Brussels LDC Action Plan.

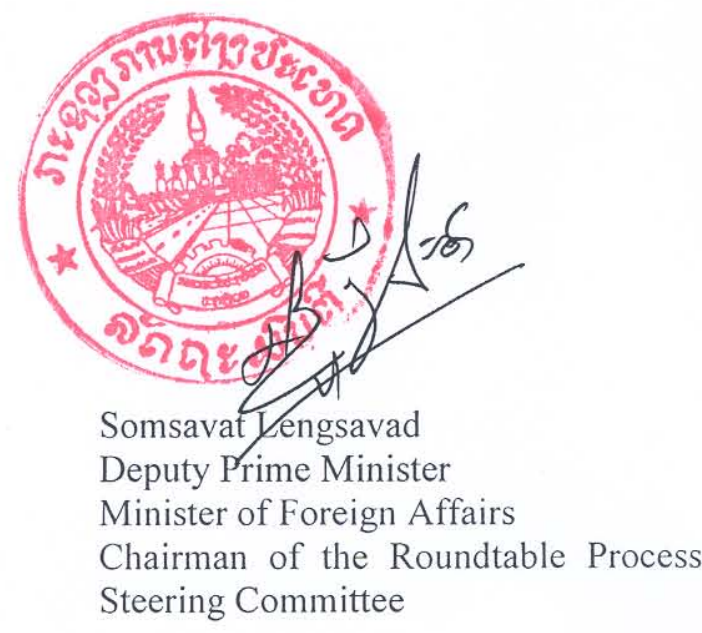




\section{PART I: The National Growth and Poverty Eradication Strategy: An Overview}

The National Growth and Poverty Eradication Strategy (NGPES) is central to the national development agenda. The NGPES encapsulates the essence of the Lao PDR's approach towards achieving the goal set in 1996 by the $6^{\text {th }}$ Party Congress, namely, exiting the group of LDCs by 2020 .

The Lao PDR's long-term national development goal is to be achieved through sustained equitable economic growth and social development, while safeguarding the country's social, cultural, economic and political identity. The foundations for reaching this goal have been laid during the past 28 years of peace and development in the country by:

- Moving consistently towards a market-oriented economy.

- Building-up the needed infrastructure throughout the country; and

- Improving the well-being of the people through greater food security, extension of social services and environment conservation, while enhancing the spiritual and cultural life of the Lao multi-ethnic population.

At the $7^{\text {th }}$ Roundtable meeting in November 2000, in Vientiane, the Government presented its strategic medium-term approach to poverty fighting, entitled "Fighting Poverty through Human Resource Development, Rural Development and People's Participation”.

In March of 2001, the $7^{\text {th }}$ Party Congress further refined the 2020 vision by specifying poverty reduction targets for 2005, 2010 and 2020 and highlighting industrialisation and modernisation priorities.

In June of 2001, the Prime Minister issued Instruction 010, identifying poverty criteria and clarifying the modalities for the preparation of an operational poverty eradication programme, based on the concept developed by the Government in the strategic approach presented at RTM 7.

The Party Congress sets the guidelines and defines the way forward. Through the 5-year National Socio-economic Development Plans, the Government translates these into specific targets and objectives and identifies strategic programmes and priorities by sector to achieve them. The Roundtable documents operationalise these plans according to resource mobilisation needs.

While each document has its particular purpose, together they form a coherent set of references that will lead the Lao PDR to the achievement of the 2020 goal. The NGPES is the Government's operational response to this over-arching objective. It builds on the medium-term strategic approach to poverty eradication", making it part of an overall "growth with equity" framework.

Since the adoption of the New Economic Mechanism and the open-door policy in 1986, considerable progress has been achieved. Key social and economic indicators have steadily improved. Economic growth rates were strong throughout the nineties, despite the Asian financial crisis. Growth since the start of the new millennium has been steady in a stable macro-economic climate. The Lao PDR has become an active partner in ASEAN and other regional co-operation initiatives.

\footnotetext{
1 “Fighting Poverty through Human Resource Development, Rural Development and People's Participation”, Government document to RTM 7, November 2000.
} 
However, much more remains to be achieved to sustain economic growth and eradicate poverty in the long term. In developing a coherent framework for growth and development - as the basis for sustainable poverty eradication - the NGPES emphasises a certain number of essential linkages between the four main sectors, several supporting sectors, cross sector priorities and specific national programmes. A community-driven and access-oriented rural development strategy will be at the base of poor-district development. Enhanced macro-economic stabilisation, private sector development, including foreign investment, public management for improved governance, and resource development, will form the basis for a sustainable long-term growth environment.

Successful implementation of the NGPES is critical. Embedded in a long-term comprehensive growth and development framework, the NGPES focuses on successive efforts to achieve the goal of poverty eradication by 2020 .

The NGPES emphasises the promotion of sustainable growth, coupled with continuous social progress and equity. In this manner, the material conditions and quality of life of the multi-ethnic population will be improved and basic poverty eradicated. The Government's strategic framework for the NGPES was based on a nation-wide consultation and participation process which highlighted the following inter-linked components:

- An in-depth assessment of the poverty situation in the country, together with its causes, with a focus on poor districts (Part II of the NGPES).

- The environment for sustainable economic growth (Part III).

- National action plans for the main strategic sectors and trans-sector areas, as well as for specific national programmes, in response to poverty eradication priorities (Part IV).

- Mobilising resources for optimal use consistent with national expenditure framework (Part V).

- A participation and implementation strategy (Part VI).

Chapters 1-7 of Part I summarise the main tenets of the national development framework by following these components. This also reflects the structure of the NGPES document. The compact presentation of the NGPES' main policy and strategy priorities and their organic interlinkages emphasises the operational implications underlying the implementation of the NGPES as well as the intrinsic coherence of the Government's policy reference for growth and poverty eradication. Part I can thus be considered as an executive summary of the NGPES.

Implementation will be achieved through the continuous strengthening of a favourable environment for sustainable growth and development and will have a particular focus on poverty eradication in the poorest districts.

\section{Chapter 1: The National Goals and Priorities}

The $7^{\text {th }}$ Party Congress (March 2001) defined the following guidelines for poverty eradication and sustainable economic growth:

$\Rightarrow$ The socio-economic development of the country must be balanced between economic growth, socio-cultural development and environmental preservation. These are the three pillars of the Lao PDR's development policy.

$\Rightarrow$ Socio-economic development must be harmoniously distributed between sector and regional development, and between urban and rural development, so as to fully and efficiently utilise human and natural resources. 
$\Rightarrow$ Socio-economic development must be based on sound macroeconomic management and institutional strengthening in order to enhance national solidarity and cohesiveness and to promote democracy within society.

$\Rightarrow$ The national development potential and strengths must be combined with regional and global opportunities in order to enable the Lao PDR to participate in regional and international economic integration.

$\Rightarrow$ Socio-economic development must be closely linked with national security and stability.

Within these guidelines, the main objectives of the long-term development strategy are:

- To sustain economic growth with equity at an average rate of about 7 per cent, considered as the necessary rate for tripling per-capita income of the multi-ethnic Lao population by $2020^{2}$.

- To halve poverty levels by 2005 and eradicate mass poverty by 2010 .

- To eliminate opium production by 2006 and phase-out shifting cultivation by 2010 .

To attain these objectives, the Government of the Lao PDR has outlined the following strategic priorities:

> Maintain an appropriate level of economic growth for the medium and long-term period in response to demographic trends.

> Enhance human resource development through education, particularly basic education at all levels and including the formal and informal sector as well as vocational training.

$>$ Develop and modernise social and economic infrastructure in order to facilitate economic development in each region of the country and to accelerate the Lao PDR's regional and international economic integration.

$>$ Facilitate access to electricity for people in all areas and regions of the country in order to foster integrated economic development.

> Promote industries utilising domestic natural resources, and actively promote small and medium-sized enterprises (SMEs) and handicrafts production.

> Develop and promote all economic sectors, particularly the private sector, including foreign direct investment (FDI) in order to expand business opportunities, placing emphasis on export-oriented sectors that have a comparative advantage.

$>$ Enhance market linkages and trade facilitation.

$>$ Strengthen existing legal and regulatory frameworks.

$>$ Create favourable conditions and mechanisms for improving financial institutions and further capital market development.

$>$ Promote economic co-operation with all partners and countries.

This refinement of the objectives and strategies has helped in the implementation of the eight priority programmes of the Government: food production; commercial production; shifting cultivation stabilisation; infrastructure development; rural development; human resource development; service development, and; foreign economic relations.

The national development strategies are deeply anchored in the Government's over-arching concern to create a positive future for the country's youth who represent over half of the population. ${ }^{3}$

\footnotetext{
${ }^{2}$ In 2020 , the population is expected to reach 8.3 million.

${ }^{3}$ People under 20 years of age represent 55 per cent of the population, and those between 20 and 40 years, 26 per cent.
} 
Lao PDR - National Growth and Poverty Eradication Strategy (NGPES)

\subsection{Defining Role of Poverty}

The perception of poverty has a defining role regarding national objectives and strategic priorities. The National Poverty Assessment is the anchor piece of the NGPES as it determines the content and scope of the main components. Initiatives leading to a more conducive environment for sustainable growth and sector action plans are directly linked to the poverty analysis. In short, the pattern and determinants of poverty define the national strategy for eradicating poverty.

As documented in Part II, the Government's and people's efforts have led to a significant reduction in the national poverty level from about 45 per cent in 1992/93 to about 38 per cent in 1997/98. Preliminary data indicate a further reduction to about 30 per cent currently. However, income disparities appear to have increased. ${ }^{4}$

Poverty is evident in a variety of factors. The Prime Minister's Instruction on the eradication of poverty provides an operational definition: 'Poverty is the lack of ability to fulfil basic human needs such as not having enough food, lacking adequate clothing, not having permanent housing and lacking access to health, education and transportation services" (Instruction No 010/PM, June $25,2001)$. The same decree outlines poverty indicators at the household, village, district, provincial and national levels. As Instruction 10 is still in the process of implementation, there are only preliminary poverty numbers available at the household and village levels.

The Government, in discussion with provincial authorities, line ministries and other stakeholders, has reached agreement that poverty reduction at the district level should be the priority focus. Districts are the most relevant and reliable level for data collection and poverty monitoring. Further, districts are the level where co-ordination, consultation and participation can best be achieved. Based on Instruction No 010/PM, the Committee for Planning and Co-operation (CPC) and the provinces have identified 72 districts as poor. A core group of the 47 poorest districts has been selected for priority investments for the period 2003-2005.

\section{Chapter 2: An Enabling Environment for Growth and Development}

Providing an enabling environment for growth and development continues to be a top priority of the Government as it is a prerequisite for eradicating poverty. The Government has reached agreement with the international financial institutions on the necessary reforms to achieve a sound environment for growth. The NGPES details these reforms and presents matrices for monitoring progress.

\subsection{Macroeconomic Stability}

Enhancement of the overall environment requires the maintenance of macro-economic stability. This includes: prudent monetary, fiscal, exchange rate and interest rate policies; improved taxation, trade and industrial policies, and; strengthening of open-door policies and implementation of ASEAN commitments.

An enhanced environment for growth also requires the reinforcement of the legal framework and a level playing field for all economic actors involved. Best corporate practice must be applied to the banking system to mobilise capital, especially in support of small and medium size enterprise and rural areas. Improvement of the financial sector (including a national strategy and action plan for micro-credit) is a high priority. Further reform is needed concerning state-owned enterprises and land use management.

\footnotetext{
${ }^{4}$ Official data from LECS III will be available in the first half of 2004.
} 


\subsection{Private Sector Development}

The private sector, trade and domestic and foreign direct investment (FDI) are expected to be prime factors in driving the economy and every effort must be made to ensure a positive business environment for them. Consultation with the private sector will be enhanced and licensing and other regulatory concerns streamlined. Further, the transparency of the tax code will be improved and the corporate law framework strengthened. Greater effort will be made to ensure that Lao and English versions of all laws are made available after passage, and consultations with domestic and foreign private sector representatives will be conducted during drafting. Increased foreign investment in the Lao PDR will contribute to technology transfer and management expertise, as well as export growth; the procedures and incentives for FDI are being given priority attention. Policies and measures to encourage small and medium-sized enterprises particularly adapted to the Lao PDR are also given high priority.

\subsection{The Role of Regional Integration}

Regional integration, in the context of peace and security, is imperative for the Lao PDR. The NGPES outlines the appropriate conditions needed to further enhance our integration into the region - through the many initiatives of ASEAN, but also in the context of the Greater Mekong Sub-region (GMS) in which the Lao PDR is an active partner. The formulation of a "Growth Triangle Plan" between Laos, Vietnam and Cambodia illustrates the Government's commitment to regional integration. So does the Lao PDR's participation in the Mekong-Ganga Basin Commission and in the "Emerald Triangle" for the development of tourism between Laos, Cambodia and Vietnam. Agreements on border trade and the promotion of the Special Economic Zone in Savannakhet-Seno are further illustrations.

\subsection{Resource Development and Growth}

Resource development and growth initiatives are part of the further strengthening of an enabling macro-economic environment. Future growth enhancing investments and development priorities which reflect the economic potential of the country's natural resource base have been identified by the Government as a vehicle for increasing national revenues and, thus, poverty eradication. Hydropower, mining, tourism and wood- and agro-processing industries are the highest priorities for investments leading to economic growth and increased revenues. Royalties and taxes to the Government will comprise the bulk of these revenues. Emphasis will be placed on the promotion of economic growth centres throughout the country in order to further develop the national resource base with its rich endowment of natural resources including water resources, land, forestry and bio-diversity. ${ }^{5}$ This includes the delineation of regions to better integrate economic, infrastructure, trade and services development ${ }^{6}$. Macro-economic stability, private sector development, trade facilitation and regional integration policies and strategies all feed into expanding this resource base to promote economic growth nation-wide.

\footnotetext{
${ }^{5}$ It is estimated that over two thirds of the GDP derive from natural resources.

${ }^{6}$ North, Centre, South and Border areas. The Northern Region Development Strategy, supported by the ADB, illustrates this idea of enhancing regional economic growth by providing an appropriate planning and investment reference. This study could provide a genuine approach to regional development and serve as a model approach for other regions of the country.
} 


\section{Chapter 3: Governance and the Role of Government}

With the transition to a more market-based economic system, the Government must be fully responsive to the needs of both public and private enterprise. At the same time, however, it must provide the policy and regulatory framework that conserves the environment and improves the livelihoods of the Lao people. Strengthening the rule of law in all areas and continuing policy reform is an integral part of the Government's commitment to improved governance. Ensuring efficient public service delivery through improved organisational structures and procedures, and creating a productive and motivated professional civil service adhering to high ethical standards is a top priority. Improved governance is an integral part of the Government's effort to strengthen the overall environment for growth and development.

\subsection{Governance and Poverty Reduction}

Improvements in governance are directly linked to poverty reduction for limited public resources must be used effectively and efficiently in reaching out to help the poor. Importantly, in the transition to a more market-based economy, the system of decision-making must be more community-based, transparent and accountable. For the past decade, the Government has embarked on wide-ranging public administration reforms, designed to create an effective, efficient and low-cost public administration, together with the requisite institutional and legal framework. $^{7}$

Despite these reforms, public administration still suffers from duplication of mandates, insufficient co-ordination, inadequate management rules and procedures, and very low salaries. The latter in particular greatly weakens the ability of the public service to operate effectively. The Government is committed to strengthening the incentives for strong performance in all areas, especially in the delivery of basic services such as education and health care. It will continue to refine the organisational structure and role of government and enhance a framework conducive to further growth of all economic sectors, including the private sector. Most importantly, the Government is committed to a system of governance that ensures stability and respect for the social, cultural and environmental interests of the multi-ethnic Lao people. Only by ensuring stability and unity can the Lao PDR provide an efficient framework for economic growth with equity.

\subsection{Strengthening the Capacity of the Government and Rule of Law}

The NGPES outlines a wide range of measures to strengthen the capacity of the Government at all levels to better fulfil its vital role. Among these measures are strengthening of the public service, especially at the district level. ${ }^{8}$ The redefinition of central-local relations is an important initiative.

By being more community-based, the Government expects that public services will be more responsive to community needs. The Government places great importance on strengthening dialogue between central and local authorities, the population at large, and social organisations. Administrative reforms to improve the functioning of Government and the civil service will assist in strengthening accountability, transparency and ethical behaviour.

\footnotetext{
${ }^{7}$ These reforms are documented in Government of Lao PDR, Public Service Reform, People's Participation, Rule of Law and Sound Financial Management: A Policy Paper of the Government of the Lao PDR on Governance Issues, April 2003.

${ }^{8}$ A new Decree on the Civil Service Statue enables the Government to introduce more performance-oriented human resource management practices. Also, an Anti-Corruption Decree (Decree NO. 193/PM, 1999) rewards integrity and performance, and curtails activities that lead to a possible conflict of interest or an abuse of office.
} 
To help ensure that all citizens and particularly the poor and disadvantaged have effective legal rights, the Government will emphasise greater transparency of and access to the legal system. Of particular interest to rural people, a master plan for integrated land management is under preparation, highlighting community-led decision-making and resource allocation.

Sound, accountable and transparent financial management is an integral part of the Government efforts to increase efficiency of public management and resource allocation.

\section{Chapter 4: The NGPES' Operational Framework}

Drawing on the national poverty assessments, the NGPES' medium-term operational framework comprises four main sectors, various supporting sectors, several cross-sector priorities as well as specific national programmes addressing poverty eradication. Each sector has a nationwide mandate to contribute to build-up the country and its capacities and to foster its economic and social integration. The sector/supporting sector action plans mainly address their nation-wide mandate.

The four main sectors are agriculture/forestry, education, health, and infrastructure, especially rural roads.

The supporting sectors (potential growth sectors) comprise the emerging industrial development through energy and rural electrification, agro-forestry, tourism, mining and construction materials industries. Trade facilitation and market linkages pervade most sectors and have an important impact on poverty eradication. A sound financial sector is necessary to support broad-based sustainable growth, poverty eradication and macro-economic stability. Strong bank and non-bank financial institutions will channel financial resources to productive use and ensure wide access to financial services.

Cross sector priorities encompass environment, gender, information and culture, population and social security. An all-cross-cutting issue is capacity building.

Three poverty-related national programmes - the National Drug Control programme, the UXO Decontamination programme and the National Action Plan for HIV/AIDS/STD - complete the NGPES' operational, 'sector-based' framework.

All sectors refer, in one way or another, to i) macro-economic requirements to improve their role and mandate, ii) private sector/market orientation/trade facilitation to enhance efficiency, iii) capacity building priorities, iv) environmental concerns, v) gender equity, vi) governance and institutional strengthening, and vii) co-ordination among sectors and agencies to achieve higher synergy.

These are important characteristics of the NGPES and as such represent a significant step to ensure its successful implementation.

\subsection{Agriculture/Forestry Development}

From a poverty eradication perspective, the most important policy-related objective regarding agriculture/forestry development is improvement of household food security. Contributing to this objective, and improved living standards more generally, market-based farming will be enhanced, disparities between lowland and sloping land farming reduced, and sustainable forest and watershed management enforced. 
Lao PDR - National Growth and Poverty Eradication Strategy (NGPES)

\subsection{Education and Health Development}

In education, the priorities are increased access to education for all people, especially for the under-privileged, strengthening of non-formal education, vocational training, improvement of teachers' qualifications and the relevance of school curricula, and improved management of the education sector.

In the health sector, priorities include strengthening and improving of the quality of health care at the grassroots level, particularly in under-served areas. Safe drinking water, sanitation systems and improved nutritional standards are equally urgent priorities.

\subsection{Infrastructure Development}

Road infrastructure priorities include maintaining the existing primary and rural road networks, through increasingly decentralised road management, and further developing of the rural road network and all-weather road provincial/district linkages.

Investments in infrastructure continue to be an essential component in promoting economic growth nation-wide and enhancing the country's integration into the region and complementing investment efforts undertaken through the various regional corridors. Comprehensive infrastructure is essential to help farmers access improved services and local, national and regional markets.

A functional and well-maintained road network is a precursor to transport and trade services, and to the installation of electric power supply in rural areas.

\subsection{Supporting Sectors}

Supporting or accompanying sectors include rural electrification, tourism and industrial development (with an emphasis on small and medium-sized enterprises) as well as trade promotion and development. In particular, market linkages and trade facilitation is an essential factor for the expansion of key sectors such as agriculture, industry and tourism. Mainstreaming trade priorities into sector development has a powerful impact on poverty eradication. A positive trade environment is a priority. Likewise, a sound and competitive banking sector encourages savings and channels financial resources to productive use. It is the foundation for all economic sectors, including the private sector, to contribute to economic growth.

\subsection{Cross-Sector Priorities}

Environmental conservation and natural resource management are a high priority, for they are integral to poverty eradication. Accordingly, close attention is given to conserving the rich biodiversity of the land.

In addition, close attention is given to community-based forest management, upgrading deteriorated ecological areas, countering industrial pollution and other concerns.

Gender equality is an important national goal, which is reflected in the Constitution, in major international commitments and in the establishment of a National Commission for the Advancement of Women (NCAW). Ensuring equal access for women to basic services and productive resources is a matter of equity, efficiency and effectiveness.

Other cross-sector concerns that the NGPES addresses as important means to improve livelihoods include cultural and spiritual enhancement; national identity and cultural heritage; and strengthening the social security system and emergency relief. 
In particular, the population policy ${ }^{9}$ including reproductive health, family planning, and hygiene, leading to a balanced population growth and distribution reflects a long-term development requirement to ensure sustainable poverty eradication.

Of the highest importance is capacity building across the board, but particularly for decentralisation management and development planning. These are two areas for which the Government envisages major initiatives responding to needs.

\subsection{Selected National Programmes}

The NGPES includes national programmes related to poverty eradication, several of which started some time ago. These programmes will be intensified, with particular reference to the 47 poorest districts.

The national programmes include those addressing drug control, UXO decontamination and HIV/AIDS. These programmes contribute to the national rural development programme, which aims to systematically reduce the number of poor districts. This effort coincides with and completes the focal development area approach.

\section{Chapter 5: Rural Development and the Poor-District Focus}

Rural development is central to the Government's poverty eradication efforts as rural poverty is of prime concern and a community-based approach to its eradication is essential. The Government's rural development strategy has two major components: improving access to essential factors of development; and strengthening a comprehensive, poverty-focused planning process at the district level to ensure all initiatives are mutually supportive and co-ordinated.

Improving access means improving access to production inputs, markets, human resources, social services and rural finance. These five categories include a wide range of factors, including rural infrastructure (roads, irrigation), technology, education and health services and natural resource management. Market information, market linkages and trade facilitation and other factors are needed to help the transition from subsistence to commercial farming, and from overwhelming dependence on agriculture to a more diversified economy (see Chart, next page).

However, improving essential factors of development will only be effective if all the factors are mutually supportive. Thus, the Government places a great deal of emphasis on enabling the rural poor to attack their own poverty.

A particular challenge is developing alternatives to pioneering shifting cultivation, hence the need to support initiatives for diversification into livestock, horticulture and cash crops. Also, forestry, agro-forestry and NTFPs offer alternatives. Poor households in rural areas must first and foremost secure their food supply, hence planning must start with this basic reality.

Capacity building at the district and village level is urgently needed, including skills in determining land use and watershed management, as well as capacity for social/environmental impact analysis and mitigation regarding rural and other developments. Complementarity in all undertakings at the district level is necessary, including for the elimination of poppy cultivation and UXO decontamination.

\footnotetext{
${ }^{9}$ See National Population and Development Policy, 1999.
} 


\section{Diagram 1: Rural Poverty Eradication - Strategic Approach}

\section{CATALYST 1: Services}

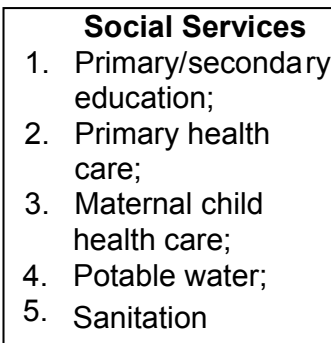

\section{CATALYST 2: Empowerment}

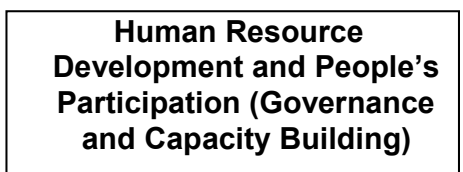

\section{CATALYST 3: Capital}

\section{Rural Finance and Capital}

1. Farmer production credit;

2. Village and district funds credit; domestic investment

3. Foreign direct investment

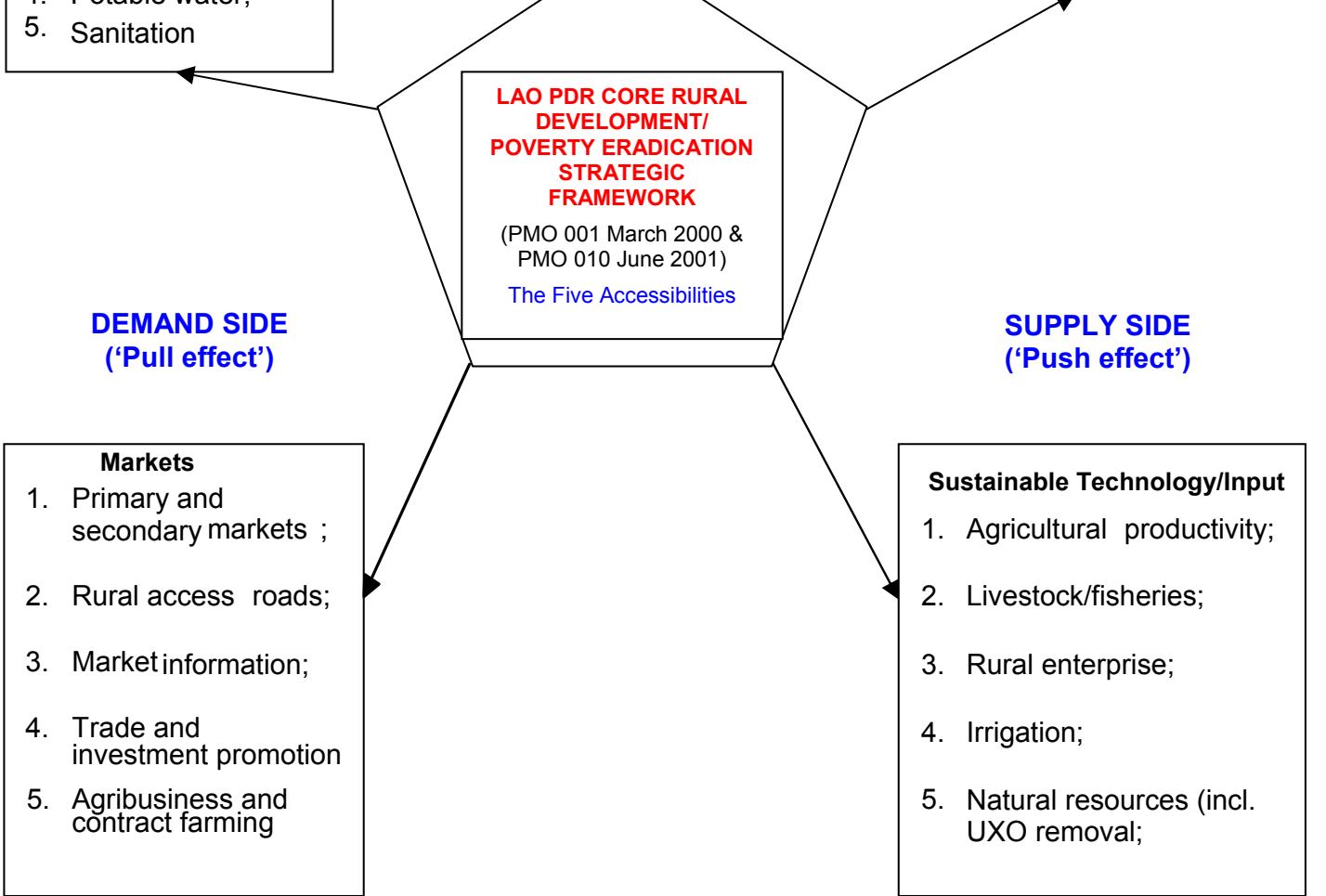

MAF: Department of Planning

Together, accessibility and community-driven planning are the essence of the poverty eradication/rural development strategy of the Government. The chart below outlines the key factors determining accessibility, and the linkages between them which require careful planning especially at the "grass roots" level.

To ensure that economic growth and modernisation benefits the poor, 47 districts have been selected for priority investments over the period to 2005. Following this, the remaining 25 districts (of the 72 poor districts identified) will receive priority attention. In this context, the focal development area approach, integrated watershed management and small towns development are important for they offer essential services and economic opportunities that do not reach the most remote and isolated communities. 
The Government intends to encourage "development funds" for the poorest districts, particularly village and district funds, which will provide support to households and villages to enable them to engage in income generating activities. Income generation empowers people to undertake initiatives and to expand their range of choices to improve their livelihoods. In such a way, through the village and district funds, the present lack of capital, which has been identified as a major cause of poverty, will be addressed.

Thus, village development and district development funds will play an important role in enhancing local development. In channelling resources to these funds, the Government conveys its conviction that development should be community-driven and that Government funds should only be used for what people cannot do themselves to eradicate poverty. Conditions must be enhanced in such a way as to enable people to organise themselves and to improve their livelihoods according to their own initiatives and visions of the future.

\section{Chapter 6: The Thammasat Way of Development}

The Government of the Lao P.D.R. follows a harmonious "triangular" approach to development, where - as in the case of the traditional Lao kettle - balance depends on three legs: economic growth, social/cultural development, and conservation of natural resources.

Economic growth must be based on sound management of natural resources and enhanced social and cultural development. Likewise, social and cultural development has to be backed up by solid economic growth, while appropriate resource management is fundamental to improving living standards. The three "legs" are mutually supportive. The Government thus favours a balanced approach to poverty reduction. Socio-economic development, as mentioned earlier, has to be balanced with population growth.

The Lao PDR's approach has much in common with the thammasat way of development, ${ }^{10}$ where local solutions are to be found respecting the natural context, productive forces, technology, values and traditions on which the country's future is built. The implications of the thammasat way for national development are being studied.

Within the outlined national development framework food security, industrialisation and modernisation are particular concerns of the Government. Food security has always been a top priority. Achieving a basic level of food self-reliance does not mean food autarky. But it does mean that the national economic system, which is essentially based on agriculture, must be able to provide sufficient food for the population. Achievement in 2000 of national rice sufficiency, for the first time in the history of the Lao PDR, was a major milestone.

However, overall rice sufficiency does not necessarily mean that sufficient food is available everywhere. The task is to ensure that all people have access to sufficient food to meet their basic needs throughout the year. Food vulnerability has to be reduced if agricultural diversification is to be encouraged, if children are to be sent to school, and if opportunities for self-development are to be acted upon.

For this reason, the Government of the Lao PDR aims, through the district approach to poverty eradication, to ensure that all possible measures are undertaken to address food insecurity at the household, village and district level. A village focus, within an enabling district environment, is ideal as traditional villages function as unified entities for household development. Targeting the poorest districts during the period to 2005 will address food access most effectively and efficiently.

${ }^{10}$ The Thammasat Way of Development - A Lao-Japan Study on development alternatives in the Lao PDR, NERI, 2002. 
Development and growth of the national economy also depends on the successful achievement of a well-conceived industrialisation and modernisation policy.

The industrial sector, including the manufacturing sector, accounts for about 22 per cent of GDP and is growing at around 7-8 per cent annually. This is not enough, however, to respond to the need for employment to absorb the rising number of young people entering the labour market. Nor is this rate sufficient to ensure adequate growth of the national economy. The relatively low rate of industrial growth, including construction, hydro-electricity and manufacturing, indicates that the national resource base is less than optimally developed. The NGPES addresses the issues involved and it is expected that by 2010 the industrial share of GDP will have risen to about 32 per cent.

In order to achieve this objective in a manner benefiting all areas, and particularly poor people, priority investments must be directed towards the following industries: electricity (because energy is critical to development and living standards); agro-forestry (because of its impact on development consistent with local capacities, cultural values and traditional factors of production); tourism (especially eco-tourism and encouragement of handicrafts production); mining (for processing and export), and; construction materials (to accommodate the growing construction industry).

A condition enabling this to happen is the development of human resource capacities and scientific and technological development. The long, medium and short-term priorities in the education sector focus, as mentioned earlier, on improving access, quality and management at all levels. Research, science and technology development must be tailored to meet local conditions and requirements, especially in the field of agricultural, forestry and livestock research. Thus, all ODA programmes and projects must include capacity building activities.

Industrialisation in the Lao PDR must be respectful of the people's values and their environment, and be on a human scale that creates the basis for employment and self-realisation. The Lao PDR has great resource potential.

The NGPES is the Government's comprehensive operational programme to achieve the 2020 goal through sustainable growth and poverty eradication. It is important to understand that it is only within such a comprehensive growth and development strategy that it will be possible to modernise the country. Only in this way can the resource base be expanded, in an ecologically sustainable way, for the benefit of the people and future generations.

Diagram 2 summarises the main elements of the NGPES, and the inputs and process leading to its preparation. 


\section{Diagram 2 : NGPES Process}

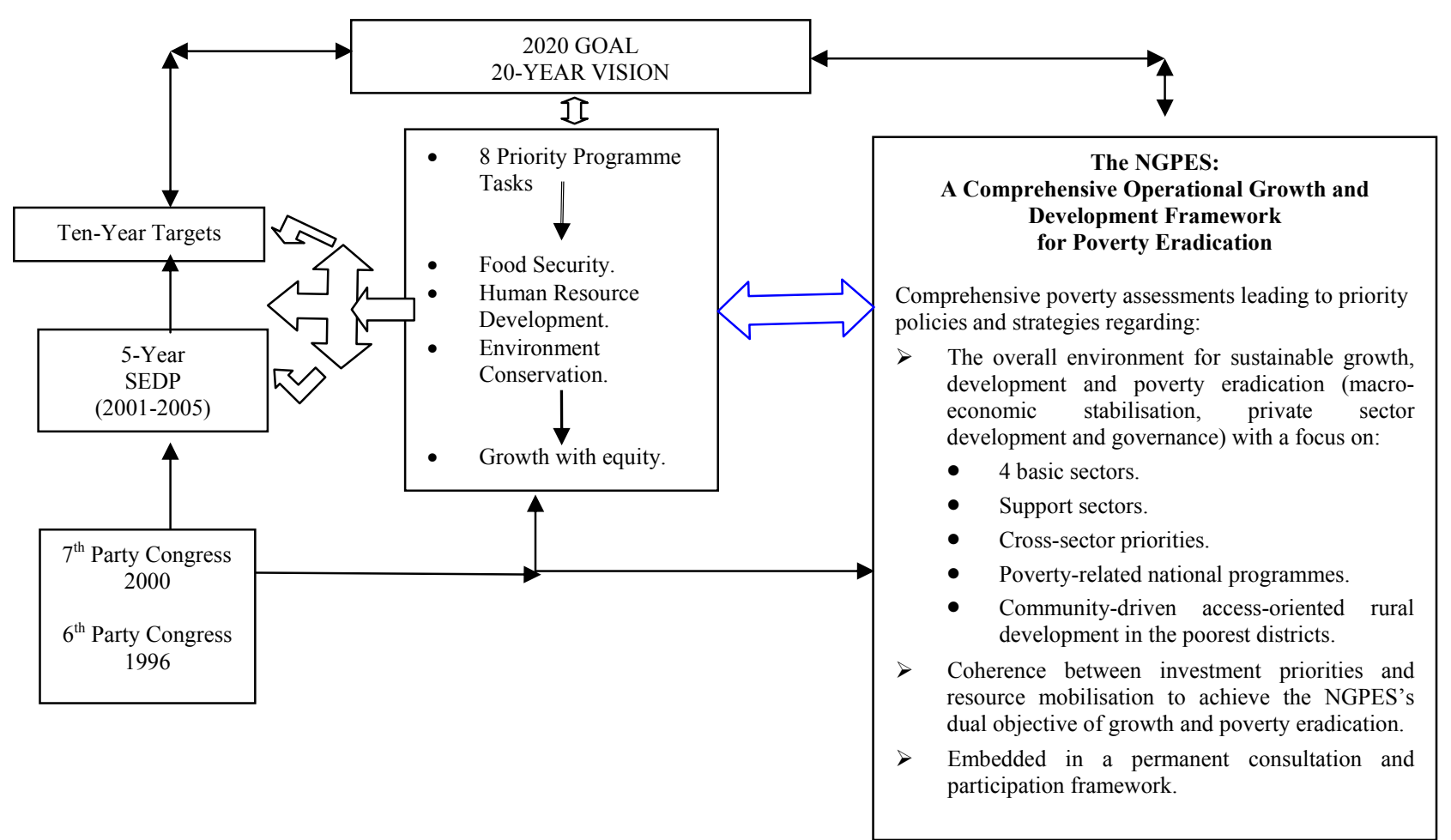

\section{Chapter 7: Mobilising and Allocating Resources}

Coherence in mobilising and allocating public resources is a basic requirement to achieve the country's development objectives, hence the importance of a medium-term expenditure framework. This framework will ensure that the implementation of the NGPES is reconciled with budget realities so that macroeconomic stability is not jeopardised and the fiscal deficit and external debt remain manageable. However, for the time being, it is not possible to fully estimate the cost of achieving the NGPES' goals. An estimation of the full implementation cost of the NGPES will be made over the next two years. This will also enable a closer link with the macroeconomic framework.

\subsection{The Medium-Term Expenditure Framework FY 2003-2004 to FY 2005-2006}

The medium-term public expenditure framework (MTEF) is an essential planning instrument and is based on a realistic projection of GDP growth rates, revenue flows to the budget and of expenditure needs.

The role of all economic sectors, including the private sector as a main engine for growth, has been stressed throughout the NGPES. Private sector development, including foreign direct investment (FDI), will provide part of the needed resources for national development. It will directly contribute to financing crucial growth investments, such as hydropower and telecommunications, and indirectly contribute by expanding the national taxable resource base through the creation of wealth as a result of a market-oriented, taxable transformation of the national resources. 
Lao PDR - National Growth and Poverty Eradication Strategy (NGPES)

The Government's MTEF (2003-2004 to 2005-2006) is based on an estimated economic growth rate of 5.9 per cent for FY 2002-2003; 6.2 per cent for FY 2003-2004; 6.5 per cent for FY 2004-2005, and; 7.0 per cent for FY 2005-2006.

These estimates reflect the expected continued and vigorous expansion of the economy and bank on the positive long-term impact of the recent measures taken to encourage production and demand. Despite the economic difficulties experienced regionally and the drop in tourism revenues this year, economic growth has remained robust thanks to the encouragement of all economic sectors and, in particular, the private sector. Private sector investments in construction materials, transformation of agricultural produce and trade contributed in important ways to the creation of wealth and employment. Likewise, public investments in various areas have contributed to enhance growth nation-wide. In particular, farmer households increased their production for market.

\section{Medium-Term Expenditure Framework up to FY 2005-2006 (Billion Kip)}

\begin{tabular}{|l|c|c|c|c|}
\hline & $\mathbf{2 0 0 2 / 0 3}$ & $\mathbf{2 0 0 3 / 0 4}$ & $\mathbf{2 0 0 4} / \mathbf{0 5}$ & $\mathbf{2 0 0 5 / 0 6}$ \\
\hline GDP Growth Rate & $5.9 \%$ & $6.2 \%$ & $6.5 \%$ & $7 \%$ \\
\hline Budget Revenue & $2,466.7$ & $2,900.6$ & $3,510.7$ & $4,244.3$ \\
\hline \multicolumn{1}{|c|}{ Revenue/GDP } & $11.3 \%$ & $11.9 \%$ & $12.6 \%$ & $13.4 \%$ \\
\hline Budget Expenditure & $4,240.5$ & $4,627.5$ & $5,046.6$ & $5,665.5$ \\
\hline \multicolumn{1}{|c|}{ Expenditure/GDP } & $19.5 \%$ & $18.9 \%$ & $18.2 \%$ & $17.9 \%$ \\
\hline Total PIP & 2,610 & 2,580 & 2,950 & 3,200 \\
- Domestically funded & 960 & 760 & 1000 & 1,100 \\
- ODA funded & 1,650 & 1,820 & 1,950 & 2,100 \\
\hline PIP/GDP & $12.2 \%$ & $10.5 \%$ & $10.6 \%$ & $10.1 \%$ \\
\hline
\end{tabular}

The growth rates expected for FY 2003-2004 to FY 2005-2006 are justified by i) the continued expansion of the private sector, including foreign investment, ii) the encouragement of small and medium-sized enterprises through planned policies and measures, and iii) the expected recovery of the regional economy now that the SARS threat seems to have retreated.

Economic growth rates of 7 per cent beyond FY 2005-2006 can be considered as the cruising speed that will characterise the Lao economy for years to come. This implies gross investment of around 26 per cent of GDP, of which private investment should be not less than 16 per cent of GDP (public investment: 10-11 per cent of GDP, of which 3.5 per cent of GDP from government budget and 7 per cent of GDP from ODA.

Annual revenue increases are estimated at 20 per cent for the coming years. The projected revenue growth will bring the revenue share of GDP up to 13.4 per cent in FY 2005-2006.

Efforts are being made to remedy the present weaknesses in capacity regarding revenue and expenditure management. In particular, monitoring of revenue and expenditure management at the central and provincial levels will be strengthened. 
The measures needed to improve the institutional framework of fiscal management and to strengthen the legal and regulatory framework are being implemented, particularly the strengthening of revenue collection mechanisms through the adoption of standardised registration, accounting and auditing systems.

At the same time, the effectiveness of the Large Taxpayers' Unit will continuously improve through the enhancement of capacities at the central and provincial levels. The strictest observance of the Budget Law, the Tax Law and the Customs Law is the basis for improved budget management. Fiscal management of the highest quality is essential for the achievement of the national development goals.

Increased revenues will come from improved tax administration and from investments, in particular private sector investments, including FDI. Projections regarding expected revenues from the mining and hydropower sector are encouraging. Increased revenues will allow the Government to progressively reduce dependency on official development assistance (ODA).

A cautious approach to revenue projections also means a cautious approach towards managing expenditure. Public expenditures must remain within the country's financial possibilities. This implies a very strict expenditure management plan as well as clearly defined priorities with respect to the progressive implementation of the NGPES. The Government chose to favour an intermediate, short-term approach, while simultaneously preparing for an in-depth, longer-term approach concerning particular priority areas in terms of their costing.

For the 2003-2004 financial year, a top priority is to substantially increase the salaries of public servants and resolve outstanding debt issues. The further strengthening of the business environment as well as the improvement of the public enterprise sector are other top priorities for FY 2003-2004.

These are fundamental commitments. In response to obvious economic imperatives, revenues collected in FY2003-2004 will thus serve to resolve debt and increase the salaries of public servants as priority. Outstanding debts cloud the outlook of the economy. Increasing the salaries of public servants is fundamental to increasing motivation and enhancing performance.

A combination of fiscal restraint and a greater revenue collection effort will enable the Government to maintain prudent macroeconomic management of the economy, together with tight monetary policy. However, the tight fiscal situation leaves little room for flexibility; total revenues are now expected to reach 13.4 per cent of GDP by 2005/06.

The planned allocation of resources for FY 2003-2004 had to be made at the expense of productive investments. In FY 2003-2004, the amount allocated to the PIP will be reduced by at least 20 per cent. From this perspective, FY 2003-2004 will be a year of transition as there is a need to streamline many operational aspects in order to prepare for FY 2004-2005 and beyond. ${ }^{11}$

\subsection{Resource Allocation for 2003-2004 FY to 2005-2006 FY}

The Government is taking a carefully-considered approach to managing public expenditure. As public expenditure must remain within the country's financial possibilities, the Government's contribution to the Public Investment Programme (PIP) has been reduced by 20 per cent from 960 billion kip in FY 2002-2003 to 760 billion in FY 2003-2004, as already mentioned. This figure is expected to rise to 1,000 billion kip in FY 2004-2005, before reaching a high of 1,100 billion kip in FY 2005-2006.

\footnotetext{
${ }^{11}$ Please refer to Part V and Annex 4 for detailed Tables regarding the MTEF.
} 
Lao PDR - National Growth and Poverty Eradication Strategy (NGPES)

However, the total projected PIP for these three fiscal years is 2,580 billion kip, 2,950 billion kip and 3,200 billion kip respectively. The Government seeks ODA support to bridge the PIP resource gap until budgetary revenues for the PIP have increased to a self-sustaining level. Thus, the resource gap remains large for the medium-term. In concert with the Lao PDR's partners in development, it is hoped that 8,730 billion kip (approximately US $\$ 870$ million) can be mobilised for the public investment programme for the period of FY2003/04 to FY2005/06. Domestic resources are expected to mobilise a third of this amount (2,860 billion kip or around US\$ 290 million).

PIP Investment Structure - FY 2002-2003 to FY 2005-2006

(In Billion of Kip and Percentages)

\begin{tabular}{|l|c|c|c|c|}
\hline Investment Structure & $\mathbf{2 0 0 2 / 0 3}$ & $\mathbf{2 0 0 3 / 0 4}$ & $\mathbf{2 0 0 4 / 0 5}$ & $\mathbf{2 0 0 5 / 0 6}$ \\
\hline Government funds & 960 & 760 & 1,000 & 1,100 \\
\hline Foreign Funds & 1,650 & 1,820 & 1,950 & 2,100 \\
\hline Total PIP & 2,610 & 2,580 & 2,950 & 3,200 \\
\hline Domestic/Total PIP & $36.7 \%$ & $29.5 \%$ & $33.9 \%$ & $34.0 \%$ \\
\hline PIP/GDP & $12.2 \%$ & $10.5 \%$ & $10.6 \%$ & $10.1 \%$ \\
\hline \multicolumn{5}{|c|}{ Sector Breakdown } \\
\hline Economic Sector & $59.7 \%$ & $59.7 \%$ & $58.05 \%$ & $56 \%$ \\
\hline Social Sector & $27.6 \%$ & $29.7 \%$ & $31.4 \%$ & $33.6 \%$ \\
\hline - Education & $11.4 \%$ & $12 \%$ & $13 \%$ & $14 \%$ \\
\hline - Health & $8.7 \%$ & $9.5 \%$ & $10.15 \%$ & $11 \%$ \\
\hline $\begin{array}{l}\text { Other Investments } \\
\text { (administration, etc.) }\end{array}$ & $13.0 \%$ & $10.6 \%$ & $10.5 \%$ & $10.4 \%$ \\
\hline
\end{tabular}

The public investment structure for FY 2003-2004 to FY 2005-2006 sees the share to the social sector steadily increasing to 33.6 per cent in FY 2005-2006. Health and education will together represent three quarters of social investments for FY 2005-2006. The economic sector remains most important and will absorb 56 per cent of the PIP in FY 2005-2006. As rural development is now under the responsibility of MAF, the agriculture/forestry sector's relative share of economic sector investments is steadily rising. The transport sector remains at the same high level in absolute value, but its relative share will slightly decline.

The domestic contribution of 760 billion kip to the PIP for FY 2003-2004 will see 300 billion kip allocated to debts from past PIP investments; 200 billion kip allocated to on-going national projects; 160 billion kip to counterpart funds to ODA projects (both ongoing and new), and; 100 billion kip to poverty eradication through the enhancement of income generating activities. Of this latter amount, 40 billion kip are earmarked for the 47 poorest districts and 60 billion kip for the improvement of extension services throughout the country, enhancement of production for the market, income generation and capacity building.

Approximately two thirds of the PIP goes to the sectors (line ministries) and one third directly to the provinces. The latter is allocated sector-wise and concerns both district and provincial projects. 
The Government has adopted a more district poverty-focused orientation in the PIP by progressively allocating a greater share of expected new budgetary revenues to the poor districts to ensure that they become increasingly integrated into the national economy, while maintaining the necessary investment for growth nation-wide.

While it is difficult to cost the NGPES and to predict future revenues available to the Treasury, the Government will undertake to cost the main expenditure components of the NGPES, mainly the sector goals (such as achieving universal basic education).

Government funds will go to enhancing capacity at all levels in fields such as planning, management and technical capacity-building. This will enable all levels to assume their fiscal and planning responsibilities. Particular emphasis will be given to the district level. Funds will be used in support of on-going projects to enhance their impact and to ensure their sustained success. For example, UXO-related activities and the development of alternative production schemes in support of drug elimination. Furthermore, population dimensions, with an emphasis on reproductive health, the prevention of HIV/AIDS and micro-credit and income generating activities are clear priorities for the Government.

All activities linked to rural development, access to markets (thanks to a major effort to develop rural infrastructure), access to health and education (as major development catalysts) and capacity building for local planning and decentralisation management, are major priorities, as is capacity building in all undertakings.

The Government's expectations are that towards the end of 2003, 8 to 10 comprehensive district plans will be ready to enable an efficient allocation of resources to support district efforts to eradicate poverty. Such comprehensive district plans should be prepared for all 47 districts to guide and justify resource allocation for the coming years.

With regard to the 40 billion kip earmarked for the poorest districts, in addition to the projects supported through other areas of the PIP, the Government intends to use them as a "development fund" for the poorest districts. The 40 billion kip will be channelled through village and district funds which will provide support to households and villages to enable them to engage in income generation activities. Income generation empowers people to undertake initiatives and to expand their range of choices to improve their livelihoods. Thus, through the village and district funds the present lack of capital, which has been identified as a major cause of poverty, will be addressed.

In this way, village and district development funds play an important role in enhancing local development. In channelling resources to these funds, the Government conveys its conviction that development should be community-driven and that Government funds should not be substituted for what people can do by themselves to eradicate poverty. The national strategy, presently under preparation, and the action plan for the expansion of rural finance and micro-credit will provide an additional practical framework for the future use of these funds.

Conditions must be enhanced in such a way as to enable the people to organise themselves and to improve their livelihoods by themselves according to their own initiatives and visions of the future. Institutional and managerial requirements necessary to efficiently run these funds and initiatives obviously will be given highest priority.

Comprehensive investments in infrastructure continue to be an essential component in promoting economic growth nation-wide and enhancing the country's integration into the region. Investments will complement investments already made in the various regional corridors, as well as help farmers access improved services and markets at the local, national and regional level. 
With regard to the crucial issue of recurrent expenditure, an in-depth exercise to estimate the recurrent cost involved in projects, according to established sector ratios, has been carried out. The methodology that has been developed enables the systematic estimation of recurrent expenditure according to the various types of recurrent expenditures (maintenance, equipment replacement, repairs, electricity and water costs, training, etc.). Workshops have been organised to introduce this methodology to the different sectors.

The Government's resources, based on the MTEF, will not be in a position to fully respond to these needs in the medium-term. For this reason, the Government intends to further consult with its partners in development in order to identify appropriate mechanisms which will enable the Government to gradually assume responsibility for recurrent expenditures, as has been the case with the Road Maintenance Fund.

\subsection{ODA Management and Co-ordination}

ODA is critical to implementation of the Government's investment programme as it accounts for approximately four-fifths of total public investment. As such, ODA contributes importantly to building the necessary conditions for sustainable growth and poverty eradication. In 2001, new bilateral and multilateral ODA agreements amounted to US\$ 393 million (of which grants were US\$ 206 million). ODA disbursements amounted to US\$ 380 million. The ODA component in the public investment programme, over the past years, varies between approximately 90 per cent for the communication and transport sector to about 60 per cent for rural development. The overall ODA contribution to the PIP amounted to 66 per cent in FY 2002-2003 (see Table above).

The present concentration of ODA in the communications and transport sector is justified because investments in basic infrastructure are still vital. Indeed, investment in transportation infrastructure has been an essential condition for growth and improvement of the livelihood of the Lao multi-ethnic population. However, as access throughout the country is improving, including access to the remote districts, investments in social sectors will see their share growing. The transport/communication sector will remain high in absolute value because of its importance for economic growth nation-wide, but it will see its relative share decline.

Aid co-ordination will be improved. Sector-wide planning, as mentioned, but also strengthened co-ordination and consultation between sectors as well as between the central, provincial and district levels, will greatly enhance aid co-ordination and efficiency. Increased and systematic use of the various sector co-ordination fora will enhance co-ordination and consultation between sectors and the donor community.

\subsection{Participatory Planning, Implementation and Monitoring}

Participatory Planning, Implementation and Monitoring are fundamental to the NGPES. For the Government, the NGPES is an on-going process; consultation will thus continue even after the adoption of the NGPES by the National Assembly. The essence of the NGPES is its "rolling character", implying "post-NGPES" consultations and building on the approach that led to its preparation. The Government-launched Roundtable process has been an exhaustive consultation exercise with various segments of the Lao multi-ethnic population and with the international donor community (including bilateral, multilateral partners in development and international NGO). It is the Lao culture and tradition to continue intense consultations even after completion of a policy document so as to ensure its adaptation and implementation in the local context. This will also be the case for the NGPES. 
All initiatives identified in the NGPES include important aspects of participatory planning, implementation and monitoring. Development planning will increasingly be based on local participation through appropriate planning manuals and participation processes.

Capacity building for these purposes is a priority, especially at the district level. The Government will continue to redefine central-local relations ("decentralisation") by making villages implementation units, districts planning and fiscal units, and provinces strategic units. Appropriate monitoring criteria will be elaborated for each sector to ensure that measures to reduce poverty levels are being implemented and progressively refined.

Implementation of the NGPES will entail strengthening of capacities at every level so that participation becomes truly meaningful and a major tool for planning, implementation and monitoring. The Committee for Planning and Co-operation (CPC) will be in charge of the planning and investment aspects of the NGPES, and guide its implementation, with the active involvement of all Government agencies concerned and in co-ordination with local authorities. The National Statistical Centre will serve as the central agency for monitoring the poverty situation; it will co-ordinate regularly with all ministries, social organisations and local authorities and partners in development.

To ensure overall co-ordination regarding the NGPES' implementation will be the task of a National Steering Committee, while resource mobilisation will be the task of the Ministry of Foreign Affairs.

A technical working committee, headed by the Director General of the Department of General Planning, and including most members of the former NPEP Committee, will work on the NGPES' operationalisation, costing, and monitoring.

Among the first priorities leading to the NGPES implementation are the finalisation of an operational approach to participatory district planning and the consequent preparation of district plans to serve pro-poor and pro-growth investment in the poorest districts as well as the launching of a sector-wide approach in education and health, the further operationalisation and prioritisation of all sectors and sub-sectors programmes, and the consistent implementation of the various reform programmes. 


\section{PART II: Poverty Assessment of the Lao PDR}

Poverty in the Lao PDR is complex and can be viewed from many perspectives. For the Lao multi-ethnic culture, poverty has a particular meaning, as it refers to those families that have been stricken by misfortune and/or are the least well-off in a given community. ${ }^{12}$ That is why household poverty is an important criterion for poverty assessment at the district level. Villages provide a measure of welfare, a natural safety net to compensate for shortcomings in livelihood within the village.

The understanding of 'poverty' in the Lao culture must be taken into account in designing sector programmes for eradicating basic poverty. Livelihood improvement has a series of manifestations highly relevant to identifying strategic approaches to poverty reduction. For this reason, the Government prefers to stress the improvement of livelihoods, focusing on peoplecentred, participatory development. These are positive and socially mobilising concepts, embracing all segments of society and not only those identified as poor.

There are many methods of poverty measurement and analysis, including: poverty lines; participatory poverty assessments; vulnerability indexes; and the Human Poverty Index. ${ }^{13}$ Poverty measurement in the Lao PDR is still in the initial stages. Poverty analysis in the Lao PDR has drawn heavily from the Lao Expenditure and Consumption Surveys (LECS), which take place every 5 years, starting in 1992/93. LECS II was conducted in 1997/98, just prior to the full impact of the Asian financial crisis. Data collection for the LECS III was completed in February 2003, and results from the survey will be available by year end. As noted in the Preface and Part I, the level of poverty has declined considerably since 1992/93 to date.

Part I also provided a summary of Prime Ministerial Instruction No. 10 on poverty reduction. More fully, the Degree states the following: "Poverty is the lack of ability to fulfil basic human needs, such as: not having enough food [i.e. less than 2,100 calories per day/capita], lack of adequate clothing, not having permanent housing, not capable of meeting expenses for health care, not capable of meeting educational expenses for one's self and other family members, and lack of access to transport routes". Instruction 10 specifies that "there is to be a systematic accounting of village and district poverty levels. Thereafter, these findings must be incorporated into the poverty eradication planning.

To assess poverty in the Lao PDR, both quantitative (Chapter 1) and qualitative measures (Chapter 2) have been employed.

Quantitative measurement using poverty lines: The poverty line methodology is the result of joint efforts by the National Statistics Centre, SIDA, ADB, and the World Bank. The Lao Expenditure and Consumption Surveys have provided the data for the analysis.

There are two poverty lines: (1) the food poverty line, and (2) an overall poverty line. These are equivalent in the first instance to a lack of food security, and in the second to lacking the combination of food and non-food necessities.

\footnotetext{
${ }^{12}$ For instance, in the Prime Minister's Instruction regarding "decentralisation" (PM/01/March 11, 2000) villages are encouraged, before formulating a village development plan, to collect data and to observe the living conditions of each family, ranking them accordingly into wealthy, self-sufficient and poor families.

${ }^{13}$ This is the method used by the United Nations in the Human Development Index which looks at the lack of capabilities: illiteracy, malnutrition, life expectancy, lack of health care. The direct measurement is the lack of access to goods and services, such as: fuel, health and sanitation, education, communications, clean water, that is, things that are necessary human capacities.
} 
The food poverty line threshold is 2100 calories per day per person, which WHO and other international organisation have determined as the basic requirement for people in Lao PDR. ${ }^{14}$ Those with less than this daily calorie intake are considered to be living below the food poverty line. The cost of acquiring this intake, plus 20 per cent for non-food necessities (e.g., shelter, clothing), determines the overall poverty line.

Qualitative Assessment: Qualitative analysis of poverty in the Lao PDR started in 1997, based on "Rapid Poverty Assessment (RPA)" techniques developed by the then State Planning Committee. ${ }^{15}$ RPAs were undertaken in three provinces (Luang Namtha, Bolikhamxay and Attapeu). Together with a series of regional consultation workshops on poverty, the information gathered played an important role in preparing a National Poverty Alleviation Action Plan. ${ }^{16}$

Qualitative analysis nation-wide began with the Participatory Poverty Assessment $(\mathrm{PPA})^{17}$ in 2000 , which emphasised causation and perceptions of poverty throughout the multiethnic population. The PPA recorded the experiences and concerns of the people in order to identify and initiate appropriate actions to reduce poverty. This was accomplished by combining information on poverty (statistical, cultural, anthropological, institutional, economic, etc.) with an understanding of the views of poor people.

\section{Chapter 1: Poverty Situation in the Lao PDR}

\subsection{From a Quantitative Perspective}

Quantitative poverty analyses carried out in the Lao PDR during the 1990s and recent years employ several key methodological features:

- Use of the data of the 1992/93, 1997/98, and 2002/03 Lao Expenditure and Consumption Surveys (LECS I, II and III)

- Use of an absolute definition of poverty (as distinct from a relative definition of poverty)

- Use of an income-based (cost of basic needs) approach to the measurement of poverty

- Use of consumption as the measure of individual income

- Use of two poverty lines, a lower poverty line based on minimum food needs and a more comprehensive and higher poverty line that includes provision for non-food necessities.

LECS III has been completed, and results from the survey will be available by the end of year 2003. The third LECS is more comprehensive compared to the previous surveys. It includes expanded modules on health, education, the labour force and other interests. The survey of how time is used applies to each household member above nine years of age (the previous LECS provided data for only one household member). LECS III also has a price questionnaire concerning 121 commodities in village markets, as well as other fields relevant to assessing economic and social development in the Lao PDR as a whole. However, the sample size is too small to allow for in-depth analysis below the provincial level. It will, however, enable analysis of poverty from an urban/rural perspective.

\footnotetext{
${ }^{14}$ The details of the method for constructing the food poverty line is provided in Annex 1 of this document.

${ }^{15}$ There were designed to obtain information on poverty/well-being at the village/community level as well as the household level and focused on gaining an insight into the perception, the nature and the causes of poverty. Cf. Government document to the $7^{\text {th }}$ RTM "Fighting Poverty", Nov. 2000, op. cit., p 41-44.

${ }^{16}$ Cf. Government Report to RTM 6 (1997), p.28.

${ }^{17} \mathrm{NSC}$ with support from ADB, 2000.
} 
Lao PDR - National Growth and Poverty Eradication Strategy (NGPES)

Annex 1 provides a detailed discussion of poverty measurements, including the distinction between consumption and expenditure.

\subsection{Trends in Poverty Reduction}

As shown in Table 1, in terms of real per capita consumption Vientiane Municipality is the wealthiest region in the country while the North is the poorest. Per capita consumption in Vientiane Municipality increased at an average annual rate of 10.8 per cent between 1992/1993 and 1997/1998. This was more than twice the rate of increase in per capita consumption in other regions. For the Lao PDR as a whole, the average annual increase in real per capita consumption was 5.8 per cent. Households have clearly benefited from economic growth.

\begin{tabular}{|l|c|c|c|}
\hline \multicolumn{4}{|c|}{$\begin{array}{c}\text { Pable 1: } \\
\text { Per Capita Real Consumption by Region } \\
\text { (In Kip; March 97 to Feb 98=100 }\end{array}$} \\
\hline \multicolumn{1}{|c|}{ Regions } & $1992-93$ & $1997-98$ & Growth Rate \\
\hline Vientiane municipality & 34,676 & 59,577 & 10.8 \\
\hline North & 20,184 & 25,770 & 4.9 \\
\hline Central & 25,720 & 32,586 & 4.7 \\
\hline South & 23,623 & 29,504 & 4.4 \\
\hline Lao P.D.R. & 24,595 & 32,848 & 5.8 \\
\hline
\end{tabular}

Source: N. Kakwani, Bounthavy Sisouphanhthong and Phonesaly Souksavath: Poverty in Lao PDR (May 2001).

During this period, real per capita consumption in the rural areas increased by 5.4 per cent per year while urban consumption increased by 9 per cent. Thus, the disparity between urban and rural consumption has increased, as shown in Table 2.

\begin{tabular}{|l|c|c|c|c|c|c|}
\hline \multicolumn{7}{|c|}{ Table 2: } \\
\multicolumn{7}{|c|}{$\begin{array}{c}\text { Per Capita Real Consumption by Regions and Rural and Urban Areas } \\
\text { (In Kip; March 97 to February 98=100 (Lao urban areas) }\end{array}$} \\
\hline & \multicolumn{3}{|c|}{ Urban areas } & \multicolumn{3}{c|}{ Rural areas } \\
\hline Regions & $1992-93$ & $1997-98$ & $\begin{array}{c}\text { Growth } \\
\text { rate }\end{array}$ & $1992-93$ & $1997-98$ & $\begin{array}{c}\text { Growth } \\
\text { rate }\end{array}$ \\
\hline Vientiane municipality & 36,438 & 62,098 & 10.7 & 29,378 & 55,304 & 12.7 \\
\hline Northern region & 23,498 & 32,914 & 6.7 & 19,495 & 24,995 & 5.0 \\
\hline Central region & 30,111 & 42,477 & 6.9 & 24,872 & 31,197 & 4.5 \\
\hline Southern region & 30,842 & 39,938 & 5.2 & 22,138 & 28,378 & 5.0 \\
\hline Lao P.D.R & 31,035 & 48,721 & 9.0 & 22,609 & 29,668 & 5.4 \\
\hline
\end{tabular}

Source: N. Kakwani, Bounthavy Sisouphanhthong and Phonesaly Souksavath: Idem

As shown in Table 3 , the head count index ${ }^{18}$ or incidence of poverty was 38.6 per cent in $1997 / 98$, compared to 45 per cent in 1992/93. The North had the highest incidence of poverty, at 52.5 per cent. Some 830,000 people in the North are below the poverty line and they account for about 45 per cent of the total number of poor in the Lao PDR. There were considerable variations in the rate of progress in poverty reduction. The North not only is the poorest region, it has experienced the slowest rate of reduction in poverty.

\footnotetext{
${ }^{18}$ The head count index shows the percentage rate of the population with consumption of food and non-food essentials lower than the poverty line. For the Lao PDR in 1997/98, the overall poverty line was 15,218 kip per person per month; for urban and rural people the poverty line was 19,270 kip and 14,407 kip per person per month, respectively.
} 
Lao PDR - National Growth and Poverty Eradication Strategy (NGPES)

In contrast, Vientiane Municipality, the wealthiest of the regions, experienced a 50 per cent drop in poverty between the two surveys. The Central Region also experienced a slow rate of poverty reduction, but the incidence of poverty is still lower than in the South.

\begin{tabular}{|c|c|c|c|}
\hline \multicolumn{4}{|c|}{$\begin{array}{c}\text { Table 3: } \\
\text { Percentage of Poor by Regions and Provinces }\end{array}$} \\
\hline Regions/provinces & $1992-93$ & $1997-98$ & $\begin{array}{c}\text { Annual rate in decrease } \\
\text { of poverty }\end{array}$ \\
\hline Vientiane municipality & 24.4 & 12.2 & -13.9 \\
\hline Northern region & 58.4 & 52.5 & -2.1 \\
\hline Phongsaly & 68.7 & 64.2 & -1.3 \\
\hline Louang Namtha & 60.3 & 57.5 & -1.0 \\
\hline Oudomxay & 51.1 & 73.2 & 7.2 \\
\hline Bokeo & 63.5 & 37.4 & -10.6 \\
\hline Louang Prabang & 62.7 & 49.4 & -4.8 \\
\hline Houa Phanh & 78.4 & 74.6 & -1.0 \\
\hline Xaygnaboury & 30.1 & 21.2 & -7.0 \\
\hline Central region & 39.5 & 34.9 & -2.5 \\
\hline Xieng Khoang & 57.3 & 34.9 & -9.9 \\
\hline Vientiane province & 28.1 & 24.3 & -2.9 \\
\hline Borikhamxay & 10.6 & 25.8 & 17.8 \\
\hline Khammuane & 43.7 & 41.6 & -1.0 \\
\hline Savannakhet & 45.7 & 37.1 & -4.2 \\
\hline Xaysomboom-SZ & & 55.0 & \\
\hline Southern region & 45.9 & 38.4 & -3.6 \\
\hline Saravanh & 36.7 & 39.6 & 1.5 \\
\hline Xékong & 65.9 & 45.7 & -7.3 \\
\hline Champasak & 43.6 & 35.6 & -4.1 \\
\hline Attapeu & 72.2 & 45.3 & -9.3 \\
\hline Lao PDR & 45.0 & 38.6 & -3.1 \\
\hline
\end{tabular}

Source: N. Kakwani, Bounthavy Sisouphanhthong and Phonesaly Souksavath: Idem

As also shown in Table 3, Houa Phanh province in the North is the poorest province, with 74.6 per cent of people below the poverty line in 1997/1998. There are many provinces with a poverty head count higher than 50 per cent. In the Central Region, Xaysomboun Special Zone has the highest incidence of poverty (31,500 poor people - see Annex 1, Table 1.4), while Savannakhet is the province with the highest absolute number of poor $(264,000)$ (idem). Champasak province has the highest number of poor people in the South $(189,000)$, while Sekong has the highest poverty incidence.

\subsection{Poverty in Urban and Rural Areas}

Table 2 shown earlier indicated the significant differences in per capita consumption between urban and rural areas. In 1997/98, the level of poverty in urban areas was 27 per cent, compared to 41 per cent in rural areas. Poverty in urban areas decreased much more than in the rural areas in the five-year interval between the 1992/93 and 1997/98. Nevertheless, living conditions in some urban areas are difficult, especially as poor people must live on a cash basis. 
Lao PDR - National Growth and Poverty Eradication Strategy (NGPES)

Most urban poor have a low level of education and no permanent jobs, which increases their vulnerability (defined as lack of food security, in the first place).

To date, there is no study on urban poverty in the country as a whole ${ }^{19}$. However, a PPA was carried out for Vientiane Municipality where the nature, causes and linkages of poverty were investigated $^{20}$. Key findings included i) the diversity of poor people, ii) an interdependence between households within poor communities, iii) uncertainty in tenure and frequent flooding as causes of poverty. The PPA also found particularly vulnerable groups and individuals whose conditions contributed to, and were often a cause of, their poverty. Table 4 summarises the most vulnerable groups.

\begin{tabular}{|l|c|}
\hline \multicolumn{2}{|c|}{ Table 4: Vulnerable Groups in Vientiane Municipality } \\
\hline Vulnerable Groups & Percentage \\
\hline Physical and mentally handicapped/blind & $18.5 \%$ \\
\hline Drug alcohol user & $14.5 \%$ \\
\hline The elderly living alone & $14.0 \%$ \\
\hline Female headed household & $8.4 \%$ \\
\hline Isolate individuals & $7.2 \%$ \\
\hline Young children & $6.7 \%$ \\
\hline Youth and school drop-outs & $5.5 \%$ \\
\hline Unemployed & $4 \%$ \\
\hline (Convicted) criminals & $4 \%$ \\
\hline Destitute & $2.7 \%$ \\
\hline Beggars & $2.2 \%$ \\
\hline Rural migrants and illegal migrants & $1.6 \%$ \\
\hline Homeless/Squatters & $1.6 \%$ \\
\hline Street children & $1.6 \%$ \\
\hline Partially, temporarily employed & $1.6 \%$ \\
\hline Lazy people & $1.1 \%$ \\
\hline Others & $2.7 \%$ \\
\hline
\end{tabular}

Source: VUDAA/ADB Study, Poverty in Vientiane, 2000.

\subsection{Socio-Economic Aspects of Poverty}

Table 5 indicates the relationship between poverty and access to basic infrastructure. Clearly, the poor have much less access to infrastructure, compared to the less-poor. For example, only 38 and 17 per cent of poor people have access to an all-weather road or electricity, respectively. In terms of distance, the poor are on average 13 kilometres from a road, compared to 9 kilometres for the less-poor. Access to piped water is also limited. Complete primary schools are not as available to the poor as to the less-poor people, but - as found by the PPA - this factor is not considered an important cause of poverty. Basic health services are very deficient in areas where the poor people mostly reside. Disparities in rural areas are marked, although less so than in urban areas.

\footnotetext{
${ }^{19}$ As mentioned before, LECS III will for the first time provide a quantitative analysis of urban poverty.

${ }^{20}$ The PPA was carried out by the Vientiane Urban Development and Administration Authority (VUDAA) with support from the ADB (Poverty in Vientiane, 2000). There was also a small town PPA conducted by the Department of Housing and Urban Planning, MCTPC, with support from the ADB (November 2001).
} 
Lao PDR - National Growth and Poverty Eradication Strategy (NGPES)

\begin{tabular}{|l|c|c|c|}
\hline \multicolumn{5}{|c|}{ Table 5: } \\
\hline \multicolumn{4}{|c|}{ Percentage of Poor and Less-poor People with Access to Infrastructure } \\
\hline Access to & Poor & Less-poor & Total \\
\hline \multicolumn{4}{|c|}{ areas } \\
\hline Road in dry season & 70.8 & 84.8 & 79.4 \\
\hline Road in wet season & 38.4 & 61.5 & 52.5 \\
\hline Electricity & 17.1 & 40.0 & 31.6 \\
\hline Pipe water & 38.6 & 57.1 & 49.9 \\
\hline Public transport & 38.2 & 57.1 & 49.7 \\
\hline Primary school & 86.4 & 87.6 & 87.1 \\
\hline Complete primary school & 43.0 & 55.6 & 50.7 \\
\hline Medical practitioner & 46.8 & 57.2 & 53.2 \\
\hline Trained nurse & 63.0 & 63.7 & 63.4 \\
\hline Immunisation & 87.7 & 90.2 & 90.9 \\
\hline Birth attendant & 44.6 & 50.5 & 38.2 \\
\hline Pharmacy & 23.8 & 37.5 & 32.1 \\
\hline Community health worker & 41.7 & 45.9 & 94.3 \\
\hline Hospital/Health centre* & 84.2 & 95.7 & 7.2 \\
\hline \multicolumn{3}{|c|}{ Rural areas } \\
\hline Road in dry season & 67.8 & 80.7 & 43.2 \\
\hline Road in wet season & 32.2 & 51.3 & 19.0 \\
\hline Electricity & 10.1 & 25.6 & 44.5 \\
\hline Pipe water & 34.6 & 51.9 & \\
\hline Public transport & 32.6 & 47.2 & \\
\hline Source: LECS II & $*$ Less than 6 hours away & \\
\hline
\end{tabular}

\section{Sector Perspectives on Poverty}

\section{Education}

For the poor people, education is not usually perceived as a possibility for poverty alleviation. School-related expenses (including fees) and the need to have all family members help in securing basic necessities discourage enrolment or continued schooling. Nonetheless, there is a strong correlation between poverty and education. The incidence and severity of poverty is greatest among preliterate households. A multivariate analysis of household poverty ${ }^{21}$ shows that every extra year of education of the head of household raised welfare by two per cent. Thus, even though lack of education may not be considered as a direct cause of poverty, increasing the level of education is shown to be one of the necessary factors for poverty reduction.

Improving access to education for all, enhancing the quality of education and strengthening management of the sector are thus priority areas for public investment as are non-formal education and vocational training.

\section{Health}

Health remains a pressing social issue. Mortality and morbidity rates are high, particularly among ethnic groups in mountainous areas where poverty is severe.

The fertility rate is 4.6 and the population growth rate is 2.8 per cent (2000). Maternal morbidity is 530 deaths per 100,000 live births, and infant mortality is 82 deaths per 1,000 live births. Communicable diseases such as malaria, dysentery, cholera, haemorrhagic fever (dengue), intestinal parasites, tuberculosis, acute respiratory infections and measles are still common.

\footnotetext{
${ }^{21}$ Kakwani et al.2001,op.cit.
} 
Life expectancy remains low at 59 years. While the health indicators have improved substantially over the past ten years, they compare unfavourably by regional standards.

Poverty leads to health problems, and health problems lead to further poverty. Poor access to medical care and poor conditions such as the lack of clean drinking water are major factors affecting health in the Lao PDR. Improving health care on an equitable and nation-wide basis and providing access to clean water for all are priorities for public investment.

\section{Agriculture}

Agricultural systems in the Lao PDR are usually classified based on major production systems and topography, as influenced by the Mekong watershed. Lowland areas are made up of alluvial plains located primarily along the Mekong and its tributaries. The bulk of the nation's food is produced in the lowland areas ${ }^{22}$.

On rolling hills and in lower and mid-level mountain slopes, shifting cultivation is practised. In these areas, subsistence farming is still the norm; there is also heavy reliance on forests for plant and animal food, medicinal plants, and wood for fuel and shelter. Poverty is increasing in some areas, as population growth competes for limited arable land and shorter fallow periods limit shifting cultivation, resulting in lower yields.

While an over-simplification ${ }^{23}$, progress in poverty reduction has been much more intense in the Mekong corridor or lowlands than in the uplands. In addition to differing agricultural potential, this reflects differences in the quality and availability of basic services. Because roads are better, access to markets for lowland farmers is easier. Banking and other services are also better. Diversification and commercialisation have progressed considerably. For the most part, uplands farmers continue their traditional ways and practices, and face many hardships.

The area-based development (focal area) approach, which is at the basis of the Government's rural development strategy, places a high priority on improved services, more sustainable land use, and increased incomes among the rural poor. Investment in rural development needs to be greatly intensified, especially in the poorest districts.

\section{Infrastructure/Transport}

As noted earlier, there is close correlation between the absence of essential transportation and communication infrastructure and poverty, especially for remote areas. Many districts are not linked to the main national transportation network and most villages are not linked to the main district or provincial roads. Economic growth is therefore hampered and poverty persists. The development and improvement of rural roads is a poverty alleviation objective in itself, but it is also a basic condition for the creation of an enabling environment for a market economy.

\section{Gender Dimensions of Poverty}

Women and men experience poverty differently in the Lao PDR, even within the same ethnic group or community. Women tend to work much longer hours than men do as they are primarily responsible for their families' food security, a responsibility that is especially difficult in the case of upland families that have relocated to lowland areas.

\footnotetext{
${ }^{22}$ A large part of which is inhabited by Tai-Kadai ethnic groups.

${ }^{23}$ Because poverty is also present in the "non-poor" districts. Cf. Table 8 where the 72 poor districts absorb 160,000 poor households; the number of poor households nation-wide has been estimated at 270,000.
} 
If families cannot grow sufficient rice in their new location, they may return to their old shifting cultivation fields, which could be a considerable distance away. The heavy workload of minority women involved in opium production, and the burden on them of addicted household members, is a major cause for concern.

Lao women have lower literacy rates than men (59.1 per cent, compared with 81.7 per cent). ${ }^{24}$ Women on average have had 3 years of school (2 years in rural areas), compared to 4 years for men. However, there has been improvement, especially in urban areas: young rural women aged 15-19 have now 4 years of school compared to 5 years for young rural men, and both young women and men in urban areas have now an average of 7 years of schooling. Several reasons for the low school attendance of poor girls in rural areas, especially in higher grades, have been identified. They include the girls' household responsibilities, the cost of clothing and school supplies, the distance to the nearest school, language barriers for ethnic minority girls, and questions about the quality and relevance of formal education for these girls.

As more young women and men migrate from remote areas to towns and cities for work, young ethnic minority women with little education and limited knowledge of Lao language will have few opportunities and will be at greater risk of exploitation. In the majority of ethnic groups, women do not speak Lao, which severely limits their ability to engage with health care workers, extension workers, traders and others outside the village. They are doubly disadvantaged by limited access to family planning services; in combination with high fertility rates there is very high risk of health complications or death for both mother and child.

Recommendations to improve the position of women include the following: ${ }^{25}$ (1) reduction of women's heavy workload through appropriate technologies and improved access to water supply; (2) improvement of women's and girls' educational levels; (3) improvement of maternal and child health, including family planning; (4) more income generation opportunities (e.g., rice mills, handicraft production) for women through skills training and micro-finance; and (5) more budgetary resources for programmes addressing women's needs. There is an urgent need to address gender disparities.

\subsection{Evaluating Poverty Using Vulnerability Index}

Rather than consumption as a measure of poverty, the vulnerability index is constructed using social and economic indicators deemed as the key determinants of food insecurity and vulnerability. It examines risk factors at the household and village level, as well as the coping responses to these factors. The main objective of this research has been to help delineate poor districts. ${ }^{26}$ The vulnerability or poor district index includes four indicators relating to income and food production (such as rice production per person, large livestock per person, forested area per family, and use of roads (distances up to 6 kilometres), and two which relate to social development (maternal and infant mortality rates and the percentage of illiteracy).

The analysis indicates that of the 142 districts so far assessed, 37 are identified as very poor since they are satisfying less than 2 of the 6 indicators included in the index. Another 25 districts (considered as poor) met only 2 of the criteria. There are 23 districts that satisfy 5 or 6 of the indicators, while the majority, 58 districts (considered as medium), met 3-4 of the criteria. In summary, some 40 per cent of the districts in Lao PDR are considered poor and very poor.

\footnotetext{
${ }^{24}$ National Statistical Centre, Basic Statistics of the Lao PDR 2001. Also, the LECS II and LHRD 2000.

${ }^{25}$ Lao Women's Union (LWU) and the State Planning Committee Workshop (August 2000).

${ }^{26}$ This started as a co-operative effort between the World Food Programme and the National Statistical Centre in researching poverty. The data used came from the LECS 2 (1997/98), the Agricultural Census of 1998/99, and the 1995 Census.
} 
The analysis complements the quantitative analysis, especially since both it and the vulnerability index are primarily based on the LEC surveys. ${ }^{27}$ However, differences in time periods and perspective result in some non-uniformity. In particular, the vulnerability analysis addresses human security concerns by identifying, in a very participatory way, threats and risks at the local levels that could hinder poverty reduction.

\subsection{Inequality and Economic Growth}

Income inequality is another dimension of poverty. Table 6 shows that income disparities, as measured by real consumption, widened between 1992/93 and 1997/98. The lowest income quintile accounted for only 8 per cent of total consumption in $1997 / 98$, compared to 9.3 per cent in 1992/93. In contrast, the highest quintile accounted for 44.4 per cent of total consumption in 1997/98, compared to 38.4 per cent in 1992/93. During this period, the Gini coefficient (a measure of inequality) rose to 35.7. While this coefficient is low relative to the degree of inequality that prevails in other countries in the region, the rise in the coefficient indicates that the benefits of economic growth accrued more to the rich than the poor people.

\begin{tabular}{|l|c|c|c|}
\hline \multicolumn{4}{|c|}{ Table 6: Income Inequality } \\
\hline \multicolumn{1}{|c|}{ Regions/provinces } & $1992-93$ & $1997-98$ & Growth rate \\
\hline Gini coefficient & 28.6 & 35.7 & 4.4 \\
\hline Quintile shares & & & \\
\hline First & 9.3 & 7.8 & -3.5 \\
\hline Second & 13.5 & 11.8 & -2.7 \\
\hline Third & 16.9 & 15.4 & -1.8 \\
\hline Fourth & 21.9 & 20.6 & -1.2 \\
\hline Fifth & 38.4 & 44.4 & 2.9 \\
\hline
\end{tabular}

Source: LECS I and II

To some extent, increases in income inequality are difficult to avoid in the early stages of development. Infrastructure and other investments inequitably benefit most those closest to new investment development. Those in remote areas are relatively unaffected. Progressively, however, the economy is becoming more integrated. The Government of the Lao PDR aims at achieving high economic growth within a context of equity. The very purpose of the NGPES is to outline an operational approach leading to this objective.

\section{Chapter 2: Qualitative Participatory Approaches to Poverty Analysis}

Qualitative poverty analysis focuses on listening to the subjective ideas of people who are defined as poor or who consider themselves to be poor. ${ }^{28}$ In other words, qualitatively, one wants to understand how each poor group understands and experiences poverty.

The Participatory Poverty Assessment (PPA), first undertaken in 2000 and extended in 2002, set out to answer the following questions:

\footnotetext{
${ }^{27}$ WFP, "Poverty Research", July 2000.

${ }^{28}$ In the Lao language, 'poor'/thuk/ is the condition of suffering arising from the human condition (in the Buddhist sense), as opposed to a physically defined condition as in English (derived from two Indo-European roots 'to produce' + 'little'). In Khmou, the term means 'unfortunate', an attribute associated with fate rather than economic status. Each ethnic group has similarly independent associations with the word 'poor'.
} 
1. Who are the Poor?

2. Where are they located?

3. When did they become poor?

4. What is poverty in the eyes of the poor?

5. Why did they become poor?

6. In the view of the poor, how may poverty be alleviated?

It was found that the poor people are primarily ethnic minority swidden cultivators. While poverty occurs throughout the country, it is less severe in Xayaboury, Vientiane Province and Vientiane Municipality than elsewhere. However, as found by the PPA, the poor people do not view themselves as being in an endemic state of poverty. Villages were subsisting in relatively stable agro-ecosystems, the outside perception of endemic poverty has been created by reliance on a numerical definition of poverty. In the minds of villagers, poverty is an issue of livelihood; as long as the villages are able to meet their consumption needs, they do not consider themselves poor. When agro-systems are disrupted or other upheavals occur, poverty may follow.

\subsection{Causes of Poverty}

Again based on the PPA, the main indicator of poverty - as determined by the poor themselves - is the degree of rice sufficiency. Thus, commonly cited causes of poverty include insufficient amounts of land for cultivation, and natural disasters, such as flooding or drought.

Basic aspects of poverty include the following:

> The indicator of poverty is rice sufficiency; the indicator of wealth is livestock.

> The main problems (related to rice sufficiency) include the reduction of land available for swidden cultivation, livestock disease, ill-health, hiring out labour, lack of necessary technical knowledge, lack of access to roads, lack of clothing, and poor housing.

$>$ The main causes of poverty are (in order of importance): (i) problems associated with land; (ii) livestock loss because of lack of veterinary services; (iii) lack of cash investment to make livelihood improvements; (iv) natural disasters; (v) environmental problems; and (vi) lack of water for agriculture.

> Other causes are: lack of local leadership; relocation ${ }^{29}$; lack of health services; too many children; lack of knowledge of the market; lack of government services; low agricultural prices; addiction to opium; and UXO.

As is to be expected, there are regional variations in the importance of these various causes of poverty. Land allocation and soil depletion problems appear to be especially important to the northern and eastern regions, while for the southern region natural disasters are a major concern. Large family size is cited as top concern for people in the central region. Opium addiction is cited only in the case of the north. Lack of roads and pests and livestock diseases are problems common to all regions.

\subsection{Follow-up to the PPA}

In 2002, there was a follow-up to the original PPA which enabled tracking developments over the two-year interlude in 55 representative villages in 13 provinces. ${ }^{30}$

\footnotetext{
${ }^{29}$ The National Resettlement and Compensation Policy will address many of the issues linked to this problem. This policy is now finalised.

${ }^{30}$ The original sample was 84 poor villages from 18 provinces and 43 districts in the 2000 PPA. The report entitled:
} 
In general, the study showed that most villages experienced improvement over the two-year period. However, some showed no improvement or had become worse off.

Villages that showed progress benefited from improved roads, enabling access to paddy land and markets. They also benefited from donor-assisted projects such as the construction of schools and health clinics and provision of medicine kits. Some benefited from improved irrigation and UXO removal.

In the villages where overall income increased, implying a decrease in poverty, it was found that increases in production were being realised by only a few households, and in many cases the majority of households had remained the same or were worse off than in 2000 . That is to say, an inequality gap has appeared within villages, both in villages of the same ethnicity, and in villages where several ethnic groups have been consolidated.

With respect to villages that remained the same between 2000 and 2002, problems encountered included repeated moves, lack of land (especially paddy fields), and UXO preventing cultivation. With respect to villages that had become worse off, lack of land was again a major problem. In particular, the reduction of traditional fallow cycles following new land allocation regulations is causing soils to deplete and yields to decrease. Despite its overall high level of poverty, the Northern Region appears to be more dynamic. The Southern Region showed less change over the two-year period.

\subsection{Public Investment Programme Poverty Impact Study}

Very recently, the Government has adopted a participatory monitoring approach concerning the contribution of Public Investment (PIP) projects to assess poverty reduction. The review is still in progress and to date selected northern provinces have been visited (Louang Prabang, Oudomxay, Louang Namtha, and Houa Phanh). The findings include the following:

- Most people say they are better off because of infrastructure investments, especially roads that allow access to the sale and purchase of goods and access to health and education services. However, forest products are being depleted.

- Agricultural production has not improved; village relocations often result in insufficient produce for sustainable livelihoods.

- Livestock disease remains a major problem and has not been resolved.

- Infrastructure projects tend to result in a few individuals becoming wealthy.

\section{Chapter 3: Poverty Criteria and District Poverty}

Criteria have been developed in order to assist local authorities in monitoring changes in poverty, especially in poor households and districts, and to help the district and provincial authorities themselves to better understand the poverty situation at the grassroots level. These officially used criteria are divided into three levels as follows:

* Household level: Households considered as poor are households with an income (or the equivalent in kind) of less than kip 85,000 kip (100,000 kip for urban and 82,000 kip for rural) per person per month (at 2001 prices). This sum allows the purchase of about 16 kilograms of milled rice per person per month; the balance is insufficient to cover other necessities, such as clothing, shelter, schooling and medical costs.

\footnotetext{
"Summary of the Recent Research Results on Poverty Assessment" is available as Working Paper No. 3 under the NSC/ADB Participatory Poverty Monitoring and Evaluation Project.
} 
Lao PDR - National Growth and Poverty Eradication Strategy (NGPES)

Village level: Villages considered as poor villages are:

$>$ Villages where at least $51 \%$ of the total households are poor.

$>$ Villages without schools or schools in nearby and accessible villages.

$>$ Villages without dispensaries, traditional medical practitioners or villages requiring over 6 hours of travel to reach a hospital.

> Villages without safe water supply.

$>$ Villages without access to roads (at least trails accessible by cart during the dry season).

- District level: Poor districts are:

- Districts where over $51 \%$ of the villages are poor.

- Districts where over $40 \%$ of the villages do not have local or nearby schools.

- Districts where over $40 \%$ of the villages do not have a dispensary or pharmacy.

- Districts where over $60 \%$ of the villages without an access road.

- Districts where over $40 \%$ of the villages do not have safe water.

On the basis of these criteria, 72 districts have been identified as poor (see accompanying map). As stated in Part I, at this juncture, the district level is the most relevant and reliable level for data collection and poverty monitoring. Furthermore, the district represents the level where co-ordination between all government services is best achieved. Of the 72 districts, 47 have been identified for priority intervention during 2003-5005.

\begin{tabular}{|l|c|c|c|c|}
\hline \multicolumn{5}{|c|}{$\begin{array}{c}\text { Table 7: Number and Percentage of Poor Villages and Households by Province using the } \\
\text { Criteria of PM Decree No.10 (for the 72 Districts Identified as Poor) }\end{array}$} \\
\hline \multicolumn{1}{|c|}{ Province } & $\begin{array}{c}\text { Number of } \\
\text { Poor Villages }\end{array}$ & $\begin{array}{c}\text { \%of Poor } \\
\text { Villages }\end{array}$ & $\begin{array}{c}\text { Number of Poor } \\
\text { Households }\end{array}$ & $\begin{array}{c}\text { \% of Poor } \\
\text { Households }\end{array}$ \\
\hline Vientiane Municipality & 27 & 73.0 & 191 & 4.4 \\
\hline Phongsaly & 369 & 94.4 & 9,241 & 53.3 \\
\hline Louang Namtha & 195 & 88.6 & 7,918 & 70.0 \\
\hline Oudomxay & 500 & 91.6 & 18,288 & 60.1 \\
\hline Bokeo & 114 & 64.0 & 5,082 & 52.6 \\
\hline Louang Prabang & 246 & 76.4 & 12,964 & 72.2 \\
\hline Houa Phanh & 636 & 91.1 & 21,299 & 65.1 \\
\hline Xaygnaboury & 136 & 47.4 & 8,040 & 30.9 \\
\hline Xieng Khouang & 204 & 47.6 & 9,228 & 35.4 \\
\hline Vientiane & 129 & 84.9 & 4,190 & 33.7 \\
\hline Borikhamxay & 134 & 88.2 & 10,885 & 71.2 \\
\hline Khammouane & 310 & 82.7 & 7,658 & 36.8 \\
\hline Savannakhet & 523 & 72.5 & 21,086 & 57.5 \\
\hline Saravanh & 119 & 65.7 & 5,483 & 61.2 \\
\hline Xékong & 153 & 85.5 & 3,966 & 82.4 \\
\hline Champasak & 160 & 51.1 & 5,893 & 19.7 \\
\hline Attapeu & 99 & 86.1 & 6,261 & 69.3 \\
\hline Xaysomboun & $\mathbf{4 2 6}$ & $\mathbf{7 6 . 7}$ & $\mathbf{1 6 0 , 5 9 2}$ & 58.0 \\
\hline Total & 53.7 & & \\
\hline Source: Nation & & & \\
\hline
\end{tabular}

Source: National Statistical Centre, 2003 
Lao PDR - National Growth and Poverty Eradication Strategy (NGPES)

In total for these 72 districts, there are 4,126 villages and 160,592 households that are classified as poor. In percentage terms, 76 per cent of the villages in these districts are poor and 50 per cent of the households are poor. Houa Phan province has the highest (absolute) number of poor villages and households, while Phongsaly province has the highest percentage of poor villages. Table 7 summarises the village and household data. Annex 1 (Tables 1.2 and 1.3) provides poverty-related information for each of the districts, including the number of poor villages and households. See also Map of the 72 poor districts on the following page.

The identification of the 72 poorest district was made, as mentioned, on the basis of Instruction 010, LECS II and provincial information regarding the number of poor households. Table 1.2 and 1.3 of Annex 1 list these 72 districts according to village and household criteria. Out of the 72 districts, 40 have been identified as very poor districts. For reasons of national equity, 7 other districts (of the remaining 32) have been added to this number. The rationale in choosing the 40 poorest districts is reflected in Table 8 . These districts have the highest incidence of poverty (70 per cent), calculated on the number of poor households (see Table 1.3). The remaining districts have a poverty incidence of 35 per cent. Together, the poverty incidence is 55 per cent for the 72 poorest districts, as compared to 23 per cent of the "non-poor" districts. The overall poverty incidence is the same ( 55 per cent) when dividing the group into 47 and 25 districts, as shown in Table 9. However, the Government's priority appears clear: it is where the poverty incidence is deepest that priorities will be set even if the target group (the 40 poorest districts) represent only 20 per cent of the population. In other words, in the 70 "less poor" districts, poverty concerns 19 per cent of the population, while in the 72 poorest districts more than half of the population is poor.

\begin{tabular}{|c|c|c|c|c|c|c|c|}
\hline \multicolumn{8}{|c|}{ Table 8: Poverty and Poor District Classification } \\
\hline \multirow[b]{2}{*}{ Indicators } & \multicolumn{7}{|c|}{ District Type } \\
\hline & \begin{tabular}{|c|}
40 districts \\
identified as \\
very poor
\end{tabular} & $\begin{array}{c}32 \text { districts } \\
\text { identified as } \\
\text { poor }\end{array}$ & \begin{tabular}{|c|} 
Total 72 \\
identified \\
as poor \\
districts
\end{tabular} & \begin{tabular}{|c|}
47 districts \\
identified \\
as priority \\
$(2003-2005)$
\end{tabular} & \begin{tabular}{|c|}
25 poor \\
districts out \\
of 72 \\
districts \\
identified as \\
poor \\
\end{tabular} & $\begin{array}{c}\text { Total 70 } \\
\text { districts } \\
\text { identified } \\
\text { as Non- } \\
\text { Poor }\end{array}$ & $\begin{array}{c}\text { Total } 142 \\
\text { districts }\end{array}$ \\
\hline $\begin{array}{l}\text { Average poverty incidence } \\
\text { (proportion poor } \\
\text { households) }\end{array}$ & 70 & 35 & 55 & 64 & 38 & 23 & 39 \\
\hline $\begin{array}{l}\text { Average Population share } \\
\text { (district population/total } \\
\text { population ) }\end{array}$ & 0.5 & 0.6 & 0.5 & 0.5 & 0.5 & 0.9 & 0.7 \\
\hline $\begin{array}{l}\text { Average poor population } \\
\text { share (district poor / total } \\
\text { poor population ) }\end{array}$ & 1.1 & 0.6 & 0.9 & 2.1 & 0.6 & 0.6 & 0.7 \\
\hline $\begin{array}{l}\text { Percentage of district to } \\
\text { total population }\end{array}$ & 19.7 & 18.3 & 37.8 & 24.3 & 13.5 & 61.4 & \\
\hline \begin{tabular}{|l|}
$\begin{array}{l}\text { Percentage of poor to total } \\
\text { poor population }\end{array}$ \\
\end{tabular} & 43.2 & 19.0 & 62.2 & 46.9 & 15.3 & 37.8 & \\
\hline Percentage of poor & & & 50.6 & & & 18.9 & \\
\hline
\end{tabular}


Lao PDR - National Growth and Poverty Eradication Strategy (NGPES)

\section{Chapter 4: Poverty and Social Indicators}

The National Statistical Centre is charged with the establishment of national social indicators. Tables $9-12$ indicate the present status of the main social indicators related to poverty eradication. Most of the social indicators have seen marked improvements over the 1995-2000 period, even though many of them still remain relatively low by world standards. For example, there has been a significant increase in literacy, for both men and women. However, the situation of some ethnic minorities remains of concern, especially for groups like Hmong-Mien women. In 1995 (the latest information available until the next census), their literacy rate was only 8 per cent. Generally, ethnic disparities are greater than gender disparities.

The NGPES poverty eradication objectives are in line with the country's commitment to achieve the Millennium Development Goals (MDG) as well as the Brussels LDC Action Plan. The improvement of the social situation as reflected in the social indicators has always been in the centre of the national socio-economic development plans. The Lao PRD being a party to the Millennium Development Declaration underlines this commitment.

\begin{tabular}{|l|c|c|c|c|c|}
\hline \multicolumn{6}{|c|}{ Table 9: Education Indicators } \\
\hline & North & Central & South & Vientiane & Lao PDR \\
\hline Educational attainment index & 59 & 75.5 & 67.5 & 90 & 68.5 \\
\hline Adult literacy rate & 59 & 75.5 & 67.5 & 90 & 68.5 \\
\hline Adult literacy rate - women & 44 & 64 & 51 & 84 & 55 \\
\hline Adult literacy rate - men & 74 & 87 & 84 & 96 & 82 \\
\hline $\begin{array}{l}\text { \% schools with complete } \\
\text { primary cycle }\end{array}$ & 32 & 51 & 50 & 76 & 43 \\
\hline Primary gross enrolment rate & 68 & 83 & 79 & 92 & 77 \\
\hline
\end{tabular}

Source: NHDR 2001

\begin{tabular}{|l|c|c|c|}
\hline \multicolumn{3}{|c|}{ Table 10:Literacy rates by Ethno-linguistic Groupings (1995) } \\
\hline $\begin{array}{c}\text { Ethno-linguistic } \\
\text { Family }\end{array}$ & Male Literacy Rate & $\begin{array}{c}\text { Female Literacy } \\
\text { Rate }\end{array}$ & Total Literacy Rate \\
\hline Lao-Tai & $84.4 \%$ & $62.3 \%$ & $72.9 \%$ \\
\hline Mon-Khmer & $55.6 \%$ & $19.9 \%$ & $36.9 \%$ \\
\hline Hmong-Mien & $45.7 \%$ & $8.1 \%$ & $26.5 \%$ \\
\hline Tibeto-Burman & $22.3 \%$ & $12.0 \%$ & $17.0 \%$ \\
\hline LAO PDR & $73.5 \%$ & $47.9 \%$ & $60.2 \%$ \\
\hline
\end{tabular}

Source: NSC 1995 Census. 


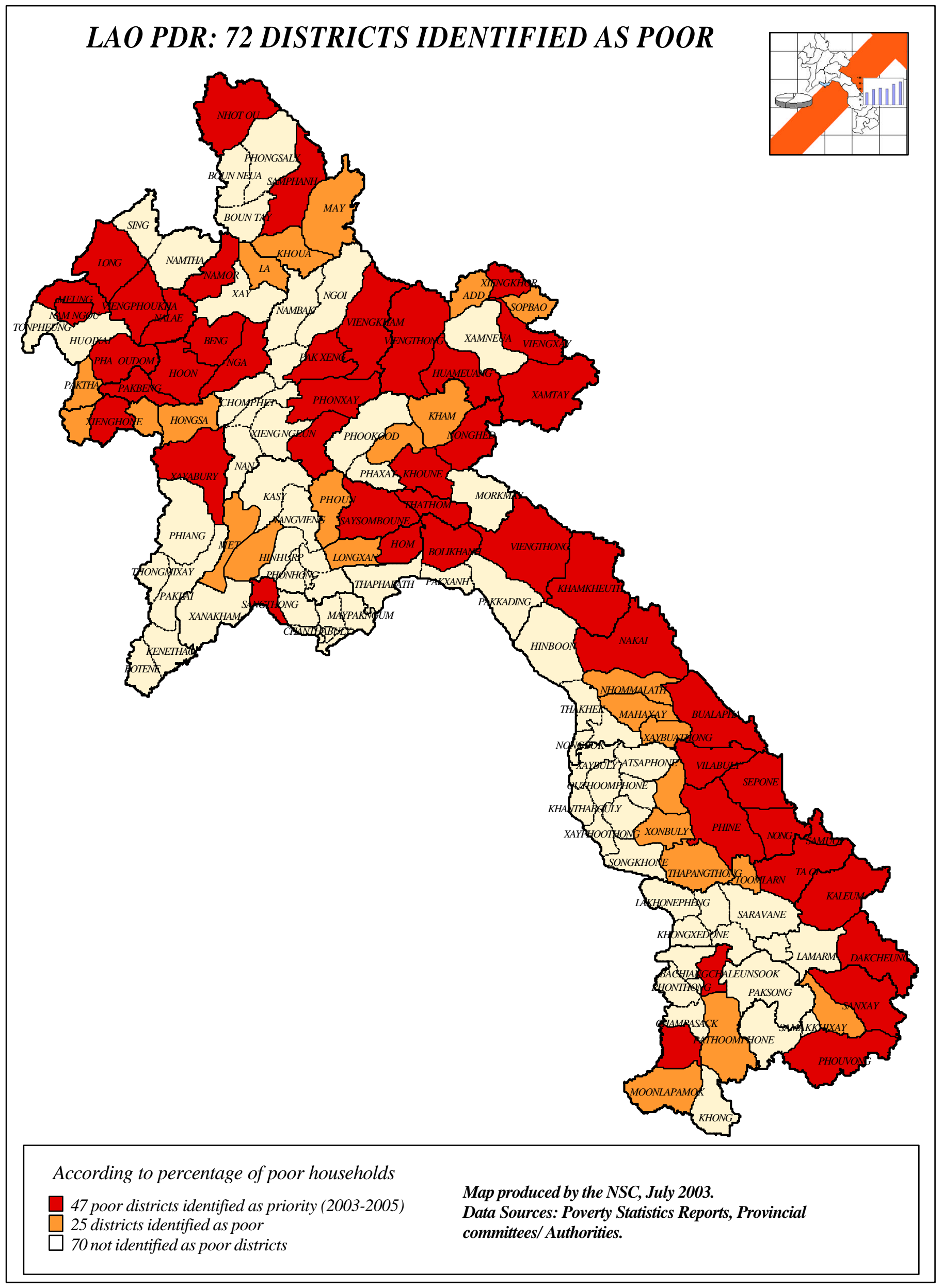


Lao PDR - National Growth and Poverty Eradication Strategy (NGPES)

Table 11: Health Indicators by regions (2000) and for the Lao PDR (1995 and 2000)

\begin{tabular}{|l|c|c|c|c|c|c|}
\hline & North & Central & South & Vientiane & $\begin{array}{c}\text { Lao PDR } \\
1995\end{array}$ & $\begin{array}{c}\text { Lao PDR } \\
2000\end{array}$ \\
\hline Life expectance at birth & 57.1 & 59.6 & 57.6 & 62.8 & 51 & 58.7 \\
\hline Under-five mortality rate & 118 & 99 & 107 & $*$ & 170 & 107 \\
\hline Maternal mortality rate & 540 & 440 & 700 & $*$ & 560 & 530 \\
\hline $\begin{array}{l}\% \text { villages with } \\
\text { immunisation program }\end{array}$ & 86 & 88 & 72 & 95 & n.a. & 87 \\
\hline $\begin{array}{l}\text { \% pregnant women } \\
\text { immunised against } \\
\text { tetanus }\end{array}$ & n.a. & n.a. & n.a. & n.a. & 24.6 & 45 \\
\hline $\begin{array}{l}\text { \% HHs with access to } \\
\text { primary health care }\end{array}$ & 67 & 78 & 82 & 78 & n.a. & 75 \\
\hline $\begin{array}{l}\% \text { villages with hospital } \\
\text { more than 8 hrs away }\end{array}$ & 13 & 5 & 6 & 0 & n.a. & 8 \\
\hline $\begin{array}{l}\text { \% medical care in HH } \\
\text { consumption }\end{array}$ & 2.5 & 2 & 2.6 & 1.8 & n.a. & 2.2 \\
\hline $\begin{array}{l}\text { HHs with access to } \\
\text { piped water or protected } \\
\text { well (\%) }\end{array}$ & 32 & 64 & 48 & 89 & 15 & 50 \\
\hline $\begin{array}{l}\text { Prevalence of malaria } \\
\text { (per 1,000) }\end{array}$ & 49 & 59 & 82 & 7 & n.a. & 55 \\
\hline
\end{tabular}

Source: NHDR 2001; NSC 2000. * included in Central figure

\begin{tabular}{|l|c|c|c|}
\hline \multicolumn{4}{|c|}{ Table 12 : Gender Status Indicators (2000) } \\
\hline & Urban & Rural & Lao PDR \\
\hline Live births by females age 15-49 (\% last year) & 10 & 18 & 17 \\
\hline Percentage of married women using contraception & 54 & 27.8 & 32.2 \\
\hline Proportion of births at home \% & 44.3 & 91.3 & 86 \\
\hline Time use in education females (under 14) & 4.3 & 2.9 & 3.1 \\
\hline Time use in education males (under 14) & 6.3 & 3.3 & 3.7 \\
\hline Time use in education females 15-19 & 3.9 & 1.5 & 1.9 \\
\hline Time use in education males 15-19 & 5.4 & 1.9 & 2.4 \\
\hline Number of years in school female & 5 & 2 & 3 \\
\hline Number of years in school male & 6 & 4 & 4 \\
\hline Number of years in school female 15-19 & 7 & 4 & 4 \\
\hline Number of years in school male 15-19 & 7 & 5 & 5 \\
\hline
\end{tabular}

Source: NHDR 2001, Lao Reproductive Health Survey 2000, LECS II, MOE.

\section{Chapter 5: Poverty Research and Monitoring}

On-going research on the poverty situation in the Lao PDR is needed to incorporate all factors relevant to poverty reduction, including variables resulting from geography, ethnicity and culture. Poverty research and monitoring is also important in guiding the redefinition of centrallocal relations and for formulating the Public Investment Program; in both cases central and local officials will need training so as to effectively address the needs of the poor. 
Lao PDR - National Growth and Poverty Eradication Strategy (NGPES)

Capacity building at the national, provincial and district levels is a major concern. Increasing capacity at the district level will de facto enable village participation in the planning process; questionnaires are being structured to enhance interactions between district officials and villagers for data collection and planning purposes. The result will be improved targeting of projects for poverty alleviation, more efficient allocation of resources within the framework of the 'decentralisation' programme and the PIP and, most importantly, local ownership of the project planning process.

New approaches to poverty research and monitoring will be required, including combining participatory exercises with traditional household surveys. This approach combines quantitative and qualitative analyses of poverty measurement, leading to better poverty eradication strategies.

Poverty monitoring is the task of the National Statistics Centre (NSC). This includes monitoring of the NGPES with regard to its poverty eradication priorities. For an appropriate monitoring of the NGPES's implementation, the NSC will strengthen the linkages between quantitative and qualitative analyses, building on three steps, as outlined in the following 3 sections.

\subsection{Poverty Monitoring of Households via Village Level Statistical Data}

There is a need for reliable data on districts and villages, especially within the context of districts being the planning and fiscal units and villages the implementing units. The "Village Statistics Book" is a useful instrument for monitoring of the socio-economic profile of villages. The implementation of the "Village Statistics Book" is progressing, with 11 provinces having completed the first round of household poverty monitoring. This will become the basis for locating household poverty nation-wide. Procedures regarding poverty monitoring at the local level must still be strengthened.

\subsection{Quantitative Poverty Monitoring Using the LECS III 2002/03 Survey}

The LECS III 2002/03 survey has been modified and expanded to better analyse poverty. Improvements include: rural prices; questions relating to household assets and income from agriculture and business; and questions relating to housing, education, health, and use of time of all household members. Data collection has been completed; a preliminary report will be completed by the end of 2003 .

\subsection{Qualitative Poverty Monitoring Using Participatory Methods}

Quantitative research on poverty must be carried out in unison with qualitative research. Participatory monitoring and evaluation of poverty is important, which includes listening to the poor express their needs and gaining a thorough understanding of the gender, cultural and livelihood dimensions of their circumstances.

Finally, monitoring of sector programmes and initiatives is important. Again, this requires data and measurement tools so as to evaluate the contribution to poverty reduction. Projects supported by donor agencies should be reviewed from this perspective. 


\subsection{Linkages between national and international efforts}

The NGPES reflects the Lao PDR's on-going commitment to sustainable growth and poverty eradication. This is perfectly consistent with the internationally defined goals regarding poverty reduction through the MDG Declaration and the LDC Brussels Summit.

Monitoring progress in implementing the NGPES objectives and programmes will also serve to help the Government monitor progress in implementing its international commitments. To this effect, a national steering committee and national data bank have been established to specifically monitor progress towards meeting international goals of poverty reduction, in particular the MDGs.

\section{Chapter 6: Poverty Vulnerability Assessments and Coping Strategies}

The Government believes that, in order to overcome poverty, individual households must be responsible for taking self-help initiatives - within an enabling context that is the State's responsibility. The participatory poverty assessments have reinforced the Government's conviction that the best way to proceed in fighting poverty is to improve the enabling environment at the grassroots level. This means: improving access to all rural and remote areas; developing rural infrastructure; implementing various economic reforms for increased market integration of the rural areas (market linkages, trade facilitation); enhancing people-centred resource management; facilitating access to quality health and education services; provision of credit; and other measures.

It also means addressing human security concerns; that is, threats and risks at the local level. For this reason, the Government undertook human security surveys or vulnerability assessments on an experimental basis in three provinces (Savannakhet, Luang Prabang and Vientiane provinces) $)^{31}$. Vulnerability analysis identifies risk patterns within a specific area and assists planners and local representatives in developing appropriate responses. Also, vulnerability analysis identifies coping responses to risk, together with possible options.

The vulnerability assessments carried out in the three provinces yielded important insights ${ }^{32}$. Women and men in the surveyed households expressed four areas of vulnerability - economic, environmental, social, and cultural. Vulnerability is expressed from the villagers' point of view, hence at times identified risks and threats varied from conventional views of poverty. External risks are perceived as greater than internal risks. Where there are well-developed coping strategies, vulnerability is perceived as less of a worry.

The most vulnerable, vulnerable and least vulnerable were determined according to their degree of ownership, access to assets and gender of household head. Generally, the most vulnerable are those who experience rice shortages, are landless, or the household is headed by a woman with no means of alternative livelihood. Those living at the very edge of subsistence in fragile environments and those experiencing health and addiction problems are also most vulnerable.

\footnotetext{
${ }^{31}$ Committee for Planning and Co-operation (CPC) in partnership with UNCRD, "Study on integrating human security concerns in local development in three provinces of the Lao PDR ", April 2002.

${ }^{32}$ See Annex 1.3-6.
} 
Moderately vulnerable households are those that experience economic, environmental, social or cultural threats but have some means to cope - such as assets or an alternative livelihood. The least vulnerable households are those facing few threats and risks, and who have assets to rely on when their primary means of livelihood is compromised.

On the basis of the three provinces surveyed, households in remote villages with poor road access are highly vulnerable, as are resettled households that lack assets. Smaller villages are found to experience greater vulnerability than larger ones, as they tend to be more dependent on subsistence agriculture and lack alternative means of livelihood to generate a cash income. Poverty is essentially a question of food vulnerability.

\subsection{Sources of Vulnerability}

Annex I includes the results from the three provinces surveyed, indicating both women's and men's perceptions of vulnerability. Generally, women expressed more economic threats to their security than men. Both women and men identified low income and shortage of capital or credit as serious economic threats. Shortages of rice are of greater concern to women while shortage of cultivable land is of greater concern to men. Other sources of economic vulnerability are landlessness, lack of employment opportunities, debt, and too many children to support.

In terms of environmental threats, both women and men are concerned with the impact of weather changes and natural disasters (floods and droughts) on crops. Women are more concerned with water shortages and water quality than men. Poor soil quality and the prevalence of pests and livestock disease are also threats. For some villages, the presence of unexploded ordnance (UXO) is a threat, as is deforestation.

Regarding social threats, women are most concerned with poor health and low education and skills, concerns shared by men who also identified weak village authorities as a source of vulnerability.

While cultural and social threats often overlap, households surveyed in all three provinces identified drug abuse as a serious concern. Women are concerned with loss of tradition and both women and men identified problems with youth. Theft and domestic violence are seen as threats in some cases. Drugs and lack of income generating opportunities are identified as factors contributing to the vulnerability of the country's youth. Lack of income generation opportunities can lead to young people migrating to urban areas in search of work. This in turn can leave ageing families without support, increasing their vulnerability.

In terms of seasonality, vulnerability to health problems and livestock disease is highest in the wet season, while vulnerability to crop failure is highest in the dry season. In terms of life cycle, vulnerability of children is a concern, reflecting their lack of education and skills. In some villages, aged persons without family support are found highly vulnerable.

The most significant aspects of the vulnerability assessments can be summarised as follows:

- Larger villages with good access are less vulnerable.

- Resettled populations, even in larger villages, are more vulnerable.

- Many of the perceived threats are external, that is, beyond the control of the villagers.

- Stronger households, and in particular women, have a keener perception of threats.

- Vulnerability is directly related to the range and quality of assets owned/controlled by a household.

- The link between resource mismanagement and natural disasters, and hence vulnerability, is not perceived. 
- Ethnicity and vulnerability are directly related, as certain ethnic groups have a limited range of assets and mechanisms to manage them.

\subsection{Coping Strategies}

When faced with economic, environmental, social and cultural threats, people adopt "coping strategies". The CPC/UNCRD study classified these into three categories:

1. Coping strategies that decrease vulnerability in the short and long terms;

2. Coping strategies that decrease vulnerability in the short term but increase vulnerability in the long term; and

3. Coping strategies that increase vulnerability in the short and long terms.

Coping strategies need to be incorporated into the planning process, especially at the village and district levels. Clearly, it is the first category that should be encouraged. Annex 1 includes tables indicating the coping strategies of the first category being used in the villages surveyed. Further, the tables distinguish between the strategies of women and men.

Women in almost all surveyed villages in the three provinces use a wider range of positive coping strategies than men. The differences in coping strategies between women and men indicate differences in exposure to vulnerability and access to assets, as well as the gender division of labour. Common positive coping strategies used by women are reducing expenses, raising livestock and poultry, and gardening. Those commonly engaged in by men are growing alternative crops and raising livestock. Other positive coping strategies are handicraft production, vending, and encouraging and co-ordinating with neighbours for joint activities. To address social concerns, villagers access health care and encourage and counsel children. Making alcohol and fishing are other ways of coping. Men mention requesting authorities for help as a coping strategy, which can be useful if there is an appropriate response by local authorities.

In the future, local planning will give increased attention to these coping strategies.

\subsection{Policy Implications}

From the vulnerability and coping analysis, the Government has drawn the following conclusions:

1. While it is essential that most poverty reduction programmes and projects should focus on agriculture, education and health services, and provision of infrastructure, more effort is needed to reduce vulnerability at the local level and to enhance coping strategies.

2. Four areas appear critical to strengthening positive coping strategies and to reducing negative coping strategies:

- Human resources development through provision of a wide range of skills related to economic activities, community organisation, and environmental protection and management.

- Environmental management of land, water, and forests resources. Traditional techniques need to be studied as well as new techniques for improvement of land quality, management of water during floods and droughts, and protection and replenishment of forest resources, starting at the village level. Dependence on the vast but dwindling environmental resources is a primary coping strategy with dangerous implications in the long term if the resources are depleted and degraded.

- $\quad$ Access to credit seems to be the key to initiating alternative means of livelihoods to reduce vulnerability and food shortages. 
Lao PDR - National Growth and Poverty Eradication Strategy (NGPES)

- $\quad$ Community mobilisation for participation in planning and implementation of projects for livelihoods, infrastructure, environmental resource management, and cultural preservation.

3. While applying strategies to achieve the above, the peculiarities of each district have to be taken into account such as the geographic location, natural resources endowment, asset ownership and management patterns of local communities, as well as their cultural and lifestyle patterns.

The vulnerability and coping analyses have provided the Government with important new insights that will further enhance its approach to poverty eradication. Vulnerability assessment techniques have already been incorporated in management and training courses, ${ }^{33}$ with the result that many local planning officials are now able to undertake vulnerability assessments related to economic, environmental, social and cultural concerns. ${ }^{34}$ These training programmes must now be extended throughout the country.

One essential aspect has been stressed again and again and that is the vulnerability created by food insecurity. For this reason, the Government intends to intensify its co-operation with programmes such as those of the World Food Programme (WFP), which promotes 'food for work' (e.g., food for schools). Food security must be ensured while the people and communities engage in development activities that help them to achieve longer-term sustainable development.

The Government's policy priorities concerning the implementation of a coherent approach to poverty eradication are summarised below:

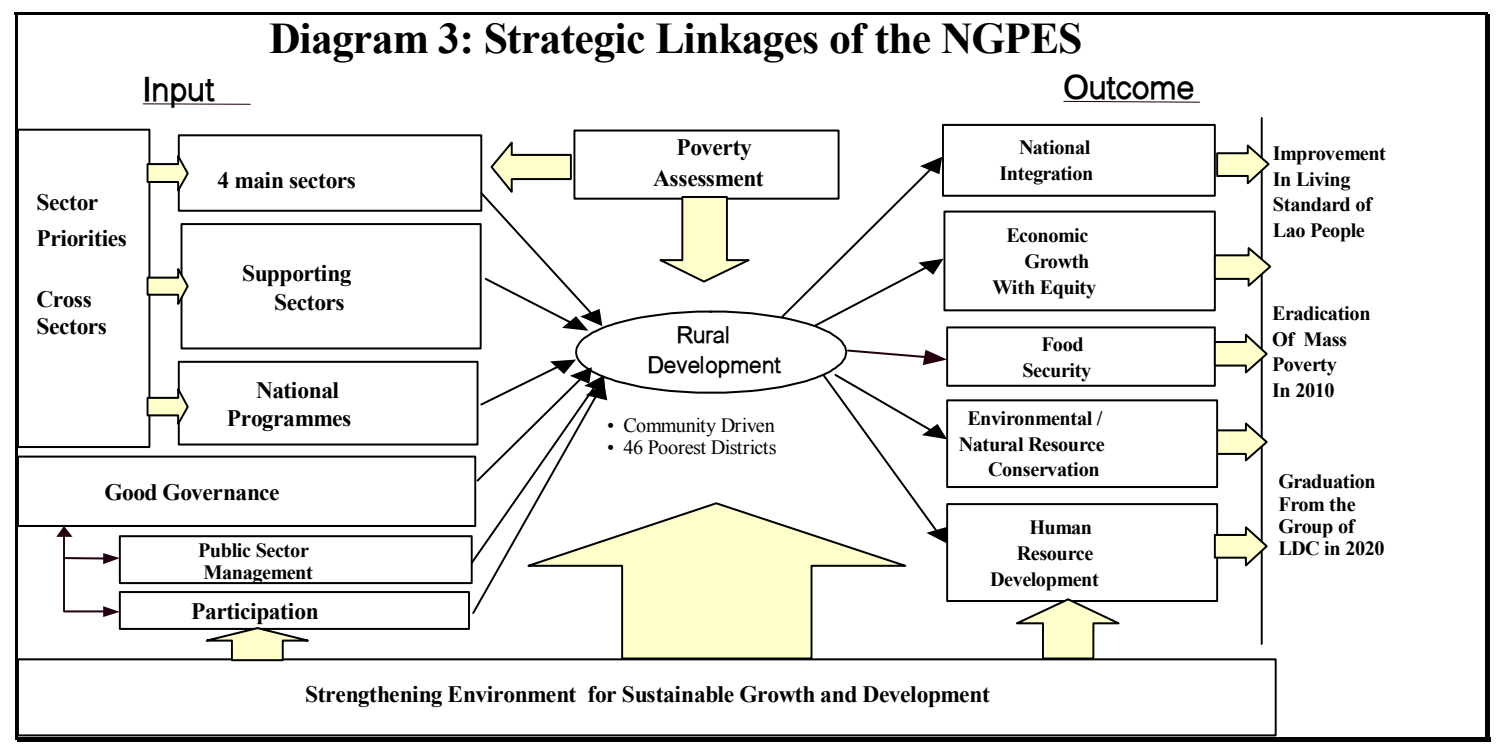

\footnotetext{
${ }^{33}$ By CPC in co-operation with UNCRD and JICA.

34 This was also one of the recommendations of the PPA.
} 


\section{PART III: Strengthening the Overall Environment for Sustainable Growth and Development}

The National Long-Term Development Framework (NDF) builds on progress since 1975 to realise the Government's goal of poverty eradication by 2020. The NDF incorporates the guidelines of the $6^{\text {th }}$ and $7^{\text {th }}$ Party Congresses (1996 and 2001, respectively). Table 13 provides a summary of the main elements of the NDF, including the long-term development indicators regarding living standards of the Lao multi-ethnic population. The main objectives and targets for the period 2001-2010 and for 2001-2005 are also presented. The NGPES is the NDF's operational strategic format.

Table 13 : ELEMENTS OF THE 2020 DEVELOPMENT VISION
Sustained Economic Growth with Equity
\begin{tabular}{|l|c|c|c|c|}
\hline Indicators & $\mathbf{2 0 0 0}$ & $\mathbf{2 0 0 5}$ & $\mathbf{2 0 1 0}$ & $\mathbf{2 0 2 0}$ \\
\hline Total population (million) & 5.2 & 5.9 & 6.6 & 8.2 \\
\hline Population growth rate (\%) & 2.6 & 2.5 & 2.3 & 2.2 \\
\hline GDP growth rate (\%) & 5.8 & 7.0 & 7.0 & 7.0 \\
\hline - Agriculture (\%) & 4.9 & 4.5 & 4.2 & 3.8 \\
\hline - Industry (\%) & 8.5 & 10 & 10 & 8.5 \\
\hline - Service (\%) & 5 & 10 & 10 & 9 \\
\hline Life expectancy at birth (years) & 59 & 63 & 67 & 70 \\
\hline Adult literacy over 15 years (\%) & 70 & 78 & 84 & 90 \\
\hline Total enrolment rate & 70.2 & 85 & 90 & 95 \\
\hline Infant mortality under 5 (per 1,000 live births) & 82 & 62 & 40 & 20 \\
\hline Maternal mortality (per 100,000 live births) & 530 & 350 & 250 & 130 \\
\hline Access to clean water (\% of population) & 52 & 57 & 100 & 100 \\
\hline Source: CPC - 2000 & & & & \\
\hline
\end{tabular}

The Government's development vision and strategies will continue to be refined through broad-based participation and refinement of short and medium-term plans by sector ministries and agencies. Training and capacity building will be strengthened at all levels, in order to deepen understanding of the policy issues and to better ensure that development plans and programmes are adapted to local conditions and needs. 'Post-NGPES' consultation will generate new analysis and insights. Realising the development vision will not be easy. Many intermediate steps will be needed. Five and ten-year objectives have been formulated so as to systematically improve the people's material, social, cultural and spiritual well-being, resulting from continuous economic growth and focus on the poorest districts. Box 1 below outlines the objectives and targets to 2010 . 


\section{Box 1: MAIN OBJECTIVES AND TARGETS FOR THE PERIOD 2001-2010}

- Nationally balanced and sustainable social/economic development, and transformation of the country towards modernisation and industrialisation.

- Enhance human resource development through: improved and extended education, training and health systems; create a favourable environment for the Lao multi-ethnic people to adapt to and manage the country in a global context: and improve the quality of life and increase community participation in the national development process.

- Eradicate basic mass poverty and phase out slash-and-burn cultivation by 2010 :

> Strive for a GDP growth rate of not less than 7 per cent per annum, focusing on industrialisation and modernisation, resulting in the following sector shares of GDP: agriculture 36.6 per cent (2001: 51.3 per cent), industry 31.5 per cent (2001: 26.6 per cent) and services 31.9 per cent (2001: 26.1 per cent). In order to achieve this objective, an investment/GDP ratio of 25 per cent per annum must be obtained.

$>$ Continue to build sectoral and regional economic structures, in order to effectively use natural and human resources in each region of the country.

$>$ Improve gradually the living standards of the multi-ethnic people.

$>$ Encourage food and commercial production, to establish food security by ensuring rice and food supply to the whole country.

$>$ Promote export of agricultural commodities.

$>$ Spur rural development, in order to progressively reduce mass poverty in rural areas. Slash-andburn cultivation should be transformed by encouraging farmers to take up new occupations and sedentary productive activities.

$>$ Continue developing socio-economic infrastructure in order to facilitate the expansion of other sectors, and increased exports.

$>$ Pay more attention to the cultural and social issues and human resource development by improving the quality of education in all branches and at all levels so as to be able to cope with the next step of development.

$>$ Control serious illnesses such as malaria and dysentery and prevent an HIV/AIDS epidemic.

$>$ Provide clean water for everybody by the year 2010 .

$>$ Continue implementing ongoing priority projects and study the implementation of new projects deemed necessary.

- And by doing so, to enhance peace and integration, national security and stability.

Source : CPC - 2000

The NGPES, as mentioned, translates the NDF's development objectives for 2005, 2010, and 2020 into an operational format. ${ }^{35}$

Part III addresses one of its main strategic thrusts, namely macro-economic stability, strengthening the business environment, and public management consolidation. These are top priorities for the Government, both from the longer-term perspective of building-up the country and economy and the short-and medium-term goals of poverty eradication.

${ }^{35}$ See Annex 2. Table 2.1 provides a synoptic view of the main economic and financial indicators from 1992 to their projections for 2003-2005. 


\section{Chapter 1: Macroeconomic Stability as a Fundamental Requirement for Growth and Poverty Eradication}

A stable macroeconomic framework is critical. The Asian financial crisis had a very negative impact on the Lao economy. High rates of inflation, steep depreciation of the currency and large fiscal and trade deficits occurred in Lao PDR during the crisis period (1997-2000). Geopolitical tensions (the 9/11 terrorist attack and Iraq war) and the SARS crisis hampered recovery, especially since the promising tourism industry and trade have been so seriously affected.

\subsection{Overview of Macro-economic Performance During the Past Decade}

Nevertheless, the overall performance of the economy has remained strong, as reflected in the annual average rate of growth of GDP of 6.3 per cent during the past 10 years (1992-2002). In particular, the industry and service sectors grew very strongly. The agriculture sector - allimportant from an employment perspective - has maintained steady growth in recent years, bolstered by an extensive irrigation investment programme launched by the Government just prior to the Asian crisis. In 2003, industry accounts for about 24 per cent of GDP, up from 16.7 per cent in 1992. The service sector share edged up to around 26 per cent, while agriculture's share fell from 58 per cent to 50 per cent. $^{36}$

Prior to the Asian financial crisis, foreign direct investment (FDI) also contributed strongly to growth of the economy. FDI disbursements were US \$128 million in 1997, but - as elsewhere in many parts of Asia - have dropped to much lower levels since the crisis.

The net result of these developments was that the 2000 target for GDP per capita could not be achieved. Instead of increasing over the 1996 level, GDP per capita actually fell by almost onefifth to US \$331. High inflation and sharp depreciation of the national currency (kip) severely undermined income when expressed in US dollars.

Inflation rose to 134 per cent in 1999; stabilisation measures quickly reduced inflation to 30 per cent in 2000 and to single digit levels in 2001 and 2002. However, the high inflation contributed to a steep decline in the exchange value of the national currency (kip), from 900 kip to the US dollar just before the crisis to about 10,500 kip to the dollar currently.

In addition to the impact of the Asian financial crisis, internal financial imbalances (notably high fiscal, trade and current account deficits) chronically affected macroeconomic stability. In October 1999, the Government took a series of important policy measures, including enhancement of tax and non-tax revenue collection and tightening of expenditure management. Also, budget financing through the banking sector was stopped. Trade reform and export promotion contributed to a more sustainable current account deficit.

These and other measures have supported a markedly improved macroeconomic environment since 2000. In that year, as a guide to monetary and fiscal management, the Government released its Macroeconomic Policy and Reform Framework. This framework is being progressively implemented and is an integral part of the NGPES. It includes three main reform programmes: the Poverty Reduction and Growth Facility (PRGF - IMF); the Financial Management Adjustment Credit (FMAC - WB) and the associated Financial Management Capacity Building Credit (CB-FMAC); and the Banking Sector Reform Programme (BSRP - ADB). A recent Public Expenditure Review has contributed further to the reform process. ${ }^{37}$

\footnotetext{
${ }^{36}$ See Annex 2, Table 2.2.

${ }^{37}$ World Bank, International Monetary Fund and Asian Development Bank, Lao PDR Public Expenditure Review and
} 
The PRGF supports the Government in strengthening macroeconomic stability through encouraging credit restraint, fiscal prudence, and a flexible exchange rate regime. More particularly, components of the PRGF include improvement of the treasury system, enhanced fiscal reporting and accountability, and tax measures to increase revenues. Trade and the role of the private sector are yet other areas included in the programme.

The FMAC addresses three areas: public sector reform (budget accounting and control, natural resource management); reform of state-owned enterprises (strengthening oversight capacity, enterprise restructuring, rate charges); and financial sector reform (banking, microfinance). The CB-FMAC focuses on capacity building to help implement these reforms.

The BSRP addresses restructuring of the SOCBs, including of areas critical to proper banking practices (strengthening of the legal framework and the commercial court) as well as capacity building and policy development.

All these reform programmes are well underway and are yielding good results. Through time, they will contribute strongly to economic growth and poverty reduction.

\subsection{Macro-economic Policy Measures and Poverty Reduction}

In addition to the above, the Government has defined detailed macroeconomic policy measures for the following areas: i) fiscal policy, ii) monetary and exchange rate policy and iii) investment promotion policy. In combination, these measures will have a highly positive impact on the real sector, particularly the agriculture, industry and service sectors. ${ }^{38}$

Transparent and consistent implementation of fiscal policy is essential. A number of steps are presently implemented such as the improvement of debt management, both internal and external, the strengthening of the revenue system, the tightening of expenditure management tightened with a longer-term view to gradually balance current and capital expenditures, substantially increase wages and salaries and strengthen social security. Public investment must be more effective and resources safeguarded for the social sectors - particularly for the poorest districts. Management and co-ordination of ODA must also be strengthened to maximise its effectiveness.

Sufficient budgetary resources must be mobilised to coherently implement the NGPES. All economic sectors, including the private sector as the main engine for growth, must be encouraged to produce wealth and thus expand the taxable resource base. Private sector development, including foreign direct investment (FDI), will provide part of the needed resources for national development. It will directly contribute to financing crucial growth investments, and indirectly by expanding the national taxable base through the creation of wealth as a result of a marketoriented, taxable transformation of the national resources.

A strict Medium-Term Expenditure Framework (MTEF) will preside over revenue and expenditure management, and define the country's financial possibilities. A well-mastered MTEF is also a guarantee for strengthened macro-economic management and thus poverty eradication. ${ }^{39}$

\footnotetext{
Country Financial Accountability Assessment, June 2002.

${ }_{38}$ Given the importance of the trade sector for growth and poverty eradication, trade policies and priorities are dealt with as a supporting sector (Part IV, Chapter 5.1).

${ }^{39}$ Part V provides a detailed analysis of the MTEF of FY2003-2004 to FY 2005-2006.
} 
The Government is striving to achieve a much stronger national revenue base through i) continuous improvement of revenue collection and modernisation of the tax system, ii) the enhancement of private sector development, including foreign direct investment, and iii) increased revenue flow to the Treasury from investments undertaken through the valuing of the national resource base (such as mining, hydropower, plantation industry).

In particular, the Government will address the major structural weaknesses that presently constrain the fiscal system. These weaknesses include a lack of ability and competence, inexperience, insufficient mastering of fiscal decentralisation and a less than optimal monitoring of revenue and expenditure management at the provincial level. Among the measures taken are the improvement of the institutional framework for fiscal management and the strengthening of the legal and regulatory framework. The Government redoubles its efforts to enhance capacity at all levels, to expand the use of appropriate management technology and a better clarification of institutional responsibilities and job descriptions.

To further enhance a sound macroeconomic framework, the Government is giving heightened and urgent attention to price stability and reform of the financial sector. Thus, sound monetary and exchange rate policy, and banking require appropriate measures for creating the conditions for sustainable growth and poverty reduction. Monetary policy will focus on restraining inflation, and the Bank of the Lao PDR (BOL) will refrain from deficit financing and excessive expansion of the money supply. The exchange rate will continue to be managed on a floating basis, while ensuring that the spread with the parallel market rate remains small.

Reform of the banking system includes establishing and enforcing prudential lending practices, as well as stopping credit to bad borrowers. Credit will be extended on a commercial basis, ensuring that market discipline is instituted and maintained. Financial services will be extended throughout rural areas, and to the private sector. ${ }^{40}$

Governance of the SOCBs will be strengthened and a more effective banking environment, through strengthened corporate management, will strongly enhance sound banking practices. La Banque pour le Commerce Extérieur Lao and the newly merged Lao Development Bank will, thanks to improved management, allow for rationalisation in their branch banking and head office operations.

Governance agreements with the BOL, the Ministry of Finance and the SOCBs boards and management define the principles and responsibilities underlying the restructuring programme, and make provision for independent audits. Defaults in the repayment of loans will be pursued vigorously, including through new prudential regulations and supervision and a revamped legal and judicial system concerning commercial cases. The high levels of non-performing loans, especially of SOEs, must be redressed. Limitations on asset growth will apply to SOCBs with high ratios of non-performing loans. Phased recapitalisation will ensure greater soundness. Increased competition among banks, including by private banks, will lead to a commerciallybased banking system.

A revamped legal and judicial system for commercial cases will include improvement of the documentation requirements for loan applications and greater understanding of contract provisions. The introduction of a commercial division in the court system will expedite rulings on creditor/debtor disputes. In turn, this will provide the leverage needed to force compliance by enterprises with the contract provisions of loans extended to them by the banking system. Credit discipline is essential to mobilise financial resources and to facilitate proper intermediation.

\footnotetext{
${ }^{40}$ This aspect is dealt with in more detail under "supporting sectors" as the financial sector is by definition an essential support to the functioning of the real economy.
} 
Lao PDR - National Growth and Poverty Eradication Strategy (NGPES)

The third area of macro-economic priorities is the promotion of an investment climate conducive to a strengthened business environment.

\section{Chapter 2: An Enabling Business Environment for Enhancing Growth and Eradicating Poverty}

The targeted economic growth rate of 7 per cent per annum over the next decade is necessary in order to achieve the 2020 goal of exiting the status of a least developed country. Achieving this target will require high levels of investment and savings. The necessary investment level has been estimated at 26-28 per cent of GDP, some 10-11 per cent of which will be by the public sector while some the remaining 16-17 per cent will be by the private sector, including FDI. In part, this high level of investment will be achieved through the implementation of large-scale projects such as the Nam Theun 2 hydropower project and mining projects.

All sectors must perform strongly in order to achieve an increase in domestic savings to help finance future investment requirements. In particular, the private sector must grow continuously, bringing with it new technologies and know-how, and competitive products.

The business environment for enhancing growth and eradicating poverty is thus critical. Investment policies and incentives will contribute to improving the business environment, notably for export production. Development of the natural resource-based industries will directly and indirectly create new job and income opportunities, including in poor and remote areas.

\subsection{Macro-economic Stability and Financial Flows to the Private Sector}

As elaborated upon in earlier chapters, macroeconomic stability is fundamental to creating a positive environment for business enterprise, especially private sector enterprise. Fiscal, monetary, and exchange rate policies must be in harmony, including credit limits consistent with price stability. An efficient and effective public sector is also fundamental; business enterprise and again especially private sector enterprise - is dependent on the economic and social services provided by Government.

The banking and financial sector reforms outlined earlier are vital to encouragement of the private sector. Resource mobilisation and financial intermediation are the market means for guiding and supporting the private sector. A sound financial system, based on strong corporate management, will also encourage small and medium-sized enterprises to engage in productive activities. In this way, the private sector will increasingly become the link between growth and poverty reduction. In this way, too, the gap between rural and urban areas will be narrowed.

Of course, there are many dimensions to supporting the private sector; the identification of these dimensions has been greatly assisted by close consultation with the private sector, including foreign investors.

\subsection{Specific Measures to Accelerate Private Sector Development}

Meetings with the domestic private sector as well with foreign investors (First Foreign Investment Forum, May 2002) have identified four major areas contributing to enhancement of the business environment: information and consultation; legal, regulatory and administrative streamlining; macroeconomic management as well as co-ordination and management capacity. ${ }^{41}$

\footnotetext{
${ }^{41}$ See Report of the $1^{\text {st }}$ Foreign Investment Forum, Department for the Promotion and Management of Domestic and Foreign Investment (DDFI), CPC, May 2002.
} 
Information and consultation are key factors for a harmonious relationship with the private sector. Accordingly, the following steps will be taken: acceleration of the publication of English versions of all laws and regulations with regard to investment; publication of a newsmagazine on investment activities; and regular publication of important economic documents such as the national budget.

Direct consultation will be regularised with the Department for the Promotion and Management of Domestic and Foreign Investment, the Lao Chamber of Commerce and Industry (LCCI) and the GMS Business Forum Secretariat. The Ministry of Industry and Handicrafts held a widely attended meeting on industrial policy with the private sector in May 2003, follow-up meetings with the private sector will be held at regular intervals. ${ }^{42}$ The National Steering Committee for the Production of Commercial Goods will be strengthened to serve as a high-level body for co-ordinating economic policies and private sector development.

With regard to legal, regulatory and administrative streamlining, measures include the following: licence renewals; the ceilings on tax-deductible investment expenditures, the approval system for imports and exports; and business registration and licensing. Further, the establishment of a central register of all legal documents instruments related to private sector development is a high priority. ${ }^{43}$

Macroeconomic reform priorities focus on the restructuring of the financial sector. Improved credit risk management is a priority. Complementary measures presently under study include the enforcement of the Secured Transaction Law, and amendments to the Decree on Commercial Banks, which will permit the establishment of foreign bank branches outside Vientiane.

Improvement of co-ordination and management capacity includes enforcement of laws concerning bankruptcy, secured lending, dispute resolution and debt recovery. Enforcement of the new Tax Law will contribute to transparency and fairness, and will facilitate collection at the local level.

Additional measures include phasing-out the lump sum tax method for small businesses, and training of tax officials to improve overall administration. Strict penalties now apply to businesses and individuals that do not comply with the Tax Law.

As a matter of principle, the Government of the Lao PDR has increasingly involved the private sector in areas that until recently have been public responsibilities or areas of state enterprise. ${ }^{44}$ This trend will continue, as highlighted in the sector action plans (Part IV).

\section{Chapter 3: Consolidating Public Sector Governance}

As part of the drive for macroeconomic stability, and the conditions for economic growth with equity, it is important that there be efficiency, transparency and accountability in public sector management.

${ }^{42}$ The private sector was consulted on the NGPES on April 26, 2003.

${ }^{43}$ The dialogue meeting on the industrial action plan contains a series of proposals regarding the improvement of the regulatory framework, which will serve as a priority reference in this reform area.

${ }^{44}$ For example, in the transport sector, private provision of transport services, the use of private contractors for infrastructure and maintenance, and the awarding of concessions for management of airport terminal buildings are now standard procedures. The private sector already undertakes most road design, construction and maintenance. Although there is a general lack of management and technical skills, and strong competition from companies in neighbouring countries, the Government does it utmost to encourage these emerging national sectors to play an important role. 
Since the establishment of the Lao PDR, governance issues have played an important role in the country's efforts to foster national unity and establish the basis for sustainable and equitable development. The Government's policy document on governance issues ${ }^{45}$ provides a comprehensive approach for improving public sector management, and has been fully integrated into the NGPES. Sound governance is essential to achieving a stable and open society, where the rights of the people are guaranteed by an efficient administration of the law.

The Government's policy document on governance issues stressed four priority areas, regarding the consolidation of public sector management, namely i) public service improvement, ii) central-local relations, iii) legal framework and iv) socio-economic management.

\subsection{Public Service Improvement}

Improved public service, realistically applied, requires increasing the knowledge, ability and qualifications of civil servants in accordance with short and long-term needs. It also requires preventing negative social phenomena, to ensure that the country has a peaceful society and a stable political situation. Finally, and most importantly, it requires meeting the needs of the multi-ethnic Lao people in the most effective and efficient manner possible. Improved governance means, among other benefits, that scarce public resources are not wasted in unnecessary procedures and costly expenses - that are borne with most difficulty by the poor.

Increased transparency and streamlined government decision-making are necessary elements in improving the functioning of the public sector in the Lao PDR. Accordingly, the Government has established a Committee for Governance and Public Administration Reform, under the direct supervision of the Prime Minister. While the Government has no plans to fundamentally change the structure of the Government organisation, it is constantly striving to ensure that the lines of authority and division of responsibility best meet the needs of the country. In order to ensure that ministries are correctly fulfilling their functions and to support the Decree on Anti-Corruption (Decree No.193/PM, 2/11/1999), the Government has established Departments of Inspection in each ministry.

Since the Asian financial crisis in 1997/98, budgetary constraints have caused the Government to face particular difficulties in attracting and retaining qualified and motivated staff. Internal macroeconomic instability and high rates of domestic inflation resulted in serious erosion of civil service salaries. The Government recognises that this has undermined the motivation of civil servants (including teachers and medical personnel) and has caused absenteeism and in some cases the levying of unofficial fees or other charges. Consequently, the Government has been reviewing the pay and compensation system; salary levels have been increased (significantly in 2000) to the extent possible within existing budget constraints. It is also gradually introducing a merit-based appointment and promotion system to ensure a more highly qualified civil service at all levels.

In summary, the following are priorities:

- Development of a lean, responsive and cost-effective public administration.

- Modernisation of civil service personnel management, including job descriptions and merit-based recruitment and promotion, and the use of PMIS.

- Development of a productive and highly motivated and customer-oriented civil service

- Development of an honest and ethical civil service.

- Training and development to enhance professionalism in the civil service.

- ICT to facilitate, streamline and create communication networks across the Government.

45 "Public Service Reform, People's Participation, Rule of Law and Sound Financial Management”, Government Document on Governance Issues, presented at the policy dialogue meeting, April 4, 2003. 
Lao PDR - National Growth and Poverty Eradication Strategy (NGPES)

\subsection{Central-Local Relations}

Poverty is greatly affected by the lack of accessibility of public services affordability, and their poorer quality in many instances. Much of this is related to the cost and difficulty of extending services to all areas of the country, especially to remote villages in mountainous terrain. But poor access to services is also exacerbated by lack of knowledge of rights and information about how the Government works, contributing to exclusion from decision-making. This hampers community participation and creates gaps between policy and practice.

The Government is committed to ensuring that the Lao people are closely consulted in all areas of decision-making and that they participate fully in the economic, social, cultural and political development of the country. To this end, the Government is redefining central-local relations. Instruction No.01/PM (11/3/2000) streamlines the responsibilities by the following designations: 'the provinces as the strategic units, the districts as the planning and fiscal units, and the villages as the implementation units'. Within this framework, each ministry is gradually defining the central, provincial, district and village levels of responsibility, as part of a fully integrated approach to improving the management and delivery of public services.

The Government is also experimenting with a new form of local administration. The Urban Development Administrative Authorities, currently responsible for urban services in five urban areas, will soon be expanded to a further six towns across the country. ${ }^{46}$ The UDAAs will be able to respond more efficiently to the needs of urban areas.

To help supply essential social and economic services, and to help overcome budgetary limitations, the Government is encouraging the participation of the private sector and mass organisations. The Government has paid particular attention to studying methods of co-ordination between the state and society to ensure that all sectors have an opportunity to participate in the development process.

Redefinition of central-local relations can only be undertaken on a step-by-step basis, according to the capacity of local level officials to assume new responsibilities and the ability of the Central Government to monitor compliance with national priorities. In this context, therefore, the Government will proceed with the following priorities:

- Improving communication with the people, especially in the remote areas.

- Clarification of responsibilities for each level of government.

- Redeployment of human resources from centre to local level.

- Improving capacity for participatory planning and implementation at the local level, and

- Improving the monitoring capacity of the central government.

By bringing local authorities, particularly from the village level, more into the decisionmaking and implementation process, the needs of the poorest areas will be better met.

\subsection{Legal Framework for all People}

The Government is committed to ensuring that all people are equally treated before the law, and that all laws reflect the real needs and priorities of the Lao people. The Government recognises that not all people in the society have equal access to and knowledge of their legal rights and responsibilities. Further, some people need to be given special consideration.

\footnotetext{
${ }^{46}$ Namtha district (Luang Nam Tha province), Xay district (Oudomxay province), Xamneua district (Huaphan province), Pek district (Xieng Khouang province), Vang Vieng district (Vientiane province) and Pakkxan district (Bolikhamxay province).
} 
Accordingly, top priority with respect to the legal framework is to ensure justice for the remote and disadvantaged peoples, especially in the poorest areas of the country. Special attention is being given to justice for children, young people and women.

Continued improvements in transportation, communications, and education systems are essential to securing 'justice for all'. Other measures are also needed. Language barriers to the legal system must be resolved. The Government is discussing the best means to provide legal assistance for the multi-cultural (and multi-lingual) population generation. The provision of translation services by the Ministry of Justice is necessary, even if the variety of different languages in our country makes the financial costs very high.

The strategic objectives to improve the legal sector in favour of the poor are to:

- Ensure the establishment of a clear, well-integrated legal framework.

- Strengthen the capacity of all institutions in the legal and justice sectors.

- Strengthen formal and informal methods of dispute resolution.

- Ensure predictable and transparent mechanisms for legal enforcement, and

- Improve the ability of all the peoples of Lao PDR to access the justice system.

\subsection{Socio-economic Management: Land Use and Administration}

While earlier chapters have already addressed key socio-economic management issues, including financial sector reform, another key issue is land use and administration. Improved land management and administration is a prerequisite for the sustained economic growth with equity, especially for the all-important agriculture/forestry sector. Accordingly, a National Land Use Planning and Land Development Department has been established in the Prime Minister's Office. This Department is the Government's lead agency concerning land use policy; it is preparing a master plan for integrated land management and land planning, which is expected to form part of the Roundtable process' policy dialogues. ${ }^{47}$

\section{Chapter 4: Sustainable Revenue Development}

The revenue position of the Government is critical, for unless its position strengthens it will be very difficult to provide the public services essential to enhancing social development and livelihoods, to support business enterprise and overall economic growth. Nor will the Government be able to fulfil all the measures designed to eradicate poverty, including in the most remote and poorest areas of the country. Economic growth leads to both revenue growth and poverty reduction, prompting the Government to be very active in building-up and strengthening the conditions for economic growth. Nonetheless, in the medium-term, to keep the momentum for growth and poverty eradication, the Government continues to experience a large resource gap, despite tax reforms and enhanced collection efforts. The international community has been very generous in extending official development assistance to the Lao PDR.

The long-term goal will be to close the revenue gap and reduce the dependency on ODA. The Government expects to progressively reduce both through improved revenue collection and tax administration and expansion of the national revenue base. To expand the national revenue base, sustained growth of private sector enterprise will be vital.

\footnotetext{
${ }^{47}$ The master plan draws from "Issues and Options for a Policy and Strategy Vision Programme for Land Administration Related to Land Use Planning to the Year 2020".
} 
To have a clear view on how the revenue base will evolve over time, the Government will strengthen its capacity to prepare medium to long-term public revenue and expenditure projections that include the following elements: ${ }^{48}$

- A realistic base case projection of GDP, with high and low case alternatives in the event that the base case proves too conservative or too optimistic.

- Revenue projections based on the GDP projections, disaggregated to show growth in each of the revenue sources (e.g., imports re customs duties).

- Supplementary revenues expected from tax reforms (e.g., introduction of a value-added tax) and improved administration (e.g., from the Large Taxpayers' Unit).

- Revenue losses expected from phasing in of AFTA/CEPT.

This will be completed with case projections of expenditure according to sector requirements (sector-wide planning, for instance) and particular priorities (wage and salary increases, for instance) to assess options with regard to available revenues. A task force will be needed to prepare such public expenditure framework, and time and resources will be needed to do the task properly - especially in terms of estimating the resource needs associated with the NGPES goals, such as universal primary education and health services for all.

The Government is working to ensure that revenue increases from tax reforms and administrative measures are both efficient and equitable, and in a manner that supports the goal of poverty alleviation. Recent income tax changes and the new Tax Law are designed to be consistent with these objectives. The progressive tax structure reflects the principle that taxes should not be levied on citizens who have little tax paying capacity. The Land Tax is set at a low rate, in acknowledgement that most farmers are in this category. Several of the exemptions from the Turnover Tax have been introduced to assist the poor, such as the exemption from tax on family-based sales of agricultural and handcraft products by farmers and co-operative members.

Revenue projections will be based on sound assumptions. In addition to macroeconomic simulations and trend analysis, the prospects of the main sectors of the economy will be assessed, in particular agriculture. Modernisation and commercialisation of the agriculture sector is projected to result in steady growth of 4-5 per cent annually. A well-managed forestry will enhance the overall growth of the sector. The increasing integration of the economy means that the agro-industries and other sectors will benefit from these developments, cumulatively building up the Government's revenue base.

Another source of growth relates to the recent surge in approvals for proposed foreign direct investment projects. Eighty-four projects were approved in FY 2001-02, totalling \$494 million. This represents a tenfold increase over approvals the previous year, even though actual disbursements remained about the same ( $\$ 74$ million). This development is linked to the gradual improvement in the regional economy, but also to the more positive environment for FDI in the Lao PDR. The expected boost in FDI inflows will greatly spur economic growth, and growth in the revenue base for the Government.

This link is well illustrated by the Nam Theun 2 hydropower project. Indicative revenue flows to the Government from this project, over 25 years of operations, are estimated to be at least US\$ 1.8 billion, of which royalties represent US\$ 776 million, income tax US\$ 423 million and dividends US\$ 622 million. ${ }^{49}$

\footnotetext{
${ }^{48}$ NERI is currently developing a model that can be used to assess the evolution of the resource base and revenue flows. The first detailed results should be available early 2004 .

${ }^{49}$ Source: Nam Theun 2 Cash flow model.
} 
FDI in the mining industry is already starting providing a healthy injection of revenues for the Government. Over the next ten years (2003-14) total earning from the mining industry are projected to be more than US\$ 1.5 billion, of which approximately US\$ 500 million will accrue to the Government in the form of royalties (US\$ 40 million) and taxes (US\$ 460 million) ${ }^{50}$ It is estimated that newly opened or about to open copper and gold mines will create more than one thousand jobs for local people, and lead to even more jobs through the multiplier effect. Investments in the tourism and tree plantation sectors are also generating economic growth and growth in the revenue base against which tax and non-tax revenues can be drawn.

The Lao PDR's strategic location as a land link for the GMS countries should act as yet another boost to economic growth. The GMS Subregion (Cambodia, Lao PDR, Cambodia, China/Yunnan Province, Myanmar, Thailand, and Vietnam) is one of the most dynamic in the world, with a population soon approaching 300 million. Completion of transport corridors and other projects linking the Subregion offer great benefits for the Lao PDR. The transport corridors will include special economic zones (SEZ) and industrial estates, such as the SEZ proposed for Savannakhet-Seno. These investments will further increase the Government's revenue base.

The regional approach to development is incorporated in the Five-Year Socio-Economic Plan. Four regions have been distinguished to better target and implement the Plan: the Northern Region, the Central Region, the Southern Region, and Border areas. The latter are of strategic importance for strengthening the safety and security of the nation, and they play an important role in enhancing trade and tourism. At the same time, the border areas require attention because of the need to stop illegal trade (wildlife, timber, drugs etc.), the trafficking of women and children, and the HIV/Aids endemic, and other concerns.

There are no particular administrative structures as such for these regions, but the Government considers them appropriate planning and investment co-ordination entities. Despite differences in development levels among the provinces forming a region, each region faces a common set of needs, such as trade facilitation with adjacent provinces in neighbour countries. Such considerations make the region an appropriate reference point from which to plan development and help eradicate poverty.

The Government is increasingly promoting regional development planning and investment. This is illustrated by preparation of a Northern Region Development Strategy and the formulation of a "Growth Triangle" between the Lao PDR, Vietnam and Cambodia. Membership in ASEAN and the AFTA, and active involvement in the GMS Program, underscore the Lao PDR's commitment to regional co-operation and integration. ${ }^{51}$ The Lao PDR's participation in the Mekong-Ganga Basin Commission and the "Emerald Triangle" for the development of tourism between Laos, Cambodia and Vietnam further demonstrates the Lao PDR's involvement in regional development.

Taken together, these initiatives will strengthen economic growth and the revenue base for the Government. However, revenue mobilisation remains one of the most difficult and important challenges facing the Government. Much rests on meeting the challenge successfully. Donor assistance and advice in this regard is needed.

\footnotetext{
${ }^{50}$ Source: Oxiana (LXM) LRM estimates based on information in the FS provided by Lane Xang Minerals Ltd

${ }^{51}$ An example of this determination are the recent decrees signed by the Prime Minister on the Border Trade in Boten (Louang Namtha) and the special economic zone in Savannakhet-Seno as two potential new growth centres.
} 


\section{PART IV: National Sector Plans to Promote Sustainable Growth and Poverty Eradication}

In its Report to the $7^{\text {th }}$ RTM (November 2000), the Government highlighted, within a "growth with equity' framework, the main sectors, supporting sectors, cross-sector priorities, and national programmes vital to sustainable growth and poverty eradication. The NGPES incorporates and elaborates upon these areas of focus:

- The "main sectors" of agriculture/forestry, education, health, and transport (esp. road infrastructure).

- The "supporting sectors" include trade, tourism, manufacturing and energy.

- Cross-sector priorities, including environment, gender, population and capacity building.

- National poverty-related priority programmes such as drug control, UXO decontamination and HIV/AIDS.

The various sectors, national programmes and cross-sector concerns have been chosen in consideration of the country's development obstacles, needs and opportunities, but also in response to the poverty assessments described in Part II. By careful investment and support for each policy area, and by sound macroeconomic management and improved governance, the Government expects the following results:

$>$ Food security, which is perceived as an essential accomplishment for poverty reduction. ${ }^{52}$

$>$ Human resource development, enabling diversification and modernisation of the economy, together with effective participation by the people.

$>$ National integration, leading to reducing regional and rural/urban income gaps by facilitating a more equal sharing of resources and access to public goods.

$>$ Social progress, leading to quality education and healthcare for all, improved status of children, women and ethnic minorities; and other social services.

Each sector ministry has a nation-wide mandate to help build an integrated economy, while at the same time focusing on initiatives and programmes that benefit poor districts. One cannot be achieved at the expense of the other; a balance must be struck between investments that are needed to build the country as an essential condition for sustainable long-term poverty eradication, and those investments that have an immediate impact on reducing poverty.

As noted earlier, the 47 poorest districts and a further 25 less-poor districts have been identified through a consultation process and PM Instruction 010. Most of these districts, particularly the poorest villages within them, are difficult to access. This has discouraged investment and hindered international assistance. With improving access, following extensive investments in roads, communications and other infrastructure, all sector strategies are better able to contribute to the Government's top priority - meeting the 2020 goal of exiting the status of least-developed country. In this way, solidarity within the Lao PDR's multi-ethnic society will be strengthened.

The following chapters summarise the sector and supporting sector strategies, cross-sector priorities and national programmes designed to both strengthen economic growth and eradicate poverty.

\footnotetext{
52 The PPA and RPA showed that 'enough food' was considered as the first condition to exit poverty.
} 


\section{Chapter 1: Poverty-Focused Agriculture/Forestry Development Plan: Policy and Investment Priorities}

A top priority for the Government of the Lao PDR is to modernise the agriculture and forestry sector in a manner that fully meets sustainable practices and that achieves food security and better livelihoods for all Lao people. The goal of poverty eradication and graduation from LDC status by 2020 depends on a more productive agriculture and forestry sector. Farming defines the character of the country, and working the soil and raising of livestock and fishery are second-nature to the Lao multi-ethnic population. It is a character that the Government is committed to protecting. In addition to strengthening the quantity and quality of agricultural output, this requires management of the Lao PDR's forests in a manner that both conserves this essential resource and encourages sustainable forestry practices.

The agriculture and forestry sector provides the economic, social and cultural base for more than 80 per cent of the population, and accounts for more than 50 per cent of GDP. Subsistence farming is still widespread, characterised by low inputs (little use of fertilisers or quality seeds) and low outputs (yields), with the result that farming incomes are very low, especially in the poorest districts. The Government is firmly of the view that more progress in modernising the sector can and must be made, while respecting the traditions of the Lao way of life and the rich diversity of its ethnic minorities.

All levels of government and all stakeholders will exercise great care in this endeavour. The marked differences between the lowlands and uplands of the Lao PDR call for very different approaches to agricultural reform. Transition from central planning to a more market-based economy calls for much greater reliance on the private sector, and a more supportive role for the Government. The marked differences between pioneer and rotational shifting cultivation call for different approaches. Ethnic sensitivities and language barriers call for highly localised policy and programme responses.

There are many challenges but also many opportunities ahead. The Government is committed to a fully participatory process, from the village level up, in meeting these challenges and realising opportunities. The Lao PDR is strategically situated in a huge and ever growing regional market, offering trade and investment opportunities that can lift the agricultural sector into the new millennium. The Government's development plan for the agricultural sector builds on these opportunities in a comprehensive and compelling manner.

\subsection{Goals for the Agriculture and Forestry Sector}

The Government has clear development objectives for the agricultural and forestry sector to 2020, designed to contribute to the overarching goal of poverty alleviation:

- Ensure food security for all Lao people.

- Maintain a growth rate in agricultural output of 4-5 per cent annually.

- Promote commodity production, especially for export.

- Stabilise shifting cultivation and eradicate poppy cultivation.

- Diversify and modernise the agricultural and forestry sector.

- Conserve the natural environment and protect threatened species and habitats.

- Maintain a healthy and productive forest cover as an integral part of the rural livelihood system, and generate a sustainable stream of forest products.

- Improve rural livelihoods. 
The Government recognises that these are ambitious goals; public and private sector partnership, together with support from its international partners in development, will be needed to meet them.

\subsection{Situation Analysis}

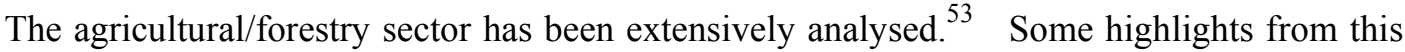
analysis include the following:

- An estimated 620,000 households depend on agriculture, of which some 490,000 rely on subsistence farming.

- The Lao agriculture is dominated by three main farming systems: dry-land rice cultivation, employing shifting cultivation techniques in the northern and eastern mountain regions; paddy rice cultivation along the Mekong River; and the cultivation of horticulture crops in the highland areas of the south.

- $\quad$ Rice is the single most important crop, accounting for 40 per cent of agricultural output; in addition to paddy rice, rural households obtain their basic food needs from raising livestock and fishery and gathering non-timber forest products (NTFP).

- Agricultural output has risen steadily over the past decade, by 4-5 per cent annually on average; rice output has increased following irrigation investments and other initiatives since the mid 1990s; livestock production has increased by 50 per cent, and fishery by 160 per cent.

- While the country's food needs are currently being met from domestic production, a stable supply remains uncertain because of inappropriate farming and domestic marketing systems.

- The crop sub-sector is characterised by low use of improved varieties of rice, fertilisers or pesticides; irrigation and double cropping are also quite limited; agricultural support (e.g., extension services) remains inadequate due to budget and technical limitations; crop yields per hectare are below average for the region; and harvest and post-harvest technologies are weak.

- Agricultural development is closely interwoven with rural development; poor market access reflects lack of all-weather roads linking rural areas to domestic and international markets; distribution networks have yet to be established in most areas.

- Relative to the uplands, the lowland areas are more mechanised and make more use of agricultural inputs (improved seeds, fertiliser); because of better transport links, they are also more market-oriented and commercialised.

- Reassessment of the land-forest allocation programme ${ }^{54}$ is needed, particularly as it applies to upland areas where shifting cultivation is widespread; shortened fallow periods, together with population pressures, have resulted in declining yields and hardship in some upland areas.

${ }^{53}$ Including: Lao PDR, MAF, The Government's Strategic Vision for the Agricultural Sector, 1999; JICA/MAF, Master Plan Study on Integrated Agricultural Development in Lao PDR, 2001; A Strategic Vision for an Integrated Watershed Management Approach for Sustainable Upland Development and Poverty Alleviation in Lao PDR, 2002.

${ }^{54}$ MAF Instruction No. 8 on Land-forest Allocation outlines the objectives, targets and objectives for village forest land allocation. The intention is to have a national allocation system for all types of land in villages across the country, to define boundaries, land-use rights and management guidelines in an endeavour to achieve 60 per cent forest cover by 2020. Land-forest allocation can be to families, villages, or collectives, with three-year provisional permits extendible to a permanent land title if compliance with land-use plans is proven.

${ }^{55}$ Shifting cultivation is of two forms: rotational and pioneer. Rotational cultivation involves rotation of cleared plots in cycles of 7 to 15 years, depending on soils and other conditions. During the fallow periods the soil and the forest cover regenerates, and thus are sustainable if population pressures and/or land allocation provisions do not interfere with the traditional cycle. Pioneer shifting cultivation as practiced by some is not sustainable, as it involves utilising 
Lao PDR - National Growth and Poverty Eradication Strategy (NGPES)

- Preliminary results from the most recent survey (2000-2002) suggest that forest cover has further diminished from the level in 1992, due to a number of causes under assessment.

\subsection{Strategic Responses}

The Government of Lao PDR is pleased with progress to date in modernising and strengthening the agriculture sector. As shown by participatory poverty analysis, progress in improving food security is of utmost importance for the poor.

The Government's strategy for maintaining this progress combines building on success to date while introducing new thrusts to speed modernising and strengthening of the sector. Since the needs and circumstances of lowland and upland cultivation are unique, the Government has differentiated its strategic responses. Table 14 illustrates a market-based approach for the lowlands. However, due to the lack of basic infrastructure and other services, and the widespread poverty and lack of capacity of people in upland areas to break out of poverty, the Government must and will take a more proactive approach to helping them.

Table 14: Alternative Agricultural Development Strategies ${ }^{56}$

\begin{tabular}{|c|c|}
\hline Lowlands /Mekong Corridor & Sloping/Uplands \\
\hline $\begin{array}{l}\text { Improve and diversify farming systems with increased } \\
\text { and intensified cash crop, livestock and fisheries } \\
\text { production. }\end{array}$ & $\begin{array}{l}\text { Plan land-use zoning based on bio-physical (slope and } \\
\text { land capability) and socio-economic parameters. }\end{array}$ \\
\hline $\begin{array}{l}\text { Expand and intensify value added processing by } \\
\text { promoting local and foreign investment. }\end{array}$ & $\begin{array}{l}\text { Accelerate participatory land allocation and land use } \\
\text { occupancy entitlement. }\end{array}$ \\
\hline $\begin{array}{l}\text { Develop market research and information systems and } \\
\text { regional market links between producers and wholesale } \\
\text { and retail buyers throughout the region. }\end{array}$ & $\begin{array}{l}\text { Diversify farming systems and agro-forestry development } \\
\text { through adaptive research, trials and demonstrations of } \\
\text { farmers' fields. }\end{array}$ \\
\hline \multirow{3}{*}{$\begin{array}{l}\text { Develop internationally accepted product grades and } \\
\text { standards. }\end{array}$} & Promote community management of natural resources. \\
\hline & $\begin{array}{l}\text { Sustainable land use management with soil erosion } \\
\text { control, afforestation, plantation forestry and conservation } \\
\text { management. }\end{array}$ \\
\hline & Strengthen demand driven extension programs. \\
\hline $\begin{array}{l}\text { Rehabilitate, expand and intensify irrigation schemes with } \\
\text { community based management. }\end{array}$ & $\begin{array}{l}\text { Expand and intensify small-scale community managed } \\
\text { irrigation schemes. }\end{array}$ \\
\hline $\begin{array}{l}\text { Strengthen and expand rural credit facilities through free } \\
\text { competition and market determined interest rates. }\end{array}$ & $\begin{array}{l}\text { Develop and expand rural savings and credit systems; } \\
\text { target credit to support technology adoption by the poor. }\end{array}$ \\
\hline \multirow[t]{2}{*}{$\begin{array}{l}\text { Strengthen rural and agribusiness lending by SOCBs and } \\
\text { private commercial banks. }\end{array}$} & $\begin{array}{l}\text { Strengthen the capacity and legal framework of SOCBs in } \\
\text { commercial banking transactions. }\end{array}$ \\
\hline & $\begin{array}{l}\text { Open community market access by upgrading and } \\
\text { expanding feeder roads and market information . }\end{array}$ \\
\hline
\end{tabular}

The Government's Strategic Vision for the Agricultural and Forestry Sector, which has guided progress in recent years, includes seven key themes, as summarised below:

1. Participatory Planning, so as to ensure sensitivity to local needs and circumstances, and to support preparation of district plans for lowland areas and the preparation of integrated watershed plans for upland areas; village and district level action is the main catalyst for growth of the agricultural sector.

2. Lowland Transformation, whereby the strengths of lowland farmers (market access, more modern farming techniques) help expand exports of commodities (the Commodity Production Programme).

the land until it is exhausted. Shortened fallow periods, in addition to resulting in declining yields, give rise to excessive weeds - forcing much more labour to maintain crops.

${ }^{56}$ MAF, The Government's Strategic Vision for the Agriculture Sector, December 1999. 
3. Sustainable Development of Sloping Lands and Environmental Management, including protection of National Bio-Conservation Areas (NBCAs), regulation of harvesting of NTFPs, and a multi-sector and community-based approach to land allocation and management.

4. Stabilisation of Shifting Cultivation, the Government aims to stabilise shifting cultivation by 2005 , through the promotion of on-farm and off-farm activities, facilitated by district extension workers knowledgeable in alternative rural livelihoods.

5. Expansion of Irrigation, projects are being managed more effectively and new projects are expanding the area under irrigation.

6. Human Resource Development, emphasis is being given to upgrading MAF staff, especially at the district level, to improve participatory planning, extension techniques and understanding of the market system and role of the private sector.

7. An Enabling Environment for Business Development, this is central to promoting economic growth with equity, as stated in Part III of the NGPES.

The Government has adopted an area-focused development approach, which places a high priority on more sustainable land use and the identification and designation of agro-ecological classifications. Forest conservation is integral to this approach. In particular, the river basins and watersheds must be better managed and protected, otherwise the country will lose control of its vast hydrological resources, resulting in flooding or drought, soil erosion and other highly damaging consequences for the agricultural sector and the hundreds of thousands of dependent households. Further, the Lao PDR's rich bio-diversity will be lost, again at great cost to the people, especially the poorest. Most rural households gather food, medicine, firewood and other products from the forests; for those in mountainous areas, forest products frequently serve as the main source of income.

In particular, area-focused development aims at providing a whole range of alternatives to remote communities. Area-focused development opportunities include livestock-based farming, non-timber-forest-products-based upland farming systems and others already devised upland development strategies, including more viable land allocation systems. In this way, people have options to choose from in order to improve their livelihood locally without having to move.

The area-based approach thus addresses directly or indirectly the issue of the dynamics of population mobility in Laos. Most of Laos' population has always been a population on the move for a number of reasons: in the past, as a consequence of 60 years of wars (the establishment in 1975 of the Lao PDR brought peace to the country), but also through shifting cultivation and poppy cultivation (people move to new places as a consequence of declined land fertility) and of other factors (road development, available development zones and/or markets, population pressure, and so forth). As a fact of life, people who move in search of improved conditions for livelihood and access to social services are in general poor, living in remote, scattered communities, with very fragile livelihood systems and without access to the needed social services. The development, both in the upland and lowland regions, of flatland areas is another development alternative pursued by the Government in response to movements of villages from areas where there is not enough carrying capacity. The Government does its utmost to prepare these focal areas in a systematic and organised manner to ensure that such moving villages, on a spontaneous or participatory and planned basis, have a chance to 'consolidate' in the best possible way. The Government's policy of providing development options in targeted areas ('area-focused development'), be it in the plains or the mountainous areas, that have economic potential is a sound policy. Villages, and especially the poorer ones, have a great deal of resilience in addressing the complexities of the uplands, including moving to more favourable areas to have better lives, to opt for new survival strategies from own initiatives. 
Thanks to the area-focused development approach, people/communities have a possibility to establish themselves in their chosen territories as this approach aims to provide the necessary conditions for strengthening livelihood and food security and access to essential services (roads, electricity, schools, medical facilities, water, and sanitation). With a successful implementation of a focused, harmonised area-based development approach, the impact of wide-spread voluntary movements of people, undertaken without preparation and at great risks, can be mitigated successfully. For this reason, the Government gives great importance, in order to avoid people hardship, to discuss with them their movements and to prepare them in a participatory and consultative way. Systematic emphasis on community participation will help realise positive outcomes. Thus, the area-focused development approach tries to respond to the peoples' aspirations. It also helps to reduce shifting cultivation and poppy cultivation while enhancing local development potential, through provision of local infrastructure, access to basic social services, encouragement of food and commodity production as well as income-generating activities. In this way, the area-focused approach will help foster and achieve transition from subsistence level rural activities to more market-oriented production favouring accumulation of wealth and private initiatives. However, given limited public resources, both financial and human, implementation faces constraints. This approach implies close co-ordination between all sectors involved to work together in order to focus resource allocation in specific areas or territories as part of a coherent and integrated district development plan.

The participatory poverty assessments carried out since 2000 have drawn attention to the need to ensure that these focal development areas can support the new inhabitants, and that issues related to livelihood, ethnicity and others, including immediate access to basic services and food security, are properly addressed. The Government's priority is thus to improve the implementation of these policies in order to respond to people's aspirations to improving their livelihood and access to services while having an opportunity to settle down, if they wish so.

Chapter 8 of Part IV of the NGPES elaborates on the area-focused rural development approach and in particular on district planning to ensure coherence and co-ordination for focused resource allocation.

\subsection{Poverty-Focused Agriculture/Forestry Development Priorities}

The Government's development plan for the agriculture and forestry sector is both national and local in its application. National policies and programmes must address factors that apply throughout the country, such as the trade regime under which agricultural products are exported and imported. Such policies, together with the national transportation network and other framework infrastructure, play a vital role in helping to modernise and commercialise the agricultural sector. As such, they play a vital role in helping to reduce poverty. The Government is constantly reassessing its policies and programmes that bear upon the agriculture and forestry sector, to ensure they serve the sector effectively and efficiently while favouring the interests of both the poorest and less poor people.

While the economy is progressing towards the stage where transformation and growth will be possible, it is important that national policies and programmes be adapted to changing circumstances. In this spirit, for instance, the Government is reassessing the Land-Forest Allocation Programme. A policy dialogue process for this purpose has been established.

The first and foremost concern is improving conditions and opportunities in the 47 poorest districts. The second priority concern must be the other 25 districts identified as poor. Once the circumstances of these districts are more satisfactory, remaining pockets of poverty will need to be resolved. The agriculture-related aspects of poverty will be addressed following the principles of sustainable resource utilisation and land-use planning: 
Food security and Food self-sufficiency: Through the Food Production Programme, the Government is committed to meeting its obligation made at the 1996 World Food Summit (FAO, Rome): to reduce the number of undernourished people by 50 per cent of the 1996 level by no later than 2015. From the point of view of Lao villagers, the fundamental causes of their poverty are those that affect rice yields and numbers of livestock. ${ }^{57}$

In direct response, the Government's poverty-focused agricultural development includes the following measures, with special emphasis on poor households:

- Participatory surveys in districts and villages, to clarify local needs and adjust extension services in response to socio-economic/agro-ecological conditions.

- Distribution of improved paddy seed to increase yields.

- Training district level extension agents/farmers on improved cultivation techniques.

- More effective use of existing irrigation systems.

- Strengthening the animal health control system through distribution of vaccines and training farmers in their use.

- Strengthening livestock and fisheries extension systems, and

- Strengthening information networks on productivity, disease, and markets.

Reduction in vulnerability: This includes minimising risks to rural households from drought and flood damage and livestock diseases. Also, risks associated with the market-based system are being addressed. Specific measures include:

- Controlling unsustainable harvesting and export of NTFPs.

- Improving agricultural practices and land management to ensure sustainable use, together with disease and pest control.

- Rehabilitating and improving the operation and maintenance of irrigation schemes, and development of groundwater resources.

- Construction of flood protection structures in flood prone areas.

- Improvement of access roads and access to credit.

- Improvement of information on local and regional market conditions.

Increasing the value of outputs: Through the Commodity Production Programme, the Government is promoting agricultural exports. Specific measures include:

- Market incentives for farmers, including private sector contract farming.

- Establishment of a grading and classification system to improve product quality.

- Participatory land use planning and resource management.

- New crops based on agro-zoning and market-based private sector investment.

- Application of area-based applied technology.

- Strengthening of the participatory agricultural extension system; also private sector extension services, farmer vocational training and model family farms.

- Livestock health and fisheries promotion programs.

- Development and distribution of area-based applied technology.

Strengthening of rural communities to ensure increased earnings from value-added processing activities: Programmes for strengthening community-based institutions, rural finance and credit programmes, market data collection and dissemination, and the organisation of farmer groups will contribute to the strengthening of rural communities.

\footnotetext{
${ }^{57}$ Lao PDR (CPC) and the Asian Development Bank, Participatory Poverty Assessment, December 2000.
} 
The Government's development plan includes support for access to and availability of market and price information. Land use rights and villagers' ownership of land use rights are being strengthened through review of procedures for land allocation to farmers and land titling. Additional measures include the following:

- Formation and training of farmer organisations, including water users/irrigation associations, and joint liability credit and contract farming producer groups.

- Construction of district feeder roads and improvement of market access roads.

- Rural finance mobilisation, tailored to meet farmer needs (i.e., credit for improved seeds, fertilisers, agricultural chemicals, draught animals, etc.), based on market determined interest rates and open competition.

- Training for villagers in organisation and management of contract farming and village savings and credit groups; also, support for Village Development Funds.

- Facilitating agro-processing at the household, community, and rural levels.

\subsection{Agriculture Policy Priorities}

The above outline provides the main elements of the Government's development plans for the agriculture sector. However, there is much more in the details of market orientation, participation, human resource development, decentralisation, diversification, technology transfer, sustainability, and integrated watershed management. Forestry is addressed in a subsequent section.

\section{Market Orientation}

Market principles are being blended with community-based initiatives to facilitate the transformation from subsistence to commercial farming. In this context, farmers are being assisted to diversify into cash crops, horticulture, livestock, fishery and NTFP, based on socioeconomic and agro-ecological considerations in each region. Applied research and district extension services support these initiatives. The principal elements of the market orientation include:

- Removal of distortions for agribusiness development in the functioning of factor markets, such as subsidised credit and fertiliser, and clarification of laws and regulations (e.g., licensing) to reduce impediments and transaction difficulties experienced by the private sector.

- Increased credit availability through a strengthened Agriculture Promotion Bank and other financial institutions; structured loans to meet farmers' needs and facilitate microfinance.

- Facilitation of land occupancy entitlement, land tenure, titling and village management.

- Training of MAF staff at all levels in principles of market-based agricultural system.

- Strengthening the ability of communities to compete in local and regional markets, including through establishment of a market information system.

- Establishment of a grading and certification system for commercial crops and NTFP.

- Support for establishment of agro-processing by private sector and farmers' groups.

- Trade facilitation and regional economic integration; expand the Common Effective Preferential Tariff Inclusion List.

- Formalising cross-border trade flows. 


\section{Participation and Human Resource Development}

Community-based participation is viewed as the catalyst for diversifying and modernising the agricultural sector. Indeed, community-based participation is fundamental to the area-focused development approach that forms the core of the Government's strategic plan for the agriculture sector. For participation to be effective, a long-term commitment is needed to build capacity at the local level. The main elements include the following:

- Fully decentralised "bottom-up" participatory planning.

- Strengthen capacity of communities to participate in development planning and to take responsibility for natural resources management.

- Extend and improve the quality of the school system, as an investment in upgrading the skills of farmers and their ability to participate effectively in community interests.

- Extend and improve the informal education system, to improve literacy in rural areas, especially in the poorest districts.

- Introduce farmer vocational training and on-the-job training, particularly in the poorest districts.

- Support women's groups to participate in the review of training and extension services.

- Train provincial and district agricultural personnel in planning, monitoring and evaluation, project formulation and implementation.

- Review of the Land-Forest Allocation Programme to make it more participatory and community-led, including by the following measures:

$>$ Technical assistance to improve the land allocation process.

$>$ Develop capacity at provincial and district levels to better address land allocation.

$>$ Undertake periodic reviews of allocation procedures concerning NBCAs.

- Promote community-based irrigation plans and farmer organisations.

\section{Decentralisation}

Consistent with a more market-based approach and an area-focussed development approach, the Government is redefining central-local government relations: " the provinces as the strategic units, the districts as the planning and fiscal units, and the villages as the implementation units". Accordingly, the Ministry of Agriculture and Forestry is reviewing responsibilities at each level to develop a fully integrated yet highly responsive system to local needs and opportunities. The MAF will:

- Develop procedures and capabilities for participatory land-use planning within area-based programmes and projects.

- Strengthen the overall capacity of PAFOs and DAFOs, especially the latter.

- Transform MAF to become a farmer-service organisation, capable of responding quickly to farmers' needs in a market-based economy.

- Continue to expand upon decentralisation of development planning, research and extension functions; also, community-managed irrigation systems.

- Regarding integrated management of watersheds and the transformation of lowlands, the responsibilities are:

Provincial level:

$>$ Ranking of watersheds.

$>$ Strategic development options.

$>$ Priorities for sub-watersheds. 
District level:

$>$ Watershed zoning.

$>$ Specific development interventions.

$>$ Identification of buffer zones and conservation areas.

The village level is the implementing unit.

\section{Diversification}

To encourage cash crops, horticulture and livestock as supplements and alternatives to rice cultivation diversify, the Government is relying primarily on market incentives and better services (e.g., rural roads and access to credit) to assist farmers willing to diversify. As noted earlier, in the case of uplands areas the Government is taking a more proactive approach, in recognition of the special hardships they face. In addition, the Government's objective to phase out shifting and poppy forms of cultivation requires special assistance. The Government will:

- Strengthen multi-sector approach to reduce shifting agriculture.

- Indicative planning based on comparative advantage and rural socio-economic indicators.

- Assist shifting cultivation farmers to become successful sedentary farmers.

- Assist poppy growers to develop alternative livelihoods.

- Strengthen and extend irrigation systems, for both sloping and lowland areas.

- Design and implement pilot groundwater irrigation schemes.

- Promote seed multiplication services.

- Strengthen the animal health control system and livestock extension system.

- Introduce a meat inspection system.

- Provide technical assistance to private sector for animal improvement and breeding.

- Establish participatory extension systems to promote inland fisheries.

- Promote private sector participation in plantation forestry and agroforestry.

- Promote cultivation of NTFPs.

\section{Technology Transfer}

Available technologies offer the potential to greatly increase crop yields, horticulture produce and livestock production. Also, domestic research can contribute significantly to raising agricultural output. According, the Government's development plan for the agriculture sector includes the following:

- Develop an integrated extension system to transfer agricultural production technologies to the poor people and upgrade the capacity of NAFES in extension, particularly for uplands areas.

- Ensure that research (NAFRI) and extension services (NAFES) are demand-driven.

- Extension programme for adaptive research and demonstrations on farmers' fields.

- Introduce basic post-harvest handling and processing methods to farm families and communities.

- Develop area-based applied technology and agro-zoning.

- Develop suitable technologies for overall improvement in livestock production.

- Develop applicable technology for inland fisheries, including pond management and feeding. Also, develop improved varieties of inland fish. 
Lao PDR - National Growth and Poverty Eradication Strategy (NGPES)

\section{Sustainability}

The Government's development plan for the agricultural sector balances growth and conservation concerns, taking into account the socio-economic and agro-ecological conditions of each region. Long-term sustainability of the Lao PDR's natural resource base is essential for poverty eradication. The Government's commitment to finding and maintaining the proper balance is reflected in points already raised. Further measures include the following:

- Raise awareness of government officials and farmers regarding need for sustainable practices.

- Strengthen the capacity of provincial and district offices to undertake natural resource planning and management.

- Education and training in modern agricultural technology, and in local farming techniques and knowledge.

- Promote farming systems that are best suited to soil and hydrologic structures, to prevent degradation and minimise siltation and runoff.

- Prevent encroachment, illegal activities and bio-diversity degradation in NBCAs by law enforcement, capacity building and village participation in conservation.

- Control unsustainable harvesting and exporting of NTFPs.

- Map flood risk areas and strengthen and extend flood control structures.

- Identify and conserve local aquatic resources.

- Sustainable forestry management is addressed separately.

\section{Integrated Watershed Management}

The Government recognises that the Lao PDR's watersheds have an essential role in natural resource conservation. They also play an essential role in maintaining a healthy agriculture and forestry sector. In co-operation with the Mekong River Commission, MAF has developed a multi-sector and community-based process for area-based socio-economic and integrated agricultural development. Accordingly, in addition to measures listed above, the Government is committed to rebuilding the watershed through integrated management methods, including the following:

- Decentralise responsibilities, as indicated earlier.

- Implement integrated area-based natural resources management centred on watersheds.

- Pilot projects (three conducted so far) in integrated watershed management.

- Develop integrated watershed management models, adapted to different geographical locations and reflecting different socio-economic and biophysical conditions.

- Develop IWM plans for 8 northern provinces (location of the priority watersheds).

\subsection{Sustainable Forestry Management}

The Government is committed to reversing deforestation and to achieving 60 per cent forest coverage by 2020 . The Lao PDR is blessed with valuable, productive and ecologically unique forests. They are an important source of food, medicine, energy, and income for the people, particularly for the poor people and ethnic minorities in remote mountainous areas. Forests contribute 7-10 per cent of the GDP, and 15-20 per cent of the non-agricultural GDP. The forestry industry accounts for about one-third of total exports; forest royalties account for about 11 per cent of total government revenues.

Employment in the wood processing industry makes up one-quarter of all manufacturing jobs. Forests also conserve the country's rich bio-diversity and protect its soils, watersheds, and water resources. Conservation of the forests, while at the same time building a strong forestry industry, is a difficult challenge. It must be met. 
The $1^{\text {st }}$ National Conference on Forests in 1989 called for establishment of a comprehensive forestry legal system, urgent actions for ecosystem/wildlife conservation and strengthening of forest institutions and human resource development. More recently, the $7^{\text {th }}$ Party Congress in 2001 set the development targets for 2005, 2010, and 2020, which were subsequently endorsed by the National Assembly. In addition to the goal of 60 per cent forest cover noted above, these targets included stabilising shifting cultivation by 2005 and phasing it out completely by 2010 . Tree plantations for commodity production are to be strongly promoted, with the aim of rehabilitating and reforesting approximately 1.5 million hectares. The $7^{\text {th }}$ Party Congress also called for accelerated classification and delineation of forests for protection, conservation and production purposes. As stated earlier, maintenance of a healthy and productive forest cover is integral to the rural livelihood support system.

The Government has taken a series of actions to realise these objectives. National Conservation forests have been established throughout the Lao PDR, and now cover more than 12 per cent of the total land area. The legal framework has been strengthened, including by promulgation of the Forestry Law and related laws and the issuance of implementing regulations. Several Prime Minister Orders and Decrees now control harvesting and sales of forest products. The Government has sharply reduced the annual harvest of logs, from a peak of 734,000 m3 in 1999 to some $260,000 \mathrm{~m} 3$ in both 2000/01 and 2001/02. Over the past ten years there has been a noteworthy reduction in the area under shifting cultivation. Establishment of the National Agriculture and Forestry Research Institute and the National Agriculture and Forestry Extension Service now provide co-ordinated and field-oriented research and extension services, contributing to developing alternatives to shifting cultivation. Over the past five years some 113,000 ha have been planted with trees. ${ }^{58}$ Over the five years to 2000 , land and forest allocation was carried out in more than 5,300 villages; this included the allocation of degraded land for farming and tree plantations, and the allocation of forests for protection or other uses.

Still, more action is needed to conserve the forests and put the forest industry on a sustainable basis. The Government is presently completing an analysis of recent survey material compiled from satellite data during 2000-02, in order to update the status of forest cover in the Lao PDR. However, forest cover is clearly much less than it was in the mid-1960s (about 70 per cent) and it appears to be somewhat less than in 1992 (47 per cent). In many areas, forest degradation is as serious as deforestation. The Government is deeply concerned by this situation.

Management of forests needs to be strengthened to deal with such issues as lack of an integrated land and forest management system, insufficient law enforcement, weak institutional capacity and the lack of funds and resources.

The Government will take strong measures to ensure that the forests are revitalised and that the forestry industry operates within allowable harvest limits. A strategy paper has been drafted under the leadership of MAF, supported by SIDA and JICA, and is being considered by the cross ministerial steering committee assigned to guide the strategy's development. ${ }^{59}$

It incorporates the lessons learned from numerous production, conservation, reforestation, and forestry plantation projects. The Government is anxious to complete the dialogue process and recognises the need for extensive consultation with community groups and all other stakeholders.

\footnotetext{
${ }^{58}$ It is estimated that approximately 75,000 hectares have survived, constituting the current national stock of standing tree plantations. Individual farmers or entrepreneurs account for almost 50 per cent of the planted area, with plantations averaging 20-30 ha. The Government is implementing tree plantation projects in co-operation with ADB, JICA, DANIDA, SIDA, the Swiss Government and GTZ.

${ }^{59}$ Formulation of the Forestry Strategy to the Year 2020 (FS2020) was initiated as a policy dialogue in September 2000. The Ministry of Agriculture and Forestry has been assigned as the lead agency and a cross ministerial steering committee - headed by the President of the Committee for Planning and Co-operation - has been established to guide the development of the strategy.
} 
Lessons learnt include the success of participatory forest management. ${ }^{60}$ A Sustainable Forestry and Rural Development programme is under consideration that will further develop models for participatory management of production forests and community forestry, and reform timber royalties and prices. In addition, a Tree Plantation for Livelihood Improvement project is currently being formulated at the Department of Forestry. Both projects aim to develop alternative sources of income for rural households and contribute to the reduction of poverty.

Consistent with these initiatives, the Government strives to implement the following measures to alleviate poverty and to ensure more sustainable management of Lao forests:

- Enhance village-based natural resource management for poverty alleviation.

- Revise the system for harvest determination, from focus on capacity of the wood industry to focus on sustainable supply.

- Restructure the wood industry in Lao PDR to bring processing capacity into closer accord with a sustainable raw material supply.

- Control unsustainable harvest and export of NTFPs by unregulated traders and promote sustainable participatory management and processing of NTFPs.

- Promote tree planting; formulate mechanisms (through collaboration among MAF/DOF, NAFRI, and STEA) for certifying sustainably managed tree plantations.

- Prevent encroachment, illegal activities and bio-diversity degradation by effective law enforcement, capacity building, and the participation of villagers in conservation activities.

- Formulate a national land use policy and introduce land use planning at both the macro and field levels.

The Government is committed to a reform agenda for the Lao forestry sector. The improved forest management and utilisation program seeks to bring the production forest under long-term, scientific-based management through implementation of the following measures:

$>$ Define forest management units and prepare management plans.

$>$ Strengthen the legal and regulatory framework.

$>$ Increase reliance on market approaches and mechanisms.

$>$ Restructure state-owned enterprises.

> Complete the decentralisation process and capacity building at local level, facilitating community-based forestry management, and

$>$ Effective mobilisation of resources and international co-operation.

As stated in the Strategic Vision for the Agriculture Sector, the Government is fully committed to preserving significant areas of natural forests to conserve biological diversity and to protect its many regional environmental assets. To this end, MAF is employing an area-based and decentralised development approach, centred on integrated watershed/river basin management, with the environmental benefit of providing protection to natural forests.

The establishment of agro-ecological zones nation-wide will delineate land for lowland/flatland and sloping land agriculture, bio-diversity conservation, and watershed and sloping land suitability classification. Using this approach, the MAF will promote the wide replication of community-managed natural resources, including the participatory management of production forests. The Land and Forest Allocation Programme is being modified to be more community-led.

\footnotetext{
${ }^{60}$ World Bank / Sida / Ministry of Foreign Affairs, Government of Finland, Lao PDR Production Forestry Policy: Status and Issues for Dialogue, Vol. 1, Main Report, 11 June 2001.
} 
Lao PDR - National Growth and Poverty Eradication Strategy (NGPES)

Support for increased private sector participation in plantation forestry and agroforestry is being intensified to relieve pressure on natural forests. Improved environmental management of natural forests will be demonstrated by an expansion of forest cover, reduction of soil erosion, and other biophysical indicators.

\subsection{Priority Programmes for Agriculture and Forestry}

In the course of preparing a master plan for agricultural development to the year 2020, MAF has identified numerous projects that will enhance agricultural productivity, upgrade product quality, and reduce the vulnerability of poor communities. The proposed projects are detailed in the master plan and are being considered by the Government. ${ }^{61}$

The first group of eleven projects includes activities related to fisheries, livestock, non-timber forest products (NTFP), seed multiplication, horticulture, and rural finance. These are high priority activities because they can be implemented almost immediately, have a significant impact on value added, and most importantly generate increased income and create employment opportunities for poor households in rural areas. The projects with the highest priority are listed on Table 15.

\begin{tabular}{|c|c|l|}
\hline \multicolumn{3}{|c|}{ Table 15: Poverty-Focused High Priority Projects } \\
\hline Priority & $\begin{array}{c}\text { Reference to } \\
\text { Master Plan }\end{array}$ & \multicolumn{1}{c|}{ Name of Project / Programme } \\
\hline 1 & LF-10 & Aquaculture Improvement and Extension Project \\
\hline 2 & LF-11 & Fish Seed Centre Rehabilitation / Expansion Project \\
\hline 3 & LF-2 & Animal Health and Quarantine Improvement \\
\hline 4 & RF-11 & Expansion of Micro-Finance Activities \\
\hline 5 & LF-12 & Rural Aquaculture Development Project \\
\hline 6 & SC-4 & Research on Sustainable Management/Utilisation of NTFPs \\
\hline 7 & AC-5 & Outer City Horticulture Promotion Program \\
\hline 8 & AC-1 & Rice Seed Multiplication Improvement Project \\
\hline 9 & MR-8 & Processing and Marketing of NTFPs \\
\hline 10 & AC-21 & Basic Seed Production Technology Improvement Project \\
\hline 11 & LF-6 & National Animal Health Centre Improvement \\
\hline
\end{tabular}

The most important short- and medium terms factors to be addressed through implementation of these high priority projects include the following:

Aquaculture projects

$>$ Insufficient investment in freshwater fisheries activities.

$>$ Lack of knowledge and technical capacity to practice alternative livelihoods.

$>$ Lack of knowledge of integrated fish-paddy farming system.

$>$ Low protein intake of rural people due to dependency on diminishing wildlife.

${ }^{61}$ Projects have been selected based on the needs of a cross-section of constituencies. As part of the formulation of an Action Plan for implementing the Master Plan for Integrated Agricultural Development in Lao PDR (October 2001), the MAF held discussions with the Master Plan Study team and held stakeholder workshops to prioritise and establish a sequence for agricultural development projects and programmes. A scoring and evaluation exercise was conducted for 58 projects and programmes divided into four groups; priorities 1,2,3, and 4. Only priority projects I and II are considered for 2003-2005. 


\section{$\underline{\text { Livestock projects }}$}

High mortality rates of livestock from ordinary and epidemic diseases.

$>$ Limited knowledge among farmers of livestock diseases.

$>$ Low level of investment compared to the importance of the subsector.

$>$ Limited coverage and low quality of animal health activities.

$>$ Low protein intake of the general population.

Non-timber forest products projects

$>$ Income from NTFPs is largely derived from unprocessed primary products, due to lack of knowledge of processing possibilities, and

$>$ Lack of awareness of the need for harvesting of NTFPs on a sustainable basis.

\section{$\underline{\text { Seed projects }}$}

$>$ Lack of private sector investment in seed technology.

$>$ Absence of private sector traders in seed varieties suitable to local conditions.

$>$ Small local market for hybrid seed varieties.

$>$ High cost, low quality, and poor suitability of imported seeds.

$>$ Lack of local sources of improved varieties of basic seeds, and

$>$ Lack of research and extension services re improved varieties of rice.

\section{$\underline{\text { Micro-finance projects }}$}

$>$ Only a small percentage of the rural population has access to credit.

$>$ Credit for irrigation, rural access roads, crop storage, processing facilities etc. is limited.

$>$ Guidelines and procedures for borrowing are not readily available.

$>$ Financial institutions are inexperienced in managing micro-finance programmes, and,

$>$ Borrowers (farmers and SME investors) have little experience in financial management.

\section{Outer City Horticulture Programme}

$>$ Tracts of land nearby towns suitable for horticulture remain under-utilised.

$>$ Migrants from rural areas to towns are unable to access these tracts.

$>$ Urban employment often does not meet the needs of poor households in suburban areas.

> Migrants lack access to credit for investment in peri-urban agricultural activities.

$>$ Suburban horticultural crop producers lack knowledge of urban marketing techniques.

\begin{tabular}{|c|c|l|}
\hline \multicolumn{3}{|c|}{ Table 16 : Poverty-Focused Second Level Priority Projects } \\
\hline Priority & $\begin{array}{c}\text { Reference to } \\
\text { Master Plan }\end{array}$ & \multicolumn{1}{c|}{ Name of Project / Programme } \\
\hline 1 & SC-3 & $\begin{array}{l}\text { On-farm Agroforestry Adaptive Research for Sustainable } \\
\text { Upland Farming Systems }\end{array}$ \\
\hline 2 & AC-4 & Crop Diversification Programme \\
\hline 3 & AC-10 & Sericulture Development Project \\
\hline 4 & AC-16 & Fruit Cultivation Technology Research Programme \\
\hline 5 & AC-15 & Vegetable Cultivation Technology Research Programme \\
\hline
\end{tabular}


The projects with the second highest priority are listed on Table 16. Priority in this group is given to research, extension, and crop diversification initiatives. The proposed projects are expected to facilitate increased diversification of the agriculture sector and offer livelihood alternatives (such as sericulture) for rural poor people.

\subsection{Overall Coherence, Institutional Development and Capacity Building}

The poverty-focused agricultural/forestry development plan is a major component of the Government's overall strategy of economic growth with equity. The essence of the plan is the application of the seven thematic approaches for agricultural development, and area-specific development that reflects local socio-economic and agro-ecological conditions. In this way, the Government will ensure food security while diversifying agriculture, thereby reducing poverty through income generation and the creation of employment opportunities. Further, the plan will strengthen the capacity of farmers, provincial and district agriculture officers, and agricultural researchers and technicians, enabling them to modernise the agriculture sector and compete in a market-oriented economy.

The promotion of agro-industrial development, including SMEs, will be concentrated in lowland/flatland areas and selected borderland areas, where agriculture has reached a certain level of sophistication and where producers are more market-oriented. An important element in the promotion of agribusiness and agro-industries is the establishment of a positive business environment, while promoting ecologically sound development (Cf. Part III, Chapter 2 and 3). In addition to an improved regulatory and overall business environment, the Government will strengthen the financial system (notably the Agriculture Promotion Bank) and streamline lending procedures (Cf. Part III, Chapt.2). A mobile credit network will be established to circulate among rural villages to bring banking services to farmers. The Government views credit access as critical to facilitating the growth of small-scale enterprises, leading to value-added agricultural products.

Many elements of the Government's comprehensive approach to growth and poverty eradication bear importantly upon the agriculture/forestry sector, including initiatives for the transportation, education, energy, and trade sectors. In all cases, care has been taken to ensure that there is a coherent, well integrated and co-ordinated approach - reinforcing the policies and programmes described in this Chapter. In particular, care has been taken to reduce if not eliminate impediments to the growth and competitiveness of the agricultural/forestry sector.

The Government is especially concerned that the capacity of its staff to serve and support the agricultural/forestry sector is strengthened, and that the capacity of farmers and other participants in the sector have the skills and techniques to compete effectively and efficiently in open market conditions. The Government's objective is to have farming system generalists at the grassroots level capable of providing adaptive research-based extension services to farmers. Accordingly, the Government will reassess the education and training systems, together with the research and extension services, to ensure that human resource development is "fast-tracked" 62 . Initial efforts will focus on the training of trainers and a core research staff in vital areas such as seed multiplication and fish breeding, followed by further training of research technicians and district extension agents. Vocational training schools will be established. Gender priorities are set forth in Part IV, Chapter $6 .{ }^{63}$

62 A 1996 assessment of MAF personnel needs reported that there was a deficit of 713 district staff, who were expected to function as farming systems extension workers, and a provincial surplus of 227 staff, designated as subject matter specialists. The situation was re-examined in 2001 and showed no change. MAF/JICA, Master Plan Study: Integrated Agricultural Development in Lao PDR, Main Report, October 2001, Summary, p. S-9.

${ }_{63}$ Annex 3 (Table 3.1) provides a detailed policy/programme development matrix for the agriculture/forestry sector. 


\section{Chapter 2: Poverty-focused Education Development Action Plan: Policy and Investment Priorities}

Education is a major determinant in meeting the goals of poverty eradication. The people of Lao PDR must be literate and possess knowledge about modern agricultural methods and other skills, to be able to meet international competition and standards. A special effort will be made to further realise the social and cultural requirements of all ethnic groups so that the education system promotes equality. An improved education system will ensure girls and boys will have equal chances to succeed. The Government places great emphasis on individual and community initiative, and the need for strong leadership at the local level. Strong leadership is needed to take charge and help realise the opportunities that will arise as the country becomes increasingly integrated both nationally and regionally. Besides being fundamental to strengthening the capacity of people to work efficiently and to expanding their horizons, improvements in education will generate important health and good governance benefits for the country as a whole.

Participatory poverty assessments indicate that education is a low priority for the poor people $^{64}$ Many poor villagers view education as unavailable, unaffordable and/or secondary to securing their livelihood. The Government is determined to change this view, through improving the education system and showing its real value in a modernising economy. The proper design and management of increased investments in education will make a significant contribution to reducing poverty.

The Government's three principles of increased equitable access, improved quality and relevance, and strengthened management provide the framework for achieving "education for all". Further, the Government's efforts aimed at redefining central-local relations (decentralisation) will enable greater efficiency and effectiveness in providing education services. Nonetheless, the task ahead is very demanding, both because there is so much to do to upgrade the existing system and so much to do to extend the system to remote villages. The young age structure of the population adds to the challenge. The Government will gradually increase the share of education in the national budget and encourage support and active participation of all stakeholders.

\subsection{Goals for the Education System}

The Government's goals for education and training include the following: ${ }^{65}$

- Universalisation of quality basic education at the primary level ${ }^{66}$ and continued expansion of participation at lower secondary level, ensuring that all people have the opportunity to apply their education to serve the socio-economic program.

- Eradication of illiteracy, thus providing poor people with a means of helping to improve their quality of life.

- Expansion of vocational, technical and higher education to meet the demands of the new labour market and to improve economic rates of return on human capital investment.

- Training of skilled workers, technicians, professionals, and intellectuals to have the capacity to apply modern science and technology to serve development needs.

- Gradual improvement of the quality of national education to international standards.

\footnotetext{
${ }^{64}$ PPA 2000, op.cit.

${ }^{65}$ The priorities are stated in more detail in The Education Strategic Vision Up to the Year 2020, Ministry of Education, October 2000; also Education Strategic Planning: 20 years, 10 years and 5 years Development Plan for Education.

${ }^{66}$ Currently five years, but in the longer term, extending primary school to 6 years is planned.
} 
Lao PDR - National Growth and Poverty Eradication Strategy (NGPES)

- Establishment of education as a core of human resource development and the planning and management of appropriate invest in education, and

- Establishment of education as a right and responsibility of all people in the society.

Specific targets for education and training to the year 2020 are shown in Table 17 below:

\begin{tabular}{|c|c|c|c|c|c|c|}
\hline \multicolumn{7}{|c|}{ Table 17: Selected Education Targets } \\
\hline & \multirow{2}{*}{\multicolumn{2}{|c|}{$\begin{array}{l}\text { Whole } \\
\text { Country }\end{array}$}} & \multirow{2}{*}{\multicolumn{4}{|c|}{$\begin{array}{c}47^{\circ} \\
\text { Districts }\end{array}$}} \\
\hline & & & & & & \\
\hline & 2005 & 2006 & 2006 & 2010 & 2015 & 2020 \\
\hline Pre-school (per cent) & 10 & 11 & 12 & 16 & 22 & 30 \\
\hline Primary (per cent) & 86 & 87 & 70 & 90 & 95 & 98 \\
\hline Lower Secondary (per cent) & 52 & 53 & 42 & 63 & 74 & 85 \\
\hline Upper Secondary (per cent) & 26 & 27 & 20 & 28 & 31 & 34 \\
\hline Higher Education (per 100,000 pop.) & 480 & 500 & 90 & 520 & 650 & 850 \\
\hline Literacy percentage (age 15-40 years) & 87 & 87 & 75 & 90 & 93 & 95 \\
\hline Literacy percentage (age $15+$ ) & 78 & 78 & 65 & 83 & 87 & 90 \\
\hline
\end{tabular}

Additional targets include:

- Reduce repetition and drop-out rates by 2-3 per cent per annum.

- Upgrade untrained teachers to achieve basic qualifications, and

- Improve management of the education sector.

\subsection{Current Education Status}

There have been very significant achievements over the past decade in extending and improving the education system. For example, the net enrolment rate (NER) for primary school rose from 58 per cent to nearly 80 per cent during the 1990s. As another indicator of growing participation in the school system, the net intake rate (NIR) has been steadily rising. ${ }^{67}$ Also, the proportion of formally qualified teachers has risen considerably. Reflecting improving access and quality, repetition and dropout rates have fallen significantly, contributing to greater internal efficiency of the school system. ${ }^{68}$ Increasing percentages of children are completing all five grades. The LECS 3 2002/03 household survey is expected to show further improvements in enrolment rates and qualifications of teachers. Since the early 1990s, development assistance has provided extensive support in strengthening all aspects of the education system, especially for school construction.

Despite these achievements and overall progress, there are many weaknesses and deficiencies in the education system. Highlighted below are the most serious problems that need to be redressed:

- 15 per cent of villages in the Lao PDR are without a primary school, and most villages lack a complete primary school (i.e., all five grades); the situation in the Northern Region is of particular concern; nation-wide, 90 per cent of schools in the poorest districts are incomplete, and more than 40 per cent of students attend an incomplete school; urban areas have much better school facilities than rural areas.

\footnotetext{
${ }^{67}$ The net intake rate measures the number of six year olds who commence school as a proportion of six year olds in the population.

${ }^{68}$ Whereas in 1996 each primary school graduate represented on average 10 years of teaching, now each graduate is associated with only about 8 years of teaching.
} 
- Based on national school census data over the past five years, differences in access between the poorest districts and the less-poor districts are lessening, but differences in quality appear to be widening; the proportion of trained teachers is rising steadily in the less-poor districts, but it is falling in the poorest districts.

- Shortages of qualified teachers are acute in many districts; approximately 20 per cent of primary school teachers are unqualified to teach.

- Divergence is also evident for textbooks; there one textbook per 2.3 pupils in the 47 poorest districts, compared to one textbook per 1.5 pupils in the less-poor districts.

- Net enrolment rates vary widely, from almost 100 per cent in Vientiane to little more than 50 per cent in some northern and southern provinces; primary school age children are twice as likely to be out of school in the poorest districts as in the less-poor districts.

- Gender disparities in enrolment are significant in some areas, notably in the Northern Region where the economic cost of sending girls to school is considered high - especially by some ethnic groups - given the priority for food security and household needs; gender differences have not diminished in the 47 poorest districts; for the country as a whole, the girl/boy share of primary school students is 45 per cent versus 55 per cent.

- Language is a serious barrier to school enrolment, with the result that ethnic minorities have much lower net enrolment rates and much higher dropout and repetition rates.

- Late school entry is common; some 60 per cent of six-year olds in the 47 poorest districts are not enrolled in school.

- Only about 50 per cent of children complete primary school, about 20 per cent enrol in secondary education, and about five per cent complete the full six years; vocational training opportunities are limited; less that 2 per cent of Lao children go to university.

- As noted in the introduction, many poor families do not see the relevance of formal education for improving their livelihoods; lack of interest by parents discourages children from attending school. ${ }^{69}$

- Overall adult literacy is about 70 per cent; some 70 per cent of the labour force have either no education or never completed primary school.

Table 18 provides an overview of the education system in the Lao PDR, showing the number of schools (private and public) and the number of students for each level of schooling (pre-school, primary, secondary, vocational, technical and university). In total, about 1.2 million children and young people were enrolled in the education system in 2001/02. That is, some 23 per cent of the total population were enrolled in the school system, reflecting the young age structure of the population. In terms of the under 19 age group, some 50 per cent of school age children and young persons were enrolled in school. The role of the private sector is noteworthy, as it has financed schools and training institutes at all levels, especially at the secondary level. In 2002, the number of high school graduates reached 29,000 (1975: 440).

In summary, although considerable progress has been achieved, the current status of education in the Lao PDR is still below what is needed to lift the country out of poverty. A very large investment is needed to ensure that the younger generation receives complete primary education, and that growing numbers of students gain secondary, vocational, technical and university education. In addition to universal literacy and basic numeracy, the country needs skilled and highly knowledgeable people to adapt new technologies and to be the leaders of tomorrow.

${ }^{69}$ This is a particularly serious problem among some ethnic groups living in upland areas. See CPC/ADB, Participatory Poverty Assessment Lao PDR, May 2001. There is a strong correlation between years of education of the head of household and years of education attained by the children. 


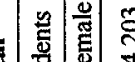

4

. 을

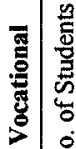

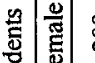

I

눈 형

$n$

त $\frac{2}{2}$

ชิ

$\cong \cong$

$\overrightarrow{8}$
6

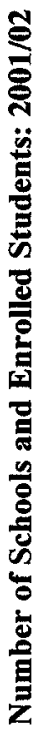

مُ

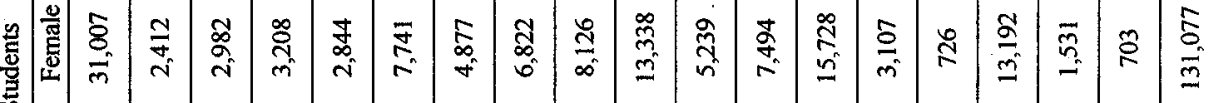

ब

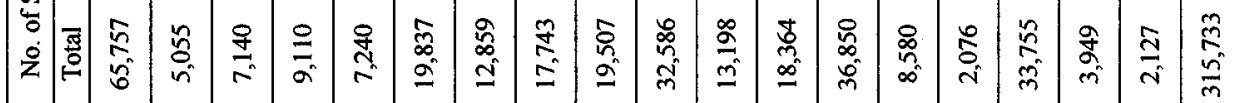

窟

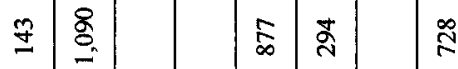

है

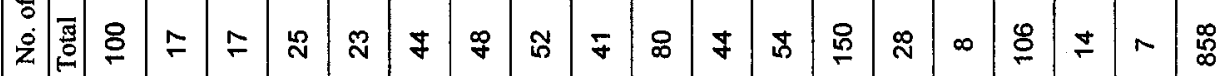

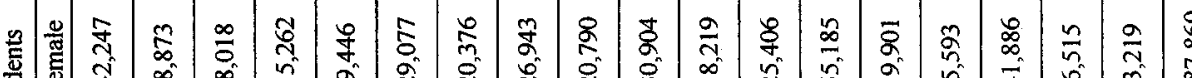

ż

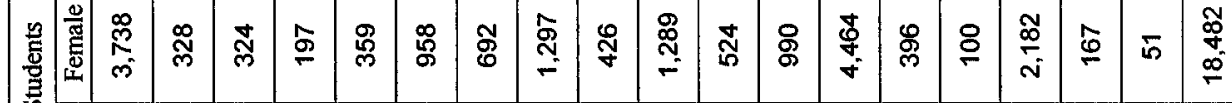

焉

窟

焉

递

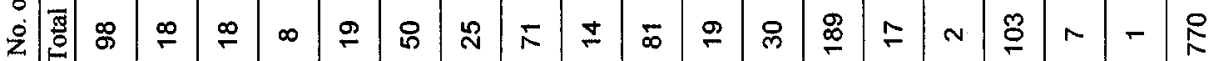




\subsection{Poverty-focused Education Priorities}

The Government is committed to increasing the resources available for the education system, in recognition that improved education is fundamental to eradicating poverty. Past allocations, especially following the outbreak of the Asian financial crisis in 1997, have been insufficient, reflecting very tight fiscal circumstances. This has resulted in difficulties in meeting recurrent expenditures (e.g., teachers' salaries). There is a serious imbalance between recurrent and capital expenditures; whereas the ratio is now about 55:45, the Government is targeting a ratio of 70:30 by 2008 . The Government is also committed to raising the share of the consolidated (central plus provincial) budget for the education sector; from 10.1 per cent (planned) for 2001/02 to 15 per cent by $2005 / 06 .^{70}$

Somewhat less than 50 per cent of total public recurrent expenditure on education is allocated to primary education. The proportion varies substantially among the provinces. In light of the importance of primary education in helping to break the cycle of poverty, the Government is committed to a target of 50 per cent by 2004 . Some 16 per cent of the education budget is allocated to lower secondary education, 8 per cent to upper secondary education, and 7 per cent to higher education. ${ }^{71}$

The Government's education development plan will focus on the 47 districts identified as the poorest districts in the country. Table 17 indicated targets for these 47 districts, namely: to achieve a 70 per cent enrolment rate for primary education, and 42 and 20 per cent enrolment rates for lower secondary and upper secondary education, respectively. Also, the literacy rate will be raised to 65 per cent.

\subsection{Strategic Framework for Development of the Education Sector}

The strategic framework for the development of the education sector in the long term rests on three major pillars: (a) Increasing equitable access; (b) Improving quality and relevance; and (c) strengthening education management and improving efficiency.

\section{Increasing Equitable Access to Education}

Inequities in Access. In Lao PDR, access is broadest at the primary level, more constrained at the lower secondary level, and still more constrained at other levels. There are several reasons for constraints on access, including:

- Poverty: the poor participate less at every level of education than the non-poor;

- Location: those who live in accessible areas participate more than those in remote areas;

- Population density: urban populations participate more in formal education than rural or remote populations;

- Gender: males participate more than females in most sub-sectors; and

- Language: those who speak Lao as a first language participate more than others.

These reasons are inter-related. Remote communities tend to be poor and populated by ethnic minorities. Poor families are less likely to send their children to school than less poor families. Socio-economic differences in educational participation increases with each stage in the education system. The Government aims to widen access patterns to include those groups who do not now participate fully.

\footnotetext{
${ }^{70}$ In 2000/01, education's share of the consolidated budget was 7.4 per cent.

${ }^{71}$ Of the balance, 4 per cent is for pre-school, 3 per cent is for teacher training, and 11 per cent for MOE administration.
} 
Balanced Sector Development. The sequential nature of formal education implies that increasing participation in upper secondary or post secondary education must begin at basic education or before. What is needed is balanced development of the education sector.

The most important target for increasing equitable access is universal quality primary education by 2015 , with equitable access and completion as medium-term objectives. This is a very large undertaking, involving extensive construction of new classrooms, training of new teachers, and production of new instructional materials. It also involves addressing geographic and gender disparities, delays in school entry, incomplete schools, internal efficiency, and quality and relevance, especially for the remote, poor, and ethnic minority communities.

The introduction of multi-grade teaching at the provincial level responds to a situation where the number of student is relatively low and the ratio teacher/student is low.

Candidates for the large numbers of additional primary school teachers required should normally be at least lower secondary school graduates and preferably upper secondary school graduates. They will attend teacher-training colleges (TTCs). The teachers of these future teachers should normally be at least TTC graduates and (for upper secondary school teachers and TTC teachers) university graduates.

More equitable access must be extended beyond primary school to other levels. Non-formal education and training in literacy, numeracy, and livelihood skills directly support community development, leading to improved living standards. Similarly, vocational, technical, and formal education and training directly support improved productivity and lead to higher living standards. Structural changes are needed in the vocational and technical education and training sub-sector to make it more responsive to emerging labour market demands.

The expansion of primary education is driving the demand for secondary schooling, supported by the community, GOL, ODA and the private sector. Expansion of primary, secondary, and higher education is phased sequentially. The resource requirements for universal primary education and expansion of higher levels of the education system must be realistically evaluated, including not only costs to the Government but also costs to families and communities.

\section{Improving the Quality and Relevance of Education}

Quality and Relevance. Increasing access to education must go together with relevant high quality learning outcomes. The gradual transition of the Lao economy from subsistence agriculture to a technology and service base requires a workforce that is at least literate and numerate. There will be a gradually increasing labour market demand for specialisation in commercial, technical, and professional skills. In addition to the socio-economic dimension, education must also fulfil personal needs for meaningful growth and development.

Perceptions and Participation. The perception of education held by parents and the community is crucial for promotion of participation. If they regard schooling as irrelevant to their own situation or their children's expected situation in the future, they are less likely to make the sacrifices necessary to ensure the education of their children. ${ }^{72}$

\footnotetext{
${ }^{72}$ The Compulsory Education Decree of 1996 (No. 138/PMO/96, August 15, 1996) mandates participation in primary schooling and does not allow students to drop out until they have completed the course or reached the age of 14 . However, non-enrolment, late starting and high dropout rates are still serious problems in many areas.
} 
The participation of out-of-school youth and adults in formal or non-formal education and training (for example in literacy training or livelihood training) is also dependent on perceptions of relevance and utility. This reality underscores the Government's commitment to improving the quality and relevance of the education system.

Content and Methods. Quality and relevance of education and training are influenced by the content and methods of delivery. The curricula and syllabi content of instruction must reflect priority outcomes for the Lao education system and be perceived by the community as meaningful and useful. Equally, the teachers and the instructional materials must be capable of effectively supplying the content in a manner and language that students can efficiently assimilate.

The Government's goal of universal basic education by 2015 requires the voluntary participation of virtually all school age children and the acceptance by their families. Making the curriculum and instructional materials and methods meaningful, relevant, and useful in the perception of the children, their parents, and the community must proceed in parallel with implementation of the Compulsory Education Decree. The Government is committed to this twotrack approach.

Local Needs and Local Options. The primary school curriculum is flexible and can be adapted to the situation according to the context as long as it remains within Ministry guidelines. It specifies that "about 20 per cent of local curriculum can be added" ${ }^{73}$ This 20 per cent of local content is seldom if ever applied. The Government will encourage district and village education authorities to exercise this option in order to improve the relevance of the curriculum. The Government will also instruct district and village education authorities to exercise their authority in applying the Compulsory Education Decree, particularly their responsibility for the implementation and resourcing of primary education. ${ }^{74}$ In combination, these steps by the Government will help make schooling more relevant to local needs.

Quality of the Teaching/Learning Process. The Government is committed to strengthening the quality of the teaching/learning process is order to strengthen the quality of instruction. Accordingly, the Government will pursue the following: (a) measures to steer teachers to teach in remote areas; (b) measures to provide teacher training to persons from remote and ethnic minority communities who will return to their communities and teach; and (c) measures to improve the efficiency and effectiveness of the teaching/learning processes in ethnic minority communities.

In addition, the Government continues to strengthen the role of the pedagogical advisers at all levels.

The Government provides salary incentives for teaching in remote and mountainous areas. This incentive salary supplement ranges from $15-25$ per cent of gross salary and is not subject to taxation. In addition, since small remote communities often have too few children of school age to make it economically feasible to provide one teacher for each grade, the Government provides a salary supplement for multigrade teaching. It ranges from $25-50$ per cent of the base salary. In combination, these two supplements provide a typical primary school teacher with an incentive increment in take-home pay of approximately 70 per cent. Graduates from teacher colleges receive an additional bonus of 10 per cent.

\footnotetext{
${ }^{73}$ MOE. "Primary Education Curriculum". Vientiane: MOE and NRIES. 1998. Page 9.

${ }^{74}$ No. 138/PMO/96, "Decree on Compulsory Education", August 15, 1996.
} 
The Government recognises, however, that salary incentives may not be sufficient to attract qualified teachers to remote areas. MOE policy is to increase the number of qualified ethnic minority teachers, especially at the primary level. This policy is supported by several development co-operation projects targeted specifically on poor districts. ${ }^{75}$ Over the past three years, the proportion of ethnic minority primary school teachers has risen gradually, at approximately the same rate as the proportion of ethnic minority students. ${ }^{76}$

An important measure to improve the efficiency and effectiveness of the teaching/learning process involves the language of instruction. The ethno-linguistic complexity of the Lao PDR poses great difficulties in providing effective educational services, especially for ethnic minority children entering primary school who do not speak or understand the Lao language of instruction. The Government has recently approved an Ethnic Group Development Plan as part of its ongoing consideration of how best to respond to the education needs of the multi-ethnic Lao population. ${ }^{77}$

\section{Strengthening Education Management}

Decentralised Management. The Government's third strategic thrust for improving the education system is strengthening education management, importantly through the decentralisation of management. Under the Government's decentralisation process initiated in 2000, MOE delegates and shares responsibilities with the Provincial Education Services (PES) and the District Education Bureaus (DEB). ${ }^{78}$ Decentralised management covers:

- Planning management.

- Budget formulation and financial management.

- Personnel management.

- Management of property, equipment, and materials, and

- Academic and technical management.

Decentralised management will make the education system, especially the primary and lower secondary levels and non-formal education, more responsive to the needs of communities. In turn, this will improve the relevance of the education system to the needs of the poor. Because the poor are often marginalised, however, education officials must increase their "poverty awareness". In multi-ethnic, multi-linguistic communities, this "poverty-awareness" will need to include sensitivity to the cultural needs of ethnic minorities.

Management Development, Organisational Development. In order to implement the changes needed to improve access of the poor to quality education, the Government is committed to strengthening the administrative and management capacity at all levels (central, provincial, district, community, and institutional). This includes information-based planning, finance and procurement management, personnel management, management of property and equipment, and academic and technical management.

\footnotetext{
75 ADB, Basic Education (Girls) Project (BEGP) and Second Education Quality Improvement Project (EQIP II); AusAID, Lao-Australian Basic Education Project (LABEP);World Bank,Second Education Development Project (EDP II); and Sida, Teacher Training Enhance and Status of Teachers (TTEST) project.

${ }^{76}$ Ethnic minority students and teachers are under-represented in the classroom, but their representation improved over the period 1999/2000 - 2001/2002. Also, the ratio of ethnic minority students to ethnic minority teachers improved.

${ }^{77}$ Support will be provided through the Work Bank-finance Second Education development Project.

78 MOE Decree. No. 1500/DOP.02, March 3, 2002. Decree on Implementing the Decentralization in Education Sector. Prime Minister Decree No. 01/PO, March 11, 2000, Building up the Province as a Strategic Unit, District as a Planning Unit, and Village as an Implementing Unit. Declaration of the State Planning Committee No. 128/SPC, June 11,2000 , related to implementing of the decree No. 01/PO. Under the decree, MOE centrally is responsible for technical schools, teacher training colleges, and higher education.
} 
Lao PDR - National Growth and Poverty Eradication Strategy (NGPES)

The Government is reviewing capacity development needs at the institutional level. Lines of reporting and authority need to be clarified to ensure that the Government's education goals and guidelines are adhered to at all levels. ${ }^{79}$

Information-Based Policy Development. Related to consistency in policy, the Government will strengthen the capacity of MOE, the PESs, the DEBs, the communities, and institutions to develop policy, gather resources, develop strategic priorities, and implement change. In support of improved, information-based policy analysis and decision making, a Policy Analysis Division will be created within MOE. This unit will be responsible for providing policy support, management of the policy analysis program, and staff development in policy analysis. Financial resources will also be provided for a series of policy studies, including education sector financing and language policy and practice concerning teaching non-Lao speaking primary grade students.

Management will be further strengthened by enhancing the capacity of the Ministry to use tools such as education management information system (EMIS), geographic information system (GIS) and information and communication technology (ITC) within the local area network. (LAN). The reform of the inspection system aims to provide more systematic support by developing and conducting annual training courses for school staff in order to strengthen both the academic and management performance.

\subsection{Poverty-focused Application of the Strategic Framework}

The Government's actions to strengthen the education system, especially the primary level, will contribute importantly to poverty reduction. To ensure that its actions benefit the poor, the Government will undertake additional steps on behalf of the 47 districts identified as requiring priority attention over the next two years. These steps are summarised in the Tables 19-21 below. More detailed information is provided in the background document to the NGPES.

\begin{tabular}{|c|c|}
\hline \multicolumn{2}{|r|}{$\begin{array}{l}\text { Table 19: District-Focused Education Priorities } \\
\text { Improving Equitable Access }\end{array}$} \\
\hline $\begin{array}{l}\text { Long term } \\
\text { objective }\end{array}$ & Achieve Education for All by 2015 \\
\hline $\begin{array}{l}\text { Short term } \\
\text { objective } 1\end{array}$ & $\begin{array}{l}\text { Significantly increase access to complete primary schooling, especially in } 47 \\
\text { poorest districts. Promote multi-grade teaching. Encourage enrolment at correct } \\
\text { age, and of girls and ethnic minorities. Provide special training for teachers in } \\
\text { remote and ethnic minority areas. }\end{array}$ \\
\hline $\begin{array}{l}\text { Short term } \\
\text { objective } 2\end{array}$ & $\begin{array}{l}\text { Reduce illiteracy, especially among adult women, and promote skills training. Use } \\
\text { formal and informal methods, and improve Community Learning Centres }\end{array}$ \\
\hline $\begin{array}{l}\text { Long term } \\
\text { objective }\end{array}$ & Facilitate economic growth, reduce regional differences and eradicate poverty \\
\hline $\begin{array}{l}\text { Short term } \\
\text { objective } 1\end{array}$ & $\begin{array}{l}\text { Increase primary completion rate, especially in the } 47 \text { poorest districts. Improve } \\
\text { internal efficiency by reducing repetition and dropout rates; establish remedial } \\
\text { classes in selected schools. }\end{array}$ \\
\hline $\begin{array}{l}\text { Short term } \\
\text { objective } 2\end{array}$ & $\begin{array}{l}\text { Reduce differences in major indicators between } 47 \text { poorest districts and national } \\
\text { averages. }\end{array}$ \\
\hline $\begin{array}{l}\text { Short term } \\
\text { objective } 3\end{array}$ & $\begin{array}{l}\text { Expand post-primary schooling. Develop primary and lower secondary cluster } \\
\text { schools. Establish vocational schools in poor regions and provinces. Encourage } \\
\text { private provision of education. }\end{array}$ \\
\hline
\end{tabular}

\footnotetext{
${ }^{79}$ Formulation of recurrent expenditure budgets for primary, secondary and vocational education is undertaken by provincial and district officials in consultation with the Ministry of Finance. Steps are needed to ensure that budget decisions reflect the goals and guidelines of the MOE, and that lines of reporting between the PES and DEBs are clear.
} 


\begin{tabular}{|c|c|}
\hline \multicolumn{2}{|r|}{$\begin{array}{l}\text { Table 20: District-Focused Education Priorities } \\
\text { Improving Quality and Relevance of Education }\end{array}$} \\
\hline $\begin{array}{l}\text { Long term } \\
\text { objective } 1\end{array}$ & Reach international standards in quality of education at all levels of education \\
\hline $\begin{array}{l}\text { Short term } \\
\text { objective } 1\end{array}$ & $\begin{array}{l}\text { Ensure qualified teachers are assigned to schools in poor districts and villages. } \\
\text { Introduce bilingual teaching processes, especially for the first grades of primary } \\
\text { schooling. Also, training in multi-grade teaching. }\end{array}$ \\
\hline $\begin{array}{l}\text { Short term } \\
\text { objective } 2\end{array}$ & $\begin{array}{l}\text { Improve school conditions and access to instructional materials. Renovate schools and } \\
\text { ensure availability of textbooks. Ensure content of instruction meets the needs of the } \\
\text { poor. Focus on curriculum aspects in which the poor have most difficulty and on which } \\
\text { they would benefit differentially. Provide more localised support instruction material. } \\
\text { Strengthen linkages between education and labour market demand. }\end{array}$ \\
\hline $\begin{array}{l}\text { Short term } \\
\text { objective } 3\end{array}$ & $\begin{array}{l}\text { Improve regulations and raise level of inspections. Improve staffing for schools by } \\
\text { developing a new establishment formula for schools to provide additional teachers in } \\
\text { small and incomplete schools. Reforms the inspection system to provide more } \\
\text { systematic support for schools }\end{array}$ \\
\hline $\begin{array}{l}\text { Short term } \\
\text { objective } 4\end{array}$ & $\begin{array}{l}\text { Improve and strengthen pedagogical support systems for primary and secondary. } \\
\text { Provide pedagogical assistants and in-service training for teachers. Reform the teacher } \\
\text { education system. Develop teaching/learning aids for Lao language teaching to ethnic } \\
\text { minority children and distribute Lao language teacher guides. }\end{array}$ \\
\hline
\end{tabular}

\begin{tabular}{|l|l|}
\hline \multicolumn{2}{|c|}{$\begin{array}{c}\text { Table 21:District -Focused Education Priorities } \\
\text { Strengthening Education Management }\end{array}$} \\
\hline $\begin{array}{l}\text { Long term } \\
\text { Objective 1 }\end{array}$ & $\begin{array}{l}\text { Sustain institutional development towards pro-poor policy development and sector } \\
\text { decentralised management }\end{array}$ \\
\hline $\begin{array}{l}\text { Short term } \\
\text { objective 1 }\end{array}$ & $\begin{array}{l}\text { Improve central and regional management and administration of education sector. } \\
\text { Strengthen planning capacity (e.g., EMIS) across all levels of education delivery. }\end{array}$ \\
\hline $\begin{array}{l}\text { Short term } \\
\text { objective 2 }\end{array}$ & $\begin{array}{l}\text { Appoint well trained administrators and school directors for the management of } \\
\text { schools and institutions. Provide management and administrative training courses. }\end{array}$ \\
\hline $\begin{array}{l}\text { Short term } \\
\text { objective } 3\end{array}$ & $\begin{array}{l}\text { Improve deployment of teachers. Improve selection of candidates for teacher training } \\
\text { and the allocation of both permanent and contract teachers. Review current quota } \\
\text { systems for allocation of teachers to provinces, districts and schools. }\end{array}$ \\
\hline $\begin{array}{l}\text { Short term } \\
\text { objective 4 }\end{array}$ & $\begin{array}{l}\text { Promote community participation in schools. Promote establishment of pupil-parent } \\
\text { associations at all levels of education. }\end{array}$ \\
\hline $\begin{array}{l}\text { Long term } \\
\text { Objective 2 }\end{array}$ & $\begin{array}{l}\text { Allocate sufficient resources to enable the education sector to achieve its long term } \\
\text { objectives }\end{array}$ \\
\hline $\begin{array}{l}\text { Short term } \\
\text { objective 1 }\end{array}$ & $\begin{array}{l}\text { Improve resource use in education sector. Better balance recurrent/capital expenditures } \\
\text { and plan donor projects on a sector-wide basis. Training in information-based policy } \\
\text { analysis Implement decentralisation of education. Provide capacity building }\end{array}$ \\
\hline $\begin{array}{l}\text { Short term } \\
\text { objective 2 }\end{array}$ & $\begin{array}{l}\text { Improve the flow of funds to schools and institutions. Improve financial management } \\
\text { of PES and DEB offices. Establish an education development fund. }\end{array}$ \\
\hline
\end{tabular}

\subsection{Emerging and Cross-Sector Issues}

In addition to increasing equitable access to quality education for all Lao people, especially the poor, the Government must address a number of emerging and cross-sector issues that importantly involve the education system. These include the following: 
- HIVIAIDS: This pandemic needs to be treated as a social issue, not just as a health issue. MOE will develop instructional and reading materials on life skills for preventing spread of the disease.

- Drugs and Drug Control: In collaboration with MOH and other ministries, MOE will develop awareness programmes to help eradicate drug use among school students.

- Information and Communications Technology (ICT): The Government will encourage investment in computer technology and facilitate use of the internet, particularly in remote and poor areas. Education and training in ICT will be promoted.

- Distance Education: The Government is planning to create a distance education centre at the National University of the Lao PDR.

- Unexploded Ordinances (UXO) Decontamination: UXO awareness is mainstreamed into standard teaching schedules.

- School Feeding Programme: MOE promotes primary school participation of poor and vulnerable children, especially girls, in food-insecure areas through a school feeding programme. $^{80}$

- Population: MOE is strengthening its research and instructional capacity to support the Government's policy of balancing population growth and socio-economic development;

- Health Education: MOE aims to integrate health education and promotion into the primary and secondary curriculum, and to expand school sanitation;

- Gender Equity: MOE mainstreams gender equity into virtually all its activities; it also has a number of specific "pro-girls" activities.

- Children with Special Needs. For children with special needs, MOE focuses on inclusive education.

\subsection{Roles and Responsibilities for Sector Development}

As noted earlier, the Ministry of Education is responsible for formal and non-formal education at all levels. As also indicated, this responsibility is now shared with the Provincial Education Services and the District Education Services, with provincial authorities responsible for secondary and vocational education and district authorities responsible for pre-school, primary and informal education. MOE is responsible to higher education, technical schools and teacher training colleges.

Individual communities also play a strong role in development of the education sector. They often support primary education, including through the construction and maintenance of school facilities, the employment of teachers, and the payment of teacher salaries (or forms of assistance such as land and housing).

The private sector is a further participant. Over the past decade there has been impressive growth in private sector education activity. As indicated in Table 18, there are numerous private schools at the pre-school, primary, and secondary levels. There are also private vocational schools, especially for language courses, computer skills, and business administration and management. Private colleges have emerged in urban areas. The Government welcomes the participation of the private sector, for it enhances educational opportunity and enables public funds to be used in support of the poor, remote areas where the private sector is unlikely to be active.

The Government also welcomes, of course, the very generous support of the international community. In the early 1990 s, very little international support was extended to the education sector but the growing recognition of its importance - both by the Government and the international community - in fighting poverty has resulted in a major shift in priorities.

\footnotetext{
${ }^{80}$ Supported by the United Nations World Food Programme.
} 
In 2001/02, $\$ 38$ million was disbursed to the education sector by multilateral, bilateral and NGO organisations. This represented slightly more than 10 per cent of total international assistance to the Lao PDR. Remarkably, 20 per cent of assistance from international NGOs was directed to the education sector; bilateral and multilateral agencies directed 12 and 8 per cent, respectively, of their assistance to the education sector. Collectively, international assistance financed more than 70 per cent of capital expenditures (mainly schools) for education.

To strengthen its partnership with the international community in support of the education sector, the Government has welcomed establishment of the MOE-Partner Co-ordination Forum. Dialog with development partners is essential in order to ensure that development of the education sector is sound and well-balanced, including between recurrent expenditures and investment in capital facilities. Partnership and dialog among all stakeholders is a recurrent theme of the NGPES, but it merits special emphasis concerning the education sector.

A five-year policy/programme development matrix for the education sector is attached in Annex 3 (Table 3.2). 


\section{Chapter 3: Poverty-focused Health Development Plan: Policy and Investment Priorities}

The Government of Lao PDR began the new millennium with a vision of health care to 2020, setting out goals and programmes in response to the needs and priorities of the Lao people ${ }^{81}$. Since formulation of the 2020 vision and strategy, the Government has made further progress in developing a sector wide approach to health care. Over the past two years, the Ministry of Health, together with the support and advice of Japan and other stakeholders, has prepared a master plan for achieving basic health care for all and for meeting the millennium goals. ${ }^{82}$

Health care is a vital dimension of the National Growth and Poverty Eradication Strategy, both because it so importantly affects the welfare of the Lao people and because it bears importantly upon the ability of young people to learn and for those in the labour force to work productively. Investment in health care is a long-term commitment, requiring expansion of the health system and improvements in the quality of service. Through time, effective and efficient use of resources devoted to the sector will yield very large material and non-material benefits to the Lao people. The contribution to poverty reduction will be significant.

The Government is determined to achieve high health standards. The NGPES sets out in summary form the agenda for the next 5-10 years, and the general course of action to 2020 . More work is required to focus the agenda consistent with budget constraints, and the assistance of the Lao PDR's partners in development in this regard will be important. In particular, detailed costing of the programmes necessary to achieve the health goals must be undertaken. The Government's resources are extremely limited and there is a great deal at stake in ensuring that resources for the health sector are employed as effectively and efficiently as possible. Primary health care will be the focus. If life styles are consistent with good hygiene principles, then much of the burden of disease and ill-health is preventable.

\subsection{Goals for the Health Sector}

The Government has a comprehensive set of goals and objectives for the health sector. The overarching goals are as follows:

- A nation-wide health service that is fair and equal according to gender, age, social rank, tradition, religion, ethnicity, and geographic location.

- Basic health services that respond to people' needs and expectations and that gain people's trust.

- Substantial improvement in people's health status, especially of the poor.

To achieve these goals, the priorities are "access with quality" while emphasising preventive health care. The Government is committed to meeting the Millennium Development Goals, which includes meeting a number of health-related targets - as shown in the accompanying table.

\footnotetext{
${ }^{81}$ Ministry of Health, Government of the Lao PDR, Health Strategy up to the Year 2020, May 2000

${ }^{82}$ Ministry of Health, Government of the Lao PDR, Japan International Cooperation Agency, Lao Health Master Planning Study, February 2002
} 


\section{Table 22: Health-Related Millennium Development Goals (MDGs)*}

\begin{tabular}{|c|c|c|}
\hline \multicolumn{3}{|c|}{ Goal 1: Eradicate extreme poverty and hunger } \\
\hline $\begin{array}{l}\text { Target 2: halve, between } 1990 \text { and } \\
\text { 2015, the proportion of people who } \\
\text { suffer from hunger. }\end{array}$ & $\begin{array}{l}\text { Indicator 4: Prevalence of under- } \\
\text { weight children }(<5) \text {. } \\
\text { Indicator 5: Proportion of population } \\
\text { below minimum level of dietary } \\
\text { energy consumption. }\end{array}$ & $\begin{array}{l}\text { Current status in the Lao PDR: } \\
\text { The target is to reduce malnutrition in } \\
\text { children under } 3 \text { years from } 40 \% \\
(2001) \text { to } 30 \% \text { (2005). }\end{array}$ \\
\hline \multicolumn{3}{|l|}{ Goal 4: Reduce child mortality } \\
\hline $\begin{array}{l}\text { Target } 5 \text { Reduce by two-thirds, } \\
\text { between } 1990 \text { and } 2015 \text {, the under- } \\
\text { five mortality rate. }\end{array}$ & $\begin{array}{l}\text { Indicator 13: Under } 5 \text { mortality rate. } \\
\text { Indicator 14: Infant mortality rate. } \\
\text { Indicator 15: Proportion of } 1 \text { year old } \\
\text { children immunised against measles. }\end{array}$ & $\begin{array}{l}\text { Current status in the Lao PDR: } \\
\text { The U5MR was } 170 \text { in } 1995 \text { and } 106 \\
\text { in } 2000 \text {; target of } 80 \text { for } 2005 \text { and } 50 \\
\text { by } 2010 \text {. The IMR was } 104 \text { in } 1995 \\
\text { and } 82 \text { in } 2000 \text {; target of } 60 \text { by } 2005 \\
\text { and } 40 \text { by } 2010 .\end{array}$ \\
\hline \multicolumn{3}{|l|}{ Goal 5: Improve maternal health } \\
\hline $\begin{array}{l}\text { Target 6: reduce by three-quarters, } \\
\text { between } 1990 \text { and } 2015 \text {, the maternal } \\
\text { mortality ratio. }\end{array}$ & $\begin{array}{l}\text { Indicator 16: Maternal mortality } \\
\text { ratio. } \\
\text { Indicator 17: Proportion of births } \\
\text { attended by skilled health personnel. }\end{array}$ & $\begin{array}{l}\text { Current status in the Lao PDR: } \\
\text { MMR was } 656 \text { in } 1995 \text { and } 530 \text { in } \\
2000 \text {; target is } 350 \text { by } 2005 \text { and } 200 \\
\text { by } 2010 .\end{array}$ \\
\hline \multicolumn{3}{|c|}{ Goal 6: Combat HIV/AIDS, malaria and other diseases } \\
\hline $\begin{array}{l}\text { Target 7: Have halted by } 2015 \text {, and } \\
\text { begun to reverse, the spread of } \\
\text { HIV/AIDS. }\end{array}$ & $\begin{array}{l}\text { Indicator 18: HIV prevalence among } \\
\text { 15-24 old year pregnant women. } \\
\text { Indicator 19: Contraceptive } \\
\text { prevalence rate. } \\
\text { Indicator 20: Number of children } \\
\text { orphaned by HIV/AIDS. }\end{array}$ & $\begin{array}{l}\text { Current status in the Lao PDR: } \\
\text { National policy to have } 90 \% \text { of pop. } \\
\text { aware of HIV prevention methods by } \\
2005 \text {; condom use to reach } 80 \% \\
\text { among high-risk groups. }\end{array}$ \\
\hline $\begin{array}{l}\text { Target } 8 \text { : Have halted by } 2015 \text {, and } \\
\text { begun to reverse, the incidence of } \\
\text { malaria and other major diseases }\end{array}$ & $\begin{array}{l}\text { Indicator 21: Prevalence and death } \\
\text { rates associated with malaria. } \\
\text { Indicator 22: Proportion of pop. in } \\
\text { malaria risk areas using prevention } \\
\text { and treatment measures. } \\
\text { Indicator 23: Prevalence and death } \\
\text { rates from TB. } \\
\text { Indicator 24: Proportion of TB cases } \\
\text { detected and cured under DOTS. }\end{array}$ & $\begin{array}{l}\text { Current status in the Lao PDR: } \\
\text { National policy to reduce morbidity } \\
\text { and mortality rates to } 13 / 1000 \text { and } \\
3.4 / 1000 \text {, respectively, by } 2005- \\
\text { representing sharp decreases from } \\
\text { levels in } 2000 \text { ( } 53 / 1000 \text { and } 6.7 / 1000 \\
\text { for morbidity and mortality, } \\
\text { respectively). } \\
\text { TB morbidity and mortality rates to } \\
\text { be reduced by } 30 \% \text { by } 2005 \text {. DOTS } \\
\text { to achieve } 85 \% \text { cure rate. }\end{array}$ \\
\hline \multicolumn{3}{|c|}{ Goal 7: Ensure environmental sustainability } \\
\hline $\begin{array}{l}\text { Target 10: Halve, by } 2015 \text {, the } \\
\text { proportion of people without } \\
\text { sustainable access to safe drinking } \\
\text { water. }\end{array}$ & $\begin{array}{l}\text { Indicator 29: Proportion of pop. with } \\
\text { sustainable access to improved water } \\
\text { source. } \\
\text { Indicator 30: Proportion of pop. with } \\
\text { access to improved sanitation. }\end{array}$ & $\begin{array}{l}\text { Current status in the Lao PDR: } \\
\text { National policy is to increase access } \\
\text { to clean water from } 52 \%(2000) \text { to } \\
57 \%(2005) \text {, and to achieve } 80 \% \\
\text { coverage by } 2010 \text {. } \\
\text { Access to sanitation to increase to } \\
45 \% \text { by } 2005 \text {, and to } 55 \% \text { by } 2010 \text {. }\end{array}$ \\
\hline
\end{tabular}

* As based on the UN Millennium Declaration.

\section{2 Current Health Status}

Considerable progress has been achieved over the past ten years in improving the health system in the Lao PDR and, more importantly, in improving the health of the Lao people. For example, life expectancy at birth has increased from less than 50 years before the 1990s to about 59 years currently. Still, Laos' health status is among one of the less favourable in the region. 
Communicable diseases, such as malaria, diarrhoea, cholera, dengue haemorrhagic fever, intestinal parasitism, tuberculosis, acute respiratory infection, measles, and STD/AIDS, remain common or are serious threats. At the same time, non-communicable diseases and health issues are emerging, such as drug addiction, cancer, diabetes, hypertension, cardiovascular diseases, neuralgic diseases, and mental illness, as well as traffic accidents. The Lao PDR is in transition to a more modern society, inheriting new health problems while yet to fully control more traditional problems - including the very high infant and maternal mortality rates stemming from weak health services. The following sub-sections illustrate what has been accomplished and the challenges ahead.

\section{Progress in Improving the Health System and Health Indicators}

- The number of health facilities has increased by 75 per cent compared to five years ago;

- The Lao PDR has been declared free of poliomyelitis since 2000.

- Other target diseases such as neonatal tetanus, measles, pertussis, and diphtheria have substantially decreased.

- Mortality from malaria has been reduced by 60 per cent in rural areas (compared to 1996).

- Leprosy has decreased from $1.5 / 10,000$ in 1995 to $0.6 / 10000$ currently.

- Access to clean water in rural areas has increased from 31.8 per cent in 1995 to 56 per cent currently.

- Access to latrines has increased from 29.6 per cent in 1995 to 36.3 per cent currently.

- Maternal, infant and under five infant mortality rates (MMR, IMR and U5MR, respectively) have dropped significantly:

$\begin{array}{lrc} & \frac{1995}{656} & \frac{2000}{530} \\ \text { - MMR } & 104 & 82 \\ \text { - IMR } & 170 & 106 \\ \text { - U5MR } & \end{array}$

\section{Challenges Ahead}

- As noted earlier, the health status of Lao people compares poorly by regional standards.

- Recent surveys and reports indicate serious disparities in health indicators and in access to and in the quality of health services. ${ }^{83}$

- Infant and under five mortality rates are twice as high in rural areas compared to urban areas, while maternal mortality rates are more than three times higher; in remote mountainous areas and among ethnic minorities the disparities are even more marked.

- Limited access to health services is one of the reasons for these disparities; almost 30 per cent of the population in the north (the poorest region of the Lao PDR) live $16 \mathrm{~km}$ from a health centre; language is also a serious barrier to use of health services.

- Severe poverty, malnutrition, illiteracy, superstition, non-hygienic lifestyles and opium growing are other causes for low utilisation of public health services.

- The low quality of services is yet another cause.

- Availability of four essential drugs (chloroquine, paracetamaol, antibiotics and ORS) is much less in rural areas; only 40 per cent of villages have ready access to these drugs; the drug revolving funds are poorly managed.

\footnotetext{
${ }^{83} \mathrm{MOH}, 2000$, National Health Survey 2000; Lao PDR Reproductive Health Survey, 2000; WHO, Country Health Information Profiles 2000, UNDP, National HDR Report: Lao PDR 2001; Lao PDR, CPC/NSC, LECS II, $1997 / 98$.
} 
- Health personnel are limited, especially doctors who concentrate in urban areas; the shortage of female health workers discourages women from using health centres.

- Only a third of the population makes use of public health services; households meet more than 50 per cent of their health costs through out-of-pocket expenses - mainly for drugs; Government financing accounts for only 10 per cent of total health expenditure. ${ }^{84}$

- The heavy reliance on private health care drives the poor deeper into poverty.

As this illustrates, there are many health challenges ahead. They reflect the LDC status of the Lao PDR and the budget constraints facing the Government as it endeavours to meet the diverse needs of the Lao people. In addition, new diseases and ailments have begun to afflict the Lao people, reflecting the transition to a more modern society. This very transition, however, brings with it the potential to generate the income and resources required to meet health needs.

\subsection{Poverty-focused Health Priorities}

Increased support for the health sector, especially for recurrent expenditure, is a priority. Per capita expenditure on health care is about US\$12; most health expenditure in the Lao PDR is privately financed. In 2001/02, the health sector was allocated 5.5 per cent of the national budget; this was equal to 1.3 per cent of GDP.

Health priorities will focus primarily on the 47 poorest districts. For these, the Ministry of Health has set the following targets for 2005:

- $80-85$ per cent of the population will have access to PHC.

- 60-65 per cent have access to clean water.

- 45 per cent have access to sanitation.

- Infant mortality will fall to $60 / 1000$ live birth, the under-five mortality rate to $80 / 1000$ live births, and the maternal mortality rate to $350 / 100,000$ live births.

- Availability of essential drugs at reasonable prices and of safe quality.

For all 72 poor districts, the MOH has set the following targets for 2010:

- 100 per cent of the population in all the 72 poor districts will have access to PHC.

- 75 per cent will have access to clean water and 55 per cent to sanitation.

By 2010, the MOH expects that the national IMR will have dropped to $40 / 1000 \mathrm{LB}$, the U5MR to 50/1000LB, and the MMR to 200/100,000.

\subsection{Strategic Responses for Poverty-focused Health Development}

To achieve the public health goals, objectives and targets outlined above, the Government, through the $\mathrm{MOH}$ and other supporting ministries and agencies at all levels, will focus on the implementation of 12 major strategic programmes:

$>$ Strategic Programme 1: Information, Education, and Communication (IEC).

$>$ Strategic Programme 2: Expansion of the Rural Health Service Network.

> Strategic Programme 3: Upgrading the Capacity of Health Workers (with emphasis on ethnic minority health workers, and gender and locational balance).

> Strategic Programme 4: Maternal and Child Health Promotion.

> Strategic Programme 5: Immunisation.

\footnotetext{
${ }^{84}$ Official development assistance accounted for 35 per cent of total health expenditure in 1999/00.
} 
> Strategic Programme 6: Water Supply and Environmental Health.

$>$ Strategic Programme 7: Communicable Disease Control.

$>$ Strategic Programme 8: HIV/AIDS/STD Control.

$>$ Strategic Programme 9: Village Drug Revolving Funds Development.

> Strategic Programme 10: Food and Drug Safety.

$>$ Strategic Programme 11: Promotion of Traditional/Modern Medicine Co-operation.

$>$ Strategic Programme 12: Strengthen Sustainability of Health Sector.

\section{Details of these programmes are as follows:}

\section{Health Information, Education and Communication (IEC).}

The IEC campaign is an important programme for communicating policy directives on health to the Lao multiethnic people, particularly to people in remote, hard to reach areas. Information about hygiene and proper lifestyle (the ' 3 cleans' principle: boiled water drinking, cooked food, and hands washing before eating and after using latrine) is a major element of preventative health care. It will contribute dramatically to reduced morbidity and mortality and significantly to poverty reduction, as poor health is one of the causes of poverty. By 2005, the IEC campaign will reach out to at least 85 per cent of total villages. To achieve this target, the IEC campaign will include the following activities:

- Re-organise and improve IEC activities at all levels, focusing on high-risk areas.

- Initiate health broadcasts for local radio stations in Lao and ethnic languages in selected provinces (Oudomxay, Xiengkhouang, Borikhamxay, Khammouane, Xekong, Attapeu).

- Initiate health programmes and material for TV channels and newspapers; also, initiate videos and other material for public distribution.

- Co-ordinate with the Ministry of Education to integrate health education and health promotion into the primary and secondary school curriculum.

- Expand the primary school sanitation programme.

- Mobilise the LWU, Youth Union, Trade Union, National Front, and Buddhist monks to conduct the IEC campaign with the people.

\section{Expansion of the Rural Health Service Network}

The health service network must be completed. However, PHC services are lacking in many rural and remote areas and, when it does, the quality of the service is often low. There is a shortage of qualified health workers at the district and health centre levels. In many cases, the health workers do not speak the language of the patients, leading to misunderstanding and reluctance to visit health centres. These issues are particularly severe when the patient is female and the caregiver male from a different ethnic group, which may cause women to avoid modern health care completely. The job descriptions of the prevention and health promotion centres as well as hospitals are not clear. Their role and functions are not clearly defined and staff morale is low. In most health facilities, medical equipment is lacking and/or substandard. Many different brands have been purchased or donated creating difficulties in maintenance. Utilisation of health centres is low reflecting the low quality of service.

By 2005, the PHC network will be extended to reach more than 80 per cent of villages, enabling remote and poor villages to have access to basic health care and referral services to hospitals, health centres, pharmacies, and to private and public clinics. Eighty per cent of remote villages should have health providers, drug kits and a village health committee. Essential equipment and staff should be provided to district hospitals and health centres (HC). To reach this target, the Government will expand the PHC as follows: 
- Formulate initiatives drawing on lessons learned from current and previous programmes.

- Strengthen district health systems through incentives for health staff to occupy posts in remote areas, with a particular effort to attract female and ethnic minority health workers.

- Improve and expand the PHC from provincial level to village level by:

- Establishing village health committees (VHC) in each village responsible for mobilising hygiene campaigns, with strong female representation and reflecting the ethnic composition of the village.

- Adding another 100 health centres by 2005 and another 213 by 2010 , for a total of 913.

- Upgrading the quality and skills of the three regional hospitals, to serve as $2^{\text {nd }}$ and $3^{\text {rd }}$ level referral hospitals capable of dealing with most general emergencies; regional hospitals should also be able to upgrade the skills of provincial and district staff in different specialties, and be able to provide technical support and supervision.

- Improving provincial hospitals to make them $2^{\text {nd }}$ level referral hospitals, with facilities for preventive services, consultation, diagnosis, treatment, and basic rehabilitation services; they should be capable of emergency surgery, Caesarean operations and other essential obstetric care, orthopaedics, and abdominal surgery; the target is to upgrade 13 provincial hospitals.

- Improving district hospitals to become $1^{\text {st }}$ level referral hospitals, especially in focal development areas and poor districts; district hospitals should act as the technical front for disease prevention, treatment and rehabilitation, and the supply of essential drugs for the grass roots level (HC and village); they should be able to treat some emergency cases; the background document for the NGPES provides details regarding type A and B district hospitals, and the plans for their upgrading.

- Promote the role of women, in co-operation with men, in supporting the expansion of the primary health care network in the remote rural areas by, among other things:

- Transferring social mobilisation to the LWU for projects such as reproductive health, birth spacing, nutrition and others when appropriate.

- Increasing the number of female members in the Village Health Committees and training them to educate other women in the villages to be responsible for maintaining the ' 3 cleans' principle, sleeping under impregnated bed nets including when overnight at rice fields, condom use for birth spacing and HIV/STD prevention, vaccination use, use of iodised salt for cooking.

- Involving both males and females in decision making and sharing responsibility.

- Ensuring the active participation of women in the organisational structure of the health sector at all levels.

\section{Upgrading the Capacity of Health Workers}

Improving and upgrading of health personnel is important and must be a continuous priority. To produce doctors that are able to provide comprehensive services such as emergency surgery, emergency obstetrics, and the management of public health programmes in rural and remote areas, it is necessary that the quality of training of doctors be improved so they have sufficient skills and confidence. $\mathrm{MOH}$ envisages a two-year internship in primary health care after completion of medical school be instituted.

Health personnel at the district, $\mathrm{HC}$, and village levels require skill upgrading. Rural people tend to make much less use of public health services when feverish than do urban people, indicating - among other factors - less confidence in the quality of services available in rural areas. 
The inadequate number of skilled staff and their frequent absence, together with the lack of medicine and distance, discourage use. Recruits to medicine from poor districts are underrepresented, as are recruits from ethnic minorities. Most training institutions are situated in urban areas and are therefore distant from the problems of the rural poor.

Accordingly, the immediate priority will be to increase the number of health personnel working at the village and district levels, with emphasis on the poorest 47 districts. Special efforts will be made to increase the good behaviour, morale and capacity of health personnel at the district and village levels parallel with the provision of essential drugs and necessary medical equipment to the district hospital, the $\mathrm{HC}$, and the drug revolving funds at the village level.

Priorities include:

- Expansion of the number of nursing schools (Oudomxay and Xiengkhouang).

- The rehabilitation of several nursing schools.

- The establishment of primary health care training centres in the Northern Region (Luangnamtha, Xayaboury, Phongsaly, Houaphanh and Bokeo); particular effort to attract trainees from ethnic minority groups.

- Village health providers such as VHV/TBA; 50 per cent of trainees (especially Village Health Providers) should be women.

- Organise health management training courses for district health officials.

- Provide refresher courses for postgraduate specialists and doctors.

- Distribute widely to medical staff at all levels manuals on National Treatment Standards. also, information regarding health laws, guidelines, rules and regulations.

\section{Promotion of Mother and Child Health (MCH)}

As noted earlier, considerable progress has been made in lowering maternal, infant, and under five mortality rates. Also, the fertility rate has dropped from 6-7 in the early 1990s to 4.9 currently. About a third of families now use modern family planning methods. Very significantly, especially for young people, the Lao PDR has been declared polio free since 2000.

However, maternal, infant and under five mortality rates are still much higher than in neighbouring countries, and much higher than acceptable even given the status of LDC. Despite progress in recent years in the Lao PDR, there is no room for complacency.

Reasons why the MMR, IMR, and U5MR are still high:

- Only 35 per cent of pregnant women attend any antenatal care.

- Delivery at health facilities and with assistance by medical staff or by a trained TBA represent only 16-18 per cent of deliveries; delivery at home where the conditions are not safe and post natal care (PNC) is not available is common.

- The fertility rate is still high, especially for ethnic minorities in remote areas, reflecting limited use of modern family planning methods and low attendance at health facilities.

- Women marry at an early age with a median age of first marriage of 18.7 years. multiparous women are at risk of weakened health status.

- Less than 25 per cent of children under five are regularly given health and nutrition check-ups; 40 per cent of children have severe to moderate malnutrition or stunting.

- Coverage for children under 1 year old and for pregnant women has not yet reached the control level of 80 per cent.

- Exclusive breast-feeding up to the age of 4 months is low, as is babies breast-fed with colostrum; most infants fed with rice or some other food at less than 4 months.

- Use of ORS to treat diarrhoeal diseases of children is low (24 per cent).; 
Lao PDR - National Growth and Poverty Eradication Strategy (NGPES)

- $\quad$ Reasons why the use of reproductive health services by Lao women is low include lack of access, qualified female personnel, and language and cultural barriers.

Targets to achieve by 2005 for MCH:

$>$ Reduce the IMR from 82/1,000 LB (2000) to 58/1,000 LB.

$>$ Reduce the U5MR from 106/1,000 LB (2000) to 80/1,000 LB.

$>$ Reduce the MMR from 530/100,000 LB to 355/100,000 LB.

$>$ Increase the use modern family planning technique to 45 per cent.

$>$ Increase the quality of life of mothers and children gradually by promoting health and providing a quality health service.

More specific targets include raising use of ANC services to 50 per cent, increasing delivery with medical staff to 30 per cent, and raising routine immunisation coverage to 80 per cent. To achieve these and other targets listed in the background document, the following measures will be undertaken:

- Improve the quality of MCH services by upgrading the skills/capability of health staff.

- Strengthen the MCH network by organising mobile teams to assist high-risk mothers and children and improve the referral system.

- Increase the awareness and understanding of $\mathrm{MCH}$ and safe motherhood.

- Control ARI diseases and diarrhoea among children under 5.

- Promote breast-feeding, supplementation of vitamin A and iron, iodised salt use.

- Promote better nutrition.

- Monitor, supervise and evaluate MCH activities.

\section{Immunisation (EPI) for Women and Children}

Routine immunisation now covers about 60 per cent of the target population, but this is still far below the control level of 80 per cent. Children, women and pregnant women living in remote and hard to reach areas, which also contain a disproportionate number of the poor, have not been vaccinated fully due to many reasons, such as:

- $\quad$ Lack of vaccinators and lack of transport for outreach.

- Insufficient funds.

- Poor communications, including language barriers, and

- Beliefs and superstitions of people, particularly some ethnic groups.

Immunisations have consistently been shown to be one of the most cost-effective health interventions. Vaccine preventable conditions are more common among the poor while at the same time the poor are often the group most difficult to reach with immunisation services. Also, immunisation services in the Lao PDR have remained dependent on external funding, leading to planning and implementation constraints. Further, immunisation has remained separate from other health services; opportunities for mutual enhancement of services have been missed.

From 2003 to 2005, special efforts will be made by the Government to achieve 85 per cent vaccination coverage of mothers and children in rural areas. Priorities include supplemental immunisation activities, the organisation of a national immunisation day for measles vaccine, introduction of the hepatitis B vaccine into the routine immunisation schedules, expansion of the rabies vaccination network to all 18 provinces, and better co-ordination, supervision and monitoring of $\mathrm{MCH}$. 


\section{Water Supply and Environmental Health}

Water supply and environmental health activities are vital to controlling disease outbreaks, particularly epidemics of diarrhoeal diseases and cholera. All 18 provinces have projects to improve water supply and environmental health. Still, only about 55 per cent of the population have access to piped or protected well water and less than 40 per cent of households have sanitary latrines; less than 10 per cent of primary schools have proper latrines. These conditions have resulted in outbreaks of diarrhoeal diseases and/or cholera in several areas. The number of patients and deaths has been high.

From 2003 to 2005, the Government will expand the clean water supply and environmental health programme. The following targets will serve to focus the programme: increase access to clean water to 65-70 per cent of the population; increase use of hygienic latrines to 45-50 per cent of the population, and equip at least 20 per cent of primary schools with hygienic latrines. More ready access to clean water will decrease the time spend on collecting water, and ease the burden for women who are the major water carriers.

\section{Control of Communicable Diseases}

\section{Malaria Control}

Malaria is the major disease afflicting the Lao PDR, particularly in the case of poor people living in remote and hard to reach areas. In recent years, special efforts have been devoted to malaria control, including insecticide impregnation of bed nets (IBN). All 18 provinces have participated in this program, and so far the programme has reached 118 districts and 5,824 villages. Almost 1.6 million people in the target villages have been protected by IBN. Consequently, there has been no malaria outbreak in recent years. The morbidity rate from malaria has been reduced to $46 / 1,000 \mathrm{LB}$ and the mortality rate to $4.5 / 100,000$. The parasite index rate is 11 per cent (2001 latest indicator), but this is still high. In part, this reflects limited coverage of the IBN programme; only one-third of villages have so far benefited from the programme. Supplies of chemoprophylaxis in highly endemic areas has not been adequate.

Targets for 2005 include reducing the parasite index rated to 8-10 per cent, the morbidity to $12.8 / 1,000 \mathrm{LB}$, and the mortality to $3.4 / 100,000$. The number of people using IBN is targeted to increase to over 60 per cent of the population. Treatment and referral capabilities will be strengthened. Retreatment of bed-nets with insecticide is relatively simple for most but assistance for the poor and vulnerable will need to be maintained. Dissemination of information about malaria control will continue to be a priority, as will continued expansion of the IBN programme and upgrading of medical staff to treat the disease.

\section{Dengue Fever Control}

Outbreaks of dengue fever have continued to occur in the Lao PDR since 1998, with children 6-15 being the most affected. The incidence of the disease appears to be decreasing, with only 1,718 cases and 4 deaths in 2002 . However, the campaign to eradicate the disease has not been as active as it should be, and provincial and district surveillance systems have been limited especially at the $\mathrm{HC}$ and village levels. There has also been lack of co-ordination between the epidemiology, disease control, and health education units. 
The objective is to control dengue fever and ensure that deaths from it are minimal. Priority activities include training of medical staff concerning case management, enhancing the health education campaign focusing on the three clean principles, covering all water receptacles, using larvicide regularly where appropriate, and information on how to neutralise the Aedes aegypti and establish a surveillance system for early detection of the disease.

\section{Control of Other Communicable Diseases}

Acute Diarrhoeal Diseases (ADD)/Cholera.

Outbreaks of $\mathrm{ADD} /$ cholera are still a serious problem, particularly in remote areas where health services are weak. In 2000, there were 12,440 cases and 520 deaths (case fatality rate $>4$ per cent). The lack of clean water and non-hygienic eating habits, and more generally lack of application of the ' 3 cleans' principle, were the main causes.

The Government is striving to prevent further occurrences of ADD/cholera, and to minimise fatalities for occurrences. People in endemic areas will be mobilised to practice the ' 3 cleans' principle. IEC materials will be made available, translated into local languages. Supplies of VHV and ORS will be made available in areas where outbreaks have occurred, to prevent dehydration and shock. Early detection will also be strengthened.

\section{$\underline{\text { Tuberculosis }(\mathrm{TB})}$}

TB is an increasing problem, especially among the poor who are less likely to be able to afford treatment. Efforts to diagnose the disease have been limited, as not all provinces have so far been surveyed and the TB network has not extended to reach remote rural areas. The supervision system of the network from central to provinces, and to districts and villages is insufficient.

The health system is striving to cope with the disease, and the Government hopes to see considerable progress in the near term in reducing the morbidity and mortality rates due to TB. It is also anticipates that treatment will be effective in achieving an 85 per cent cure rate. Priority activities include: expansion of the TB control network to 5 provinces so far not covered; training of health workers in all provinces and districts on the fundamentals of treatment using DOTS; and upgrading of skills of diagnosing the disease.

\section{Control of Intestinal Parasitism}

The infection rate of school-age children by soil transmitted helminths is more than 50 per cent, as is the infection rate of the overall population from food transmitted helminths (such as Taeniasis and liver flukes. The latter reflects poor hygiene and lack of practice of the ' 3 cleans'. Campaigns warning of the dangers of eating raw fish and meat have not been sufficiently effective. The objective is to reduce these rates by half by 2005 . Priority activities include: national surveys of the extent of the problem; health education in schools, and the development of a policy and action plan for parasite control.

\section{Communicable Disease Control, Surveillance and Response}

Improved surveillance is critical to disease control and response. The recent phenomenon of SARS (Severe Acute Respiratory Syndrome) highlights the necessity of having a capable surveillance capacity for both known and unknown diseases. The Government is committed to strengthening the system, especially in terms of the poorest districts and most remote villages. This is viewed as an essential measure in preventing serious outbreaks of diseases such as diarrhoea or cholera, malaria, and dengue fever. The target for 2005 is to achieve a nation wide system whereby disease detection is more assured, allowing time for preventive measures. 
Major activities to be implemented from 2003 to 2005 include: improving the reporting system on disease surveillance, in particular from village to district and from district to province; training of medical staff at central, regional and provincial hospitals on disease surveillance and outbreak response; developing the laboratory capacity of regional and provincial hospitals for detection; and establishing an Early Warning of Outbreak and Recognition System among a network of central, provincial and district hospitals.

\section{Control of HIV/AIDS/STD.}

The prevalence of HIV infection in the Lao PDR is low, particularly when compared to much higher rates in neighbouring countries. However, data on HIV/STD infection are limited and there is no room for complacency. This is particularly the case since STD prevalence is approaching 50 per cent in certain high risk populations, increasing the risk of HIV infection. Also, increasing cross-border movements of people exposes the Lao PDR to the AIDS pandemic. The terrible human, social and economic costs of the pandemic mean that every measure must be taken to prevent its spread.

The Participatory Poverty Assessment (ADB-2001) showed low levels of HIV awareness in rural and remote regions. Unfortunately, as demonstrated by the experience of other countries, there is a strong link between poverty and vulnerability to HIV/AIDS. The migration of young people to towns both in the Lao PDR and in neighbouring countries too often results in prostitution and unsafe sex practices, leading to the potential for a significant increase in the incidence of HIV. Awareness about HIV/AIDS must be increased, for information about the disease and how to protect against it is essential for prevention. Winning the fight against the disease is critical to meeting the goals for poverty reduction and graduation from LDC status.

The Government considers control of HIV/AIDS as one of its national programmes. Because of the importance of fighting the spread of HIV/AIDS, and because it involves other sectors (e.g., the education sector), Chapter 7 of Part IV provides a detailed cross-sector action plan.

\section{Village Drug Revolving Fund}

Drug revolving funds (DRF) play an important role in medical assistance, particularly for sick persons in remote areas. The nearest health facility may be many hours away by foot, the only means of transport for villages lacking road access. A village DRF, including drug kits, provides a range of medicines that can bring relief if not a cure. Of course, care must be taken that drugs supplied by DRFs are used properly. Improper use could make poverty worse, as people spend money while not achieving any health benefit. Most DRFs have mechanisms to exempt the very poor from charges. These mechanisms need to be studied and strengthened.

The Government's near-term objective is to provide drugs kits to people living in remote areas and to have trained staff in villages able to use the drug kits properly. To achieve this target, priority activities include: the expansion of district drug revolving funds; the provision of drugs kits to villages in remote areas; the training of VHV for drug kit management under strict supervision by district hospitals; and the printing and dissemination of training manuals for trainers to train village health volunteers (VHV) and drug kit guidelines to be distributed to VHV.

\section{Improving Food and Drug Safety \\ Regarding Drug Safety}

Many common drugs are imported, most by private companies. Quality control is uncertain and often substandard. Some 5,400 villages have no access to health facilities and do not have drug kits. Those villages that do have revolving drug funds too often find that the fund is barely functioning due to weak management. 
Most villagers are reliant on drug sellers; many of whom have no license or registration and have likely purchased the drugs from illegal sources. Pharmacies are largely limited to urban centres, and most purchases ( 70 per cent) are without consultation with a medical officer.

The poor are most vulnerable to the sale of illegal and fake drugs, as the poor tend to live in areas where regulation and inspection is weakest. Also, the poor tend to purchase the cheapest alternative available, which may be fake, counterfeit or sub-standard.

Furthermore, drug use in state and private health facilities is often not proper. Financial incentives (e.g., the link between medical fees and drug prescriptions) promote the overuse of drugs. Improper drug use is a waste of money, which affects the poor severely. It contributes also to problems such as anti-microbial drug resistance and adverse effects from drug interactions.

\section{Regarding Food Safety}

Domestic and regional production of food and drink products has increased, however the producers and importers of such products do not always ensure quality or safety for consumers. Producers, in general, lack technical skills; the contamination or addition of harmful substances, such as pesticide residues, formaldehyde, and food colours, is still common. Consumers lack know-how regarding selection of quality food, and even simple checks on expiry dates are usually overlooked. Poor people have low rates of literacy and may be affected even more by the lack of safety standards.

The application of laws and regulations concerning food and drugs is inadequate. Further, the qualifications of inspectors are neither adequate nor strictly adhered to. The monitoring system concerning food safety and food-borne diseases is weak, including at border points.

The Government will ensure that Lao people consume food and drugs of that are safe and of high quality. To achieve these targets, priority activities include: training workers in the food and drug industry with appropriate skills in quality and safety management; ensuring proper regulations and laws concerning food and medical products; developing standards for food and drugs; establishing or reforming the food and drug inspection units at immigration check points; and strict regulatory control of food and drug advertisements by the private sector.

\section{Promotion of Co-operation Between Traditional and Modern Medicine}

Forty-one per cent of the Lao PDR is densely forested and an even larger area has some forest cover, providing a rich plant life. However, the protection of this plant life and use for disease treatment purposes has not been under any type of effective regulation. Use of traditional medicines using plant materials can be very beneficial, and can be combined with modern medicine. On the other hand, certain traditional practices are expensive and potentially harmful. Closer co-operation between traditional and modern health practices will encourage beneficial traditional practices and limit the harmful ones.

The Government encourages the culture of traditional medicine, particularly when practised in combination with modern medicine. Accordingly, the Government will encourage health centres to include traditional medicines, and will include such medicines in drug kits. Priorities will include: promotion of traditional medicine plantations to replace the tobacco and opium plantations in the northern provinces as well as the promotion of plantations of Anoectochilus formausos (King of medicine of Taiwan); use of traditional medicine at hospitals health centres at all levels; co-operation with other countries such as Vietnam, China, Japan, USA, and Korea, to develop traditional medicines for local production and export; development of the law for the protection and management of medicinal plants; promotion of traditional medicine for local consumption and research into expanding the use. 


\section{Strengthen Sustainability of the Health Sector Establishing Community Health Insurance}

Cost recovery, mainly through drug revolving funds and fees for diagnostic examinations, has been practised in the hospitals since 1995, enabling major hospitals to cover as much as 60 per cent of their budgets from fees. While this has increased the resources available to the health sector, it has may have limited access to health services for the poor - even though revolving funds have some exemption mechanisms. The solution is to establish a Community Health Insurance (CHI) Fund, whereby small monthly payments cover the risk of large expenditures in the event of illness. That is, establishment of a pre-payment and risk pooling system.

An initial CHI fund has been established in the Lao PDR, which will help prevent large medical expenses from pushing people into poverty, or those already poor further into poverty. By 2005 , it is hoped that voluntary community health insurance will cover 10 to 15 per cent of the population. Through the use of regular capitation payments to providers, this mechanism will also help promote stable financing of health facilities. Further, pre-payment will encourage members to seek care early when conditions are easier to treat. Avoidance of heath care to save money is particularly common among poor and less-poor alike. However, the extremely poor are unlikely to be able to afford to make monthly payments. A mechanism to pay for the poor, such as equity funds from the Government, may be necessary. Priority activities in establishing a Community Health Insurance Fund include: data collection and analysis of three pilot projects; mobilisation of understanding about the fund; establishment of a committee for management of the fund, and; training of key management personnel.

\section{Improving Management of the Health Sector}

Priority activities include: review and incorporation of the recommendations for improving management of the health sector as recommended in the Lao Health Master Planning Study and recently completed public expenditure review for the Lao $\mathrm{PDR}^{85}$; support for health staff who are working in the hard-to-reach and remote areas; clarification of statutes or bylaws for hospitals and health centres at all levels; preparation of a draft law on curative medicine; organisation of a medical society and ways of increasing the status of health workers at all levels; regular supervision and monitoring of the health service network; a survey of the health status of the population; greater co-ordination among $\mathrm{MOH}$ levels and between government departments, and with various donor supported projects; and greater co-ordination with the private sector to encourage integration of all health related activities at district and health centre levels.

Sustainable financing of health services is a major issue as the Lao PDR's health system has become quite dependent on donor funding and on out-of pocket payments by patients. The health budget will steadily increase, as will its share of GDP. In addition, improved planning and more integration of services rather than depending solely on project approaches will improve efficiency in the use of resources allocated to the health system. Insurance schemes, both mandatory and voluntary, would increase the stability of health care financing.

Improvement of the legal and regulatory framework for health will include stronger enforcement of the public health law, development of a curative law and the issuing of realist and enforceable regulations in many areas such as waste management, drinking water quality, etc. Professional standards will be improved through the development of medical and nursing councils to oversee professional licensing and quality assurance. Regularly updated and enforceable guidelines will assist in improving the quality of health services in both preventive and curative services, facilitating a more standardised level of delivery of care. ${ }^{86}$

\footnotetext{
${ }^{85} \mathrm{MOH} / \mathrm{JICA}$, Lao Health Master Planning Study, February 2002; World Bank, International Monetary fund and Asian Development Bank, Lao PDR Public Expenditure Review, June 2002.

${ }^{86}$ Annex 3 (Table 3.3) provides a detailed policy/programme development matrix for the health sector.
} 


\section{Chapter 4 : Transport and Poverty Eradication: Policy and Investment Priorities}

The Ministry of Communication, Transport, Post and Construction (MCTPC) is responsible for the planning, budgeting and development of the communication network. The MCTPC is responsible for all modes of transport and its infrastructure, including roads and road transport, inland waterways and ports, railways and aviation and airports. In addition, the remit of the MCTPC includes urban water supply and sanitation, post and telecommunications, and urban development.

Continued improvements in Lao's transportation system are fundamental to supporting economic growth and realising the goals and objectives outlined in the NGPES. Whilst considerable progress has been made over the past decade in extending and upgrading the system, there are still many areas that are remote and isolated. The rural poor have identified this as one of the main causes of their poverty. Due to the difficulty in accessing markets to sell their surplus agricultural produce and other goods, the rural poor are locked into subsistence farming. Lack of access to all-weather roads, or roads of any kind, has also meant lack of access to schools, health facilities and other basic services, such as electricity and potable water. Thus, the lack of infrastructure results in intergenerational poverty, for poor people have limited opportunity and capacity to climb out of their poverty.

Continuing to improve and maintain the transportation system is very costly, well beyond the limited means of the Government at this juncture in development. Yet the resources must be mobilised for otherwise the Lao PDR will be unable to take advantage of new opportunities as it becomes more market based and integrated with neighbouring countries. Long viewed as "landlocked", the Lao PDR is increasingly being viewed as a "land link" for the six countries that share the Mekong River. The Lao PDR's partners in development have been very supportive in helping to realise both this vision and the more immediate task of connecting villages to districts, districts to provincial capitals, and the capitals or districts to National Road 13 (NR13). NR13 now runs the length of the country connecting with China in the north and Cambodia in the south. The country's partners in development have also been very supportive in helping to build other aspects of the transportation system, including corridors linking the Lao PDR with Thailand, Viet Nam and Myanmar, and upgrading airports and strengthening the transport agencies.

The challenge ahead is planning the next generation of transport infrastructure investment. The Government's commitment to eradicating poverty means that the priority focus must be, with continued improvement of the arterial network, the improvement of improved transportation facilities for the poorest districts, giving them year round access to basic services, markets, and new opportunities. At the same time, strong economic growth for the country as a whole will be promoted, including provision for growth of urban centres. All investments must be sustainable, which means planning must be carried out in an integrated manner with other sectors so that investments in roads, air services and river transportation result in more productive lifestyles. Finding the "right balance" at local level includes community participation, with all stakeholders being careful to fully appreciate the economic, social, cultural and environmental stakes involved.

\subsection{Goals for the Transportation Sector}

The main goal of the Government for the transportation sector is to fully integrate the economy, thereby providing an enabling environment for trade and commerce and access for all Lao people to basic services. ${ }^{87}$

\footnotetext{
${ }^{87}$ MCTPC/Government of Lao PDR, June 2000, Strategic Directions for Development of the Road Sector.
} 
The arterial road network has been substantially rehabilitated and developed over the past two decades. However, rural accessibility needs urgent attention and to this end, the Government's priority is to strengthen the provincial/district/community road network to all weather standards. This will ensure that the benefits from arterial road improvements flow through to the rural population. Lower transport costs and better integration of the economy will stimulate production in rural areas and contribute significantly to poverty reduction.

More specific and other additional goals include the following:

- All-weather road access for poor districts and "focal areas": related objectives include access to health and education services, access to markets and strengthening of economic development; also drug eradication and help for ethnic minorities.

- Strengthen transport linkages with neighbouring countries: strengthen regional integration and trade opportunities, to expand beyond limited domestic market.

- Institutional capacity building: strengthen the ability of the MCTPC and its provincial departments to plan and manage the transport/communications sector. Also, progressively implement more accountable management.

- Road maintenance: first priority is maintenance of the all-weather road network which is critically linked to an efficient operation of the Road Maintenance Fund. ${ }^{88}$

- Road-use regulation: protect road assets by enforcing measures regulations concerning overweight vehicles.

- Protect the environment and ensure social equity: fully apply MCTPC's Environmental Guidelines, including implementation of resettlement and construction mitigation plans, as well as post-construction monitoring.

- Road safety: establish a National Road Safety Council and introduce low cost, high return road safety measures.

- Private sector participation: strengthen the domestic contracting industry to enable it to compete effectively for construction and maintenance projects.

- Community participation: involve local communities in the processes of road planning and construction, and in the maintenance of district and community roads.

The Government also places high priority on continued upgrading of the Lao PDR's air services and on expanding river transportation on the Mekong. The Lao PDR's first rail section is planned, following the Government of Thailand's recent decision to provide support for extension of the railway line $(3.5 \mathrm{~km})$ from the Friendship Bridge to a terminal in Thanaleng, Lao PDR.

\subsection{Current Status of the Transport Sector}

As shown in Tables 23 and 24, the dominant mode of transportation is by road, which accounts for about 70 per cent of freight traffic and 85-90 per cent of passenger traffic. River transport accounts for most of the remaining freight traffic and for about 8 per cent of passenger traffic. Domestic air transport plays an important role in providing links between urban areas and other parts of the country.

${ }^{88}$ Roads rehabilitated or reconstructed are now maintained under the MCTPC 10 year Rolling Maintenance Programme. Decree 09/PM, January 2001 established the Road Maintenance Fund, with the assistance of the World Bank, Sida, and Asian Development Bank. 
Lao PDR - National Growth and Poverty Eradication Strategy (NGPES)

Table 23: Freight Traffic in Lao PDR by Transport Mode: (million kilometre tons)

\begin{tabular}{|c|c|c|c|c|c|c|c|c|}
\hline \multirow[b]{2}{*}{ Year } & \multirow{2}{*}{$\begin{array}{l}\text { Motor } \\
\text { Vehicles }\end{array}$} & \multirow{2}{*}{$\begin{array}{l}\text { Water } \\
\text { Ways }\end{array}$} & \multirow[b]{2}{*}{ Airways } & \multirow[b]{2}{*}{ Total } & \multicolumn{4}{|c|}{ Percentage share } \\
\hline & & & & & Motor & River & Air & Total \\
\hline 1990 & 97.7 & 51.6 & 0.2 & 149.5 & 65.4 & 34.5 & 0.1 & 100.0 \\
\hline 1995 & 81.6 & 82.2 & 1.8 & 165.6 & 49.3 & 49.6 & 1.1 & 100.0 \\
\hline 2000 & 162.2 & 58.9 & 0.6 & 221.7 & 73.2 & 26.6 & 0.3 & 100.0 \\
\hline 2001 & 171.1 & 64.0 & 0.4 & 235.5 & 72.7 & 27.2 & 0.2 & 100.0 \\
\hline 2002 & 163.4 & 102.7 & 0.6 & 266.7 & 61.3 & 38.5 & 0.2 & 100.0 \\
\hline
\end{tabular}

Table 24: Passenger Traffic in Lao PDR by Transport Mode: (millions of passenger-km)

\begin{tabular}{|l|l|l|l|l|l|l|l|l|}
\hline \multirow{2}{*}{ Year } & Motor & Rehicles & River & \multirow{2}{*}{ Ways } & Airways & Total & \multicolumn{4}{|c|}{ Percentage share } \\
\cline { 6 - 9 } & & & & & Motor & River & Air & Total \\
\hline 1990 & $12,588.0$ & 469.0 & 120.8 & $13,177.8$ & 95.5 & 3.6 & 0.9 & 100.0 \\
\hline 1995 & $13,243.0$ & 436.0 & 109.8 & $13,788.8$ & 96.0 & 3.2 & 0.8 & 100.0 \\
\hline 2000 & $16,426.0$ & $1,835.0$ & 499.9 & $18,760.9$ & 87.6 & 9.8 & 2.7 & 100.0 \\
\hline 2001 & $19,124.0$ & $1,855.0$ & 446.6 & $21,425.6$ & 89.3 & 8.7 & 2.1 & 100.0 \\
\hline 2002 & $23,251.0$ & $2,025.0$ & 467.2 & $25,743.2$ & 90.3 & 7.9 & 1.8 & 100.0 \\
\hline
\end{tabular}

Source: National Statistical Centre, 2003, Statistical Year Book 2002.

Over the past 15 years a high percentage of the Government's public investment programme has been devoted to rebuilding the road system, with impressive results. The entire road network amounts to about $32,600 \mathrm{~km}$, comprising $7,160 \mathrm{~km}$ of national roads, $8,950 \mathrm{~km}$ of provincial roads, $6,620 \mathrm{~km}$ of district roads and an estimated $9,800 \mathrm{~km}$ of community/access roads (Table 25). Of the total road network, some $4,590 \mathrm{~km}$ are paved, with the remaining sections either gravel or earth roads (MCTPC, 2002). Recent investment has been concentrated on the upgrading of the arterial road network, notably NR13. Some of the critical east-west links connecting Thailand and western Lao PDR to the border with Viet Nam are either complete (NR6 and NR7) or expected to be complete by 2004 (NR8 and NR9). The Northern Economic Corridor (NR3) connecting Thailand via Lao PDR to China is expected to be completed by 2007. Now attention is increasingly on the local road network.

Table 25 gives an indication, of the status of the road network and examples of projects, implemented or planned by the MCTPC either directly, through its DCTPCs or in co-operation with the line ministries. Co-operation with the line ministries include elements specifically targeted to the economic development of rural areas and to facilitate access to markets of agricultural products, as well as to social services, thereby contributing directly to the conditions for fighting poverty. These elements are described in Annex 3.

Table 25: Road Inventory and Pavement Type in Lao PDR, 2002

\begin{tabular}{|c|c|c|c|c|c|c|c|c|c|c|c|c|}
\hline \multirow{2}{*}{ Region } & \multicolumn{4}{|c|}{ National Roads $(\mathrm{km})$} & \multicolumn{4}{|c|}{ Provincial Roads $(\mathrm{km})$} & \multicolumn{4}{|c|}{ Urban/District/Community (km) } \\
\hline & Paved & Gravel & Earth & Total & Paved & Gravel & Earth & Total & Paved & Gravel & Earth & Total \\
\hline North & 1,4157 & 1,061 & 340 & 2,816 & 2 & 1,119 & 1,612 & 2,734 & 78 & 735 & 2,383 & 3,197 \\
\hline Centre & 1,355 & 578 & 242 & 2,175 & 232 & 1,571 & 1,726 & 3,530 & 224 & 2,101 & 3,514 & 5,840 \\
\hline South & 1,059 & 478 & 630 & 2,168 & 102 & 1,256 & 1,327 & 2,660 & 120 & 757 & 6,595 & 7,518 \\
\hline Lao PDR & 3,830 & 2,118 & 1,212 & 7,160 & 337 & 3.947 & 4,666 & 8,952 & 423 & 3,595 & 12,492 & 16,529 \\
\hline
\end{tabular}

Source: MCTPC (2003) - Summary of Road Statistics for 2002 
The country is now much better integrated than at the beginning of the 1990s and significant progress has been made in securing the sustainability of these investments. Nevertheless, continued development and strengthening of the transportation system in the Lao PDR is still required, and significant challenges remain:

- Only just over 50 percent of the national road network is paved with about 70 per cent of the national road network trafficable throughout the year.

- Restricted trafficability of the provincial and district road network during the rainy season; less than 60 per cent of district centres have year-round access.

- According to the 1997/98 LECS 2 survey, more than 40 per cent of villages are six kilometers or more from a main road and nearly half are not accessible during the rainy season.

- Villages in the Northern Region are particularly isolated; some have no access to social services and markets, even during the dry season, underscoring the need for a major effort to upgrade rural roads.

- Despite growth rates of about 17 per cent annually, traffic on the road system is light; on the national road network, the average traffic flow varies between 250-1000 vehicles daily, while on district/community roads the average traffic flow is one tenth of these levels.

- The Lao PDR has one of the lowest road densities in the region $\left(13.7 \mathrm{~km} / \mathrm{km}^{2}\right)$ reflecting its relatively large land area and small population. Traffic volumes are very low ${ }^{89}$ in part because the small yet widely dispersed population and the mountainous terrain in much of the country makes provision of transportation services very costly.

- Financing of maintenance of the local road network remains uncertain. The recently established Road Maintenance Fund is directed to firstly maintaining national roads with funding for maintenance of local road networks increasing progressively as the requirements of the arterial network are covered ${ }^{90}$.

- Overweight vehicles are a serious problem contributing to road deterioration.

- Road accidents have increased sharply, underscoring the need for educational programmes on road safety and other measures ${ }^{91}$.

- Although a rail system would provide an alternative mode of transport, high development costs means that the system is likely to be limited in the short/medium term to the short link now planned into the Thai rail system.

- Domestic and cross-border transit agreements must be facilitated in order not to hamper the optimal use of the transportation system, and impede the growth of trade.

- Institutional capacity to manage the overall transportation system continues to require strengthening, especially at the provincial and district levels.

\subsection{Poverty-focused Transportation Priorities}

The LECS 2 and participatory poverty assessments found a high correlation between lack of road access and severe poverty. The very poor (17 per cent of the population) live in areas where infrastructure is especially scarce; on average, the very poor are at least 15 kilometres from a main road and 70 per cent have no road access during the rainy season.

\footnotetext{
${ }^{89}$ Volumes on primary roads are $250-1000$ vehicles per day, while traffic on community roads are a tenth of these levels. The number of registered vehicles is currently increasing at about 17 per cent annually.

${ }^{90}$ Several donor projects are directed to upgrading and maintaining provincial, district and community roads.

${ }^{91}$ Two donor-assisted projects are providing support to improve road safety and other assistance is planned.
} 
As indicated in Chapters 2 and 3 of Part IV, travel times to access education and health facilities are generally long for remote villages. It may take 1-3 days for villagers to reach health facilities and between 2-3 hours for children to reach the nearest primary school. Attendance at secondary school normally requires boarding in a distant village or town. Lack of access also makes it very difficult to attract qualified education and health personnel.

The main focus now is on upgrading the local road network, thereby integrating all villages into the national economy. The focus will first be on ensuring access for the 47 poorest districts identified as priorities during the 2003/05 period. MCTPC has completed all-weather links to five districts and construction of access roads is ongoing for five other districts. Projects are planned for the short/medium term for yet six other districts. The remaining districts will be addressed on a priority basis in the medium term, critically dependent on the availability of ODA funding. The additional 25 poor districts will be the focus in following years. Upgrading of the rural road systems and facilitating their maintenance is a major component of the Government's approach to poverty reduction. Reduced transport costs and better access will enable rural areas to modernise and diversify their economies, leading to more productive and higher-earning activities.

\subsection{Principles of Poverty-Focused Transport Interventions}

\section{Market Orientation}

Legislation is now in place covering the commercialisation/privatisation of all remaining state and provincial enterprises. Administrative mechanisms in the MCTPC, Ministry of Finance and the Prime Minister's Office for transfer of enterprises have also been established. However, the Government's preferred course of action is for the state enterprises to be commercialised as a first step towards privatisation. The Business Law No. 03/NA, 1994 makes State Enterprises financially autonomous, making them responsible for paying dividends to the Government to service the capital extended to them, and giving them responsibility for developing their own goals and plans, consistent with a market-based economic system.

All road contracting is undertaken on the basis of Decree No.95/CM on Government Procurement and the MOF Implementing Rules and Regulations No.2642/MF. This legislation determines that all civil works are to be let, as far as possible, through competitive bidding procedures; the contractor is responsible for procuring his own resources (materials, money, men and machines). Similarly, local consultants are to be employed for provision of the detail engineering and construction supervision services. MCTPC, or its respective DCTPC, acts as the employer.

The Road Law 04/NA/99 provides the enabling legislation for a domestic contracting and consulting industry. The law covers the creation and registration of road construction and consulting companies, as well as the provision for an association of road engineering companies. The MCTPC has drafted implementing legislation for institutionalising the provisions of the Law.

The major local contractors are in the main former SOE's which were set up with equipment supplied under ADB, WB, Japan, SIDA and UNDP funding (when road construction work was carried out under Force Account). Following Decree 95/CM, all works are now procured under competitive bidding procedures and the former source of equipment is no longer available. The majority of aid supplied equipment is now reaching the end of its useful life, putting in jeopardy the ability of domestic contracting firms to compete for projects. In an attempt to address this problem the MCTPC has entered into discussions with ADB on the possibility of establishing an equipment financing scheme linked to a project loan. 
Commercial transport services in the Lao PDR are controlled by statute and by custom. The main laws are the Road Transport Law of 1997 and the Regulations on the Establishment of Transport Businesses of 1996. Except in the case of the Vientiane municipal bus services and the Lao State Fuel Company, all commercial operations are now undertaken by the private sector. Business licences for transport are issued either at the national or provincial level and transport operations (passenger and freight services) are generally administered through transport associations.

\section{Participation}

Local communities are encouraged to participate in the processes of the planning, construction and maintenance of local road networks. Through this process, road planners can be made more fully aware of community concerns and aspirations, and the community itself can be better informed of what is being planned and how there are likely to be affected.

Communities participate in the maintenance of access and feeder roads in their areas; local people supply labour and the Government assists with technical expertise and equipment. Local communities, looking to fight poverty, are to be paid in cash for their labour on feeder roads, for it would not be considered fair that such poor communities provide unpaid labour that would normally be put to productive use in agricultural or other subsistence earning activities.

Increasingly, a community participation process is used for the selection of feeder/access roads and project identification. Once the village survey has collected the baseline data and identified the priority zones, community participation in road projects involves each village:

- Identifying and prioritising village road infrastructure needs.

- Identifying the activities that need to be undertaken to meet these needs.

- Indicating who is willing to participate and/or take responsibility for project implementation and detailing individual inputs.

- Selecting a project manager to ensure preparation of the work plan for implementation.

Such a participatory approach will be followed when planning access/community roads. ${ }^{92}$

\section{Decentralisation}

In recent years, in accordance with the Government's policy, MCTPC has increasingly delegated responsibility for work to the DCTPC in their respective provinces. This has given the provinces ownership and involvement in the road sector at all levels, including districts and the rural community. Some 60 per cent of the Ministry's staff are now based in the provinces.

MCTPC staff are primarily responsible for the management and construction of national roads, internationally financed construction of local roads, transport policy and overall network monitoring as well as (in collaboration with the Provincial Governors) the appointment of the Director and Deputy Director of the DCTPC. The provincial authorities appoint the remaining DCTPC staff. Responsibilities of the DCTPC include land acquisition and settlements of any conflict between a contractor and local people, maintenance of the national roads and management of local road construction and maintenance.

\footnotetext{
${ }^{92}$ This approach was developed by the IRAP ('Integrated Rural Accessibility Planning') project. The approach was used for road projects such as the community access component of the East-West Corridor Project.
} 
Lao PDR - National Growth and Poverty Eradication Strategy (NGPES)

\section{Sustainability}

The Road Maintenance Fund (RMF), established under Decree No.09/PM, 2001, is designed to ensure a sufficient and stable domestic source of revenue for road maintenance. Under the decree, 10 percent RMF annual revenue is allocated to the local road network (provincial, district and community roads), 0.5 percent to road safety programs, and up to 90 percent, after allowing administration cost of the fund, to national roads. The amount to local roads will be increased once the full cost of maintaining the national road network is covered by the fund.

Revenues to the RMF are derived from a fuel levy, heavy vehicles surcharge, international transit fees and other road user charges, together with, on-going donor assistance in the medium term. The RMF operates a dedicated bank account and is managed by a seven member advisory board with a secretariat for day to day administration. The anticipated budget/maintenance needs are given in the table below. The RMF will gradually increase the domestic funding for road maintenance. The first annual increase in the fuel levy, delayed because of the adverse international oil market, is now due in October 2003. Ongoing donor assistance to meet the maintenance needs of the road network will continue to be required in the short and medium term (See Table 26).

Table 26: Road Maintenance Fund and Maintenance Budget

\begin{tabular}{|l|c|c|c|c|c|c|c|c|}
\hline Fiscal Year & $\mathbf{0 3 / 0 4}$ & $\mathbf{0 4 / 0 5}$ & $\mathbf{0 5 / 0 6}$ & $\mathbf{0 6 / 0 7}$ & $\mathbf{0 7 / 0 8}$ & $\mathbf{0 8 / 0 9}$ & $\mathbf{0 9 / 1 0}$ & Total \\
\hline Maintenance National roads & 12.1 & 9.4 & 12.5 & 13.6 & 14.9 & 19.5 & 20.0 & 102 \\
\hline Maintenance Local roads & 7.0 & 7.8 & 8.6 & 9.4 & 10.2 & 10.8 & 11.4 & 65.2 \\
\hline Total Maintenance & 19.1 & 17.2 & 21.1 & 23.0 & 25.1 & 30.3 & 31.4 & 167.2 \\
\hline External Funding & 10.1 & 6.6 & 8.0 & 6.0 & 6.5 & 6.0 & 0 & 43.2 \\
\hline RMF Income & 4.0 & 5.7 & 8.6 & 12.3 & 18.7 & 26.0 & 34.3 & 109.6 \\
\hline Total & 14.1 & 12.3 & 16.6 & 18.3 & 25.2 & 32.0 & 34.3 & 152.8 \\
\hline National Roads & 12.1 & 10.5 & 14.4 & 15.9 & 22.1 & 28.1 & 30.2 & 133.3 \\
\hline Local Roads (10\%) & 1.41 & 1.23 & 1.66 & 1.83 & 2.52 & 3.20 & 3.43 & 15.28 \\
\hline Road Safety (0.5\%) & 0.07 & 0.06 & 0.08 & 0.09 & 0.12 & 0.16 & 0.17 & 0.75 \\
\hline Expenses & 0.50 & 0.50 & 0.50 & 0.50 & 0.50 & 0.50 & 0.50 & 3.50 \\
\hline RMF Shortfall/surplus National Roads & 0 & +1.1 & -1.9 & +2.3 & +7.2 & +8.5 & +11.2 & -1.9 \\
\hline RMF Shortfall/surplus Local Roads & -7.0 & -6.7 & -10.5 & -7.1 & -3.0 & -2.3 & -0.2 & -36.8 \\
\hline
\end{tabular}

\section{Multi-sector Approach}

Road improvements are critical not only for the generation of improved transport services (tuc-tuc, pick-up and bus), but often serve also as a instrumental precursor or catalyst for delivery of other services such safe water supply and sanitation, improvement of drainage, alternative cropping programs in drug growing areas, non-formal education, HIV/AIDS awareness along the road corridors, and the installation of electric power supplies in rural areas. MCTPC will continue to liase with other agencies in order to include cross-sector activities in projects. These projects include those within the responsibility of the MCTPC, such as, urban water supply and sanitation, telecommunications, village dwellings, and local airstrips as well as those under other line Ministries, such as healthcare, educational training, tourism, and electrical power. 
Examples of cross-sector interventions include (i) water and sanitation, clean water and airstrip associated with roads in Phongsaly; (ii) roads to historic sites in Xieng Khouang to support economic growth through tourism as part of a major road project; (iii) access roads linked to international road corridors stimulating socio-economic activities; (iv) feeder roads in Houaphan to encourage alternative cropping to drug growing, and; (v) river bank protection through transferred techniques providing alternative employment and contributing to poverty eradication.

\subsection{Policies to be Promoted}

Priorities for the road sector network will take into account including: the contribution to poverty reduction; the capital and ongoing maintenance costs of the road; the number of people served; access provided to markets, education and healthcare; reduction in vehicle operating costs and travel time; economic development potential, and; national integration. When considering investment policies, a balance must be struck between improvement of existing roads, provision of strategic access, reduction in transport costs, and the development of maintainable access to rural communities. Given the significant constraints on sector funding, investment projects will target high priority roads which extend access to the rural areas, and support multi-sector objectives.

The Government's transport initiatives include the following road-related initiatives to improve access to poor districts:

- Further improvement of the all-weather arterial road network including international roads connecting neighbouring countries through the Lao PDR.

- Rehabilitation/construction of community feeder roads to connect to the all weather system as components of main civil works projects. These roads will follow existing alignments in order to minimise environmental and resettlement impacts.

- Connect "Focal Development Areas" to the all weather network in order to provide access to markets, agricultural support, healthcare, educational services, and non-agricultural employment.

- Encourage community participation in planning and execution of road sector activities.

- Encourage the employment of local people and ensure no gender discrimination.

Over the medium term, MCTPC will endeavour to mobilise resources to complete the Government's policy objective of all weather roads linking the national capital to the provincial capitals. Six provincial capitals and the special zone are still without sealed roads providing all weather access to the national capital: Attapeu, Oudomsay, Luang Namtha, Houayxai, Phongsaly, Sayaboury and Xaysomboun. The completion of these links will facilitate access to rural areas and thereby assist in the generation of economic development, the flow on effects of which will promote the upgrading and rehabilitation of the local road network. Also as part of the Government's aim to promote economic growth, road links connecting the remaining provincial capitals to international borders are on-going or planned. These provinces include Saravane, Sekong, Attapeu, Oudomsai, Xaisomboun, and Luang Prabang. In the long term, the Government aims to complete NR1, the central north-south spine, which will provide a key internal and external corridor for trade.

In addition, to pursue the overall policy of Government, the MCTPC is discussing with other concerned sectors (e.g., Ministry of Finance, the Prime Minister's Office, Ministry of Foreign Affairs, Customs, etc.), the significance of roads as conduits for improving transport systems facilitating trade and the movement of goods internally, in transit between neighbouring countries and internationally. 
With respect to air services, the four main airports are of a reasonable standard and six provincial airports are due to be upgraded to improve navigational aids, length of runways and terminal buildings. Strengthening the positive image of Lao Aviation (now Lao Airlines) is essential to promote tourism and trade, underscoring the need to continue upgrading measures. With respect to water transportation, the four country agreement (Myanmar, Lao PDR, Thailand and PR of China) to facilitate navigation on the upper Mekong, will help create riverine economic corridors in the northern region of the Lao PDR, providing alternative access to villages and district centres, especially in the wet season. The Government's initiatives for the transport sector also include the recently announced Thai/Lao rail link.

\subsection{Budget and Funding Requirements}

The average expenditure on the road network during the late 80 's was circa US $\$ 37 \mathrm{~m}$ per annum, this rose during the 90 's to an average of above US\$60m per annum. For the fiscal years $00 / 01$ and $01 / 02$ the budgetary to actual disbursements were US $\$ 61.5 \mathrm{~m}$ to US $\$ 44.9 \mathrm{~m}$ and US $\$ 34.6 \mathrm{~m}$ to US $\$ 46.1 \mathrm{~m}$ respectively. The budget requirements to meet the Government's strategies and associated capital investments in the medium-term, together with the budget requirements for the air, waterways and rail sub-sectors, are indicated in Annex 3 (Table 3.4).

\subsection{Investment Support, Institutional Strengthening and Capacity Building}

The Government will continue to depend upon the support of its development partners, including the World Bank, Asian Development Bank, SIDA, Japan/JICA, OPEC, IFAD, KfW, UNCDF and EU to implement rehabilitation/reconstruction projects in the transport sector. The costs of extending, upgrading and maintaining the transport system are very high. For example, the cost per km of road varies dramatically, from over US $\$ 200,000$ per kilometre to a low of US $\$ 20,000$, depending on the type of road and the terrain.

In order to provide an enabling environment to construct and maintain the infrastructure, the continuation of training of the DCTPCs, as well as of contractors and consultants, is required in the areas of:

- Working in a competitive bidding environment.

- Understanding the technical specifications required.

- Planning and financial management.

- The procurement process.

- Operational control costs.

- Equipment management.

- Site safety and safe working practises.

- Contract management.

- Environmental impact and mitigation.

With regard to an enabling business environment for the further development of the national road construction capacity, eight priorities have been identified:

- Further development of the regulatory framework.

- Management system development.

- National Transport Safety Strategy implementation.

- Capacity development of central MCTPC level institutions.

- Capacity development of local level (provincial/district) institutions.

- Financial management development.

- Procedures/routines for inter-sector issues; and,

- Continual development of sustainable financing mechanisms (e.g., RMF). 


\section{Chapter 5: Industrialisation and Modernisation: Vital Role of the Supporting Sectors}

The NGPES includes a number of "supporting sectors" that will contribute both directly to job creation and hence poverty reduction, and indirectly to the strengthening the four core sectors (agriculture, education, health and transport). The $7^{\text {th }}$ Party Congress (2001) defined industrialisation and modernisation of the Lao PDR as a gradual process, from relying heavily of the agricultural sector to a more diversified economy with higher productivity and more advanced technology. The Government's strategy for industrialisation and modernisation gives priority to the development of the energy sector, agro-forestry, manufacturing, tourism, mining and construction materials.

Currently, the industry sector accounts for 24.5 per cent of GDP. The manufacturing component of industry accounts for 18 per cent of GDP and provides employment in the formal sector to almost 100,000 people, equivalent to about 4 per cent of the total labour force. ${ }^{93}$ Major manufacturing sub-sectors are food and beverages, garments and wood processing. Manufacturing accounts for about two-thirds of total exports, while exports of electricity accounts for most of the balance.

Industrialisation contributes markedly to economic growth, which is a pre-condition for sustainable and comprehensive poverty eradication. However, industrialisation, if it is not well planned and monitored, can result in a number of undesirable outcomes: excessive concentration in large urban areas; a sharp rise in urban poverty if there are insufficient job opportunities; difficulties in securing permanent residence or registration, limiting both job access and access to social services; and the possibility, especially for vulnerable groups, of falling prey to social evils.

The Government thus favours a mix of industries and activities:

- Labour intensive industries.

- Natural resource-based industries.

- Small and medium scale enterprises.

- Agro-industries.

- Technology transfer and upgrading of the quality of industrial products.

- Establishment of industrial zones.

The development of labour-intensive manufacturing industries, particularly the textile and garment sub-sectors and natural resource-based industries, will enhance employment creation and income generation, including for the poor. The Government attaches great importance to the development of small and medium-scale enterprises, and of village crafts. These enterprises will be encouraged to develop export markets and possible import-substitution products; the latter is constrained by the small size of the domestic market. Special attention will be paid to the functional and technical challenges facing Lao enterprises. These challenges include lack of information, obsolete production equipment, low level of competitiveness, and limited production capacity. Responding to such challenges in a more market-based economic system requires the Government to be very selective in deciding the best form of support.

\footnotetext{
${ }^{93}$ Ministry of Industry and Handicrafts/UNIDO, Lao PDR: Medium-term Strategy and Action Plan for Industrial Development, April 2003.
} 
In order to ensure regional balance in industrialisation and modernisation of the economy, the Government will encourage industries to locate in rural areas and to establish rural industry centres. Measures for this purpose may include: land provision; support for inputs; tax holidays; market information; and science and technology training. To this end, local authorities are encouraged to provide necessary information on the specific conditions of their regions.

Efforts will also focus on developing and modernising industries that support the agriculture and rural sectors (e.g., wood processing, chemical and organic fertiliser, animal feeding, vegetable oil, silk and cotton spinning, paper mills, sugar plants, agricultural tools). Very importantly, small-scale private enterprises will be encouraged to establish and/or expand, and to adopt long-term business plans leading to increasing employment. Other initiatives will include establishing industrial zones in Vientiane Municipality, Savannakhet, Champassak and Oudomxay provinces, with Savannakhet being established as a special economic zone.

A comprehensive 'Action Plan for Industrial Development and SME's' will become the reference for industrial development. This Action plan is presented below (5.6).

For the real economy to function adequately and be supported sustainably in its growth, three conditions must be met: i) a financial system enhancing savings and access to financial services, ii) market linkages and trade facilitation enhancing access to market opportunities, and iii) a public enterprise sector which functions according to market principles.

For this reason, the Government gives high importance to financial sector reforms, promotion and development of trade linkages and to restructuring the state-owned enterprise sector. Each of these three supporting areas, which are essential to a successful industrial development, will be briefly dealt with later in this Chapter (5.7 - 5.9).

In the medium-term, the following sectors supporting industrialisation and modernisation will contribute to achieving the national growth and poverty eradication objectives.

\subsection{Energy and Rural Electrification}

Concurrently with large and medium-sized hydropower projects, more attention will be given to small-size power plants for supplying electricity to rural areas. Every effort will be made to ensure that 70 per cent of the households have electricity by 2010 .

The Lao PDR's hydropower potential is very considerable and its development offers extensive benefits for the country. Hydropower is already a major contributor to economic output, government revenues, and export earnings. However, only 623 Megawatts (MW) of an estimated 18,000 MW of hydropower potential has so far been developed. The Lao PDR has one of the lowest levels of electrification in Asia; only 20 per cent of all villages and 34 per cent of households have access to electricity. The development of the country's hydro-electrical potential and rural electrification is thus integral to the national development framework.

The key challenges in accelerating power development that the Government will address include the need for:

$>$ A better and a more transparent integration of social and environmental concerns.

$>$ Curtailing possible over-dependency of the economy on hydropower development.

$>$ Increasing domestic tariffs to cover financial production costs, at least in urban areas, with a transparent subsidy scheme for poor rural areas.

$>$ More effective sub-regional co-operation in producing and distributing electricity.

$>$ Prioritisation of proposed hydropower projects and development of suitable financing.

$>$ Improvement of the regulatory framework and encouragement for increased private sector investment. 
Institutional strengthening, especially in financial planning, management, and negotiation capacity with developers.

The Government plans to expand electrification in remote areas through two methods. One is to expand the grid to comparatively easily accessible areas. The other is to provide off-grid supplies to remote areas where it is difficult to expand the present grid due to environment or cost reasons. Only ten per cent of rural areas are provided with grid electricity. From a gender equity perspective, easier access to electricity will facilitate the lives of women and reduce their household chores while contributing to poverty eradication. Since women in rural areas spend a great time in gathering fuel wood, at the expense of other more productive activities, increased accessibility to electricity in rural areas will improve living standards and help reduce poverty.

Energy consumption of the main economic sectors is increasing on average 10 per cent per year. Therefore, the expansion of energy production in tandem with that of the electricity network is a major supporting priority for economic growth, especially in rural and remote areas. To achieve expansion of energy production and the electricity network, the policy and investment priorities include the following:

- Expand the electricity network to full coverage, starting with provinces and districts with very limited access to electricity.

- Complete construction of small and medium-scale projects (up to about $60 \mathrm{MW}$ ) for domestic utilisation using government investment funds.

- Proceed with the Nam Theun 2 project with international investors.

- Construct a $500 \mathrm{KM}$ high voltage electric transmission system.

- Continue mini-developments (micro-hydropower, solar and wind energy projects for offgrid power supply in remote areas.

\subsection{Agro-forestry Industry}

The Lao PDR's comparative advantage in the agriculture/forestry sector will help develop medium and small-scale agro-forestry industries consistent with the capacity of people in each region. By combining potentiality, cultural values and traditional factors of production with modern techniques, both domestic and export markets can be accessed. The following products or activities will be promoted: food processing, semi-ready-made and ready-made manufactured products such as vegetable oils, cotton and silk, hand-weaving, traditional medicine manufacturing, household utensils, decoration and furnishing items, and souvenirs.

\subsection{Tourism Industry}

There has been very strong growth in the Lao tourism sector since 1990, from only 14,400 international arrivals to 735,600 arrivals in 2002 . Tourism is now a major contributor to national income (7-9 per cent of GDP) and employment. Tourism is a labour intensive industry and contributes directly to poverty reduction. There is considerable potential for greatly expanding the sector, drawing on visitors to the region and highlighting their interest in Lao's stunning natural environment, its history, cultural heritage and rich ethnic diversity. However, the tourism industry faces constant challenges because of changing customer preferences, travel patterns, information technology and unpredictable events such as SARS.

The Lao PDR's tourism strategy favours pro-poor, community-based tourism development, the enhancement of specific tourism-related infrastructure improvements, and sub-regional tourism co-operation. ${ }^{94}$

\footnotetext{
${ }^{94}$ Formulation of the strategy drew upon the results of the National Seminar on Sustainable Tourism Development in the Lao PDR, held in March 2002.
} 
Current activities include: awareness initiatives focusing on tourism benefits and environmental and cultural conservation and enhancement; awareness programmes on prevention of HIV/AIDS, sexual exploitation and trafficking of women, and; information on successful regional experiences.

Other elements of the national tourism strategy include:

- Identification and development of tourism products (i.e., possibilities for communitybased tourism, etc.).

- Development of small-scale tourism-related infrastructure (such as information centres, community lodges, viewing points, walking trails).

- Capacity building for tourism-related local micro-enterprises and communities.

- Gender specific programmes (training of women to develop and to run microenterprises).

- Participation programmes for ethnic minorities.

- Training in marketing and eco-tourism, and identification of eco-tourism ventures.

- Promotion of community-based tourism networks in-country and in the subregion..

Sub-regional co-operation for sustainable tourism is an important aspect of the Government's tourism strategy. The establishment of tourism marketing and promotion boards within the Greater Mekong Sub-region and the ASEAN framework will promote and facilitate tourism. In this spirit, the Government will seek co-operation with neighbouring countries to improve tourist facilities at border posts and to streamline immigration and customs regulations.

Human resources development related to tourism is necessary as there is an acute shortage of trained manpower. HRD needs include language training as well as training in all matters related to tourism development (e.g., hotel and guesthouse management, tourism guide work, housekeeping services, and site management). Training activities will be decentralised to some provinces that experience increased inflow of tourism (Champassak, Oudomxay, Luang Prabang). The Government envisages the establishment of a national committee for tourism education and training.

\subsection{Mining Sector}

The Lao PDR's mining sector has received a strong boost from commencement of operations in 2003 of the Oxiana Gold Mine in Sepon, Savannakhet. The mine is proving highly profitable and is generating royalties for the Government; tax revenues will increase sharply when the tax concessions are completed in 2-4 years time. The mine is expected to start producing copper in the near future. Other mines, including a gold mine in the Northern Region, are under assessment. The Lao PDR is endowed with a variety of metallic and non-metallic minerals, including (in addition to gold and copper) tin deposits in Khammouane province, anthracite deposits at Saravan, Vientiane, and Phongsaly, lignite deposits in the northern provinces, salt and gypsum deposits in Savannakhet province, potash in the Vientiane basin, the Phou Nhouan iron ore deposit in Xieng Khouang province, the Ban Houei Sai sapphire deposit, and cement limestones, glass sand, and clay deposits in various provinces.

The Government will ensure that development of the mining activities are conducted in an environmentally and socially sustainable manner, while making a significant contribution to economic development at all levels of society. In this spirit, the Government, in partnership with private sector interests, will work with the communities involved to ensure: 
- A full understanding of the impacts.

- A climate of trust and co-operation.

- Guidelines for development and operation of the mine.

- Resettlement and compensation for any loss of assets and earnings.

- Assistance programs centred on asset creation and human capital formation.

These principles are being applied to the Oxiana Gold Mine and will apply to all future mining activities.

\subsection{Construction Materials Industry}

As the Lao economy industrialises and modernises, and as urbanisation progresses, the construction materials industry will continue to grow. There are also opportunities for export to neighbouring countries. In 2001, recorded consumption of construction materials was still only US\$56 million, of which domestic production accounted for US\$31 million. Bricks and other materials for local use are not included in these figures. Domestic production consists mainly of plastic tubes, pipes, cement, corrugated roofing, iron bars, gravel and marble. Also, concrete electricity poles, wire, nails and some other products are produced locally. Lao PDR will need to continue to import bulk construction materials that are based on capital intensive and large-scale production.

To help strengthen the construction materials industry, the Government will emphasise the following: human resource development; science and technology development; infrastructure development for transit services, and; reform of the legal and judicial framework for private sector enterprise. Review of the Government's procurement procedures will ensure that domestic suppliers get a fair chance to compete with foreign suppliers of building materials.

\subsection{Action Plan for Industrial Development and SMEs}

The Government is in the process of preparing a Strategic Action Plan for Industrial Development, with the objective of promoting sustainable manufacturing activities in the Lao PDR as a means of creating new employment opportunities and thereby reducing poverty. ${ }^{95}$ The Plan will be the subject of a policy dialogue meeting, as part of the Government's roundtable process. A series of studies on various manufacturing industries were important inputs into the formulation of the draft Plan. These include studies on: the food processing and packaging sector; the construction materials industry; the wood processing industry; the handicraft industry; and the textile and garment industry. In addition, other studies have addressed: integration into ASEAN; industrial land development; technology needs for the manufacturing sector, and; small and medium-sized enterprise development.

The Government's industrial and handicrafts policy includes the following elements:

- Efficient utilisation of the Lao PDR's natural resources as the basis for the industry and handicraft sector.

- Encourage manufacturing and handicraft industry that mainly use domestic factor inputs.

- Combine modern techniques with local creativeness and traditional techniques.

- Promote and strengthen small and medium-sized enterprises that are adapted to potential and ability of people.

- Initiatives in support of industrialisation, including land policy, training, and trade facilitation.

\footnotetext{
${ }^{95}$ This has been done with the support from the Governments of Belgium, Luxembourg, and the Republic of Korea, under the direction of UNIDO.
} 
- Infrastructure to integrate rural/urban areas, giving poor people the opportunity to participate in new manufacturing/handicraft-related opportunities.

- Identify potential areas for investment and business enterprise.

- Ensure sustainable development in poor communities.

The Government is committed to strengthening the business environment for the industry/manufacturing sector. Numerous laws (e.g., the Manufacturing Industry Law) and Prime Ministerial Decrees (e.g., intellectual property, trade marks, procurement) play an influential role on investment in the Lao PDR. The Government will seek to eliminate deficiencies in the legal framework, and to create strong incentives for both domestic and foreign investors. Further, the Government will ensure that all legal instruments are known by business persons, especially small businesspersons outside of Vientiane Municipality. Handicraft production will be encouraged by including it as a priority sector in the law on domestic investment

To ensure that the benefits of growth are distributed equitably, the Government will encourage the manufacturing sector to invest in all regions. Presently, Vientiane Municipality accounts for 55 per cent of total manufacturing output, followed by Khammouane province (15 per cent), Savannakhet province ( 9 per cent), Vientiane province ( 8 per cent) and Champassak province ( 6 per cent). The Northern Region, consisting of seven provinces, accounts for only 2.5 per cent of total manufacturing output, even though it accounts for 34 per cent of all manufacturing businesses.

The Government is in the process of preparing a Prime Minister's Decree on Support for the Development of Small and Medium-sized Enterprises. The following areas have been identified as priorities:

- An enabling legal, regulatory and administrative environment for SMEs.

- Enhancing competitiveness of SMEs.

- Expanding of domestic and international markets for SMEs.

- Improving access to financing by SMEs.

- Improving access to appropriate work premises.

- Creating favourable conditions for establishment of business organisations.

- Encouraging entrepreneurial attitudes within the society.

To help advise upon appropriate Government initiatives in support of the industry/ manufacturing sector, by the Government is working with the Lao National Chamber of Commerce and Industry (LNCCI), the local Chambers of Commerce and Industry and the Business Groups under the LNCCI. The setting up of an appropriate institutional and advisory framework will assist in designing and implementing SME development programmes, as well as helping to ensure that women and ethnic minorities participate fully in new manufacturing opportunities.

\subsection{Banking and Financial Support Sector}

Strengthening of the financial and banking sector is a necessary condition for sustained growth. Banking sector reform is central to achieving macro-economic stability and poverty reduction as well as supporting all forms of enterprise and trade. Success in strengthening the sector will spur growth of SMEs and private investment. It will also assist in working with the international financial agencies in the global campaign against money laundering. ${ }^{96}$

\footnotetext{
${ }^{96}$ Annex 2 (Table 2.5) provides a matrix regarding policy priorities for strengthening the financial and banking sector.
} 
Of special concern are improved financial services to rural areas. Currently, only a small percentage of farmers have access to such services. With improvements in the transportation and communications network, and the increase in the capacity of the banking sector, it is now possible to move towards expanding the system. To this end, the Agricultural Promotion Bank (APB) will be transformed into a self-sustaining, market-oriented rural financial institution. Policy-based lending will be phased out in favour of strictly commercial criteria within 3 years. Rural and micro-finance institutions will fall within the regulations and guidelines established by the BOL. A variety of micro-finance institutions will be encouraged. A national strategy for rural credit and micro-finance, as well as a corresponding action plan, are under preparation. The second draft of the strategy and action plan to promote rural and microfinance has mustered broad support from all stakeholders involved. Major objectives of the strategy and action plan for the future of rural and micro-credit include:

$>$ Support for market-oriented reforms.

$>$ Creating a legal space for a variety of sustainable micro-finance institutions (MFI's).

$>$ Ensuring MFI autonomy in setting interest rates and making other business decisions.

$>$ Creating an MFI Forum, and;

$>$ Restructuring APB into a financially self-sustainable rural finance institution.

With regard to improving intermediation and outreach of the national banking system to promote the higher growth required for poverty reduction, the priorities of the reform programme in the medium term are aimed at improving the performance of the state-owned commercial banks (SOCB). This will be done by i) resolving the stock of non-performing loans (NPLs), ii) strengthening prudential supervisory regulations and compliance, iii) enhancing SOCB corporate governance, iv) undertaking legal reform and judicial strengthening, vi) reforming state-owned enterprises (see next section), vii) extending financial services to rural areas (see above) and vii) developing the private sector.

\subsection{State-owned enterprise reform programme}

The reform programme regarding the state-owned enterprises (SOE) aims to strengthen the financial management of existing $\mathrm{SOE}$, enterprise restructuring and utility tariff reforms. The implementation of this reform programme will greatly contribute to the successful achievement of financial sector reforms, in particular with regard to the elimination of non-performing loans in the banking system, for which a limited number of SOE's have disproportionately contributed. At the same time, the reforms undertaken in matters of utility tariffs will enable public entities to function on a cost-recovery basis, particularly in the areas of electricity, water, transport and telecommunications, which are vital for industrialisation and modernisation.

The reforms undertaken will also contribute to equalise conditions between the private sector and SOEs, thus enhance growth and poverty eradication.

\subsection{Poverty-focused Trade Development}

Trade is an essential, all-encompassing factor for the expansion and development of key sectors as well as for other 'supporting' sectors. 
Trade is a powerful stimulus for economic growth. As trading activities increase, they create immense opportunities for supply side responses in all sectors of the economy. Resulting new investment opportunities lead to increases in output, particularly in agriculture and industry, giving rise to the growth of various service industries such as transport, banking, insurance, communication and tourism. Employment opportunities increase and incomes grow, giving rise to increased demand-side responses. This process gathers momentum, fuelled by trade and commerce.

The Government recognises that trade is important to the country's poverty reduction efforts. As such, it places great emphasis on trade and most sectors have incorporated a trade and commerce element into their poverty eradication strategies.

\section{Integrated Framework}

The Integrated Framework (IF) is an initiative of the WTO and other core multilateral agencies to provide technical assistance with a view to improving the trade-related capacity of LDCs and to integrate them more effectively into the world economy. This is expected to promote trade and development and thus lead to poverty eradication. The IF encourages mainstreaming trade into overall national development plans and poverty eradication strategies.

The Government is fully committed to take full advantage of this integrated framework to enhance trade facilitation and market linkages within and outside the country. To this end, a strategic approach is being prepared.

\section{Pro-poor Trade Development Strategy}

To enhance the trade sector's role as a dynamic force in promoting development and poverty eradication, and especially to encourage poor people to engage in trade activities, the Government's pro-poor trade strategy banks on the following key elements:

- Continuing sustainable trade policy reforms.

- Mainstreaming trade into national growth and poverty reduction strategies.

- Rationalising and streamlining trade administration procedures.

- Upgrading the capacity of service delivery system in the trade sector.

- Improving trade facilitation.

The main function of the Government's trade policy is to provide a healthy policy environment for the development of trade and commerce, with particular regard to reducing obstacles and hindrances. With such a trade policy, the productive sectors will be encouraged to invest, produce and market their products in a free market environment. The Government will act to rationalise the trade policy administration procedures, both in foreign and domestic trade, with a view to reducing time and transactions costs.

This reflects the Ministry of Commerce's (MOC) strengthened position in matters of trade policy administration. In this context, 'import administration' (rather than 'import controls') and 'price surveillance' (rather than 'price controls') better reflect the MOC strategic approach to trade facilitation and administration. Trade policy in general, and the import licensing system in particular, will give due attention to current account balance and balance of payments through policy developments consistent with competitive market system principles. 


\section{Policy Improvements}

\section{Rationalising Policy on Protection}

There is a need to protect and promote new domestic industries, however, at some stage producers need to reach the levels of efficiency and quality of those of overseas markets. This is necessary for both efficient import substitution and export orientation of domestic production. For this to happen, domestic producers need to be exposed to foreign competition, but in a sustainable manner. On this basis, the Government aims to phase out industry protection beyond the infancy period. Consideration will be given to the possibility of replacing protective quantitative restrictions with tariffs, wherever possible, as they are a better and more efficient means of protection because they work through the market system. More vulnerable traditional economic activities, particularly in agriculture, may need a longer period of protection for adjustment to the emerging competitive market environment.

\section{Foreign Trade}

The expansion of foreign trade will be achieved through the establishment of more bilateral trade relations and regional and international integration. In addition, border trade with neighbouring countries will be enhanced under the new land-linked programme, together with the development of border trade zones and special economic zones. North-South and East-West corridors will be developed with improved national road and checkpoint networks.

The Government will implement the CEPT under AFTA by reducing tariffs on a range of products to $0-5$ per cent by 2008 . This will almost eliminate remaining trade barriers between the Lao PDR and its ASEAN counterparts and thus increasing trade. These tariff reductions, as well as the harmonisation of standards and rules, will mean that the ASEAN market will be a favourable environment to attract foreign investment, particularly with regard to export orientated investment.

The Government has finalised arrangements to sign a bilateral trade agreement with the USA. The signing of this agreement is expected to establish normal trade relations with the USA and help attract more foreign investment.

\section{Import Administration}

It is important for sustainable development that the Lao PDR lives within its means. This means that the country's expenditure on imports should approximate its total income from exports of goods and services, foreign aid receipts and net inflows of capital. Containing imports is mainly a function of macroeconomic management. As such, the Government will provide a sound import administration system. This system will be consistent with a liberal and free market trade regime and in accordance with the country's obligations under AFTA and other international requirements. The application of quantitative and other restrictions on imports will be minimal and only to the extent required for social security and infant industry protection.

\section{Export Development}

The Lao PDR has been GSP status from 35 countries, China being the latest country to have given the Lao PDR this preferential status ${ }^{97}$. This status is a significant opportunity to expand exports.

The promotion of export development and production activities will be achieved through:

- Rationalising of export administration procedures reduce time taken for processing license applications, etc.

\footnotetext{
${ }^{97}$ Recently, New Zealand, Canada and Australia have also granted Lao exports duty free entry.
} 
- Researching on products in which Laos would have a comparative advantage.

- Disseminating market intelligence on overseas market opportunities, procedures, GSP and other tariff concessions etc to prospective exporters.

- Providing information on investment opportunities and facilities to domestic and foreign investors using a variety of mass media as well as ICT networking. This will mainly be done by the information service of the Lao Trade Promotion Centre.

- Improving trade facilitation.

\section{Domestic Trade}

The development of domestic trade is vital for the overall development of the economy. The private sector will be encouraged and supported by the Government to engage in trading activities that will facilitate the unrestricted distribution of goods and services throughout the country. Such trade-oriented distribution is essential to prevent shortages of consumer and investment goods, as well as unnecessary increases in their prices.

The production and marketing of domestic goods both locally and overseas will be encouraged through the following measures:

- Creating market opportunities for domestic products by regularly organising exhibitions and trade fairs within and outside the country.

- Publishing of information on the availability of domestic products and the prevailing prices, as well as other basic information needed by traders and consumers.

- Providing producers and traders with information on the use and availability of Generalised System of Preferences (GSP) available to the Lao PDR from several developed countries.

- Promoting the development of trade and commerce related infrastructure, such as rural marketplaces, transport and communication.

- Promoting the availability of banking, finance and credit facilities, particularly for medium and small-scale enterprises.

\section{New Initiatives}

The Government is taking a number of new initiatives in order to improve the policy environment in the trade sector.

\section{Fair Trading Commission}

Anti Monopoly and Competition: In order for the country and its people to fully benefit from trade and business development, the Government will promote competition and fair-trading practices in the business sector. Restrictive business practices by dominant firms such as transnational corporations can impede the realisation of the benefits of trade liberalisation. To prevent such practices and other monopoly elements emerging in the economy, the Government will take steps to promote more competition.

Competition will ensure greater efficiency in production, export development and trading activities. Action is being taken to introduce an anti-monopoly and competition law.

Consumer Protection: It is essential, particularly for a newly emerging market economy, to have measures to protect the consumer from hazardous products and unethical trade practices. To this end, the Government is taking steps to introduce consumer protection legislation. In order to implement the policies and legislation on competition and consumer protection, a Fair Trading Commission will be established under the Ministry of Commerce (MOC). 
A Fair Trading Unit will be set up within MOC to provide administrative support to the Commission. Assistance is being obtained from UNCTAD and other aid agencies for the preparation of necessary legislation, for training of staff and for raising community awareness and understanding of competition and consumer protection. Community awareness will be raised through seminars, workshops and public awareness programs.

\section{Commercial Law Reforms}

The liberalised trade and commercial regime that is emerging in the Lao PDR through the new market mechanism requires an appropriate legal framework to ensure its smooth functioning. To this end, the Government has taken steps to review and revise the existing laws relating to trade and commerce, particularly the Business Law of 1994.

\section{Train-For-Trade Programme}

Train-For-Trade is an UNCTAD sponsored technical assistance project for the Lao PDR and Cambodia which is aimed at trade related capacity building in the two countries. This four-year project is scheduled to start in September 2003. During this period, UNCTAD will conduct training and other technical assistance activities in the Lao PDR with a view to improving the skills of Lao officials and other staff engaged in trade related activities.

\section{Trade Training Centre}

The Trade Ministry's TTC is designed to provide short-term courses for the staff of the MOC, along with other relevant ministries and provincial governments, to upgrade their trade-related skills. The TTC facility will be utilised both by the IF Initiative and the Train-For-Trade Programme for conducting skills training activities. UNCTAD is in the process of arranging for supply of computers, audio-visual and other equipment needed to make the TTC fully operational.

\section{Lao Chamber of Commerce}

The Chamber of Commerce has an important role to play in promoting trade and business development. To make this role more effective, the Government has taken steps to make the Chamber of Commerce independent.

In conjunction with the Lao Chamber of Commerce, the Government intends to make full use of the Greater Mekong System (GMS) Business Forum in Vientiane in order to promote trade and business relations with other countries in the region.

Annex 3 (Table 3.10) provides a detailed trade matrix. 


\section{Chapter 6: Inter-Sector Priorities}

The NGPES ensures inter-sector issues are addressed in the development and implementation of sector plans, in particular gender equity and environmental conservation. Population policy and social security are other important inter-sector issues, as are information and cultural issues. A particularly crucial inter-sector priority in all the NGPES endeavours, is capacity building. Inter-sector priorities are addressed in the following sections.

\subsection{Gender Strategy for Poverty Reduction}

\section{Issues}

Lao women play critical roles in agriculture and other economic activities, and are primarily responsible for maintaining their families' food security and health. The Government recognises that it will not be able to realise the goals of reducing poverty and improving national education, health and population indicators without the active participation of all women, particularly poor and ethnic minority women.

Therefore, the Government is taking concrete steps in all key economic sectors and through national programmes to: support poor women's economic activities; improve their access to basic services such as education and health and productive resources, such as extension services; involve them in local decision-making, and; generally take their needs into account in developing national policy.

Promoting gender equality is an important national goal, as reflected in Articles 22 and 24 of the 1991 Constitution, in numerous international commitments (e.g., the Convention on the Elimination of All Forms of Discrimination Against Women) and in the recently established National Commission for the Advancement of Women - Lao PDR (NCAW-Lao). Ensuring equal access to basic services and productive resources is a matter of equity (fundamental fairness), efficiency (poor women are a valuable resource) and effectiveness (women's support is needed to implement national policies on shifting cultivation, opium production, education, health and population). Under the guidance of the new NCAW-Lao, it is expected that all ministries will develop strategies and action plans to promote gender equality at national, provincial, district and village levels. ${ }^{98}$

Line ministries have begun to mainstream gender concerns by:

- Establishing high-level gender working groups.

- Collecting sex-disaggregated data relevant to poverty reduction and other national goals.

- Using the data to develop a gender profile or assessment of the sector.

- Developing a gender strategy and action plan, identifying issues or problems related to women's participation in the sector and actions to redress them.

- Providing gender training and capacity-building to staff.

- Improving the gender and ethnic balance of staff at all levels.

- Screening all new policies, programs and projects from a gender perspective.

- Consulting local women in the design of new projects for poverty reduction, and ensuring that they participate in project activities, including extension services and training.

\footnotetext{
${ }^{98}$ Guidelines have been developed for a National Gender Action Plan to integrate the gender strategies and action plans of ministries, agencies and mass organisations. The development of such a national plan will be guided and co-ordinated by the NCAW-Lao.
} 


\section{Strategic Responses}

In the agriculture sector, gender concerns will be integrated in specific programmes and projects through a number of measures. Research and project planning will include:

$>$ Gender-related data and needs assessments.

$>$ The inclusion of women in project activities.

$>$ The application of gender equity in extension and training services.

$>$ The use of gender-related indicators to monitor projects.

$>$ Affirmative action concerning staffing of provincial and district staff, including extension workers.

$>$ Gender focal points in villages to promote improved agricultural practices.

$>$ Account of women's traditional rights in land reallocation, land titling and resolution of land disputes.

$>$ Assistance to women in accessing rural savings and credit schemes.

In the education sector, gender gaps in literacy and school enrolment and completion rates, particularly among ethnic minority groups, must be redressed. This is critical both to achieving the Government's education and literacy goals and the goal of poverty reduction. Accordingly, emphasis will be placed on increasing the availability, quality and relevance of primary and secondary education for girls, particularly poor and ethnic minority girls; ensuring that vocational and technical school programs are accessible to women, particularly poor and ethnic minority women, and; approaches to non-formal education that are highly beneficial to women.

Lessons will be drawn from past and current projects for increasing the number of ethnic minority teachers, improving the relevance of primary school materials and providing incentives for girls to attend school. Provinces and districts will be encouraged to develop locally appropriate material to supplement the core curriculum, and to schedule primary and secondary school classes to encourage school attendance. Other approaches include distance learning and "bridging" courses to enable students (particularly women) to enter vocational and technical schools.

In the health sector, the Government has set improvements in several key health indicators by 2005 , notably substantially reduced maternal and infant mortality rates. Improving women's access to primary health care, particularly reproductive health services, will be essential for achieving key health goals. Further, women - particularly women in poor villages and districts must be involved to ensure successful implementation of immunisation, clean water and other public health programs.

Gender concerns, therefore, will be addressed through all major health care initiatives. Specific measures will include:

$>$ Training of ethnic minority women for all aspects of health services.

$>$ Designation of a gender focal point in each provincial and district primary health centre.

$>$ Gender and ethnic balance in village health committees.

> Gender and ethnic balance in all in-service and specialised training for health staff and health care providers.

> Incentive packages for health care workers assigned to remote districts and villages.

$>$ Use of radio and other media to promote health education to men and young people, particularly relating to birth spacing and prevention of STD/HIV/AIDS infection.

$>$ Expanding access to reproductive health services, especially for ethnic minority women. 
In transport, the Government is committed to ensuring that the needs and concerns of women are properly taken into account in planning and implementing road and other transport-related infrastructure. Negative environmental and social impacts must be taken into account, especially since they tend to fall more heavily on poor women. Therefore:

> Local communities, including women, will be consulted in the design of transport and other infrastructure projects.

> Environmental and social assessments of new road construction and other infrastructure projects will include analysis of gender-related benefits and impacts.

> Community development projects will be designed to ensure that rural communities benefit from roads and other infrastructure projects.

$>$ Gender data will be collected to monitor the impacts of these projects.

$>$ Women representatives will participate in community road maintenance funds.

The Ministry of Communication, Transport, Post and Construction (MCTPC) will co-ordinate with the Ministry of Health, mass organisations and other agencies to carry out awareness campaigns (in relevant languages) on HIV/AIDS and other health risks at road construction camps, in communities along road corridors, and at transit stops and border crossings. The MCTPC will also co-ordinate with other agencies working on UXO in connection with plans for road construction in affected areas.

Due to different education levels, access to credit and assumptions about appropriate work for women and men (amongst other factors), women and men often have different opportunities and face different constraints as business owners and workers in sub-sectors such as trading, handicraft production, manufacturing, tourism and information technology. Under the new Lao NCAW, it is expected that all relevant ministries will mainstream gender concerns in their policies, planning and activities. This will ensure that women as well as men can participate fully in the country's economic development. Gender issues are also being addressed through national programmes dealing with the prevention of HIV/AIDS, trafficking in women and children and illegal drug use, and also national programmes dealing with population policy and UXO.

Finally, there are a number of gender issues in the area of governance that are relevant to poverty reduction. Women represent about one-third of all government employees, but not many women are in leadership positions at the national, provincial, district or village levels. At technical levels, ethnic minority women are not well represented, particularly in the ranks of extension workers, health care workers and teachers. The Government is committed to correcting these imbalances. The Government also recognises that poverty cannot be reduced substantially without the involvement of women at the local level. Therefore, village leaders and committees will be encouraged to include more women in local decision-making. In the area of legal awareness and rights, the Lao Women's Union will continue to work with the Ministry of Justice, other ministries and external agencies to promote women's legal awareness and access to justice.

Priorities regarding gender equity are detailed in the gender policy/programme matrix in Annex 3 (Table 3.5). 


\subsection{Environment Conservation and Poverty Eradication}

\section{Issues}

The Government's Five-Year Socio-Economic Development Plan (2001-2005) emphasises the vital importance of environmental conservation in achieving long-term sustainable economic growth and poverty eradication. The environment and natural resources are the foundation for the livelihoods of most rural people, particularly for the poor and ethnic minorities. Environmental degradation, such as deforestation and soil erosion, results in natural disasters (floods) and other consequences that disproportionately impact on the poor. The urban poor are also badly affected by environmental degradation, through unclean water, lack of proper sanitation, and other problems. Smoke from indoor cooking causes serious respiratory ailments for both the rural and urban poor for neither may have access to, or be able to afford, electricity and thus have to rely on open fires for cooking and light.

The Government recognises that solutions for environmental conservation have to be founded in the broader context of national development, wherein each sector integrates environmental principles in its policies, programmes and projects. Assurance of this is, therefore, the overarching environmental concern of the Government. Sector action plans must be anchored in ecologically sound approaches to resource management and enhance social and cultural development.

The main elements of the National Environmental Action Plan 2000 (NEAP) and the Environment Strategy for 2003-2020 are an integral part of the NGPES. Responsibility for monitoring the achievement of national environmental targets lies with the Science, Technology and Environment Agency (STEA). Environment and natural resource management is a crosscutting theme that will be effectively integrated within all sector strategies and the community-based initiatives focused on the 47 poorest districts.

\section{Current Environmental Trends}

The State of the Environment Report of 2001 (STEA, 2001) identifies five areas of environmental concerns:

- Deforestation and Forest Quality Degradation: Forest coverage has been declining steadily from more than 70 per cent of the total land area up to the mid 1960s to about 47 per cent in 1998; the Department of Forestry is in the process of determining trends since 1998 based on satellite data collected during 2000-02. Rural people, who comprise 80 per cent of the population, are generally highly dependent on forests, especially as sources of food, raw materials, revenue and traditional medicines. Villagers may obtain half of their income and half of their dietary protein from forest products. Forest degradation is highly detrimental. The effects are especially severe for the poorest segments of the population, particularly women and ethnic groups, whose livelihood are often closely tied to the health of the surrounding forests.

- Land Degradation: Swidden or dry-rice cultivation, with lower yields, is predominantly practised by poor villagers living in the highland areas. More than one-third of the country area has a slope of more than 30 per cent. Cultural and ethnic diversity play a major role in determining the type of agricultural practices.

- Access to Water Resources: Although Lao P.D.R. has the highest per capita renewable freshwater resources in Asia, only 60 per cent of the urban and 51 per cent of the rural population has direct access to a good water supply. Only 35 per cent of the cultivated land has access to irrigation. 
Lao PDR - National Growth and Poverty Eradication Strategy (NGPES)

- Threats to Bio-diversity: Deforestation and forest quality degradation have adversely contributed to bio-diversity losses over the past three decades. Unsustainable forest management, wildlife trades, excess and inappropriate fishing, and growing demand for agricultural and residential areas also lead to bio-diversity losses.

- Decline in Urban Environment: Proper planning is needed in providing urban services to avoid exacerbating pollution and affecting negatively the well-being of the urban population. Solid waste and wastewater management will receive further attention.

\section{Poverty and the Environment}

Environmental conditions have a major impact on the livelihood, health, opportunity and security of the poor. A preliminary analysis of environmental conditions in the poorest districts of Lao PDR indicates the following: ${ }^{99}$

- Deforestation and Agricultural Land: While the deforestation rate for the poorest districts is about the same as the national average, these districts have experienced a far greater decline in agricultural land. However, they have, on average, 52 ha of high-density forest area per household, suggesting that with access and knowledge to efficiently use the forest resources, the well-being of the poor could be improved while conserving the forests.

- Land Degradation: About half of the total land area in the poorest districts has an average slope of more than 30 per cent. With little technical and financial support in finding more productive options to dry-rice cultivation, the poor have had to supplement low crop yields by resort to already declining NTFPs.

- Water Resources and Environmental Health: The poorest districts have less than half the national average of daily water use, due to less access to water for either personal use or irrigation purposes. Water and sanitation-related health problems are acute, as are acute respiratory infections; indoor air pollution is a serious problem.

- Bio-diversity: 13 districts out of the poorest districts have more than half of their total land area covered by forest; many are located in the National Bio-diversity Conservation Areas. The poor rely heavily on the availability of NTFPs, wood and other products from the forests. Bio-diversity conservation is one of the crucial factors determining the livelihood of the poor.

- Vulnerability from Natural Disasters: Over the past decade, the Lao P.D.R. has suffered from severe droughts and floods. In the year 2000, for example, $1,104 \mathrm{~km}^{2}$ in seven provinces were flooded, affecting 450,000 people.

\section{Strategic Responses}

The overall objective of the draft National Environment Strategy 2003-2020 is "to sustainably utilise natural resources and protect and conserve the environment to ensure the sustainable development of the country while reducing poverty and enhancing the quality of life and health of the Lao people." To achieve this objective, three main strategies have been identified:

1. Improve the management of natural resources through increased participation and protection:

Strengthen participation, especially by the poor, in the preparation and implementation of national and local plans, policies and strategies.

$>$ Co-manage environmental services and resources with the poor through strengthening community management of environmental resources.

\footnotetext{
${ }^{99}$ Data used in this section was compiled from S. Dasgupta, et al., 2002 Poverty-Environment Nexus in Cambodia, Lao PDR and Viet Nam.
} 
Lao PDR - National Growth and Poverty Eradication Strategy (NGPES)

Protect access the poor already have to critical resources (entitlement to land, water, trees, pastures, fishing grounds).

$>$ Expand the natural asset base of the poor (community forest rights).

$>$ Reduce subsidies for environmental services that benefit the less-poor.

Undertake ecological zoning of the Lao PDR.

2. Improve the institutional framework and its capacity through strengthening the institutional framework and raising public awareness and political commitment:

$>$ Develop a sound legislative and legal framework for property rights, water resources, forestry, land management and bio-diversity.

$>$ Use market based instruments as much as possible.

$>$ Build capacity for more effective environmental management.

$>$ Deepen public awareness and political commitment.

$>$ Improve public access to environmental information.

$>$ Introduce environmental education as standard part of the curriculum.

$>$ Integrate environmental concerns into private sector decision-making; promote industry-wide codes of conduct and environmental auditing.

3. Improve the environmental management in industrial and construction sectors:

$>$ Promote environmental infrastructure and technology that benefit the poor.

$>$ Promote the development of environmentally friendly private sector products such as clean technology, energy efficiency technology and eco-tourism.

\section{Policy and Programmes Priorities}

The policy and programme priorities for the environment are summarised in Annex 3 (Table 3.6).

\subsection{Population Policy for Poverty Reduction}

Balancing population growth with socio-economic development is an important element of the poverty reduction strategy. In line with the Programme of Action adopted by the International Conference on Population and Development (Cairo, 1994), the Government has formulated a National Population and Development Policy (NPDP), adopted in 1999. The main policy goals of the NPDP are to:

- Support measures to achieve a rate of population growth compatible with socioeconomic development and employment opportunities available within the country.

- Ensure safe motherhood and enable couples to responsibly decide the number and spacing of their children.

- Improve the status of women and the multi-ethnic populations by improving access to education, health, social welfare and socio-economic development.

- Promote a balanced distribution of population between rural and urban areas and between different parts of the country.

- Incorporate population factors and concerns into all social and economic policies, plans and programmes. 
Since 1993, Mother and Child Health and birth spacing services have been introduced at 542 primary health care facilities and all referral hospitals of the country. Additionally, health volunteers in more than one third of the country's villages received basic training on how to disseminate information on reproductive health and family planning. However, success has not been uniform and disparities persist, in particular in rural areas of the country where poverty and fertility rates are markedly higher, and where age of marriage is earlier and development opportunities fewer. Also, the expansion has occurred at the expense of quality in some locations, and with limited integration of services. Therefore, consolidating gains in coverage, improving service quality, broadening the range of services offered and more fully integrating service delivery at all levels, especially at the community level, are the next priorities.

Two main programmes will be at the forefront of the Government's population policy for poverty reduction: Reproductive Health and Population and Development.

The purposes of the Reproductive Health Programme include:

- Increasing the use of reproductive health services and information leading to responsible and safe sexual behaviour.

- Creating an enabling environment for the provision of quality, integrated services and counselling on reproductive health.

Activities under this programme will include special focus on ethnic groups and institutional strengthening and training.

The 'Population and Development' Programme focuses on the following inter-related outputs:

- Strengthened advocacy capacity of key organisations (e.g., the National Coordinating Committee for Population and Development) for the implementation of the NPDP and its Action Plan, and support to key population/gender issues.

- Strengthened capacity of CPC and other agencies for data collection, analysis, training, research and dissemination of information on gender and population issues.

- Strengthened capacity of NCCPD, CPC and other organisations for the co-ordination and implementation of the national population programme.

\subsection{An Efficient Social Security System to Prevent Poverty}

The Government is concerned for peoples' ability to protect themselves against economic adversity. Thus, the establishment of an efficient social security system for all Lao people is a long-term objective. Public servants are covered by a comprehensive range of provisions including pensions and health care financed partly through a six per cent deduction from salaries and partly from the state budget.

In 1999, the Government adopted a Decree on Social Security System for Enterprise Employees, establishing the foundation of a National Social Security Scheme. It called for the creation of a Social Security Organisation (SSO) which began operating in June 2001. The SSO administers the Social Security Scheme for enterprise workers in the private and the SOE sectors. The Scheme provides protection coverage in respect of a comprehensive range of contingencies/risks including:

> Access to health care from an approved health care provider by insured workers and their families.

$>$ Long-term pensions in respect of old age, invalidity and surviving dependants.

$>$ Short-term benefits in respect of incapacity for work by virtue of sickness or maternity.

$>$ Benefits in respect of incapacity for work by virtue of an employment-related injury, sickness or death. 
Initially, coverage will focus only on workers in private and state-owned enterprises with 10 employees and more in Vientiane Municipality. The coverage will gradually extend to workers of smaller-size enterprises and to other provinces of the country. ${ }^{100}$ The strengthening and extension of the social security system is another element of the poverty eradication programme.

\subsection{Information and Culture}

Improved information by all Ministries, at all levels, is increasingly serving community-based development and overall transparency. Budgetary documents released by the Ministry of Finance are one example of the Government's commitment to openness and dialogue. In addition, the Ministry of Culture and Information will increasingly use mass media to help disseminate information and enhance public awareness of Government policies and programmes. Every effort will be made to find ways of ensuring that information reaches the poor, and that the poor have ways of communicating back to public officials and community leaders.

Priorities in the cultural field will focus on the preservation of the national cultural heritage, historic sites, heritage towns and temples to attract tourists and generate income for local people. At the same, the rehabilitation and construction of art and musical schools and cultural villages will continue.

\subsection{Capacity Building}

Capacity building is an essential element of the NGPES. In its policy paper on governance issues, the Government emphasises capacity building as a major requirement for improved public administration, strengthened legal and regulatory frameworks, and good governance in general.

Capacity building issues and the sector and supporting sector responses to them have been outlined in the various sector strategies. Most sectors have developed, or are developing, their own capacity building programmes and projects, in response to specific sector needs, and incorporate capacity building elements into their activities more generally.

The overarching need to enhance capacity is supported by the Decree on ODA Management and Utilisation (No208/PM/Oct.30, 2002) which stipulates that all ODA programmes and projects must contain capacity building elements to ensure their successful implementation.

With respect to the capacity necessary for sound public management and administration, the Government has created the National Organisation for the Study of Politics and Administration (NOSPA). The NOSPA has a central role in training the Government's middle and high-ranking officials, at central and provincial levels, in fields related to public administration and governance. This role will be strengthened.

A new area for capacity building, vital to the successful implementation of the NGPES, is decentralisation management and development planning. In line with PM Instruction 01 ('decentralisation') and PM Instruction 010 ('poverty eradication'), the Government will ensure efficiency and effectiveness of capacity building activities in decentralisation management and development planning by taking the following steps:

$\Rightarrow$ Develop an inventory of current capacity building initiatives, programmes and projects for government staff, funded and implemented by both the Government and its partners in development.

\footnotetext{
${ }^{100}$ This is being assisted by the Government of Belgium and the UNDP.
} 
$\Rightarrow$ Identify and prioritise capacity building requirements at all levels and prepare a framework for the implementation of capacity building programmes, which respond to these needs across time and place.

$\Rightarrow$ Create a comprehensive capacity building strategy based on the inventory of on-going initiatives, programmes and projects as well as on the ranking of needs.

$\Rightarrow$ Implement the capacity building strategy through a co-ordinated approach. Particular care will be given to ensuring close co-ordination between line ministries and provincial, district and village authorities, as well as with the Lao PDR's partners in development.

By taking these steps, the Government believes that a high level of synergy, complementarity and efficiency can be achieved. It will also enable better monitoring the capacity building programmes and allow specific needs, in response to particular priorities of the NGPES, to be taken into account. These measures will especially benefit the district and provincial levels as improved provincial and district planning and management capacities are among the highest priorities. Improved capacity of local administration, including fiscal management and development planning and implementation, will greatly enhance the effectiveness of their poverty eradication efforts.

Appropriate institutional arrangements, at both micro and macro levels, to carry out and coordinate these activities are presently being studied.

The Government is looking forward to support in this essential endeavour. It is only through a co-ordinated approach that the Government can ensure improved levels of competence throughout the country, responding to both long-standing and arising needs. 


\section{Chapter 7: Poverty-Related National Programmes}

The Government has initiated, with the assistance of the Lao PDR's development partners, a number of poverty-related national programmes, including the National Drug Control Programme and the UXO Decontamination Programme. Other national programmes (e.g., the Mother and Child Programme; clean water by 2010) are addressed in the relevant sector chapters ${ }^{101}$. Because of its importance, additional attention is given here to the National Plan of Action for Response to HIV/AIDS ${ }^{102}$.

\subsection{The National Drug Control Programme}

Illicit drug supply is linked with illicit drug demand, the financing of which reduces household assets. Related to these crimes may be petty thefts to support drug abuse, domestic violence, large scale organised drug trafficking, which may in turn lead to entrenched organised crime wielding undue influence in the country. Organised crime may extend its reach to other criminal activities, affecting the security, stability and peace of the country. Security, stability and peace is a condition which is necessary for poverty eradication.

The supply and demand of both opium and Amphetamine Type Stimulants (ATS) is a major concern for the country. Opium addiction is high in opium growing areas. UNODC publication "World Global Illicit Drug Trends 2002" identified the Lao PDR as the world's second largest consumer of opiates in per capita terms. ATS have been spreading rapidly among young people in recent years. Although injecting drug use appears to be still low, ATS abuse may result in highrisk behaviour, increasing vulnerability to HIV/AIDS. Drug abuse and HIV/AIDS affect health and work productivity, increasing vulnerability to poverty.

\section{Opium}

The National Drug Control Programme addresses a complex problem, for poppy cultivation is both a source of income yet also a source of poverty, especially in the Northern Region of the country.

In 2002, opium production occurred in 67 districts; of these, 32 are among the 47 poorest districts and 45 are among the 72 poor districts. Opium is produced by approximately 50,000 households in about 1,600 villages - mostly in the remote highlands of ten Northern provinces, which account for 90 per cent of total production for the country. The recently released (June 2003) UNODC figures, based upon remote sensing/satellite data and field surveys, indicate that approximately 12,000 ha are under opium cultivation, a 15 per cent decline compared to $2002 .{ }^{103}$ Still, raw opium production amounts to approximately 112 metric tons, of which 65 tons (58 per cent) are consumed domestically for addiction, social and medical purposes. Some 47 tons are exported.

The Government, in solidarity with the global concern regarding drug elimination, is determined to end the production of opium. Accordingly, the Government has established the Lao National Commission for Drug Control and Supervision (LCDC) within the Prime Minister's Office.

\footnotetext{
101 (E.g., Part IV, Chapter 3: Poverty-focused Health Development Plan).

${ }^{102}$ Part IV, Chapter 3 provides a summary of the Government's approach to the HIV/AIDS pandemic.

${ }^{103}$ United Nations Office on Drugs and Crime (UNODC), June 2003.
} 
The Government is well aware of the social and economic benefits to be obtained from eradicating opium cultivation and from the reduction in drug abuse within the country. More than 52,000 people in the areas concerned are drug addicts, with weak health and unable to perform productive activities. They become a burden for other members of the household who have to spend time and money to provide health care and treatment for them.

\section{Amphetamine Type Stimulants}

The Lao PDR is now facing a new drug problem: a serious ATS epidemic. ${ }^{104}$ Abuse of ATS drugs is mainly an urban problem, but it is spreading to rural areas. ATS use is increasingly common among the student population, and among outside groups. ATS abuse is also becoming a potential factor in the spread of HIV/AIDS.

\section{Strategic Responses}

The goal of the opium control programme is to eradicate opium poppy cultivation by the year 2005 through an accelerated rural development programme in the major opium producing districts. In response to both the opium and ATS problems, the Government is preparing a comprehensive Master Plan on Drug Control, comprising a balance between alternative development, demand reduction and law enforcement.

Alternative development replaces opium production with alternative income sources and simultaneously develops irrigation, transportation, credit access, health, education and other economic and social services - including improved cropping and livestock production practices. Employment and income opportunities from outside traditional agriculture will be explored, such as forestry derived employment, processing of local products and other value-added activities such as handicraft production and tourism.

Community-based drug demand reduction focuses on the health and economic well-being of the individuals and families using drugs. ${ }^{105}$ Community-based drug demand reduction seeks to raise community knowledge of the harmful effects of opium and to focus assistance on community efforts to reduce the incidence of new addiction. Efforts will be concentrated on detoxification and community based rehabilitation programmes. With regard to ATS and other drugs, the national demand reduction strategy focuses on prevention and counselling activities, and on treatment and rehabilitation.

Law enforcement is a separate national governmental responsibility that operates in parallel with alternative development and community-based demand reduction.

The overall programme is implemented by the LCDC in collaboration with UNDCP. Individual projects are executed together with local authorities by UN agencies, bilateral and multilateral agencies, and NGOs.

\section{Policy and programme priorities}

The Government is deeply committed to implementing all international conventions and resolutions to which it is party, including the UN goal of eliminating or significantly reducing opium production by 2008 . Indeed, the $7^{\text {th }}$ Party Congress (2001) approved targets to eliminate poppy cultivation by 2005 .

\footnotetext{
104 The word ATS has been adopted to refer to synthetic central nervous system stimulant drugs such as amphetamine, metamphetamine and the chemically related 'ecstacy group' (MDMA). In the Lao PDR, ATS is mainly metamphetamine and is called 'ya-baa' (crazy drug).

105 National Drug Demand Reduction Strategy in the Lao PDR, draft, December 2002.
} 
To achieve this target, the LCDC co-ordinates at the central level with all stakeholders in the collection of information, the setting of yearly targets, the preparation of appropriate projects to eliminate poppy cultivation, and the mobilisation of domestic and international resources to finance the projects.

In order to achieve the elimination of opium poppy cultivation by 2005 , future priorities will focus on the following activities: ${ }^{106}$

- Provide each locality with the necessary annual budget to implement their opium poppy cultivation elimination plan.

- Continue mobilising funds, domestically and internationally, to support the implementation of rural development projects to replace opium-growing activities.

- Facilitate access to credit for other productive activities, such as animal raising and handicrafts production.

- Facilitate detoxification and rehabilitation programmes and initiatives.

- Continue drug awareness programmes and other initiatives to prevent return to opium poppy growing.

- Facilitate voluntary relocation to areas offering better services and more diversified economic opportunities.

An estimated US $\$ 68$ million will be needed over the next six years in order to carry out investments in the opium growing districts, both for new drug control projects and for other projects that are complementary.

In order to eliminate opium cultivation in the 47 poorest districts, investments must be made in the following essential activities:

- Awareness programmes and law enforcement.

- Creation of alternative income sources, giving equal or better returns than possible from poppy cultivation.

- Treatment and rehabilitation for addicts.

- Monitoring action to stop opium cultivation, drug consumption and trade.

To implement these activities, a Programme Facilitation Unit (PFU) has been established jointly by LCDC and UNDCP. Also, a National Anti-Drug Trust Fund has been established. A national training and resource unit will be established under the Ministry of Labour and Social Welfare, to develop/provide drug counselling courses. Private enterprises will also be encouraged to establish drug counselling activities.

The drug control programme is being mainstreamed into national development priorities. This includes identifying practical alternative development approaches for improving village livelihoods and linking these to mainstream national development efforts.

One of the top priorities of the Government is to provide the necessary social and economic infrastructure and help establish income alternatives so that villagers do not have to resort to poppy cultivation. Simultaneously, this will improve the health status of many people and contribute importantly to poverty reduction.

Annex 3 (Table 3.7) provides a list of the completed, on-going and planned projects concerning eradicating poppy cultivation.

\footnotetext{
${ }^{106}$ See also "Five-Year Action Plan to Eliminate Opium Poppy Cultivation in the Lao PDR", LNCDCS, 2001.
} 
Lao PDR - National Growth and Poverty Eradication Strategy (NGPES)

\subsection{The UXO Decontamination Programme}

UXO contamination is a very serious problem for the Lao PDR. In addition to the human suffering and loss of life, UXO contamination blocks development in large areas of the country. Thus the national UXO Decontamination Programme addresses an important factor in fighting poverty.

\section{Issues}

During a ten-year period (1964 to 1973), the Lao PDR experienced intense ground battles and aerial bombings. An estimated 30 per cent of the ordnance failed to explode, leaving large areas of the country littered with unexploded ordnance (UXO). Severe UXO contamination still affects 15 provinces, particularly the provinces of Savannakhet, Xiengkhouang, Saravane, Khammouane, Sekong, Champassak, Huaphan, Attapeu, and Luang Phrabang. The areas affected represent over 50 per cent of all agricultural land. ${ }^{107}$

Three decades after the Indochina War, many people are still being killed or badly crippled from ordinance. The litter of highly dangerous ordnance denies access to much needed land, deters the planting of crops and grazing of livestock, and hinders collecting fuel and water. It also discourages movement between villages and slows transport/communication works, and generally undermines social and development activities.

\section{Strategic responses}

The UXO issue must be addressed in a co-ordinated and effective manner. Increased action is needed both to clear the contaminated land and to raise awareness of the threat posed by unexploded ordnance. The Lao National UXO Programme ("UXO Lao") was established in 1996, supported by a Trust Fund administered by UNDP. UXO Lao trains, equips and employs de-mining staff, surveys contaminated areas, educates impacted communities, and clears unexploded bombs and landmines.

The activities of UXO Lao contribute not only to saving lives but also to increasing the social and economic opportunities for some of the poorest districts. The main challenge of the UXO programme at this stage is to "mainstream" $\mathrm{UXO} /$ mine action into developmental programming in order to:

- Ensure that the planning of operations relates closely to national priorities such as poverty reduction, phasing out shifting cultivation and opium elimination.

- Increase the pace of clearance, thereby opening land for agricultural production.

- Mobilise resources required for humanitarian UXO action programming.

UXO Lao currently operates in 9 of the 17 provinces targeted. Additional survey work is urgently needed in districts with high contamination rates to determine the required UXO clearing programmes. Priority attention will be given to the poorest districts. UXO actions will be planned, budgeted and conducted in close co-ordination with all stakeholders. A national strategic plan "The Safe Path Forward" has been approved. Institutional and managerial arrangements are being strengthened.

Annex 3 (Table 3.8) provides UXO Contamination Data by Province/District.

${ }^{107}$ MOAF/JICA, Master Plan Study on Integrated Agricultural Development in Lao PDR, October 2001. 


\subsection{National Plan of Action for HIV/AIDS/STD}

The Lao PDR is largely free of the HIV/AIDS pandemic, but - as discussed in Part IV, Chapter 3 - there is not room for complacency. ${ }^{108}$ Through appropriate action, the Government is determined to maintain and improve upon the low rates of prevalence and incidence of the disease identified to date.

In January 2002, the Government formulated a National Strategic Plan (NSP) on HIV/AIDS/STD for 2002 to 2005. Aware of the urgency to prevent further spread of HIV, the Government will now develop a National Plan of Action to operationalise the NSP and to assist in resource mobilisation.

As reflected in the NSP, the Government's top priorities concerning the HIV/AIDS pandemic are:

- Surveillance: reliable data on the epidemiological situation of the country is critical and more survey work is required.

- $\quad$ STD prevention and treatment: sexually-transmitted infections among service women and truck drivers are high. This could lead to a fast evolving HIV/AIDS epidemic. The Global Fund for HIV/AIDS, Tuberculosis and Malaria will help fund STD prevention projects in five provinces.

- $\quad$ Prevention of HIV among youth: adequate preparation of young people before they become sexually active is essential for sustained effectiveness. Life skills education concerning sexual health is therefore a high priority.

- $\quad$ Prevention of HIV among mobile populations: mobile population groups are among the more vulnerable groups to STD, including HIV; some migrants go to surrounding countries which have much higher HIV prevalence than Lao PDR.. Thus, prevention of HIV among mobile population groups is a high priority.

- $\quad$ Prevention of HIV among service women; commercial sex work is illegal in the Lao PDR but educational and other prevention activities must be openly directed to service women.

- $\quad$ Care, support and treatment; some 1,020 patients are currently ill with HIV/AIDS; nondiscriminatory care is important. Home-based care is practical, and has been piloted in Savannakhet.

Prevention of STDs includes advocacy of safe sexual behaviour (condom use) and ensuring that blood supplies are safe. Other issues include the prevention of the transmission of HIV from mother to child, among drug users and among the general population and ethnic minorities.

In addition, there are a number of managerial and institutional priorities:

- Policy development and advocacy.

- Strengthening institutional arrangements.

- Strengthening country-wide surveillance and other research.

- Emerging issues of importance (drug use and gender aspects).

\footnotetext{
${ }^{108}$ HIV seroprevalence in the Lao PDR is remarkably low as compared with neighbouring countries; less than 1 per cent of the surveyed population.
} 
To successfully prevent further spread of the HIV/AIDS pandemic, the Government recognises that a strong institutional framework is necessary. The Government will:

$\Rightarrow$ Take a multi-sector approach in which responsibilities/activities will be decentralised to the provinces but which will be well co-ordinated.

$\Rightarrow$ Strengthen the legal framework.

$\Rightarrow$ Build the capacity of the National Committee for the Control of AIDS (NCCA) to take decisions quickly and with authority and act decisively in transmitting information and resources to fight the epidemic.

The Government will need the assistance of the Lao PDR's partners in development in this very important programme.

Annex 3 (Table 3.9) provides a policy/programme matrix for the prevention and treatment of HIV/AIDS. 


\section{Chapter 8: Community-Driven Rural Development, Poor Districts and Poverty Eradication}

\section{Issues}

Since PM Instruction 001 (March 2000) and PM Instruction 010 (June 2001) are fundamental to the Government's approach to rural development, and since rural development is fundamental to poverty reduction, it is important to review again briefly their main provisions.

Instruction 001 redefines central-local relations by establishing provinces as strategic planning units, districts as programme and project planning and budgeting units and villages as the main focus for programme and project implementation. Provinces are expected to formulate their own 5-year strategic plans and corresponding budgets, consistent with the national 5-year socio-economic development plan, the NGPES and the fiscal framework. In turn, districts are responsible for their planning and budgeting processes, again in accordance with the national and provincial plans and fiscal framework. In addition to being the implementing units for programmes and projects, villages are responsible for revenue collection based on production. Villages must also collect data on their socio-economic conditions and classify themselves by one of three categories: well-off, self-sufficient and poor. Further, villages must monitor the impact of development on household income improvement and poverty reduction.

Instruction 010, "Concerning the Establishment of a Plan for the Eradication of Poverty", provides an official definition of poverty: ${ }^{109}$

- Poor households are those with insufficient income to secure a minimal food ration of 2,100 calories/capita/day, equivalent to $85,000 \mathrm{kip} /$ capita/month.

- Poor villages are those where more than 51 per cent of the households are poor and have limited access to schools, health facilities, roads and clean water.

- Poor districts are those where more than 51 per cent of the villages are poor and 40 per cent have no access to schools, health, or clean water and 60 per cent have no access to roads.

An essential policy underpinning this instruction is that "grass roots levels should take initiatives in poverty alleviation (through development) in their own areas". Rural development, therefore, is at the centre of the Government's development and poverty eradication efforts.

In particular, the "area-focused development approach" targets both remote areas where poverty is endemic and areas with growth and development potential. Development is addressed in an integrated manner, by opening up access to remote areas, stabilising shifting cultivation, facilitating economic activities in a increasingly market-oriented context, improving livelihoods through access to social services and integrating all the regions of the country into a dynamic national economy. The area-focused development approach concentrates rural development in clusters or zones (khet/tasseng), where a wide range of activities (agriculture, social services, institutional capacity building, infrastructure and markets) are undertaken in a synergistic manner to boost household income and eradicate poverty.

${ }^{109}$ See Part II, Chapter 3. 
Under PM Instruction 013 (May 2002), the Ministry of Agriculture and Forestry is responsible for planning and co-ordinating rural development in the Lao PDR. This follows from the importance that agriculture plays in the lives of most rural people, and the importance of a comprehensive approach to rural development in raising agricultural productivity. As shown by the LECS 2 data, improved agricultural performance is dependent upon better road and market access and access to productive land, irrigation, extension (technology/information) services and - over the longer-term - to education and health services. The Government has concluded that rural development and improved agricultural performance must be addressed comprehensively and in an integrated manner.

At the same time, regional differences call for distinct approaches, especially respecting the differing needs and circumstances of the lowlands (along the Mekong corridor) and upland areas. The lowlands have better transportation infrastructure and are able to access markets. This has spurred commercialisation of the agricultural sector. Further, better access to and quality of education, health and other services (e.g., credit, electricity and telecommunications) has led to a cycle - whereby increased agricultural productivity enables people in the lowlands to invest in themselves and their livelihoods, thereby greatly reducing poverty and opening up new income opportunities. Improvements in their circumstances, including much reduced infant and child mortality rates, has encouraged family planning and lower fertility rates, with the result that the dependency ratio has also fallen sharply. ${ }^{110}$

In contrast, the uplands are locked in a vicious circle of poverty. The mountainous terrain has made it difficult and costly to provide all-weather roads. Consequently, many villages are isolated and lack access to markets and services available in most lowland areas. Irrigation is limited and shifting cultivation is widely practised. Subsistence farming is still the norm for most households, leaving little if anything for investment for a better future.

These two different realities (upland and lowland agriculture) are reflected in planning for rural development. The rural development strategy for the lowlands is directed to facilitating markets and supporting private sector initiatives, whereas the Government's strategy for the uplands is more proactive in assisting farmers in seeking out new opportunities and helping them to realise these opportunities. ${ }^{111}$ In both cases, however, the Government's strategy is highly sensitive to livelihood systems, particularly with regard to the paramount need of poor rural households to secure their food supplies.

Improved forest management will greatly benefit the rural poor, for they depend heavily on non-timber forest products (NTFPs) to supplement their incomes and enhance their livelihoods. For those living in remote, mountainous areas, as much as 40-60 per cent of household income is derived from NTFPs. Firewood is a vital energy source. Over-harvesting of NTFPs by outside traders, over-harvesting of the forests themselves, and the relentless pressure for more agricultural land are combining to deplete the natural resource base. Forestry and agriculture are closely interrelated, for healthy forests secure the land base and regulate the water flows, and thereby protect the soils and nurture agricultural crops. Properly managed, forests can be a renewable resource, providing NTFPs, sustainable forestry revenues, and a variety of agro-forestry opportunities for rural people. For this reason, conservation of the forests is fundamental to protecting the agricultural base and improving the lives of rural people.

\footnotetext{
${ }^{110}$ The dependency ratio is the ratio of non-working age population (children below age 15 and people above age 64) to the working age population.

${ }^{111}$ As elaborated upon in Chapter 1, Part IV, especially pp. 56-57, under 'area-focused development approach'.
} 
In this spirit, and as described more fully in Chapter 1, Part IV, the Government is reviewing both its forestry policy and the land-forest allocation programme. Population pressures on scarce arable land has resulted in shortening the swidden cycle, leading to loss of soil productivity and increased labour needed to deal with weeds that flourish on the depleted soils. Shifting cultivation is being practised on progressively less productive land. For some, resort to opium cultivation is a coping strategy to offset declining rice crops, with disastrous effects for the social fabric. Upland farmers urgently need help in making the transition to intensive farming methods, whereby three hectares of land per household can yield good livelihoods on a sustainable basis. The Government's priorities in the 47 poorest districts will address this need.

Opportunities for higher value crops and livestock husbandry are developing. The improving road network throughout the Lao PDR and trade liberalisation with neighbouring countries offers the possibility of diversifying from subsistence farming into cash crops and other agricultural products. As noted above, this is already happening in the lowlands. Upland areas must have the same opportunity. The Northern Region of the Lao PDR is of particular concern, as it has the highest incidence of poverty and faces the greatest challenges in overcoming remoteness and lack of access to markets and services. However, even in the north there is increasing evidence of the transition to more modern agricultural methods and practices.

Despite its weaknesses, the agricultural sector has a strategic advantage, for the Greater Mekong Subregion ${ }^{112}$ has a population approaching 300 million with a growing demand for more protein and other food products. This very large market could become a significant consumer of rice, livestock, vegetables and other farm produce from the Lao PDR. Further, exports of NTFPs, handicrafts, and agro-forestry products (e.g., cardamom, benzoin, paper mulberry) could contribute substantially to improving household incomes. Ethnic diversity adds to the mix of opportunities, for each has their unique strengths. For example, the Tai Dam are experts at sericulture, the Hmong are experts at cattle raising, the Khmou have detailed knowledge of forests, and the Akha have expert knowledge of herbal medicines. This local knowledge will be incorporated into rural development programmes and projects.

\section{Strategic Responses}

In the Lao PDR, rural poverty is directly linked to access to resources and to the availability of social services. Resource access includes availability and tenure of land, forest and non-forest timber resources, livestock security, and access to agricultural inputs (credit and irrigation services) and markets. Needed social services include education and health services, clean water and sanitation.

Based on the poverty analysis described in Part II, the Government's rural development strategy addresses essential development constraints, including:

$>$ Inadequate infrastructure.

$>$ Limited and poorly developed human resources.

$>$ Poor health conditions.

$>$ Inadequate potable water and facilities.

$>$ Poor agricultural support and delivery services.

$>$ Limited access to inputs and markets.

$>$ Lack of medium and short term credit. 112 The Greater Mekong Subregion includes Cambodia, Lao PDR, Myanmar, Thailand, Vietnam and Yunnan Province
of the People's Republic of China. 
In addressing these constraints, the Government is encouraging and facilitating a strong community-based approach. Planning therefore involves a highly participatory process. As indicated by the poverty analysis, the Government's main task is to enhance the conditions that enable people to take charge of their destinies. The Government's rural development strategy has thus two major components: improving access to essential factors of development, and a comprehensive, poverty-focused planning process at the district level to ensure that all initiatives are mutually self-supporting and complementary.

Improving access essentially means improving people's access to:

> Production inputs and sustainable natural resource management technologies ('supplyside').

> National and regional markets through physical (roads and trade facilitation) and institutional linkages ('demand-side').

$>$ Human resource and community institutional development.

$>$ Social services development.

$>$ Rural finance mobilisation.

There are close interrelationships among these five factors or pillars. Human resource and community institutional development, social service development and the mobilisation of rural finance are preconditions, or catalysts, for successful initiatives on the supply and demand side. Furthermore, food insecurity must be addressed as a first priority, especially for the 47 poorest districts. Without food security for themselves, households have neither the time nor the inclination to engage in activities leading to longer-term improvement of their livelihoods. This concern will be addressed through the comprehensive district development planning system, which, together with improved accessibility, is at the core of the Government's rural development strategy.

This strategy favours a pro-active focal development area approach, so as to concentrate resources in strengthening and empowering local communities to eradicate their poverty. The five essential pillars of rural poverty eradication and the linkages among them were illustrated in Part I (page 9), as a way of summarising the rural poverty eradication strategy. The demand (markets) and supply (technology, inputs) pillars act as push/pull forces on rural production, while the three other pillars - social services (education, health), empowerment (HRD and participation), and rural finance (credit, investment) - act as facilitators for the process of modernisation and diversification. These five pillars, however, must be bound together by a comprehensive community-driven planning process.

This approach ensures flexibility and adaptation to each particular local situation. Various development activities and initiatives that take place at the district or village levels will become much better integrated, enabling more effective use of limited resources and maximising benefits. This includes activities and initiatives under the village and district development funds ${ }^{113}$, private sector initiatives and projects such as the Poverty Reduction Fund (PRF). Activities and initiatives under national programmes (e.g., UXO decontamination and opium eradication) will also now be much better co-ordinated.

\footnotetext{
${ }^{113}$ The share of the investment budget specifically allocated to the 47 poorest districts will be channelled through these village and district development funds. These will enhance the access of resources enabling people to engage in income generation activities. See also Part V of the NGPES.
} 
The Government's rural development priorities are directly linked to its poverty eradication targets. By concentrating resources on focal development areas, and more particularly on the 47 specially targeted poorest districts, the Government will ensure economic growth with equity and major gains in poverty reduction.

The major constraints on poverty eradication in the poorest districts include:

- Lack of communications and access to markets.

- Inadequate social services, poor health and low educational levels.

- Linguistic barriers.

- Large families and high dependency ratios.

- Low productivity.

- Inadequate infrastructure including roads and irrigation.

- Lack of extension services and knowledge of new technologies.

- Lack of access to markets and market information.

- Absence of rural credit and veterinary services.

In the 47 districts, accessibility to the five pillars of rural development is very low and hence Government action will favour priority activities linked to each one of them. Particular emphasis will be given to the following improvements:

- Production capacity (inputs and technology, including improved rice seeds, crop diversification, animal health care, strengthening of the district extension service, and improved operations of existing irrigation systems).

- Rural infrastructure to facilitate access to markets, rural credit, etc.

- Human and village/district institutional development.

- Social services (education, health, clean water, sanitation).

The community-driven, poverty-eradication rural development strategy emphasises that:

$>$ Development should be people-centred and the principle of community self-development should be the overarching goal; projects should facilitate the implementation of village development plans.

$>$ No physical works should be implemented without prior establishment of participatory beneficiary institutions (e.g. Water-user Associations, Road Maintenance Groups, School Committees, etc.) and provision for O\&M expenditures.

$>$ Labour-based construction technology, to maximise rural employment opportunities and community sense of ownership.

$>$ Food security as a top priority, through rice intensification; irrigation should be peoplecentred and small scale.

$>$ Projects should operate within the framework of existing institutions at the district and village level.

$>$ Rural financial services should support both short-term lending for farmers and medium term lending for village-based rural enterprises.

$>$ Project planning should include both more accurate estimates of the investment costs and provision for recurrent costs.

$>$ Institutional capacity building should be incorporated in all projects. 
Following from these principles, the Government's rural development strategy banks on the following Community Self-Development Vision:

$>$ Capacity building of local institutions, with particular emphasis on empowerment.

$>$ A development process that is community-owned and community-supported. Resources will be allocated in accordance with the strategic visions embodied in the planning framework prepared at the community level.

$>$ Local plans and institutional empowerment should be preconditions to any external Government or donor-financed assistance for rural development programmes.

$>$ The use of external resources should complement, not substitute for, locally provided resources and management. ${ }^{114}$

$>$ Food self-sufficiency as a precondition for activating the rural development process.

$>$ A "national innovation system" of research and experimentation, that enables immediate dissemination of successes in rural development so as to enable all farmers to benefit from advances achieved (e.g. village-level vaccination techniques, new forage techniques, etc. $\left.{ }^{115}\right)$.

The identification of investment priorities for the poorest 47 districts will include the following steps:

$>$ Preparation of district profiles, starting with the 47 poorest districts, to identify issues, the status of various factors and a review of present interventions in order to better ensure complementary actions.

$>$ Development of participatory district plans to serve as guides for future interventions.

$>$ Development of integrated focal area development plans.

$>$ Identification of community-based initiatives for priority support.

$>$ Sequencing of interventions to ensure a co-ordinated approach.

To help realise this approach, institutional capacity building to strengthen village and district institutions is of utmost importance.

The rural development strategy will give highest priority to increasing livestock production. Research and extension services for this purpose will be strengthened, as will the prevention of livestock disease. Again, successful innovations in livestock production and disease prevention will be shared on a nation-wide basis. It will also be desirable to share experiences in identifying the social, economic and environmental factors that enable farmers to modify their traditional practices - especially regarding upland shifting cultivators.

Innovation and experimentation will have many dimensions. Promotion of SMEs and increased foreign investment will be important to success of rural development. Also, the development of small towns with strong links to rural areas will be important. To this end, a National Urban-Rural Basic Infrastructure Development Strategy is under preparation; the objective is to fulfil the Government's request of extending the benefits of urban development to the entire population.

\footnotetext{
${ }^{114}$ PMO Instruction 010 , June 2001 on poverty and poverty reduction embodies the principle of community selfdevelopment " ...the people themselves will be in charge of their own poverty alleviation, as poverty alleviation is the task of the whole population.

${ }^{115}$ CIAT research and experimentation in the Northern region.
} 
A network of well-structured urban growth centres will greatly contribute to commercialisation of the agriculture sector. It will also enable the Lao PDR to avoid costly errors and to build the country's development on a sound basis.

The district focus for rural development presents a challenge of great complexity. Most importantly, real resources will be transferred to the districts ${ }^{116}$, to give meaning to empowerment. In addition to improved rural credit services, the Government strongly endorses the establishment of funds for community development. The establishment of the Poverty Reduction Fund (PRF-Decree PM/073) in May 2002 is designed to effectively and efficiently deliver resources to poor villages. The PRF is expected to enable poor communities to assess their own needs and priorities and to determine how best to use resources to maximise social and economic development on a sustainable basis.

The Government expects to have workable community-driven district profiles for all 47 districts within the next 18 months. Broad participation will be promoted to ensure strong community ownership and local transparency and accountability. Extensive facilitation and training will be provided throughout this process, to ensure that poor villagers, including women, participate in decision-making and benefit from project inputs. Many issues, however, still await solutions, which will be identified step-by-step in close co-operation with all stakeholders.

\footnotetext{
${ }^{116}$ For FY 2003-2004, 40 billion kip will be channelled directly to the 47 districts through local funds. See Part V.
} 


\section{Part V: Mobilising and Allocating Resources - Reconciling Development Priorities with the Budgetary Resource Envelope}

The Government will strive to mobilise and allocate available resources according to the most urgent priorities. A medium-term expenditure framework (MTEF) will guide this process, providing a realistic assessment of the Government's financial resources and constraints.

To enhance transparency and accountability, the Government now publishes detailed information (in both Lao and English) about the Budget. In 2002, the Budget Implementation Report for FY 2000-2001 and the Budget Plan for FY 2001-2002 were published in the Official Gazette of March 25, 2002. The Budget Plan is a consolidated budget for all levels of government, and indicates allocations by ministries, provinces and sectors. The Budget Implementation Report for FY 2001-2002 and the Budget Plan for FY 2002-2003 were published in the Official Gazette of April 25, 2003.

The NGPES stresses the role of all economic sectors, including the private sector as a main engine for growth, and insists on the enhancement of a favourable business environment as one of the pillars of macro-economic stability and growth. The Government expects that the private sector, including foreign direct investment, will be an essential partner in helping to finance investments critical to sustaining growth, such as hydropower and telecommunications projects. In turn, this growth will greatly strengthen the Government's revenue base. While the Government hopes to eventually become self-reliant, continued support by the Lao PDR's partners in development will be critical both to keep the momentum of growth and development for conserving the environment, and for improving the overall quality of life of the Lao multiethnic population.

The main elements of the MTEF for 2003/4-2005/6 and the planned resource allocation for the same period are presented in Chapter 5.1 and 5.2 respectively. Measures for strengthening the effectiveness and accountability of the public investment programme (PIP) are addressed in Chapter 5.3.

FY 2003-2004 will necessarily be a year of transition and preparation for the implementation of the NGPES up to 2020. Decisions by the Government regarding the legal and regulatory framework, capacity building, and strengthening the environment for growth of the private sector, will be critical. These will require time to become effective. Sector-wide planning to define medium-term investment priorities and their costing, as well as the operationalisation of various sector action plans, will also be initiated during FY 2003-2004. For this reason, the Government considers the coming fiscal year as a year of testing approaches and preparing for the future.

\section{Chapter 1: The Medium-Term Expenditure Framework}

The baseline scenario for the period 2001-2005 was elaborated in the framework of the Poverty Reduction and Growth Facility (PRGF) and forecasted annual economic growth rates of $6.5-7.5$ per cent, a one-digit inflation target, a gradual increase of the revenue/GDP ratio up to 15 per cent by 2005 , as well as a consequent allocation of funds towards the public investment programme. This scenario reflected a sound and justified faith in the potential of the national economy and the Government's policies and strategies to stimulate equitable economic growth and eradicate poverty. 
However, events have led to a re-estimation of the resource gap. The original revenue targets for 2002-2003 to 2005-2006 was optimistic. Tax policy changes introduced in 2002-2003 were designed to enhance production, boost demand and lead to growth in the revenue base. ${ }^{117}$ These policy measures were taken with a clear view of their positive and lasting impacts that will take place once businesses have adjusted to the new and stimulating environment. This requires time and the impacts of these measures have yet to materialise in relation to increased demand and production. It is now apparent that more time will be needed to gain the expected revenue growth. Also, there have been external developments that have very negatively impacted on the Government's revenue position. These included the outbreak of SARS, which sharply reduced the number of tourists visits to the Lao PDR. Regional and global economic recovery has been slower than expected, in part because of the effects of international terrorism and war.

Faced with these circumstances, the Government reassessed the medium-term expenditure framework, taking into account a lower rate of economic growth and the negative impact on revenues. Revenue projections have had to be considerably modified. This jeopardised a number of NGPES targets, such as an increasing revenue/GDP ratio and a declining fiscal deficit/GDP ratio. At the same time, inflation rose to double-digit levels, reflecting higher food prices stemming in part from severe floods in 2002.

In view of the developing fiscal problems, the Government took a series of counter-measures. Revenue measures included i) the enforcement of import duties and excise and turnover taxes on imported petroleum products, ii) the introduction of a new, inflation-based excise tax on luxury goods (e.g., mobile phones), and iii) the enforcement of fees and the collection of other service charges, including stamp duty. For FY 2002-2003, these measures are expected to increase revenues by approximately 53 billion kip. In turn, public expenditures were reduced - by approximately 30 billion kip for FY 2002-2003 - largely by postponing some projects not yet initiated. In addition, an increase of 30 per cent in the basic wages of public servants, planned for FY 2002-2003, was reduced to 15 per cent, resulting in a further reduction in expenditure by 50 billion kip. Savings of 22 billion kip in external debt service charges resulted from India's cancellation of the Lao PDR's debts to it and changes in the SDR/US \$ exchange rate.

These revenue and expenditure measures demonstrate the Government's commitment to sound macroeconomic management. They will exert their full fiscal impact in FY 2003-2004 and beyond. The Government is closely monitoring increases in the money supply to maintain price and exchange rate stability.

Based on the policy measures already undertaken and the adjustment to lower expectations for growth, the Government has adopted a revised MTEF which will be the reference for FY 2003-2004 to FY 2005-2006. This scenario is presented in Tables 27.1 to 27.3.

The revised Medium-Term Expenditure Framework is based on an estimated economic growth rate of 5.9 per cent for FY 2002-2003. Growth rates are estimated at 6.2 per cent for FY 2003-2004, 6.5 per cent for FY 2004-2005 and 7.0 per cent for FY 2005-2006. These estimates are in line with recent historical patterns. Inflation is targeted to be at single digit levels throughout this period.

The strengthened growth rates projected for FY 2003-2004 to FY 2005-2006 are justified by the expected continuous expansion of the private sector, including foreign investment, and the expected recovery of the regional economy now that the SARS threat appears to have retreated and the global economy is more stable.

\footnotetext{
${ }^{117}$ The policy changes included i) lowering the turnover tax from 5 per cent to 3 per cent for domestic products, ii) shifting from the lump sum collection of customs and excise duties to percentage rates for petroleum products and iii) a more liberal use of business tax exemptions to stimulate economic growth.
} 


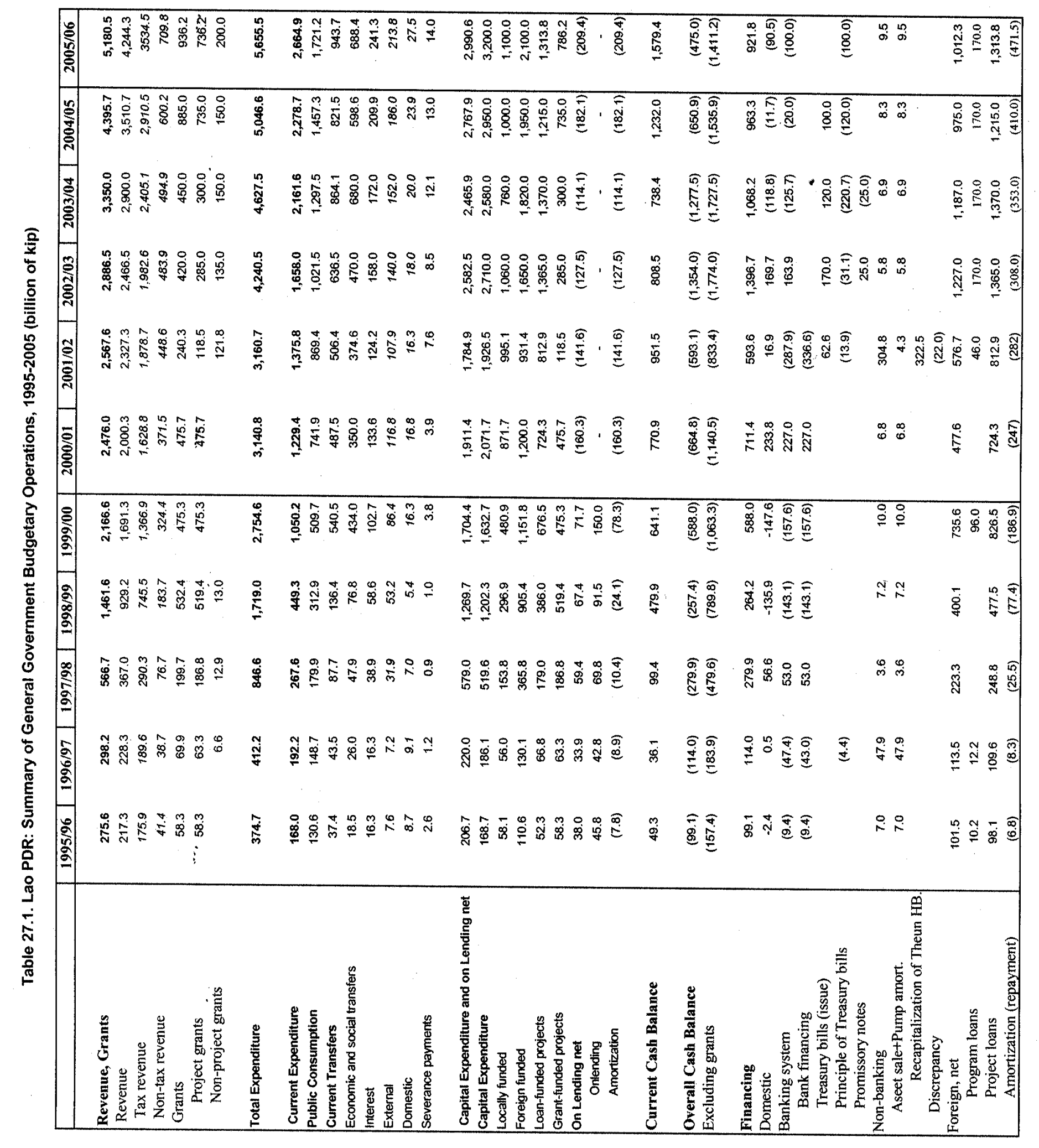


Table 27.2. Lao PDR: Government Revenues, 1995-2005 (billion of kip)

\begin{tabular}{|c|c|c|c|c|c|c|c|c|c|c|c|}
\hline & $1995 / 96$ & $1996 / 97$ & $1997 / 98$ & $1998 / 99$ & $1999 / 00$ & $2000 / 01$ & $2001 / 02$ & $2002 / 03$ & $2003 / 04$ & $2004 / 05$ & $2005 / 06$ \\
\hline Total Revenue, grants & 275.6 & 298.2 & 566.7 & $1,461,6$ & $2,166.6$ & $2,476.0$ & $2,567.5$ & $2,886.5$ & $3,350,0$ & $4,395.7$ & $5,180.5$ \\
\hline Total Revenue & 217,3 & 228.3 & 367.0 & 929.2 & $1,691,3$ & $2,000.3$ & $2,327.2$ & $2,466.5$ & $2,900.0$ & $3,510.7$ & $4,244.3$ \\
\hline Tax Revenue & 175.9 & 189.6 & 290.3 & 745.5 & $1,366.9$ & $1,628.8$ & $1,878.7$ & $1,982.6$ & $2,405.1$ & $2,910.5$ & $3,534.5$ \\
\hline Profit tax & 20.7 & 23.4 & 33.4 & 80.4 & 186.5 & 205.2 & 242.7 & 282.5 & 371.4 & 527.7 & 667.1 \\
\hline Income tax & 13.5 & 11.5 & 19.5 & 69.6 & 117.1 & 145.4 & 125.5 & 168.4 & 220.2 & 254.1 & 288 \\
\hline Agricultural/land tax & 2.1 & 2.5 & 3.0 & 4.8 & 7.4 & 16.7 & 19.3 & 30.0 & 35.1 & 35.3 & 43.5 \\
\hline Business licenses & 0.2 & 0.2 & 0.3 & 0.3 & 1.3 & 0.4 & 0.8 & 1.2 & 1.5 & 1.8 & 5.3 \\
\hline Minimum tax & & & & & & 7.4 & 9.9 & 29.7 & 37.1 & 44.6 & 30.5 \\
\hline Turnover tax & 33.9 & 40.0 & 62.8 & 159.8 & 290.0 & 318.0 & 374.7 & 380.9 & 453.3 & 473.5 & 549.3 \\
\hline Excise tax & 15.5 & 17.9 & 50.2 & 157.3 & 226.2 & 371.3 & 285.9 & 375.9 & 488.7 & 563.9 & 756 \\
\hline Import duties & 40.6 & 47.0 & 51.4 & 98.5 & 134.6 & 178.9 & 240.3 & 280.3 & 350.4 & 455.3 & 546.4 \\
\hline Export duties & 6.0 & 6.3 & 10.4 & 24.4 & 41.2 & 56.7 & 50.6 & 61.9 & 77.4 & 92.9 & 111.4 \\
\hline Registration & 1.5 & 1.8 & 2.1 & 4.9 & 7.2 & 11,1 & 12.4 & 15.0 & 18.8 & 22.5 & 27.0 \\
\hline Other fees & 6.6 & 6.2 & 13.9 & 33.3 & 46.6 & 61.4 & 91.6 & 126.1 & - 128.4 & 134.6 & 162.6 \\
\hline Natural resource tax & 0.7 & 1.1 & 2.0 & 5.3 & 14.1 & 23.6 & 16.9 & 15.4 & 20.0 & 23.1 & 27.6 \\
\hline Timber royalties & 34.6 & 31.7 & 36.8 & 89.5 & 272.5 & 181.5 & 361.8 & 160.0 & 135.0 & 200.0 & 222.2 \\
\hline Hydropower royalties & & & 4.5 & 17.4 & 22.2 & 51.2 & 46.3 & 54.3 & 67.9 & 81.5 & 97.7 \\
\hline Nontax Revenue & 41.4 & 38.7 & 76.7 & 183.7 & 324.4 & 371.5 & 448.5 & 483.9 & 494.9 & 600.2 & 709.8 \\
\hline Leasing & 3.8 & 4.9 & 9.6 & 11.4 & 15.2 & 38.9 & 22.0 & 59.9 & 71.9 & 86.3 & 69.1 \\
\hline Concession & 0.4 & 0.2 & 0.5 & 1.0 & 1.7 & 1.4 & 1.6 & 1.9 & 2.6 & 2.7 & 3.2 \\
\hline Fines & 5.1 & 4.2 & 6.9 & 8.8 & 14.4 & 26.9 & 12.7 & 17.9 & 21.9 & 25.8 & 45.6 \\
\hline Administrative fees & 1.6 & 1.7 & 3.6 & 11.3 & 17.2 & 26.4 & 84.6 & 35.4 & 41.8 & 50.2 & 50.3 \\
\hline Depreciation/dividends & 5.2 & 9.4 & 7.7 & 22.0 & 41.7 & 67.2 & 84.2 & 155.5 & 124.8 & 142.6 & 162.9 \\
\hline Interest & 15.5 & 8.3 & 15.4 & 88.9 & 79.1 & 76.3 & 56.2 & 53.3 & 56.0 & 62.4 & 92.2 \\
\hline Overflight & 9.8 & 10.0 & 33.0 & 40.3 & 122.5 & 114.4 & 187.2 & 160.0 & 176.0 & 230.4 & 276.5 \\
\hline Irrigation fees, others & & & & & 32.6 & 20.0 & & & & $\cdot$ & \\
\hline Grants & 58.3 & 69.9 & 199.7 & 532.4 & 475.3 & 475.7 & 240.3 & 420.0 & 450.0 & 885.0 & 936.2 \\
\hline \multicolumn{12}{|c|}{ (in percent of GDP) } \\
\hline Total Revenue, grants & 16.7 & 14.3 & 15.2 & 16.5 & 16.9 & 16.0 & 14.8 & 13.3 & 13.7 & 15.8 & 16.4 \\
\hline Total Revenue & 13.1 & 10.9 & 9.8 & 10.5 & 13.2 & 12.9 & 13.4 & 11.3 & 11.9 & -12.6 & $\uparrow 3.4$ \\
\hline Tax Revenue & 10.6 & 9.1 & 7.8 & 8.4 & 10.6 & 10.5 & 10.8 & 9.1 & 9.8 & 10.5 & 11.2 \\
\hline Profit tax & 1.3 & 1.1 & 0.9 & 0.9 & 1.5 & 1.3 & 1.4 & 1.3 & 1.5 & 1.9 & 2.1 \\
\hline Income tax & 0.8 & 0.6 & 0.5 & 0.8 & 0.9 & 0.9 & 0.7 & 0.8 & 0.9 & 0.9 & 0.9 \\
\hline Agricultural/land tax & 0.1 & 0.1 & 0.1 & 0.1 & 0.1 & 0.1 & 0.1 & 0.1 & 0.1 & 0.1 & 0.1 \\
\hline Business licenses & 0.0 & 0.0 & 0.0 & 0.0 & 0.0 & 0.0 & 0.0 & 0.0 & 0.0 & 0.0 & 0.0 \\
\hline Turnover tax & 2.0 & 1.9 & 1.7 & 1.8 & 2.3 & 2.1 & 2.2 & 1.8 & 1.9 & 1.7 & 1.7 \\
\hline Excise tax & 0.9 & 0.9 & 1.3 & 1.8 & 1.8 & 2.4 & 1.6 & 1.7 & 2.0 & 2.0 & 2.4 \\
\hline Import duties & 2.5 & 2.3 & 1.4 & 1.1 & 1.0 & 1.2 & 1.4 & 1.3 & 1.4 & 1.6 & 1.7 \\
\hline Export duties & 0.4 & 0.3 & 0.3 & 0.3 & 0.3 & 0.4 & 0.3 & 0.3 & 0.3 & 0.3 & 0.4 \\
\hline Registration & 0.1 & 0.1 & 0.1 & 0.1 & 0.1 & 0.1 & 0.1 & 0.1 & 0.1 & 0.1 & 0.1 \\
\hline Other fees & 0.4 & 0.3 & 0.4 & 0.4 & 0.4 & 0.4 & 0.5 & 0.6 & 0.5 & 0.5 & 0.5 \\
\hline Natural resource tax & 0.0 & 0.1 & 0.1 & 0.1 & 0.1 & 0.2 & 0.1 & 0.1 & 0.1 & 0.1 & 0.1 \\
\hline Timber royalties & 2.1 & 1.5 & 1.0 & 1.0 & 2.1 & 1.2 & 2.1 & 0.7 & 0.6 & 0.7 & 0.7 \\
\hline Hydropower royalties & $*$ & $\cdot$ & 0.1 & 0.2 & 0.2 & 0.3 & 0.3 & 0.2 & 0.3 & 0.3 & 0.3 \\
\hline Nontax Revenue & 2.5 & 1.9 & 2.1 & 2.1 & 2.5 & 2.4 & 2.6 & 2.2 & 2.0 & 2.2 & 2.2 \\
\hline Leasing & 0.2 & 0.2 & 0.3 & 0.1 & 0.1 & 0.3 & 0.1 & 0.3 & 0.3 & 0.3 & 0.2 \\
\hline Concession & 0.0 & 0.0 & 0.0 & 0.0 & 0.0 & 0.0 & 0.0 & 0.0 & 0.0 & 0.0 & 0.0 \\
\hline Fines & 0.3 & 0.2 & 0.2 & 0.1 & 0.1 & 0.2 & 0.1 & 0.1 & 0.1 & 0.1 & 0.1 \\
\hline Administrative fees & 0.1 & 0.1 & 0.1 & 0.1 & 0.1 & 0.2 & 0.5 & 0.2 & 0.2 & 0.2 & 0.2 \\
\hline Depreciation/divịends & 0.3 & 0.5 & 0.2 & 0.2 & 0.3 & 0.4 & 0.5 & 0.7 & 0.5 & 0.5 & 0.5 \\
\hline Interest & 0.9 & 0.4 & 0.4 & 1.0 & 0.6 & 0.5 & 0.3 & 0.2 & 0.2 & 0.2 & 0.3 \\
\hline Overflight & 0.6 & 0.5 & 0.9 & 0.5 & 1.0 & 0.7 & 1.1 & 0.7 & 0.7 & 0.8 & 0.9 \\
\hline \multicolumn{12}{|l|}{ Memorandum Item: } \\
\hline GDP at current prices & $1,654.5$ & $2,086.0$ & $3,730.3$ & $8,839.0$ & $12,835.0$ & $15,470,0$ & $17,385,0$ & 21.758 .9 & 24.426 .0 & $27,766,9$ & $31,654.3$ \\
\hline Amortization & 7.0 & 8.2 & 25.5 & 24.1 & 81.7 & 160.3 & 141.6 & 127.5 & 114.1 & 182.1 & 209.4 \\
\hline Asset sale & 6.8 & 47.9 & 3.6 & 7.1 & 9.3 & 6.8 & 4.1 & 5.1 & 6.1 & 7.3 & 8.4 \\
\hline Pump amortization & & & & & & & 0.2 & 0.7 & 0.8 & 1.0 & 1.1 \\
\hline
\end{tabular}




\begin{tabular}{|c|c|c|c|c|c|c|c|c|c|c|c|}
\hline & $1995 / 96$ & 1996/97 & $1997 / 98$ & 1998/98 & 1999/00 & $2000 / 01$ & 2001102 & $2002 / 03$ & 2003104 & $2004 / 08$ & $2005 / 06$ \\
\hline Total Expenditure & 374.7 & 412.2 & 846.6 & $1,719.0$ & 2.754 .6 & 3.140 .8 & $3,160.7$ & $4,240.5$ & 4.627 .5 & 5.046 .6 & 5.655 .5 \\
\hline Current Expenditure & 168.0 & 192.2 & 267.6 & 449.3 & 1.050 .2 & 1.229 .4 & $1,375.6$ & $1,658.0$ & $2,161.6$ & $2,278.7$ & $2,664.9$ \\
\hline Public Consumption & 130.6 & 148.7 & 179.8 & 312.9 & 509.7 & 741.9 & 869.4 & $1,021.5$ & $1,297.5$ & $1,457.3$ & $1,721.2$ \\
\hline Wages and salaries & 83.0 & 91.8 & 117.0 & 180.7 & 335.4 & 411.8 & 547.2 & 651.5 & 872.0 & 965.8 & $1,156.0$ \\
\hline Materials and supplies & 47.6 & 56.9 & 62.8 & 132.2 & 174.3 & 330.1 & 322.2 & 370.0 & 425.5 & 491.5 & 565.2 \\
\hline \multicolumn{12}{|l|}{ Other current ekpenditure } \\
\hline Current Transfers & 37.4 & 43.5 & 87.7 & 136.4 & 540.5 & 487.5 & 506.4 & 636.5 & 864.1 & 821.5 & 943.7 \\
\hline Economic and social transfers & 18.5 & 25.0 & 47.9 & 76.8 & 434.0 & 350.0 & 374.6 & 470.0 & 680.0 & 598.6 & 688.4 \\
\hline Interest & 16.3 & 16.3 & 38.9 & 58.6 & 102.7 & 133.6 & 124.2 & 158.0 & 172.0 & 209.9 & 241.3 \\
\hline External & 7.6 & 7.2 & 31.9 & 53.2 & 86.4 & +16.8 & 107.9 & 140.0 & 152.0 & 186.0 & 213.8 \\
\hline Domestic & 8.7 & 9.1 & 7.0 & 5.4 & 16.3 & 16.8 & 16.3 & 18.0 & 20.0 & 23.9 & 27.5 \\
\hline Severance payments & 2.6 & 1.2 & 0.9 & 1.0 & 3.8 & 3.9 & 7.6 & 8.5 & 12.1 & 13.0 & 14.0 \\
\hline Capital Expendlture and on Lending net & 206.7 & 220.0 & 579.0 & $1,269.7$ & $1,704.4$ & 1.911 .4 & $1,784.9$ & $2,582.5$ & $2,465.9$ & $2,767.9$ & $2,990.6$ \\
\hline Capltal Expenditure & 168.7 & 186.1 & 519.6 & $1,202.3$ & 1.632 .7 & $2,071.7$ & $1,926.5$ & $2,710.0$ & $2,580.0$ & 2.950 .0 & $3,200.0$ \\
\hline Locally funded & 58.1 & 56.0 & 153.8 & 296.9 & 480.9 & 871.7 & 995.1 & 1.060 .0 & 760.0 & 1.000 .0 & $1,100.0$ \\
\hline Foreign funded & 110.6 & 130.1 & 365.8 & 905.4 & $1,151,8$ & $1,200.0$ & 931.4 & $1,650.0$ & $1,820.0$ & $1,950.0$ & $2,100,0$ \\
\hline Loan-funded projects & 52.3 & 66.8 & 179.0 & 386.0 & 676.5 & 724.3 & 812.9 & $1,365.0$ & $1,370.0$ & $1,215.0$ & $1,313.8$ \\
\hline Grant-funded projects & 58.3 & 63.3 & 186.8 & 519.4 & 475.3 & 475.7 & 118.5 & 285.0 & 300.0 & 735.0 & 786.2 \\
\hline On Lending net & 38.0 & 33.9 & 59.4 & 67.4 & 71.7 & $(160.3)$ & $(141.6)$ & $(127.5)$ & $(114.1)$ & (182.1) & $(209.4)$ \\
\hline Onlending & 45.8 & 42.8 & 69.8 & 91.5 & 150.0 & & & & & & \\
\hline \multicolumn{12}{|c|}{ (in percent of GDP) } \\
\hline Total Expenditure & 22.6 & 19.8 & 22.7 & 19.4 & 21.5 & 20.3 & 18.2 & 19.5 & 18.9 & 18.2 & 17.9 \\
\hline Current Expenditure & 10.2 & 9.2 & 7.2 & 5.1 & 8.2 & 7.9 & 7.9 & 7.6 & 8.8 & 8.2 & 8.4 \\
\hline Public Consumption & 7.9 & 7.1 & 4.8 & 3.5 & 4.0 & 4.8 & 5.0 & 4.7 & 5.3 & 5.2 & 5.4 \\
\hline Wages and salaries & 5.0 & 4.4 & 3.1 & 2.0 & 2.6 & 2.7 & 3.1 & 3.0 & 3.6 & 3.5 & 3.7 \\
\hline Materials and supplies & 2.9 & 2.7 & 1.7 & 1.5 & 1.4 & 2.1 & 1.9 & 1.7 & 1.7 & 1.8 & 1.8 \\
\hline Other current expenditure & - & . & $\cdot$ & $\cdot$ & $\cdot$ & $\cdot$ & $\cdot$ & $\cdot$ & - & - & $\cdot$ \\
\hline Current Transfers & 2.3 & 2.1 & 2.4 & 1.5 & 4.2 & 3.2 & 2.9 & 2.9 & 3.5 & 3.0 & 3.0 \\
\hline Economic and social transfers & 1.1 & 1.2 & 1.3 & 0.9 & 3.4 & 2.3 & 2.2 & 2.2 & 2.8 & 2.2 & 2.2 \\
\hline Interest & 1.0 & 0.8 & 1.0 & 0.7 & 0.8 & 0.9 & 0.7 & 0.7 & 0.7 & 0.8 & 0.8 \\
\hline Externa! & 0.5 & 0.3 & 0.9 & 0.6 & 0.7 & 0.8 & 0.6 & 0.6 & 0.6 & 0.7 & 0.7 \\
\hline Domestic & 0.5 & 0.4 & 0.2 & 0.1 & 0.1 & 0.1 & 0.1 & 0.1 & 0.1 & 0.1 & 0.1 \\
\hline Severance payments & 0.2 & 0.1 & 0.0 & 0.0 & 0.0 & 0.0 & 0.0 & 0.0 & 0.0 & 0.0 & 0.0 \\
\hline Capital Expenditure and on Lending & 2.5 & 10.5 & 15.5 & 14.4 & 13.3 & 12.4 & 10.3 & 11.9 & 10.1 & 10.0 & 9.4 \\
\hline Capital Expenditure & 10.2 & 8.9 & 13.9 & 13.6 & 12.7 & 13.4 & 11.1 & 12.5 & 10.6 & 10.6 & 10.1 \\
\hline Locally funded & 3.5 & 2.7 & 4.1 & 3.4 & 3.7 & 5.6 & 5.7 & 4.9 & 3.1 & 3.6 & 3.5 \\
\hline Foreign funded & 6.7 & 6.2 & 9.8 & 10.2 & 9.0 & 7.8 & 5.4 & 7.6 & 7.5 & 7.0 & 6.6 \\
\hline Loan-funded projects & 3.2 & 3.2 & 4.8 & 4.4 & 5.3 & 4.7 & 4.7 & 6.3 & 5.6 & 4.4 & 4.2 \\
\hline Grant-funded projects & 3.5 & 3.0 & 5.0 & 5.9 & 3.7 & 3.1 & 0.7 & 1.3 & 1.2 & 2.6 & 2.5 \\
\hline On Lending & 2.3 & 1.6 & 1.6 & 0.8 & 0.6 & $(1.0)$ & $(0.8)$ & $(0.6)$ & $(0.5)$ & $(0.7)$ & (0.7) \\
\hline \multicolumn{12}{|l|}{ Memorandum Item: } \\
\hline GDP at current prices (billions of kip) & $1,654.5$ & 2.086 .0 & $3,730.3$ & $8,839.0$ & $12,835.0$ & 15.470 .0 & $17,385.0$ & $21,758.8$ & 24.426 .0 & $27,766.9$ & 31.654 .3 \\
\hline Real GDP (billions of kip; 1990) & 878.9 & 939.7 & 982.2 & $1,047.7$ & $1,112.1$ & $1,176.3$ & $1,245.7$ & $1,317.9$ & $1,397.0$ & $2,058.2$ & $2,346.3$ \\
\hline Real Growth rate (percent) & 6.9 & 6.9 & 4.5 & 6.7 & 6.2 & 5.8 & 5.9 & 5.8 & 6 & 6.5 & 7.0 \\
\hline CPI (percent; period average) & 18.8 & 14.4 & 64.1 & 140.2 & 40.6 & 8.4 & 8.9 & 8.0 & 9.0 & 7.0 & 7.0 \\
\hline CPI (percent; end of period) & & & 106.3 & 122.6 & 9.7 & 6.2 & 14.6 & 15.0 & 9.0 & 7.0 & 7.0 \\
\hline Average exchange rate $(\mathrm{kip} / \$)$ & 924 & 1,044 & 2,693 & 6,220 & 7,718 & 8,540 & 9,744 & 10,000 & 10,500 & 11,500 & $12,000.0$ \\
\hline
\end{tabular}


Lao PDR - National Growth and Poverty Eradication Strategy (NGPES)

At the same time, many of the public investments, as well as the macro-economic policies and reforms undertaken by the Government, will come to fruition. Even more importantly, the strict measures adopted by the Government regarding revenue collection will have a lasting impact on growth; more revenue will support additional public investments critical to trade and private enterprise in general. For these reasons, the Government's growth projection for the economy -7 per cent annually after 2005 - is considered realistic and achievable.

With regards to revenues, the policy and administrative measures now in place are forecast to result in revenue growth of 20 per cent for FY 2003-2004 and for following years. Consequently, revenue as a share of GDP is expected to rise to 13.4 per cent by FY 2005-2006. The Government has adopted a cautious approach concerning revenue projections and it is hoped that a larger share will actually materialise. However, the cautious approach reinforces the Government's emphasis on macro-economic stability.

The lower share of revenues as a percentage of GDP, when compared to the earlier scenario, entails a corresponding reduction of expenditures as a percentage of GDP so as to hold the fiscal deficit in check. Expenditures for FY 2003-2004 will increase by 6 per cent to 4,627.5 billion kip, amounting to 18.9 per cent of GDP; expenditures for FY 2002-2003 are forecast at 19.5 per cent of GDP. Despite fiscal restraint in FY 2003-2004, the Government has made provision for higher public service salaries and the resolution of debt arrears. Consequently, the amount that can be allocated to domestically-funded public investment will drop to 760 billion kip for FY 2003-2004 (from 960 billion kip in FY 2002-2003) before rising again in FY 2004-2005 and beyond. Foreign-funded PIP expenditures are expected to increase throughout the period, with a sharp increase in grants offsetting a decline in loans. Overall public investment is projected to stabilise at about 10 per cent of GDP by 2005-2006, with the domestically-funded share at 3.7 per cent of GDP and the foreign-funded share at 6.6 per cent.

To sustain economic growth, total investment (public and private) will have to increase to some 26-28 per cent of GDP. To achieve this target, the Government will continue to give strong support to the private sector. The Government will also ensure that the quality of investment is high. Clearly, there is a close interdependency between public and private investment.

To ensure strong public investment, the weak revenue situation will be redressed. Among the causes of this revenue situation is the lack of capacity at all levels of government - especially at the local level - respecting administration of the tax system. Insufficient preparation regarding fiscal decentralisation and lack of clarity with regard to the responsibilities of each level of government for tax collection have contributed to a poor revenue performance. These difficulties have been compounded by a less than strict monitoring of revenue and expenditure management at the provincial level. Strong efforts are presently being taken to remedy these weaknesses. In particular, the very liberal application of tax and customs exemptions to encourage private sector investment is under revision. More generally, there is insufficient mastering of budget preparation and management. Most of these issues are being addressed through the Financial Management Adjustment Credit, a programme supported by the World Bank.

The Government is redoubling its efforts to strengthen capacity at all levels by encouraging the transfer of knowledge, the improvement of skills, the expanded use of appropriate management technology, and better clarification of institutional responsibilities. In particular, the Government is implementing measures to improve the institutional framework for fiscal management - including new budget nomenclature that will facilitate tracking of recurrent expenditures. Improved fiscal management will help ensure the achievement of the Government's development and poverty reduction goals. 


\section{Further Revenue Considerations}

Implementation of the NGPES requires substantial mobilisation of budgetary resources. In the long term, the national revenue base will be broadened and deepened through continuous improvement of revenue collection, modernisation of the tax system and growth of the revenue base. Part III, Chapter 5 provides a detailed account of the expected growth in revenue in the medium and longer term. The main points will now be briefly summarised.

A VAT system is an important part of the tax administration reforms. This issue has been studied for some time. In preparation for the introduction of a VAT, the number of enterprises has been established; a draft law is being finalised and data concerning the likely impact are being refined. It is essential that for the successful introduction of a VAT that the necessary conditions be in place. Only once this is achieved, will the VAT greatly enhance the efficiency of tax administration.

The Government is taking steps to strengthen revenue collection mechanisms through the adoption of standardised registration, accounting and auditing systems. At the same time, the effectiveness of the Large Taxpayers' Unit is being improved, including by training programmes to enhance capacities at the central and provincial levels. The strict observance of the Budget Law, the Tax Law and the Customs Law is the basis for improved budget management.

The Government gives particular attention to additional revenues that will flow from successful investments, especially in the mining and hydropower sectors. These revenues will importantly contribute to lifting budgetary revenue to higher, more sustainable levels. Annex 4, Table 4.1 provides a conservative assessment of expected revenues over the long term. Expected revenues from the gold and copper mining industry will contribute more than 14 per cent of tax revenues from FY 2006-2007 onwards. Together with the expected revenues from the Nam Theun 2 hydropower project, these two revenue sources will represent about one quarter of total revenues from FY 2009-2010 onwards. Yet additional revenues will accrue from royalties and the profits tax.

The impact of these elements cannot be easily quantified. They are, however, a precondition for stabilising and ultimately raising the level of revenues as a share of GDP. The need for new tax sources and improved tax collection is heightened by the expected loss in customs revenues as a consequence of implementation in 2008 of the Common Effective Preferential Tariff (CEPT), under the ASEAN Free Trade Area (AFTA).

In combination, an improved tax effort and larger revenue base will enable the Government to both strengthen public services while progressively reducing the country's dependency on official development assistance (ODA). 


\section{Chapter 2 : Resource Allocation and Investment Requirements}

As indicated earlier, prudent fiscal management requires that public expenditures remain within the country's financial capabilities. A strict expenditure management plan is needed, incorporating priorities under the NGPES.

"Costing of the NGPES", that is, estimation of the implied costs of achieving the NGPES goals up to 2020, is a task that goes beyond the Government's capacity at this juncture. The task is complicated by the fact that the NGPES is intended to be a dynamic programme, adapting to new circumstances and opportunities as they arise. The Government has favoured an intermediate, medium-term approach to budget reconciliation while simultaneously preparing for an in-depth, longer-term approach. This will be done in the context of an annually adjusted medium-term expenditure framework and a 3-year "rolling" PIP.

Public investments under the NGPES have a dual purpose: to enhance the conditions for sustainable growth and development and to eradicate poverty. One objective cannot be achieved at the expense of the other. Focus on the 72 poor districts (and in the first phase, the 47 poorest among them) stems from the national poverty assessment. The poverty assessment (Part II) clearly showed that half of the country's districts were at risk of being "left behind" or "delinked" from the rest of the economy. Further, disparities are increasing between these 72 mostly mountainous districts and the other 72 districts in the Lao PDR. In response, the Government is reformulating the PIP by progressively allocating a greater share of expected new budgetary revenues to the poor districts, to ensure that they become more and more integrated into the national economy, while maintaining the necessary investment for growth nation-wide. Improved access to these districts, as a result of investments in integrating the country, makes this new focus possible.

In recent years and for most of the past decade some 65 per cent of the public investment programme has been allocated to "growth and development" investments, contributing to the building up of the country. These investments include the major part of transport and communication, irrigation and other investments linked to infrastructure. The balance of public investment, approximately 35 per cent, can be considered as "social development" investments, including for health, education, rural development, and social welfare. These investments relate directly and indirectly to poverty reduction.

Taking as reference the spatial distribution of ODA disbursements, ${ }^{118}$ it appears that approximately one third of 'growth investments' and one fifth of 'social development investments' under the PIP benefit the 72 poor districts. Thus their share of total public investment over the years has been approximately 30 per cent. In turn, if one third of this share has accrued to the 47 poorest districts, their share of total public investment would be approximately 10 per cent. The relatively low share of the PIP for the 47 poorest districts reflects the fact that access to these mostly remote districts is difficult; a large share of the PIP for transport infrastructure will continue to be necessary to improve access to these districts.

\footnotetext{
${ }^{118}$ See Foreign Aid Reports 1999-2000, 2000-2001 and 2001-2002. ODA accounts for approximately 75-80 per cent of public investment.
} 
In the absence of a more refined means for estimating public investment shares for the poor and poorest districts, the assumptions presented above are realistic. The Government is presently developing methods to facilitate tracking investments in poor districts. Also, improved data collection and analysis based on the new budget nomenclature, together with strengthened expenditure management, will enable the Government to better monitor public investments in poor districts.

Table 28 indicates the actual and planned PIP allocations by sector in absolute and relative terms for FY 2001-2002 to FY 2005-2006. Consistent with the consolidated budget for all levels of Government, the PIP includes public investments at the provincial and district/local levels.

Public investment in the economic sectors will continue to be very important. Economic sectors accounted for 50.9 per cent of PIP outlays in FY 2001-2002, and are projected to account for a high of 59.7 per cent in FY 2003-2004; this will decline to 56 per cent by FY 2005-2006. As rural development is now under the responsibility of MAF, agriculture/forestry's share in the PIP is shown as steadily rising. The transport sector remains at the same high level in absolute value because of its importance for economic growth nation-wide, but its relative share will slightly decline.

PIP allocations for the social sectors are steadily growing, from 27.4 per cent in FY 20012002 to 33.6 per cent in FY 2005-2006. Health and education will represent more than 75 per cent of social investment in 2005-2006, compared to only 66 per cent in FY 2001-2002.

As indicated above, the PIP also contains allocations for the provinces. Table 4.2, Annex 4 shows how allocations in the PIP are divided between sectors and provinces for FY 2002-2003. Approximately two thirds of the PIP goes through the sectors (line ministries), while one third goes directly to the provinces (which in turn allocate funds to their districts). Table 4.3, Annex 4 provides detailed information concerning PIP outlays in FY 2002-2003 at the provincial level, according to domestic and foreign contributions. There is presently no detailed information available regarding district investments. This shortcoming is in the process of being redressed.

Both the Government and its partners in development are concerned that adequate provision be made for operating and maintenance expenditures. Otherwise investments in health and education facilities will be insufficiently provisioned and staffed, and capital equipment of all kinds (including roads) will not be properly maintained. Consequently, rates of return from public investment will be far below the expected levels. This has been a recurring problem. The Government's determination to resolve this problem is reflected in PM Decree 058, which stipulates that large investment projects must explicitly cite the associated recurrent costs.

With the support of the World Bank, research has been conducted to establish the approximate ratios between expected recurrent expenditures and the capital costs of various categories of public investment (roads, schools, hospitals, water systems, sanitation etc.). Further, estimates have been made for the recurrent expenditures associated with all projects listed in the 2002-2003 PIP. The estimates have been projected for 15 years, reflecting on-going operating costs and regular and periodic maintenance. Workshops have been organised to familiarise ministry and provincial staff with the concepts and methodology involved. From this process, it appears that recurrent costs are on average about 15 per cent of the capital costs of ODA-funded projects, and about 12 per cent of the capital costs of domestically-funded projects. That is, annual provision should be made - over the lifetime of the project - for recurrent expenditures averaging at $12-15$ per cent of the project costs. 
Table 28 : Actual and Planned Amounts for PIP by Sectors in absolute value, and by Percentages

( In bllllon of klp )

\begin{tabular}{|c|c|c|c|c|c|c|c|c|c|c|}
\hline \multirow[t]{2}{*}{ Sectors } & \multicolumn{2}{|c|}{$\begin{array}{c}2001 / 2002 \\
\text { ( actual) }\end{array}$} & \multicolumn{2}{|c|}{$\begin{array}{c}2002 / 2003 \\
\text { ( actual) }\end{array}$} & \multicolumn{2}{|c|}{$\begin{array}{l}2003 / 2004 \\
\text { ( planned) }\end{array}$} & \multicolumn{2}{|c|}{$\begin{array}{l}2004 / 2005 \\
\text { (planned) }\end{array}$} & \multicolumn{2}{|c|}{$\begin{array}{l}2005 / 2006 \\
\text { ( planned) }\end{array}$} \\
\hline & Value & $\%$ & Value & $\%$ & Value & $\%$ & Value & $\%$ & Value & $\%$ \\
\hline Economic Sectors & 979.82 & 50.86 & $1,549.00$ & 59.35 & $1,540.26$ & 59.70 & $1,712.48$ & 58.05 & $1,792.00$ & 56.00 \\
\hline 1. Agriculture & 309.59 & 16.07 & 461.00 & 17.66 & 464.40 & 18.00 & 560.50 & 19.00 & 640.00 & 20.00 \\
\hline 2. Industry & 78.99 & 4.10 & 95.00 & 3.64 & 129.00 & 5.00 & 162.25 & 5.50 & 192.00 & 6.00 \\
\hline 3. Transport & 584.50 & 30.34 & 985.00 & 37.74 & 921.06 & 35.70 & 960.23 & 32.55 & 896.00 & 2.00 \\
\hline $\begin{array}{l}\text { 4. Other economlc sectors } \\
\text { (servlce) }\end{array}$ & 6.74 & 0.35 & 8.00 & 0.31 & 25.80 & 1.00 & 29.50 & 1.00 & 64.00 & 2.00 \\
\hline Social Sectors & 527.67 & 27.39 & 720.00 & 27.59 & 766.26 & 29.70 & 927.78 & 31.45 & $1,076.80$ & 33.65 \\
\hline 5. Education & 216.35 & 11.23 & 299.00 & 11.46 & 309.60 & 12.00 & 383.50 & 13.00 & 448.00 & 14.00 \\
\hline 6. Publlc Health & 151.81 & 7.88 & 229.00 & 8.77 & 245.10 & 9.50 & 299.43 & 10.15 & 352.00 & 11.00 \\
\hline 7. Culture/Information & 73.78 & 3.83 & 67.00 & 2.57 & 95.46 & 3.70 & 109.15 & 3.70 & 126.40 & 3.95 \\
\hline 8. Labour/Social Welfare & 85.73 & 4.45 & 125.00 & 4.79 & 116.10 & 4.50 & 135.70 & 4.60 & 150.40 & 4.70 \\
\hline 9. Other soclal sectors & & & & & & & & & & \\
\hline Other ( service, provision ) & 419.01 & 21.75 & 341.00 & 13.07 & 273.48 & 10.60 & 309.75 & 10.50 & 331.20 & 10.35 \\
\hline TOTAL & $1,926.50$ & 100.00 & $2,610.00$ & 100.00 & $2,580.00$ & 100.00 & $2,950.00$ & 100.00 & $3,200,00$ & 100.00 \\
\hline Of whlch domestlc Funds. & & & & & & & & & & \\
\hline Poverty eradication & & & & & 100.00 & 3.60 & 120.00 & 4.00 & 144.00 & 4.43 \\
\hline Of which for 47 districts & & & & & 40.00 & 1.44 & 48.00 & 1.60 & 58.00 & 1.78 \\
\hline & & & & & \multicolumn{4}{|c|}{ Total 2003-2006: } & \multicolumn{2}{|l|}{$8,730.00$} \\
\hline PIP as $\%$ of GDP & 10.90 & & 12.20 & & 11.50 & & 10.60 & & 10.10 & \\
\hline
\end{tabular}


Findings under this process, in combination with the revised MTEF, underscore the need for a whole new approach to managing public investment. It is clear that Government resources are simply too limited to make adequate provision. The Government will continue to consult intensively with its partners in development to find a better balance of support between recurrent and capital expenditures. Ideally, support for capital expenditures should be accompanied for support for the associated recurrent expenditures; the establishment of the Road Maintenance Fund provides a possible model.

As noted earlier, the present budget nomenclature and manner of budget preparation, together with weaknesses in monitoring provincial and district expenditures, present difficulties in tracking expenditures. It is expected that most of these problems will be solved during FY 2003-2004, in accordance with the FMAC timetable.

\section{$\underline{\text { Strict PIP Guidelines }}$}

The Government, in July 2003, adopted strict guidelines for preparation and implementation of the PIP. They include:

- Implementation of Decrees 135 and 058, concerning the preparation of the National Development Plan and the public investment programme.

- Freezing of all public investments for offices and administrative buildings.

- Re-evaluation of several projects regarding their necessity and efficiency.

- Freezing of some bigger projects that have no immediate positive economic and social impact.

- Systematic freezing of any unnecessary investment at all levels.

- Requirement of a conclusive feasibility study for the approval of all new projects before they can be approved.

- Prioritisation of projects nearing completion.

- Elaboration of technical standards and unit costs for infrastructure investments.

- Improved monitoring and reporting regarding implementation of projects.

- Judicious allocation of Government counterpart funds.

- Improved debt management.

As a result of these strict guidelines and overall budget constraints, the domestic contribution to the public investment programme will drop - as indicated earlier - to 760 billion kip for FY 2003-2004, from 960 billion kip in FY 2002-2003.

\section{$\underline{\text { Resource allocation }}$}

In addition to the lower than expected revenues, the reduced PIP reflects the Government's commitment to substantially increase the salaries of public servants, to improve recurrent expenditures more generally, to resolve outstanding debt issues and to provide business incentives. The tight fiscal situation of the Government means that the PIP for 2003-2004 (i.e., the 760 billion kip from domestic sources) has been allocated in the following manner:

300 billion to assume the debts, especially provincial debts, of past PIP investments.

200 billion for on-going and new national projects.

160 billion for counterpart funds to ODA projects (on-going and new projects).

100 billion for poverty eradication through the enhancement of income generating activities; of this amount, 40 billion kip are earmarked for the 47 poorest districts and 60 billion kip for the improvement of extension services throughout the country, enhancement of market production (income generation) and capacity building. 
The allocation of 100 billion kip under the PIP for poverty eradication is consistent with the start of the implementation of the NGPES. Excluding the amount allocated for paying past investment arrears, almost 22 per cent (100 billion of 460 billion) of domestic investment funds will be directed to poverty eradication. Approximately 1 billion kip has, in principle, been allocated to each of the 47 poorest districts; some of the 47 districts are covered by the Poverty Reduction Fund (PRF) or other means. As the budget situation improves, so too will allocations to the poorest and less poor districts/provinces.

Government funds will go to enhancing capacity at all levels in fields such as planning, management and technical capacity-building. This will enable all levels to assume their fiscal and planning responsibilities and particular emphasis will be given to the district level. Funds will be used in support of on-going projects to enhance their impact and to ensure their sustained success.

For example, UXO-related activities and the development of alternative production schemes in support of drug elimination. Furthermore, population dimensions, with an emphasis on reproductive health, the prevention of HIV/AIDS, micro-credit activities and income generating activities, are clear priorities for the Government. So too is capacity-building in all undertakings.

In particular, all activities linked to rural development, access to markets (thanks to a major effort to develop rural infrastructure), access to health and education (as major development catalysts) and capacity building for local planning and decentralisation management, are major priorities.

The Government's expectations are that towards the end of FY 2003-2004, 8 to 10 comprehensive district plans will be ready to enable an efficient allocation of resources to support the district efforts to eradicate poverty. Such comprehensive district plans will be prepared for all 47 districts to guide and justify resource allocations for the coming years.

With regard to the 40 billion kip earmarked for the poorest districts in addition to the projects supported through other areas of the PIP, the Government intends to use them as a "development fund" for the poorest districts. They will be channelled through village and district funds which will provide support to households and villages to enable them to engage in income generating activities. Income generation empowers people to undertake initiatives and to expand their range of choices to improve their livelihoods. In such a way, through the village and district funds, the present lack of capital, which has been identified as a major cause of poverty, will be addressed.

Thus, village development and district development funds play an important role in enhancing local development. In channelling resources to these funds, the Government conveys its conviction that development should be community-driven and that Government funds should not be substituted for what people can do by themselves to eradicate poverty. Conditions must be enhanced in such a way as to enable the people to organise themselves and to improve their livelihoods by themselves according to their own initiatives and visions of the future. In this respect, the Government strongly wishes to encourage the replication of successful initiatives aimed at enhancing income generation.

Once finalised, the national strategy, presently under preparation, and the action plan for the expansion of rural finance and micro-credit. will provide an additional practical framework for the future use of these funds.

Institutional and managerial requirements necessary to efficiently run these funds and initiatives obviously must be given highest priority.

Investments in infrastructure continue to be an essential component in promoting economic growth nation-wide and enhancing the country's integration into the region and complementing investment efforts undertaken through the various regional corridors. 
Comprehensive infrastructure is essential to help farmers access improved services and local, national and regional markets. This has been clearly indicated in the 5-pillar approach of the Government to rural development, whereby an important objective is to enable individual initiative in pursuing new market opportunities.

\section{$\underline{\text { Sector Priorities }}$}

Priorities have been identified in the respective sector policy papers, and address all areas critical to achieving the NGPES goals. However, most sector strategies still need to be made operational. This will be undertaken over the next year in preparation for FY 2004-2005. The Government considers sector-wide planning, rather than programme or project-driven planning, to be an essential building-block in developing a more coherent and complementary use of scarce public resources.

Given the reduced budgetary allocations for the PIP and the fact that a substantial portion of available counterpart funds are already committed to on-going and planned projects, relatively little new investment is scheduled for FY 2003-2004. Sector priorities must reflect what is sustainable over the long run, even in the face of prolonged budgetary constraints. More analysis is needed to maximise synergies between sector investments. The Government places great importance on this exercise because it will determine both the allocation of its own resources and set priorities for allocating ODA resources. In light of these assessments, and in light of expected domestic revenues, the Government will determine sector envelopes. This process will enable line ministries and provincial authorities to define their top priorities, and evaluate ODA will be more effectively allocated.

\section{Investment Priorities of Main Sectors for the Short and Medium-Term}

The following priorities are indicative, but they indicate where the Government wishes to mobilise domestic and foreign resources, both public and private.

\section{Agriculture/Forestry}

- More analysis is needed of land use zoning so as to harmonise resource allocation and provide guidance to investors.

- Governance and capacity building are major priorities, especially at the district level, as are research and extension services.

- Immediate priorities in the poorest districts include animal health (vaccination), small irrigation schemes, small animal raising and fish ponds.

- Access to markets and production inputs are on-going priorities for the poorest districts.

\section{Education}

- Universal primary education is the first priority, followed by pre-school and lower secondary education.

- The poorest districts and ethnic minority girls need greater support.

- The supply of learning materials, of qualified teachers and of schools need improvement.

- School management, including clarification of roles under decentralisation, is a priority.

- An improved payment system is needed to ensure that teachers are paid on time. 


\section{Health}

- Implementation of the 12 strategic programmes is the overarching set of priorities.

- In the poorest districts, the priority is expansion of the health services network to provide better access to quality care and to drugs and other essential medical supplies.

- The skills of health workers need to be upgraded, and greater emphasis given to ethnic minority workers.

- Continued emphasis on mother and child health care is needed to reduce the high rates of mother and child morbidity and mortality in remote areas.

- Water supply and environmental health programmes are other priorities and will prevent diarrhoeal and/or cholera.

\section{Transport and Communications}

- Specific transport priorities for the medium term (outlined in Part IV, chapter 4) highlight the need to strengthen linkages between the national and rural road networks.

- For the poorest districts, strengthening of the rural road system is the top priority, so as to give access to markets and critical services (health, education).

- Improvement of road maintenance is a priority.

- Extension of telecommunications services to the poorest districts is needed to improve information exchanges, technology transfer, and access to markets.

\section{Chapter 3: Strengthening Effectiveness and Accountability}

Strengthening of the effectiveness and accountability of the PIP depends on a number of achievements. The operational implications of sector priorities and their costs must be thoroughly assessed, including the longer-term national financial implications.

Besides preparation of comprehensive plans for the poorest districts, activities to be undertaken during FY 2003-2004 include long-term programming and costing for the core sectors, especially for the health and education sectors. Related to this exercise, sector-wide action plans will be developed during FY 2003-2004. Donor support for these activities is needed.

Another prerequisite is reconciliation of priority expenditures (both recurrent and capital) with the expected budgetary resources for the next 5 to 10 years. This is a very complex and timeconsuming exercise. Here too, technical assistance would be most helpful.

Improvements to NGPES over the coming years will include a closer link between the macroeconomic framework and the various growth and poverty eradication programmes (e.g., sector resource envelopes). This will be based on an improved public expenditure programme as well as improved budget formulation, execution and monitoring. In particular, prioritisation of sector programmes will be completed and a further effort will be undertaken with regard to the gender, rural-urban differences and ethnic dimensions of poverty.

Strengthening effectiveness and accountability of NGPES implementation also requires an estimation of the full implementation cost of the NGEPS, as well as of the implementation capacity of the Government.

Furthermore, demand-driven funding priorities will be identified in accordance with the already mentioned sector and poor district investment prioritisation. At the same time, as a first step to costing, PIP data and overall sector expenditures will be refined, setting the stage for realistic sector resource envelope projections. 


\section{PART VI: Participation, Monitoring, Evaluation}

Both the Preface and Part I highlighted the intense participatory processes leading to formation of the NGPES, and the need for monitoring and evaluation that will follow as implementation proceeds over the short, medium and long term. It is appropriate that the concluding portion of the NGPES returns to these processes for they are central to successful implementation.

The National Growth and Poverty Eradication Strategy is the outcome of a process starting well in advance of the First National Workshop on Poverty Alleviation in 1996 and the $6^{\text {th }}$ RT Meeting in 1997. In its preparation, numerous consultations have taken place, including the Rapid Poverty Assessments (in 1997), the $7^{\text {th }}$ RT Meeting (in 2001) and the Participatory Poverty Assessments (from 2000-02).

The Roundtable process has involved ongoing consultation, ${ }^{119}$ conceived and led by the Government with a view to engaging the donor community (including bilateral, multilateral and NGO partners) in constructive dialogue on key policies and strategies. This has taken place within the framework of national ownership, transparency and accountability and leading to the achievement of the country's 2020 goal. The $7^{\text {th }}$ RT Meeting reflected this constructive dialogue, with a strong endorsement of the Government's "Fighting Poverty through Human Resource Development, Rural Development and People's Participation". Indeed, this has provided a foundation for the NGPES, which is an elaboration and extension of themes that the Government has developed over the past several years through its highly participatory process with all stakeholders.

The consultative process itself has broadened over the years to include major dialogue meetings on private sector development and the Nam Theun 2 - all within the broader context of the preparation of the NGPES. The main proposals from the private sector related to education, vocational training, macro-economic management, village development funds, handicrafts promotion and a number of other important areas. Consultations with the private sector, mass organisations and academia have been highly useful and many of the suggestions have been incorporated into the NGPES.

Consultation with the international NGOs has also been extensive and very useful. This consultation reflects the spirit and substance of the $10^{\text {th }}$ Conference of the NGO Forum on Cambodia, Laos and Vietnam, which was jointly organised with the Government of the Lao PDR and the Fund for Reconciliation. Almost all ideas advanced during consultations with the NGOS can be found in the NGPES in one form or another, in particular with regard to rural development.

A policy dialogue on governance has been held, during which the Government presented its priorities concerning civil service reform, public sector management, central-local relations (decentralisation) and the rule of law. In addition, discussions have been ongoing concerning the agriculture/forestry, health, education and transport sectors. In each case, the best way to formulate support in a manner that most effectively contributes to economic growth with equity and to poverty eradication, has been examined.

\footnotetext{
${ }^{119}$ With the support of the UNDP.
} 
In order to ensure coherence in the preparation of the NGPES, a Steering Committee has been created composed of all key ministries and agencies, including: $\mathrm{CPC}, \mathrm{MOF}, \mathrm{MOE}, \mathrm{BOL}, \mathrm{MOH}$, MOAF, MCTPC, STEA, National Statistics Centre, the Ethnic Minority Committee of the National Assembly and three mass organisations. Members also include MIH, MOC and other agencies involved in cross-cutting and/or thematic issues such as STEA, the Department of Public Administration and Civil Service, MOLSW and the Prime Minister's Office.

As has been stressed throughout the document, the NGPES is an on-going process. Participation and consultation does not stop with the publication of the document. On the contrary, the Government views the NGPES as "a work in progress". Like the Public Investment Programme, the NGPES has a "rolling" character, requiring constant updating and revision as experience and circumstances warrant.

The Lao culture and tradition requires continuous consultations even after a policy document has been completed, so as to ensure its adaptation and implementation in the local context. ${ }^{120}$ In this way, local concerns and recommendations lead to improvements in a given policy or document, since people can more easily react to proposals and suggest improvements once a policy or a document is understood in its entirety. This will also be the case for the NGPES and will facilitate community-driven implementation.

All priorities identified in the NGPES include aspects of participatory planning, implementation and monitoring. Capacity building for participatory planning is a top priority and development planning will increasingly be based on local participation through appropriate planning manuals and participatory processes. In particular, capacity building for the 47 poorest districts is essential for they must prepare on an urgent basis, district-wide development plans.

Once the National Assembly has approved the NGPES, the Government will distribute the document to all district and provincial offices as well as to all ministries and agencies at the central level. The NGPES will serve as the country's reference and inspiration for all future development endeavours.

Every effort will be made to further involve the wider public, including private sector, academia and social organisations. This will form the basis for spontaneous and structured dialogue that will continue and deepen the many consultations that have already contributed to the foundation of the NGPES. The English translation of the document will be made widely available to the Lao PDR's partners in development and to other stakeholders, including foreign investors. Further, the Government will organise workshops to help develop familiarity and full understanding of the key strategic thrusts and processes of the NGPES. Since the NGPES is strongly based on community participation, most of these workshops will take place at the local level. Sector workshops will also be important.

In this way, the Government's sustained effort to eradicate poverty will become a mass mobilisation exercise, empowering local communities and providing a coherent framework for mutually supportive actions by all stakeholders. In this way, too, the circumstances and opportunities for the Lao multi-ethnic population will greatly improve.

\footnotetext{
${ }^{120}$ Many of the Government's policies and strategies as well as legal texts are under constant revision as they are adjusted or updated following nation-wide debate and the incorporation of new information and ideas.
} 
In the implementation of the NGPES, the role of mass organisations cannot be underestimated. The Lao Women's Union and Lao Front of National Construction have taken a leading role by developing plans to undertake the following activities once the NGPES has been endorsed by the National Assembly:

\section{Lao Women's Union}

- Disseminate the NGPES to LWU staff in 3 regions particularly within the 47 poorest districts. This will be achieved using the medium of radio, television, newspaper and training.

- Assist the establishment of poverty reduction funds by providing financial management skills training in the 47 poorest districts.

- Monitor and evaluate the mainstreaming of gender issues into the social and economic sectors, including education, health, agriculture/forestry and infrastructure.

- Strengthen the capacity of the LWU at the grassroots level through training workshops.

- Promote employment activities through training on food preparation and nutrition, transforming raw materials into finished products or goods for further processing.

- Promote health care knowledge, especially health care for women.

\section{Lao Front of National Construction}

- Provide support to poor families to enable them to understand their environment, find coping strategies and help them climb out of poverty.

- Promote all strata of society and all social organisations to participate in poverty reduction throughout the country, especially in the 47 poorest districts. This will be achieved by providing examples of good experiences in poverty reduction in other places, and by encouraging investments which will promote production and help poor people engage in income-generating activities.

- Disseminate the NGPES to all strata of society and social organisations.

Monitoring and evaluation are integral elements of the NGPES. Part II provided a detailed discussion of what will be involved as implementation of the NGPES gathers momentum. All levels of Government have agreed that monitoring and evaluation are essential to proceeding in the most effective and efficient manner possible. This will done while fully maintaining the social, cultural and environmental character of the country and its national unity and stability.

Monitoring of progress in fulfilling the Millennium Development Goals will provide the ultimate test for the NGPES' success. 
ANNEXES 


\section{Annexes}

\section{Annex 1: Poverty-Related Information and Survey Results}

Table 1.1: Definition of Poverty Lines

Table 1.2: Causes of Poverty by Region and Priority

Table 1.3: List of 72 Poor Districts by Province (household poverty)

Table 1.4: List of 72 Poor Districts by Province (poor villages)

Table 1.5: Women's Perception of Sources of Vulnerability

Table 1.6: Men's Perception of Sources of Vulnerability

Table 1.7: Women's Perception of Coping Strategies

Table 1.8: Men's Perception of Coping Strategies

\section{Annex 2: Information on Macro-Economic and Governance Environment}

Table 2.1: National Development Framework: Targets and Performance Indicators

Table 2.2: Main Economic and Financial Indicators: 1992 to 2005

Table 2.3: Policy Matrix for Revenue Collection

Table 2.4: Policy/Programme Matrix for Improving Public Expenditure Management

Table 2.5: Policy/Programme Matrix for the Financial Sector

Table 2.6: Governance Initiatives

\section{Annex 3: Sector/Cross-sector and National Programmes Matrices}

Table 3.1: Policy/Programme Development Matrix for the Agricultural/Forestry Sector Table 3.2: Policy/Programme Development Matrix for the Education Sector Table 3.3: Policy/Programme Development Matrix for the Health Sector Table 3.4: Policy/Programme Development Matrix for the Transport Sector Table 3.5: Policy/Programme Development Matrix for Gender Equity Table 3.6: Policy/Programme Development Matrix for Environmental Conservation Table 3.7: Projects Concerning the National Drug Control Programme Table 3.8: UXO Contamination Data by Province/District

Table 3.9: Policy/Programme Matrix for the Prevention of HIV/AIDS

Table 3.10: Trade Matrix

\section{Annex 4: Information on PIP and Selected Revenue Projections}

Table 4.1: Long-Term Revenue Projections (Nam Theun 2 and Mining Revenues)

Table 4.2: PIP Domestic and Foreign Sources of Funding, FY2002-2003

Table 4.3: PIP Sector and Provincial Allocations, FY 2002-2003 


\section{Annex 1}

\section{(Poverty-Related Information and Survey Results)}

Table 1.1: Definition of Poverty Lines

Table 1.2: Causes of Poverty by Region and Priority

Table 1.3: List of 72 Poor Districts by Province (household poverty)

Table 1.4: List of 72 Poor Districts by Province (poor villages)

Table 1.5: Women's Perception of Sources of Vulnerability

Table 1.6: Men's Perception of Sources of Vulnerability

Table 1.7: Women's Perception of Coping Strategies

Table 1.8: Men's Perception of Coping Strategies 


\section{Table 1.1 Definition of Poverty Lines}

1. In developing poverty lines, the guiding principle is to develop the poverty line as a single national standard definition of poverty, adjusting it as necessary for spatial and temporal price differences. Although the process is complex, it can be reduced to the following sequence of relatively simple steps:

2. Identification of a household survey with reliable and detailed data on household expenditures that can be used to develop the poverty line (detail is particularly important in the case of food expenditures). The choice of a particular survey determines the baseline year for the poverty study.

3. A reference food basket is developed that includes a detailed list of per capita expenditures on various food items (including home-produced food) among low-income consumers. The definition of the low-income reference group often varies from one study to the next. The items included in the reference food basket are often limited in practice by the availability of price data (such as from a consumer price index). In some studies, more than one reference food basket is developed for people residing in different regions. However, this violates the principle of having a uniform national standard of poverty; and it is not recommended.

4. Expenditure on each item in the reference food basket is divided by its price, thereby converting the reference food basket items from a list of expenditures into a list of physical quantities of food consumed.

5. The physical quantities of each food item in the reference food basket are multiplied by calorie conversion factors in order to calculate the total number of calories contained in the reference food basket.

6. The cost per calorie (or equivalently, its inverse, the number of calories purchased by a single unit of the national currency) is computed by dividing the total expenditure on the items in the food basket by the estimated number of calories in the food basket. The estimated cost per calorie may be adjusted for regional price differences, using a spatial price index for food.

7. The estimated cost per calorie in each region is multiplied by the minimum daily number of calories needed by an average person (e.g., 2,100) to obtain an estimate of the cost of meeting a person's minimum daily nutritional needs. This is usually called the "food poverty line." It may be expressed on a daily or monthly basis.

8. The cost of meeting minimal non-food basic needs (e.g., clothing, housing, transportation, education and health care) is estimated. This is called the "non-food allowance," and it can be obtained in a variety of ways. Usually, however, it is based on the non-food share of total consumption in a national sample of persons whose per capita consumption (adjusted for spatial price differences) is "near" the food poverty line. Some poverty studies obtain more than one nonfood allowance (e.g., one for each region). However, this too violates the principle of using a uniform national poverty standard and is not recommended. Instead, a single national non-food allowance should be estimated and adjusted for spatial and temporal price differences using a spatial price index for non-food items.

9. The baseline period "poverty line" in each region is calculated as the sum of the food poverty line and the non-food allowance.

10. Poverty lines for other periods are obtained by adjusting the baseline period poverty line for food and non-food price changes, using suitable price indexes. Some studies adjust the food poverty line for price changes but then obtain a new non-food allowance. This is not recommended as it too violates the principal of applying a uniform national poverty standard to both periods. 


\begin{tabular}{|c|c|c|c|c|}
\hline \multicolumn{5}{|c|}{$\begin{array}{c}\text { Table 1. 2: } \\
\text { Causes of Poverty by Region and Priority }\end{array}$} \\
\hline \multirow{2}{*}{$\begin{array}{l}\text { Prio- } \\
\text { rity }\end{array}$} & \multicolumn{4}{|c|}{ Causes of Poverty } \\
\hline & North & Central & East & South \\
\hline 1 & $\begin{array}{l}\text {-livestock disease } \\
\text {-land allocation } \\
\text { shortened fallow } \\
\text { cycles }\end{array}$ & $\begin{array}{l}\text {-pests (insects, rats, } \\
\text { birds, wild pigs) } \\
\text {-land area too small } \\
\text {-lack of credit } \\
\text {-too many children }\end{array}$ & $\begin{array}{l}\text {-Land allocation } \\
\text { shortened fallow } \\
\text { cycles } \\
\text {-This caused soils to } \\
\text { deplete and } \\
\text { environment to } \\
\text { decline }\end{array}$ & $\begin{array}{l}\text { - natural disasters, } \\
\text { flooding and } \\
\text { drought }\end{array}$ \\
\hline 2 & $\begin{array}{l}\text {-soils depleted and } \\
\text { environment } \\
\text { declined } \\
\text {-produce destroyed } \\
\text { by pests }\end{array}$ & $\begin{array}{l}\text { - no irrigation and } \\
\quad \text { water supply } \\
\text { - no education } \\
\text { - health facility not } \\
\quad \text { accessible } \\
\text { - poor health }\end{array}$ & $\begin{array}{l}\text {-livestock disease } \\
\text {-land for rice } \\
\text { production not } \\
\text { sufficient }\end{array}$ & $\begin{array}{l}\text { - lack of roads to } \\
\text { market produce }\end{array}$ \\
\hline 3 & -opium addiction & $\begin{array}{l}\text {-lack of roads } \\
\text {-lack of } \\
\text { "intelligence" (i.e. of } \\
\text { self-esteem?) }\end{array}$ & $\begin{array}{l}\text { - lack tech knowledge } \\
\text { and skills }\end{array}$ & -livestock disease \\
\hline 4 & $\begin{array}{l}\text {-natural disasters } \\
\text {-lack irrigation and } \\
\text { water supply } \\
\text {-lack tech knowledge } \\
\text {-poor health affects } \\
\text { production } \\
\text {-lack of knowledge of } \\
\text { market \& } \\
\text { commerce } \\
\text {-no market }\end{array}$ & $\begin{array}{l}\text { - no paddy } \\
\text {-lack of technical } \\
\text { knowledge } \\
\text { - poor health }\end{array}$ & $\begin{array}{l}\text { - lack of road to village } \\
\text { - no revolving funds to } \\
\text { improve livelihood }\end{array}$ & $\begin{array}{l}\text {-lack tech } \\
\text { knowledge and } \\
\text { skills }\end{array}$ \\
\hline 5 & $\begin{array}{l}\text {-no land for rice } \\
\text { production } \\
\text {-poor education } \\
\text {-lack of leadership } \\
\text {-theft of cattle, } \\
\text { buffaloes } \\
\text { - crops encouraged } \\
\text { had no market value } \\
\text { - ban on opium } \\
\text { production } \\
\text { - no roads }\end{array}$ & & $\begin{array}{l}\text {-natural disasters, } \\
\text { flooding, drought, } \\
\text { logging } \\
\text {-land given in } \\
\text { replacement for } \\
\text { swidden under } \\
\text { land allocation not } \\
\text { usable } \\
\text {-lack of tech knowledge }\end{array}$ & $\begin{array}{l}\text {-pests } \\
\text { - land losing } \\
\text { fertility, } \\
\text { environment is } \\
\text { declining } \\
\text { poor health in } \\
\text { labour force } \\
\text { affects production }\end{array}$ \\
\hline 6 & $\begin{array}{l}\text {-no village chief } \\
\text {-cannot hire labour to } \\
\text { assist with } \\
\text { harvest } \\
\text {-prices are increasing } \\
\text {-resettlement } \\
\text {-lack of labour } \\
\text { because young } \\
\text { people are } \\
\text { leaving the } \\
\text { village for the } \\
\text { city or going to } \\
\text { look for work in } \\
\text { Thailand and do } \\
\text { not come home }\end{array}$ & & $\begin{array}{l}\text {-lack irrigation, water } \\
\text { supply } \\
\text {-lack of health services } \\
\text {-lack commercial } \\
\text { knowledge and } \\
\text { ability to compete }\end{array}$ & $\begin{array}{l}\text {-pests } \\
\text {-soils are } \\
\text { depleting, } \\
\text { natural } \\
\text { resources are } \\
\text { dwindling } \\
\text {-poor health } \\
\text { affects } \\
\text { production }\end{array}$ \\
\hline
\end{tabular}




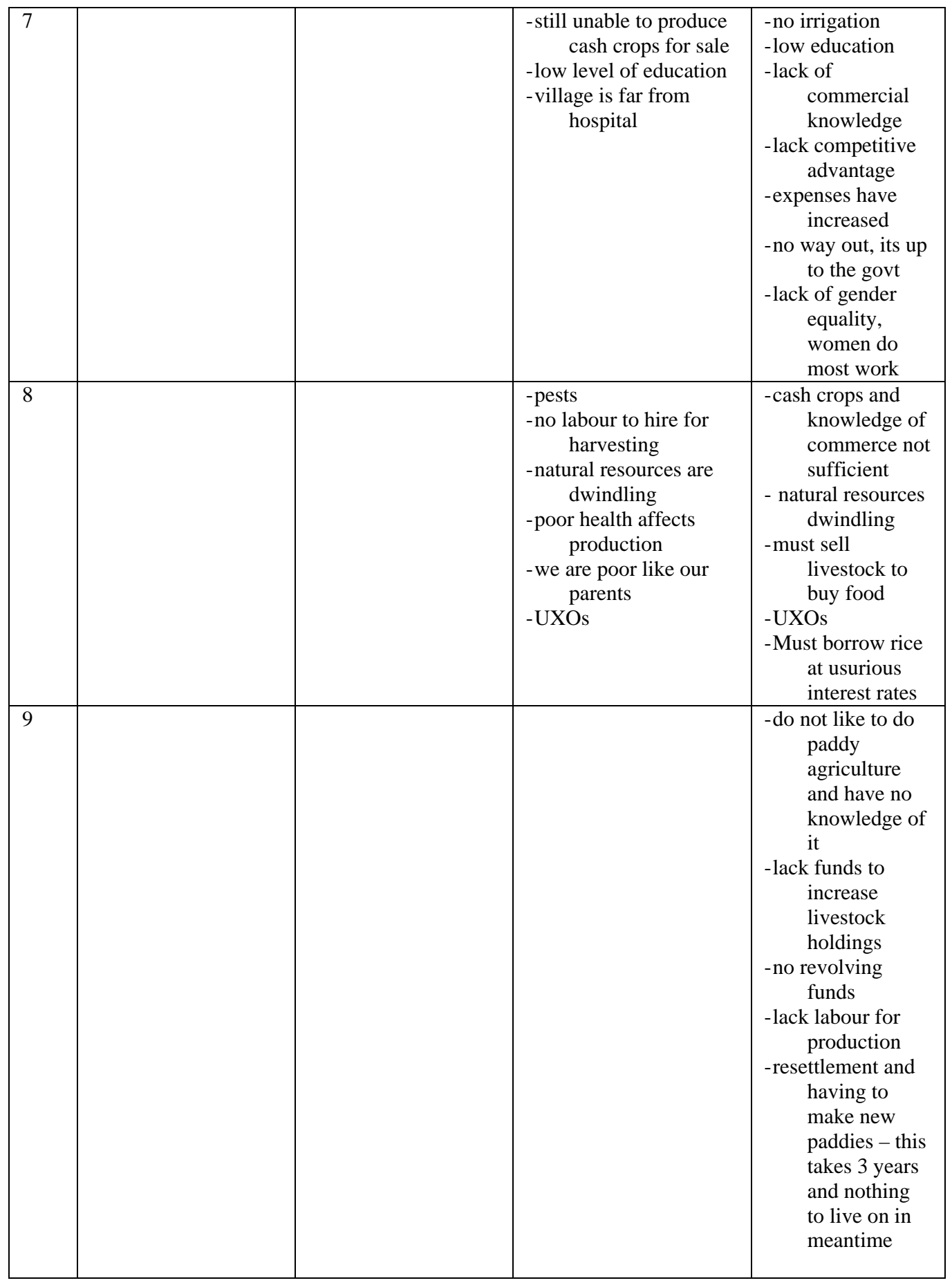


Table 1.3: List of 72 poor districts by provinces and poverty criteria ( household poverty), 2001/2002.

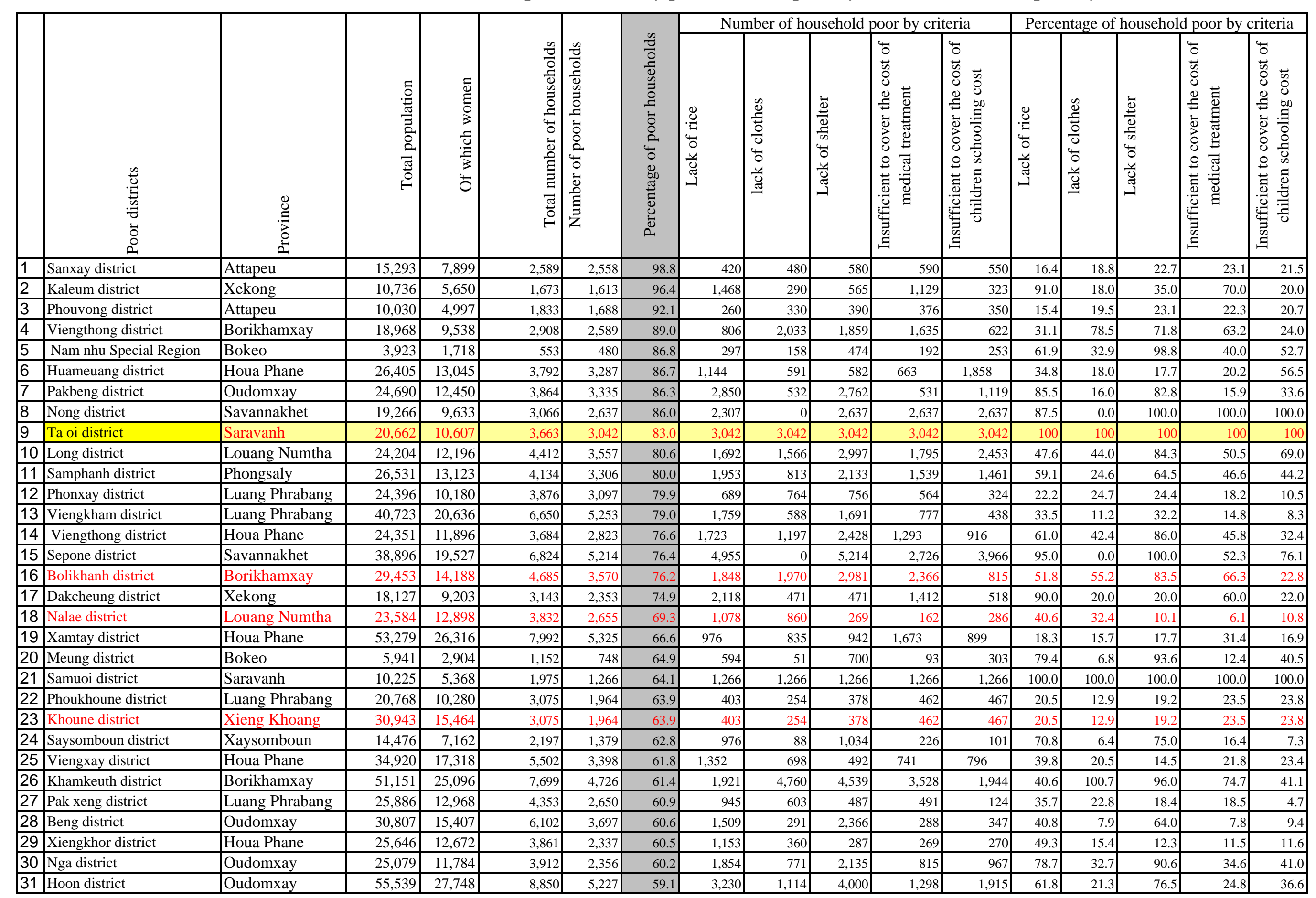




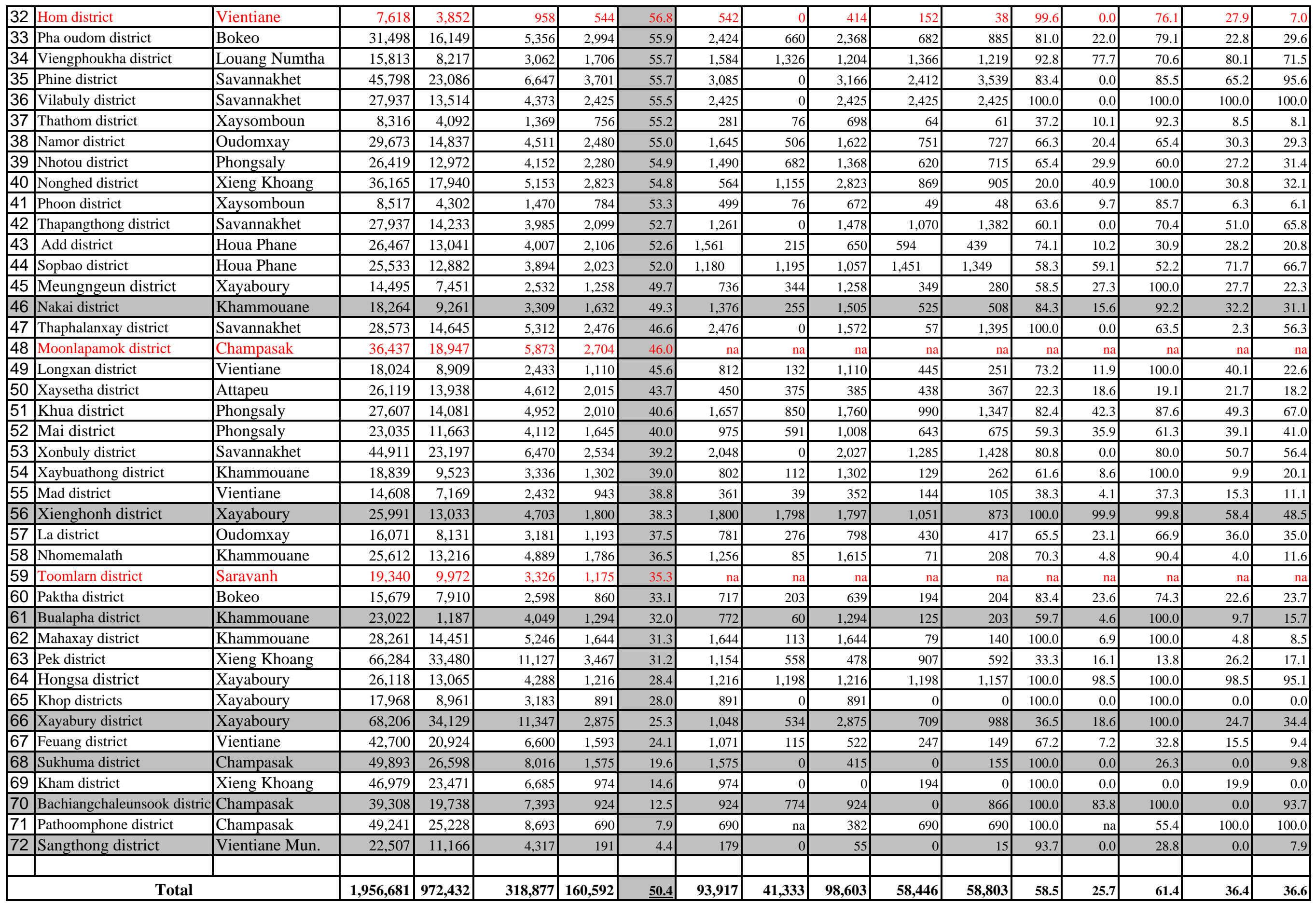

Source: National Statistical Center, Poverty Statistical Reports, Provincial Committees/Authorities as of March 2003 
Table 1.4: List of 72 poor districts by provinces and poverty criteria ( poor village), 2001/2002.

\begin{tabular}{|c|c|c|c|c|c|c|c|c|c|c|c|c|c|c|c|}
\hline & \multirow[b]{2}{*}{ 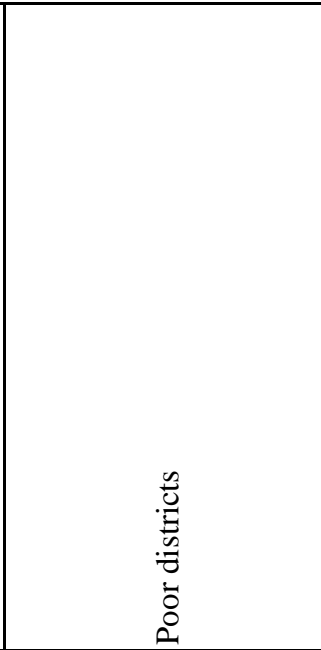 } & \multirow[b]{2}{*}{ 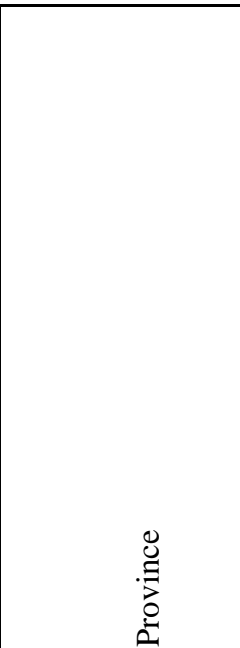 } & \multirow[b]{2}{*}{ 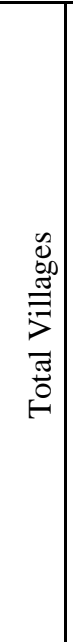 } & \multirow[b]{2}{*}{ 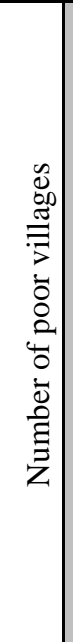 } & \multirow[b]{2}{*}{ 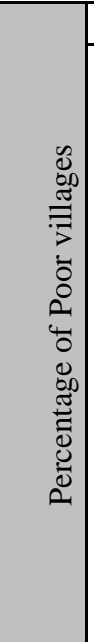 } & \multicolumn{5}{|c|}{ Village's criteria } & \multicolumn{5}{|c|}{ Poor villages by criteria in percentage } \\
\hline & & & & & & 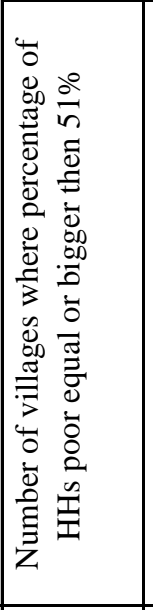 & 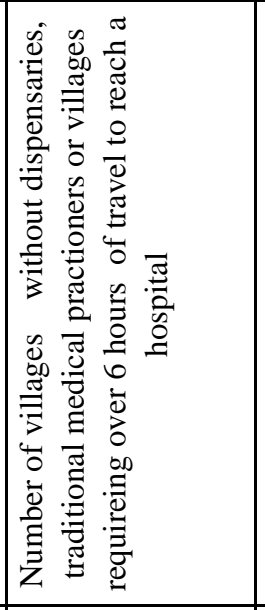 & 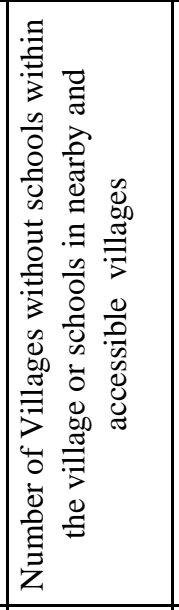 & 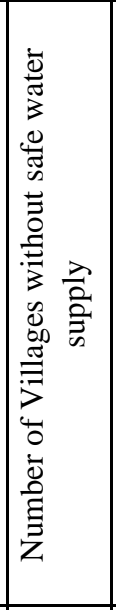 & 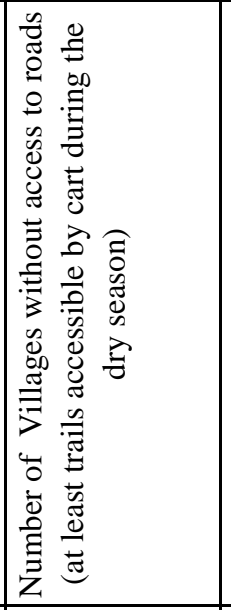 & 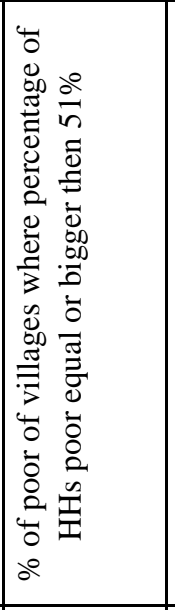 & 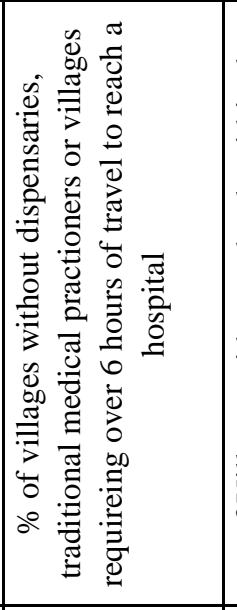 & 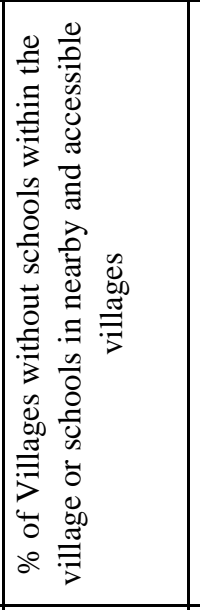 & 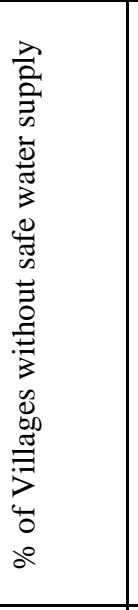 & 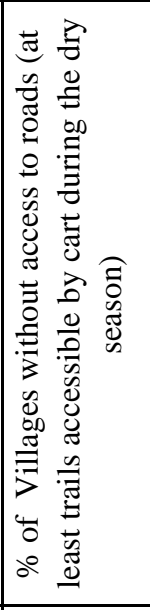 \\
\hline 1 & Sanxay district & Attapeu & 59 & 55 & 93.2 & 55 & 40 & 45 & 55 & 55 & 100.0 & 72.7 & 81.8 & 100.0 & 100.0 \\
\hline 2 & Kaleum district & Xekong & 74 & 63 & 85.1 & 63 & 72 & 26 & 59 & 23 & 100.0 & 115.0 & 40.5 & 93.1 & 36.5 \\
\hline 3 & Phouvong district & Attapeu & 25 & 25 & 100.0 & 25 & 20 & 15 & 23 & 24 & 100.0 & 80.0 & 60.0 & 92.0 & 96.0 \\
\hline 4 & Viengthong district & Borikhamxay & 36 & 36 & 100.0 & 34 & 8 & 5 & 38 & 11 & 94.4 & 22.2 & 13.9 & 105.6 & 30.6 \\
\hline 5 & Nam nhu Special Region & Bokeo & 11 & 10 & \begin{tabular}{l|l}
90.9 \\
\end{tabular} & 10 & 4 & 0 & 8 & 0 & 100.0 & 40.0 & 0.0 & 80.0 & 0.0 \\
\hline 6 & Huameuang district & Houa Phane & 88 & 85 & 96.6 & 85 & 41 & 7 & 63 & 40 & 100.0 & \begin{tabular}{l|l}
48.2 \\
\end{tabular} & \begin{tabular}{l|l}
8.2 \\
\end{tabular} & 74.1 & 47.1 \\
\hline 7 & Pakbeng district & Oudomxay & 73 & 70 & \begin{tabular}{l|l}
95.9 \\
\end{tabular} & 80 & 36 & 26 & 61 & 57 & 114.3 & 51.4 & 37.1 & 87.1 & 81.4 \\
\hline 8 & Nong district & Savannakhet & 80 & 75 & 93.8 & 75 & 75 & 75 & 75 & 75 & 100.0 & 100.0 & 100.0 & 100.0 & 100.0 \\
\hline 9 & Ta oi district & Saravanh & 56 & 41 & 63 & 35 & 35 & 35 & 35 & 13 & 100 & 100 & 100 & 100 & 37 \\
\hline 10 & Long district & Louang Numtha & 91 & 85 & 93.4 & \begin{tabular}{l|l}
82 \\
\end{tabular} & 62 & 51 & 58 & 61 & 96.5 & \begin{tabular}{l|l|}
72.9 \\
\end{tabular} & 60.0 & \begin{tabular}{l|l|}
68.2 \\
\end{tabular} & 71.8 \\
\hline 11 & Samphanh district & Phongsaly & 89 & 89 & 100.0 & 85 & 31 & 20 & 81 & 75 & 95.5 & 34.8 & 22.5 & 91.0 & 84.3 \\
\hline 12 & Phonxay district & Luang Phrabang & 72 & 67 & \begin{tabular}{l|l}
93.1 \\
\end{tabular} & 15 & 20 & 5 & 13 & 14 & 22.4 & 29.9 & 7.5 & 19.4 & 20.9 \\
\hline 13 & Viengkham district & Luang Phrabang & 113 & 100 & 88.5 & 32 & 15 & 10 & 31 & 12 & 32.0 & 15.0 & 10.0 & 31.0 & 12.0 \\
\hline \begin{tabular}{|l|}
14 \\
\end{tabular} & Viengthong district & Houa Phane & 80 & 78 & 97.5 & 74 & 78 & 6 & 72 & 28 & 94.9 & 100.0 & 7.7 & 92.3 & 35.9 \\
\hline 15 & Sepone district & Savannakhet & 160 & 128 & 80.0 & 128 & 128 & 128 & 128 & 128 & 100.0 & 100.0 & 100.0 & 100.0 & 100.0 \\
\hline 16 & Bolikhanh district & Borikhamxay & 44 & 36 & 81.8 & 26 & 18 & 0 & 15 & 7 & 72.2 & 50.0 & 0.0 & 41.7 & 19.4 \\
\hline \begin{tabular}{|l|}
17 \\
\end{tabular} & Dakcheung district & Xekong & 105 & 90 & \begin{tabular}{l|l}
85.7 \\
\end{tabular} & 90 & 73 & 60 & 63 & 60 & 100.0 & 81.6 & 66.6 & 69.9 & 66.6 \\
\hline 18 & Nalae district & Louang Numtha & 83 & 66 & 79.5 & 31 & 4 & 0 & 39 & 39 & 47.0 & 6.1 & 0.0 & \begin{tabular}{l|l}
59.1 \\
\end{tabular} & 59.1 \\
\hline \begin{tabular}{|l|}
19 \\
\end{tabular} & Xamtay district & Houa Phane & 180 & 177 & 98.3 & 106 & 138 & 11 & 156 & 135 & 59.9 & 78.0 & 6.2 & 88.1 & 76.3 \\
\hline 20 & Meung district & Bokeo & 25 & 15 & 60.0 & 15 & 3 & 1 & 10 & 2 & 100.0 & 20.0 & 6.7 & 66.7 & 13.3 \\
\hline \begin{tabular}{|l|}
21 \\
\end{tabular} & Samuoi district & Saravanh & 58 & 34 & 58.6 & 34 & 34 & 30 & 34 & 34 & 100.0 & 100.0 & \begin{tabular}{l|l|}
88.2 \\
\end{tabular} & 100.0 & 100.0 \\
\hline \begin{tabular}{|l|}
22 \\
\end{tabular} & Phoukhoune district & Luang Phrabang & 50 & 18 & 36.0 & 11 & 8 & 12 & 8 & 9 & 61.1 & \begin{tabular}{l|l}
44.4 \\
\end{tabular} & 66.7 & 44.4 & 50.0 \\
\hline \begin{tabular}{|l|}
23 \\
\end{tabular} & Khoune district & Xieng Khoang & 90 & 38 & \begin{tabular}{l|l}
42.2 \\
\end{tabular} & 11 & 8 & 12 & 8 & 9 & 28.9 & 21.1 & 31.6 & 21.1 & 23.7 \\
\hline \begin{tabular}{|l|}
24 \\
\end{tabular} & Saysomboun district & Xaysomboun & 32 & 27 & 84.4 & 24 & 2 & 1 & 15 & 0 & 88.9 & \begin{tabular}{r|}
7.4 \\
\end{tabular} & \begin{tabular}{l|}
3.7 \\
\end{tabular} & 55.6 & 0.0 \\
\hline \begin{tabular}{|l|}
25 \\
\end{tabular} & Viengxay district & Houa Phane & 131 & 102 & \begin{tabular}{l|l}
77.9 \\
\end{tabular} & 83 & 3 & 0 & 71 & 47 & 81.4 & 2.9 & 0.0 & 69.6 & 46.1 \\
\hline \begin{tabular}{|l|}
26 \\
\end{tabular} & Khamkeuth district & Borikhamxay & 72 & 62 & 86.1 & 50 & 7 & 0 & 28 & 27 & 80.6 & 11.3 & 0.0 & \begin{tabular}{l|l}
45.2 \\
\end{tabular} & 43.5 \\
\hline 27 & Pak xeng district & Luang Phrabang & 87 & 61 & 70.1 & 18 & 13 & 0 & 21 & 9 & 29.5 & \begin{tabular}{l|l}
21.3 \\
\end{tabular} & 0.0 & 34.4 & 14.8 \\
\hline \begin{tabular}{|l|}
28 \\
\end{tabular} & Beng district & Oudomxay & 74 & 69 & 93.2 & 38 & 2 & 1 & 38 & 17 & 55.1 & 2.9 & 1.4 & 55.1 & 24.6 \\
\hline 29 & Xiengkhor district & Houa Phane & 66 & 57 & 86.4 & 45 & 57 & 0 & 32 & 34 & 78.9 & 100.0 & 0.0 & 56.1 & 59.6 \\
\hline 30 & Nga district & Oudomxay & 90 & 81 & \begin{tabular}{l|l}
90.0 \\
\end{tabular} & \begin{tabular}{l|}
62 \\
\end{tabular} & 37 & 26 & 74 & 61 & 76.5 & \begin{tabular}{l|}
45.7 \\
\end{tabular} & 32.1 & 91.4 & 75.3 \\
\hline \begin{tabular}{|l|}
31 \\
\end{tabular} & Hoon district & Oudomxay & 160 & 153 & 95.6 & 113 & 26 & 46 & 142 & 82 & 73.9 & 17.0 & 30.1 & 92.8 & 53.6 \\
\hline
\end{tabular}




\begin{tabular}{|c|c|c|c|c|c|c|c|c|c|c|c|c|c|c|c|}
\hline 32 & Hom district & Vientiane & 13 & 13 & 100.0 & 13 & 6 & 1 & 11 & $4 \mid$ & 100.0 & 46.2 & 7.7 & 84.6 & 30.8 \\
\hline 33 & Pha oudom district & Bokeo & 95 & 66 & 69.5 & 50 & 27 & 28 & 39 & \begin{tabular}{l|l}
46 \\
\end{tabular} & 75.8 & 40.9 & 42.4 & 59.1 & 69.7 \\
\hline 34 & Viengphoukha district & Louang Numtha & 46 & 44 & 95.7 & 37 & 31 & 3 & 23 & 6 & 84.1 & 70.5 & 6.8 & 52.3 & 13.6 \\
\hline 35 & Phine district & Savannakhet & 116 & 88 & 75.9 & 88 & 88 & 88 & 88 & 88 & 100.0 & 100.0 & 100.0 & 100.0 & 100.0 \\
\hline 36 & Vilabuly district & Savannakhet & 103 & 80 & 77.7 & 80 & 80 & 80 & 80 & 80 & 100.0 & 100.0 & 100.0 & 100.0 & 100.0 \\
\hline 37 & Thathom district & Xaysomboun & 28 & 25 & 89.3 & 17 & 0 & 0 & 19 & 0 & 68.0 & 0.0 & 0.0 & 76.0 & 0.0 \\
\hline 38 & Namor district & Oudomxay & 93 & 80 & 86.0 & 53 & 43 & 25 & 68 & \begin{tabular}{l|l}
38 \\
\end{tabular} & 66.3 & 53.8 & 31.3 & 85.0 & 47.5 \\
\hline 39 & Nhotou district & Phongsaly & 87 & 87 & 100.0 & 50 & 36 & 14 & 87 & 57 & 57.5 & 41.4 & 16.1 & 100.0 & 65.5 \\
\hline 40 & Nonghed district & Xieng Khoang & 112 & 87 & 77.7 & 87 & 30 & 0 & 57 & \begin{tabular}{l|l}
41 & \\
\end{tabular} & 100.0 & 34.5 & 0.0 & \begin{tabular}{c|c}
65.5 \\
\end{tabular} & 47.1 \\
\hline 41 & Phoon district & Xaysomboun & 26 & 20 & 76.9 & 17 & 0 & 0 & 17 & 0 & 85.0 & 0.0 & 0.0 & 85.0 & 0.0 \\
\hline 42 & Thapangthong district & Savannakhet & 77 & 48 & 62.3 & 48 & 48 & \begin{tabular}{l|l}
48 \\
\end{tabular} & 48 & \begin{tabular}{l|l}
48 & -120 \\
\end{tabular} & 100.0 & 100.0 & 100.0 & 100.0 & 100.0 \\
\hline 43 & Add district & Houa Phane & 78 & 67 & 85.9 & 61 & 18 & \begin{tabular}{l|l}
19 \\
\end{tabular} & 38 & \begin{tabular}{l|l}
47 & -1 \\
\end{tabular} & 91.0 & 26.9 & 28.4 & 56.7 & 70.1 \\
\hline 44 & Sopbao district & Houa Phane & 75 & 70 & 93.3 & 45 & 1 & $2 \mid$ & 66 & $29 \mid$ & 64.3 & 1.4 & 2.9 & \begin{tabular}{l|l}
94.3 \\
\end{tabular} & 41.4 \\
\hline 45 & Meungngeun district & Xayaboury & 29 & 19 & 65.5 & 19 & 1 & 1 & 5 & \begin{tabular}{l|l}
2 & \\
\end{tabular} & 100.0 & 5.3 & \begin{tabular}{|l|}
5.3 \\
\end{tabular} & 26.3 & 10.5 \\
\hline 46 & Nakai district & Khammouane & 67 & 48 & 71.6 & 41 & 19 & 12 & 48 & $27 \mid$ & 85.4 & 39.6 & 25.0 & 100.0 & 56.3 \\
\hline 47 & Thaphalanxay district & Savannakhet & 78 & 46 & 59.0 & 46 & 46 & \begin{tabular}{l|l}
46 \\
\end{tabular} & 46 & \begin{tabular}{l|l}
46 \\
\end{tabular} & 100.0 & 100.0 & 100.0 & 100.0 & 100.0 \\
\hline 48 & Moonlapamok district & Champasak & 66 & 50 & 75.8 & 27 & na & na & na & na & na & $\mathrm{na}$ & na & na & na \\
\hline 49 & Longxan district & Vientiane & 36 & 32 & 88.9 & 32 & 19 & 32 & 22 & 20 & 100.0 & 59.4 & 100.0 & 68.8 & 62.5 \\
\hline 50 & Xaysetha district & Attapeu & 31 & 19 & 61.3 & 19 & 10 & \begin{tabular}{l|l}
9 & \\
\end{tabular} & 15 & 16 & $\begin{array}{l}100.0 \\
\end{array}$ & 52.6 & 47.4 & \begin{tabular}{l|l}
78.9 \\
\end{tabular} & 84.2 \\
\hline 51 & Khua district & Phongsaly & 120 & 103 & 85.8 & 43 & 45 & 6 & 84 & 84 & \begin{tabular}{c|c}
41.7 \\
\end{tabular} & 43.7 & 5.8 & 81.6 & 81.6 \\
\hline 52 & Mai district & Phongsaly & 95 & 90 & 94.7 & 34 & 42 & $27 \mid$ & 82 & 65 & 37.8 & \begin{tabular}{|c|}
46.7 \\
\end{tabular} & 30.0 & 91.1 & 72.2 \\
\hline 53 & Xonbuly district & Savannakhet & 107 & 58 & 54.2 & 58 & 58 & 58 & 58 & 58 & $\begin{array}{l}100.0 \\
\end{array}$ & 100.0 & 100.0 & 100.0 & 100.0 \\
\hline 54 & Xaybuathong district & Khammouane & 66 & 60 & 90.9 & 17 & 12 & 1 & 60 & 0 & 28.3 & 20.0 & 1.7 & 100.0 & 0.0 \\
\hline 55 & Mad district & Vientiane & 41 & 37 & 90.2 & 22 & 2 & 1 & 33 & 25 & 59.5 & 5.4 & 2.7 & 89.2 & 67.6 \\
\hline 56 & Xienghonh district & Xayaboury & 57 & 35 & 61.4 & 35 & 10 & 11 & 35 & 10 & 100.0 & 28.6 & 31.4 & 100.0 & 28.6 \\
\hline 57 & La district & Oudomxay & 56 & 47 & 83.9 & 27 & 32 & 12 & 35 & 33 & 57.4 & 68.1 & 25.5 & 74.5 & 70.2 \\
\hline 58 & Nhomemalath & Khammouane & 71 & 57 & 80.3 & 19 & 16 & 1 & 51 & 0 & 33.3 & 28.1 & 1.8 & 89.5 & 0.0 \\
\hline 59 & Toomlarn district & Saravanh & 67 & 44 & 65.7 & 44 & 43 & \begin{tabular}{l|l}
9 \\
\end{tabular} & 41 & na & 100.0 & 98.5 & 20.5 & 93.2 & na \\
\hline 60 & Paktha district & Bokeo & 47 & 23 & 48.9 & 12 & 6 & 6 & 13 & 13 & 52.2 & 26.1 & 26.1 & 56.5 & 56.5 \\
\hline 61 & Bualapha district & Khammouane & 82 & 76 & 92.7 & 22 & 35 & 25 & 76 & 17 & 28.9 & 46.1 & 32.9 & 100.0 & 22.4 \\
\hline 62 & Mahaxay district & Khammouane & 89 & 69 & 77.5 & 14 & 0 & 1 & 64 & 0 & 20.3 & 0.0 & 1.4 & 92.8 & 0.0 \\
\hline 63 & Pek district & Xieng Khoang & 113 & 26 & 23.0 & 7 & 32 & 0 & 26 & 6 & 26.9 & $\mid 123.1$ & 0.0 & 100.0 & 23.1 \\
\hline 64 & Hongsa district & Xayaboury & 56 & 25 & 44.6 & 25 & 0 & 5 & 8 & 12 & 100.0 & 0.0 & 20.0 & 32.0 & 48.0 \\
\hline 65 & Khop districts & Xayaboury & 33 & 9 & 27.3 & 9 & 0 & 0 & 0 & 0 & 100.0 & 0.0 & 0.0 & 0.0 & 0.0 \\
\hline 66 & Xayabury district & Xayaboury & 112 & 48 & 42.9 & 34 & 21 & 0 & 37 & 28 & 70.8 & 43.8 & 0.0 & 77.1 & 58.3 \\
\hline 67 & Feuang district & Vientiane & 62 & 47 & 75.8 & 16 & 0 & 0 & 47 & 0 & 34.0 & 0.0 & 0.0 & 100.0 & 0.0 \\
\hline 68 & Sukhuma district & Champasak & 60 & 29 & 48.3 & 29 & 29 & 20 & 19 & 29 & 100.0 & 100.0 & 69.0 & 65.5 & 100.0 \\
\hline 69 & Kham district & Xieng Khoang & 114 & 53 & 46.5 & 53 & 35 & 0 & 38 & 28 & 100.0 & 66.0 & 0.0 & 71.7 & 52.8 \\
\hline 70 & Bachiangchaleunsook distr & Champasak & 94 & 39 & 41.5 & 39 & 39 & 39 & 0 & 39 & 100.0 & 100.0 & 100.0 & 0.0 & 100.0 \\
\hline 71 & Pathoomphone district & Champasak & 93 & 42 & 45.2 & 42 & 42 & 0 & 42 & \begin{tabular}{l|l}
42 \\
\end{tabular} & 100.0 & 100.0 & 0.0 & 100.0 & 100.0 \\
\hline 72 & Sangthong district & Vientiane Mun. & 37 & 27. & 73.0 & 0 & 0 & 0 & 27 & 0 & 0.0 & 0.0 & 0.0 & 100.0 & 0.0 \\
\hline \multicolumn{3}{|c|}{ Total } & 5,382 & 4,126 & 76.7 & 3,072 & 2,106 & 1,280 & 3,209 & 2,225 & 74.5 & 51.0 & 31.0 & 77.8 & 53.9 \\
\hline
\end{tabular}

Source: National Statistical Centre, Poverty Statistical Reports, Provincial Committees/Authorities as of March 2003 
Table 1.5: Women's perception of sources of vulnerability

\begin{tabular}{|c|c|c|c|c|c|c|c|c|c|c|c|c|c|c|}
\hline \multicolumn{3}{|r|}{ 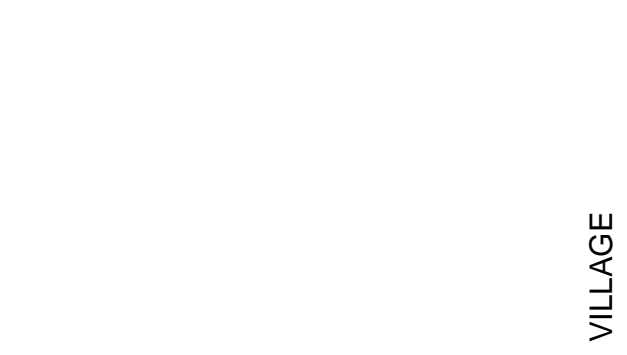 } & 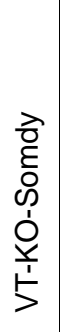 & 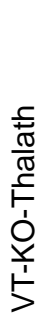 & $\begin{array}{l}\frac{0}{2} \\
\frac{0}{\pi} \\
\sum_{1} \\
\sum_{1}^{\circ} \\
5\end{array}$ & 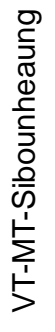 & 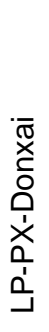 & 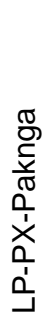 & 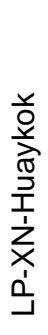 & 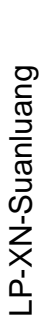 & 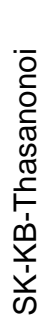 & 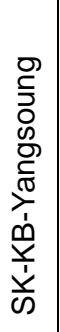 & 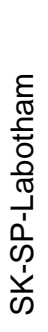 & 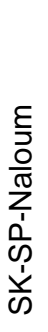 \\
\hline \multirow{11}{*}{ 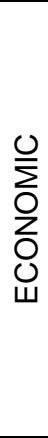 } & Shortage of rice & & $\star$ & & & 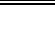 & 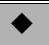 & 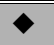 & 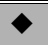 & 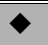 & & $\bar{\square}$ & 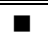 & \\
\hline & Landless & & & & & & & & & $\bullet$ & & & 口 & \\
\hline & Limited land for cultivation & & & & & & & $\bullet$ & & $\bullet$ & 口 & 口 & & $\square$ \\
\hline & Lack of family labour & & & & & & & & & & & & & \\
\hline & Lack of capital** & & & & & & $\bullet$ & $\bullet$ & $\diamond$ & $\diamond$ & 口 & 口 & 口 & $\square$ \\
\hline & No sources to borrow money & & & & & & & & & & & & & \\
\hline & Low income & & & & & & $\bullet$ & $\bullet$ & 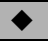 & 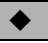 & 口 & 口 & 口 & \\
\hline & Irregular income & & & & & & & & & & & & & \\
\hline & Lack of employment & & & & & & 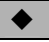 & $\bullet$ & & 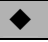 & & & & \\
\hline & Debt & & & & & & & & & & & & & \\
\hline & Too many children & & & & & & & & $\bullet$ & $\diamond$ & & & & \\
\hline \multirow{12}{*}{ 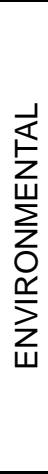 } & Flooding & & & & & & & & & $\bullet$ & 口 & 口 & & \\
\hline & Drought & & & & & & & & & $\bullet$ & 口 & 口 & & \\
\hline & Weather changes & & & & & & $\diamond$ & 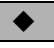 & & & 口 & 口 & & \\
\hline & Shortage of water & & & & & & & & $\bullet$ & & 口 & & & \\
\hline & Unclean water & & & & & & & & & & & & & \\
\hline & Crops destroyed by insects & & & & & & & & $\diamond$ & $\diamond$ & & & & \\
\hline & Crops destroyed by animals* & & & & & & $\bullet$ & $\bullet$ & & & & & & \\
\hline & Poor soil quality & & & & & & $\bullet$ & & $\bullet$ & $\bullet$ & & & & \\
\hline & Poor road access & & & & & & & & & & & & & \\
\hline & Livestock disease & & & & & & 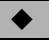 & 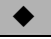 & & $\bullet$ & & & & \\
\hline & Deforestation & & & & & & & & & & & & & \\
\hline & UXO & & & & & & & & & & & & 口 & - \\
\hline \multirow{9}{*}{$\begin{array}{l}\frac{1}{\Delta} \\
0 \\
\text { ৫ }\end{array}$} & Low education & & & & & & 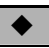 & & 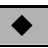 & 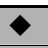 & & & 口 & $\square$ \\
\hline & Low skills & & & & & & & $\bullet$ & $\bullet$ & $\bullet$ & - & & & \\
\hline & $\begin{array}{l}\text { Lack of opportunities for skills } \\
\text { development }\end{array}$ & & & & & & & & & & & & & \\
\hline & Lack of employment opportunities & & & & & & & & $\bullet$ & & & & & \\
\hline & Health & & & & & & $\bullet$ & $\bullet$ & $\bullet$ & $\bullet$ & 口 & & 口 & 口 \\
\hline & Low inter-village communication & & & & & & & & & & & & & \\
\hline & $\begin{array}{l}\text { Low intra-village communication/ } \\
\text { assistance }\end{array}$ & & & & & & $\bullet$ & $\bullet$ & & & & & & \\
\hline & Resettlement & & & & $\star$ & & & & $\bullet$ & & & & & \\
\hline & Weak village authority & & & & & & $\bullet$ & $\diamond$ & & & & & & \\
\hline \multirow{6}{*}{ 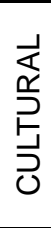 } & Drug abuse & & & & & & 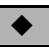 & $\diamond$ & & & $\mathbf{\square}$ & 口 & & \\
\hline & Problems with youth behaviour & & & & & & & & & & - & 口 & & \\
\hline & Prostitution & & & & & & & & & & & & & \\
\hline & Conflict with spouse & & & & & & & & & $\bullet$ & & & & \\
\hline & Theft & & & & & & $\diamond$ & $\bullet$ & $\bullet$ & & & & & \\
\hline & Loss of tradition & & & & & & & $\bullet$ & & & 口 & 口 & & \\
\hline
\end{tabular}


TABLE 1.6: MEN'S PERCEPTION OF SOURCES OF VULNERABILITY

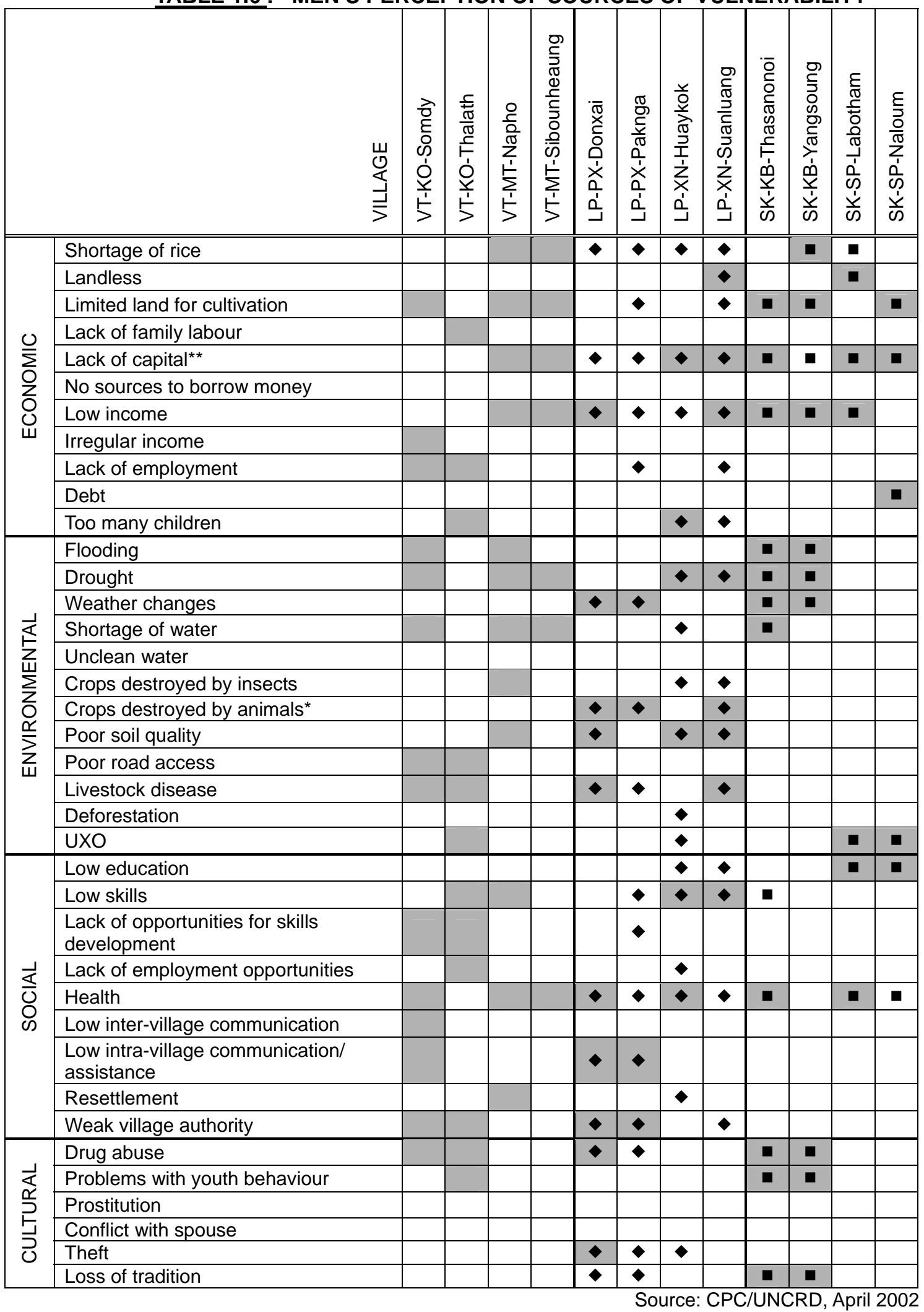

Notes:

Includes wild animals and cattle ${ }^{* *}$ Includes poor housing conditions 
TABLE 1.7 : COPING STRATEGIES : WOMEN'S PERCEPTION

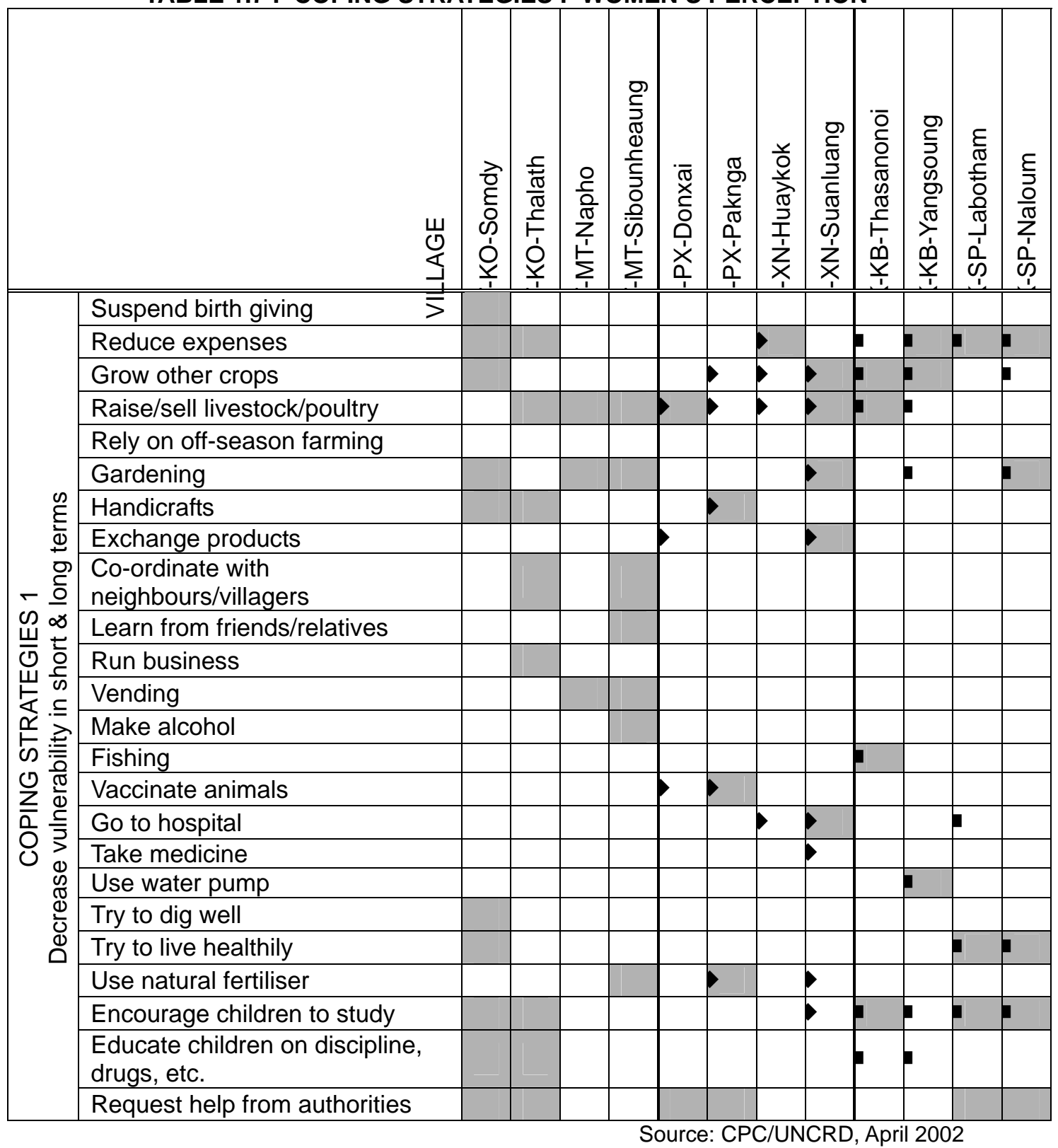

NOTE:

1. The symbol $\boldsymbol{\nabla}$ is used where help from authorities was requested by villagers. The extent of government response is not known and therefore, this factor is placed under coping strategies 1,2 , and 3.

2. "Raise livestock/poultry" was placed under Coping Strategies 1 and 2 because it is not clear whether buffaloes are included or not in the villagers' definition of animals.

3. Boxes for both women and men are shaded where a similar number of women and men use the same coping strategies. 
TABLE 1.8 : COPING STRATEGIES : MEN'S PERCEPTION

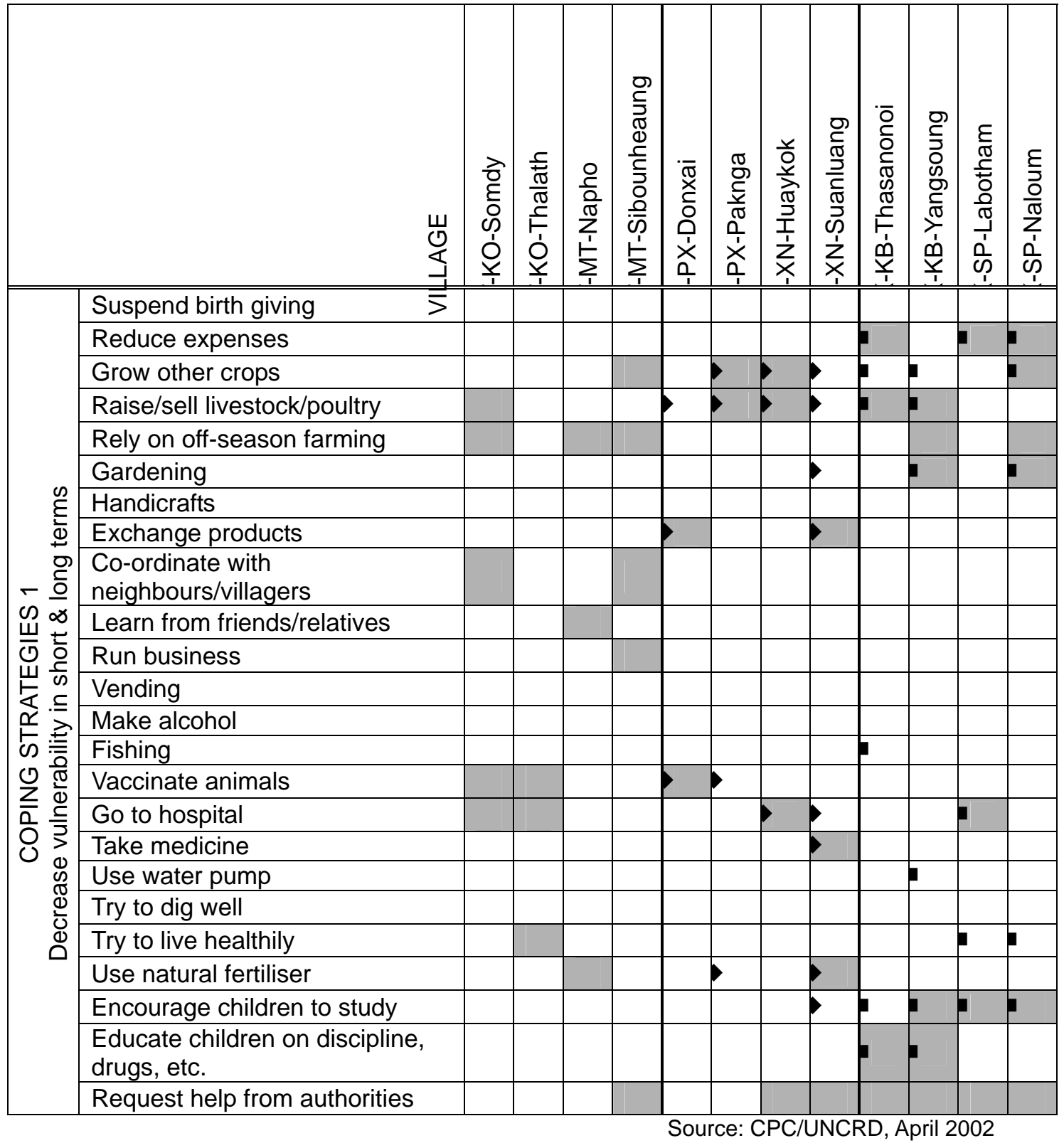

NOTE:

1. The symbol $\boldsymbol{\nabla}$ is used where help from authorities was requested by villagers. The extent of government response is not known and therefore, this factor is placed under coping strategies 1,2 , and 3 .

2. "Raise livestock/poultry" was placed under Coping Strategies 1 and 2 because it is not clear whether buffaloes are included or not in the villagers' definition of animals.

3. Boxes for both women and men are shaded where a similar number of women and men use the same coping strategies. 


\section{Annex 2}

\section{(Macro-Economic and Governance Environment)}

Table 2.1: National Development Framework: Targets and Performance Indicators Table 2.2: Main Economic and Financial Indicators: 1992 to 2005

Table 2.3: Policy Matrix for Revenue Collection

Table 2.4: Policy/Programme Matrix for Improving Public Expenditure Management

Table 2.5: Policy/Programme Matrix for the Financial Sector

Table 2.6: Governance Initiatives 
Table 2.1 : National Development Framework - Development Target Areas and Main Reference Performance Indicators 2005 Priority Development Targets Improving Living Standards

- Overall poverty incidence reduced Performance Indicators Time Frame

Monitoring Source

- Life expectancy increased

- Access to clean water improved

- Child mortality under 5 reduced

- Maternal mortality rates reduced

- Vaccination coverage increased
- Overall poverty incidence declines (from 38.6\%) to $<25 \%$

- Poverty incidence in Northern region declines (from 52.5\%) to $35 \%$

- Life expectancy increases (from 59 years) to 63 years

- No of rural villages with access to clean water raises to $60 \%$ (from 45\%)

- Under 5 child mortality declines (from 106) to 82 / 1000

- Maternal mortality declines (from 530) to $350 / 1000$
Improving Livelihoods through Rural Development, Access to Markets and Local Planning

- Districts linked to provincial capital

- Villages linked to district capital

- Access to electricity increased

- Rural infrastructure improved

- Access to rural credit extended

- District plans developed

- Greater community participation

- People's coping strategies enhanced

- Reduce shifting cultivation

- Reduce opium-related poverty

Human Resource Development
- $60 \%$ of rural villages with access to power (from 35\%)

- Public spending on rural infrastructure increases by $2 \% / y e a r$ in real terms

- Masterplan for rural credit developed and approved

- Legal and regulatory environment for rural and micro finance clarified

- APB's role clarified

- Village funds extend to cover all 46 districts

- 15 districts out the 46 poor districts will have integrated district plans

- Village development plans developed

- Local planning takes coping strategies into account

- Reduce unsustainable shifting cultivation to less then 30 per cent

- Eliminate poverty-related opium production
- All 46 poor districts will have integrated districts plan

2005

1

Mon

- Expenditure on Education increased

- Access to education improved

- Adult literacy rates increased

- Education expenditure will raise to $15 \%$ of total budget

- Net overall primary enrolment increased (from $77 \%$ ) to $85 \%$

- $\quad$ Proportion of female/primary enrolment $>45 \%$

- Proportion of female/lower secondary enrolment $>40 \%$

- Overall adult literacy increases (from $74 \%$ ) to $80 \%$

- Female adult literacy increases (from $60 \%$ ) to $65 \%$

- Expenditure on Health increased 1 - Health expenditure will raise to $10 \%$ of total budget

2005

2005

2005

2005

2005

CPC - NSC

CPC - NSC

NCS

MOH - NSC

$\mathrm{MOH}-\mathrm{NSC}$

$\mathrm{MOH}$ - NSC

$\mathrm{MOH}$ - NSC

2005

Government Organisation, Central-local Relations, Capacity Building, Participation and other Governance Issues

- Improve government organisation and civil service management

- Central-local Relations redefined

- Enhance gender equity

- Governance programme finalised and adopted

- Public service streamlined

- Legal texts finalised (Law on Government, Local administration, etc.) and adopted

- Gender mainstreaming undertaken by all sectors concerned

Community participation enhanced

\begin{tabular}{|c|r|}
\hline 2005 & MCTPC - NSC \\
& MCTPC - NSC \\
2005 & MOIH - NSC \\
Annual & MOF - CPC \\
2003 & BOL \\
2004 & MOF - MOJ - BOL \\
2004 & MOF - BOL \\
2005 & MOF - CPC \\
2003 & CPC \\
2004 & CPC \\
2005 & CPC \\
$2003-2005$ & CPC \\
2005 & MAF \\
2005 & \\
\hline
\end{tabular}

\begin{tabular}{|l|r|}
\hline 2005 & MOE - MOF \\
2005 & MOE \\
2005 & MOE \\
2005 & MOE \\
2005 & MOE \\
2005 & MOE \\
2005 & MOH - MOF \\
\hline
\end{tabular}

2003

2003-2005

2004

DPACS

DPACS

2003-2005

2003-2005 
Table 2.1 : NDF - Main Performance Indicators (cont'd)

Growth with equity

implemented

- Strong economic growth

- Price stability

- Budget revenues increased

- Expenditure better managed

- Fiscal deficit reduced and stabilised

- Financial sector becoming healthier

- External trade increased

- Real economy adjusted to needs

- Maintain high level of investment ratio

- Private sector investment enhanced

- Business environment enhanced

- Environmentally sustainable growth

- Land Management and Administration streamlined
- Average annual growth of 6-7 per cent

- Annual inflation less than 10 per cent

- Revenues increase (from $12.8 \%$ ) to $14-15 \%$

- Expenditure management action plan (regulation, procedures, reporting, etc.) implemented

- Budget deficit reduced to $<4.5-5 \%$ of GDP

- Banking sector reform programme on course (SOCB restructured)

- Widening and deepening financial services outreach

- Annual export growth rate at $10 \%$ (by progressively removing trade barriers

- Agriculture output growth steady at $4.0 \%$ year; industry growth rate increasing to $10 \% / 2005$; services sector growth increasing to $9 \% / 2005$

- Overall investment ratio to GDP attains 34-35 per cent, with public

investment at 12-13 percent and private investment at 22-23 per cent

- Government saving increased to 4-5 per cent of GDP

- FDI and domestic private investment increases steadily

- Relevant laws and legal regulations revised and implemented

- Regular consultation meetings held with private sector

- Enacting and implementing regulatory framework regarding EIA, natural resource management, etc.

- National Master plan for integrated land use and land development planning discussed (policy dialogue), finalised and adopted
Annual

Annual

2005

2003-2005

2005

2003-2005

2003-2005

Annual

Annual

2003-2005

Annual

Annual

2003-2005

Annual

2003-2005

2003-2004
$\mathrm{NSC}-\mathrm{CPC}$

$\mathrm{BOL}-\mathrm{NSC}-\mathrm{CPC}$

(MOF - annual budgets

published)

MOF

MOF - CPC

BOL

$\mathrm{MOF}-\mathrm{BOL}$

$\mathrm{MOC}-\mathrm{CPC}-\mathrm{NSC}$

MAF/MIH/MOC - CPC

BOL - CPC

NSC - CPC

$\mathrm{BOL}-\mathrm{CPC}$

Legal texts published by

MOC
CPC

STEA and concerned agencies/ministries

DONLUPAD 
Table 2.2 : Main Economic and Financial Indicators of Lao PDR from 1992-2002 and Projections for 2003-2005

\begin{tabular}{|c|c|c|c|c|c|c|c|c|c|c|c|c|c|c|}
\hline & \multicolumn{11}{|c|}{ Actual Implementation } & \multirow{2}{*}{$\begin{array}{l}\text { Est. } \\
2003\end{array}$} & \multicolumn{2}{|c|}{ Projections } \\
\hline Items & 1992 & 1993 & 1994 & 1995 & 1996 & 1997 & 1998 & 1999 & 2000 & 2001 & 2002 & & 2004 & 2005 \\
\hline 1. Total GDP Growth (\%) & 7.0 & 5.9 & 7.7 & 7.5 & 6.9 & 6.9 & 4.0 & 7.3 & 5.8 & 5.8 & 5.9 & 5.8 & 6.5 & 7.0 \\
\hline of which: - Agriculture ( growth/share) & $8.3 / 58.0$ & $2.7 / 56.3$ & $8.3 / 56.6$ & $3.1 / 54.3$ & $2.8 / 52.2$ & $7 / 52.2$ & $3.1 / 51.8$ & $8.2 / 52.2$ & $4.9 / 51.8$ & $3.8 / 50.8$ & $4.0 / 49.9$ & $2.2 / 48$ & $3.5 / 47.2$ & $4.5 / 47.3$ \\
\hline - Industry (growth/share) & 7.5/16.7 & 10.3/17.4 & $10.7 / 17.8$ & 13.1/18.8 & $17.3 / 20.6$ & $8.1 / 20.8$ & $9.2 / 21.9$ & $8 / 22.0$ & $8.5 / 22.6$ & $9.7 / 23.4$ & $10.1 / 24.5$ & $11.5 / 26$ & $11.4 / 26.6$ & $10 / 25.2$ \\
\hline - Services ( growth/share) & $3.9 / 25.3$ & $7.7 / 26.3$ & 3.9/25.6 & $12.0 / 26.9$ & $8.5 / 27.2$ & $7.5 / 27$ & $5.5 / 26.3$ & $6.7 / 25.8$ & $4.9 / 25.5$ & $5.7 / 25.8$ & $5.7 / 25.0$ & $7.5 / 25$ & $7.4 / 26.2$ & 9/27.5 \\
\hline 2. GDP at constant prices ( billion of kip) & 681.80 & 721.84 & 777.72 & 835.69 & 893.26 & 955.01 & 993.16 & $1,065.45$ & $1,127.1$ & $1,192.1$ & 1,262 & 1,335 & 1,421 & 1,520 \\
\hline 3. GDP at current prices ( billion of kip) & 844.35 & 953.29 & $1,107.75$ & $1,430.36$ & $1,725.69$ & $2,200.71$ & $4,240.20$ & $10,328.60$ & $13,669.5$ & $15,701.8$ & $18,390.4$ & $22,536.1$ & 24,616 & 25,695 \\
\hline GDP in million of Dollar & $1,179.26$ & $1,329.55$ & $1,542.83$ & $1,747.54$ & $1,863.60$ & $1,746.60$ & $1,286.47$ & $1,453.50$ & $1,742.4$ & $1,770.0$ & $1,819.2$ & $2,132.7$ & $2,333.2$ & $2,335.9$ \\
\hline 4. Inflation ( average annual rate ) (\%) & 9.9 & 6.3 & 6.8 & 14.35 & 18.8 & 14.2 & 61.38 & 128.4 & 23.1 & 7.84 & 10.7 & 15.6 & 12.6 & 12.0 \\
\hline 5. Growth of money supply - M2 ( \% ) & 49 & 64.59 & 31.9 & 16.43 & 26.76 & 65.76 & 113.3 & 78.36 & 45.53 & 20.06 & 26.8 & 18.0 & 18.0 & 18.0 \\
\hline 6. Exchange rate ( Kip/ one of US Dollar) & 716 & 717 & 718 & 819 & 926 & 1,260 & 3,296 & 7,106 & 7,846 & 8,871 & 10.109 & 10,567 & 10,551 & 11,000 \\
\hline 7. Total government revenue ( Billion of Kip) & 130.5 & 156.0 & 208.7 & 241.1 & 283.7 & 334.9 & 822.9 & $1,403.3$ & $2,484.9$ & $2,317.1$ & $2,858.3$ & $3,121.4$ & $3,743.0$ & $4,415.0$ \\
\hline - excluding grant & 90.5 & 117.8 & 140.5 & 171.1 & 223.1 & 237.9 & 442.8 & $1,071.8$ & $1,729.0$ & $2,011.0$ & $2,270.5$ & $2,671.4$ & $3,273.0$ & $3,915.0$ \\
\hline 8. Total government expenditure(Billion of kip) & 175.0 & 188.6 & 266.0 & 310.1 & 374.7 & 463.1 & $1,145.7$ & $1,708.7$ & $3,016.2$ & $3,054.6$ & $3,748.7$ & $4,336.2$ & $4,827.3$ & $5,616.0$ \\
\hline of which:- current expenditure (Billion of Kip) & 93 & 130.2 & 147.6 & 166.4 & 172.7 & 199.5 & 299.1 & 541.4 & $1,094.8$ & $1,295.6$ & $1,419.3$ & $1,755.3$ & $2,144.1$ & $2,800.0$ \\
\hline 9. Overall budget deficit ( As \% of GDP) & -0.6 & -3.8 & -5.2 & -4.8 & -5.3 & -5.8 & -7.6 & -3 & -3.9 & -4.7 & -4.9 & (5.9) & (4.7) & (4.7) \\
\hline - Deficit excluding grant ( As \% of GDP) & -1.0 & -8.3 & -11.3 & -9.7 & -8.8 & -10.2 & -16.6 & -6.2 & -9.4 & -6.7 & -8.1 & (8.1) & (6.8) & (6.6) \\
\hline 10. Total value of exports ( Million of US $\$$ ) & 133 & 240.5 & 300.4 & 307.6 & 317.2 & 312.7 & 336.8 & 301.5 & 330.3 & 311.1 & 306.6 & 359.3 & 347.0 & 370.0 \\
\hline 11. Total value of imports ( Million of US $\$$ ) & 165 & 265.6 & 431.9 & 564.1 & 588.8 & 689.6 & 647.9 & 552.8 & 535.3 & 523.1 & 446.9 & 482.0 & 571.0 & 600.0 \\
\hline 12. Current account balance ( Million of US $\$$ ) & -52 & -41.2 & -96.7 & -132.8 & -229.6 & -177.6 & -33.6 & -75.7 & -8.5 & -78.6 & -41.5 & $(33.3)$ & (30.4) & (17.7) \\
\hline Deficit as $\%$ of GDP & $(4.41)$ & (3.10) & $(6.27)$ & $(7.60)$ & $(12.32)$ & $(10.17)$ & $(2.61)$ & $(5.21)$ & $(0.49)$ & (4.45) & (2.29) & (1.63) & $(1.40)$ & $(0.76)$ \\
\hline 13. Official gross reserves ( in months/ imports) & 2 & 2 & 2 & 3 & 2 & 2 & 3 & 2.3 & 3.2 & 3.9 & 5.7 & 4.8 & 5.2 & 5.3 \\
\hline 14. National savings ( as \% of GDP ) & n.a & n.a & n.a & n.a & n.a & n.a & n.a & n.a & 19.4 & 17.0 & 18.1 & 20.1 & 21.9 & 22.5 \\
\hline of which: - government savings (as $\%$ of GDP) & -0.3 & -1.5 & -0.6 & 0.3 & 2.9 & 1.7 & 3.4 & 5.1 & 4.6 & 4.6 & 4.7 & 4.5 & 4.1 & 4.3 \\
\hline 15. Total Investment ( Billion of kip) & n.a & n.a & n.a & n.a & n.a & n.a & n.a & n.a & $2,857.30$ & $3,275.03$ & $3,706.67$ & $4,581.2$ & $6,472.5$ & $8,916.2$ \\
\hline of which: - Government-PIP ( Billion of Kip ) & 86.0 & 101.9 & 118.0 & 166.1 & 205.5 & 248.7 & 290.5 & $1,295.1$ & $1,914.0$ & $2,115.4$ & $2,136.4$ & $2,610.0$ & $2,918.9$ & $3,289.0$ \\
\hline as $\%$ of GDP & 10.2 & 10.7 & 10.7 & 11.6 & 11.9 & 11.3 & 6.9 & 12.5 & 14.0 & 13.5 & 11.7 & 12.3 & 12.5 & 12.8 \\
\hline - Private (Billion of Kip ) & n.a & n.a & n.a & n.a & n.a & n.a & n.a & n.a & 943 & 1,160 & 1,570 & 2,066 & 3,614 & 5,627 \\
\hline as $\%$ of GDP & n.a & n.a & n.a & n.a & n.a & n.a & n.a & n.a & 6.9 & 7.4 & 8.6 & 10.1 & 15.8 & 21.9 \\
\hline 16. Total FDI approved ( Million of US \$) & 335.1 & 347.8 & 2598.3 & 804.9 & 1292.65 & 138.78 & 122.3 & 116.8 & 20.4 & 42 & 493.8 & 550.0 & 500.0 & 500.0 \\
\hline Real FDI inflow through Bank ( Million of US \$) & 7.8 & 35.8 & 59.2 & 88.4 & 128 & 86.3 & 45.3 & 51.6 & 6.3 & 2.6 & 24.3 & 48.7 & n.a. & n.a. \\
\hline 17. ODA ( Million of US Dollar ) & n.a & n.a & n.a & n.a & 416.6 & 370.9 & 240 & 354.5 & 331.45 & 385.7 & 378.4 & 438.7 & 428.1 & 440.9 \\
\hline of which: grants & n.a & n.a & n.a & n.a & 241.3 & 200.4 & 148.3 & 252.2 & 227.8 & 285.2 & 236.3 & 213.9 & 256.0 & 263.7 \\
\hline 18. Total foreign debt service ( $\mathrm{M} \$ \mathrm{US}$ ) & 9.6 & 9.4 & 9 & 13.3 & 15.5 & 19 & 21.3 & 28.4 & 28.8 & 34.9 & 37.4 & 37.5 & 38.5 & 37.0 \\
\hline 19. Population ( 1000 '.persons ) & 4,360 & 4,474 & 4,591 & 4,605 & 4,723 & 4,847 & 4,975 & 5,108 & 5,245 & 5,380 & 5,520 & 5,660 & 5,800 & 5,940 \\
\hline 20. GDP per capita (US $\$ /$ person ) & 270.47 & 297.17 & 336.06 & 379.49 & 394.58 & 360.35 & 258.59 & 284.55 & 332.21 & 328.33 & 328.81 & 375.5 & 385.55 & 393.25 \\
\hline
\end{tabular}

1/. Updated data provided by NSC, MOF, BOL, CPC annual and 5-year socio-economic reports

2/ Projections of main indicators are according to Government's commitment to PRGF proposal report. These consist of real and nominal GDP, inflation targets, savings and investments (with some adjustments) 
Table 2.3: Matrix of Policies / Strategies for Revenue collection

\begin{tabular}{|c|c|c|c|c|c|c|}
\hline Policy Area (s) & Objectives / Targets & $\begin{array}{c}\text { Measures } \\
\text { (Strategies) }\end{array}$ & $\begin{array}{l}\text { Planned } \\
\text { Timetable }\end{array}$ & $\begin{array}{l}\text { Monitoring } \\
\text { Indicators }\end{array}$ & $\begin{array}{l}\text { Reporting } \\
\text { Frequency }\end{array}$ & $\begin{array}{l}\text { Reporting } \\
\text { Agency }\end{array}$ \\
\hline $\begin{array}{l}\text { Ensure fiscal } \\
\text { stability and } \\
\text { budget } \\
\text { healthy } \\
\text { through the } \\
\text { control of } \\
\text { inflation } \\
\text { single digit } \\
\text { level. }\end{array}$ & $\begin{array}{l}\text { Increase revenue by } \\
14 \text { to } 16 \% \text { of GDP } \\
\text { (increase on average by } \\
0.5-1 \% \text { annually). In } \\
\text { FY } 2004 / 2005 \text {, revenue } \\
\text { must be not less than } \\
15 \% \text { of GDP. ( Based } \\
\text { on Baseline Scenario ) } \\
\text { - Reducing fiscal } \\
\text { deficit by } 0.5 \text { to } 1 \% \text { of } \\
\text { GDP annually. }\end{array}$ & $\begin{array}{l}\text { - Centrally and strictly manage foreign } \\
\text { exchange revenue; ensure that foreign reserve is } \\
\text { strengthened; strictly implement national saving } \\
\text { policy in all areas, in order to gradually eradicate } \\
\text { unnecessary subsidies and reduction of fiscal } \\
\text { deficit in accordance with the target. } \\
\text { - } \quad \text { Stop or cancel direct policy lending. } \\
\text { - } \quad \text { Stop or reduce accumulated debt of state- } \\
\text { owned enterprises (SOEs). } \\
\text { - } \quad \text { Stop the continuous credit to inefficient SOEs. } \\
\text { - Prepare the Medium Term Expenditure } \\
\text { Framework including demand for foreign } \\
\text { financing } \\
\text { - Mobilise all resources to ensure the } \\
\text { requirement of total expenditure and poverty } \\
\text { eradication. } \\
\text { - Improve fiscal policy in line with creating } \\
\text { favour condition for economic growth; actively } \\
\text { enhance commercial production to provide basis } \\
\text { for labour, goods and money market expansion. } \\
\text { - Improve fiscal and credit regulation to enhance } \\
\text { and facilitate the expansion of sound economic } \\
\text { activities of medium and small-scale enterprises. } \\
\text { - Reapply } 5 \% \text { for turnover tax on petroleum } \\
\text { products (as stated in Tax Law) } \\
\text { - Increase excise duties on luxury goods } \\
\text { - Study exemptions in order to reduce them } \\
\text { - Start improvement of custom-tax management } \\
\text { and administration including LTUs, and reduce } \\
\text { exception range. } \\
\text { - Continue collection of lose loans. } \\
\text { - Continue to implementation of decentralisation } \\
\text { policy accordingly to Decree 192/P.M } \\
\text { - Introduction VAT to supersede turnover tax }\end{array}$ & $\begin{array}{l}\text { Immediate } \\
\text { Immediate } \\
\text { Immediate } \\
\text { Immediate } \\
\text { Under way } \\
\text { On-going } \\
\text { FY 2002/03- } \\
\text { 2004/05 } \\
\text { 2006-2007 } \\
\text { NA 2003 } \\
\text { NA 2003 } \\
\text { 2005-2006 }\end{array}$ & $\begin{array}{l}\text { Change in } \\
\text { Consumer Price } \\
\text { Index } \\
\text { - Percentage of } \\
\text { Revenue, } \\
\text { expenditure and } \\
\text { fiscal Deficit to } \\
\text { GDP } \\
\text { Debt service } \\
\text { Ratio } \\
\\
\\
\end{array}$ & $\begin{array}{cc}- & \text { Monthly } \\
- & \text { Quarterly } \\
- & \text { Every 6 } \\
\text { months } \\
\text { - } & \text { Annually }\end{array}$ & $\begin{array}{l}\text { National } \\
\text { Audit Agency } \\
\text { Budget } \\
\text { Department } \\
\text { Fiscal Policy } \\
\text { Department }\end{array}$ \\
\hline
\end{tabular}




\begin{tabular}{|c|c|c|c|c|c|c|}
\hline $\begin{array}{l}\text { II. Ensure } \\
\text { continuous socio- } \\
\text { economic growth; } \\
\text { improve economic } \\
\text { structure in } \\
\text { accordance with } \\
\text { sectors- } \\
\text { agriculture, } \\
\text { industry/handicraf } \\
\text { t and service; } \\
\text { facilitate those } \\
\text { sectors to flexibly } \\
\text { active in view to } \\
\text { achieve the } 5 \text { year } \\
\text { socio-economic } \\
\text { development } \\
\text { target. }\end{array}$ & $\begin{array}{l}\text { - Increase saving to } \\
\text { GDP from 4\% in FY } \\
\text { 2000/2001 to 6-7\% in } \\
\text { FY 2004/2005, or } \\
\text { increase by 0.5\%-1\% on } \\
\text { average each year, in } \\
\text { order to achieve } \\
\text { investment from public } \\
\text { saving at 6-7\% of GDP } \\
\text { in the end of this 5 year } \\
\text { budgeting plan. This } \\
\text { means that we must } \\
\text { mobilise external fund of } \\
\text { 5-6\% of GDP in order to } \\
\text { totalise public } \\
\text { investment at the level } \\
\text { of 12\% -13\% of GDP. } \\
\text { Solve vague debt, } \\
\text { particularly the debt } \\
\text { occurred between the } \\
\text { budget and the bank, } \\
\text { between the budget and } \\
\text { enterprises, and } \\
\text { treasury's dept. } \\
\text { Ensure appropriate } \\
\text { spending structure in } \\
\text { line with the direction of } \\
\text { salary payment, bonus } \\
\text { payment for official } \\
\text { staffs, solders, polices, } \\
\text { recurrent expenditure, } \\
\text { maintenance cost of } \\
\text { equipment and } \\
\text { government assets, } \\
\text { expenditure on national } \\
\text { defense, cultural and } \\
\text { social expenditure, and } \\
\text { appropriate public } \\
\text { investment. There- ... }\end{array}$ & $\begin{array}{l}\text { Arrange a reasonable investment structure in } \\
\text { each sector, region and economic sector in order } \\
\text { to rapidly increase investment efficiency; } \\
\text { upgrade productivity, quality and efficiency in } \\
\text { production; strengthen competitiveness of Lao } \\
\text { products in domestic, regional and global market. } \\
\text { Develop fiscal policy that is consistent with } \\
\text { enhancement and protection of production, and } \\
\text { closely related to poverty reduction for Lao } \\
\text { people, and create social balance in every aspect. } \\
\text { Create a reasonable expenditure policy } \\
\text { (including production and individual } \\
\text { expenditure) to ensure the promotion of } \\
\text { production in accordance with economic capacity } \\
\text { in each period; strictly economise spending in } \\
\text { order to increase saving. } \\
\text { Maintain relationship with foreign countries } \\
\text { and increase international economic co-operation } \\
\text { for regional integration purpose and for } \\
\text { mobilisation of fund, technology and } \\
\text { management skill on the self mastery, self } \\
\text { dependent and self strengthening basis, in order } \\
\text { to avoid risk and achieve meaningful co- } \\
\text { operation. } \\
\text { Promote foreign direct investment; increase } \\
\text { management and mobilisation of foreign grant. } \\
\text { Develop information system; use advanced } \\
\text { technology to ensure effective collection of } \\
\text { budget revenue and create transparency in } \\
\text { budgeting sector in order to determine } \\
\text { direction/policy and fiscal plan in accordance } \\
\text { with reality in each period. } \\
\text { total public expenditure framework will be } 49 \% \\
\text { and investment spending will be 51\%. }\end{array}$ & $\begin{array}{l}\text { FY 2000/01- } \\
2004 / 05\end{array}$ & $\begin{array}{l}\text { - } \\
\text { Change in } \\
\text { sectoral } \\
\text { investment to } \\
\text { GDP } \\
\text { - } \quad \text { Increase in } \\
\text { saving to GDP } \\
\text { - Number of } \\
\text { prioritised } \\
\text { projects } \\
\text { - Successfulnes } \\
\text { s of business } \\
\text { operation }\end{array}$ & $\begin{array}{cc}- & \text { Monthly } \\
- & \text { Quarterly } \\
- & \text { Every 6 } \\
\text { - } & \text { months } \\
- & \text { Annually }\end{array}$ & $\begin{array}{l}\text { Budget } \\
\text { Department } \\
\text { Treasury } \\
\text { Department } \\
\text { Fiscal policy } \\
\text { Department } \\
\text { Investment } \\
\text { Department } \\
\text { The } \\
\text { Committee } \\
\text { for Planning } \\
\text { and } \\
\text { Cooperation }\end{array}$ \\
\hline
\end{tabular}


Table 2.4 : Matrix of Action Plan for Improving Public Expenditure Management

\begin{tabular}{|c|c|c|c|c|c|c|}
\hline Policy Area & $\begin{array}{l}\text { Objectives/ } \\
\text { Targets }\end{array}$ & $\begin{array}{c}\text { Measure } \\
\text { ( Strategies, Policies) }\end{array}$ & $\begin{array}{c}\text { Planned } \\
\text { Timetable }\end{array}$ & $\begin{array}{l}\text { Monitoring } \\
\text { indicators }\end{array}$ & $\begin{array}{l}\text { Reporting } \\
\text { Frequency }\end{array}$ & $\begin{array}{l}\text { Reporting } \\
\text { Agency }\end{array}$ \\
\hline $\begin{array}{l}\text { Enhance the role } \\
\text { of the National } \\
\text { Treasury to more } \\
\text { effectively record } \\
\text { revenues, } \\
\text { expenditures, and } \\
\text { bank and non- } \\
\text { bank financing of } \\
\text { the budget }\end{array}$ & $\begin{array}{l}\text { A. } \\
\text { Regulation and } \\
\text { procedure }\end{array}$ & $\begin{array}{l}\text { Decide/clarify on key strategic issues in the design of } \\
\text { the Treasury system and the role of commitment controls. } \\
\text { ( Short term technical assistance could facilitate } \\
\text { discussion of the option ) } \\
\text { 2. Complete draft of treasury Regulations and manual } \\
\text { of procedures, consistent with the agreed detailed } \\
\text { approach to treasury reform. ( Peripatetic technical } \\
\text { assistance may be required ) } \\
\text { 3. Integrate the treasury and Accounting Regulations in } \\
\text { a single set of regulations, while resolving any } \\
\text { inconsistencies with the various accounting regulations, } \\
\text { based on the board guidelines and subsequent experience. } \\
\text { ( Technical assistance may be required ). } \\
\text { 4. Integrate Treasury staff engaged within the Ministry } \\
\text { of Finance, to be accountable to the head of the central } \\
\text { Treasury, especially regarding central government bank } \\
\text { accounts. As appropriate, have the central Treasury } \\
\text { provide management services for treasury operations in } \\
\text { provinces and districts } \\
\text { 1. Every district to transmit data on revenue, expenditure } \\
\text { and treasury balances to provinces within } 10 \text { days after } \\
\text { month-end (with a longer time frame, such as } 15 \text { days, for } \\
\text { specified remote districts), to enable provinces to produce } \\
\text { consolidated monthly reports and transmit them to the } \\
\text { central treasury within } 15-20 \text { days after month-end, to } \\
\text { allow the production of a preliminary consolidated fiscal } \\
\text { report, fully reconciled with banking data, within } 25-30 \\
\text { days after the end of each month ( Training of district } \\
\text { staff needed ) } \\
\text { 2. Close monthly accounts at end-month uniformly for all } \\
\text { levels of the government, instead of closing them in some } \\
\text { districts on the } 20^{\text {th }} \text { of the month. ( Substantial training } \\
\text { required ) } \\
\text { Identify all extrabudgetary funds and require financial } \\
\text { reporting and accounting similar to that required for the } \\
\text { budget (e.g for the Road Fund, the Environmental Fund, } \\
\text { the Unexploded Ordinance Fund, and Poverty Fund ) }\end{array}$ & $\begin{array}{c}2004-2005 \\
2003 \\
2004 \\
\\
2003-2004 \\
2004-2005\end{array}$ & $\begin{array}{l}\text { Ministerial } \\
\text { order issued }\end{array}$ & $\begin{array}{l}\text { Monthly } \\
\text { Annual } \\
\text { Annual }\end{array}$ & $\begin{array}{c}\text { Treasury } \\
\text { Department }\end{array}$ \\
\hline
\end{tabular}


C.

\section{Government}

Banking

D.

Arrears
4. Publish the budgets of all extrabudgetary funds at the same time as the annual budget plan. Progressively

integrate into the budget framework all retained revenues and their corresponding expenditures.

1. Introduce a register of all government accounts operated with the authority of the Ministry of Finance. Update the register of government bank accounts as new accounts are opened and old accounts are closed.

2. Continue process of closing bank accounts established without treasury authorisation.

3. Minimise the delays in provincial transfers of central government revenues by establishing central government bank accounts at commercial banks located in large revenue centres without BOL branches, and promptly sweep those balances into BOL accounts.

4. Establish a system of daily consolidation of data on key treasury bank balances.

5. Consolidate government bank accounts for each of government.

6. Link all treasury accounts ( with adequate communications links into a single network of treasury accounts ( Technical assistance may be required )

1. Complete a census/survey conducted jointly by Treasury Department and Budget Department of expenditure arrears as at September 30, covering all type of expenditure nation wide, including all enterprises' balances with the treasury.

2. Formulate a time bound action plan of measures to : ( 1) clear arrears accumulated up until September 30 ( including revenue sources ); and (2) ensure that no new arrears are accumulated.

3. Monitor accounts payable, enterprises' balances at the treasury, and other arrears on a monthly basis

4. Gradually eliminate the stock of arrears revealed in census. This could be partly achieved through issuance of treasury paper.

5. Update the census of expenditure as of September including any new arrears accumulated during fiscal years
2003

2003

2002-2003

Register

completed in March 2003

2003-2004

Bank accounts closed by Sept.

2003-2004

2004-2005

2003

Reports being reviewed
Treasury

Department of MOF/BOL

Treasury/Bud get

Departments 


\begin{tabular}{|c|c|c|c|c|}
\hline $\begin{array}{c}\text { Continue } \\
\text { improvements in } \\
\text { the accounting } \\
\text { system by } \\
\text { extending the } \\
\text { nomenclature } \\
\text { system and } \\
\text { applying these } \\
\text { systems as } \\
\text { computerisation } \\
\text { continues }\end{array}$ & $\begin{array}{l}\text { Budget } \\
\text { classification }\end{array}$ & $\begin{array}{l}\text { Revise the budget classification for expenditures to : } \\
\text { (1) simplify the present classification by type of } \\
\text { expenditure; (2) identify administrative units within } \\
\text { ministries; and (3) introduce a level of government } \\
\text { classification (central, provincial, and district) } \\
\text { 2. Harmonise the accounting codes with the proposed } \\
\text { revised budget nomenclature } \\
\text { 3. Utilise the classification of expenditure by } \\
\text { administrative units in the education and health sectors } \\
\text { (Technical assistance may required) } \\
\text { 4. Extend use of revised classification to other sectors } \\
\text { in line with computerisation ( Technical assistance may } \\
\text { be required ) } \\
\text { 5. Adopt a multi-module budget and accounting } \\
\text { classification system in line with the computerisation of } \\
\text { all central ministries' and provinces' budgets, and budget } \\
\text { execution systems. In particular, introduce the functional } \\
\text { classification of expenditure (as defined in the IMF's } \\
\text { GFS Manual ) and “c cost centres “ } \\
\text { 6. Introduce a single system of coding for budgeting } \\
\text { and accounting to be used in the computerised system } \\
\text { being developed. }\end{array}$ & $\begin{array}{c}2003 \\
2003-2004 \\
2004-2005 \\
2004-2005\end{array}$ & $\begin{array}{l}\text { Accounting } \\
\text { Department }\end{array}$ \\
\hline \multirow[t]{2}{*}{$\begin{array}{l}\text { Budget preparation } \\
\text { procedure should be } \\
\text { revised to bring } \\
\text { forward the budget } \\
\text { preparation cycle to } \\
\text { provide a more } \\
\text { specific expenditure } \\
\text { framework early in } \\
\text { the fiscal year. } \\
\text { Comment controls } \\
\text { should be reviewed } \\
\text { for effectiveness and } \\
\text { efficiency } \\
\end{array}$} & $\begin{array}{c}\text { Budget } \\
\text { Improvement }\end{array}$ & $\begin{array}{l}\text { 1. Clarify the various regulation and instructions on } \\
\text { expenditure control, especially the implementation of pre- } \\
\text { disbursement controls, (including on commitment ) and } \\
\text { its degree of centralisation in conjunction with line } \\
\text { ministries and provinces } \\
\text { 2. Experiment with streamlining expenditure controls } \\
\text { by the Budget and the External Financial Relations } \\
\text { Departments for selected line ministries and provinces, } \\
\text { while preserving overall fiscal management. }\end{array}$ & $2002-2003$ & $\begin{array}{c}\text { Budget } \\
\text { Department } \\
\text { Budget and } \\
\text { External } \\
\text { Financial } \\
\text { Relations } \\
\text { Departments }\end{array}$ \\
\hline & Audit and Control & $\begin{array}{l}\text { 1. Transmit to the State Authority ( SAA) the budget outcome } \\
\text { 2. The SAA to report to the National Assembly on the } \\
\text { consolidated fiscal account } \\
\text { 3. Review the role and responsibilities of the various internal } \\
\text { control and audit agencies in the MOF, the Prime Minister's } \\
\text { Office, and in spending ministries } \\
\text { 4. Rationalize the various inspection and internal audit agencies. }\end{array}$ & $\begin{array}{c}2003 \\
2003 \\
2004 \\
2004-2005\end{array}$ & $\begin{array}{l}\text { National } \\
\text { Audit } \\
\text { Authority }\end{array}$ \\
\hline
\end{tabular}


Table 2.5 : Consolidated Matrix regarding policy priorities for the financial sector

\begin{tabular}{|c|c|c|c|c|c|c|}
\hline Policy Area & $\begin{array}{l}\text { Objectives/ } \\
\text { Targets }\end{array}$ & $\begin{array}{c}\text { Measure } \\
\text { ( Strategies, Policies) }\end{array}$ & $\begin{array}{l}\text { Planned } \\
\text { Timetable }\end{array}$ & $\begin{array}{l}\text { Monitoring } \\
\text { indicators }\end{array}$ & $\begin{array}{l}\text { Reporting } \\
\text { Frequency }\end{array}$ & $\begin{array}{l}\text { Reporting } \\
\text { Agency }\end{array}$ \\
\hline $\begin{array}{l}\text { Promote } \\
\text { sustainable } \\
\text { growth through a } \\
\text { viable financial } \\
\text { sector and } \\
\text { Strengthen macro- } \\
\text { economic stability }\end{array}$ & $\begin{array}{l}\text { Control of domestic } \\
\text { asset net through } \\
\text { managing money } \\
\text { supply indicated as } \\
\text { M2/GDP. } \\
\text { M2 growth should } \\
\text { not be increased by } \\
18 \% \text { in annual } \\
\text { average }\end{array}$ & $\begin{array}{l}\text { Implementation of multi policy } \\
\text { measures by using more indirect } \\
\text { instrument ( open market, reserve } \\
\text { requirement, credit ceiling ) }\end{array}$ & 2003-2005 & 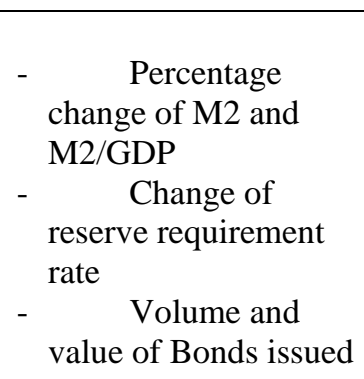 & $\begin{array}{l}\text { Monthly, quarterly } \\
\text { and annual report } \\
\text { on Monetary survey } \\
\text { and BOL official } \\
\text { report }\end{array}$ & $\begin{array}{l}\text { BoL and IFIs } \\
\text { review } \\
\text { mission report }\end{array}$ \\
\hline $\begin{array}{l}\text { Bank Credit } \\
\text { Allocation }\end{array}$ & $\begin{array}{l}\text { - Credit should not } \\
\text { increase more than } \\
21 \% \text { as an annual } \\
\text { average. } \\
\text { - Induced } \\
\text { credit culture by } \\
\text { ensuring that } \\
\text { formal } \\
\text { governance } \\
\text { structure are } \\
\text { applies } \\
\text { - Ensure } \\
\text { greater access to } \\
\text { financing by } \\
\text { creditworthy } \\
\text { private sector } \\
\text { borrowers }\end{array}$ & $\begin{array}{l}\text { All Credits allocation to meet } \\
\text { commercial basis to support } \\
\text { - Use an appropriate interest rate } \\
\text { according to the money demand and } \\
\text { supply } \\
\text { - Improved Credit Risk management } \\
\text { and commercial analysis for credit } \\
\text { generation, } \\
\text { - Improved financial disclosure by } \\
\text { borrowers }\end{array}$ & 2003-2005 & $\begin{array}{l}\text { - Growth of } \\
\text { credit for } 2003 \text { will } \\
\text { be limited to } 18 \% \\
\text { - Interest rate } \\
\text { monitoring report } \\
\text { BOL prudential } \\
\text { Supervision reports and } \\
\text { compliance on asset } \\
\text { quality and risk } \\
\text { management by on site } \\
\text { and off- site audits. } \\
\text { Financial reports and } \\
\text { audited accounts. }\end{array}$ & $\begin{array}{l}\text { - Monthly, } \\
\text { quarterly an } \\
\text { annual report on } \\
\text { Interest rate } \\
\text { monitoring } \\
\text { statistics report, } \\
\text { Monetary } \\
\quad \text { survey, } \\
\text { supervision } \\
\text { report } \\
\text { Quarterly }\end{array}$ & $\begin{array}{l}\text { BoL, MOF, } \\
\text { SOCB and } \\
\text { IFIs review } \\
\text { mission report }\end{array}$ \\
\hline
\end{tabular}




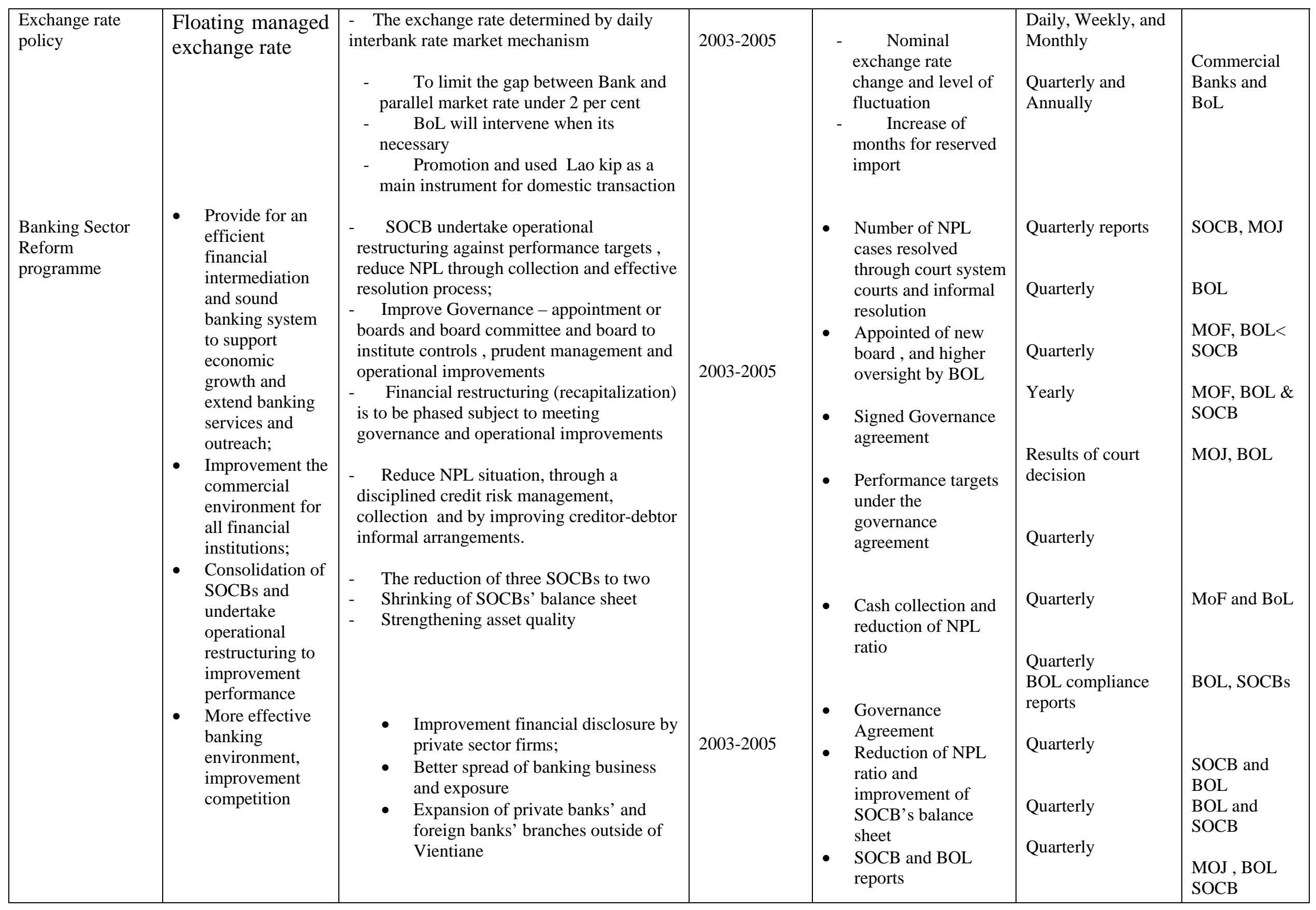




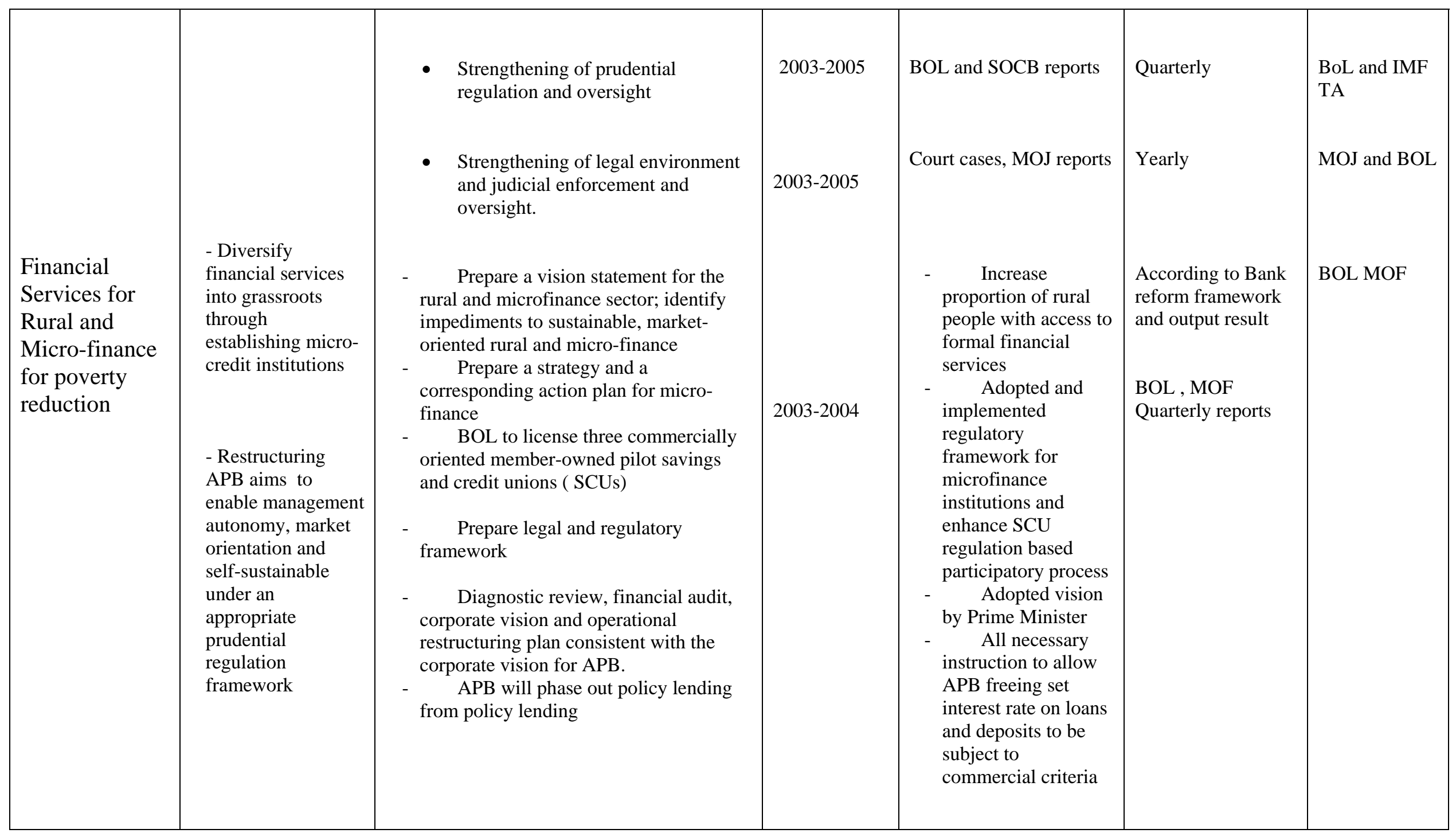




\section{Table 2.6 : Matrix of Main Priority Governance Initiatives 2003-2010}

\section{(Selected NGPES related elements)}

\section{Governance Programme Component 1: Public Service Improvements}

1. Strategic objective: Development of a cost-effective and people's centered public administration and development of a productive, highly motivated, professional and ethical public service;

- Staff attitudes shifted from compliance into commitment to citizen's satisfaction

- Personnel expenditures reduced and under control, more rational and efficient use of CS human resource

- Enhanced motivation, involvement and productivity of civil servants

- $\quad$ Promotion of examples of good customer service, creativity and innovation in the CS

- Reduced corruption and more honest, transparent and accountable the Civil Service

- Development of the civil service ethos and civil servant involvement in high quality governance

- Implementation of citizens' right to complain

\begin{tabular}{|c|c|c|c|}
\hline Priority governance Initiative & Expected products (outputs) & $\begin{array}{c}\text { Indicative time } \\
\text { table } \mathbf{e}^{1}\end{array}$ & Responsible agency \\
\hline $\begin{array}{l}\text { Approval of the Law on Local Administration and review of } \\
\text { laws, decrees and regulations on the organization and } \\
\text { functioning of the government }\end{array}$ & $\begin{array}{l}\text { Law on Local Administration adopted } \\
\text { Laws and regulations on the organization of the } \\
\text { government revised }\end{array}$ & $2003-2004$ & DPACS, MoJ, all ministries \\
\hline $\begin{array}{l}\text { Functional reviews and process improvements (organizations } \\
\text { playing a key role in the poverty alleviation) }\end{array}$ & $\begin{array}{l}\text { Missions, objectives, functions, structures and processes } \\
\text { of pilot offices and organizations revised and their needs } \\
\text { of HR assessed }\end{array}$ & $\begin{array}{l}\text { ST (2003) } \\
\text { ST (2004) }\end{array}$ & $\begin{array}{l}\text { DPACS and organizations } \\
\text { concerned }\end{array}$ \\
\hline $\begin{array}{l}\text { Civil service rightsizing \& redeployment (from central to local } \\
\text { levels) and accompanying measures }\end{array}$ & Number of civil servants reduced about $5 \%$ & 2005 & DPACS and all O\&P Dep. \\
\hline $\begin{array}{l}\text { Study on possible transfer to non governmental sector of certain } \\
\text { public service delivery functions }\end{array}$ & Report identifying transferable public services & MT & DPACS and BDO \\
\hline $\begin{array}{l}\text { Establish service standards, and ensure broader public access to } \\
\text { the government organizations' performance reports }\end{array}$ & Service standards for selected service delivering offices & M\&LT & As above \\
\hline $\begin{array}{l}\text { Promotion of improved service delivery through administrative } \\
\text { innovation }\end{array}$ & $\begin{array}{l}\text { Pilot initiatives to be defined, developed, tested, } \\
\text { assessed and best practices disseminated }\end{array}$ & S\&MT & As above \\
\hline
\end{tabular}

${ }_{1}^{1}$ ST - Short Term (1-2 years), MT - Medium Term (2-3 years), M\&LT - Medium-Long Term (3-5 years), LT - Long Term (more then 5 years), PA- permanent activity 
Publication of manuals and information brochures on the organization and mandates of governmental organizations

Development of more service oriented public servant training

programs

Implementation of the new salary scale

Improvement of the National Award system for organizational

units and individuals

Upgrading PM anticorruption decree to the level of Law

Prepare a Code of Ethics for political leadership and other

priority targets groups (tax and customs)

Improve the system of handling grievances and procedures

protecting whistleblowers

Disseminate provisions of the new Civil Service Statute related

to ethics, conflict of interests and abuse of office

Promote and reward ethical conduct in the management of the

public service, conduct regular training on anti-corruption in

government agencies

\begin{tabular}{|l|l|l|}
\hline $\begin{array}{l}\text { Manuals, brochures and directories of services published } \\
\text { and disseminated }\end{array}$ & S\&MT & As above \\
\hline Revised training programs & 2004 & $\begin{array}{l}\text { DPACS and } \\
\text { NOSPA }\end{array}$ \\
\hline New salary scale adopted and implemented & MT & MOF (DB) \& DPACS \\
\hline $\begin{array}{l}\text { Renewed Award system implemented and largely } \\
\text { publicized }\end{array}$ & S\&MT & DPACS \\
Draft anticorruption Law & MT & MOJ, PMC \\
\hline $\begin{array}{l}\text { Codes of ethics for priority targets groups drafted, } \\
\text { largely discussed and adopted }\end{array}$ & MT & DPACS \\
\hline $\begin{array}{l}\text { Department of Public Grievances of the State Inspection } \\
\text { Authority created and operational }\end{array}$ & S\&MT & SIA \\
\hline $\begin{array}{l}\text { New Civil Service Statute largely disseminated } \\
\text { Training sessions on anti-corruption }\end{array}$ & S\&MT & DPACS \\
\hline
\end{tabular}

\section{Governance Programme Component 2: People's Participation}

1. Strategic objective: Promoting a dynamic, more open, transparent and participatory society

- Legal framework facilitating further development of the CSA

- Increased participation of women in national and local governance

- Increased opportunities for Lao youth to express their concerns, expectations and ideas

- Increased citizen knowledge of government policies and programs

- Greater public awareness of critical social and economic issues

- Public administration more transparent, accessible and understandable for public

\begin{tabular}{|c|c|c|c|}
\hline Priority Governance Initiative & Expected products(outputs) & $\begin{array}{c}\text { Indicative time } \\
\text { table }\end{array}$ & Responsible agency \\
\hline $\begin{array}{l}\text { Development of legal framework for civil society associations } \\
\text { (CSA) }\end{array}$ & $\begin{array}{l}\text { Transparent rules for approval and cooperation with } \\
\text { civil society associations }\end{array}$ & MT & $\begin{array}{l}\text { MOJ, } \\
\text { National Assembly, }\end{array}$ \\
\hline $\begin{array}{l}\text { Development and implementation of Gender Mainstreaming } \\
\text { Strategy }\end{array}$ & $\begin{array}{l}\text { Gender Mainstreaming Strategy adopted } \\
\text { Seminars for government officials; }\end{array}$ & $\begin{array}{l}\text { ST } \\
\text { S\&MT }\end{array}$ & Lao Women's Union \\
\hline Enhancement of knowledge of governance among youth & Project conceived and launched & S\&MT & Lao Youth Union, MIC \\
\hline
\end{tabular}


Regulations opening access to information on public administration activities for the public

Increase availability and dissemination of laws and regulations, government policies and programs

Establishment of "Information Centers" for the public in district administration office

Use of village meetings to inform population about

development programs, budget allocation and service delivery
PM decree drafted and adopted

Regularly updated legal data base in the Internet website informing about government policies

nformation Centers progressively established, equipped, staffed and operating

Village meetings with government officials organized

periodically and on specific occasions when necessary

\begin{tabular}{|l|l|}
\hline M-LT & PMO \\
\hline $\begin{array}{l}\text { ST } \\
\text { M\&LT }\end{array}$ & POM, MÓJ, \\
\hline M\&LT & MIC \\
\hline PA & CPC \\
\hline
\end{tabular}

\section{Strategic objective: Redefining central-local relations - bringing services closer to the people}

- Progressive poverty alleviation through delivery of cost effective and easy accessible basic services for rural poor

- Improved legal framework for decentralized governance

- Development and empowerment of larger and more viable local communities

- Development of participatory municipal administration in urban areas

- Improved development planning and management at provincial, district and Kum Ban level

- Improved Human Capacity at the local level, attracted qualified personnel to work in rural district administration

- Increased gender equality in participation and control over local development

\begin{tabular}{|c|c|c|c|}
\hline Priority Governance Initiative & Expected products (outputs) & $\begin{array}{c}\text { Indicative time } \\
\text { table }\end{array}$ & Responsible agency \\
\hline $\begin{array}{l}\text { Develop capacity of provincial level as strategic unit responsible } \\
\text { for macro-management at local levels able to formulate their } \\
\text { own socio-economic plans }\end{array}$ & $\begin{array}{l}\text { Functional and organizational reviews, process re- } \\
\text { engineering, staffing plans and job descriptions, process } \\
\text { and job oriented training, }\end{array}$ & S\&MT & CPC, DPACS, Governors \\
\hline $\begin{array}{l}\text { Transform district with high economic potential into separate } \\
\text { budgetary units and benefit districts with low capacity of } \\
\text { provincial level support }\end{array}$ & $\begin{array}{l}\text { Identification and classification of the districts with high } \\
\text { economic potential, definition of the legal framework } \\
\text { and progressive implementation }\end{array}$ & M\&LT & $\begin{array}{l}\text { MOF, DPACS, concerned } \\
\text { governors }\end{array}$ \\
\hline $\begin{array}{l}\text { Develop districts' capacity as main level of development project } \\
\text { implementation, }\end{array}$ & $\begin{array}{l}\text { Development of Guidelines for Planning and } \\
\text { Management of Development Project }\end{array}$ & M\&LT & $\begin{array}{l}\text { Provincial authorities } \\
\text { DPACS, CPC } \\
\end{array}$ \\
\hline $\begin{array}{l}\text { Promote development of kum ban and project planning and } \\
\text { implementation on kum ban level }\end{array}$ & $\begin{array}{l}\text { Kum Ban promoted and developed, guidelines for } \\
\text { selection of villages in view to create kum ban }\end{array}$ & $\begin{array}{l}\text { S\&MT } \\
\text { PA }\end{array}$ & $\mathrm{CPC}$ \\
\hline $\begin{array}{l}\text { Develop new organizational and institutional modalities for } \\
\text { urban management, expand development of UDAA }\end{array}$ & $\begin{array}{l}\text { Institutional model and new organizational methods for } \\
\text { urban management tested and progressively expended }\end{array}$ & S\&MT & DPACS, MOF \\
\hline $\begin{array}{l}\text { Implement of pilot projects at central and local level to support } \\
\text { new decentralization policy }\end{array}$ & Pilot projects supporting decentralization implemented & S\&MT & DPACS, CPC \\
\hline Ensure data and statistics on local development & Data and statistics available & S\&MT PA & CPC, NSC \\
\hline $\begin{array}{l}\text { Develop legal framework for farther development of Local } \\
\text { Administration and creation of municipalities }\end{array}$ & $\begin{array}{l}\text { Law on Local Administration adopted } \\
\text { Instruction 01/PM reviewed and upgraded as decree } \\
\text { Municipal Law drafted and approved } \\
\end{array}$ & $2003-4$ & $\begin{array}{l}\text { National Assembly } \\
\text { CPC, DPACS, MOF \& MOJ }\end{array}$ \\
\hline
\end{tabular}




\begin{tabular}{|c|c|c|c|}
\hline $\begin{array}{l}\text { Mainstream gender issues in local level planning, Introduce } \\
\text { gender monitoring in local governance }\end{array}$ & $\begin{array}{l}\text { Women promotion activities, Conception and pilot } \\
\text { experiences, GRID training program for gender sensitive } \\
\text { planning at the local level }\end{array}$ & PA & LWU \\
\hline $\begin{array}{l}\text { Develop a comprehensive capacity building program addressing } \\
\text { decentralization management }\end{array}$ & $\begin{array}{l}\text { Training programs on planning, budgeting and } \\
\text { management for local staff, }\end{array}$ & S\&MT & DPACS, NOSPA \\
\hline $\begin{array}{l}\text { Further dissemination of laws and regulations targeted at the } \\
\text { local administration and local population, using popular, } \\
\text { accessible language }\end{array}$ & Laws and regulation largely disseminated & PA & MOJ, MIC, DPACS \\
\hline $\begin{array}{l}\text { Exchange of experiences with the ASEAN neighbors and } \\
\text { organizations specialized in the local governance }\end{array}$ & Exchange of experience periodically organized & PA & DPACS \\
\hline $\begin{array}{l}\text { Improve working conditions and create incentives for staff of } \\
\text { rural districts }\end{array}$ & $\begin{array}{l}\text { Improved working conditions and new incentives } \\
\text { developed and implemented }\end{array}$ & S\&MT & $\begin{array}{l}\text { DPACS, MOF } \\
\text { District authorities }\end{array}$ \\
\hline $\begin{array}{l}\text { Make appointments in remote districts compulsory during } \\
\text { probation period }\end{array}$ & $\begin{array}{l}\text { Compulsory appointment during probation period } \\
\text { introduced }\end{array}$ & S\&MT & DPACS \\
\hline $\begin{array}{l}\text { Link the monitoring of local governance development and } \\
\text { capacity building programs with the NGPES }\end{array}$ & Link established (procedures to define) & MT & $\begin{array}{l}\text { DPACS, CPC } \\
\text { Local authorities }\end{array}$ \\
\hline $\begin{array}{l}\text { Develop mechanisms adjusting local government development } \\
\text { activities to local constraints, needs and priorities, analyze } \\
\text { impact of decentralization policy on poverty }\end{array}$ & $\begin{array}{l}\text { Built-in adjustment mechanisms } \\
\text { Periodic (annual) reports on the impact }\end{array}$ & MT & DPACS, local authorities \\
\hline $\begin{array}{l}\text { Develop civic education programs on decentralization, } \\
\text { accountability and transparency in local government }\end{array}$ & $\begin{array}{l}\text { Civic education programs on decentralization and local } \\
\text { government developed, approved and implemented }\end{array}$ & MT & MOE, DPACS \\
\hline $\begin{array}{l}\text { Ensure involvement of the local populations in project } \\
\text { monitoring and evaluation of the projects }\end{array}$ & Pilot testing of public hearings, workshops & MT & Local authorities \\
\hline $\begin{array}{l}\text { Create dissemination mechanisms for successful initiatives and } \\
\text { projects }\end{array}$ & $\begin{array}{l}\text { Best practices identified and replicated in other } \\
\text { provinces and districts }\end{array}$ & MT & DPACS, CPC, MIC, Media \\
\hline $\begin{array}{l}\text { Recognize and award activities successfully addressing poverty } \\
\text { alleviation and improvements in local governance. }\end{array}$ & Improved National Award System & MT & $\begin{array}{l}\text { DPACS, CCOP and local } \\
\text { authorities }\end{array}$ \\
\hline
\end{tabular}

\section{Governance Programme component 3: Rule of Law and Access to Justice}

1. Strategic objective: Establishment of a complete, clear and coherent legal framework, ensuring predictable and transparent mechanisms for legal enforcement

- Increased public awareness of laws and the role of the legal sector

- Increased transparency in court decisions

- Better qualified judges giving consistent and transparent decisions

- Improve effectiveness and efficiency of courts 
- Increased awareness of laws among the population at large

\begin{tabular}{|c|c|c|c|}
\hline $\begin{array}{l}\text { Strengthen the capacity of the National Assembly } \\
\text { to propose, evaluate and approve sound legislation }\end{array}$ & $\begin{array}{l}\text { Legislative skills training, policy research } \\
\text { and impact assessment support }\end{array}$ & S M LT & NA \\
\hline $\begin{array}{l}\text { Continue the comprehensive compilation and } \\
\text { regular updating and large dissemination of } \\
\text { legislation }\end{array}$ & $\begin{array}{l}\text { More frequent publication and wider } \\
\text { distribution of the Official Gazette } \\
\text { CD-Rom containing legal data base of all } \\
\text { decrees and laws }\end{array}$ & $\begin{array}{l}2004 \\
\text { S M LT }\end{array}$ & MOJ \\
\hline $\begin{array}{l}\text { Establish manual of legal guidelines for ministries } \\
\text { and justice official at provincial and district levels. }\end{array}$ & $\begin{array}{l}\text { Manual produced } \\
\text { Training on use of manual prepared and } \\
\text { presented }\end{array}$ & $2003 / 4$ & $\mathrm{MOJ} / \mathrm{MOF}$ \\
\hline $\begin{array}{l}\text { Continue to enhance co-operation with other } \\
\text { agencies in order to ensure improvements in the } \\
\text { legal enforcement of court decisions. }\end{array}$ & $\begin{array}{l}\text { Regulations concerning division of } \\
\text { responsibilities between different agencies } \\
\text { approved, Law on Economic Dispute } \\
\text { Resolution approved by NA }\end{array}$ & ST & $\begin{array}{l}\text { MOJ/ PSC/ OPP/ } \\
\text { Ministry of Public } \\
\text { Security }\end{array}$ \\
\hline $\begin{array}{l}\text { Systematic publication of law books and manuals } \\
\text { and supply them to public facilities across the } \\
\text { country }\end{array}$ & $\begin{array}{l}\text { Books in each area published and distributed } \\
\text { Publication of practical manual for legal } \\
\text { dissemination Establish law journal }\end{array}$ & $\begin{array}{l}2003 \\
\text { PA, MT }\end{array}$ & MÓJ \\
\hline $\begin{array}{l}\text { Strengthen knowledge of the law through the local } \\
\text { schooling system }\end{array}$ & $\begin{array}{l}\text { Legal awareness components in secondary } \\
\text { school curriculum established }\end{array}$ & S MT & $\mathrm{MOJ} / \mathrm{MOE}$ \\
\hline $\begin{array}{l}\text { Provide legal training for legal staff at central and } \\
\text { local levels }\end{array}$ & $\begin{array}{l}\text { Action plan and curriculum for training of } \\
\text { trainers, short and long term training plan for } \\
\text { judges }\end{array}$ & S MT & MOJ/PSC/OPP \\
\hline $\begin{array}{l}\text { Speed up case resolution and improve decision- } \\
\text { making. }\end{array}$ & $\begin{array}{l}\text { Progressive reduction in number of district } \\
\text { courts to ensure sufficient number of } \\
\text { qualified judges at each court }\end{array}$ & $\begin{array}{l}\text { 2003/4 } \\
\mathrm{MT}\end{array}$ & $\mathrm{MOJ} / \mathrm{PSC}$ \\
\hline
\end{tabular}

2. Strategic objective: Improving the ability of all the peoples of Lao PDR to access the justice system.

\section{Strengthening the informal and formal mechanisms for dispute resolution}

- Easier access of the public to the legal services, streamlining of their delivery, facilitation of the training for public officials

- Better access to justice for disadvantaged groups

- Better understanding on the part of officials of the needs of priority groups

- More efficient and cost-effective alternatives to the formal court system

- Increased public confidence in the court system 


\begin{tabular}{|c|c|c|c|}
\hline Priority Governance Initiative & Expected products (outputs) & Indicative time table & Responsible agency \\
\hline $\begin{array}{l}\text { Create appeals courts and people's courts at the } \\
\text { provincial level, as well as mediation and military } \\
\text { courts. Strengthen mediation units at the village level. }\end{array}$ & $\begin{array}{l}\text { Establishment of appellate court with trained judges, } \\
\text { infrastructure and supporting staff appointed }\end{array}$ & M LT & $\mathrm{NA} / \mathrm{PSC}$ \\
\hline Improve capacity of village mediation units & $\begin{array}{l}\text { Training of mediators and establishing district justice } \\
\text { officers that facilitate and supervise the work of mediators }\end{array}$ & MT & MOJ \\
\hline $\begin{array}{l}\text { Strengthen the Bar Association to enable it to better } \\
\text { provide legal services to disadvantaged group }\end{array}$ & $\begin{array}{l}\text { Build management structure and capacity, establish } \\
\text { regulations for collecting and disbursing own revenue }\end{array}$ & S MT & MÓJ \\
\hline $\begin{array}{l}\text { Implement the policy of free legal assistance provided } \\
\text { by justice departments and district level to those in need }\end{array}$ & Regulations on priority assistance drafted and approved & S M LT & MOJ \\
\hline $\begin{array}{l}\text { Develop translation services for people of different } \\
\text { language background }\end{array}$ & Feasibility study completed & ST & MOJ \\
\hline $\begin{array}{l}\text { Restructure and update the office responsible for } \\
\text { providing legal advice to women }\end{array}$ & Office upgraded & ST & Lao Women's Union \\
\hline $\begin{array}{l}\text { Research, enhance and monitor the implementation of } \\
\text { measures to ensure the respect of women and children's } \\
\text { rights }\end{array}$ & $\begin{array}{l}\text { Reports on the fulfillment of Lao PDR's international } \\
\text { commitments } \\
\text { Collaborate with regional neighbors in monitoring of } \\
\text { trafficking in women and children }\end{array}$ & $\mathrm{PA}$ & $\begin{array}{l}\text { Lao Women's Union / MOJ/ } \\
\text { Min Labor and Social } \\
\text { Welfare/ MOFA }\end{array}$ \\
\hline
\end{tabular}

\section{Part 4: Sound Financial Management}

\section{Accountability and Transparency in Financial Management}

1. Strategic objective: Development of a sound fiscal policy and implementation of equitable revenue collection

- Planned national revenues ensured and remitted to the central treasury on a timely basis

- Increased tax base

- Rationalize fairly the incomes between various strata of society

- Taxpayers identified and treated in a fair and equitable fashion across all provinces

- Effective decentralisation of revenue collection

\begin{tabular}{|c|c|c|c|}
\hline Priority Governance Initiative & Expected products (outputs) & $\begin{array}{c}\text { Indicative time } \\
\text { table }\end{array}$ & Responsible agency \\
\hline $\begin{array}{l}\text { Revise definition of national, provincial, and district taxes and } \\
\text { monitor implementation at the provincial and district level, draft and } \\
\text { approve new laws (e.g. Tax Law) }\end{array}$ & $\begin{array}{l}\text { New tax laws in place } \\
\text { Decree \#192 amended } \\
\text { Monitoring system developed and in place }\end{array}$ & $\begin{array}{l}\text { MT } \\
\text { ST }\end{array}$ & $\begin{array}{c}\text { MoF } \\
\text { DPACS }\end{array}$ \\
\hline Review performance of the existing tax rates & $\begin{array}{l}\text { Development of review methodology } \\
\text { Implementation of review }\end{array}$ & $\mathrm{PA}$ & $\mathrm{MoF}$ \\
\hline
\end{tabular}




\begin{tabular}{|c|c|c|c|}
\hline Priority Governance Initiative & Expected products (outputs) & $\begin{array}{c}\text { Indicative time } \\
\text { table }\end{array}$ & Responsible agency \\
\hline Consider the strengthening of the personal income tax system & Review and revision of personal income tax system & LT & MoF \\
\hline Review policy to promote growth of SMEs & Ongoing review of SME growth support policy & $\mathrm{PA}$ & MoF \\
\hline $\begin{array}{l}\text { Introduce more efficient and transparent procedures for collecting } \\
\text { taxes from the small taxpayer community. }\end{array}$ & New procedures/guidelines for small taxpayer collection & PA & MoF \\
\hline $\begin{array}{l}\text { Develop a comprehensive training program. Includes establishment } \\
\text { of a tax and customs training center }\end{array}$ & $\begin{array}{l}\text { Needs assessment completed, training program developed } \\
\text { Training center opened }\end{array}$ & ST & $\mathrm{MoF}$ \\
\hline
\end{tabular}

2. Strategic objective: Development of transparent and accountable practices for expenditure planning and management and modernisation of the accounting system

- Spending patterns reflecting local priorities

- Budget preparation based on decentralized and bottom-up process

- Timely central government transfers to deficit provinces

- Application of new public sector procedures across the country at ministry and provincial level

- More effective revenue collection, more realistic, rational expenditure planning

\begin{tabular}{|c|c|c|c|}
\hline Priority Governance Initiative & Expected products (outputs) & $\begin{array}{c}\text { Indicative time } \\
\text { table }\end{array}$ & Responsible agency \\
\hline $\begin{array}{l}\text { Take steps to control or prevent new expenditure arrears. If } \\
\text { resources are available, take steps to clear stock of existing arrears }\end{array}$ & $\begin{array}{l}\text { Guidelines on prevention of expenditure arrears } \\
\text { Reduced level of expenditure arrears }\end{array}$ & ST & MoF \\
\hline Start to report expenditure arrears on a monthly basis & Monthly report on arrears & ST & $\mathrm{MoF}$ \\
\hline $\begin{array}{l}\text { Develop a plan and secure donor support for extending public } \\
\text { accounting regulations, procedures and system to all ministries and } \\
\text { all provinces. }\end{array}$ & $\begin{array}{l}\text { New accounting regulations, procedures and systems in all } \\
\text { ministries and provinces }\end{array}$ & MT & $\begin{array}{l}\text { MoF, and other } \\
\text { ministries }\end{array}$ \\
\hline
\end{tabular}

3. Strategic objective: Ensuring accountable and transparent management of ODA

- Improved project management at local level

- More harmonised project documentation, accounting, procurement and reporting system

- Co-ordination of monitoring and evaluation capacity across CPC and line ministries

- All ODA to have a capacity-building component

- All projects and programs designed taking into account past experience

\begin{tabular}{|c|c|c|c|}
\hline Priority Governance Initiative & Expected products (outputs) & $\begin{array}{l}\text { Indicative time } \\
\text { table }\end{array}$ & Responsible agency \\
\hline $\begin{array}{l}\text { Strengthen the capacity of the CPC and the line ministries for } \\
\text { the monitoring and evaluation of projects: }\end{array}$ & $\begin{array}{l}\text { Needs analysis and resultant training programs } \\
\text { Revised M\&E procedures, regular impact evaluation reports }\end{array}$ & $\begin{array}{l}\text { ST } \\
\text { MT }\end{array}$ & $\mathrm{CPC}$ \\
\hline $\begin{array}{l}\text { Develop and implement training program for improving project } \\
\text { planning and project management at the local levels }\end{array}$ & Training materials and program & MT & $\mathrm{CPC}$ \\
\hline
\end{tabular}




\begin{tabular}{|c|c|c|c|}
\hline $\begin{array}{l}\text { Streamline and harmonise project planning, budgeting and } \\
\text { monitoring procedures and methodologies, in concert with the } \\
\text { donors: }\end{array}$ & $\begin{array}{l}\text { Projects incorporated in ledgers and monthly reports, all } \\
\text { disbursements of donor-supported projects included in } \\
\text { treasury ledgers and all project accounts are transferred to } \\
\text { the national treasury }\end{array}$ & ST & $\mathrm{CPC}$ \\
\hline $\begin{array}{l}\text { Promotion of government-donor partnerships related to the } \\
\text { governance program and the NGPES }\end{array}$ & Streamlined co-ordination and reporting procedures. & ST & $\mathrm{CPC}$ \\
\hline $\begin{array}{l}\text { Streamline the distribution of responsibilities between } \\
\text { government agencies involved in the management and co- } \\
\text { ordination of aid. }\end{array}$ & Clearly documented delineation of responsibilities & MT & $\mathrm{CPC}$ \\
\hline
\end{tabular}

\section{Strategic objective: Improving efficiency in land management and administration}

- Full harmonisation of all laws and regulations

- Alternative approaches for land use allocation

\begin{tabular}{|c|c|c|c|}
\hline Priority Governance Initiative & Expected products (outputs) & $\begin{array}{c}\text { Indicative time } \\
\text { table }\end{array}$ & $\begin{array}{c}\text { Responsible } \\
\text { government agency }\end{array}$ \\
\hline $\begin{array}{l}\text { Harmonize the different laws with a view to improving the } \\
\text { coherence of the various laws. Draft and approve related regulations }\end{array}$ & Regulations in place & MT & MoF \\
\hline Take steps, over time, to finalize land use rights in the country. & To be defined & MT & $\mathrm{MoF}$ \\
\hline $\begin{array}{l}\text { Examine methodology used for land allocation, and given the } \\
\text { problems experienced, develop alternative approaches }\end{array}$ & Research document presenting alternatives & ST & MoF \\
\hline $\begin{array}{l}\text { Carryout planned policy dialogue to review policies and strategies } \\
\text { for land administration }\end{array}$ & Policy dialogue meeting & ST & MoF \\
\hline
\end{tabular}




\section{Annex 3}

\section{(Sector/Cross-sector and National Programmes Matrices)}

Table 3.1: Policy/Programme Development Matrix for the Agricultural/Forestry Sector Table 3.2: Policy/Programme Development Matrix for the Education Sector Table 3.3: Policy/Programme Development Matrix for the Health Sector Table 3.4: Policy/Programme Development Matrix for the Transport Sector Table 3.5: Policy/Programme Development Matrix for Gender Equity Table 3.6: Policy/Programme Development Matrix for Environmental Conservation Table 3.7: Projects Concerning the National Drug Control Programme Table 3.8: UXO Contamination Data by Province/District Table 3.9: Policy/Programme Matrix for the Prevention of HIV/AIDS Table 3.10: Trade Matrix 


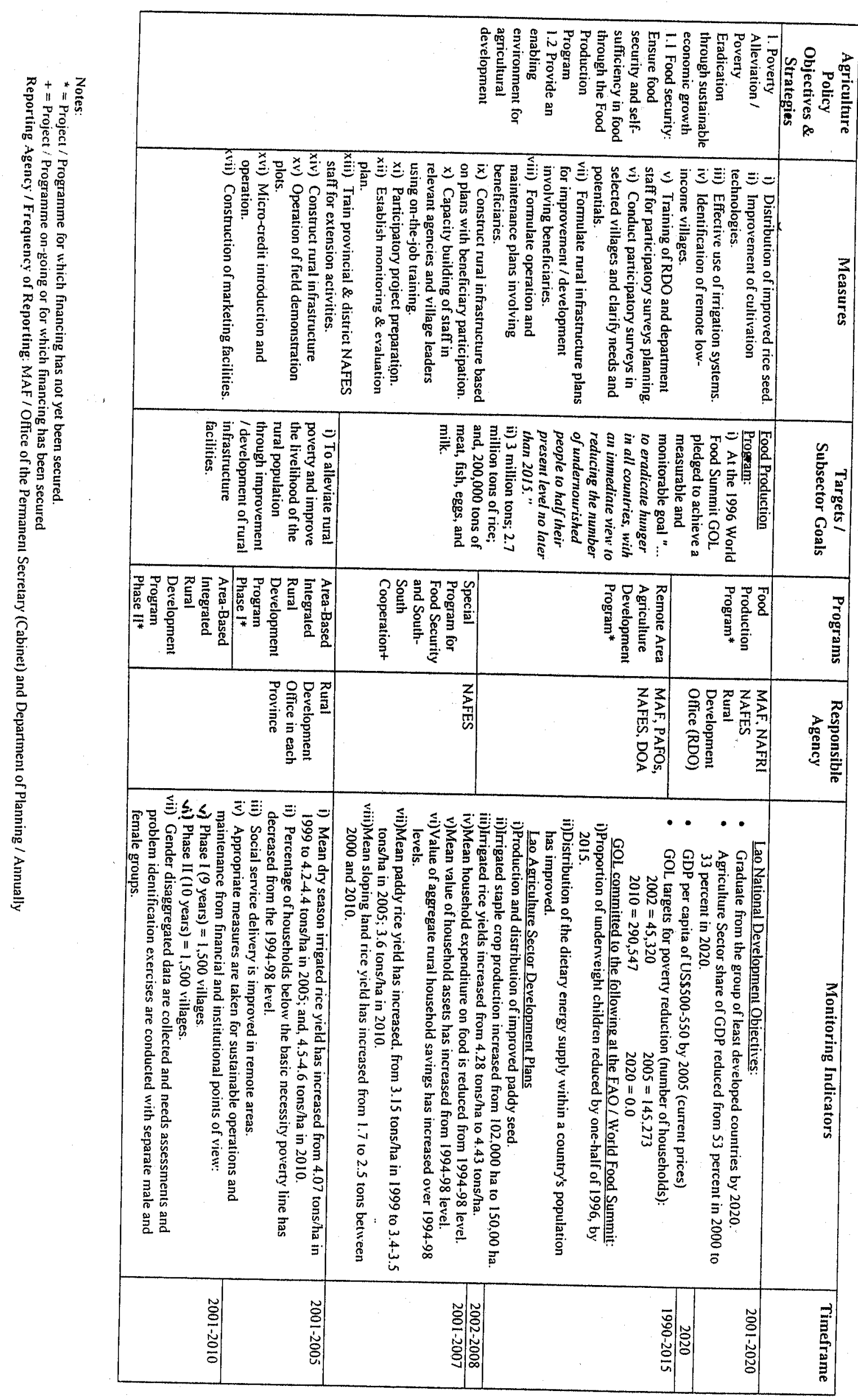

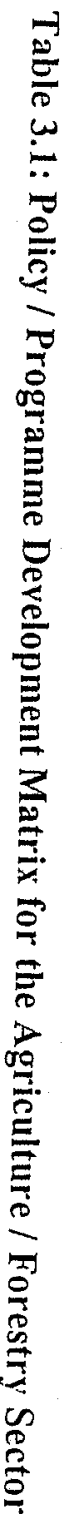




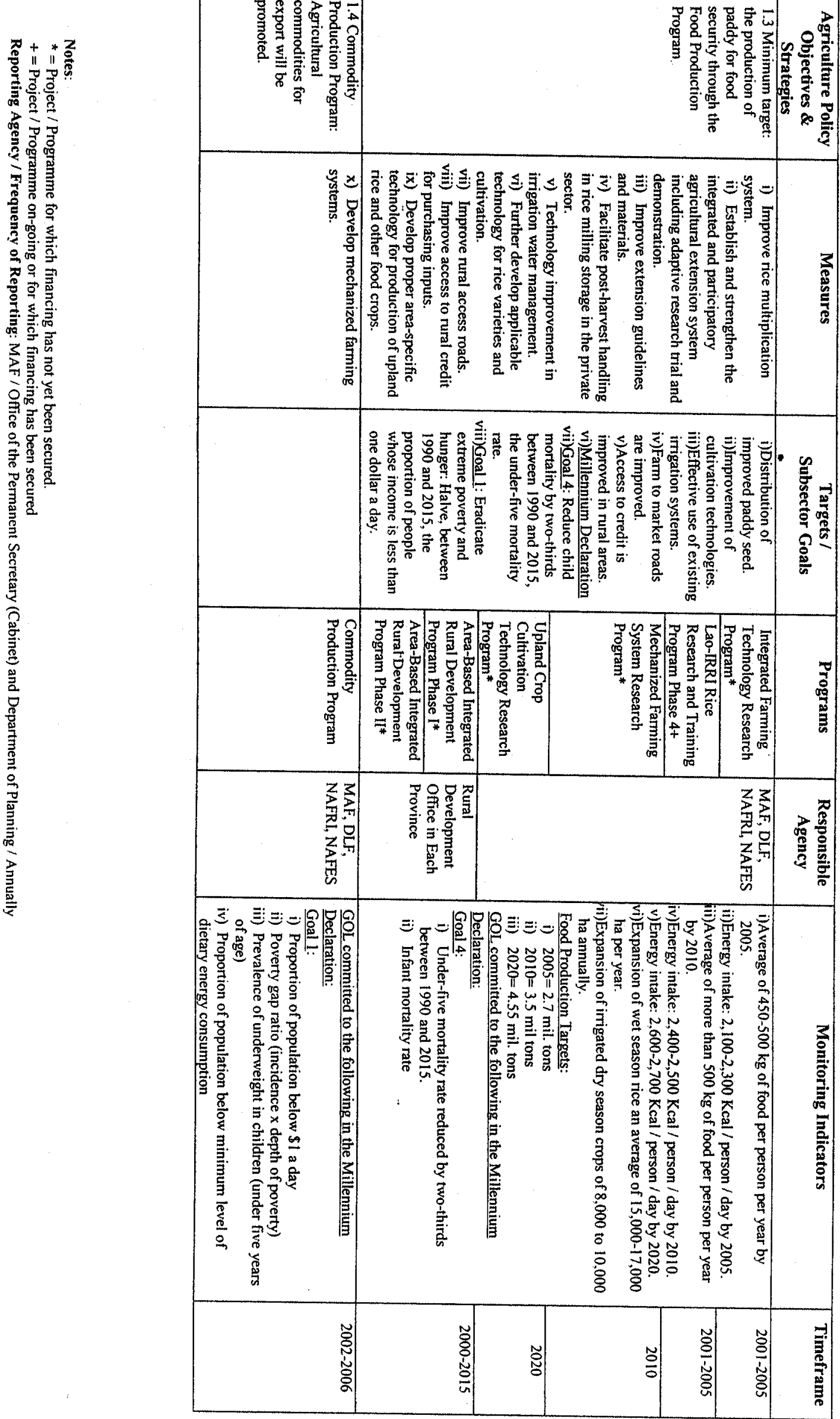




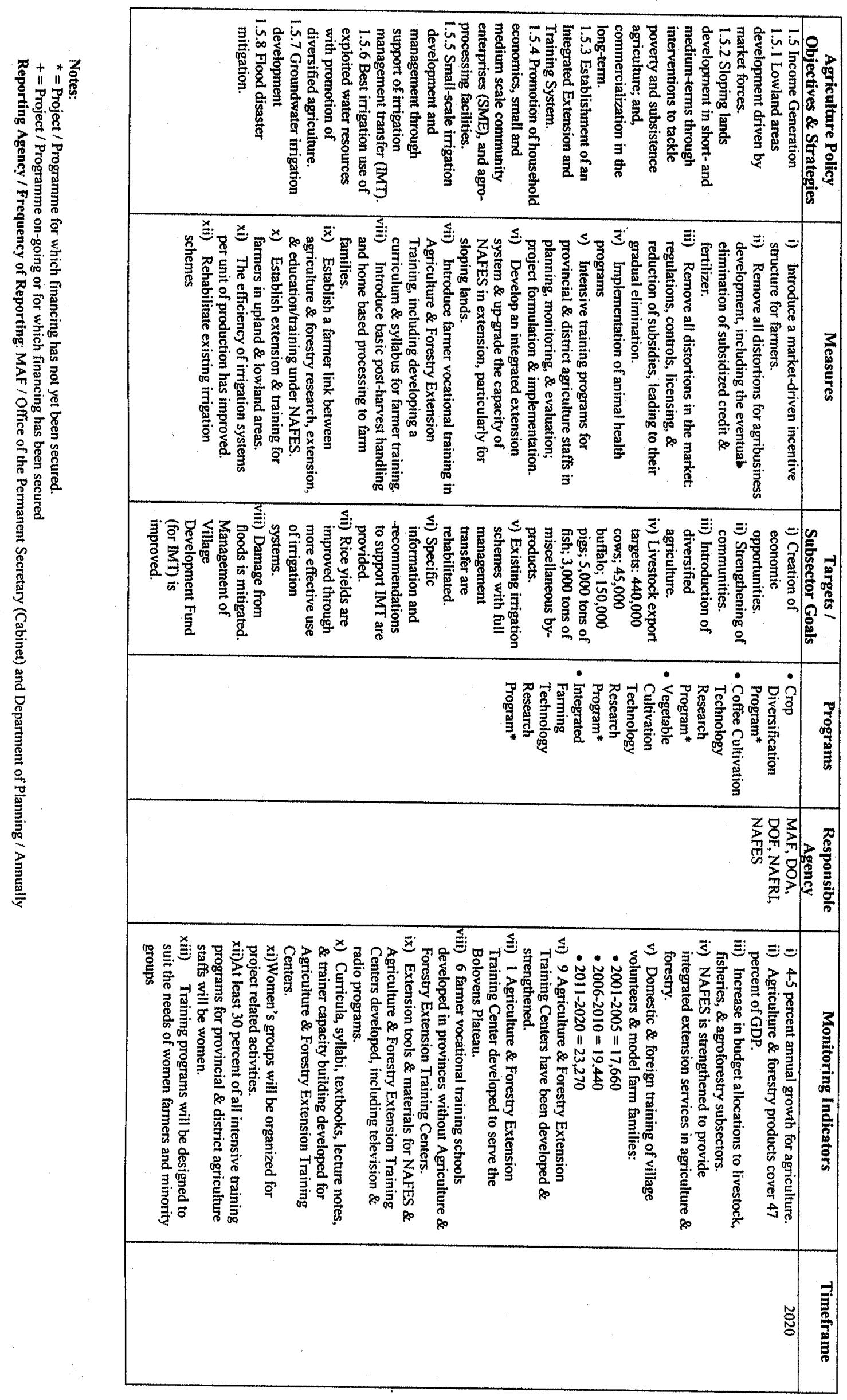



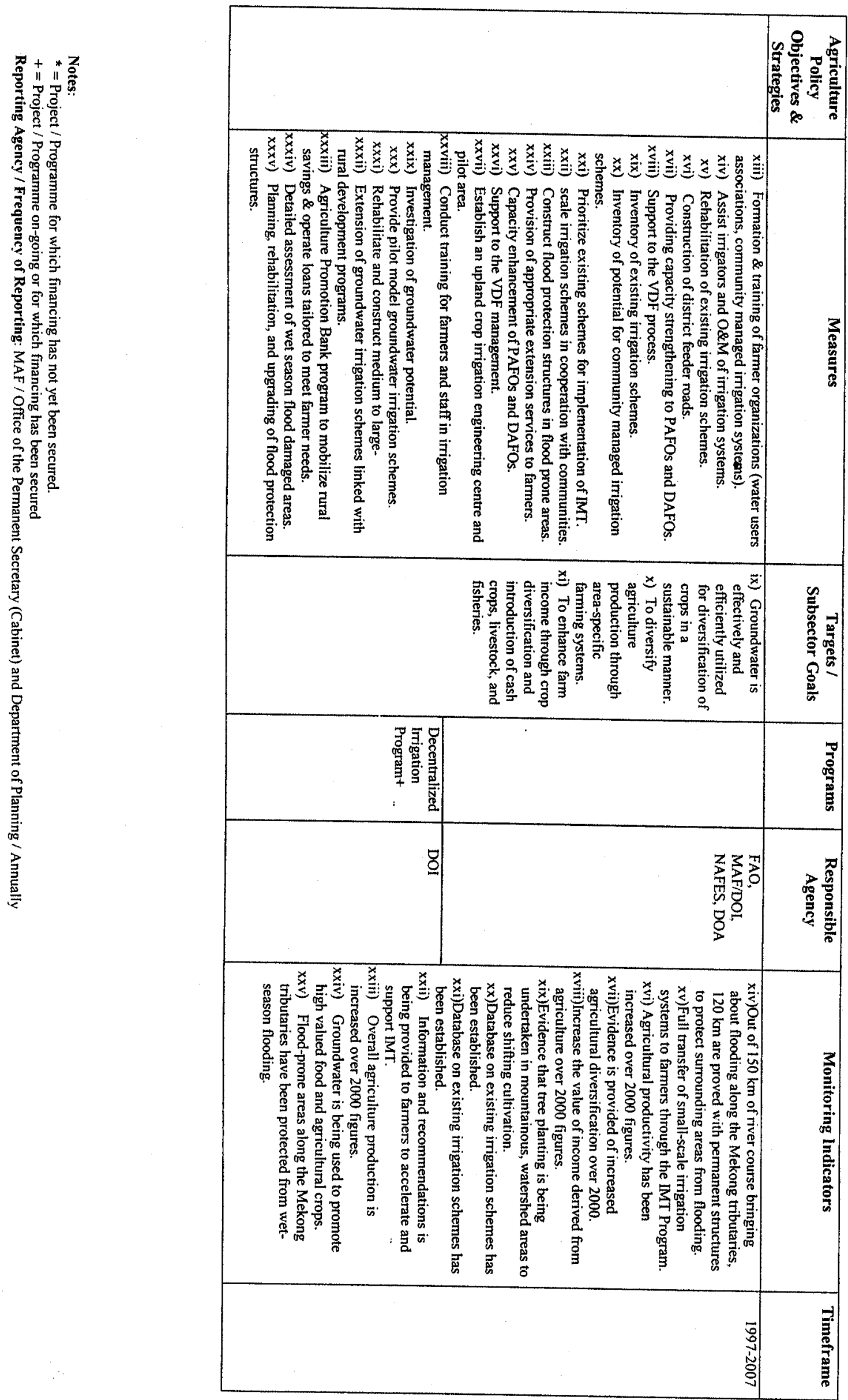


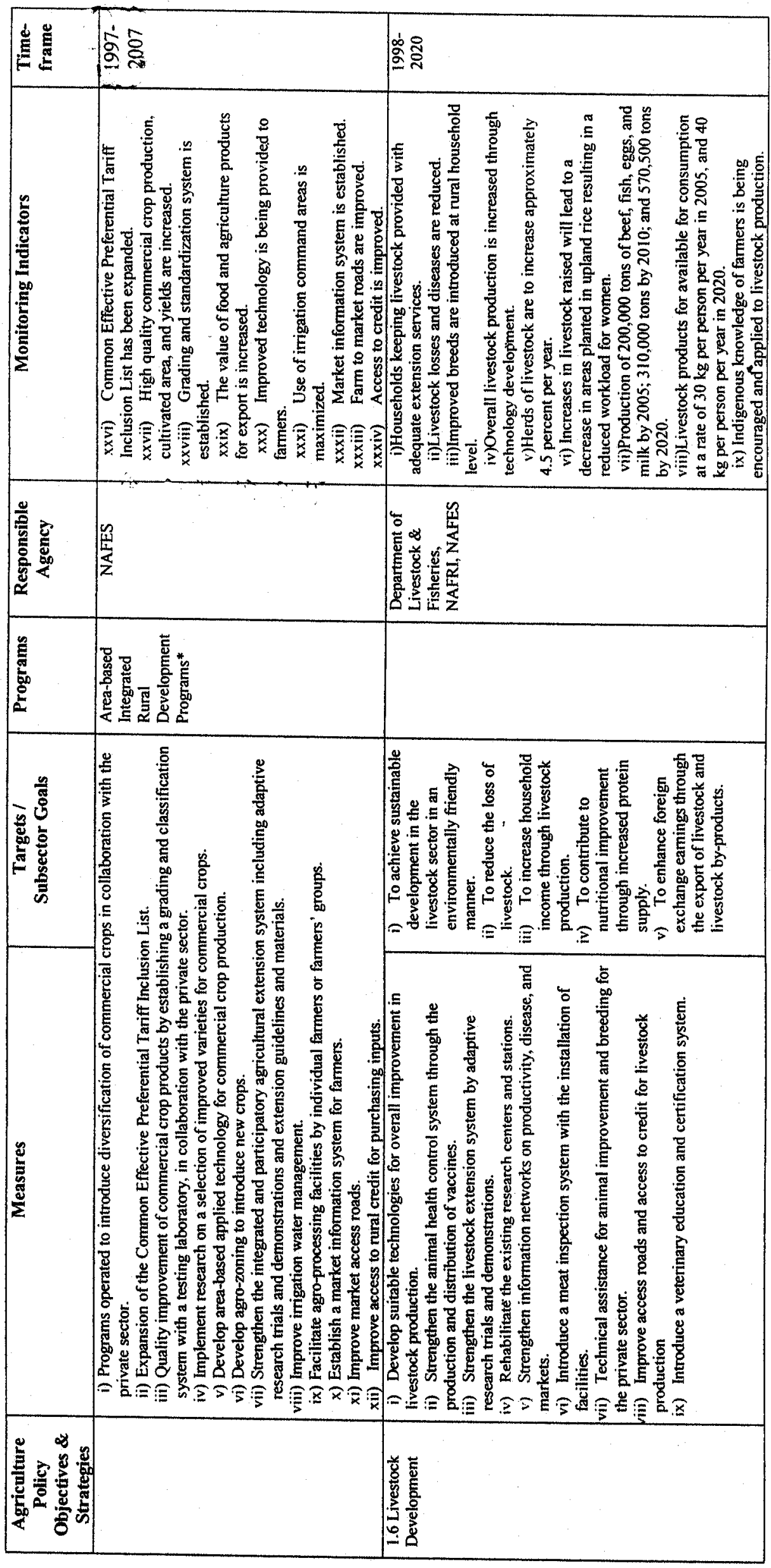




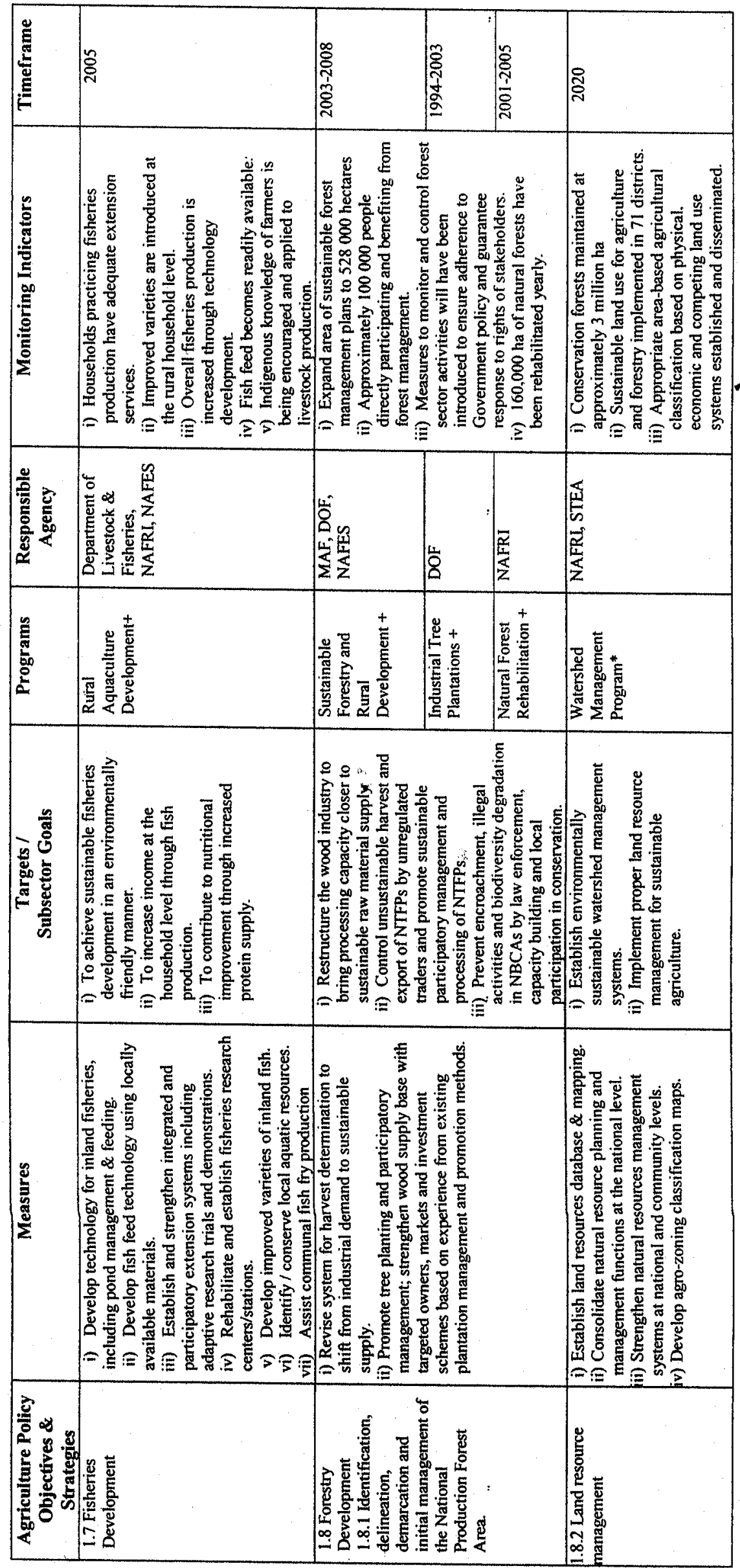




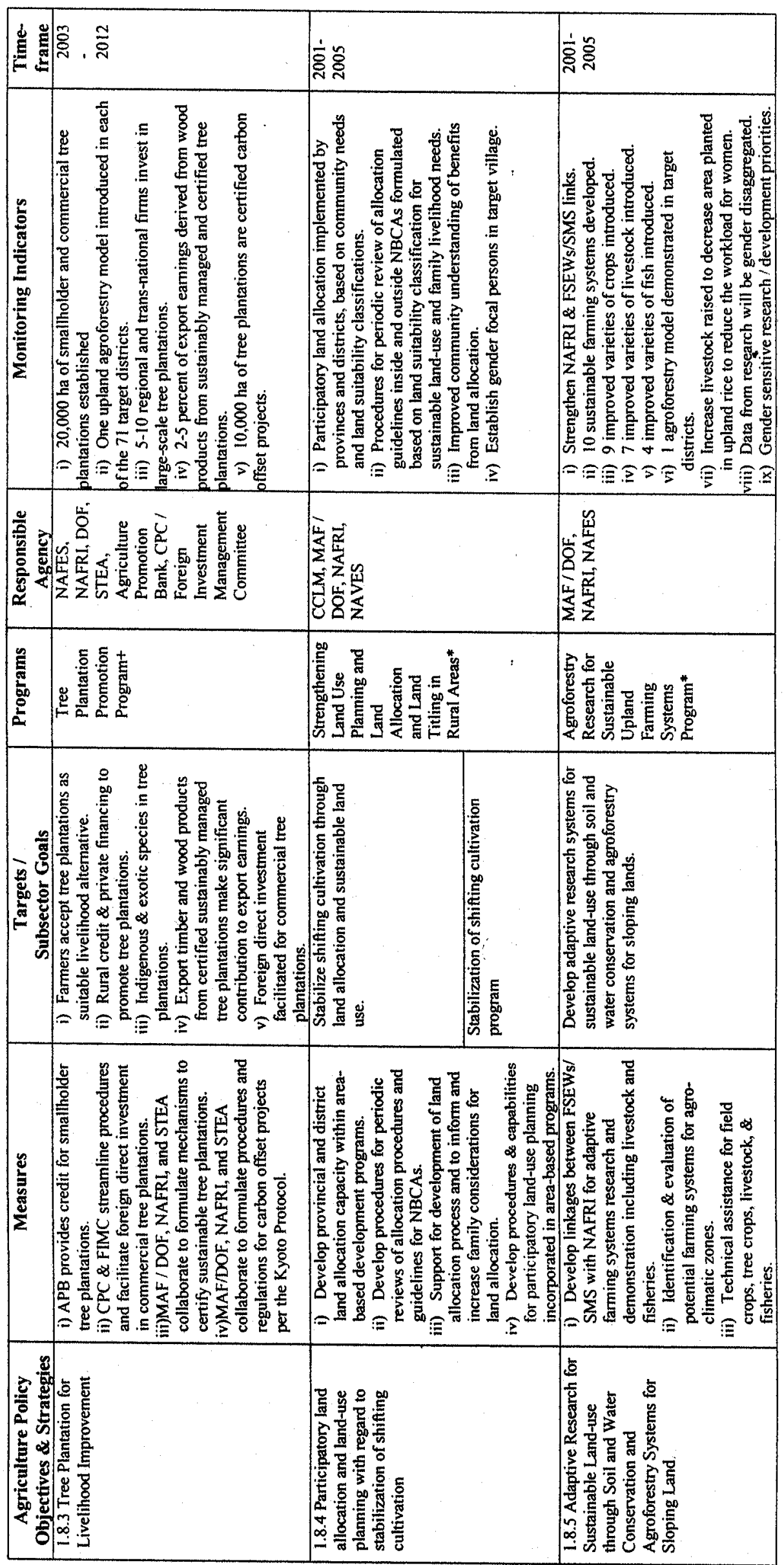

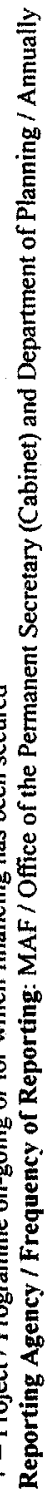




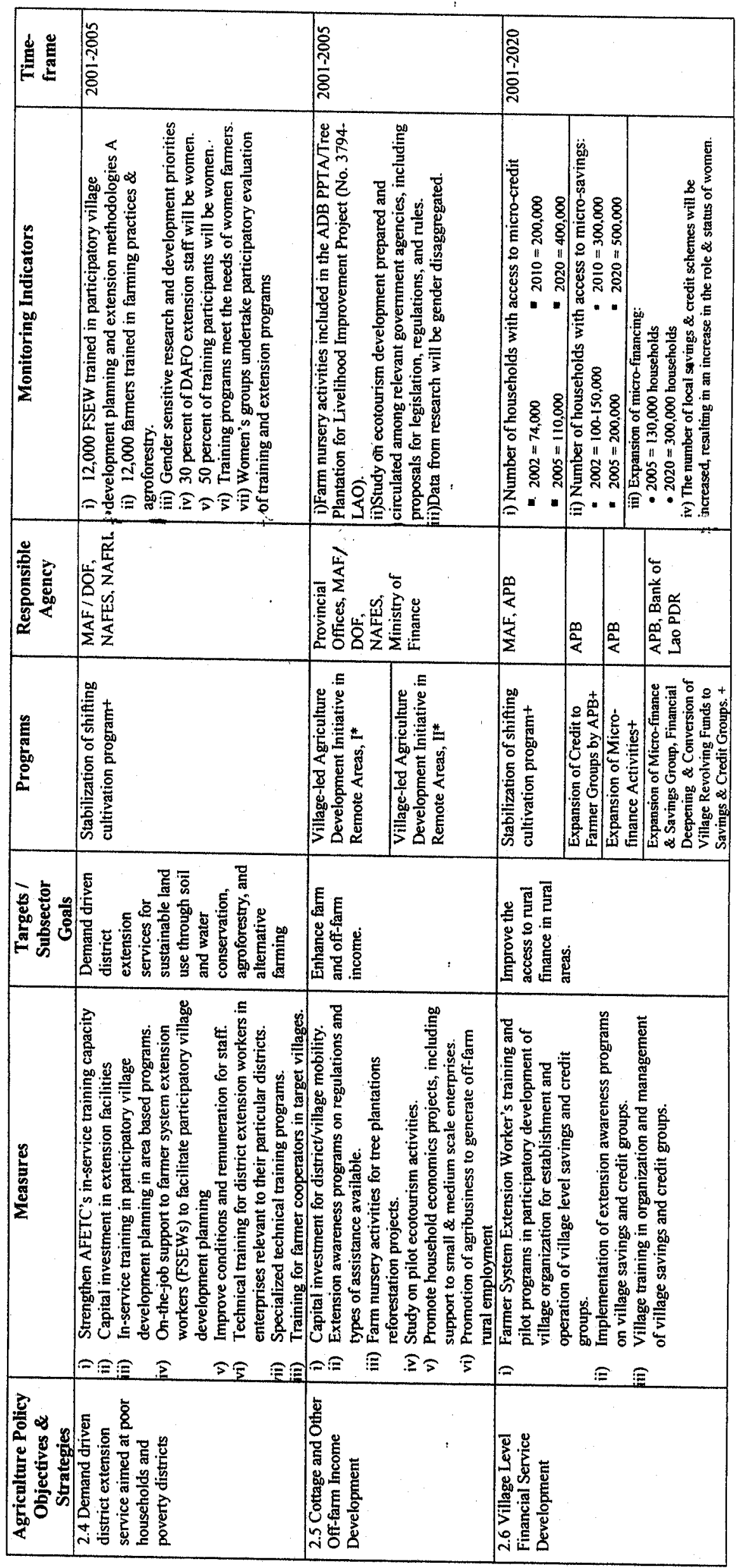




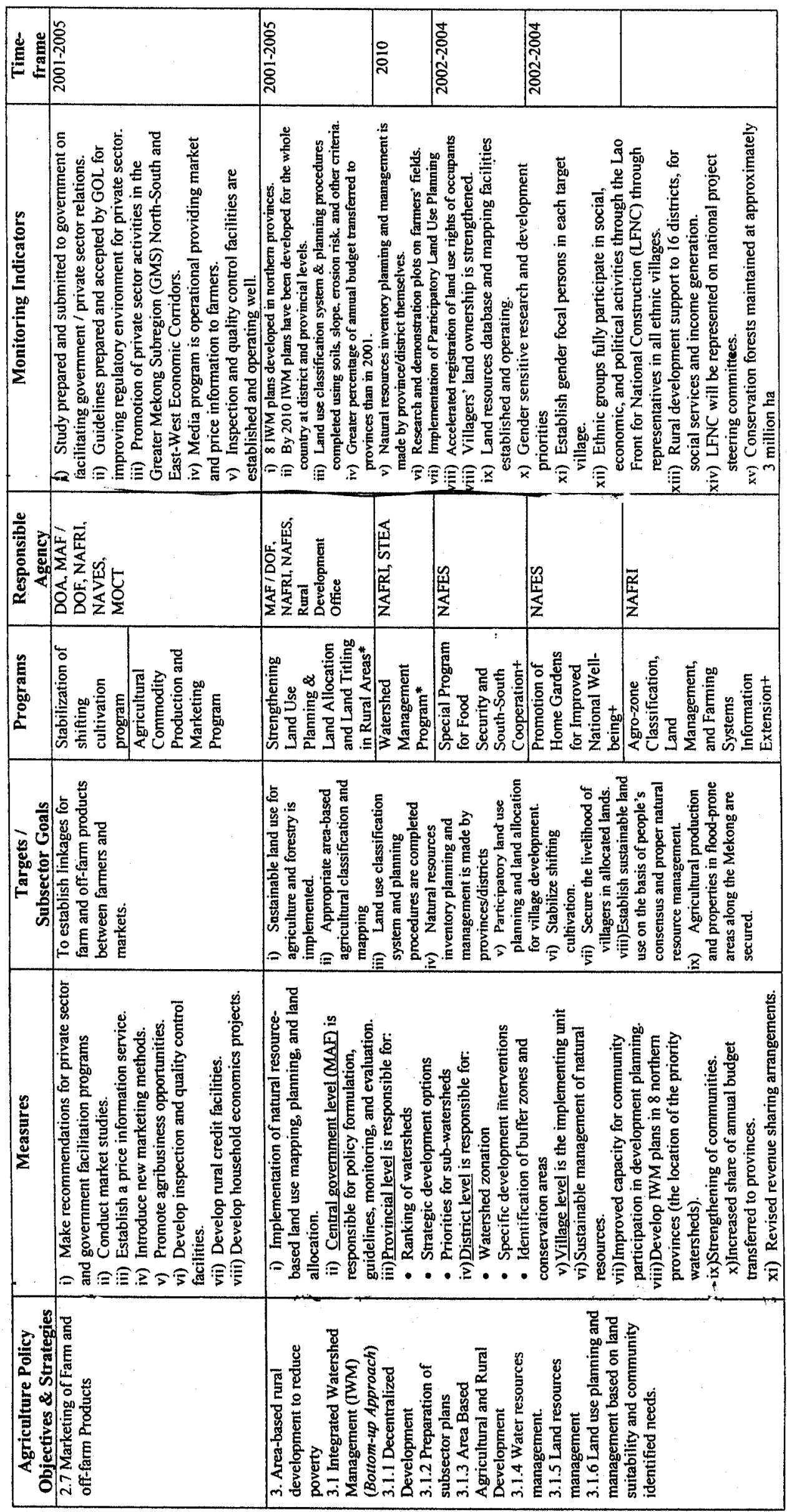

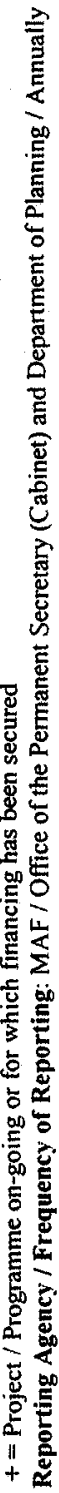


Table 3.2 Education Sector 2003-2006

\section{Improving Equitable Access Programme}

\begin{tabular}{|c|c|c|c|c|c|c|}
\hline $\begin{array}{c}\text { Policies / Objectives } \\
\text { Strategies } \\
\end{array}$ & Measures & $\begin{array}{c}\text { Targets/Sub-Sector } \\
\text { Goals }\end{array}$ & $\begin{array}{c}\text { Programs } I \\
\text { Projects }\end{array}$ & $\begin{array}{c}\text { Responsible } \\
\text { Agencies }\end{array}$ & $\begin{array}{c}\text { Monitoring } \\
\text { Indicator }\end{array}$ & $\begin{array}{l}\text { Time } \\
\text { Frame }\end{array}$ \\
\hline $\begin{array}{l}\text { A-Achieve Education For All by } 2015 \\
\text { A.1-Increase access to complete primary } \\
\text { schooling significantly, especially in } 47 \text { poorest } \\
\text { districts } \\
\text { A.1.1-Promote multigrade teaching } \\
\text { A.1.2-Upgrade existing incomplete schools to } \\
\text { having all teaching grades } \\
\text { A.2-Reduce illiteracy, especially among adult } \\
\text { women and desadvantage target groups } \\
\text { A.2.1-Conduct community based literacy } \\
\text { campaigns } \\
\text { A.2.2-Focus literacy campaign especially on } \\
\text { women, particularly in } 47 \text { poorest districts }\end{array}$ & $\begin{array}{l}\text { 1-Develop Multi grade training components for } \\
\text { pre and in service training } \\
\text { 2-Recruit multigrade teacher trainees from } \\
\text { communities where they are required, using } \\
\text { special criteria for selection } \\
\text { 3-Establish and expand school clusters to utilise } \\
\text { and allocate their assistance } \\
\text { 4-Introduce multigrade teaching to provide } \\
\text { complete primary schooling } \\
\text { 5-Review all incomplete schools in } 47 \text { poorest } \\
\text { districts and decide on which should be } \\
\text { upgraded to complete schools } \\
\text { 6-Develop Minister Decrees and Notices to the } \\
\text { concerned provinces and districts about } \\
\text { upgrading incomplete to complete schools } \\
\text { 7-Use formal and non formal teachers to conduct } \\
\text { literacy classes } \\
\text { 8-Implement literacy training for women including } \\
\text { skills training } \\
\text { 9-Training villagers, related to local market } \\
\text { demands, to improve their production and } \\
\text { increase their income by using existing potential } \\
\text { and resources focusing on agriculture and } \\
\text { livestocks } \\
\text { 10-Establish and Improve Community Learning } \\
\text { Centres in suitable locations }\end{array}$ & $\begin{array}{l}\text { i)-In service and Pre service MGT training modules } \\
\text { prepared by Sept } 2003 \\
\text { ii)-260 MGT trainees graduate by } 2005 \\
\text { iii)-Clusters established/expanded in } 47 \text { poorest } \\
\text { districts } \\
\text { iv)-Inrease proportion of students in complete schools } \\
\text { by } 20 \text { per cent } \\
\text { v)-Review all incomplete schools in } 47 \text { poorest districts } \\
\text { annually Upgrade } 25 \text { schools to complete schools } \\
\text { vi)-Publish Ministerial decree on upgrading incomplete } \\
\text { schools by September } 2003 \\
\text { vii)-Publish Notice on upgrading incomplete schools to } \\
\text { Provinces and Districts annually } \\
\text { viii)-20 per cent of primary and non formal teachers in } \\
47 \text { poorest districts conduct at least one literacy class } \\
\text { annually } \\
\text { ix)-Reduction of } 20 \text { per cent in number of illiterate } \\
\text { adults in } 47 \text { poorest districts }\end{array}$ & $\begin{array}{l}\text { Basic Education for Girl Project } \\
\text { (BEGP) } \\
\text { Education Quality Improvement } \\
\text { Project } \\
\text { (EQIP-II) } \\
\text { Education Development } \\
\text { Project (EDP-II) }\end{array}$ & $\begin{array}{l}\text { MOE/DGE/DPC/TDC } \\
\text { DTT/PESS / DEBS }\end{array}$ & $\begin{array}{l}\text { Official publication and distribution of } \\
\text { Notice to all Provinces and Districts } \\
2,760 \text { literate trainees } \\
2,760 \text { new literates } \\
\text { Construction of } 94 \text { CTC for } \\
\text { providing the training programmes } \\
188 \text { trainers/years }\end{array}$ & $2003-2006$ \\
\hline $\begin{array}{l}\text { B- To combat hunger and poverty and } \\
\text { improve the quality of life of the most } \\
\text { vulnerable to access to education } \\
\text { B.1-Reduce opportunity cost for poor families } \\
\text { to encouraging attendance of poor students } \\
\text { B.1.1-Provide snack for all students in the } \\
\text { target schools } \\
\text { B.1.2-Provide food rations for the boarding } \\
\text { students ( rice, canned fish and iodin salt) } \\
\text { B.2-Increase children's concentration by } \\
\text { providing a healthy meal }\end{array}$ & $\begin{array}{l}\text { 1-In cooperation with PESs and DEBs and } \\
\text { mass organizations } \\
\text { 2-Training the target communities on food } \\
\text { management and healthy food cooking } \\
\text { 3-More students in the target sites will have } \\
\text { more opportunities to attending school } \\
\text { 4-Training of trainers, principal and teachers in } \\
\text { all target schools }\end{array}$ & $\begin{array}{l}\text { i)-More than } 161,000 \text { primary students in } 47 \text { poorest } \\
\text { districts will benefit from the project } \\
\text { lii-More than } 17,500 \text { students in boarding schools will } \\
\text { benefit from the project } \\
\text { iii)-More than } 73,500 \text { girls will benefit from the project } \\
\begin{array}{l}\text { iv)-At least one trainer for } 47 \text { of poorest districts and } \\
\text { all principals and teachers in target schools will be } \\
\text { trained } \\
\text { v)-300 teachers and } 100 \text { administrators will be trained }\end{array}\end{array}$ & World Food Programme (WFP) & $\begin{array}{r}\text { MOE/DGE/DPC/DOP } \\
\text { DTT/PESS / DEBS }\end{array}$ & $\begin{array}{l}\text { Regular program report } \\
\text { Number of students, teachers and } \\
\text { administrators received the training }\end{array}$ & $2003-2006$ \\
\hline
\end{tabular}




\begin{tabular}{|c|c|c|c|c|c|c|}
\hline $\begin{array}{c}\text { Policies / Objectives } \\
\text { Strategies }\end{array}$ & Measures & $\begin{array}{c}\text { Targets/Sub-Sector } \\
\text { Goals }\end{array}$ & $\begin{array}{c}\text { Programs } I \\
\text { Projects }\end{array}$ & $\begin{array}{c}\text { Responsible } \\
\text { Agencies }\end{array}$ & $\begin{array}{c}\text { Monitoring } \\
\text { Indicator }\end{array}$ & $\begin{array}{l}\text { Time } \\
\text { Frame }\end{array}$ \\
\hline $\begin{array}{l}\text { B.2.1-Health \& hygiene campaign with oral } \\
\text { anthelminthic treatment in all project's schools } \\
\text { B.3-Strengthen the capacity for the sexual } \\
\text { health education and HIVIAIDS prevention } \\
\text { B.3.1-Conduct training programme and } \\
\text { training assessment } \\
\text { B.4-Expand the enrolment of inclusive } \\
\text { education } \\
\text { B.4.1-Conduct training programme in } \\
\text { selected poorest districts }\end{array}$ & $\begin{array}{l}\text { 5-Training of teachers and administrators in } \\
\text { selected poorest districts } \\
\text { 6-Training of trainers and instructors in selected } \\
\text { poorest districts }\end{array}$ & & & & $\begin{array}{l}\text { Number of new Graduates for } \\
\text { TTCs and TTSS } \\
\text { Annual school statistics } \\
\text { Per cent of enrollment rate in } \\
\text { private schools }\end{array}$ & \\
\hline $\begin{array}{l}\text { C-Facilitate economic growth through increased } \\
\text { completion of appropriate schooling } \\
\text { C.1-Increase primary completion rate, } \\
\text { especially in } 47 \text { poorest districts }\end{array}$ & $\begin{array}{l}\text { 1-Pre-Service Training of MGT teachers through } \\
5+4 \text { and } 8+3 \text { system. } \\
\text { 2-Recruit contracted teachers for the poorest } \\
\text { districts and giving to them an incentive training } \\
\text { course on MGT }\end{array}$ & $\begin{array}{l}\text { 1)- Construction of new schools in the poorest } \\
\text { districts } \\
\text { ii)- } 260 \text { ethnic teachers and } 200 \mathrm{MGT} \text { contracted } \\
\text { teachers will be recruited and trained in the poorest } \\
\text { districts }\end{array}$ & $\begin{array}{l}\text { Basic Education for Girl Project } \\
\text { (BEGP) }\end{array}$ & MOE/DGE/DPC/DOP & & $2003-2006$ \\
\hline $\begin{array}{l}\text { C.1.1-Provide special training for teachers in } \\
\text { rural, remote and minority ethnic areas, } \\
\text { especially in } 47 \text { poorest districts }\end{array}$ & $\begin{array}{l}\text { 3-Develop village based Early Childhood Care } \\
\text { Development (ECCD) and Family based ECCD } \\
\text { in cooperation with Community Learning Center } \\
\text { (CLC) using existing CLC of the village, or by } \\
\text { developing new CLC. }\end{array}$ & $\begin{array}{l}\text { iii)-20 new ECCD Centres will be established in } 47 \\
\text { poorest districts }\end{array}$ & $\mid \begin{array}{ll}\text { Education } & \text { Quality Improvement } \\
\text { Project } & \text { (EQIP-II) }\end{array}$ & $\begin{array}{c}\text { DTT/DVHE/PESS / } \\
\text { DEBS }\end{array}$ & $\begin{array}{l}\text { Number of new school buildings } \\
\text { (pres school, primary and lower } \\
\text { secondary ) have been built }\end{array}$ & \\
\hline $\begin{array}{l}\text { C.1.2-Encourage community and private } \\
\text { provision of schooling from pre-school onwards }\end{array}$ & $\begin{array}{l}\text { 4-Establish low interest loan mechanism for } \\
\text { private schools }\end{array}$ & $\begin{array}{l}\text { iv)-Expand at least two private schools in the main } \\
\text { cities }\end{array}$ & $\begin{array}{l}\text { Education Development } \\
\text { Project (EDP-II) }\end{array}$ & & $\begin{array}{l}\text { Number of private schools have been } \\
\text { build in the selected poorest districts }\end{array}$ & \\
\hline $\begin{array}{l}\text { C.2-Reduce differences in major indicators } \\
\text { between } 47 \text { poorest districts and national } \\
\text { averages }\end{array}$ & $\begin{array}{l}\text { 5-Establish remedial classes in selected schools } \\
\text { in poorest } 47 \text { districts }\end{array}$ & $\begin{array}{l}\text { v)-Reduction of } 50 \% \text { in repetition rate by } 2005 \text { in } \\
\text { participating schools }\end{array}$ & & & 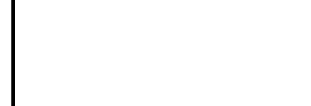 & \\
\hline $\begin{array}{l}\text { C.2.1-Encourage community and private } \\
\text { provision of schooling from pre-school onwards }\end{array}$ & $\begin{array}{l}\text { 6-Targetted assistance for girls in } 47 \text { poorest } \\
\text { districts to encourage enrolment and completion }\end{array}$ & vi)-Reduction of gender gap to 2 per cent or less & & & Number of workers have been trained & \\
\hline $\begin{array}{l}\text { C.2.2-Encourage enrolment at correct age } \\
\text { especially for girls and in rural and remote } \\
\text { areas }\end{array}$ & $\begin{array}{l}\text { 7-Establish Pre School within existing primary } \\
\text { schools (1 year) }\end{array}$ & $\begin{array}{l}\text { vii)-Expand pre-school classes within primary schools } \\
\text { by } 30 \% \text { in poorest districts }\end{array}$ & & & & \\
\hline C.3-Expand post primary schooling & $\begin{array}{l}\text { 8-Establishing and Improving Lower Secondary } \\
\text { Schools in the poorest districts }\end{array}$ & $\begin{array}{l}\text { viii)-Construction and Rehabitation } 1 \text { Lower } \\
\text { Secondary School in each poorest district. }\end{array}$ & & & & \\
\hline $\begin{array}{l}\text { C.3.1-Establish Lower Secondary School in the } \\
\text { needed areas }\end{array}$ & $\begin{array}{l}\text { 9-Conduct a survey of labour market needs } \\
\text { [regional and local] }\end{array}$ & $\begin{array}{l}\text { ix)-Completed survey report, including details on } \\
\text { poorest provinces/districts }\end{array}$ & & & & \\
\hline $\begin{array}{l}\text { C.3.2-Encourage provincial establishment of } \\
\text { vocational schools }\end{array}$ & $\begin{array}{l}\text { 10-Upgrade the existing TVE schools in the } \\
\text { northern and Southern provinces }\end{array}$ & $\begin{array}{l}\text { x)-Enrollment } 800-1000 \text { students in 6-8 courses for } \\
\text { each school }\end{array}$ & & & & \\
\hline $\begin{array}{l}\text { C.3.3-Develop basic vocational training at } \\
\text { community level }\end{array}$ & $\begin{array}{l}\text { 11-Develop basic skill/vocational training } \\
\text { including development of the model CLCs } \\
\text { through ICT programmes for poor areas }\end{array}$ & $\begin{array}{l}\text { xi)-Enrollment 500-600 students introduce of two new } \\
\text { courses } \\
\text { xii) } 30 \% \text { of young people out of school attended the } \\
\text { skills training program and have supported a } \\
\text { community revolving fund }\end{array}$ & & & & \\
\hline
\end{tabular}


Annex 3.3 : Five-Year Action Programmes for Poverty-Focused Health Sector Development

\begin{tabular}{|c|c|c|c|c|c|c|}
\hline Policy area(s) & Objectives/Targets & Strategies/Measures & $\begin{array}{c}\text { Planned } \\
\text { Timetable }\end{array}$ & Monitoring Indicators & $\begin{array}{l}\text { Reporting } \\
\text { Frequency }\end{array}$ & Agency \\
\hline $\begin{array}{l}\text { 1. Health } \\
\text { Education and } \\
\text { Information }\end{array}$ & $\begin{array}{l}85 \% \text { of rural and remote } \\
\text { villages are reached by } \\
\text { IEC activities and } \\
\text { behaviour change occurs }\end{array}$ & $\begin{array}{l}\text { 1.1 Reorganization of IEC } \\
\text { 1.2 IEC campaigns } \\
\text { 1.3 IEC in ethnic languages t } \\
\text { 1.4 Multi-sectoral cooperation }\end{array}$ & $2003-05$ & $\begin{array}{l}\text { 11.1 A framework is in place. } \\
1.2 \% \text { of the remote/rural reached } \\
1.3 \text { \# materials in ethnic languages } \\
\text { 1.4 Curriculum and activities for IEC } \\
\text { integrated into school curriculum. }\end{array}$ & Yearly & MOH \\
\hline $\begin{array}{l}\text { 2.. Expansion of } \\
\text { the service } \\
\text { network and heath } \\
\text { promotion in } \\
\text { remote areas }\end{array}$ & $\begin{array}{l}\text { 1. } 80 \% \text { of rural and } \\
\text { remote villages have a } \\
\text { village health provider, } \\
\text { essential drug kit, and a } \\
\text { village health committee. } \\
\text { 2. } 80 \% \text { of district } \\
\text { hospitals and health } \\
\text { centers have essential } \\
\text { equipment and staff. }\end{array}$ & $\begin{array}{l}\text { 2.1 Review ongoing projects } \\
\text { 2.2 Strengthen PHC - } \\
\text { emphasis on } 46 \text { poor districts } \\
\text { 2.3 Improve/expand PHC to } \\
\text { remote level with } 150 \text { new } \\
\text { HC, } 3 \text { regional hosp, } 13 \\
\text { provincial hosp, } 10 \text { Type A } \\
\text { DH, and } 46 \text { DH poor districts } \\
\text { 2.4 Promote the role of } \\
\text { women in PHC }\end{array}$ & 2003-05 & $\begin{array}{l}\text { 2.1Report } \\
\text { 2.2Guidelines, directives, principles in } \\
80 \% \text { of districts identified. } \\
2.3 \% \text { of active,village health } \\
\text { committees, \# of new health centers } \\
\text { developed, \# regional hosp improved, } \\
\text { \# provincial hosp upgraded, \# districts } \\
\text { hospitals (DH) upgraded to Type A, } \\
\text { \# DH in poor areas upgraded } \\
2.4 \text { \# and \% of committees c/women }\end{array}$ & Yearly & MOH \\
\hline $\begin{array}{l}\text { 3. Upgrading the } \\
\text { skills of health } \\
\text { staff and } \\
\text { increasing the } \\
\text { number of staff } \\
\text { from ethnic } \\
\text { minorities }\end{array}$ & $\begin{array}{l}\text { To increase the } \\
\text { proportion of health } \\
\text { workers at village and } \\
\text { district levels by } 75 \%\end{array}$ & $\begin{array}{l}\text { 3.1 Improve nursing - build } 2 \\
\text { nursing schools and rehab } 2 . \\
\text { 3.2 Train PHC workers } \\
\text { 3.3 Development of about } \\
\text { 4000 village health providers } \\
\text { 3.4 Increase ethnic health staff } \\
\text { 3.5 Improved management } \\
\text { 3.6 Refresher training for all } \\
\text { health workers once yearly } \\
\text { 3.7 Post grad medical training } \\
\text { for about } 312 \text { individuals } \\
\text { 3.8 Standard treatment } \\
\text { guidelines are used }\end{array}$ & 2003-05 & $\begin{array}{l}\text { 3.1 \# of schools built or rehabilitated } \\
2.2 \text { \# training centers built and } \\
\text { functioning } \\
3.3 \text { \# VHP functioning } \\
3.4 \text { \# HC staff trained and return to } \\
\text { their HC } \\
3.5 \text { \# managers trained } \\
3.6 \% \text { health staff receiving one } \\
\text { training course per year } \\
3.7 \text { \# individuals receive postgraduate } \\
\text { training } \\
3.8 \% \text { of facilities using standard } \\
\text { treatment guidelines }\end{array}$ & Yearly & MOH \\
\hline $\begin{array}{l}\text { 4. Promotion of } \\
\text { maternal and child } \\
\text { health }\end{array}$ & $\begin{array}{l}\text { Infant mortality reduced } \\
\text { to } 58 / 1000 \text {. } \\
\text { Child mortality reduced } \\
\text { to } 80 / 1000 . \\
\text { Maternal mortality } \\
\text { reduced to } 355 / 100000 . \\
\text { Contraceptive } \\
\text { prevalence increased to } \\
45 \% \text {. }\end{array}$ & $\begin{array}{l}\text { 4.1 Upgrading the skills of } \\
\text { MCH staff } \\
\text { 4.2 Strengthen MCH network } \\
\text { 4.3 Increased awareness } \\
\text { 4.4 Expansion of ARI and } \\
\text { CDD network } \\
\text { 4.5 EOC available at } 18 \mathrm{PH} \\
\text { and } 142 \mathrm{DH} \\
\text { 4.6 Promotion of key package } \\
\text { of interventions } \\
\text { 4.7 Monitoring/supervising } \\
\end{array}$ & 2003-05 & $\begin{array}{l}\text { 4.1 Percentage of } \mathrm{HC} \text { and } \mathrm{DH} \text { staff } \\
\text { trained in EOC, ANC, FP and MCH. } \\
\text { 4.2 Percentage of PH, DH, HC, and } \\
\text { VHP providing EOC } \\
\text { 4.3Percentage of villages receiving } \\
\text { HE } \\
4.4 \text { \# provinces, \# districts, and \# } \\
\text { villages are in the network } \\
4.5 \text { \# hospitals where EOC available } \\
4.6 \% \text { villages receiving package } \\
4.7 \text { Percentage supervision occuring }\end{array}$ & Yearly & MOH \\
\hline $\begin{array}{l}\text { 5. Immunization } \\
\text { for women and }\end{array}$ & $\begin{array}{l}90 \% \text { coverage of } \\
\text { mothers and children in }\end{array}$ & $\begin{array}{l}\text { 5.1 Supplement OPV imm. in } \\
116 \text { districts and } 2888 \text { villages }\end{array}$ & 2003-05 & $\begin{array}{l}5.1 \% \text { coverage of target population } \\
5.2 \% \text { coverage for measles in }\end{array}$ & Yearly & MOH \\
\hline
\end{tabular}




\begin{tabular}{|c|c|c|c|c|c|c|}
\hline Policy area(s) & Objectives/Targets & Strategies/Measures & $\begin{array}{c}\text { Planned } \\
\text { Timetable }\end{array}$ & Monitoring Indicators & $\begin{array}{l}\text { Reporting } \\
\text { Frequency }\end{array}$ & Agency \\
\hline children & $\begin{array}{l}\text { remote areas with the } \\
\text { core antigens }\end{array}$ & $\begin{array}{l}\text { 5.2 National immunization } \\
\text { days for measles in 2004-05 } \\
\text { 5.3 Routine immunizations to } \\
\text { achieve } 90 \% \text { coverage } \\
\text { 5.4 Introduce hepatitis B imm. } \\
7 \text { provinces/2003 and } 8 / 2004 \\
\text { 5.5 Expansion of rabies } \\
\text { immunization to all provinces } \\
\text { 5.6 Training of provincial and } \\
\text { district EPI managers } \\
\text { 5.7 Coordinate with LWU and } \\
\text { local administration } \\
\text { 5.8 Supervision and } \\
\text { monitoring of activities. }\end{array}$ & & $\begin{array}{l}\text { children } 9 \text { mo.- } 5 \text { yrs. } \\
5.3 \% \text { coverage of basic antigens } \\
\% \text { of all remote villages visited } 4 \\
\text { times/year on outreach } \\
5.4 \text { \# provinces introduced in } 2003 \\
\text { and \# provinces in } 2004 \\
5.5 \text { \# provinces Rabies vaccine } \\
\text { available }\end{array}$ & & \\
\hline $\begin{array}{l}\text { 6. Water supply } \\
\text { and environmental } \\
\text { health }\end{array}$ & $\begin{array}{l}65-70 \% \text { clean water } \\
\text { access } \\
45-50 \% \text { hygienic latrine } \\
\text { access } \\
19-22 \% \text { hygienic latrines } \\
\text { in primary schools }\end{array}$ & $\begin{array}{l}\text { 6.1 C330 gravity fed water } \\
\text { systems, } 1500 \text { bore holes, } \\
1032 \text { shallow wells, } 1250 \text { jars } \\
\text { for water collection, } 32 \text { piped } \\
\text { water schemes, and } 30 \\
\text { protected springs } \\
6.2 \text { Latrine expansion- } 81,000 \\
\text { family, } 600 \text { school latrines } \\
6.3 \text { Community mobilizaton } \\
\text { and gender awareness } \\
6.4 \text { Training } 4-7 \text { staff in each } \\
\text { province and } 2-3 / \text { district } \\
6.5 \text { Monitoring/supervision }\end{array}$ & 2003-05 & $\begin{array}{l}6.1 \# \text { of water points developed } \\
6.2 \# \text { of family latrines, \# of school } \\
\text { latrines } \\
6.3 \% \text { coverage of model village } \\
\text { program, \# of school sanitation } \\
\text { programs } \\
6.4 \# \text { trained staff } \\
6.5 \% \text { of planned supervision } \\
\text { visits/year actually conducted }\end{array}$ & Yearly & MOH \\
\hline $\begin{array}{l}\text { 7. Communicable } \\
\text { disease control } \\
7.1 \text { Malaria }\end{array}$ & $\begin{array}{l}\text { 7.1 Parasite infection } \\
\text { rate reduced to } 8-10 \% \\
\text { Morbidity reduced to } \\
\text { 12.8/1000 LB } \\
\text { Mortality reduced to } \\
\text { 3.4./100000 } \\
\text { Insecticide treated } \\
\text { bed net - } 63.1 \% \text { cover }\end{array}$ & $\begin{array}{l}\text { 7.1.1 Improved IEC through } \\
\text { multiple means } \\
\text { 7.1.2 Expansion of malaria } \\
\text { network } \\
\text { 7.1.3 To upgrade the skills of } \\
\text { health workers } \\
\text { 7.1.4 Monitoring /supervision }\end{array}$ & 2003-05 & $\begin{array}{l}\text { 7.1.1\% aware of means to treat and } \\
\text { control malaria } \\
\text { 7.1.2 \% of targets reached } \\
\text { 7.1.3 \# village health volunteers } \\
\text { trained, \# laboratory workers trained, } \\
\text { and \# frontline health workers trained. } \\
\text { 7.1.4 \# supervision visits at each level }\end{array}$ & Yearly & MOH \\
\hline 7.2 Dengue & $\begin{array}{l}\text { Dengue outbreaks are } \\
\text { prevented and if they } \\
\text { occur the case fatality } \\
\text { rate will be less than } 1 \%\end{array}$ & $\begin{array}{l}\text { 7.2.1 Case manage training } \\
\text { 7.2.2 Social mobilization } \\
\text { 7.2.3 Mosquito/larva control } \\
\text { 7.2.4 Improved surveillance }\end{array}$ & & $\begin{array}{l}\text { 7.2.1 \# staff trained } \\
\text { 7.2.2 \% of population aware } \\
\text { 7.2.3 \# staff trained } \\
7.2 .4 \% \text { of surveillance reports wkly }\end{array}$ & & \\
\hline $\begin{array}{l}\text { 7.3.1 ADD- } \\
\text { Cholera }\end{array}$ & $\begin{array}{l}\text { Cholera outbreaks will } \\
\text { be prevented and if they } \\
\text { occur the case fatality }\end{array}$ & $\begin{array}{l}\text { 7.3.1.1 Health education } \\
\text { 7.3.1.2 Access to ORS/VHV } \\
\text { 7.3.1.3. Upgrading of } 3 \text { labo }\end{array}$ & & $\begin{array}{l}\text { 7.3.1.1\% of population aware } \\
\text { 7.3.1.2 \% villages with ORS/VHV } \\
\text { 7.3.1.3 \# regional laboratories }\end{array}$ & & \\
\hline
\end{tabular}




\begin{tabular}{|c|c|c|c|c|c|c|}
\hline Policy area(s) & Objectives/Targets & Strategies/Measures & $\begin{array}{c}\text { Planned } \\
\text { Timetable }\end{array}$ & Monitoring Indicators & $\begin{array}{l}\text { Reporting } \\
\text { Frequency }\end{array}$ & Agency \\
\hline 7.3.2 TB & $\begin{array}{l}\text { rate will be less than } 2 \% \\
\text { By } 2005 \text { morbidity and } \\
\text { mortality reduced by } \\
30 \%, 70 \% \text { of Sputum + } \\
\text { identified, and DOTS } \\
\text { will achieve an } 85 \% \text { cure }\end{array}$ & $\begin{array}{l}\text { 7.3.1.4 Improved surveillance } \\
\text { 7.3.2.1 Expand TB network } \\
\text { to all provinces by } 2005 \\
\text { 7.3.2.2 Upgrade skills of staff } \\
\text { 7.3.3.1 National survey }\end{array}$ & & $\begin{array}{l}\text { 7.3.1.4 \% of surveillance reports wkly } \\
\text { 7.3.2.1 \# uncovered provinces are } \\
\text { added to network by } 2005 \\
\text { 7.3.2.2 \# Health workers trained }\end{array}$ & & \\
\hline $\begin{array}{l}\text { 7.3.3 Intestinal } \\
\text { parasites }\end{array}$ & $\begin{array}{l}\text { By } 2005 \text { intestinal } \\
\text { parasites reduce by } 50 \%\end{array}$ & $\begin{array}{l}\text { 7.3.3.2 Develop a national } \\
\text { parasite control plan } \\
\text { 7.3.3.3 To develop with } \mathrm{MoE} \\
\text { preventive and treatment } \\
\text { activities in schools }\end{array}$ & & $\begin{array}{l}\text { 7.3.3.1 Baseline data available } \\
\text { 7.3.3.2 Plan in place } \\
\text { 7.3.3.3 \# of primary schools involved } \\
\text { Number of deworming days and } \% \\
\text { participation of target population }\end{array}$ & & \\
\hline $\begin{array}{l}7.4 \text { Generalized } \\
\text { surveillance - } \\
\text { known and new } \\
\text { diseases }\end{array}$ & $\begin{array}{l}\text { By } 2005 \text { outbreaks are } \\
\text { detected early and the } \\
\text { case fatality rate is below } \\
2 \%\end{array}$ & $\begin{array}{l}\text { 7.4.1 Integrated surveillance } \\
\text { system from village to center } \\
\text { 7.4.2 Training of staff } \\
\text { 7.4.3 Improved laboratory at } 5 \\
\text { regional and } 6 \text { provincial } \\
\text { 7.4.4 Establish EWORS }\end{array}$ & & $\begin{array}{l}\text { 7.4..1 Surveillance system and } \\
\text { guidelines in place } \\
7.4 . .2 \text { \# staff trained at various levels } \\
7.4 .3 \text { \# labs operating } \\
\text { 7.4..4 \# facilities where EWORS } \\
\text { established }\end{array}$ & & \\
\hline $\begin{array}{l}8 . \\
\text { HIV/AIDS/STD } \\
\text { control }\end{array}$ & $\begin{array}{l}90 \% \text { of the target groups } \\
\text { will be aware of methods } \\
\text { of HIV/AIDS } \\
\text { prevention and will } \\
\text { change their behaviors. } \\
80 \% \text { increase in condom } \\
\text { use among high-risk } \\
18 \text { provincial } \\
\text { laboratories and } 80 \% \text { of } \\
\text { blood transfusions safe }\end{array}$ & $\begin{array}{l}\text { 8.1HIV/AIDS/STD network } \\
\text { to } 18 \text { provinces/70 districts } \\
8.2 \text { Surveillance of target } \\
\text { groups in } 6 \text { provinces in } 2004 \text {. } \\
8.3 \text { Health ed for all and } \\
\text { target- } 80 \% \text { condoms in hi } \\
\text { risk } \\
8.4 \text { Improved routine } \\
\text { surveillance through blood } \\
\text { bank - } 80 \% \text { of transfusions are } \\
\text { screened in } 18 \mathrm{PH}\end{array}$ & 2003-05 & $\begin{array}{l}\text { 8.1 \# of districts and provinces } \\
\text { covered } \\
\text { 8.2Surveillance report } \\
8.3 \text { Surveillance reports and survey } \\
\text { reports } \\
8.4 \# \text { PH with testing facility and } \% \\
\text { of transfusions screened }\end{array}$ & Yearly & MOH \\
\hline $\begin{array}{l}\text { 9. Drug revolving } \\
\text { fund (DRF) } \\
\text { expansion }\end{array}$ & $\begin{array}{l}\text { DRF established in } 5960 \\
\text { villages in remote areas } \\
\text { by } 2005 .\end{array}$ & $\begin{array}{l}\text { 9.1 Expand DRF in } 30 \\
\text { additional districts, } 2013 \\
\text { trained VHV, } 2013 \text { drug kits } \\
\text { by } 2003,5960 \text { by } 2005 \text {. } \\
9.2 \text { Supervision of DRF }\end{array}$ & 2003-05 & $\begin{array}{l}9.1 \# \text { of villages covered } \\
9.2 \text { \# monitoring visits yearly from } \\
\text { central to province, province to } \\
\text { district, and district to village. }\end{array}$ & Yearly & MOH \\
\hline $\begin{array}{l}\text { 10. Improved food } \\
\text { and drug safety. } \\
\text { 10.1 Drug safety }\end{array}$ & $\begin{array}{l}\text { To meet Good } \\
\text { Manufacturing Practice } \\
\text { Standards for 1-2 drug } \\
\text { factories. } \\
\text { To produce essential } \\
\text { drugs so that } 50 \% \text { are } \\
\end{array}$ & $\begin{array}{l}\text { 10.1.1 Train staff } \\
\text { 10.1.2 Laws and regulations. } \\
\text { 10.1.3 Drug registration } \\
\text { 10.1.4 Reduction in category } \\
\text { 3 private pharmacies. }\end{array}$ & 2003-05 & $\begin{array}{l}\text { 10.1.1. \# of workers trained } \\
\text { 10.1.2 \# laws /regulations issued. } \\
\text { 10.1.3 \% of drugs registered } \\
\text { 10.1.4 \% reduction in private } \\
\text { pharmacies registered }\end{array}$ & Yearly & MOH \\
\hline
\end{tabular}




\begin{tabular}{|c|c|c|c|c|c|c|}
\hline Policy area(s) & Objectives/Targets & Strategies/Measures & $\begin{array}{c}\text { Planned } \\
\text { Timetable }\end{array}$ & Monitoring Indicators & $\begin{array}{l}\text { Reporting } \\
\text { Frequency }\end{array}$ & Agency \\
\hline 10.2 Food safety & $\begin{array}{l}\text { supplied by local } \\
\text { manufacture. } \\
\text { To control the price of } \\
\text { essential drugs } \\
\text { The Lao people consume } \\
\text { food of high quality and } \\
\text { safety - }\end{array}$ & $\begin{array}{l}\text { 10.1.5 Regulate import } \\
\text { 10.1.6 Drug stores at } \\
\text { provincial and district levels } \\
\text { 10.1.7 Establish } 2 \text { medical } \\
\text { equipment workshops } \\
\text { 10.2.1 Train workers } \\
\text { 10.2.2 Laws and regulations. } \\
\text { 10.2.3 Register } 100 \% \text { food } \\
\text { product factories } \\
\text { 10.2.4 Establish and reform } \\
\text { inspection units at border. } \\
\text { 10.2.5 Improved laboratory } \\
\text { monitoring - } 1 \text { central and } 2 \\
\text { provincial }\end{array}$ & & $\begin{array}{l}\text { 10.1.5 One state company formed for } \\
\text { import at central and provincial level. } \\
\text { 10.1.6 \# of state drug stores formed at } \\
\text { provinces and districts } \\
\text { 10.1.7 2\# medical equip workshops } \\
\text { 10.2.1 \# of workers trained } \\
\text { 10.2.2 \# of laws approved and } \\
\text { regulations issued. } \\
\text { 10.2.3 \% of of factories registered } \\
\text { 10.2.4 \# of number of active food } \\
\text { inspection units at borders } \\
\text { 10.2.5 \# of laboratories }\end{array}$ & & \\
\hline $\begin{array}{l}\text { 11. Promotion of } \\
\text { traditional } \\
\text { medicine }\end{array}$ & $\begin{array}{l}\text { By } 2005 \text { to strengthen } \\
\text { the promotion of the } \\
\text { culture of traditional } \\
\text { medicine (TM ) }\end{array}$ & $\begin{array}{l}\text { 11.1 Promote traditional } \\
\text { medicine plantations } \\
\text { 11.2 Develop law and } \\
\text { regulations for TM } \\
\text { 11.3 Develop human } \\
\text { resources for TM } \\
\text { 11.4 Rehabilitate TM centers } \\
\text { 11.5 Conduct research on TM }\end{array}$ & 2003-05 & $\begin{array}{l}\text { 11.1 \# TM plantations established by } \\
2005 . \\
11.2 \text { \# laws and regulations in place. } \\
11.3 \text { \# numbers trained in various } \\
\text { specialities. } \\
\text { 11.4 \# TM centers rehabilitated } \\
\text { 11.5 \# Research studies completed }\end{array}$ & Yearly & MOH \\
\hline $\begin{array}{l}\text { 12. Strengthened } \\
\text { financing, } \\
\text { management, } \\
\text { quality assurance, } \\
\text { and legal } \\
\text { framework }\end{array}$ & $\begin{array}{l}15 \% \text { of population } \\
\text { covered by community } \\
\text { insurance } \\
\text { Legal and management } \\
\text { framework improved }\end{array}$ & $\begin{array}{l}\text { 12.1.1 Completion of } 3 \text { pilot } \\
\text { projects by end of } 2004 \text {. } \\
\text { 12.1. 2 Developed framework } \\
\text { for CBHI expansion } \\
\text { 12.2. Develop legal } \\
\text { framework for curative law } \\
\text { 12.3 Medical society started } \\
\text { 12.4 Improved procedures for } \\
\text { health finance/management }\end{array}$ & 2003-05 & $\begin{array}{l}\text { 12.1.1 - \# of pilots established } \\
\text { 12.1.2 \# of new projects and estimate } \\
\text { of population coverage } \\
\text { 12.2 \# laws and regulations } \\
\text { developed } \\
\text { 12.3 Medical society in place } \\
12.4 \text { Procedural manual available. }\end{array}$ & Yearly & MOH \\
\hline
\end{tabular}


Annex 3.4: Five-Year Action Programmes for Poverty-Focused Transport Sector Development

\begin{tabular}{|c|c|c|c|c|c|c|}
\hline Policy Areas / Sub-areas & Objectives/ targets & Measures & Monitoring Indicators & Timetable & Reporting Agency & Remarks \\
\hline Transport & $\begin{array}{l}\text { To contribute towards the } \\
\text { Government's efforts of } \\
\text { poverty reduction through } \\
\text { the provision of an } \\
\text { enabling, safe and efficient } \\
\text { transport sector. }\end{array}$ & $\begin{array}{l}\text { Implementation of the } \\
\text { NPEP for the Transport } \\
\text { Sector }\end{array}$ & $\begin{array}{l}\text { GDP increased from about } \\
\text { USD } 300 \text { in 2001, to about } \\
\text { USD } 1000 \text { in 2020; } \\
\text { National Transport Safety } \\
\text { Strategy under } \\
\text { implementation; number of } \\
\text { fatalities per } 10000 \\
\text { vehicles: } 5 \text {; } \\
\text { Domestic revenues } \\
\text { allocated for the } \\
\text { maintenance of the } \\
\text { transport facilities meet } \\
\text { the needs at } 95 \%\end{array}$ & $2003-2020$ & МСТРC & $\begin{array}{l}\text { The NPEP for the } \\
\text { Transport Sector is the } \\
\text { overall guiding instrument } \\
\text { for the MCTPC in helping } \\
\text { the Government reach its } \\
\text { objectives of poverty } \\
\text { reduction by 2020; } \\
\text { Indicators assume } \\
\text { concomitant progress in } \\
\text { other sectors }\end{array}$ \\
\hline $\begin{array}{l}\text { A. Maintenance of } \\
\text { transport facilities }\end{array}$ & $\begin{array}{l}\text { Routine maintenance is } \\
\text { carried out on all the } \\
\text { maintainable sections of } \\
\text { all transport facilities by } \\
\text { the end of FY 2005/06; } \\
\text { Periodic maintenance is } \\
\text { carried out in conformity } \\
\text { with the Annual Work } \\
\text { Plan and Budget, which is } \\
\text { based on the needs } \\
\text { obtained from the relevant } \\
\text { condition surveys }\end{array}$ & $\begin{array}{l}\text { A.1) Implement routine } \\
\text { road and bridge } \\
\text { maintenance programmes } \\
\text { on national roads; } \\
\text { A.2) Implement routine } \\
\text { road and bridge } \\
\text { maintenance programmes } \\
\text { on local roads; } \\
\text { A.3) Implement periodic } \\
\text { road and bridge } \\
\text { maintenance programmes } \\
\text { on national roads; } \\
\text { A.4) Implement periodic } \\
\text { road and bridge } \\
\text { maintenance programmes } \\
\text { on local roads; } \\
\text { A.5) Implement routine } \\
\text { and periodic maintenance } \\
\text { programme at airports; } \\
\text { A.6) Implement routine } \\
\text { and periodic maintenance } \\
\text { programme for inland } \\
\text { waterways; } \\
\text { A.7) Implement routine } \\
\text { and periodic maintenance } \\
\text { programme of railways. }\end{array}$ & $\begin{array}{l}\text { Completion certificates } \\
\text { and DCTPC files (or } \\
\text { equivalent) verify that } \\
\text { planned works have been } \\
\text { executed in accordance } \\
\text { with the Annual Work } \\
\text { Plan and Budget, and } \\
\text { Contract Agreements }\end{array}$ & Annually & $\begin{array}{l}\text { RAD/DCTPCs for roads } \\
\text { DCA/DCTPCs for airports } \\
\text { Waterways Division/DOR } \\
\text { for waterways } \\
\text { Railway Authority for } \\
\text { railways }\end{array}$ & $\begin{array}{l}\text { The respective (sub-)sector } \\
\text { strategies, e.g. the recently } \\
\text { reviewed Road Sector } \\
\text { Strategy shall be applied } \\
\text { when determining } \\
\text { priorities and in preparing } \\
\text { the Annual Work Plans } \\
\text { and Budgets. }\end{array}$ \\
\hline
\end{tabular}




\begin{tabular}{|c|c|c|c|c|c|c|}
\hline Policy Areas / Sub-areas & Objectives/ targets & Measures & Monitoring Indicators & Timetable & Reporting Agency & Remarks \\
\hline $\begin{array}{l}\text { B. Investment in transport } \\
\text { infrastructure }\end{array}$ & $\begin{array}{l}\text { Rehabilitation and } \\
\text { construction is carried out } \\
\text { in conformity with the } \\
\text { Annual Work Plan and } \\
\text { Budget, which is based on } \\
\text { the needs, and the } \\
\text { priorities as outlined by the } \\
\text { respective sub-sector } \\
\text { strategy }\end{array}$ & $\begin{array}{l}\text { B.1) Develop Rural } \\
\text { Transport Infrastructure } \\
\text { (RTI), applying a } \\
\text { Participatory Rural } \\
\text { Transport Planning } \\
\text { (PRTP) approach } \\
\text { B.2) Rehabilitate and/or } \\
\text { construct district and } \\
\text { provincial roads and } \\
\text { bridges in accordance with } \\
\text { a participatory planning } \\
\text { process and in line with } \\
\text { national priorities } \\
\text { B.3) Rehabilitate and/or } \\
\text { construct national roads } \\
\text { (and/or sub-regional } \\
\text { routes) and bridges in } \\
\text { accordance with national } \\
\text { priorities } \\
\text { B.4) Rehabilitate and/or } \\
\text { construct airports in } \\
\text { accordance with national } \\
\text { priorities } \\
\text { B.5) Rehabilitate and/or } \\
\text { construct inland waterways } \\
\text { / port facilities in } \\
\text { accordance with national } \\
\text { priorities } \\
\text { B.6) Construct railway } \\
\text { facilities in accordance } \\
\text { with national priorities }\end{array}$ & $\begin{array}{l}\text { B.1) } 25 \mathrm{~km} \text { of RTI per } \\
\text { district developed, in the } \\
46 \text { poorest districts as } \\
\text { outlined by the } \\
\text { Government, by 2005/06; } \\
\text { B.2) Provincial roads: } \\
\text { M. Khoun - M. Mokmai } \\
\text { ( } 88 \mathrm{km)} \\
\text { R13S - M. Thaphangthong } \\
\text { (40 km) } \\
\text { B. Houayphek (Pakxe) - } \\
\text { Champassack - } \\
\text { Soukhouma - } \\
\text { Mounlapamok (100 km); } \\
\text { District roads to be } \\
\text { decided as part of the } \\
\text { annual planning and } \\
\text { budgeting process } \\
\text { B.3) National roads: } \\
\text { Complete Road 3, } \\
\text { Houayxai - Boten } \\
\text { Complete Road 8, B. Lao } \\
\text { - Keonua } \\
\text { Complete Road 9, Xeno - } \\
\text { Lao Bao } \\
\text { Complete Road 18B, } \\
\text { Attapeu - B. Hat } \\
\text { Complete ADB } 9 \\
\text { Complete ADB 10 } \\
\text { Road 4, Xiang - Ngeun - } \\
\text { Xaignabouli ( } 87 \text { km) } \\
\text { Road 2, Ngeun - Pakbeng } \\
\text { Savannakhet Bridge } \\
\text { Houayxai Bridge }\end{array}$ & $\begin{array}{l}2003-2006 \\
2006-2008 \\
2005 \\
2006 \text { (continued } 2010 \\
\text { onwards) } \\
2003-2006 \\
2004-2006 \\
2004 \\
2004-2005 \\
2004-2006 \\
2004-2005 \\
2005-2007 \\
2005-2006 \\
2005-2007 \\
2005-2007\end{array}$ & $\begin{array}{l}\text { LRD/DOR } \\
\text { DOR/DCTPCs } \\
\text { DOR/DCTPCs }\end{array}$ & $\begin{array}{l}\text { The respective (sub-)sector } \\
\text { strategies, e.g. the recently } \\
\text { reviewed Road Sector } \\
\text { Strategy shall be applied } \\
\text { when determining } \\
\text { priorities and in preparing } \\
\text { the Annual Work Plans } \\
\text { and Budgets. }\end{array}$ \\
\hline
\end{tabular}




\begin{tabular}{|c|c|c|c|c|c|c|}
\hline Policy Areas / Sub-areas & Objectives/ targets & Measures & Monitoring Indicators & Timetable & Reporting Agency & Remarks \\
\hline B. Investment (continued) & See above & See above & $\begin{array}{l}\text { B.4) Airports: } \\
\text { Improvement / } \\
\text { rehabilitation of six minor } \\
\text { airports in Sayabouli, } \\
\text { Oudomxay, Houaxay, } \\
\text { Luang Namtha, Xam } \\
\text { Neua, and Xieng Khuang } \\
\text { B.5) Inland Waterways } \\
\text { and ports/ boat landings: } \\
\text { B. Xai port, Xiengkok } \\
\text { port, B. Mone port, B. } \\
\text { Vang } \\
\text { Erosion protection mainly } \\
\text { in Vientiane, but also } \\
\text { minor works in } \\
\text { Savannakhet, Pakse, } \\
\text { Khammouane, } \\
\text { Bolikhamxay, Bokeo, } \\
\text { Luang Prabang, and } \\
\text { Xayabouli } \\
\text { B.6) Railway constructed } \\
\text { from centre of Friendship } \\
\text { Bridge to Ban Thanaleng } \\
\text { (3.5 km) }\end{array}$ & $\begin{array}{l}2003-2006 \\
2003-2006 \\
2005-2007\end{array}$ & $\begin{array}{l}\text { DCA, DCTPCs } \\
\text { DOR / DOT } \\
\text { Railway Authority }\end{array}$ & - \\
\hline C. Capacity Development & $\begin{array}{l}\text { Central level acts as macro } \\
\text { management, provinces as } \\
\text { strategic units, districts as } \\
\text { planning and budgeting } \\
\text { units, and villages as the } \\
\text { base for implementation of } \\
\text { transport sector activities }\end{array}$ & $\begin{array}{l}\text { C.1) Develop, revise, } \\
\text { disseminate, and } \\
\text { implement / enforce the } \\
\text { regulatory framework for } \\
\text { the transport sector; } \\
\text { C.2) Establish and operate } \\
\text { sustainable transport } \\
\text { infrastructure management } \\
\text { systems appropriate to the } \\
\text { Lao environment; } \\
\text { C.3) Develop, disseminate, } \\
\text { implement and enforce a } \\
\text { National Transport Safety } \\
\text { Strategy }\end{array}$ & $\begin{array}{l}\text { The number of vehicles } \\
\text { overloaded on the national } \\
\text { road network does not } \\
\text { exceed } 5 \% \text { by 2020; } \\
\text { RMS ready by end 2003; } \\
\text { APMS or equivalent in } \\
\text { operation at major airports } \\
\text { by 2006; Other procedures } \\
\text { and routines developed } \\
\text { National Transport Safety } \\
\text { Strategy, or sector-specific } \\
\text { safety strategies available, } \\
\text { with a Road Safety } \\
\text { Strategy under } \\
\text { implementation by } 2005\end{array}$ & $\begin{array}{l}2003-2020 \\
2003-2020 \\
2003-2020\end{array}$ & $\begin{array}{l}\text { DOT } \\
\text { DOR for roads; } \\
\text { DCA for airfields; } \\
\text { DOR/DOT for waterways } \\
\text { Railway Authority for rail } \\
\text { DOT }\end{array}$ & - \\
\hline
\end{tabular}




\begin{tabular}{|c|c|c|c|c|c|c|}
\hline Policy Areas / Sub-areas & Objectives/ targets & Measures & Monitoring Indicators & Timetable & Reporting Agency & Remarks \\
\hline $\begin{array}{l}\text { C. Capacity Development } \\
\text { (continued) }\end{array}$ & As above & $\begin{array}{l}\text { C.4) Enhance the capacity } \\
\text { of central MCTPC level in } \\
\text { macro-managing the } \\
\text { transport sector; } \\
\text { C.5) Enhance the capacity } \\
\text { of provincial and district } \\
\text { authorities, in the planning } \\
\text { and implementation of } \\
\text { transport sector activities; } \\
\text { C.6) Develop and compile } \\
\text { into a coherent set of } \\
\text { Financial Guidelines, all } \\
\text { financial management } \\
\text { issues and accounting } \\
\text { principles; } \\
\text { C.7) Develop and apply } \\
\text { procedures for addressing } \\
\text { cross-cutting issues; } \\
\text { C.8) Develop further } \\
\text { financing mechanisms, to } \\
\text { ascertain a sustainable } \\
\text { source of funds for } \\
\text { recurrent works }\end{array}$ & $\begin{array}{l}\text { National Transport Sector } \\
\text { Policy and Strategy under } \\
\text { implementation; } \\
\text { District offices staffed and } \\
\text { provided basic office } \\
\text { facilities; staff trained to } \\
\text { apply participatory } \\
\text { approaches and work } \\
\text { effectively on village } \\
\text { level; VMCs strengthened } \\
\text { Improved procedures in } \\
\text { place for disbursement, } \\
\text { authorisation, budgeting, } \\
\text { reporting, accounting, and } \\
\text { audit; } \\
\text { Environmental Guidelines } \\
\text { further developed and } \\
\text { implemented; procedures } \\
\text { and routines developed for } \\
\text { the other cross-cutting } \\
\text { issues; } \\
\text { Road Maintenance Fund } \\
\text { developing as per plan; } \\
\text { revenue generating } \\
\text { mechanisms for the other } \\
\text { transport sub-sectors } \\
\text { developed, i.e. for } \\
\text { aviation, waterways, and } \\
\text { railways }\end{array}$ & $\begin{array}{l}2003-2020 \\
2003-2020 \\
2003-2006 \\
2003-2020 \\
2003-2020\end{array}$ & $\begin{array}{l}\text { MCTPC } \\
\text { DOR/DOT/DCA and } \\
\text { DCTPCs } \\
\text { Planning and Budgeting } \\
\text { Department / MCTPC } \\
\text { DOP } \\
\text { DOR, DOT } \\
\text { DCA, RA } \\
\text { PBD } \\
\text { RMF / DOR } \\
\text { DCA, DOT, DOR, RA }\end{array}$ & $\begin{array}{l}\text { Procedures and routines } \\
\text { agreed regarding gender } \\
\text { equity, governance and } \\
\text { justice, HIV, participation, } \\
\text { uxo, social/cultural } \\
\text { development, and HRD }\end{array}$ \\
\hline $\begin{array}{l}\text { D. Private/public Sector } \\
\text { Development }\end{array}$ & $\begin{array}{l}\text { The private/public sector } \\
\text { industry is offering right } \\
\text { quality on time and at } \\
\text { competitive prices }\end{array}$ & $\begin{array}{l}\text { D.1) Increase competition } \\
\text { among long-distance } \\
\text { transport service providers } \\
\text { to provide reliable, } \\
\text { affordable and safe } \\
\text { transport to all; } \\
\text { D.2) Establish a safe, } \\
\text { reliable/timely, affordable } \\
\text { and environmental- } \\
\text { friendly alternative to } \\
\text { individual urban transport }\end{array}$ & $\begin{array}{l}\text { Travelling costs and } \\
\text { traveller satisfaction } \\
\text { Passenger transport } \\
\text { services operating in } \\
\text { Vientiane, Savannakhet } \\
\text { and Luang Prabang, } \\
\text { reducing traffic congestion } \\
\text { and accidents in those } \\
\text { urban areas }\end{array}$ & $\begin{array}{r}2003-2020 \\
2003-2020\end{array}$ & $\begin{array}{l}\text { DOT } \\
\text { DOT }\end{array}$ & - \\
\hline
\end{tabular}




\begin{tabular}{|c|c|c|c|c|c|c|}
\hline Policy Areas / Sub-areas & Objectives/ targets & Measures & Monitoring Indicators & Timetable & Reporting Agency & Remarks \\
\hline $\begin{array}{l}\text { D. Private/public Sector } \\
\text { Development (continued) }\end{array}$ & As above & $\begin{array}{l}\text { D.3) Promote the further } \\
\text { development of a solid } \\
\text { contracting and consulting } \\
\text { industry; } \\
\text { D.4) Improve regularity, } \\
\text { safety and competitiveness } \\
\text { of air services; } \\
\text { D.5) Port facilities / boat } \\
\text { landings increasingly } \\
\text { managed / owned by the } \\
\text { private sector } \\
\text { D.6) Railway services run } \\
\text { by private operator }\end{array}$ & $\begin{array}{l}\text { Improved quality at } \\
\text { reduced cost; } \\
\text { Regular timetabling, } \\
\text { reduced number of aircraft } \\
\text { failures; number of } \\
\text { passenger-kms } \\
\text { Decreased budget } \\
\text { requirements for } \\
\text { management of the } \\
\text { facilities; } \\
\text { Revenue generated by } \\
\text { operator who pays user } \\
\text { fees to Railway Authority }\end{array}$ & $\begin{array}{l}2003-2020 \\
2003-2020 \\
2003-2020 \\
2005-2007\end{array}$ & $\begin{array}{l}\text { MCTPC } \\
\text { DCA } \\
\text { DOT/DOR }\end{array}$ & - \\
\hline $\begin{array}{l}\text { E. Transit and Trade } \\
\text { Facilitation }\end{array}$ & $\begin{array}{l}\text { Vientiane Plan of Action } \\
\text { fully implemented; trade } \\
\text { figures in Lao PDR tripled } \\
\text { in } 2020 \text { as compared with } \\
2000 \text {; and tourism } \\
\text { significantly increased }\end{array}$ & $\begin{array}{l}\text { E.1) Address transit } \\
\text { transport policy issues; } \\
\text { E.2) Develop particularly } \\
\text { important transit transport } \\
\text { infrastructure; } \\
\text { E.3) Improve management } \\
\text { and operational efficiency } \\
\text { within the transport sector; } \\
\text { E.4) Provision of external } \\
\text { assistance and follow-up } \\
\text { institutional mechanisms; } \\
\text { E.5) Significant results } \\
\text { yielded within aviation } \\
\text { sub-sector; }\end{array}$ & $\begin{array}{l}\text { The agreements listed in } \\
\text { Vientiane POA fully } \\
\text { implemented; } \\
\text { Route } 3 \text { completed, etc } \\
\text { Preferential transit tariffs } \\
\text { agreed; customs } \\
\text { harmonization; } \\
\text { TA grants for management } \\
\text { and development, POA } \\
\text { follow-up } \\
\text { Open Sky Policy in } \\
\text { operation }\end{array}$ & $\begin{array}{l}2003-2006 \\
2003-2020 \\
2003-2006 \\
2003-2006 \\
2003-2006\end{array}$ & $\begin{array}{l}\text { DOT } \\
\text { DOR, DCA, DOT, RA } \\
\text { DOT } \\
\text { DOT } \\
\text { DCA }\end{array}$ & - \\
\hline
\end{tabular}




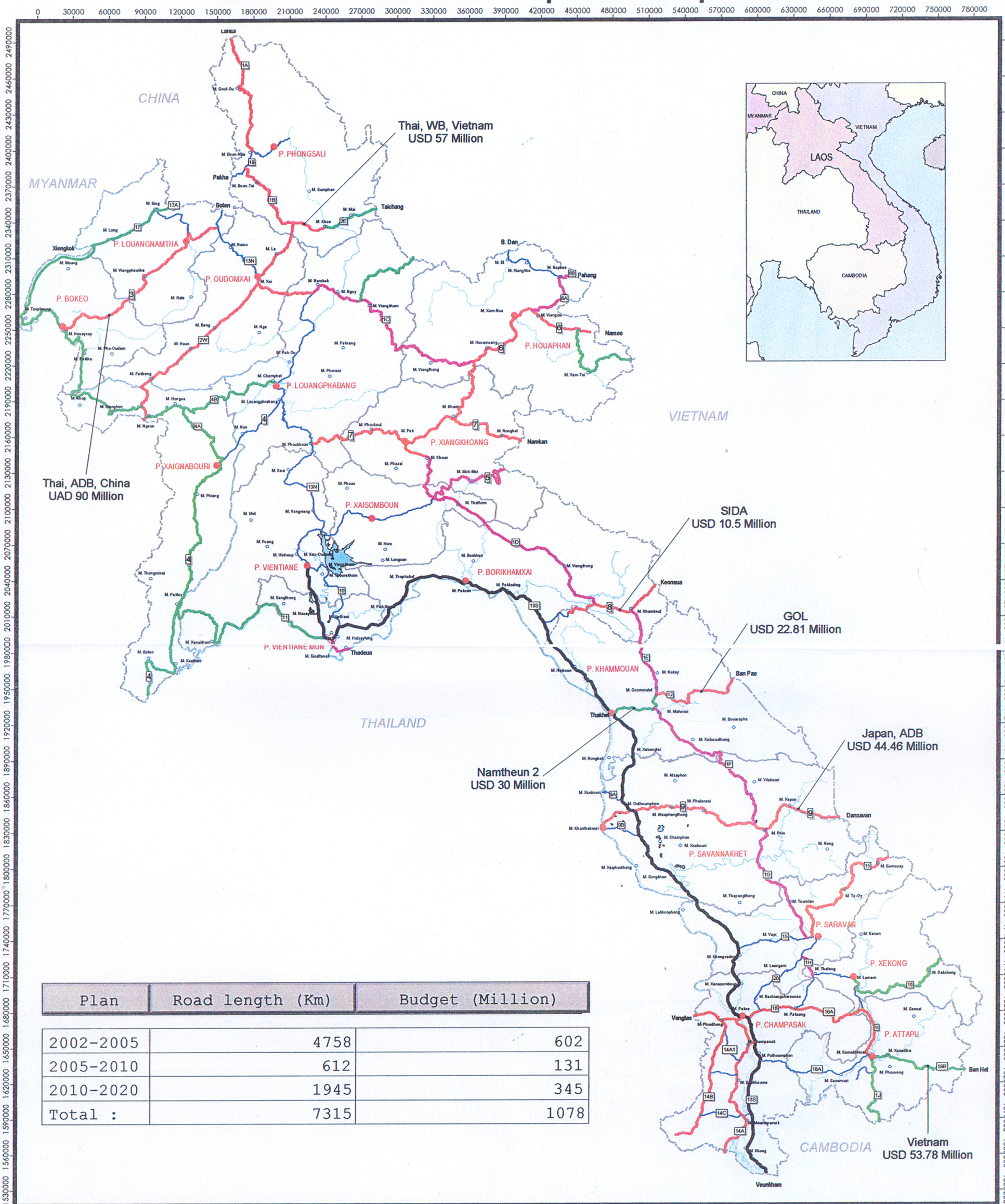

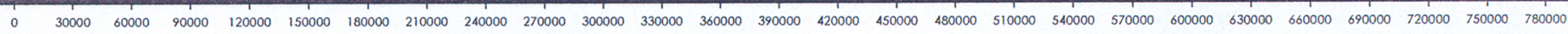
LEGEND

(10) Capital of Lao PDR

$1: 3000000$

- Provincial Capital

1:3000000
$30 \quad 0 \quad 30 \quad 60 \mathrm{Km}$


Table 3.5 Matrix of Gender Strategy

\begin{tabular}{|c|c|c|c|c|c|c|}
\hline Policy Area & Objectives/Targets & Measures (Strategies/Policies) & $\begin{array}{l}\text { Planned } \\
\text { Timetable }\end{array}$ & Monitoring Indicators & $\begin{array}{l}\text { Reporting } \\
\text { Frequency }\end{array}$ & $\begin{array}{l}\text { Reporting } \\
\text { Agency }\end{array}$ \\
\hline $\begin{array}{l}\text { Promotion of } \\
\text { Gender } \\
\text { Equality }\end{array}$ & & & & & & \\
\hline $\begin{array}{l}1 . \\
\text { Government- } \\
\text { wide }\end{array}$ & $\begin{array}{l}\text { 1. Address needs and } \\
\text { priorities of poor women, } \\
\text { especially in rural areas and } \\
\text { ethnic minority groups (and } \\
\text { thereby make progress in } \\
\text { meeting } 2005,2010 \text { and } \\
2020 \text { targets on poverty } \\
\text { reduction, health, education, } \\
\text { and other areas) }\end{array}$ & $\begin{array}{l}\text { 1.1 Establish National } \\
\text { Commission for the } \\
\text { Advancement of Women - } \\
\text { Lao PDR (NCAW-Lao) } \\
\text { 1.2 Integrate gender awareness, } \\
\text { analysis, action and } \\
\text { monitoring, initially in four } \\
\text { key NPEP sectors } \\
\text { (agriculture, education, } \\
\text { health, transport): } \\
\text { Establish high-level gender } \\
\text { working groups in MoAF, } \\
\text { MoE, MoH \& MCTPC } \\
\text { Collect sex-disaggregated } \\
\text { data related to poverty } \\
\text { reduction \& other national } \\
\text { goals } \\
\text { Develop gender profile of } \\
\text { sector } \\
\text { Develop gender strategy \& } \\
\text { action plan for sector } \\
\text { Provide gender training for } \\
\text { staff } \\
\text { Improve gender \& ethnic } \\
\text { balance of staff at all levels } \\
\text { Screen new policies, } \\
\text { programs \& projects from } \\
\text { gender perspective } \\
\text { Consult local women in } \\
\text { project design and ensure } \\
\text { their participation in project } \\
\text { implementation and } \\
\text { monitoring }\end{array}$ & $\begin{array}{l}\text { Dec. } 2003 \\
2003 \\
\text { onwards } \\
\text { June } 2004 \\
\text { Dec. } 2004 \\
2003 \\
\text { onwards } \\
2003-05 \\
2003 \\
\text { onwards } \\
\begin{array}{l}2003 \\
\text { onwards }\end{array}\end{array}$ & $\begin{array}{l}\begin{array}{l}\text { Gender working group } \\
\text { minutes \& reports }\end{array} \\
\text { Ministry \& NSC reports } \\
\text { Ministry report } \\
\text { Ministry report } \\
\text { Ministry HRD program } \\
\text { \& report } \\
\text { Ministry staffing profile } \\
\begin{array}{l}\text { References to gender } \\
\text { analysis in policy, } \\
\text { program \& project } \\
\text { documents }\end{array} \\
\begin{array}{l}\text { Records of consultation } \\
\text { meetings; } \\
\text { implementation and } \\
\text { evaluation reports; } \\
\text { surveys of women in } \\
\text { project areas }\end{array}\end{array}$ & & $\begin{array}{l}\text { MoAF/MoE/ } \\
\text { MoH/MCTPC } \\
\text { NSC/MoAF/ } \\
\text { MoE/MoH/ } \\
\text { MCTPC } \\
\text { MoAF/MoE/ } \\
\text { MoH/MCTPC } \\
\text { MoAF/MoE/ } \\
\text { MoH/MCTPC } \\
\text { MoAF/MoE/ } \\
\text { MoH/MCTPC } \\
\text { MoAF/MoE/ } \\
\text { MoH/MCTPC } \\
\text { MoAF/MoE/ } \\
\text { MoH/MCTPC } \\
\\
\text { MoAF/MoE/ } \\
\text { MoH/MCTPC }\end{array}$ \\
\hline
\end{tabular}




\begin{tabular}{|c|c|c|c|c|c|}
\hline $\begin{array}{l}\text { 2. Agriculture } \\
\text { Sector }\end{array}$ & $\begin{array}{l}\text { 2. Improve poor women's } \\
\text { productivity, food security } \\
\& \text { income, \& reduce time } \\
\text { burdens in agriculture, } \\
\text { livestock raising, fishing \& } \\
\text { sustainable use of NTFPs } \\
\text { (make progress toward } \\
2005,2010 \& 2020 \text { targets } \\
\text { for GDP growth \& poverty } \\
\text { reduction) }\end{array}$ & $\begin{array}{l}\text { 2.1 Mainstream gender concerns } \\
\text { in MoAF policies, planning, } \\
\text { staffing and activities (see } 1.2 \\
\text { above) } \\
2.2 \text { Take specific measures } \\
\text { outlined in agriculture section \& } \\
\text { matrix (e.g., gender analysis and } \\
\text { needs assessments in project } \\
\text { preparation; women's } \\
\text { participation in farmer groups; at } \\
\text { least } 50 \% \text { women in } \\
\text { extension/training; use of sex- } \\
\text { disaggregated indicators; at least } \\
30 \% \text { women in provincial and } \\
\text { district offices, including } \\
\text { extension workers; model } \\
\text { women farmers as gender focal } \\
\text { points in villages; vaccination of } \\
\text { small livestock; gender-sensitive } \\
\text { approach to land allocation \& } \\
\text { land titling) }\end{array}$ & $\begin{array}{l}\begin{array}{l}\text { See } 1.2 \\
\text { above }\end{array} \\
\text { See } \\
\text { agriculture } \\
\text { section/ } \\
\text { matrix }\end{array}$ & $\begin{array}{l}\text { See } 1.2 \text { above } \\
\text { See agriculture section/ } \\
\text { matrix }\end{array}$ & MoAF \\
\hline $\begin{array}{l}\text { 3. Education } \\
\text { Sector }\end{array}$ & $\begin{array}{l}\text { 3. Improve access, quality } \\
\text { and relevance of education } \\
\text { services to poor girls \& } \\
\text { women, especially from } \\
\text { ethnic minority groups } \\
\text { (make progress toward } \\
2005,2010 \& 2020 \text { targets } \\
\text { for adult literacy, \& } 2005 \\
\text { enrollment targets) }\end{array}$ & $\begin{array}{l}\text { 3.1 Mainstream gender concerns } \\
\text { in MoE policies, planning, } \\
\text { staffing and activities (see } 1.2 \\
\text { above) } \\
3.2 \text { Take specific measures } \\
\text { outlined in education section \& } \\
\text { matrix (e.g.,increase number of } \\
\text { ethnic minority teachers, } \\
\text { improve relevance of primary } \\
\text { school materials, provide } \\
\text { incentives for girls to attend } \\
\text { school, encourage provinces \& } \\
\text { districts to develop locally } \\
\text { appropriate materials to } \\
\text { supplement core curriculum, } \\
\text { adjust school schedules to } \\
\text { accommodate student's home } \\
\text { responsibilities, experiment with } \\
\text { distance learning, "bridge" } \\
\text { courses to prepare students for } \\
\text { vocational \& technical schools, } \\
\text { inclusion of functional } \\
\text { literacy/numeracy training in } \\
\text { extension and small business } \\
\text { support programs) }\end{array}$ & $\begin{array}{l}\begin{array}{l}\text { See } 1.2 \\
\text { above }\end{array} \\
\text { See } \\
\text { education } \\
\text { section/ } \\
\text { matrix }\end{array}$ & $\begin{array}{l}\text { See } 1.2 \text { above } \\
\text { See education section/ } \\
\text { Matrix }\end{array}$ & $\begin{array}{l}\text { MoE } \\
\text { MoE }\end{array}$ \\
\hline
\end{tabular}




\begin{tabular}{|c|c|c|c|c|c|}
\hline 4. Health Sector & $\begin{array}{l}\text { 4. Improve poor women's } \\
\text { access to primary health } \\
\text { care, especially } \\
\text { reproductive health } \\
\text { services in remote and } \\
\text { ethnic minority areas } \\
\text { (make progress toward } \\
2005,2010 \text { \& } 2020 \text { life } \\
\text { expectancy targets; } 2005 \\
\text { targets for maternal, infant } \\
\text { \& child mortality, } \\
\text { immunization \& clean } \\
\text { water) }\end{array}$ & $\begin{array}{l}\text { 4.1 Mainstream gender concerns } \\
\text { in MoH policies, planning, } \\
\text { staffing and activities (see } 1.2 \\
\text { above) } \\
4.2 \text { Take specific measures } \\
\text { outlined in health section \& } \\
\text { matrix (e.g., training \& } \\
\text { promotion of more ethnic } \\
\text { minority staff and health care } \\
\text { providers, especially at } \\
\text { provincial \& district levels, } \\
\text { gender focal points in provincial } \\
\& \text { district PHCs, at least } 50 \% \\
\text { women on village health } \\
\text { committees, gender and ethnic } \\
\text { balance in in-service and } \\
\text { specialized training, incentives } \\
\text { for health care workers in remote } \\
\text { areas, men \& youth targeted for } \\
\text { health care messages on birth } \\
\text { spacing and prevention of } \\
\text { STDs/HIV/AIDS, expanded } \\
\text { reproductive health services to } \\
\text { ethnic minority women) }\end{array}$ & $\begin{array}{l}\begin{array}{l}\text { See } 1.2 \\
\text { above }\end{array} \\
\text { See } \\
\text { health } \\
\text { section/ } \\
\text { matrix }\end{array}$ & $\begin{array}{l}\text { See } 1.2 \text { above } \\
\text { See health section/ } \\
\text { Matrix }\end{array}$ & $\begin{array}{l}\mathrm{MoH} \\
\mathrm{MoH}\end{array}$ \\
\hline $\begin{array}{l}\text { 5. Transport } \\
\text { Sector }\end{array}$ & $\begin{array}{l}\text { 5. Ensure that poor } \\
\text { women and men benefit } \\
\text { from improvements in } \\
\text { roads, transport facilities } \\
\& \text { other infrastructure }\end{array}$ & $\begin{array}{l}\text { 5.1 Mainstream gender concerns } \\
\text { in MCTPC policies, planning, } \\
\text { staffing and activities (see } 1.2 \\
\text { above) } \\
\text { 3.2 Take specific measures } \\
\text { outlined in transport section \& } \\
\text { matrix (e.g., consultations with } \\
\text { local communities, including } \\
\text { women, on design of roads and } \\
\text { transport facilities; gender } \\
\text { analysis included in EIA/SIA for } \\
\text { new transport \& infrastructure } \\
\text { projects; community } \\
\text { development projects to ensure } \\
\text { local benefits from road \& other } \\
\text { infrastructure projects; sex- } \\
\text { disaggregated monitoring of } \\
\text { project impacts; health } \\
\text { awareness campaigns in } \\
\text { construction camps, along road } \\
\text { corridors \& at transit stops) }\end{array}$ & $\begin{array}{l}\begin{array}{l}\text { See } 1.2 \\
\text { above }\end{array} \\
\text { See } \\
\text { transport } \\
\text { section/ } \\
\text { matrix }\end{array}$ & $\begin{array}{l}\text { See } 1.2 \text { above } \\
\text { See transport section/ } \\
\text { Matrix }\end{array}$ & $\begin{array}{l}\text { MCTPC } \\
\text { MCTPC }\end{array}$ \\
\hline
\end{tabular}




\begin{tabular}{|c|c|c|c|c|c|}
\hline $\begin{array}{l}\text { 6. Other Sectors } \\
\text { \& Subsectors }\end{array}$ & $\begin{array}{l}\text { 6. Promote opportunities } \\
\text { for poor women as well as } \\
\text { men in trading, handicraft } \\
\text { production, tourism \& } \\
\text { other fields; legal and safe } \\
\text { employment in } \\
\text { manufacturing (e.g., } \\
\text { garment industry) }\end{array}$ & $\begin{array}{l}\text { 6.1 Under NCAW-Lao, relevant } \\
\text { ministries will mainstream } \\
\text { gender concerns in their policies, } \\
\text { planning and activities } \\
6.2 \text { See discussion of other } \\
\text { sectors \& subsectors elsewhere } \\
\text { in NPEP document \& matrix }\end{array}$ & $\begin{array}{l}\begin{array}{l}2003 \\
\text { onwards }\end{array} \\
\text { See other } \\
\text { sections } \\
\text { on sectors, } \\
\text { subsectors }\end{array}$ & $\begin{array}{l}\text { See other sections on } \\
\text { sectors, subsectors }\end{array}$ & $\begin{array}{l}\text { Various } \\
\text { ministries } \\
\text { Various } \\
\text { ministries }\end{array}$ \\
\hline $\begin{array}{l}\text { 7. National } \\
\text { Programs }\end{array}$ & $\begin{array}{l}\text { 7. Address particular } \\
\text { vulnerabilities and needs } \\
\text { of women \& girls related } \\
\text { to HIV/AIDS risk, } \\
\text { migration and trafficking, } \\
\text { drug abuse, UXO and } \\
\text { other national concerns }\end{array}$ & $\begin{array}{l}\text { 7. See separate sections on } \\
\text { national programs related to } \\
\text { HIV/AIDS, trafficking in } \\
\text { women and girls, drug control } \\
\text { and UXO }\end{array}$ & $\begin{array}{l}\text { See } \\
\text { section on } \\
\text { national } \\
\text { programs }\end{array}$ & $\begin{array}{l}\text { See section on national } \\
\text { Programs }\end{array}$ & $\begin{array}{l}\text { Various } \\
\text { ministries }\end{array}$ \\
\hline 8. Governance & $\begin{array}{l}\text { 8. Expand opportunities } \\
\text { for women to participate } \\
\text { in decision-making at all } \\
\text { levels, and strengthen } \\
\text { women's legal literacy } \\
\text { and access to justice }\end{array}$ & $\begin{array}{l}\text { 8.1 Increase percentage of } \\
\text { women in senior government } \\
\text { positions at national, provincial } \\
\text { and district levels } \\
8.2 \text { Encourage village leaders } \\
\text { and committees to include more } \\
\text { women in local decision-making } \\
8.3 \text { Promote awareness of legal } \\
\text { rights and remedies (e.g., } \\
\text { relating to land, employment and } \\
\text { personal security) among } \\
\text { women, especially rural and } \\
\text { ethnic minority women }\end{array}$ & $\begin{array}{l}2003-05 \\
2004 \\
2003-05\end{array}$ & $\begin{array}{l}\text { Public sector } \\
\text { employment statistics } \\
\text { Number of women on } \\
\text { village committees } \\
\text { Attendance reports on } \\
\text { training workshops; } \\
\text { radio broadcasts, } \\
\text { distribution of fliers \& } \\
\text { posters; survey of } \\
\text { women after legal } \\
\text { awareness campaign; } \\
\text { land title records; } \\
\text { survey of factory } \\
\text { employees; reports of } \\
\text { domestic abuse }\end{array}$ & $\begin{array}{l}\text { MoJ/LWU/ } \\
\text { GRID }\end{array}$ \\
\hline
\end{tabular}


Table 3.6 Environment Sector Matrix 2003-2005; 2010; 2020

\begin{tabular}{|c|c|c|c|c|}
\hline Planning Horizon & Measures of Achievements & Outputs & Activities & Indicators \\
\hline \multicolumn{5}{|l|}{ Vision 2020} \\
\hline $\begin{array}{l}\text { The socio- } \\
\text { economic } \\
\text { development shall } \\
\text { be efficiently and } \\
\text { continuously } \\
\text { carried out, } \\
\text { assuring the } \\
\text { proportionality of } \\
\text { the economic } \\
\text { growth, the socio- } \\
\text { cultural } \\
\text { development and } \\
\text { the sustainable } \\
\text { conservation } 1\end{array}$ & 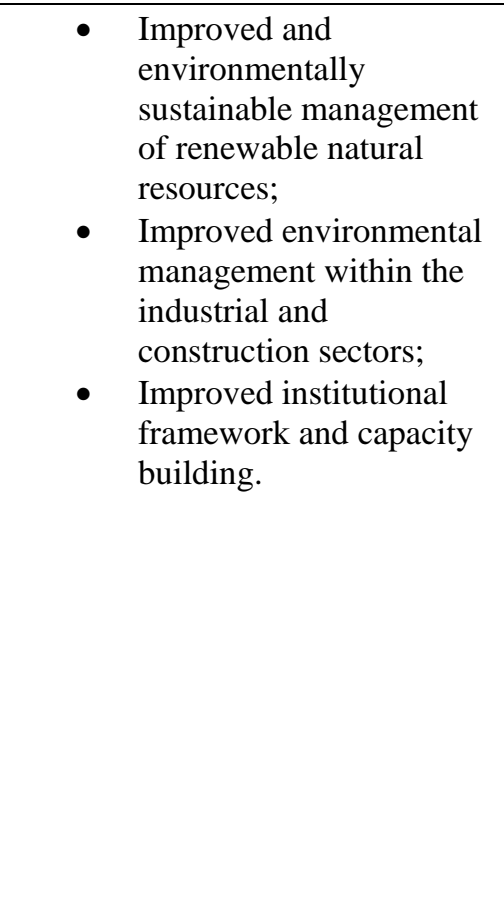 & $\begin{array}{l}\text { Government service agencies } \\
\text { responsive to participatory } \\
\text { development processes with } \\
\text { an improved capacity to } \\
\text { manage and support } \\
\text { development. } \\
\text { Reduced environmental } \\
\text { degradation through improved } \\
\text { natural resource management. } \\
\text { Public spending and } \\
\text { investment is reflects the } \\
\text { economic policy emphasis in } \\
\text { accordance with different } \\
\text { development goals and } \\
\text { sectors }\end{array}$ & 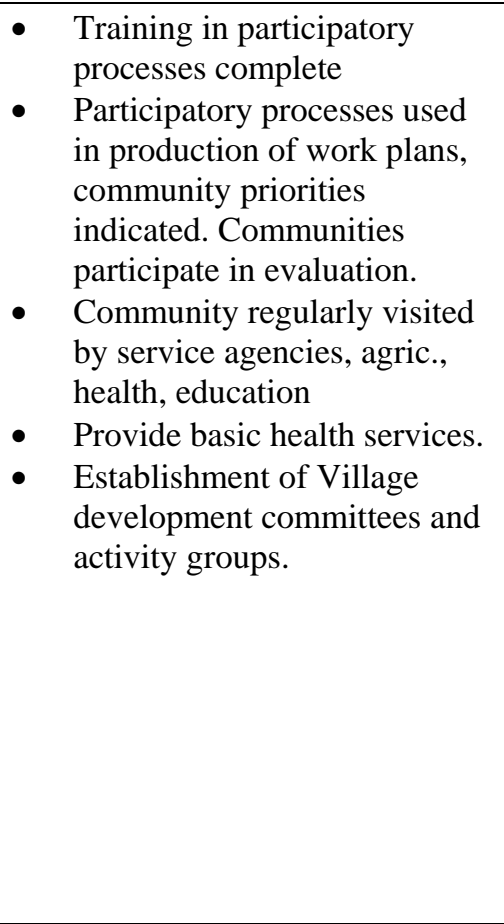 & 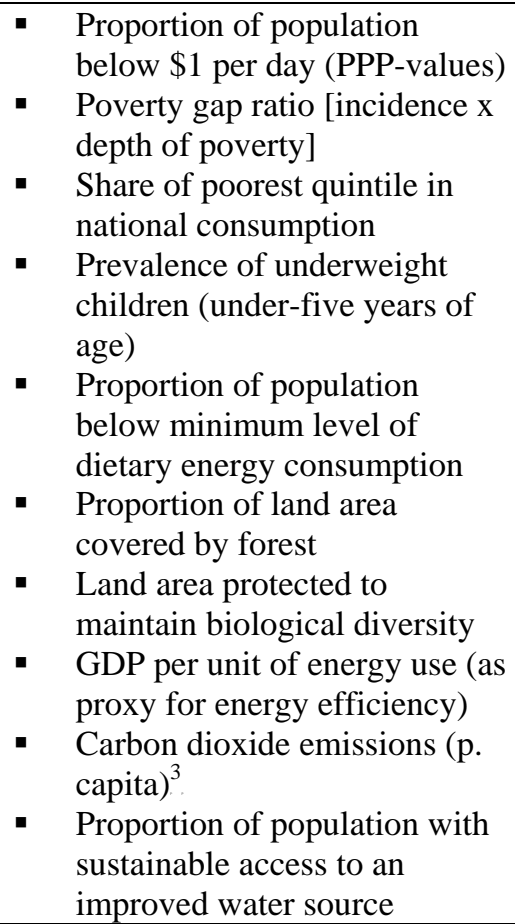 \\
\hline \multicolumn{5}{|l|}{ Goal 2010} \\
\hline $\begin{array}{l}\text { To reduce poverty } \\
\text { and improve the } \\
\text { quality of life of } \\
\text { poor communities } \\
\text { in selected districts } \\
\text { in Lao PDR and } \\
\text { improve natural } \\
\text { resource } \\
\text { management. }\end{array}$ & $\begin{array}{ll}\text { - } & \text { Treated by Health service and } \\
\text { - } & \text { Inpplied clean water } \\
\text { - } & \text { Status of Natural resource: \% } \\
\text { forest, water table, \% land } \\
\text { with soil conservation, crop } \\
\text { diversification data. } \\
\text { - } \quad \text { Food security } \\
\text { - } \quad \text { Improved adult \& primary } \\
\text { education. }\end{array}$ & $\begin{array}{l}\text { Communities enjoy improved } \\
\text { quality of life through access } \\
\text { to services. } \\
\text { Community based structures } \\
\text { are empowered to articulate } \\
\text { development needs and } \\
\text { priorities and develop } \\
\text { improved capacity for } \\
\text { technology transfer. } \\
\text { - Poor village communities }\end{array}$ & $\begin{array}{l}\text { - Training in improved farming } \\
\text { technology supplied } \\
\text { Integrate the principles of } \\
\text { sustainable development into } \\
\text { country policies and } \\
\text { programmes and reverse the } \\
\text { loss of environmental } \\
\text { resources } \\
\text { Use those economic and fiscal } \\
\text { instruments to achieve }\end{array}$ & $\begin{array}{l}\text { Rich and productive forests: } \\
\text { Sustainable and productively } \\
\text { managed forests } \\
\text { A diverse and productive } \\
\text { cultivated landscape: } \\
\text { Protection, conservation and } \\
\text { sustainable use of land } \\
\text { resources } \\
\text { Clean water: protection, } \\
\text { conservation and sustainable }\end{array}$ \\
\hline
\end{tabular}

Major policy focus on agricultural diversification and intensification, improved foreign trade, and expanding energy and transport infrastructure All of these development objectives have the potential to encroach on or otherwise interfere with the environment and biodiversity.

At present, environmental and biodiversity management conservation is not considered a high priority for government spending, especially in comparison to other sectors of the economy such as agriculture, healthcare and education, and budgets to environmental management and biodiversity conservation remain extremely low.

3. Plus two figures of global atmospheric pollution: ozone depletion and the accumulation of global warming gases 


\begin{tabular}{|c|c|c|c|c|}
\hline & $\begin{array}{ll}\text { - } & \text { Reduction in areas under } \\
& \text { slash and burn cultivation }\end{array}$ & $\begin{array}{l}\text { supported through improved } \\
\text { sustainable infrastructure } \\
\text { development } \\
\text { Improved food production } \\
\text { and food security for poor } \\
\text { communities with more } \\
\text { opportunities and intensified } \\
\text { farming systems and } \\
\text { sustainable production } \\
\text { technology. }\end{array}$ & $\begin{array}{l}\text { economic and development } \\
\text { goals, which exert a strong } \\
\text { influence on price and market } \\
\text { signals }{ }^{4} \text {. } \\
\text { Public spending and } \\
\text { investment reflects the } \\
\text { economic policy emphasis in } \\
\text { accordance with different } \\
\text { development goals and } \\
\text { sectors }\end{array}$ & $\begin{array}{l}\text { use of water resources (ground } \\
\text { water and lakes, rivers and } \\
\text { streams) } \\
\text { Biodiversity maintained: } \\
\text { Protection, conservation and } \\
\text { sustainable utilization of } \\
\text { biodiversity resources } \\
\text { Protection and improvement } \\
\text { of human settlements, } \\
\text { including urban areas, and } \\
\text { protection of cultural and } \\
\text { historical heritage. } \\
\text { Clean air and protection of the } \\
\text { atmosphere; limited air } \\
\text { pollution, limited impacts } \\
\text { from climate change and } \\
\text { maintaining a protecting ozone } \\
\text { layer }\end{array}$ \\
\hline \multicolumn{5}{|l|}{ Purpose 2003-2005 } \\
\hline $\begin{array}{l}\text { To reduce poverty } \\
\text { in a sustainable } \\
\text { manner through } \\
\text { improved food and } \\
\text { income } \\
\text { production, better } \\
\text { infrastructure and } \\
\text { services and } \\
\text { reduce } \\
\text { environmental } \\
\text { degradation } \\
\text { through improved } \\
\text { natural resource } \\
\text { management. }\end{array}$ & $\begin{array}{ll}\text { - } & \text { Enhanced food \& livelihood } \\
\text { security opportunities } \\
\text { - } \\
\text { Improved maternal \& child } \\
\text { and primary healthcare } \\
\text { Increased educational } \\
\text { attainment of primary-school- } \\
\text { aged children, improved } \\
\text { literacy, diversified vocations. } \\
\text { - Improved and } \\
\text { environmentally sustainable } \\
\text { management of renewable } \\
\text { natural resources } \\
\text { - Improved environmental } \\
\text { management within industrial } \\
\text { and construction sectors } \\
\text { - Improved institutional } \\
\text { framework and capacity }\end{array}$ & $\begin{array}{l}1 . \quad \text { Participatory } \\
\text { management of Natural Resources } \\
\text { and the Environment }\end{array}$ & $\begin{array}{l}1.1 \text { Strengthen participation } \\
\text { by the poor in decision making } \\
\text { related to access to environmental } \\
\text { resources and services through } \\
\text { facilitating participation by the } \\
\text { poor in the preparation and } \\
\text { implementation of national and } \\
\text { local plans, policies and strategies } \\
2.1 \quad \text { Co-manage and co-invest } \\
\text { in environmental services and } \\
\text { resources with the poor through } \\
\text { promoting and strengthening } \\
\text { community management of } \\
\text { environmental resources, and } \\
\text { assisting the poor to overcome the } \\
\text { high initial costs for receiving } \\
\text { better quality environmental } \\
\text { services (such as water supply and }\end{array}$ & $\begin{array}{l}\text { - Staff allocated, organogram } \\
\text { and job descriptions } \\
\text { established. } \\
\text { - Survey completed, data input. } \\
\text { Training program } \\
\text { implemented. } \\
\text { - } \\
\text { Buffer zone boundaries } \\
\text { identified and mapped under a } \\
\text { participatory process. } \\
\text { - Improved systems and } \\
\text { recommendations available. } \\
\text { - Staff and community training } \\
\text { completed } \\
\text { - Farming systems data } \\
\text { collected \& documented. } \\
\text { - Community planning } \\
\text { committees for integrated }\end{array}$ \\
\hline
\end{tabular}

4 . Price and market liberalisation, especially in the agricultural sector, has helped to overcome many of the distortions and subsidies that have in the past discriminated against environmental and biodiversity management. However, prices remain distorted or non-existent for many biodiversity goods and services, for example timber prices are one of the few remaining areas of the economy that remain unliberalized to date. On-going moves towards decentralisation and privatisation have the potential to influence the ways in which the environment and biodiversity are managed and generate sustainable benefits. As well as increasing the degree of private participation and responsibility in environmental management and biodiversity conservation, the devolution of revenue collection and budgeting to Provincial and District levels opens up new possibilities for generating income from and allocating budgets to environmental and biodiversity management.

5 At present, environmental and biodiversity management conservation is not considered a high priority for government spending, especially in comparison to other sectors of the economy such as agriculture, healthcare and education, and budgets to environmental management and biodiversity conservation remain extremely low. 


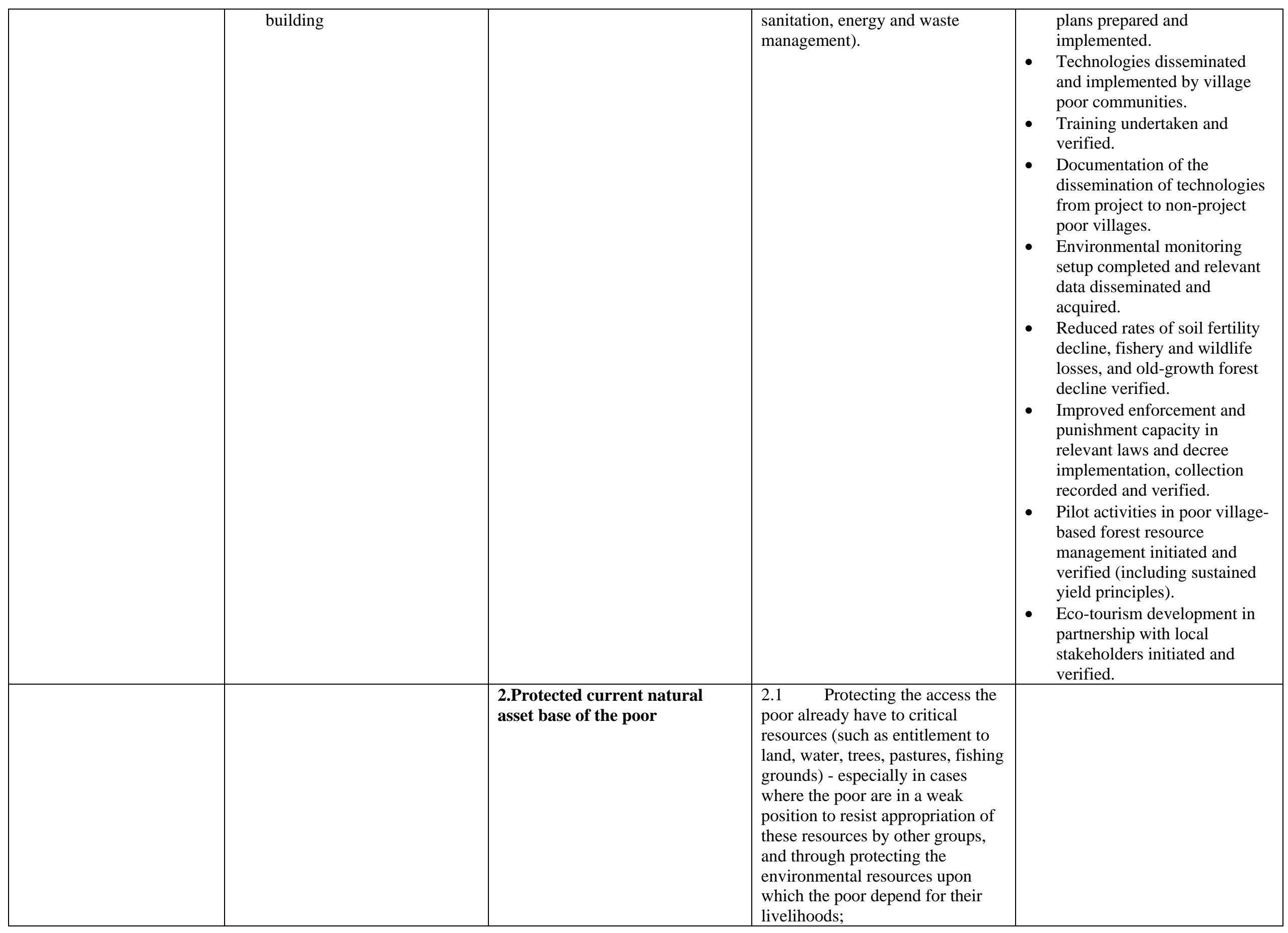




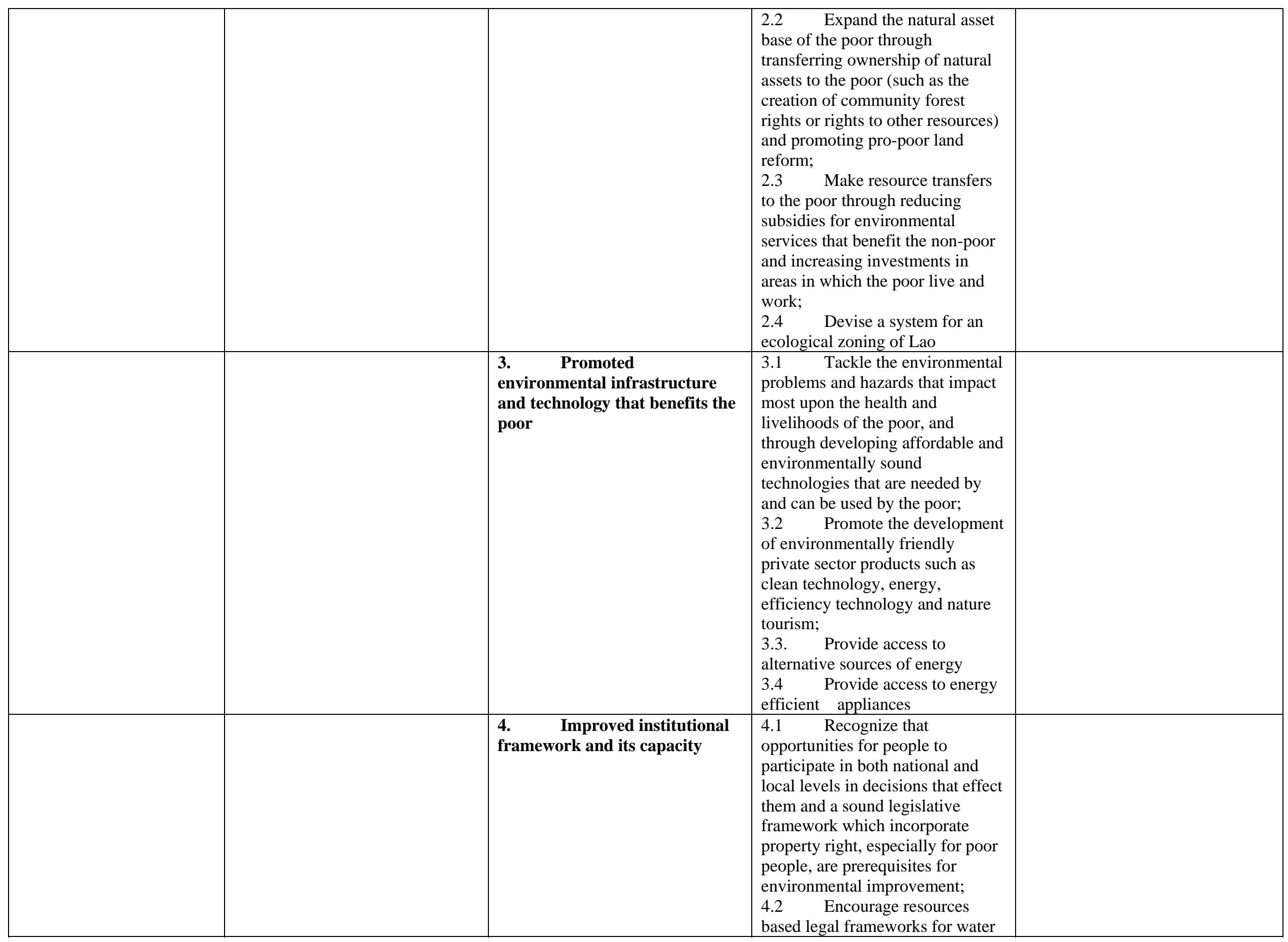




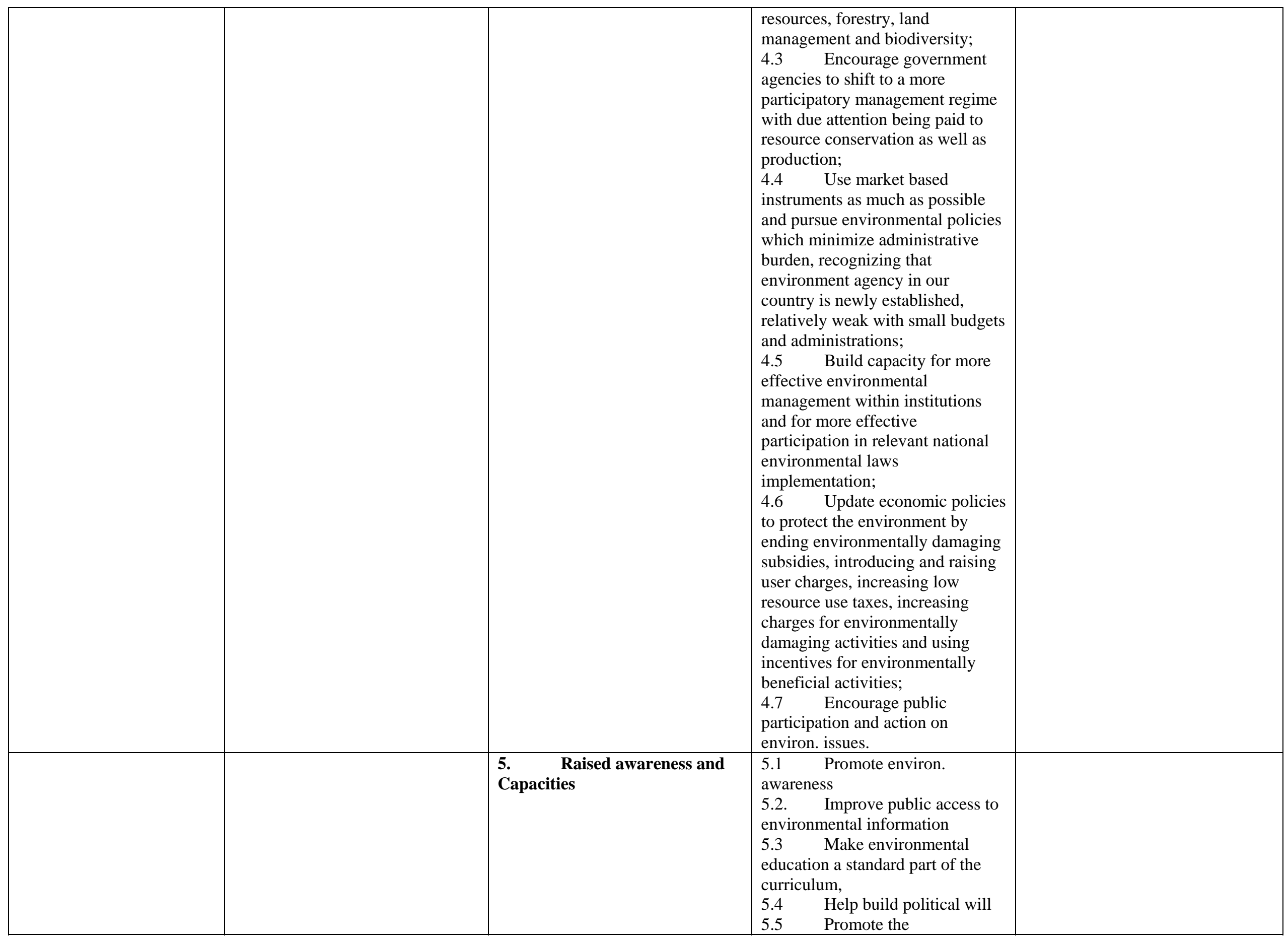




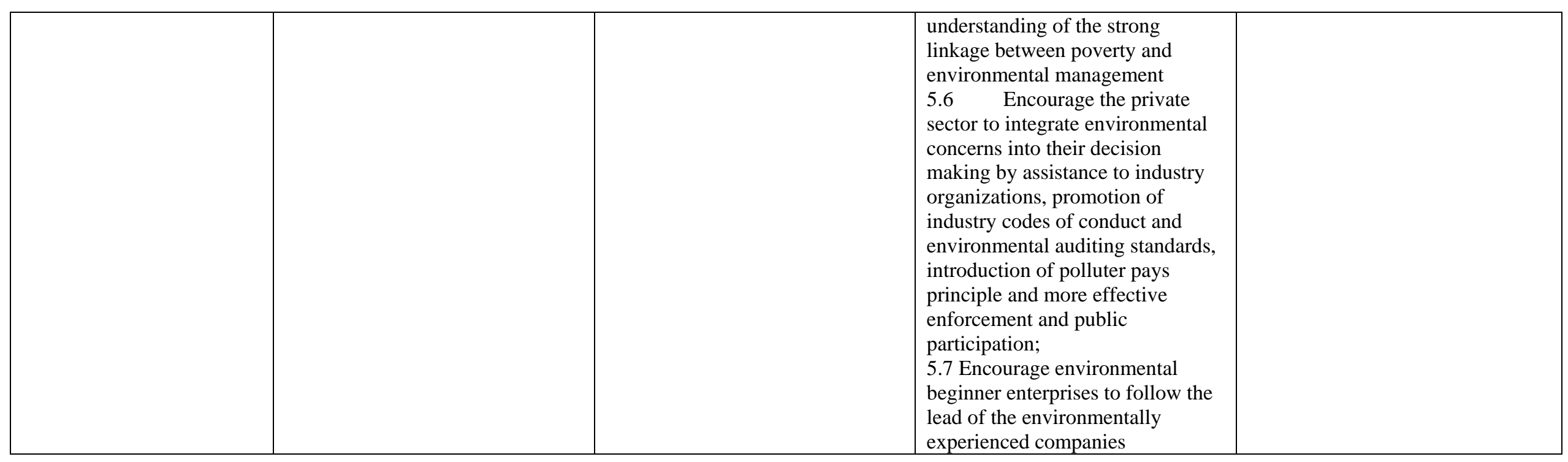


Table 3.7 List of Completed, On-going and Planned Projects addressing the Opium Supply and Demand Issues in the Lao PDR.

\begin{tabular}{|c|c|c|c|c|}
\hline No & Project Name & $\begin{array}{l}\text { Budget } \\
\text { Estimate } \\
\text { (US\$) }\end{array}$ & Duration & Donors \\
\hline$A$ & Completed Projects & $33,975,080$ & & \\
\hline 1 & $\begin{array}{l}\text { Palaveck Highland Integrated } \\
\text { Development Project, } \\
\text { Saysomboun Special Region. }\end{array}$ & $6,250,000$ & $1988-1997$ & UNDCP \\
\hline 2 & $\begin{array}{l}\text { Drug Supply and Demand Reduction } \\
\text { Project } \\
\text { in Xiengkhouang, (Phase I) }\end{array}$ & $6,258,000$ & $1992-1998$ & $\begin{array}{l}\text { UNDCP:1.704.400\$ } \\
\text { IFAD : } 3.740 .561 \$ \\
\text { GOL : } 313.357 \$\end{array}$ \\
\hline 3 & $\begin{array}{l}\text { Opium Detoxification and } \\
\text { Rehabilitation } \\
\text { in Luangprabang }\end{array}$ & 97,200 & $\begin{array}{l}\text { July1999- } \\
\text { June } 2000\end{array}$ & UNDCP \\
\hline 4 & $\begin{array}{l}\text { Pilot Alternative Development Project } \\
\text { in Bokeo } \\
\text { and Luang Namtha }\end{array}$ & $1,050,000$ & $1993-1995$ & UNDCP, -NCA \\
\hline 5 & $\begin{array}{l}\text { Alternative Development Project in } \\
\text { Bokeo and Luang Namtha, Phase I }\end{array}$ & $1,711,355$ & 1995- 1996 & UNDCP, NCA \\
\hline 6 & $\begin{array}{l}\text { Long Alternative Development } \\
\text { Project in Luang Namtha, Phase } 2\end{array}$ & $1,077,000$ & $1999-2000$ & UNDCP \\
\hline 7 & $\begin{array}{l}\text { Lao-American Integrated Rural } \\
\text { Development Project } \\
\text { in Houaphanh Province }\end{array}$ & $16,631,525$ & $1989-2001$ & USA \\
\hline 8 & $\begin{array}{l}\text { Beng Alternative Development } \\
\text { Project, Oudomxay Province }\end{array}$ & 900,000 & $\begin{array}{l}\text { Sept } 1999- \\
\text { Dec }-2001\end{array}$ & UNDCP \\
\hline B & On-going Projects & $28,814,716$ & & \\
\hline 1 & Programme Facilitation Unit (PFU) & 5.191 .000 & $\begin{array}{l}\text { July } 2000- \\
\text { June } 2006\end{array}$ & UNDCP \\
\hline 3 & $\begin{array}{l}\text { Nonghet Alternative Development } \\
\text { Project, } \\
\text { Xiengkhouang Province }\end{array}$ & 3.635 .000 & $\begin{array}{l}\text { March 1999- } \\
\text { Dec-2003 }\end{array}$ & UNDCP \\
\hline 4 & $\begin{array}{l}\text { Village- based Development } \\
\text { Component in ADB Shifting } \\
\text { Cultivation Stabilization Pilot Project } \\
\text { in Houaphanh.Province }\end{array}$ & $7,800,000$ & $\begin{array}{l}\text { March 2000- } \\
\text { Feb 2005 }\end{array}$ & $\begin{array}{l}\text { ADB: } \quad 5.700 .000 \$ \\
\text { UNDCP: } 2.100 .000 \$\end{array}$ \\
\hline 5 & $\begin{array}{l}\text { Lao-German Drug Control Project: } \\
\text { Project Coordination Unit }\end{array}$ & $1,250,000$ & $\begin{array}{c}\text { Phase I: } \\
1999-2001\end{array}$ & GERMANY/BMZ \\
\hline 6 & $\begin{array}{l}\text { Lao-German Drug Control Project: } \\
\text { Drug Control Component: } \\
\text { - Luang Namtha Province } \\
\text { - Bokeo Province } \\
\text { - Xiengkhouang Province }\end{array}$ & $1,250,000$ & $\begin{array}{l}\text { Phase I: } \\
1999-2001\end{array}$ & GERMANY/BMZ \\
\hline 7 & $\begin{array}{l}\text { Poverty Oriented Development } \\
\text { Project in Luang Namtha Province }\end{array}$ & $1,500,000$ & $\begin{array}{l}\text { Apr } 2001 \text { - Mar } \\
2004\end{array}$ & GERMANY/BMZ \\
\hline 8 & $\begin{array}{l}\text { Opium Detoxification and } \\
\text { Rehabilitation Project in } \\
\text { Luangprabang Province }\end{array}$ & 220,716 & Aug2001July2004 & JAPAN/CONSORTIUM \\
\hline 9 & Opium Elimination Project & 650,000 & Jan 2001-Dec2003 & USA \\
\hline 10 & $\begin{array}{l}\text { Long Alternative Development } \\
\text { Project in Luang Namtha Province }\end{array}$ & 220,000 & Jan-August 2001 & NCA \\
\hline 11 & $\begin{array}{l}\text { Meung \& Namjuam Alternative } \\
\text { Development Project in Bokeo Prov. }\end{array}$ & 600,000 & $1999-2001$ & NCA \\
\hline 12 & $\begin{array}{l}\text { Lao-American Integrated Rural } \\
\text { Development Project in Phongsaly } \\
\text { Province }\end{array}$ & $5,598,000$ & $1998-2001$ & USA \\
\hline 13 & $\begin{array}{l}\text { Long Alternative Development } \\
\text { Project, in Luang Namtha Province } \\
\text { Phase III }\end{array}$ & $2,030,500$ & $\begin{array}{l}\text { Oct } 2001-\text { August } \\
2004\end{array}$ & UNDCP, NCA \\
\hline 14 & $\begin{array}{l}\text { Northern Phongsaly Alternative } \\
\text { Development Project }\end{array}$ & $2,200,000$ & $\begin{array}{l}\text { July } 2001 \text { - June } \\
2003\end{array}$ & UNDCP \\
\hline
\end{tabular}


TABLE 3.8 : UXO CONTAMINATION DATA

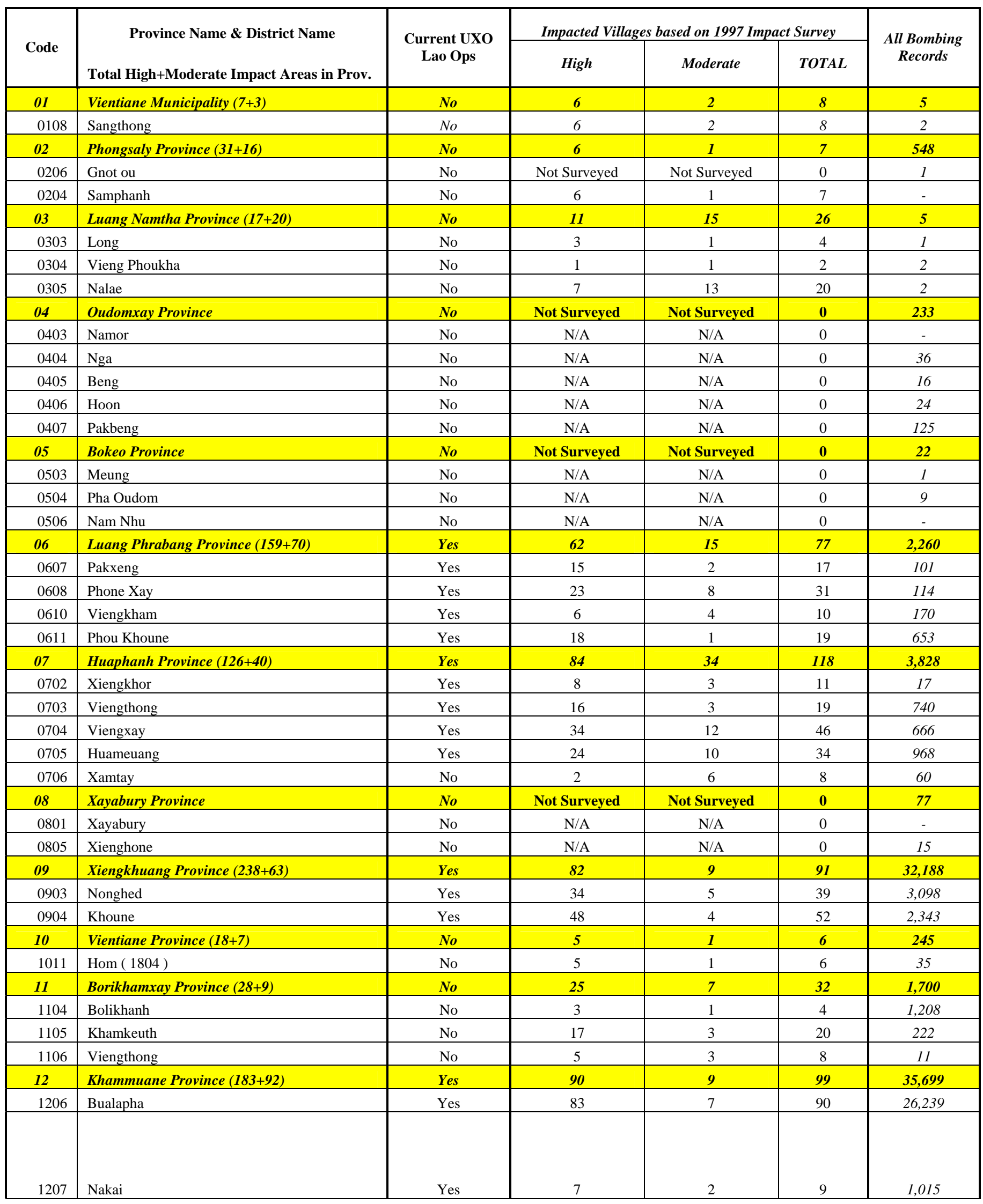




\begin{tabular}{|c|c|c|c|c|c|c|}
\hline \multirow[t]{2}{*}{ Code } & \multirow[b]{2}{*}{$\begin{array}{c}\text { Province Name \& District Name } \\
\text { (Total High+Moderate Impact Areas in Prov.) }\end{array}$} & \multirow{2}{*}{$\begin{array}{c}\text { Current UXO } \\
\text { Lao Ops }\end{array}$} & \multicolumn{3}{|c|}{ UXO Impact in Villages from the Impact Survey } & \multirow[b]{2}{*}{$\begin{array}{l}\text { All Bombing } \\
\text { Records }\end{array}$} \\
\hline & & & High & Moderate & TOTAL & \\
\hline 13 & Savannakhet Province $(352+192)$ & Yes & 260 & 97 & 357 & 61,554 \\
\hline 1305 & Sepone & Yes & 74 & 25 & 99 & 27,561 \\
\hline 1306 & Nong & Yes & 45 & 3 & 48 & 13,083 \\
\hline 1312 & Vilabuly & Yes & 69 & 20 & 89 & 9,468 \\
\hline 14 & Saravane Province $(249+154)$ & Yes & 35 & 12 & 47 & 19,282 \\
\hline 1408 & Samuoi & Yes & 35 & 12 & 47 & 2,880 \\
\hline 16 & Champassak Province $(94+97)$ & Yes & 34 & 26 & 60 & 3,650 \\
\hline 1603 & Bachiangchaleunsook & Yes & 27 & 21 & 48 & 617 \\
\hline 1608 & Soukhoumma & Yes & 7 & 5 & 12 & 36 \\
\hline 17 & Attapeu Province $(71+27)$ & Yes & 35 & 10 & 45 & 13,643 \\
\hline 1704 & Sanxay & Yes & 20 & 9 & 29 & 4,268 \\
\hline 1705 & Phouvong & Yes & 15 & 1 & 16 & 6,052 \\
\hline 18 & Xaysomboun Special Region $(28+17)$ & No & 6 & 4 & 10 & 2,612 \\
\hline 1801 & Saysomboun & No & 1 & 0 & 1 & 2,006 \\
\hline 1803 & Thathom & No & 5 & 4 & 9 & 51 \\
\hline & TOTAL & & 755 & 269 & 1,024 & \\
\hline
\end{tabular}

Based on the findings of the 1997 Impact Survey, and of a total of 11,939 villages :

1,707 villages are considered "High Impact"

856 villages are considered "Moderate Impact" 
Table 3.9 HIV/AIDS/STI Priority Matrix

Priority issue 1: Second Generation Surveillance of HIV/STD and Research Ref $\quad$ Activities

Strategy : To ensure the availability of reliable and up-to-date surveillance data on HIV/AIDS/STD

1.1 Conduct second generation surveillance (BSS, HSS, SPPS) in 4 provinces: LB, VTM, SVK,

CHS and more provinces may be added

1.2 Attend international conferences for surveillance lesson learned

1.3 Improve case reporting on HIV/AIDS/STD SUB-TOTAL

Priority issue 2 : Prevention and Treatment of STDs

\begin{tabular}{l|l|l|} 
Ref & Activities & Implementing agency
\end{tabular}

Strategy : Ensure appropriate management of STDs in at least $50 \%$ of health care system by 2005

Step 1. Provide training to $\mathrm{HCW}$ in public and private health system on the correct management of

STDs

Step 2. Ensure the availability of appropriate STD Drugs

Step 3. Integrate STD services into primary health care

Step 4. Strengthen STD case finding in antenatal clinics

Step 5. Promote health care seeking behaviour for the diagnosis and treatment of STD

Step 6.Include the promotion of safer sexual behaviour, including condom use, as integral part of treatment of STDs

$$
\text { SUB TOTAL }
$$

Priority issue 3 : Prevention of HIV among service women

\begin{tabular}{|l|l|l|}
\hline Ref & Activities & Implementing agency
\end{tabular}

Strategy : Reduce transmission of HIV infection and STDs among service women and their clients

Step 1: Reduce HIV vulnerability of service women, e.g. awareness campaigns, user friendly

health services, reduction of stigma, etc.

Step 2: Reduce STD prevalence among service women through massive presumptive

treatment of STD

$$
\text { SUB TOTAL }
$$

Priority issue 4 : Prevention of HIV Among Mobile Population

\section{Ref $\quad$ Activities}

Strategy 1: Reduce the vulnerability of mobile population group to HIV infection

Strategy 2: Make STD services and condoms available to mobile populations

$$
\text { SUB TOTAL }
$$

Budget (US\$)

(US\$)

600,000

336,800

$\mathbf{1 , 0 0 8 , 8 0 0}$

Budget (US\$)

Estimated cost

(US\$)

$2,112,980$

\begin{tabular}{r}
\hline 253,000 \\
212,000 \\
15,000 \\
45,000 \\
34,000
\end{tabular}

2,671,980

Budget (US\$)

Estimated cost (US\$)

328,490

350,200

678,690

\begin{tabular}{|c|c|c|}
\hline $\begin{array}{c}\text { Funds } \\
\text { available }\end{array}$ & $\begin{array}{l}\text { Funds non- } \\
\text { available }\end{array}$ & $\begin{array}{l}\text { Sources of } \\
\text { Funds }\end{array}$ \\
\hline 280,500 & 319,500 & $\begin{array}{l}\text { FHI: } 150000 \\
\text { WHO: } 13000 \\
\text { ADB: }\end{array}$ \\
\hline & 72,000 & \\
\hline 152,000 & 184,800 & \\
\hline 432,500 & 576,300 & \\
\hline $\begin{array}{l}\text { Funds } \\
\text { Available }\end{array}$ & $\begin{array}{l}\text { Funds non- } \\
\text { available }\end{array}$ & $\begin{array}{l}\text { Sources of } \\
\text { Funds }\end{array}$ \\
\hline $2,085,230$ & & \\
\hline 50,000 & 203,000 & \\
\hline 111,000 & 101,000 & \\
\hline 8,000 & 7,000 & \\
\hline- & 45,000 & \\
\hline 22,000 & 12,000 & \\
\hline $2,276,230$ & 395,750 & \\
\hline $\begin{array}{c}\text { Funds } \\
\text { available }\end{array}$ & $\begin{array}{l}\text { Fund non- } \\
\text { available }\end{array}$ & $\begin{array}{l}\text { Sources of } \\
\text { funds }\end{array}$ \\
\hline 37,090 & 291,400 & \\
\hline 350,000 & 200 & \\
\hline 387,090 & 291,600 & \\
\hline $\begin{array}{c}\text { Funds } \\
\text { available }\end{array}$ & $\begin{array}{l}\text { Funds } \\
\text { nonavailable }\end{array}$ & $\begin{array}{l}\text { Sources of } \\
\text { funds }\end{array}$ \\
\hline 160,195 & 285,200 & \\
\hline 567 & 50,000 & \\
\hline 160,762 & 335,200 & \\
\hline
\end{tabular}

Budget (US\$)

\begin{tabular}{l}
$\begin{array}{l}\text { Estimated cost } \\
\text { (US\$) }\end{array}$ \\
\hline 445,395 \\
\hline 50,567 \\
\hline $\mathbf{4 9 5 , 9 6 2}$ \\
\hline
\end{tabular}




\begin{tabular}{|c|c|c|c|c|c|c|}
\hline \multicolumn{2}{|r|}{$\begin{array}{l}\text { Priority issue } 5: \text { Prevention of HIV/AIDS/STD/Drugs among Youth (In } \\
\text { and out of school) }\end{array}$} & \multirow[b]{2}{*}{ Implementing Agency } & \multicolumn{3}{|l|}{ Budget (US\$) } & \multirow[b]{2}{*}{$\begin{array}{l}\text { Sources of } \\
\text { funds }\end{array}$} \\
\hline Ref & Activities & & $\begin{array}{l}\text { Estimated cost } \\
\text { (US\$) }\end{array}$ & Fund available & $\begin{array}{l}\text { Fund non- } \\
\text { available }\end{array}$ & \\
\hline \multicolumn{3}{|c|}{ Strategy 1 : Reduce the vulnerability of Youth in schools to HIV/AIDS/STD/drugs } & $1,551,800$ & $1,005,800$ & 546,000 & \\
\hline \multicolumn{3}{|c|}{ Strategy 2 : Reduce the vulnerability of Youth out-of-schools to HIV/AIDS/STD/drugs } & $1,185,700$ & 502,940 & 682,760 & \\
\hline & SUB TOTAL & & $2,737,500$ & $1,508,740$ & $1,228,760$ & \\
\hline \multicolumn{3}{|c|}{$\begin{array}{ll}\text { Priority issue 6 : } & \text { Condom Promotion and Availability }\end{array}$} & \multicolumn{3}{|l|}{ Unit: US\$ } & \\
\hline Ref & Activities & Implementing agency & $\begin{array}{l}\text { Estimated cost } \\
\text { (US\$) }\end{array}$ & $\begin{array}{l}\text { Funds } \\
\text { available }\end{array}$ & $\begin{array}{l}\text { Funds non- } \\
\text { available }\end{array}$ & $\begin{array}{l}\text { Sources of } \\
\text { funds }\end{array}$ \\
\hline \multicolumn{7}{|c|}{ Strategy : Increase the rate of condom use } \\
\hline \multicolumn{2}{|r|}{ Step 1. Promote condom use in ways that respect cultural values } & & 11,000 & - & 11,000 & \\
\hline \multicolumn{2}{|r|}{ Step 2: Ensure overall availibility of condoms throughout the country } & & 806,000 & 200,000 & 606,000 & \\
\hline & SUB TOTAL & & 817,000 & 200,000 & 617,000 & \\
\hline \multicolumn{2}{|r|}{ Priority issue 7 : Prevention of HIV through blood safety } & & \multicolumn{3}{|l|}{ Unit: US\$ } & \\
\hline Ref & Activities & Implementing agency & $\begin{array}{l}\text { Estimated cost } \\
\text { (US\$) }\end{array}$ & Fund available & $\begin{array}{l}\text { Fund non- } \\
\text { available }\end{array}$ & $\begin{array}{l}\text { Source of } \\
\text { funds }\end{array}$ \\
\hline \multicolumn{2}{|r|}{ Strategy 1: Ensure $100 \%$ safe blood transfusion in health care setting } & & 96,340 & 66,340 & 30,000 & \\
\hline \multicolumn{2}{|r|}{ Strategy 2: Reduce unnecessary and inappropriate transfusions } & & 6,000 & - & 6,000 & \\
\hline \multicolumn{2}{|c|}{ Strategy 3: Promote universal precautions } & & 50,000 & 50,000 & - & \\
\hline & SUB TOTAL & & 152,340 & 116,340 & 36,000 & \\
\hline \multicolumn{3}{|c|}{ Priority issue 8 : CARE AND SUPPORT } & \multicolumn{3}{|l|}{ Budget (US\$) } & \\
\hline Ref & Activities & Implementing Agency & $\begin{array}{l}\text { Estimated cost } \\
\text { (US\$) }\end{array}$ & Fund available & $\begin{array}{l}\text { Fund non- } \\
\text { available }\end{array}$ & $\begin{array}{l}\text { Source of } \\
\text { funds }\end{array}$ \\
\hline \multicolumn{7}{|c|}{ Strategy : Expand and develop health sector and community based care systems for PLWHA } \\
\hline 8.1 & $\begin{array}{l}\text { Organize information workshops to fight stigmatisation and } \\
\text { discrimination in } 20 \text { villages in } 4 \text { provinces per year }\end{array}$ & LRC, PCCA & 11,000 & & 11,000 & \\
\hline 8.2 & $\begin{array}{l}\text { Train health care workers ( } 5 \text { per province) for home based care in } \\
\text { Vientiane Mun., Bokeo, Champasak, following experience with pilot } \\
\text { project in Savannakhet }\end{array}$ & PCCA & 6,000 & & 6,000 & \\
\hline 8.3 & $\begin{array}{l}\text { Train family and community members of PLWHA in basic home } \\
\text { based care in same provinces }\end{array}$ & PCCA & 6,000 & & 6,000 & \\
\hline 8.4 & $\begin{array}{l}\text { Develop and distribute guidelines on treatment drugs, herbal medecine } \\
\text { and general care for PLWHA }\end{array}$ & NCCAB & 12,000 & & 12,000 & \\
\hline 8.5 & $\begin{array}{l}\text { Extend support to PLWHA associations from } 1 \text { to } 4 \text { provinces (share } \\
\text { problems, job ideas, possible treatment, etc.) }\end{array}$ & PCCA & 15,000 & & 15,000 & \\
\hline 8.6 & Involve PLWHA in projects (PCCA, DCCA projects and workshops) & PCCA & 7,500 & & 7,500 & \\
\hline 8.7 & Establish Income Generation Activities (IGA) for PLWHA & PCCA & 20,000 & & 20,000 & \\
\hline
\end{tabular}




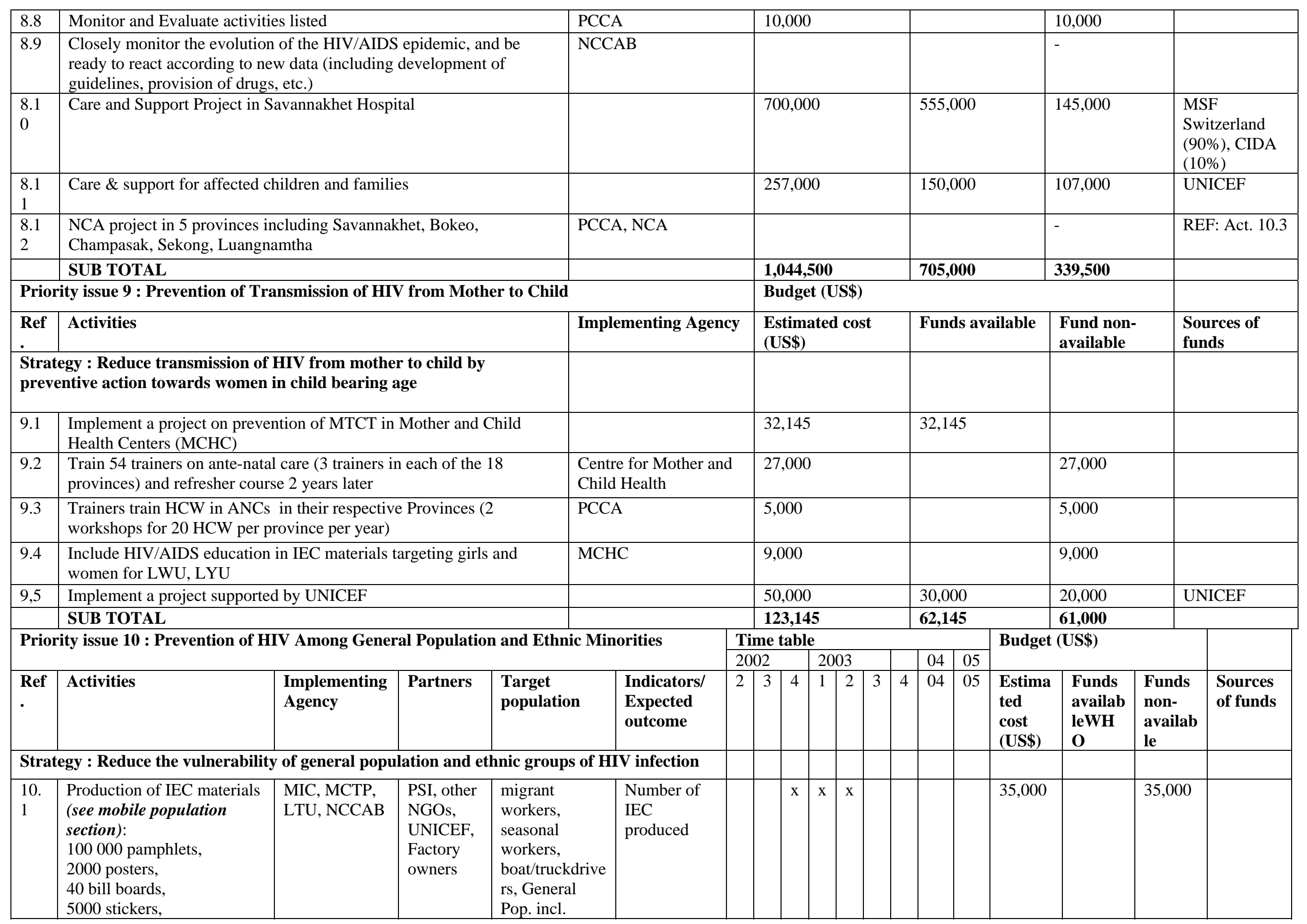




\begin{tabular}{|c|c|c|c|c|c|c|c|c|c|c|c|c|c|c|c|c|c|c|}
\hline & 8000 audio-cassettes & & & $\begin{array}{l}\text { ethnic } \\
\text { minorities }\end{array}$ & & & & & & & & & & & & & & \\
\hline $\begin{array}{l}10 . \\
2\end{array}$ & $\begin{array}{l}\text { Radio programme : LNR, } \\
\text { LPB, SVK, CPS weekly } \\
\text { programme (See mobile } \\
\text { population section) }\end{array}$ & $\begin{array}{l}\text { LNR, LPB, } \\
\text { SVR, CPR }\end{array}$ & $\begin{array}{l}\text { PCCA, } \\
\text { NCCAB, } \\
\text { UNICEF, } \\
\text { MIC }\end{array}$ & $\begin{array}{l}\text { All audiences, } \\
\text { including } \\
\text { mobile } \\
\text { populations }\end{array}$ & & & & $\mathrm{x}$ & $\mathrm{x}$ & $\mathrm{x}$ & $\mathrm{x}$ & $\bar{x}$ & $\bar{x}$ & $\mathrm{x}$ & $\begin{array}{l}140,00 \\
0\end{array}$ & 61,000 & 79,000 & UNICEF \\
\hline $\begin{array}{l}10 . \\
3\end{array}$ & $\begin{array}{l}\text { HIV prevention among } \\
\text { general public in } 5 \\
\text { provinces including } \\
\text { Savannakhet, Bokeo, } \\
\text { Champasak, Sekong, } \\
\text { Luangnamtha }\end{array}$ & PCCA, NCA & $\begin{array}{l}\text { DCCA, } \\
\text { VCCA }\end{array}$ & $\begin{array}{l}\text { Students, } \\
\text { teachers, } \\
\text { youth, general } \\
\text { population }\end{array}$ & $\begin{array}{l}\text { Number of } \\
\text { activities/Kn } \\
\text { owledge of } \\
\text { the target } \\
\text { groups } \\
\text { increased }\end{array}$ & $\mathrm{x}$ & $\mathrm{x}$ & $\mathrm{x}$ & & & & & & & 88,890 & 88890 & 0 & $\begin{array}{l}\text { NCA } \\
\text { Norway } \\
50000, \\
\text { NORAD } \\
38890\end{array}$ \\
\hline & SUB TOTAL & & & & & & & & & & & & & & $\begin{array}{l}263,89 \\
0\end{array}$ & $\begin{array}{l}149,89 \\
0\end{array}$ & $\begin{array}{l}114,00 \\
0\end{array}$ & \\
\hline
\end{tabular}

\section{PRIORITY MANAGERIAL ISSUES}

\begin{tabular}{|c|c|c|c|c|c|c|}
\hline \multicolumn{2}{|c|}{ 1. Institutional framework development } & \multirow[b]{2}{*}{$\begin{array}{l}\text { Implementing } \\
\text { Agency }\end{array}$} & \multicolumn{3}{|l|}{ Budget (US\$) } & \multirow[b]{2}{*}{ Sources of funds } \\
\hline Ref. & Activities & & Estimated cost (US\$) & $\begin{array}{l}\text { Funds } \\
\text { Available }\end{array}$ & $\begin{array}{l}\text { Funds non- } \\
\text { available }\end{array}$ & \\
\hline \multicolumn{2}{|c|}{$\begin{array}{l}\text { Strategy 1: Develop the capacity of coordinating bodies by } \\
\text { improving their ability to meet regularly and function in } \\
\text { collaborative ways. }\end{array}$} & & 176,040 & 94,340 & 81,700 & \\
\hline \multicolumn{3}{|c|}{$\begin{array}{l}\text { Strategy 2: Expand and strengthen partnerships among all national and international } \\
\text { actors }\end{array}$} & 63,000 & & 63,000 & \\
\hline \multicolumn{2}{|c|}{$\begin{array}{l}\text { 2. Policy development and advocacy for an expanded response to } \\
\text { HIV/AIDS/STD }\end{array}$} & & 94,500 & & 94,500 & \\
\hline \multicolumn{3}{|c|}{$\begin{array}{l}\text { Strategy : Strengthen policy development and advocacy targeting decision makers, } \\
\text { for an expanded response to HIV/AIDS/STD }\end{array}$} & & & & - \\
\hline \multicolumn{2}{|c|}{ 3. Capacity development } & & 285,000 & 174,000 & 111,000 & \\
\hline \multicolumn{2}{|c|}{ 4. Monitoring and Evaluation of the entire National response } & & & & - & \\
\hline \multirow{2}{*}{\multicolumn{2}{|c|}{$\begin{array}{l}\text { 4.1. Development of monitoring and evaluation system } \\
\text { TOTAL BUDGET }\end{array}$}} & NCCAB & 165,000 & 8,000 & 157,000 & \\
\hline & & & 783,540 & 276,340 & 507,200 & \\
\hline
\end{tabular}


Table 3.10 : Matrix of Poverty-focused Trade Development: Strategy, Policies and Programs

\begin{tabular}{|c|c|c|c|c|c|}
\hline $\begin{array}{l}\text { Goals and } \\
\text { Objectives }\end{array}$ & Strategies & Measures & $\begin{array}{l}\text { Focal/Target } \\
\text { areas/Sub-sector } \\
\text { Objectives }\end{array}$ & $\begin{array}{l}\text { Monitoring } \\
\text { Indicators }\end{array}$ & Timeframe \\
\hline $\begin{array}{l}\text { 1)Contribute to } \\
\text { economic } \\
\text { growth and } \\
\text { employment } \\
\text { generation } \\
\text { (use trade as an } \\
\text { engine of } \\
\text { growth) }\end{array}$ & $\begin{array}{l}\text { 2) Improving the } \\
\text { policy environment } \\
\text { for trade }\end{array}$ & $\begin{array}{l}\text { 1)Implementing AFTA-CEPT Scheme } \\
\text { 2)Expediting WTO Accession Process } \\
\text { 3)Improving WTO negotiation } \\
\text { capabilities } \\
\text { 1)Legislative reforms to meet pre- } \\
\text { WTO accession requirements } \\
\text { 2)Commercial Law reforms } \\
\text { 3)Action to replace non-tariff } \\
\text { restrictions with equivalent tariffs } \\
\text { 1)Identifying potential export } \\
\text { production activities } \\
\text { 2)Providing market information for } \\
\text { producers }\end{array}$ & $\begin{array}{l}\text { 1)Scheduled } \\
\text { timetable } \\
\text { 1)Setting up of a } \\
\text { Lao rep office in } \\
\text { Geneva } \\
\text { 1)Identified } \\
\text { personnel of } \\
\text { negotiating teams } \\
\text { 1)Legislative } \\
\text { Reform Action } \\
\text { Plan } \\
\text { 2)Review and } \\
\text { propose necessary } \\
\text { changes to } \\
\text { commercial laws } \\
\text { 1)Study on } \\
\text { equivalent tariffs } \\
\text { rates to replace } \\
\text { some non-tariff } \\
\text { barriers } \\
\text { 1)Study to } \\
\text { identify activities } \\
\text { in which Laos has } \\
\text { comparative } \\
\text { advantage } \\
\text { 1)Arrange for } \\
\text { publishing }\end{array}$ & $\begin{array}{l}\text { Action being taken } \\
\text { according to } \\
\text { schedule } \\
\text { Office being set up } \\
\text { Reaching required } \\
\text { standards } \\
\text { Completion of } \\
\text { legislative reform } \\
\text { action plan } \\
\text { Completion of } \\
\text { drafting changes to } \\
\text { commercial laws } \\
\text { Completion of the } \\
\text { study } \\
\text { Completion of the } \\
\text { study }\end{array}$ & $\begin{array}{r}2003-2004 \\
2003-2004 \\
2003-2004 \\
2003-2005\end{array}$ \\
\hline
\end{tabular}




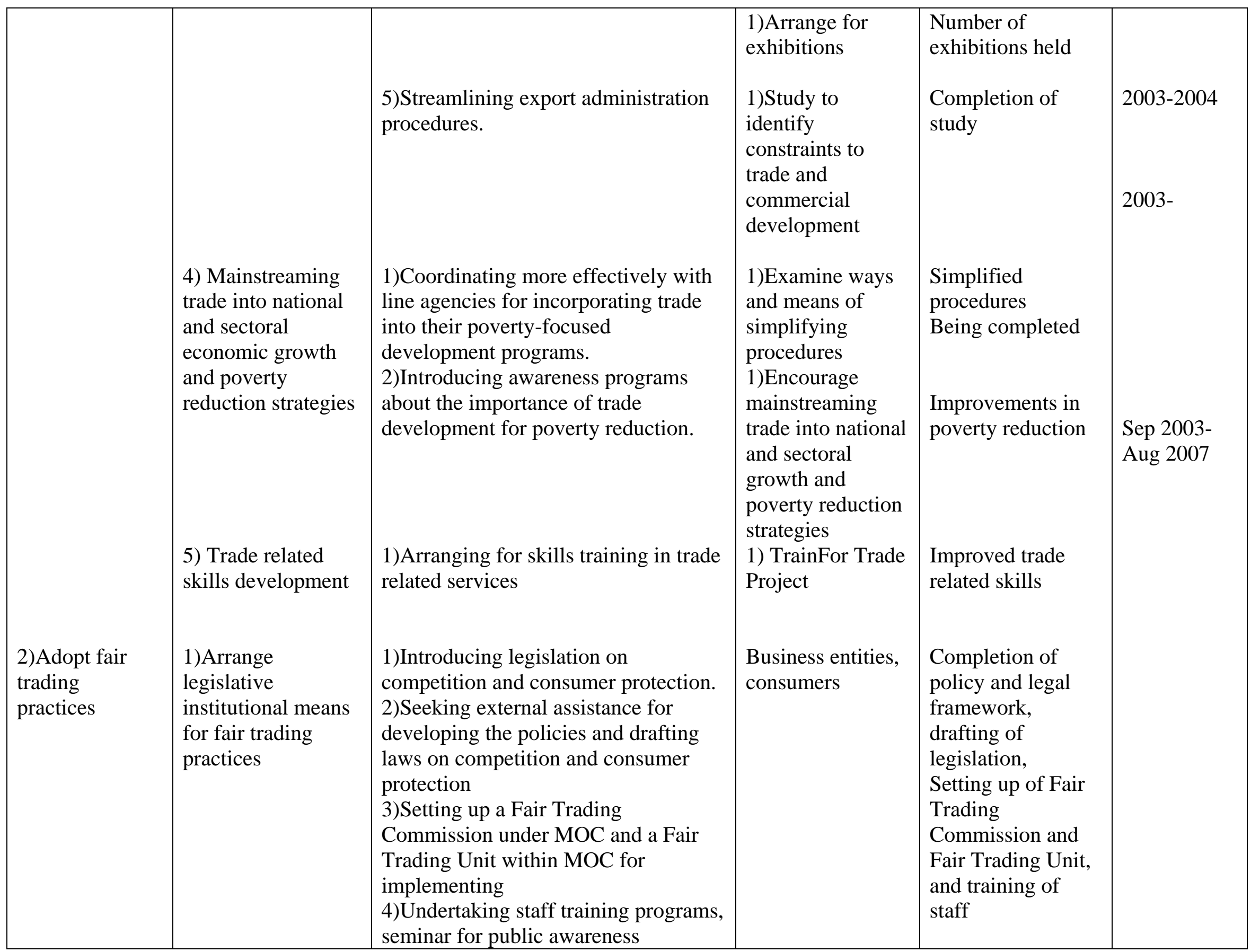


Annex 4

\section{(Information on PIP and Selected Revenue Projections)}

Table 4.1: Long-Term Revenue Projections (Nam Theun 2 and Mining Revenues) Table 4.2: PIP Domestic and Foreign Sources of Funding, FY2002-2003

Table 4.3: PIP Sector and Provincial Allocations, FY 2002-2003 


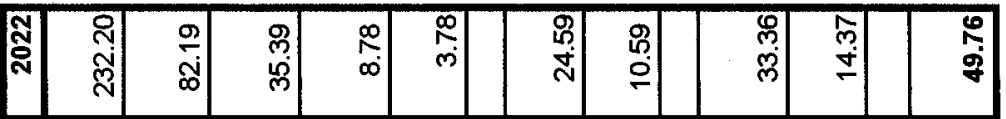

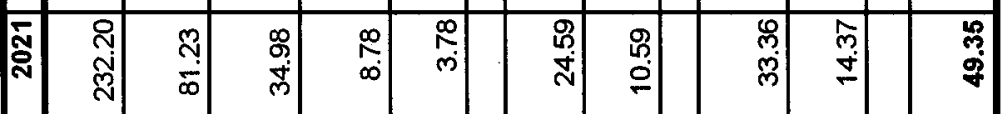

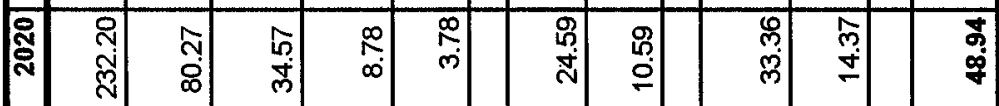

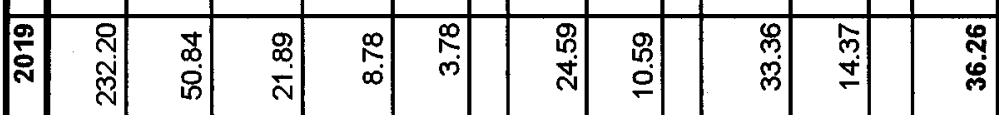

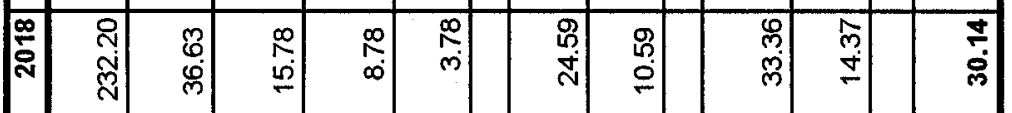

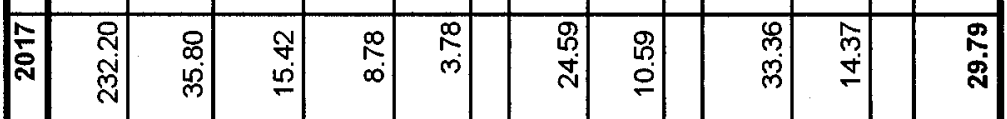

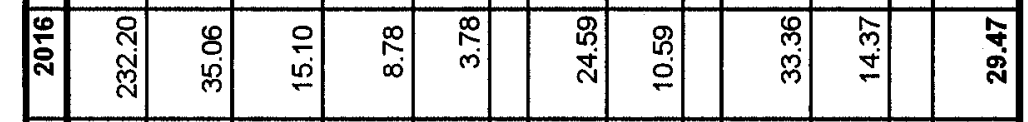

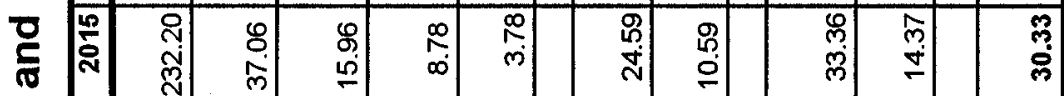

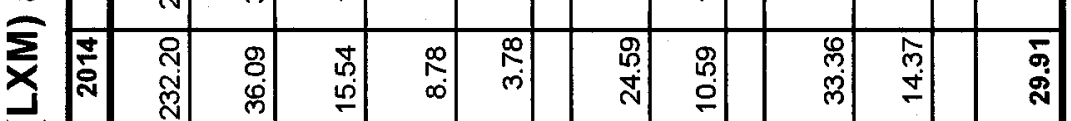

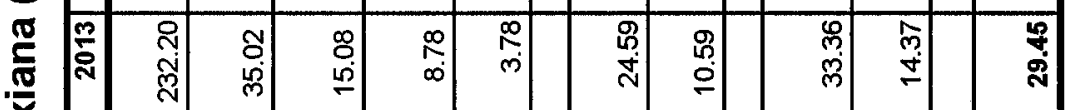

है

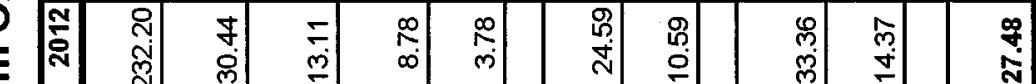

帝

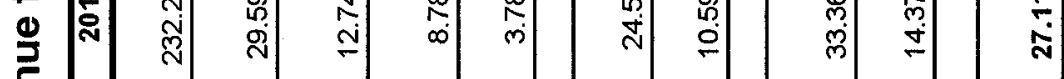

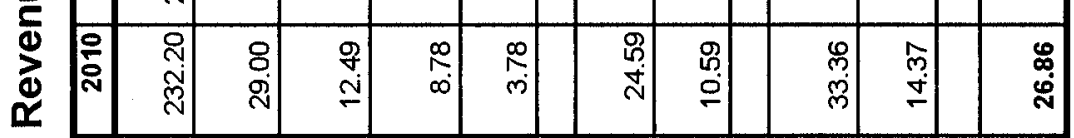

¿

.

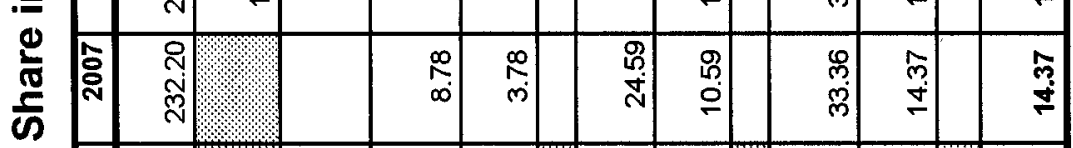

\begin{tabular}{|c|c|c|c|c|c|c|c|c|c|c|c|c|}
\hline 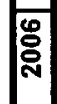 & & & & ఫֶ & & & $\begin{array}{l}: \\
\stackrel{\circ}{\mathrm{p}} \\
\end{array}$ & $\begin{array}{c}8 \\
b \\
i\end{array}$ & & & & 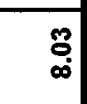 \\
\hline 8े & స్స్లి & & & Ş & $\stackrel{⿱ t}{i}$ & & 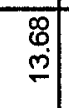 & $\begin{array}{l}\text { 帤 } \\
\text { in }\end{array}$ & & & & $\overbrace{\infty}^{\infty}$ \\
\hline 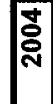 & స్ల్లి & & & $\stackrel{9}{9}$ & $\overline{\mathrm{s}}$ & & & & & हु. & & $\overline{5}$ \\
\hline & స్తి & 8 & & $\stackrel{g}{=}$ & & 8 & & & & & & $\overline{5}$ \\
\hline 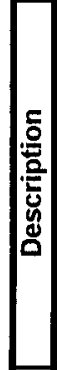 & 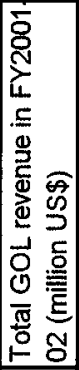 & 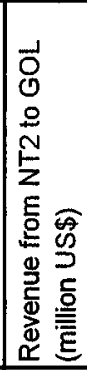 & 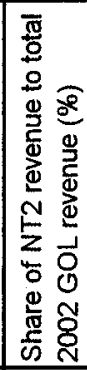 & 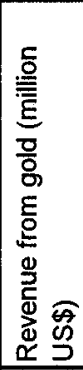 & 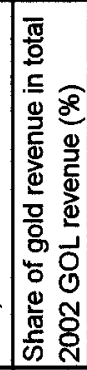 & 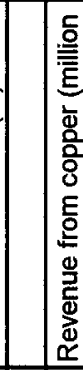 & 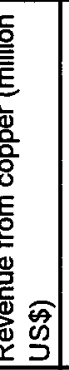 & 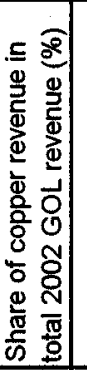 & 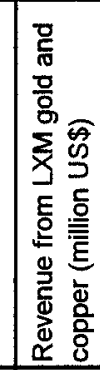 & 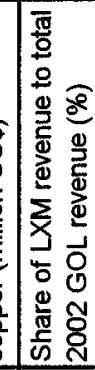 & & 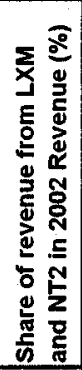 \\
\hline & - & $N$ & & $m$ & & & $\nabla$ & & ه & & & \\
\hline
\end{tabular}


|

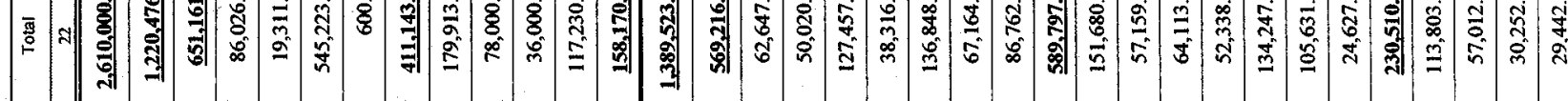

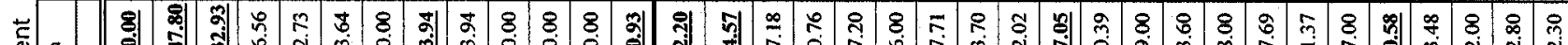
†े

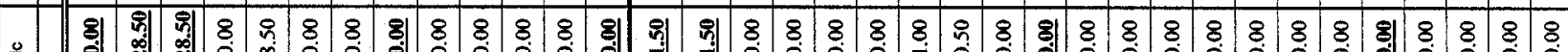

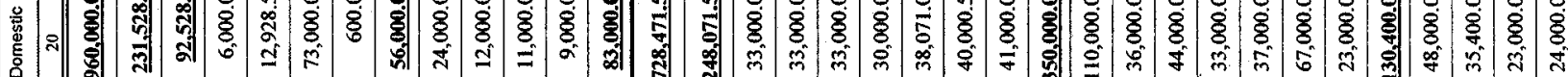

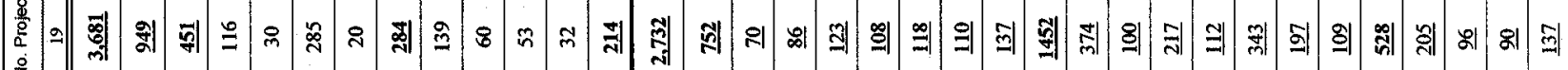

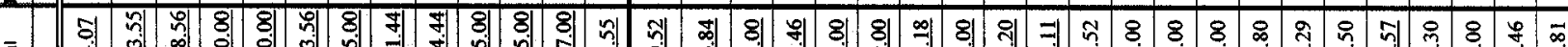

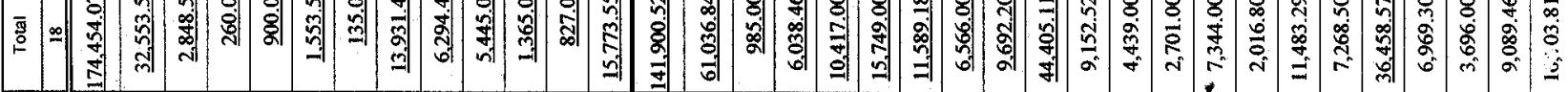

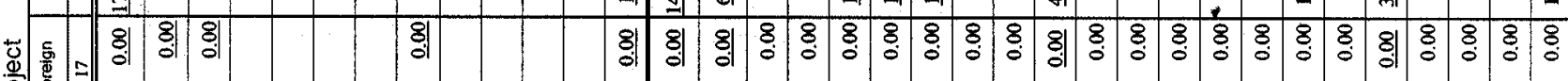

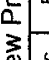
3 5 问 8 8

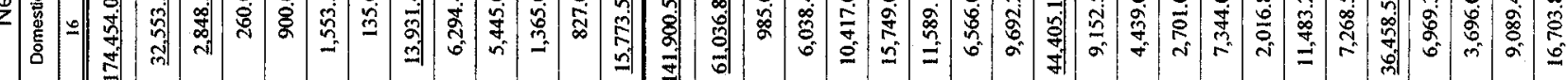

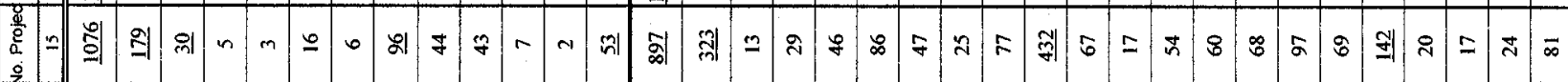

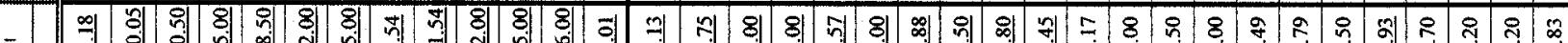

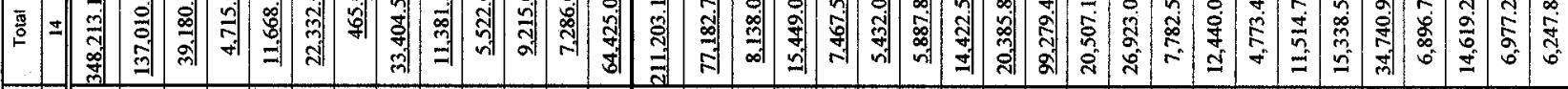

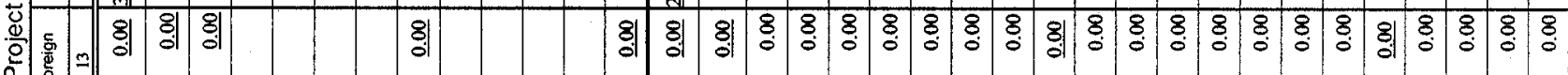
ㅁ․ㄴ.

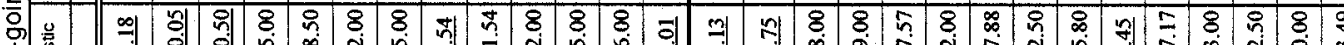

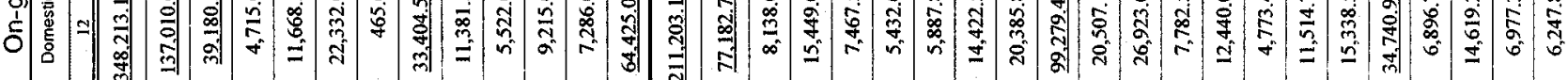

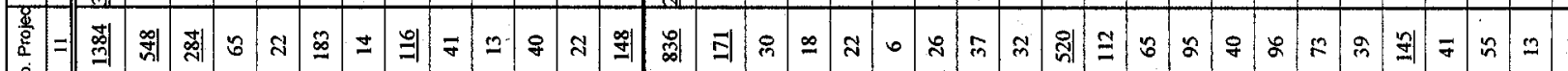

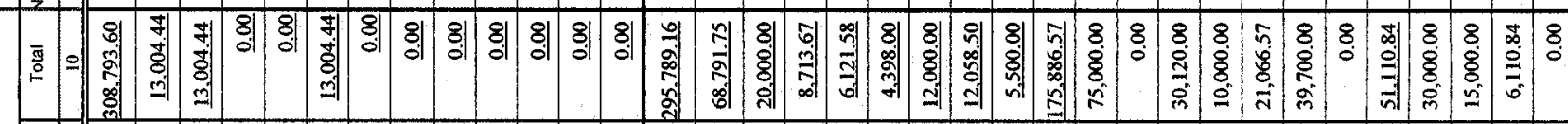

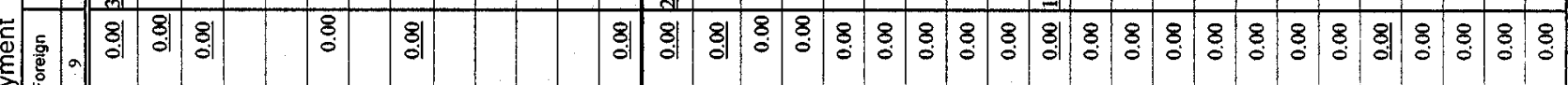

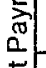

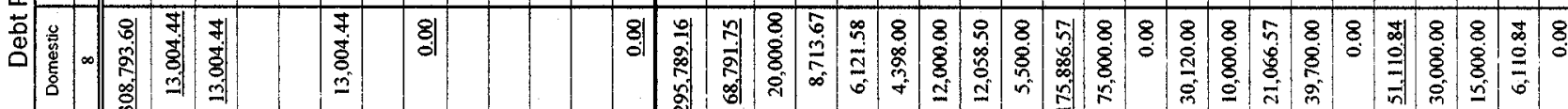

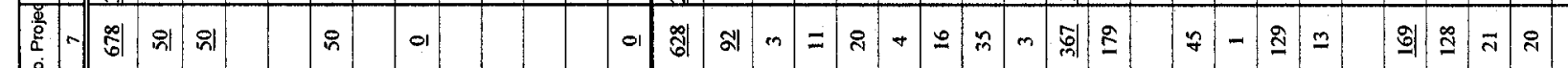

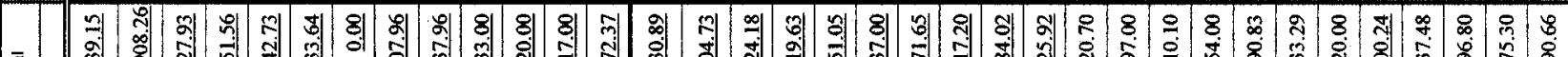

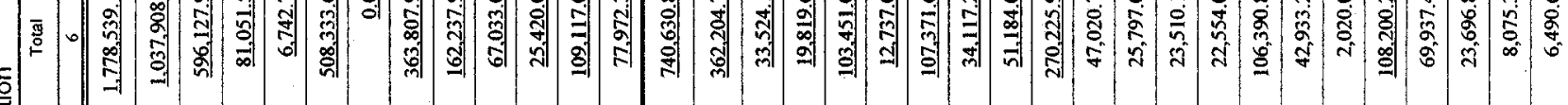

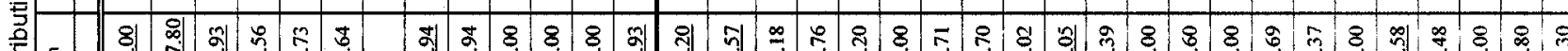

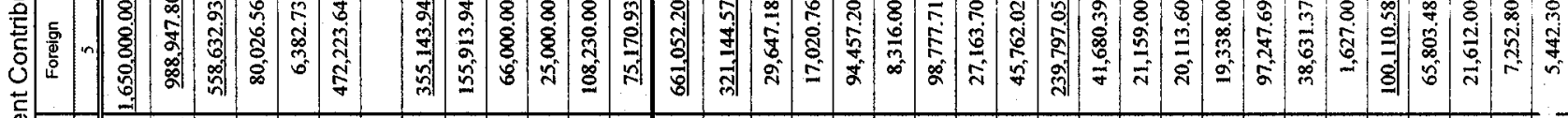

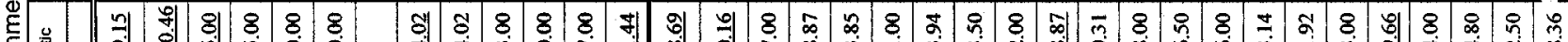

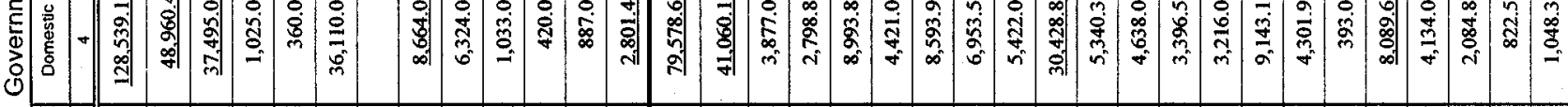
善

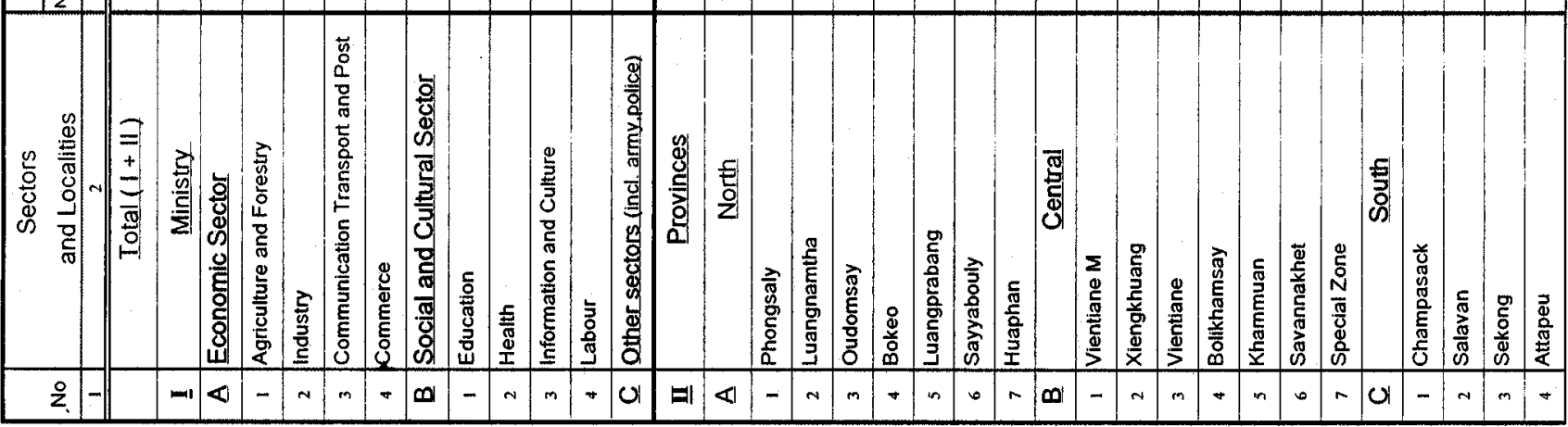


응 它
曾 * :
8
: :

\# :

吾产

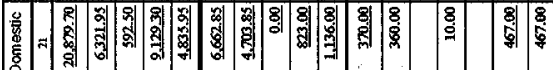
:

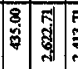
:

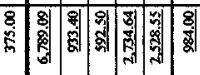

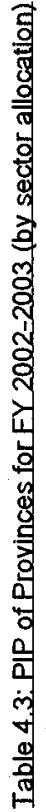
产:

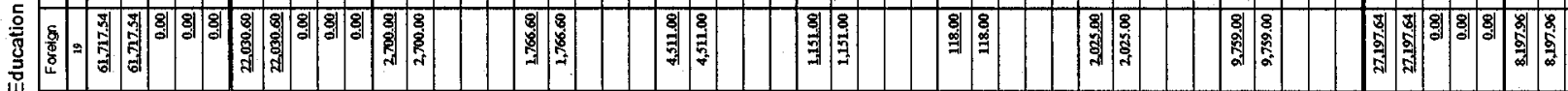

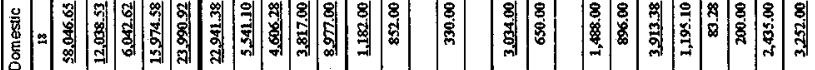

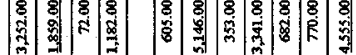

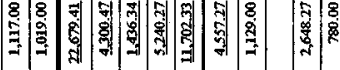

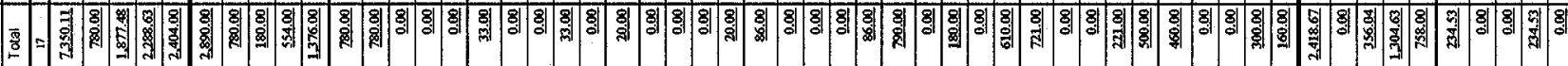

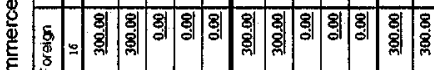
왕
:
:
:
:

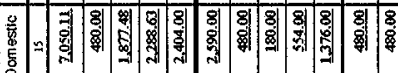
赵事
8 :
8:

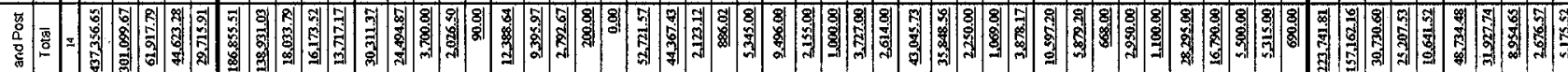

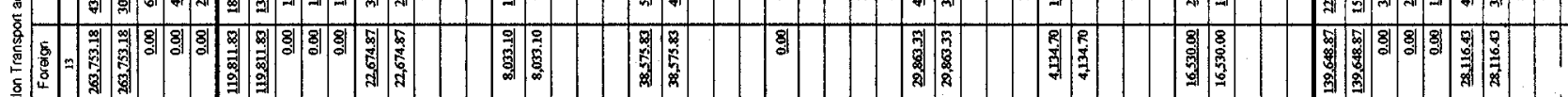

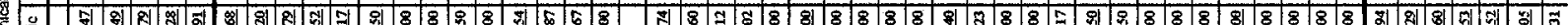

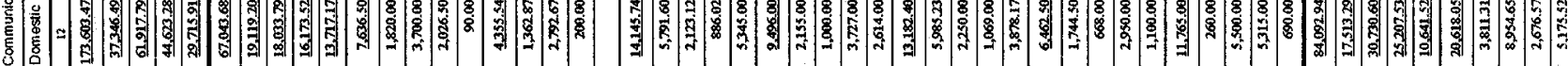

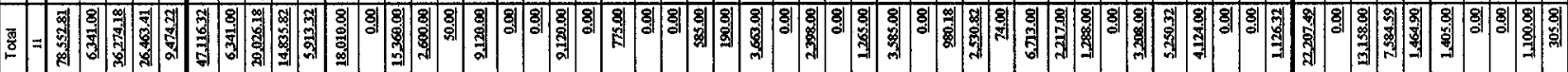
를

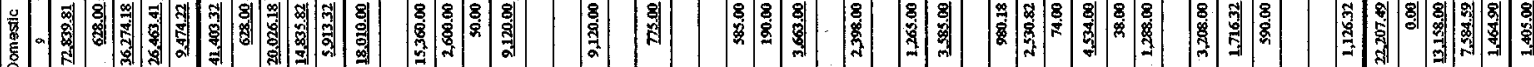

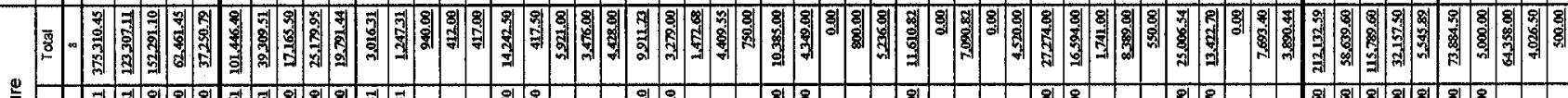

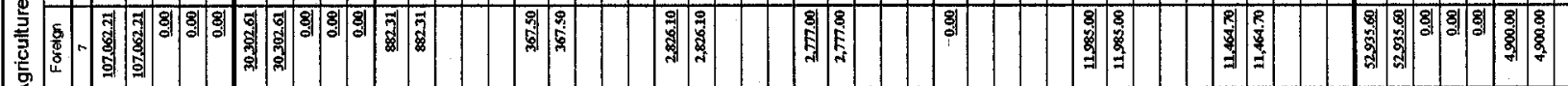

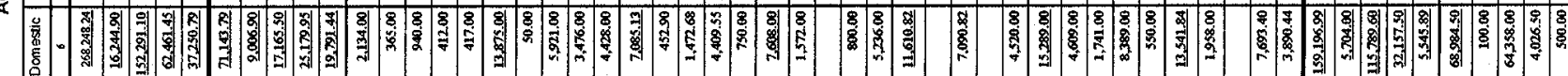

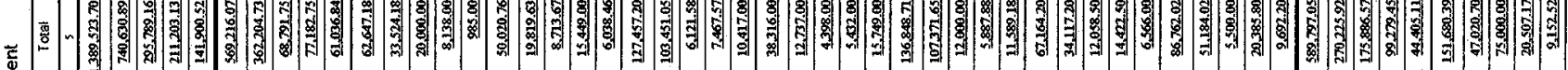
竞 प्रा

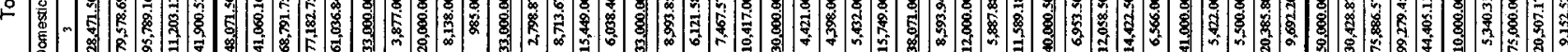

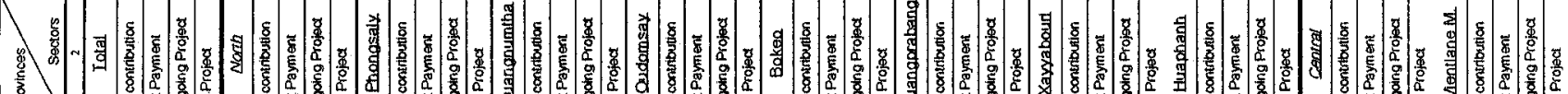




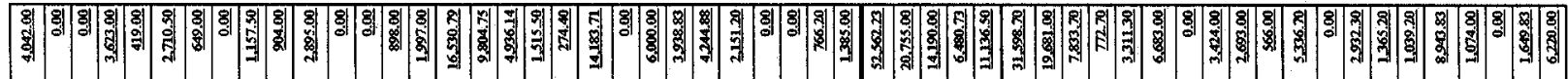

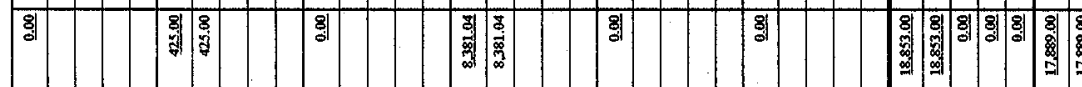

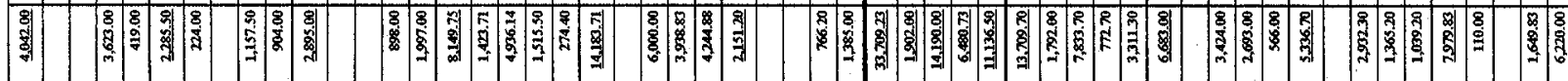

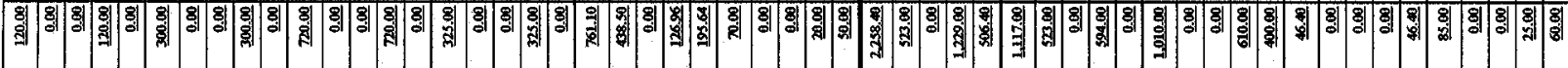
क्: 1 : ₹

亲 영:

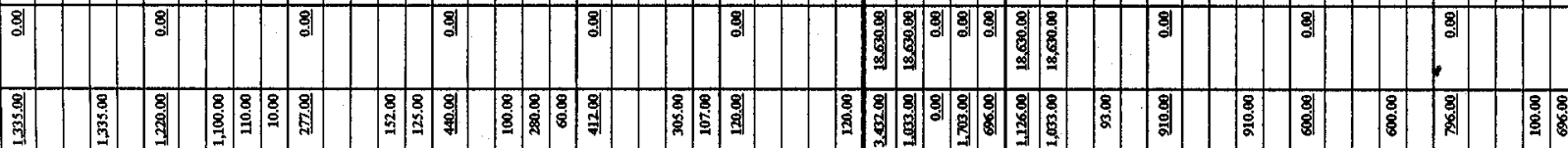

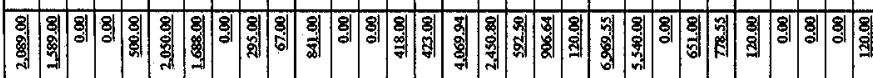

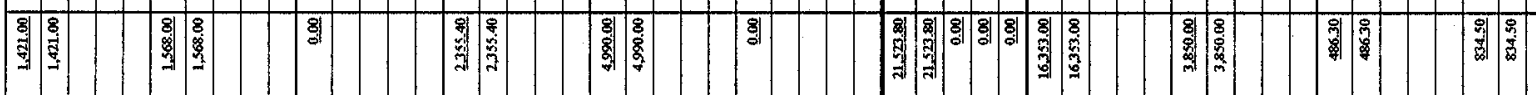

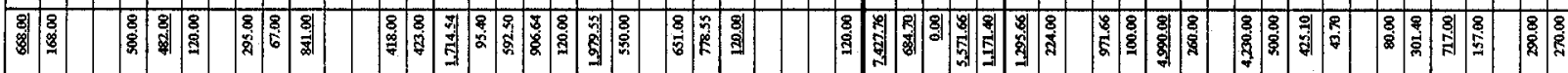
:

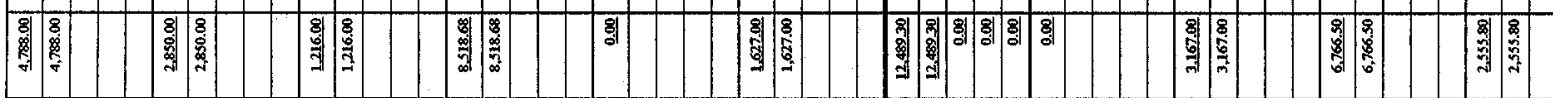

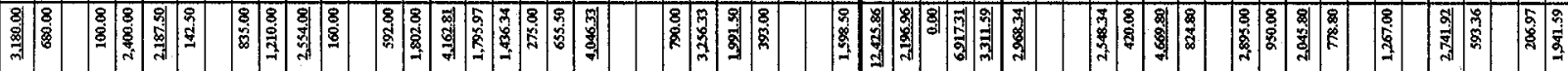

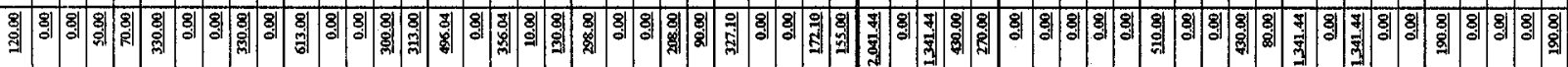

을 운 害害 贯结

क्षे:

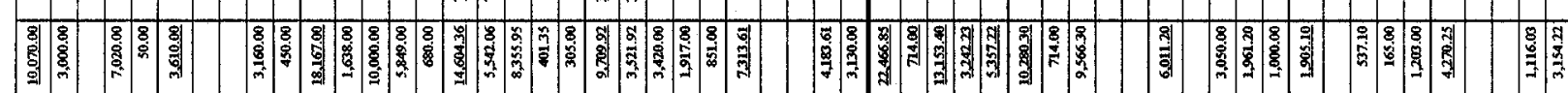

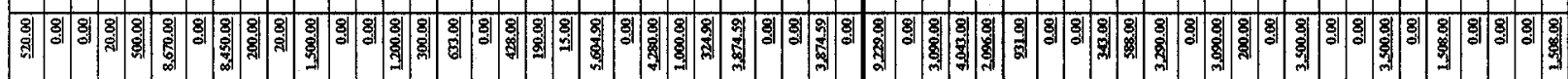

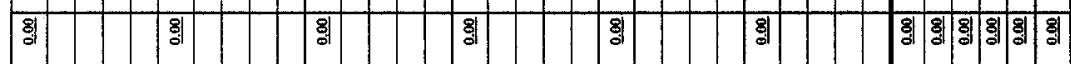

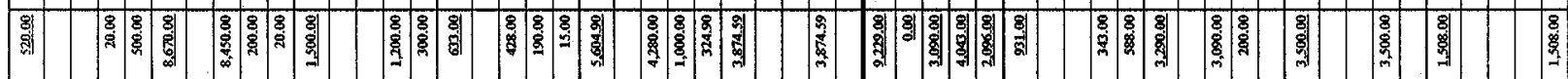

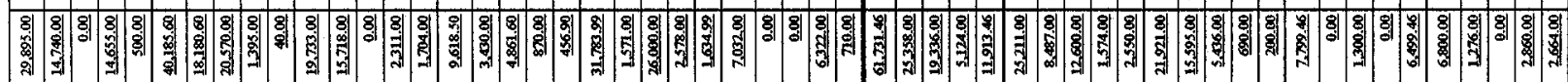
福

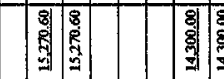

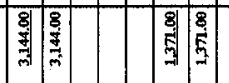
\%

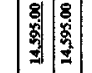

部部

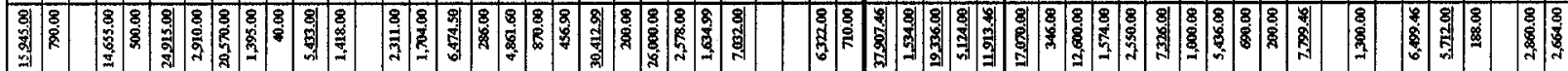
क्ष 8

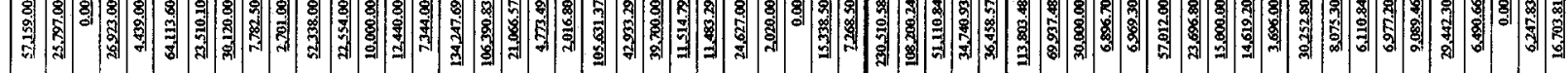

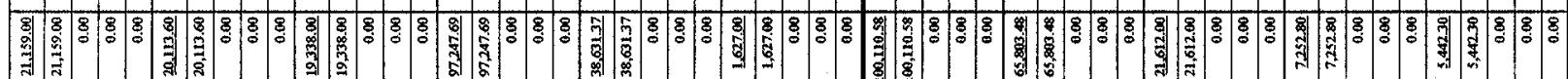

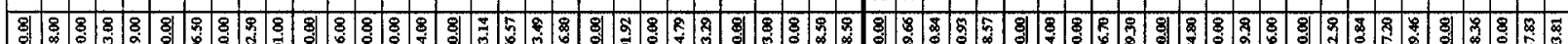

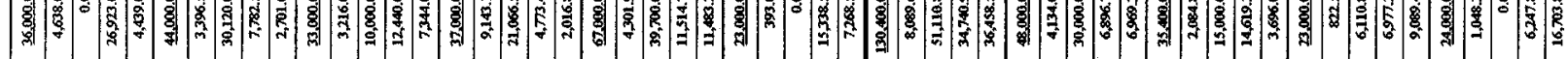




\begin{tabular}{|c|c|c|c|}
\hline $\overrightarrow{\mathrm{ADB}}$ & Asian Development Bank & FDI & Foreign Direct Investment \\
\hline ADD & Acute Diarrhoeal Diseases & FIAM & Foundation for Integrated Agriculture Management \\
\hline ADR & Alternative Dispute Resolution & FIMC & Foreign Investment Management Committee \\
\hline AFD & Agence Française de Développement & FMAC & Financial Management Adjustment Credit \\
\hline AFTA & ASEAN Free Trade Association & FSEW & Farmer System Extension Worker \\
\hline fiDS & Acquired Immune Deficiency Syndrome & FY & Fiscal Year \\
\hline ANC & Antenatal Care & GDI & Gross Domestic Investment \\
\hline $\mathrm{APB}$ & Agricultural Promotion Bank & GDP & Gross Domestic Product \\
\hline ARH & Adolescent Reproductive Health & GIS & Geographic Information System \\
\hline ARI & Acute Respiratory Infection & GMP & Good Manufacturing Practice \\
\hline ARS & Adolescent Reproductive Health & GMS & Greater Mekong Sub-region \\
\hline ASEAN & Association of South-East Asian Nations & GOL & Government of Lao PDR \\
\hline ASLO & Assessment Student Learning Outcome & GPAR & Governance and Public Administration Reform \\
\hline AUSAID & Australian Agency for International Development & GSP & General System of Preference \\
\hline BCEL & Banque Pour Le Commerce Exterieur Lao & GTZ & Deutsche Gesellschaft für Technische Zusammenarbeit \\
\hline BEI & Banque Europeenne de Development & $\mathrm{HE}$ & Health Education \\
\hline BOL & Bank of Lao PDR & $\mathrm{HC}$ & Health Centres \\
\hline BOOT & Build-own-operate and transfer basis & HIV & Human Immunodeficiency Virus \\
\hline BS & Basic Statistics & HRD & Human Resource Development \\
\hline BP & Birth Spacing & IBN & Impregnation of Bed Net \\
\hline BSRP & Banking Sector Reform Programme & ICB & International Competitive Bid \\
\hline CAA & Community Aid Abroad (Oxfam Australia) & ICRC & International Committee of the Red Cross \\
\hline CBFMAC & Financial Management Capacity Building Credit & ICT & Information Communication Technology \\
\hline CDD & Control of Diarrhoea Disease & IEC & Information, Education, and Communication \\
\hline CEPT & Common Effective Preferential Tariff & IF & Integrate Framework \\
\hline CHI & Community Health Insurance & IFAD & International Fund for Agricultural Development \\
\hline CIAT & Centro Internacional de Agricultura Tropical & $\mathrm{IFI}$ & International Financial Institutions \\
\hline CIC & Committee for International Co-operation & ILO & International Labour Organisation \\
\hline CIDA & Canadian International Development Agency & IMR & Infant Mortality Rate \\
\hline CIDSE & Cooperation Internationale pour le Développement et la & $\mathrm{IMF}$ & International Monetary Fund \\
\hline & Solidarité & IMT & Irrigation Management Technique \\
\hline CLC & Committee Learning Centre & IRAP & Integrated Rural Accessibility Project \\
\hline CMR & Child Mortality Rate & IRRI & International Rice Research Institute \\
\hline $\mathrm{CPC}$ & Committee for Planning and Cooperation & ITC & International Trade Centre \\
\hline CTPC & Communication Transport Post and Construction & IWM & Integrated Watershed Management \\
\hline DAFO & District Agriculture/Forestry Office & JBIC & Japan Bank for International Co-operation \\
\hline DAFS & District Agriculture and Forest Service & JICA & Japan International Co-operation Agency \\
\hline DCA & Department of Civil Aviation & JSE & Joint State Enterprise \\
\hline DCTPC & Department for Communication Transport Post and & JVC & Japan International Volunteer Centre \\
\hline & Construction & KfW & Kredit Anstalt fur Wiederaufbau \\
\hline DDFI & Department of Domestic and Foreign Investment & KPI & Key Performance Indicators \\
\hline DEB & District Education Bureau & LAA & Lao Airport Authority \\
\hline DH & District Hospital & LB & Live Birth \\
\hline DHS & District Health System & LBEA & Labour-based-equipment assisted \\
\hline DHUP & Department of Housing and Urban Planning & $\mathrm{LCB}$ & Local Competitive Bid \\
\hline DOF & Department of Forestry & LCCI & Lao Chamber of Commerce and Industry \\
\hline DONLUPAD & $\begin{array}{l}\text { Department of National Land Use Planning and Land } \\
\text { Development }\end{array}$ & LCDC & $\begin{array}{l}\text { Lao National Commission for Drug Control and } \\
\text { Supervision }\end{array}$ \\
\hline DOP & Department of Planning & LCRD & Leading Committee for Rural Development \\
\hline DOR & Department of Roads & LDB & Lao Development Bank \\
\hline DOTS & Directly Observed Treatment, Short Course & $\mathrm{LDC}$ & Least Developed Country \\
\hline DPACS & Department of Public Administration and Civil Service & LECS & Lao PDR Expenditure and Consumption Survey \\
\hline DRF & Drug Revolving Fund & LFNC & Lao Front for National Construction \\
\hline DTC & Drug Therapeutic Committee & LFTU & Lao Federation of Trade Unions \\
\hline DWT & Dead Weight Tonnes & LMB & Lao Mai Bank \\
\hline EAMP & Environmental Assessment and Management Plan & $\mathrm{LNCCI}$ & Lao National Chamber of Commerce and Industry \\
\hline EBA & Everything But Arms & LNGC & Lao National Grid Company \\
\hline EDL & Electricite du Laos & LTU & Large Tax-Payers Unit \\
\hline ECCD & Early Childhood Care Development & LWU & Loa Women's Union \\
\hline EDP & Education Development Project & LYU & Lao Youth Union \\
\hline EIA & Environmental Impact Assessment & MAF & Ministry of Agriculture and Forestry \\
\hline EFA & Education For All & $\mathrm{MCH}$ & Mother and Child Health \\
\hline EGAT & Electricity Generating Authority of Thailand & $\mathrm{MCHC}$ & Mother and Child Health Centre \\
\hline EL & English Language & MCTPC & Ministry of Communication Transport Post and \\
\hline EMIS & Education and Information Management System & & Construction \\
\hline EPI & Immunisation & MDG & Millennium Development Goal \\
\hline EQIP & Education Quality Improvement Project & MFN & Most Favoured Nation \\
\hline ESCAP & Economic and Social Commission for the Asia Pacific & MGT & Multi-Grade Teaching \\
\hline $\mathrm{EU}$ & European Union & MICS & Multiple Indicator Cluster Survey \\
\hline EWORS & Early Warning of Outbreak and Recognition System & MMR & Maternal Mortality Rate \\
\hline $\mathrm{FAO}$ & Food and Agriculture Organisation & MOAF & Ministry of Agriculture and Forestry \\
\hline
\end{tabular}




\begin{tabular}{|c|c|c|c|}
\hline$\overline{\mathrm{MOE}}$ & Ministry of Education & SEDP & Socioeconomic Development Plan \\
\hline MOF & Ministry of Finance & SEMFOP & Social and Environmental Management Framework and \\
\hline MOH & Ministry of Health & & the Operational Plan \\
\hline MOIC & Ministry of Information and Culture & SEZ & Special Economic Development Zone \\
\hline MOJ & Ministry of Justice & SIDA & Swedish International Development Agency \\
\hline MRC & Mekong River Commission & SM & Safe Motherhood \\
\hline MTEF & Medium-Term Expenditure Framework & SME & Small and Medium Enterprises \\
\hline NA & National Assembly & SOCB & State-Owned Commercial Bank \\
\hline NAFES & National Agriculture and Forestry Service & SOE & State-Owned Enterprise \\
\hline NAFRI & National Agriculture and Forestry Research Institute & SPC & State Planning Committee \\
\hline NAO & National Audit Office & SSO & Social Security Office \\
\hline NBCA & National Bio-Conservation Area & STEA & Science Technology and Environment Agency \\
\hline NCAW & National Commission for the Advancement of Women & STD & Sexually Transmitted Disease \\
\hline NCB & National Competitive Bid & TA & Technical Assistance \\
\hline NCCA & National Committee for Control of AIDS & TB & Tuberculosis \\
\hline NCCPD & National Co-ordinating Committee for Population and & $\mathrm{TE}$ & Teacher Education \\
\hline & Development & TM & Traditional Medicine \\
\hline NDF & National Development Framework & TT & Teacher Training \\
\hline NEAP & National Environmental Action Plan & TTC & Teacher Training Centre \\
\hline NEM & New Economic Mechanism & TTE & Teacher Training Education \\
\hline NER & Net Enrolment Rate & TVE & Technical and Vocational Education \\
\hline NFE & Non-Formal Education & TVET & Technical and Vocational Education Training \\
\hline NGO & Non Governmental Organisation & UDAA & Urban Development Administrative Authority \\
\hline NHDR & National Human Development Report & U5MR & Under Five Mortality Rate \\
\hline NIR & Net Intake Rate & UGC & Urban Growth Centres \\
\hline NORAD & Norwegian Agency for Development & UN & United Nations \\
\hline NPDP & National Population and Development policy & UNCRD & United Nations Centre for Rural Development \\
\hline NPEP & National Poverty Eradication Programme & UNCTAD & United Nations Conference on Trade and Development \\
\hline NPL & Non-Performing Loans & UNCDF & United Nations Capital Development Fund \\
\hline NR & National Road & UNDCP & United Nations Drug Control Programme \\
\hline NRSC & National Road Safety Council & UNDP & United Nations Development Programme \\
\hline NSC & National Statistics Centre & UNGASS & United Nations General Assembly Special session \\
\hline NSDV & National Strategic Development Vission & UNFPA & United Nations Population Fund \\
\hline NSP & National Strategic Plan & UNICEF & United Nations Children's Fund \\
\hline NTFP & Non-Timber Forest Products & UNIFEM & United Nations Fund for the Development of Women \\
\hline NTR & Normal Trade Relations & UNODC & UN Office for Drugs and Crime \\
\hline NUOL & National University of Laos & UXO & Unexploded Ordnance \\
\hline NURBIDS & National Urban-Rural Basic Infrastructure Development & VAT & Value-Added Tax \\
\hline & Strategy & VDF & Village Development Fund \\
\hline ODA & Official Development Assistance & VET & Vocational Education and Training \\
\hline ODI & Office for Domestic Investment & VTE & Vocational Training and Education \\
\hline OIC & Office for International Co-operation & VHC & Village Health Committee \\
\hline ORS & Oral Re-hydration Solution & VHV & Village Health Volunteer \\
\hline PAFO & Provincial Agriculture/Forestry Office & WB & World Bank \\
\hline PAFS & Provincial Agriculture/Forestry Service & WFP & World Food Programme \\
\hline PDID & Provincial Development Information Day & WHO & World Health Organisation \\
\hline PDR & People's Democratic Republic & WTO & World Trade Association \\
\hline PER & Public Expenditure Review & WUA & Water-Users Association \\
\hline PES & Provincial Education Service & & \\
\hline PHC & Primary Healthcare & & \\
\hline PI & Private Investment & & \\
\hline PIP. & Public Investment Programme & & \\
\hline PIR & Parasite Index Rate & & \\
\hline PM & Prime Minister & & \\
\hline PMIS & Personnel Management Information System & & \\
\hline PMO & Prime Minister's Office & & \\
\hline PNC & Post Natal Care & & \\
\hline POA & Plan of Action & & \\
\hline PRF & Poverty Reduction Fund & & \\
\hline PRGF & Poverty Reduction and Growth Facility & & \\
\hline PPA & Participatory Poverty Assessment & & \\
\hline RD & Rural Development & & \\
\hline RDO & Rural Development Office & & \\
\hline RHS & Reproductive Health Survey & & \\
\hline RMF & Road Maintenance Fund & & \\
\hline RPA & Rapid Poverty Assessment & & \\
\hline RTI & Reproductive Tract Infection & & \\
\hline RTM & Roundtable Meeting & & \\
\hline RTP & Roundtable Process & & \\
\hline SCFA & Save the Children Fund Australia & & \\
\hline $\mathrm{SCU}$ & Savings and Credit Union & & \\
\hline
\end{tabular}




\section{Indicators Related to Selected Millennium Development Goals}

\begin{tabular}{|c|c|c|c|}
\hline MDG & Indicator & Year & Statistics ${ }^{1}$ \\
\hline $\begin{array}{l}\text { 01: Eradicate extreme poverty } \\
\text { and hunger. }\end{array}$ & $\begin{array}{l}\text { Poverty head count ratio (per } \\
\text { cent). }\end{array}$ & $\begin{array}{l}1992-1993 \\
1997-1998 \\
2002-2003\end{array}$ & 45 \\
\hline \multirow[t]{2}{*}{$\begin{array}{l}\text { 02: Achieve universal primary } \\
\text { education. }\end{array}$} & $\begin{array}{l}\text { Net enrolment ratio in primary } \\
\text { education (per cent). }\end{array}$ & $\begin{array}{l}2001 \\
1996\end{array}$ & 71.9 \\
\hline & $\begin{array}{l}\text { Proportion of pupils starting Grade } \\
1 \text { who reach Grade } 5 \text { (per cent). }\end{array}$ & $\begin{array}{l}2000 \\
1996\end{array}$ & 56.6 \\
\hline \multirow[t]{2}{*}{$\begin{array}{l}\text { 03: Promote gender equality } \\
\text { and empower women. }\end{array}$} & $\begin{array}{l}\text { Ratio of literate females to males } \\
\text { of } 15 \text { to } 24 \text { years old (ratio of } \\
\text { female literacy rates to male } \\
\text { literacy rates). }\end{array}$ & $\begin{array}{l}2000 \\
1995\end{array}$ & 84.6 \\
\hline & $\begin{array}{l}\text { Proportion of seats held by women } \\
\text { in national parliament (per cent). }\end{array}$ & $\begin{array}{l}2002 \\
1995\end{array}$ & 9.4 \\
\hline \multirow[t]{3}{*}{ 04: Reduce child mortality. } & $\begin{array}{l}\text { Under-five mortality rate (deaths } \\
\text { per } 1,000 \text { live births). }\end{array}$ & $\begin{array}{l}1994 \\
1999\end{array}$ & 142 \\
\hline & $\begin{array}{l}\text { Infant mortality rate (deaths per } \\
1,000 \text { live births). }\end{array}$ & $\begin{array}{l}1994 \\
1999\end{array}$ & 113 \\
\hline & $\begin{array}{l}\text { Proportion of } 1 \text { year old children } \\
\text { immunized against measles (per } \\
\text { cent). }\end{array}$ & $\begin{array}{l}2000 \\
1996\end{array}$ & 41.8 \\
\hline 05: Improve maternal health. & $\begin{array}{l}\text { Maternal mortality ratio (deaths } \\
\text { per } 100,000 \text { live births). }\end{array}$ & $\begin{array}{l}1995 \\
2000\end{array}$ & 749 \\
\hline \multirow[t]{3}{*}{$\begin{array}{l}\text { 06: Combat HIV/AIDS, } \\
\text { malaria and other diseases }\end{array}$} & $\begin{array}{l}\text { Death rate associated with malaria } \\
\text { (per } 100,000 \text { people). }\end{array}$ & $\begin{array}{l}1995 \\
2002\end{array}$ & 13.5 \\
\hline & $\begin{array}{l}\text { Proportion of tuberculosis cases } \\
\text { detected under DOTS (per cent). }\end{array}$ & $\begin{array}{l}2002 \\
1996\end{array}$ & 24 \\
\hline & $\begin{array}{l}\text { Proportion of tuberculosis cases } \\
\text { cured under DOTS (per cent). }\end{array}$ & $\begin{array}{l}2002 \\
1996\end{array}$ & 72 \\
\hline \multirow[t]{3}{*}{$\begin{array}{l}\text { 07: Ensure environmental } \\
\text { sustainability }\end{array}$} & $\begin{array}{l}\text { Ratio of area protected to maintain } \\
\text { biological diversity to total surface } \\
\text { area (per cent). }\end{array}$ & $\begin{array}{l}2000 \\
1996\end{array}$ & 14.3 \\
\hline & $\begin{array}{l}\text { Proportion of population with } \\
\text { access to an improved water } \\
\text { source (per cent). }\end{array}$ & $\begin{array}{l}2002 \\
1990\end{array}$ & 28 \\
\hline & $\begin{array}{l}\text { Proportion of [urban] population } \\
\text { with access to improved sanitation } \\
\text { (per cent) }\end{array}$ & $\begin{array}{l}2002 \\
1990\end{array}$ & 41.6 \\
\hline
\end{tabular}

\footnotetext{
1 Source: LECS 1992/93; LECS 1997/98; LECS 2002/03; MOE (2000): EFA 2000; MOE: 2002 Annual Report; NSC (1995): Census '95; SPC (2001): MICS II, 2000; NA(2002); NSC (1996): FBSS '94; SPC (2001): RHS 2000; SPC (1997): MICS I ‘96; SPC (1997): MICS II 2000; CPC (2000): Census '95; CMPE (2003); NTBC (2003): Annual Report; STEA (2000): NEAP 2000; NCEHWS (2003).
} 